\title{
Access to medicines: The interface between patents and human rights. Does one size fit all?
}

Citation for published version (APA):

Sellin, J. A. (2014). Access to medicines: The interface between patents and human rights. Does one size fit all? [Doctoral Thesis, Maastricht University]. Intersentia. https://doi.org/10.26481/dis.20140619js

Document status and date:

Published: 01/01/2014

DOI:

10.26481/dis.20140619js

Document Version:

Publisher's PDF, also known as Version of record

\section{Please check the document version of this publication:}

- A submitted manuscript is the version of the article upon submission and before peer-review. There can be important differences between the submitted version and the official published version of record.

People interested in the research are advised to contact the author for the final version of the publication, or visit the DOI to the publisher's website.

- The final author version and the galley proof are versions of the publication after peer review.

- The final published version features the final layout of the paper including the volume, issue and page numbers.

Link to publication

\footnotetext{
General rights rights.

- You may freely distribute the URL identifying the publication in the public portal. please follow below link for the End User Agreement:

www.umlib.nl/taverne-license

Take down policy

If you believe that this document breaches copyright please contact us at:

repository@maastrichtuniversity.nl

providing details and we will investigate your claim.
}

Copyright and moral rights for the publications made accessible in the public portal are retained by the authors and/or other copyright owners and it is a condition of accessing publications that users recognise and abide by the legal requirements associated with these

- Users may download and print one copy of any publication from the public portal for the purpose of private study or research.

- You may not further distribute the material or use it for any profit-making activity or commercial gain

If the publication is distributed under the terms of Article $25 \mathrm{fa}$ of the Dutch Copyright Act, indicated by the "Taverne" license above, 
Access to Medicines

The Interface between Patents and Human Rights. Does one size fit all? 
School of Human Rights Research Series, Volume 64

The titles published in this series are listed at the end of this volume. 
Access to Medicines

The Interface between Patents and Human Rights.

Does one size fit all?

Jennifer Anna Sellin

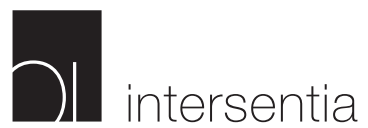

Cambridge - Antwerp - Portland 
Intersentia Publishing Ltd.

Sheraton House | Castle Park

Cambridge | CB3 0AX | United Kingdom

Tel.: +441223370170 | Email: mail@intersentia.co.uk

Jennifer Anna Sellin

Access to Medicines. The Interface between Patents and Human Rights. Does one size fit all?

ISBN 978-1-78068-247-1

$\mathrm{D} / 2014 / 7849 / 109$

NUR 828

Cover photograph (C) Vasabii - iStock/Thinkstock

(C) 2014 Intersentia

www.intersentia.com | www.intersentia.co.uk

British Library Cataloguing in Publication Data. A catalogue record for this book is available from the British Library.

No part of this book may be reproduced in any form, by print, photoprint, microfilm or any other means, without written permission from the publisher. 
Dedicated to W.T. Mugwiji 



\section{ACKNOWLEDGEMENTS}

When I started working at the Faculty of Law of Maastricht University in the fall of 2007, I did not know what to expect. It turned out to be a life-changing decision. Above all it was a learning-experience, leading to the writing of this dissertation.

At last my name is on the cover of this book, but there are many people that have had a part in its progress and completion.

The process of writing a $\mathrm{PhD}$ is both wonderful and terrifying. The freedom to go wherever your research leads you is wonderful, the knowledge that you are the primary source material is terrifying. First and foremost, I have to thank my supervisors, Prof. Fons Coomans and Prof. Anselm Kamperman Sanders, for carefully reading and commenting upon the various drafts of the chapters of this dissertation. The combination of their respective areas of expertise and the confidence they showed in this endeavour have been crucial in getting this dissertation completed.

It was Fons who asked me to consider taking on this task when I was only a studentassistant for the Maastricht Centre for Human rights. And he has been a constant guide to me through this entire process. I thank him for sharing his knowledge and expertise and, especially, for taking the time to listen. I really appreciate him as a supervisor and colleague.

This research benefited from interviews with various people, all of whom, provided me information, shared their knowledge and answered my queries without hesitation. Special thanks to Moses Mulumba who was indispensable to making the most out of my short trip to Uganda, dr. Maheshwar Singh who made my trip to New Delhi successful on both a legal and culinary level and Leena Menghaney, who was a life saver at a moment of real crisis.

I also thank the members of the Assessment Committee who kindly agreed to read and evaluate the dissertation: Prof. Menno Kamminga, Prof. Peter van den Bossche, Prof. Paul Hunt, Prof. Duncan Matthews and Prof. David Townend.

Writing a PhD can be a lonely experience. My colleagues at the Faculty, many of whom have become dear friends, have really helped to make it seem less so. Thanks to all of you who have read, commented and discussed with me various aspects of my research and, maybe even more importantly, for the coffee breaks, dinners and nights out which made my time at the faculty enjoyable. In particular to: 
Martine, with whom I shared the many highs and lows of doing a PhD (and attended too many conferences, lectures, seminars to count). Jasper, for being my trusty "sounding board"! Emanuel and Anja, for being easy-going roommates. Dyebo, who patiently listened to my ramblings and made sure I was okay when I did not turn up at the office. Carol, who shared with me some of life's lessons and for carefully proofreading this dissertation. And Anke, who taught me so much about doing research, managing the stress of a $\mathrm{PhD}$, and for her personal support, along with Adela, Birsen, and Phyllis.

A very special thank you to my paranymphs Eliza and Tamara, for their support and friendship. Ineke, my best friend, and constant inspiration. And, Whitlaw, for being a distraction (both good and bad), always being able to calm me down and loving me just the way I am, flaws and all included. I couldn't have done it without you!

And finally, my profound thanks to all my family, friends and colleagues for making sure I kept going, when giving up sometimes seemed the easier option. In particular to my parents, who taught me the most important lesson of all: that my family will always support me.

The sense of pride and satisfaction that comes from completing my dissertation is down to you. 


\section{Contents}

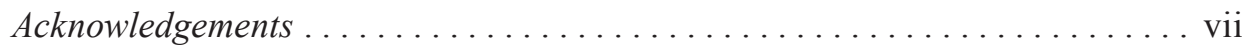

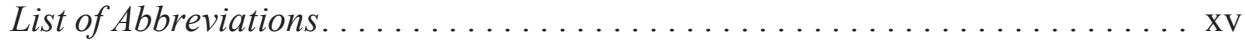

\section{Part I}

Method and Problem Statement

Chapter 1

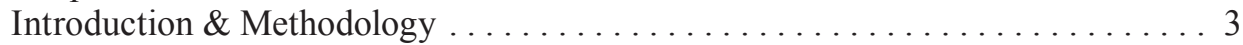

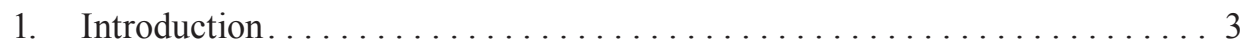

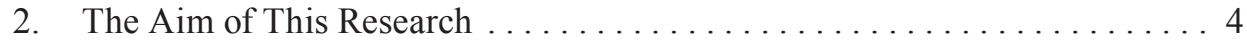

3. The Research Questions ......................... 5

4. The Method ................................. 7

4.1. Sources .............................. 10

4.2. Manner of Interpretation . . . . . . . . . . . . . . . . . . . 13

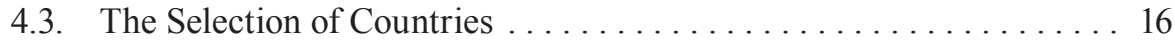

4.4. Limitations of the Study . . . . . . . . . . . . . . . . . 19

\section{Chapter 2}

Access to Medicines: the Problem . . . . . . . . . . . . . . . . . . . 21

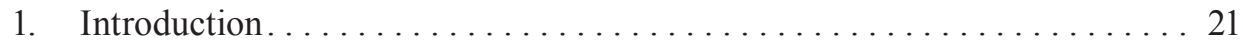

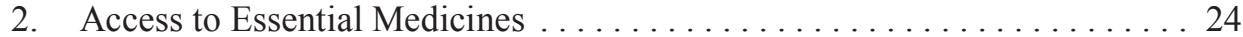

2.1. Defining Essential Medicines ... . . . . . . . . . . . . . . 24

2.2. Access . . . . . . . . . . . . . . . . . . . . . . 27

2.3. Availability and Affordability in Developing Countries. . . . . . . . . 29

2.4. Conclusion. . . . . . . . . . . . . . . . . . . . . . . . . . . . . . 32

3. The Pharmaceutical Market ....................... 32

3.1. Regulatory Review: Marketing Approval for Medicines . . . . . . . . 36

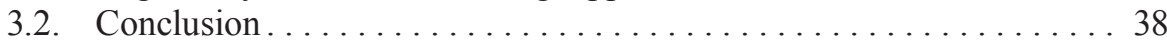

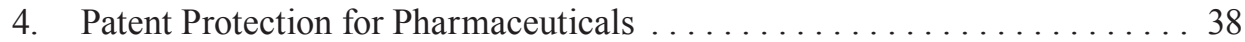

4.1. What Are Patents? . . . . . . . . . . . . . . . . . . . . . . . . . . . 38

4.1.1. Brief History of Patent Law . . . . . . . . . . . . . . . . 39

4.1.2. Why We need Patents: Rationales of Patent Protection . . . . . 44

4.2. Research and Development . . . . . . . . . . . . . . . . . 47

4.2.1. An Incentive to innovate? Neglected Diseases . . . . . . . . . . 49

4.3. Conclusion.......................... 54

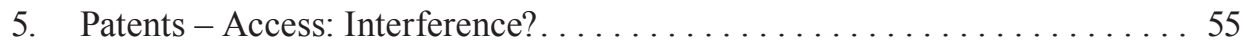

6. Conclusion............................... 60 


\section{Part II}

International Framework.

Chapter 3

A Human Right of Access to Medicines?. . . . . . . . . . . . . . . . . . 65

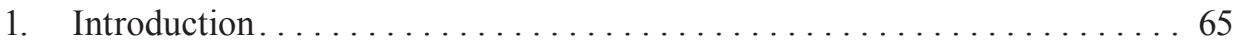

2. The International Human Rights Framework . . . . . . . . . . . 66

2.1. Brief History of the Concept of Human Rights . . . . . . . . . . . . 66

2.2. Civil \& Political Rights vs. Economic, Social \& Cultural Rights . . . 69

2.3. The UN Human Rights Framework . . . . . . . . . . . . . . . . . . . . 71

3. The Human Right to Health: Introduction . . . . . . . . . . . . . . 76

3.1. Treaty Law: Article 12 ICESCR . . . . . . . . . . . . . . . . 78

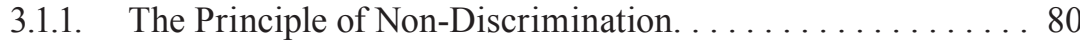

3.1.2. Limitations . . . . . . . . . . . . . . . . . . . . . . . 81

3.2. Soft Law: The Committee on Economic, Social and

Cultural Rights ........................ 82

3.2.1. Scope of the Right to Health . . . . . . . . . . . . . 82

3.2.2. States Parties' Obligations . . . . . . . . . . . . . . . . . 84

3.3. Other Treaties protecting the Right to Health...... . . . . . . . 93

3.4. Monitoring and Accountability ................... 98

3.4.1. Violations of the Right to Health . . . . . . . . . . . . . . 100

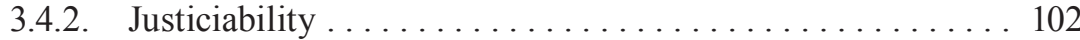

3.4.3. Case Law . . . . . . . . . . . . . . . . . . . . . . 107

3.4.4. Conclusion ......................... 116

3.5. Special Rapporteur on the Right to Health . . . . . . . . . . . . . . 117

3.6. Conclusion: Is there a Right of Access to Essential Medicines

within the Right to Health? . . . . . . . . . . . . . . . . . . . . . . . . . 121

4. The Human Right to Life: Article 6 ICCPR . . . . . . . . . . . . . . . . . 122

5. The Human Right to the Benefits of Science: Article 15 ICESCR. . . . . . . 125

6. Access to Medicines under Customary International Law. . . . . . . . . . . . 128

6.1. The International Bill of Rights . . . . . . . . . . . . . . . . . 131

6.2. A Customary Right of Access to Medicines? . . . . . . . . . . . . . . 132

7. Conclusion: A Human Right of Access to Medicines? . . . . . . . . . . . . . . 141

Chapter 4

The TRIPS Agreement: Patent Protection for Pharmaceuticals . . . . . . . . . 143

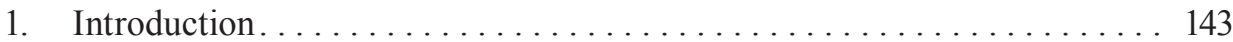

2. The World Trade Organization . . . . . . . . . . . . . . . . . 144

2.1. Negotiation Process of the TRIPS Agreement . . . . . . . . . . . . . 146

2.2. Dispute Settlement. . . . . . . . . . . . . . . . . . . . . . 151

3. The Agreement on Trade-Related Aspects of Intellectual

Property Rights . . . . . . . . . . . . . . . . . . . . . . . . . . . . . . 159 
3.1. General Provisions and Basic Principles. . . . . . . . . . . . . . . 161

3.2. Objectives and Principles . . . . . . . . . . . . . . . . 167

3.3. Transitional Arrangements . . . . . . . . . . . . . . . . . . 170

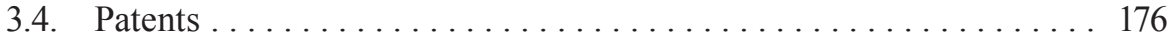

3.4.1. Article 27 TRIPS: Patentable Subject Matter . . . . . . . . . 176

3.4.2. Article 28: Rights Conferred . . . . . . . . . . . . . . . 188

3.4.3. Article 33 TRIPS: Patent Term. . . . . . . . . . . . . . . 192

3.4.4. Articles $30 \& 31$ TRIPS: Exceptions . . . . . . . . . . . . 193

3.4.5. Article 32 TRIPS: Revocation .................. 211

3.5. Protection of Undisclosed Information . . . . . . . . . . . . . 213

3.6. Enforcement of Intellectual Property Rights . . . . . . . . . . . . 216

4. Conclusion. . . . . . . . . . . . . . . . . . . . . . . . . . . . 222

\section{Chapter 5}

The Interface between Patents and Human Rights in the Context

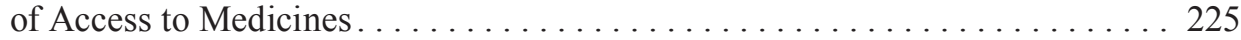

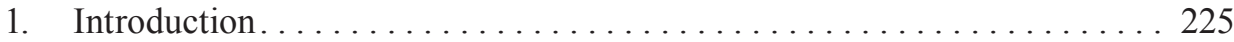

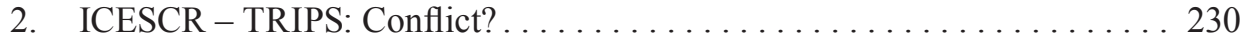

2.1. Narrow Definition of Conflict: Inconsistent Obligations? . . . . . . . 233

2.2. Broad Definition of Conflict: Tension? . . . . . . . . . . . . 234

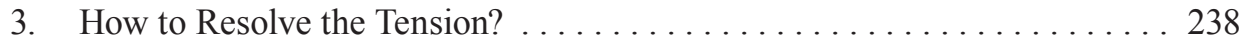

4. The Principle of Human Rights Primacy . . . . . . . . . . . . . . . . 242

4.1. The Right to Health as a Superior Norm in International Law? . . . . 245

5. Harmonious Interpretation: The Principle of Systemic Integration . . . . . . 252

5.1. The Doha Declaration on the TRIPS Agreement and Public Health \& Article 31bis TRIPS. . . . . . . . . . . . . . . . . . . . . . . . . 258

5.2. WTO Dispute Settlement Mechanism: Interpreting TRIPS in Light of Human Rights Standards? . . . . . . . . . . . . . . . . . . 270

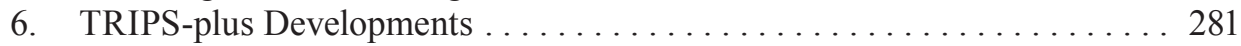

7. Conclusion................................ 288

\section{Part III}

Country Studies

Chapter 6

Access to Medicines in South Africa . . . . . . . . . . . . . . . . . 293

1. Introduction. . . . . . . . . . . . . . . . . . . . . . . . . . 293

2. HIV/AIDS and Access to Medicines. . . . . . . . . . . . . . . . . . . . . . . 294

3. A Human Right of Access to Medicines? . . . . . . . . . . . . . . . . . . . 299

3.1. The South African Constitution of 1996 . . . . . . . . . . . . . . . . 300

3.2. Cases before the Constitutional Court . . . . . . . . . . . 306

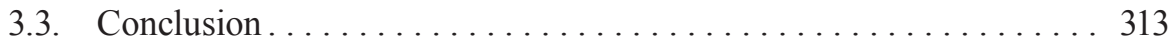


4. Patent Protection for Pharmaceuticals: Standards \& Flexibilities . . . . . . 315

4.1. The Patents Act No. 57 of $1978 \ldots \ldots \ldots \ldots \ldots \ldots$. . . . . . . . . 315

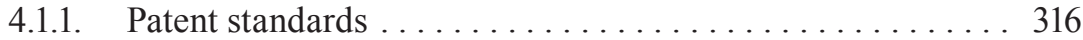

4.1.2. Exceptions ............................. 319

4.1.3. Conclusion ... . . . . . . . . . . . . . . . . . . . . 327

4.2. The Medicines and Related Substances Act No. 101 of 1965 . . . . . . 329

4.2.1. Section 15C: Measures to Ensure the Supply of

Affordable Medicines. . . . . . . . . . . . . . . . . . . 330

4.2.2. Further Measures under the Medicines Act. . . . . . . . . . 333

4.2.3. Conclusion ......................... 335

4.3. The Competition Act No. 89 of $1998 \ldots \ldots \ldots \ldots \ldots 336$

4.3.1. Abuse of Dominance . . . . . . . . . . . . . . . . . . . . . 338

4.3.2. Competition Cases . . . . . . . . . . . . . . . . . . . . . . . 341

4.3.3. Conclusion ........................ 343

5. Conclusion: Striking a Balance?. . . . . . . . . . . . . . . . 345

Chapter 7

Access to Medicines in India . . . . . . . . . . . . . . . . . . 347

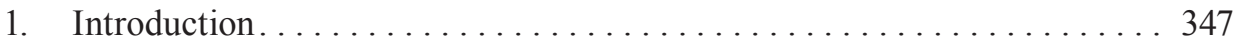

2. The Generic Pharmaceutical Industry and Access to Medicines . . . . . . . 348

3. A Human Right of Access to Medicines? . . . . . . . . . . . . . . . . . . 352

3.1. The Indian Constitution of $1949 \ldots \ldots \ldots \ldots \ldots$. . . . . . . . . . . 352

3.2. Cases before the Supreme Court. . . . . . . . . . . . . . . . 355

3.3. Conclusion ............................... 358

4. Patent Protection for Pharmaceuticals: Standards \& Flexibilities . . . . . . 360

4.1. The Patents Act of 1970. . . . . . . . . . . . . . . . . . . . . . . . . . . . . . 360

4.1.1. Transitional Periods TRIPS . . . . . . . . . . . . . . . . 362

4.1.2. Patent Standards . . . . . . . . . . . . . . . . . . . . . 367

4.1.3. Procedural Mechanisms: Opposition Proceedings \&

Revocation ............................ 378

4.1.4. Exceptions ......................... . 381

4.2. Conclusion. . . . . . . . . . . . . . . . . . . . . . . . . . . . . 394

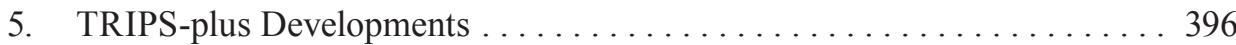

6. Conclusion. . . . . . . . . . . . . . . . . . . . . . . . . . 397

Chapter 8

Access to Medicines in Uganda . . . . . . . . . . . . . . . . . . . . . . . . . . 399

1. Introduction. . . . . . . . . . . . . . . . . . . . . . 399

2. Least-Developed Countries and Access to Medicines . . . . . . . . . . . . 400

3. A Human Right of Access to Medicines? . . . . . . . . . . . . . . . . . . 405

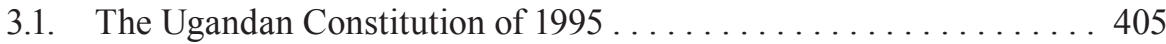

3.2. Health Legislation and Policy . . . . . . . . . . . . . . 413 
3.3. Conclusion............................ 415

4. Patent Protection for Pharmaceuticals: Standards \& Flexibilities . . . . . 415

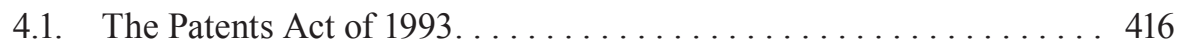

4.2. Uganda's Law Reform: The Draft Industrial Property

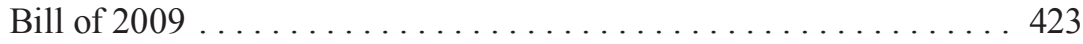

4.2.1. Patent standards . . . . . . . . . . . . . . . . . . . . . . . . 424

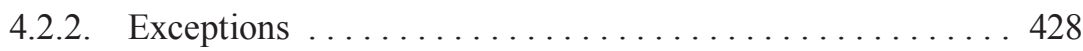

4.3. Conclusion ................................ 432

5. Conclusion................................ 434

Chapter 9

Findings, Conclusions and Recommendations................ 437

1. Patents - Access: Interference . . . . . . . . . . . . . . . . . . . . . . . . . .437

2. A Human Right of Access to (Essential) Medicines .............. 438

3. TRIPS Minimum Standards for Patent Protection .............. 444

4. The Interface between Patents and Access: Tension? . . . . . . . . . . . 446

5. Striking a Balance................................ 449

6. Conclusion \& Recommendations ...................... 457

Bibliography.................................. 461

Curriculum Vitae ................................. 491 



\section{List of Abbreviations}

\begin{tabular}{|c|c|}
\hline $\mathrm{AB}$ & Appellate Body (World Trade Organisation) \\
\hline ALP & Aids Law Project \\
\hline ARVs & antiretrovirals \\
\hline BI & Boehringer Ingelheim \\
\hline BITs & bilateral investment treaties \\
\hline CEDAW & $\begin{array}{l}\text { Committee on the Elimination of All Forms of Discrimination } \\
\text { against Women }\end{array}$ \\
\hline CESCR & Committee on Economic, Social and Cultural Rights \\
\hline $\mathrm{CRC}$ & Committee on the Rights of the Child \\
\hline DPSP & Directive Principles of State Policy (India) \\
\hline DSB & Dispute Settlement Body (World Trade Organisation) \\
\hline DSU & $\begin{array}{l}\text { Understanding on Rules and Procedures for the Settlement of } \\
\text { Disputes }\end{array}$ \\
\hline ECOSOC & UN Economic and Social Council \\
\hline EFPIA & European Federation of Pharmaceutical Industries and Associations \\
\hline EMRs & exclusive marketing rights \\
\hline ESC rights & economic, social and cultural rights \\
\hline FDA & US Food and Drug Administration \\
\hline FDI & foreign direct investment \\
\hline FTAs & free trade agreements \\
\hline GA & UN General Assembly \\
\hline GATS & General Agreement on Trade in Services \\
\hline GATT & General Agreement on Tariffs and Trade \\
\hline GDP & gross domestic product \\
\hline GNI & gross national income \\
\hline GSK & GlaxoSmithKline \\
\hline HAI & Health Action International \\
\hline HIV/AIDS & $\begin{array}{l}\text { human immunodeficiency virus/acquired immune deficiency } \\
\text { syndrome }\end{array}$ \\
\hline $\mathrm{HRC}$ & UN Human Rights Council \\
\hline HRCee & Human Rights Committee \\
\hline HRCion & UN Commission on Human Rights \\
\hline ICCPR & International Covenant on Civil and Political Rights \\
\hline ICERD & $\begin{array}{l}\text { International Convention on the Elimination of All Forms of Racial } \\
\text { Discrimination }\end{array}$ \\
\hline ICESCR & International Covenant on Economic, Social and Cultural Rights \\
\hline ICJ & International Court of Justice \\
\hline IFPMA & $\begin{array}{l}\text { International Federation of Pharmaceutical Manufacturers \& } \\
\text { Associations }\end{array}$ \\
\hline
\end{tabular}




\begin{tabular}{|c|c|}
\hline IIPA & International Intellectual Property Alliance \\
\hline ILC & International Law Commission \\
\hline IP & intellectual property \\
\hline IPRs & intellectual property rights \\
\hline LDCs & least-developed countries \\
\hline MFN & most-favoured nation treatment principle \\
\hline NCE & new chemical entity \\
\hline NDP & National Drug Policy \\
\hline NGO & non-governmental organisation \\
\hline NODPSP & $\begin{array}{l}\text { National Objectives and Directive Principles of State Policy } \\
\text { (Uganda) }\end{array}$ \\
\hline PhRMA & Pharmaceutical Research and Manufacturers of America \\
\hline PIL & Public Interest Litigation \\
\hline PMA & Pharmaceutical Manufacturer's Association \\
\hline R\&D & research and development \\
\hline SADC & Southern African Development Community \\
\hline TAC & Treatment Action Campaign \\
\hline TB & Tuberculosis \\
\hline TRIPS & Agreement on Trade-Related Aspects of Intellectual Property Rights \\
\hline UDHR & Universal Declaration of Human Rights \\
\hline ULRC & Uganda Law Reform Commission \\
\hline UN & United Nations \\
\hline UNICEF & United Nations Children’s Fund \\
\hline USTR & United States Trade Representative \\
\hline VCLT & Vienna Convention on the Law of Treaties \\
\hline WHA & World Health Assembly \\
\hline WHO & World Health Organisation \\
\hline WIPO & World Intellectual Property Organisation \\
\hline WTO & World Trade Organisation \\
\hline
\end{tabular}




\section{Part I}

\section{Method and Problem Statement}





\section{Chapter 1 \\ InTRODUCTION \& Methodology}

\section{INTRODUCTION}

The subject of this dissertation is the issue of access, or lack thereof, of medicines for patients in developing countries. The argument often made in that regard is that patent protection for medicines results in higher prices and therefore negatively impacts patients' access to such medicines. That is to say, patent protection provides the patent holder with a monopoly position for a set number of years excluding competitors from the market. Such a monopoly position is argued, particularly by the pharmaceutical industry, to be justified due to the fact that patents are vital in order to recoup their substantial research and development costs; since without patent protection pharmaceutical companies would have no incentive to invest in innovation. This issue is studied from the perspective of international human rights law and international patent law and trade law. The inclusion of intellectual property rights (IPRs), such as patents, trademarks, copyright etc, into the framework of the World Trade Organisation (WTO) through the Agreement on Trade-Related Aspects of Intellectual Property Rights (TRIPS) has brought about significant changes to the manner in which IPRs are granted, protected and enforced. It has been argued that the introduction of global minimum standards for IPRs, particularly patents, negatively affecting patients' access to affordable medicines creates tension with international human rights law, which protects access to essential medicines. ${ }^{1}$ In this study this alleged tension is researched in more detail.

Although the issue of access to medicines to an extent is a global problem, its specific characteristics differs from country to country depending on a wide range of factors on the ground, such as a country's level of development, public health burden, public health-care system, manufacturing capacity, level of intellectual property (IP) protection, environmental conditions etc. The system for protection of IPRs is largely influenced by norm-setting at the international level, particularly through the adoption of the TRIPS Agreement. The inclusion of intellectual property into the multilateral trading framework has had far-reaching consequences. It is the first international instrument to set out minimum standards for the protection of IPRs. All members of the WTO are required to implement the TRIPS Agreement's minimum standards for IP protection, which has greatly influenced domestic developments in the field of patent protection for pharmaceuticals. Consequently, it has been stated that with respect to TRIPS - and other WTO

The link between access to medicines and patents for pharmaceutical products will be set out in more detail in chapter 2 . 
disciplines for that matter - "one size does not fit all". ${ }^{2}$ Yet the question then is, does such international regulation really leave insufficient freedom for (developing) states to adopt a patent system suited to their domestic needs, thus enabling them to strike a balance between access to medicines on the one hand and patent protection for pharmaceuticals on the other?

Section 2 of this chapter sets out the aim of this dissertation, Section 3 addresses the manner in which this study is organised by posing a number of research questions, Section 4 continues with an explanation of how it has been conducted by setting out the approach, methods and sources used.

\section{The Aim of This Research}

The aim of the research is to examine whether it is possible to strike a balance between the seemingly contradictory notions of patent protection for pharmaceuticals and the right of access to (essential) medicines. The international framework intends to provide a theoretical legal analysis as to reconciling these two seemingly contradictory notions, while the country studies examine the issue from a developing country perspective.

It must be said that the issue of access to essential medicines is a topic which has been addressed by numerous academics and international and national governmental and non-governmental organisations. However, in-depth studies on the relationship between human rights and intellectual property rights addressing the issue both from an international and national perspective are lacking. Much has been written on the impact of the TRIPS Agreement, and more broadly the WTO, on human rights addressing the TRIPS flexibilities and recent developments such as the Doha Declaration on the TRIPS Agreement and Public Health. This research intends to add to that debate by approaching the issue from a developing country perspective. As such the country studies are a valuable contribution by providing insight into whether (these) developing countries recognise and acknowledge the interplay between patents and human rights with respect to access to medicines and their ability and willingness to strike a balance between access and patent protection. Examining three countries with varying levels of development allows for a degree of comparison as to whether, and if so how, these countries have achieved such a balance within the constraints of international law.

Concerning the social relevance of this research, the reader is referred to Chapter 2, where the problem at hand - access to medicines - is dealt with in detail.

2 See for example JONATHAN MICHAEL BERGER, 'Tripping over Patents: AIDS, Access to Treatment and the Manufacturing of Scarcity', Connecticut Journal of International Law, 17 (2001-2002), 157-248. 


\section{The Research Questions}

This research is broadly divided into three parts: the methodology and problem statement, the international framework and analysis and finally the country studies.

Part I sets out the introduction and methodology (chapter 1) and the problem statement (chapter 2). Chapter 2 gives an overview of the issue of access to medicines in developing countries. The starting point of this research is that a third of the world's population lacks adequate access to essential medicines. As will be shown this problem is complex and multifaceted. There are a multitude of factors which contribute to the worsening situation. For the aim of this research the essence of the problem comes down to the following: patients lack access to (essential) medicines that are available but for a variety of reasons do not reach the patient in need (short term needs of the patient); in addition lack of research and development of new medicines targeted at diseases especially prevalent in developing countries cause serious problems for patients in the long term. In order to connect the issue of access to medicines with patent protection for pharmaceuticals a preliminary question is asked:

1. Does patent protection for pharmaceuticals interfere with patients' access to essential medicines in developing countries? To be able to answer this we must define what is meant by "essential medicines", "access" and "interference".

Once a link between patent protection and access has been identified, the study proceeds with the international framework in Part II. Here the international framework with regard to the protection of access to medicines under international human rights law (chapter 3), patent protection for pharmaceuticals under the TRIPS Agreement (chapter 4), and the interface between patents and human rights (chapter 5) is elaborated. Chapter 3 gives an overview of the international human rights system. The main research question posed is the following:

\section{Is access to (essential) medicines protected under international human rights law, and if so, how?}

In that regard the right to health is examined in addition to the right to life and the right to the benefits of scientific progress. The starting point is that the primary objective of human rights is to safeguard the dignity of human beings, an approach we also find within international human rights treaties. ${ }^{3}$ Moreover, this thesis approaches the subject on the basis that all human rights, whether civil, political, economic, social or cultural, are universal, indivisible, interrelated and

3 See the Preamble to the UDHR: Recognition of the inherent dignity and of the equal and inalienable right of all members of the human family is the foundation of freedom, justice and peace in the world. 
interdependent. Global recognition of human rights is now more entrenched than ever before.

Chapter 4 proceeds with an overview of the TRIPS Agreement and investigates the following:

\section{What are TRIPS' minimum standards and flexibilities in relation to the patenting of pharmaceuticals?}

The focus is on the TRIPS Agreement because it is the first international instrument to comprehensively set out minimum standards for the protection of IPRs and, as an annex to the Marrakesh Agreement Establishing the World Trade Organisation, it requires all WTO members to incorporate its minimum standards into their domestic framework. The WTO has widespread membership throughout the world, making TRIPS one of the most influential agreements in the area of IP protection. Furthermore, contrary to previous conventions dealing with intellectual property, the agreements concluded within the WTO framework are subject to a rather robust dispute settlement mechanism.

Chapter 5 continues with a discussion on the central issue of the study, namely the interface between patents and human rights: conflict or coexistence? The starting point is that international trade law can have significant benefits for the protection and promotion of human rights. ${ }^{4}$ Fundamentally international trade may have a positive effect on poverty reduction, with obvious human rights consequences. However this does not necessarily mean that the existing trade law system of the WTO is the best possible system to pursue this goal or even beneficial to promoting and protecting human rights. ${ }^{5}$ Furthermore, both the international human rights and international trade law regimes are considered lex specialis in nature and thus specialised regimes within international law. ${ }^{6}$ This means they are sub-sets of public international law with their own specific regulations, legal instruments pertaining to a particular area of international law, whose rules and regulations are interpreted by their own (quasi-) legal expert bodies. The human rights regime is based on a number of treaties adopted (mainly) under the auspices of the UN and customary international law setting out states' obligations with respect to promoting and protecting human rights. In the context of this research the international trade regime referred to is the regime based on the agreements adopted within the framework of the World Trade Organisation. Chapter 5 poses the central questions of this research regarding the interface between patents and access:

4 See also ROBERT D. ANDERSON and HANNU WAGER, 'Human Rights, Development, and the WTO: The Cases of Intellectual Property and Competition Policy', Journal of International Economic Law, 9:3 (2006), 707-747 at 715; JAMES HARRISON, The Human Rights Impact of the World Trade Organisation (Oxford/Portland: Hart Publishing, 2007) at 38.

5 HARRISON, The Human Rights Impact of the WTO, at 40-43.

6 Ibid. at 51. 
4. Does the right of access to (essential) medicines within the framework of international human rights law conflict with patent standards for pharmaceuticals as required by the TRIPS Agreement? If so, may these allegedly conflicting norms be interpreted harmoniously in order to strike a fair balance between promoting and ensuring access on the one hand and protecting patents on the other?

Here this dissertation is limited to examining the relationship between those provisions of the TRIPS Agreement dealing with the protection of patents and international human rights law, mainly the provisions of the ICESCR, encompassing the right of access to medicines.

Part III sets out a number of case studies in order to examine how developing states cope with these (seemingly contradictory) obligations. Consequently it is asked:

5. Have the developing states examined here complied with both their obligations under international human rights law and the TRIPS Agreement with a view to striking a balance between promoting and ensuring access to (essential) medicines and patent protection for pharmaceuticals?

The countries examined are South Africa (chapter 6), India (chapter 7) and Uganda (chapter 8). The questions that arise are manifold. First, do the states under review recognise access to medicines within their constitutional and/or legislative system, via the right to health and/or life? And what is the legal status of such a right? Is it considered a justiciable right or a policy objective? Furthermore, it is necessary to examine their national intellectual property law systems. Do the selected countries grant patents for pharmaceuticals? Historically, many states did not allow for patent protection of pharmaceutical products; however, this is changing due to the requirements of TRIPS. In that regard are these countries making use of the flexibilities provided for in TRIPS, such as for example compulsory licensing? Finally, the essential question is whether these developing states have been able to, and if so how, strike a balance between protecting patents for pharmaceuticals on the one hand and guaranteeing patients adequate access to medicines on the other within their domestic legal frameworks.

Finally, the study concludes in chapter 9 with a final analysis and set of recommendations.

\section{The Method}

It must be noted that in the field of human rights research, and it seems especially if conducted by lawyers, attention to methodology is often lacking. ${ }^{7}$ It has been

7 FONS COOMANS, FRED GRÜNFELD, and MENNO KAMMINGA, 'A Primer', in Fons Coomans, Fred Grünfeld, and Menno Kamminga (eds.), Methods of Human Rights Research (Antwerp/Oxford/Portland: Intersentia, 2009) at 11. 
argued that human rights scholars often passionately believe in the value of human rights, and as a result, their research implicitly aims at improving respect for human rights. ${ }^{8}$ This is often referred to as "wishful thinking" on the part of the scholar. Human rights are fundamental both to the welfare of the individual as well as to attain broader societal goals. Thus, improving respect for human rights is a value worth contributing to. I do agree however, that human rights should not be considered a goal in themselves, but are merely an instrument to improve respect for human dignity. ${ }^{9}$ In this research I have tried to be as objective as possible and refrain from any "wishful thinking" on my part. Yet in that regard it must also be said that the underlying assumption for this research is that access to medicines, at the very least access to life-saving medicines, is an essential element for human beings to be able to live a life with dignity. There is no doubt that whether one is an academic, human rights activist, politician or a representative of a pharmaceutical corporation, an overwhelming majority believe that patients in need should receive the treatment they require. Yet the divergence lies in the manner in which such a goal should be achieved. The discussion on access to medicines, especially in the early years, has often been framed in good v. evil context; the health activists portrayed as the good characters while the pharmaceutical industry portrayed as the "bad guys". However, there is no pharmaceutical company which is in the business of inventing and manufacturing medicines, which would not want its products (i.e. the medicines) to reach its consumers (i.e. the patients). On the other hand reality is that the pharmaceutical sector is in no way a philanthropic enterprise but a fiercely competitive and commercial industry, whose main focus is to make profit and ensure its existence.

When referring to methodology, what is meant is the approach taken to conduct this legal research: more specifically how the relevant information has been found, how it has been organised and the manner in which the results have been interpreted ${ }^{10}$ As such "[m] ethods link theory and evidence, provide the basic rules of inquiry, and provide the tools that maximise the kind of inferences that are drawn". ${ }^{11}$ That is what this section aims to do. Moreover, legal research has correctly been stated to be the science of competing arguments, where various arguments in favour of, or against, certain rules or outcomes should be identified and thought through. ${ }^{12}$

8 Ibid. at 13; ANDREAS FOLLESDAL, 'Methods of Philosophical Research on Human Rights', in Fons Coomans, Fred Grünfeld, and Menno Kamminga (eds.), Methods of Human Rights Research (Antwerp/Oxford/Portland: Intersentia, 2009) at 233.

9 COOMANS, GRÜNFELD, and KAMMINGA, 'A Primer', at 13.

10 Ibid. at 14.

11 TODD LANDMAN, 'Social Science Methods and Human Rights', in Fons Coomans, Fred Grünfeld, and Menno Kamminga (eds.), Methods of Human Rights Research (Antwerp/Oxford/ Portland: Intersentia, 2009) at 41. See also, TODD LANDMAN, Studying Human Rights (London/New York: Routledge, 2006) at 58 et seq.

12 JAN SMITS, 'Redefining Normative Legal Science: Towards and Argumentative Discipline', in Fons Coomans, Fred Grünfeld, and Menno Kamminga (eds.), Methods of Human Rights Research (Antwerp/Oxford/Portland: Intersentia, 2009) at 51. 
The difficult part therefore, is to decide which of these arguments pro or contra is the better argument. According to Jan Smits this can only be answered in a specific normative setting, and the existing legal system mostly offers the appropriate framework to decide whether an argument should be adopted. As he states: arguments have to pass the test of the system. ${ }^{13}$

There is not one preferred method and this section sets out the different methods used in this study. The general research method employed in this research is desktop research, i.e. based mostly on written sources, supplemented by interviews, applying a "black letter" approach. Furthermore, I have made use of a comparative research approach, the logic of inference and inductive reasoning. Making inferences involves "using facts we know to learn something about facts we do not know" and thus moving beyond pure description. ${ }^{14} \mathrm{An}$ inductive approach entails a reasoning that constructs or evaluates propositions that are abstractions of observations and thus enables us to make generalisations based on individual instances. Conclusions are drawn from the country studies, yet it must be kept in mind that all three countries are unique and there is no such thing as a template solution.

Part of this study is descriptive or expository (the law lex lata) in that it answers questions as to what the law exactly entails by; setting out states' obligations under international law regarding access to medicines and patent protection for pharmaceuticals. In addition this research contains an evaluative element, in that it provides an assessment of the law under review and subjects it to an appraisal from the point of view of coherence (have the selected states complied with their international obligations?) and also from an external viewpoint (does the existing framework allow for the balancing of patents and human rights?). Here shortfalls are identified and improvements suggested. In that regard it is partly normative (the law lex ferenda); how should the existing framework be used to ensure access to medicines and, if access and patents are found to conflict, should access be given primacy over patent protection? In that regard the assessment of the law against an external standard references the notions of human dignity and social justice. As stated above, the underlying assumption of this research is that access to medicines is an essential element for human beings to be able to live a life with dignity.

Another element of the research is that, to a certain extent it is "empirical": namely the information collected through the country studies is seen as empirical data of how conflicting normative positions are being reconciled. "If one's research question is not what the law says but what it should say, this empirical material can be used to test whether some idea or argument was already used elsewhere and how it was received in that other jurisdiction." 15 And thus a comparative research method such as that employed in the country studies may unveil whether solutions adopted

13 Ibid. at 54.

14 LANDMAN, Studying Human Rights, at 3.

15 SMITS, 'Redefining Normative Legal Science: Towards and Argumentative Discipline', at 51-52. 
elsewhere function or not. This can in turn provide interesting examples for other countries dealing with similar issues.

Consequently, the aim of the country studies is to provide insights and in-depth understanding with a view to identifying common problems and possible approaches and solutions rather than empirical generalisations. As such, the country studies provide an insight into how developing countries have implemented the TRIPS Agreement. TRIPS alone, is a poor template for domestic implementation as it lacks definitions of key terms and includes unresolved issues. Much has already been written on this particular issue as can be seen by the sheer amount of literature on this topic. Yet, much of the existing literature takes a rather simplistic approach by reiterating recent developments. Few examine the implications of this issue within a domestic context. Although the patents - access debate very clearly has an international dimension, the solutions provided for such problems need to be implemented and workable in the domestic context. Therefore there is little added value in reiterating the options available for countries struggling with providing access to medicines if these options are not tested on the ground, where they will be used. Therefore part of the country studies will assess to what extent the countries have found workable solutions using the existing framework to enhance access. If so, these may provide inspiration for other countries dealing with similar issues.

In the following sections I will set out the research methods used in more detail. Firstly, I will address what sources have been used and how they have been collected. Secondly, I will address how the sources have been interpreted.

\subsection{Sources}

It is generally accepted that within international law, norms may derive from the following sources: treaties, custom, general principles of law, unilateral acts of states, and acts of international organisations. In that regard reference must be made to article 38.1 of the Statute of the International Court of Justice (ICJ), which, in its subsection (a) - (c), confirms that treaties, customary law, and general principles of law are primary sources of international law. Judicial decisions and doctrine (article 38.1(d) of the Statute) are not considered sources of international law in the strict sense of creating new norms, and thus they are referred to as secondary or subsidiary sources.

To answer the research questions I have looked at both primary and secondary sources. The most relevant treaties are the International Covenant on Economic, Social and Cultural Rights (ICESCR) and the TRIPS Agreement. Customary international law, simply said, is the hardening of a practice into a legally binding norm. ${ }^{16}$ As opposed to treaty law which is only binding on states party to that particular treaty, customary law binds all states, except for those states that from

16 See further MALCOLM N. SHAW, International Law (Fifth edn.; Cambridge: Cambridge University Press, 2003) at 68 et seq. 
the beginning have persistently objected to a rule of customary international law. ${ }^{17}$ According to the wording of article 38.1(b) of the ICJ Statute - "international custom, as evidence of a general practice accepted as law" - a norm only constitutes a rule of customary international law if it fulfils two requirements: it must reflect general state practice, which is the objective component, and a belief that the norm amounts to a binding legal obligation, the subjective component also known as opinio juris sive necessitatis. ${ }^{18}$ It is generally accepted that there is no inherent hierarchy between the sources of international law that is between treaties, customary law, and general principles of law except for norms of jus cogens which enjoy a status of supremacy.

Secondary sources include judicial decisions and doctrine. Here use is made of a variety of different sources, such as journals and books by academic commentators, documents by a variety of international bodies (i.e. UN human rights bodies, the World Trade Organisation, the World Health Organisation), and documents by (non-)governmental organisations. A systematic literature search has been done in databases such as HeinOnline and Westlaw International using selected keywords. The systematic search was complemented by a snowball search which delivered additional material. Relevant international and national journals have been searched online, as well as the websites of international and national (non-governmental) organisations. In addition to Maastricht University Library facilities, which allow a search of all Dutch university libraries, including the Peace Palace Library located in the Hague, a number of other library and institutes have been consulted: the Queen Mary Intellectual Property Archive (London), the library of the Institute of Advanced Legal Studies (London), the library of the World Trade Organisation (Geneva), the Library of the World Intellectual Property Organisation (Geneva) and the library of the Delhi National Law University (New Delhi).

The issue under review is examined from the perspective of international human rights law and international intellectual property law and trade law, within the context of the World Trade Organisation. The primary sources of international human rights law are mainly the treaties concluded within the UN framework. For the issue of access to medicines that is most notably the ICESCR. However, use has also been made of other human rights treaties, such as the Convention on the Elimination of All Forms of Discrimination against Women (CEDAW), United Nations Convention on the Rights of the Child (CRC), and the International Convention on the Elimination of All Forms of Racial Discrimination (ICERD). Additionally, as secondary sources, use has been made of authoritative interpretations by human rights monitoring and export bodies, particularly General Comments issued by the Committee on Economic, Social and Cultural Rights

17 International Court of Justice, Fischeries Case (United Kingdom v. Norway), 18 December 1951, at 131.

18 International Court of Justice, North Sea Continental Shelf Cases (Federal Republic of Germany v. Denmark; Federal Republic of Germany v. Netherlands), 20 February 1969, at $\$ 77$. 
(CESCR) and reports adopted by the Special Rapporteur on the Right of Everyone to the Enjoyment of the Highest Attainable Standard of Physical and Mental Health.

The principal source of WTO law is the Marrakesh Agreement Establishing the World Trade Organisation. With respect to patent protection for pharmaceuticals this dissertation limits itself to the TRIPS Agreement concluded as an annex to the Marrakesh Agreement. Furthermore, the Understanding of Rules and Procedures for the Settlement of Disputes (DSU) is also of great importance here. In addition, to these primary sources of WTO law, use has also been made of other, secondary sources such as acts of WTO bodies and reports of WTO panels and the Appellate Body (AB). Judicial decisions of a panel or Appellate Body (AB) are only legally binding for the parties to the dispute and thus do not constitute legal norms in themselves. However, they are the most important sources with respect to clarifying and interpreting WTO law as adopted reports by a panel/AB are an important part of the WTO acquis, creating legitimate expectations among members and considered by subsequent panels. ${ }^{19}$ Moreover, a panel or the AB increasingly make use of previous panel/AB decisions (and even decisions of other courts or tribunals such as the International Court of Justice or the European Court of Justice) or academic writings. ${ }^{20}$

In approaching the country studies, use has been made of legislation, related policy documents and case law from the national jurisdictions under review, although it must be mentioned here that this research does not contain an exhaustive examination of national case law with respect to the right to health and patent protection. Particularly with respect to the Ugandan case study, retrieving sources was difficult and only possible with the help of contacts in Uganda. Furthermore, as a supplementary source, interviews were conducted with academics and representatives of non-governmental organisations in South Africa, Uganda and India. These interviews were conducted with as many people as possible within the limited time and space frame, and included mostly experts from NGOs which were the most accessible. These interviews were intended to collect information not readily available at the place of research (Maastricht), to receive feedback, hear differing views and experiences, and determine the problem and tools used in the national context regarding access to medicines. ${ }^{21}$

19 WTO Appellate Body Report, Japan - Taxes on Alcoholic Beverages, adopted 1 November 1996a, WT/DS8/AB/R; WT/DS10/AB/R; WT/DS11/AB/R at 14; WTO Panel Report, United States - Import Prohibition of Certain Shrimp and Shrimp Products (Recourse to Article 21.5 DSU by Malaysia), adopted 21 November 2001 (upheld by AB report WT/DS58/AB/RW) 2001, WT/DS58/RW at §109. See also JOOST PAUWELYN, Conflict of Norms in Public International Law. How WTO Law Relates to Other Rules of International Law (Cambridge Studies in International and Comparative Law; New York: Cambridge University Press, 2003) at 110; PETER VAN DEN BOSSCHE and WERNER ZDOUC, The Law and Policy of the World Trade Organisation (Third edn.; New York: Cambridge University Press, 2013) at 51.

20 PAUWELYN, Conflict of Norms in Public International Law, at 50-51.

21 See the bibliography for the list of inteviews conducted. 


\subsection{Manner of Interpretation}

This section will set out the manner of interpretation employed in this research. As stated before, the general approach taken in this study is a "black letter" approach, and therefore the main manner of interpretation is a textual and legal analysis of the issue at hand. Use has been made of the rules of treaty interpretation as set out in the Vienna Convention on the Law of Treaties (VCLT). ${ }^{22}$ Its main article regarding treaty interpretation is article 31 which states that:

"a treaty shall be interpreted in good faith in accordance with the ordinary meaning to be given to the terms of the treaty in their context and in the light of its object and purpose." 23

This general rule of treaty interpretation entails a number of elements presented in the most logical order: the text, the context and the object and purpose of the treaty. ${ }^{24}$ There is no hierarchy regarding the tools of treaty interpretation as found in article 31 . Article 32 of the VCLT on the other hand provides supplementary tools with respect to treaty implementation. ${ }^{25}$

22 It is generally accepted that the principles of treaty interpretation as embodied in articles 31 and 31 VCLT reflect customary international law. See for information on the Vienna Convention on the Law of Treaties ANTHONY AUST, Modern Treaty Law and Practice (2nd edn.; New York: Cambridge University Press, 2007).

23 Article 31 reads as follows:

1. A treaty shall be interpreted in good faith in accordance with the ordinary meaning to be given to the terms of the treaty in their context and in the light of its object and purpose.

2. The context for the purpose of the interpretation of a treaty shall comprise, in addition to the text, including its preamble and annexes:

(a) any agreement relating to the treaty which was made between all the parties in connection with the conclusion of the treaty;

(b) any instrument which was made by one or more parties in connection with the conclusion of the treaty and accepted by the other parties as an instrument related to the treaty.

3. There shall be taken into account, together with the context:

(a) any subsequent agreement between the parties regarding the interpretation of the treaty or the application of its provisions;

(b) any subsequent practice in the application of the treaty which establishes the agreement of the parties regarding its interpretation;

(c) any relevant rules of international law applicable in the relations between the parties.

4. A special meaning shall be given to a term if it is established that the parties so intended.

AUST, Modern Treaty Law and Practice, at 234.

25 Article 32 VCLT reads as follows:

Recourse may be had to supplementary means of interpretation, including the preparatory work of the treaty and the circumstances of its conclusion, in order to confirm the meaning resulting from the application of article 31, or to determine the meaning when the interpretation according to article 31:

(a) leaves the meaning ambiguous or obscure; or

(b) leads to a result which is manifestly absurd or unreasonable. 
The first principle of treaty interpretation is that a treaty must always be interpreted in good faith, which flows directly from the pacta sunt servanda principle. $^{26}$ Thus, a treaty must be interpreted so as to enable it to have its appropriate effects. ${ }^{27}$ Treaty interpretation is limited in that it cannot lead to an interpretation running counter to the clear meaning of treaty terms, but it must be restricted to giving the appropriate meaning to rules of law. Interpretations contra legem are prohibited. ${ }^{28}$ If a certain interpretation of a treaty would lead to a ridiculous or unreasonable outcome, another interpretation must be sought. ${ }^{29}$ Secondly, the treaty terms must be given their ordinary meaning. This will most likely correspond to the drafters' intent, except if the contrary can be established. Moreover a term's ordinary meaning is determined by taking into account the context of the treaty and its object and purpose. ${ }^{30}$

The context of a treaty is comprised of the preamble and annexes, in addition to the text of the treaty of course. Article 31.2 further states that "any agreement relating to the treaty which was made between all the parties in connexion with the conclusion of the treaty" and "any instrument which was made by one or more parties in connexion with the conclusion of the treaty and accepted by the other parties as an instrument related to the treaty" will also be part of the context for the purpose of treaty interpretation. Paragraph 3 of article 31 continues stating that (a) "any subsequent agreement between the parties regarding the interpretation of the treaty or the application of its provisions"; (b) "any subsequent practice in the application of the treaty which establishes the agreement of the parties regarding its interpretation" and (c) "any relevant rules of international law applicable in the relations between the parties" shall, together with the context, be taken into account when interpreting a treaty. The underlying notion is that treaties should be interpreted in a manner that accords with the intention of the drafters and subsequent practice by parties. Subsequent practice in the application of a treaty, which established agreement among the parties regarding its interpretation, is an important and well-established element of treaty interpretation. ${ }^{31}$ For example, any normative elements which have developed under the operation of the WTO would be considered subsequent practice. ${ }^{32}$ The Appellate Body has explained what it considers to be "subsequent practice", namely a "concordant, common and consistent sequence of acts or pronouncements which is sufficient to establish a discernible pattern implying the

26 Art. 26 VCLT.

27 See also the principle of effective treaty interpretation (ut res magis valeat quam pereat): when a treaty is open to two interpretations one of which does and the other does not enable the treaty to have appropriate effects, good faith and the objects and purposes of the treaty demand that the former interpretation should be adopted. PAUWELYN, Conflict of Norms in Public International $L a w$, at 247 et seq.

Ibid. at 244.

AUST, Modern Treaty Law and Practice, at 234.

Ibid. at 235.

Ibid. at 241.

PAUWELYN, Conflict of Norms in Public International Law, at 49. 
agreement of the parties regarding its interpretation." 33 An isolated act in that regard is not sufficient. Subsequent practice may be found in the actions of the international organisation itself or its bodies, or it may be found in state practice by its members. The manner in which a treaty is applied, if such practice is common among the parties and consistent, is generally a good indication of the parties' intention. ${ }^{34}$

Furthermore, a treaty must be interpreted in the wider context of general international law, consistent with general international law, except if the treaty itself provides otherwise, although rules of a jus cogens nature cannot be replaced. ${ }^{35}$ There is a strong presumption against normative conflict in international law. ${ }^{36}$ Article $31.3 \mathrm{c}$ of the VCLT states that, together with the context: "any relevant rules of international law applicable in the relation between the parties" shall be taken into account. This reflects a "principle of systemic integration" emphasising the unity of international law where rules should not be considered in isolation of general international law. ${ }^{37}$

Consequently, the main focus of article 31 VCLT for treaty interpretation is to clarify the meaning of the text of a treaty. Therefore, when interpreting a treaty one has to look at the treaty as a whole, include all relevant materials and assess their respective weight and value. Moreover, article 32 VCLT states that recourse may also be had to supplementary means of interpretation "to confirm the meaning resulting from the application of article 31, or to determine the meaning when the interpretation according to article 31: (a) leaves the meaning ambiguous or obscure, or (b) leads to a result which is manifestly absurd or unreasonable." 38 Supplementary means of interpretation include the preparatory work and the circumstance of a treaty's conclusion. However, the travaux préparatoires of a treaty may be

33 Japan - Taxes on Alcoholic Beverages, at 12-13.

34 AUST, Modern Treaty Law and Practice, at 241.

35 Ibid. at 250.

36 INTERNATIONAL LAW COMMISSION, Fragmentation of International Law: Difficulties Arising from the Diversification and Expansion of International Law. Report of the Study Group of the International Law Commission. Finalised by Martti Koskenniemi (UN Doc. A/ CN.4/L.682; 2006) at §37; PAUWELYN, Conflict of Norms in Public International Law, at 207.

37 INTERNATIONAL LAW COMMISSION, Fragmentation of International Law, (UN Doc. A/ CN.4/L.682) at \$413 et seq; PAUWELYN, Conflict of Norms in Public International Law, at 253. See for a discussion on the role of article 31.3(c) VCLT with respect to the interpretation of the TRIPS Agreement in light of broader societal interests, such as public health chapter 5, section 5.2.

38 There are also other supplementary means of treaty interpretation not codified in the Vienna Convention on the Law of Treaties such as for example taking into account other treaties on the same subject which use the same or similar terms, or assuming that parties to a treaty did not intend the treaty to be incompatible with customary international law. Other methods of treaty interpretation include: lex posterior derogat legi priori (when two rules apply to the same matter, the later in time prevails), lex specialis derogat legi generali (a specific rule prevails over a general rule). See AUST, Modern Treaty Law and Practice, at 249; KOEN DE FEYTER, 'Treaty Interpretation and the Social Sciences', in Fons Coomans, Fred Grünfeld, and Menno Kamminga (eds.), Methods of Human Rights Research (Antwerp/Oxford/Portland: Intersentia, 2009) at 215. 
incomplete or misleading and are then considered less valuable than other elements. ${ }^{39}$

With respect to the country studies, a comparative analysis is conducted. National legislation and case law is interpreted in line with the legal practice from that particular jurisdiction. In that regard, use has been made of doctrine and supplementary interviews. Furthermore, it must be noted that there is a difference between a formal commitment at the international level (signing and ratifying a treaty) and implementation of that commitment into the domestic context through (constitutional) legislation and policy. A formal commitment at the international level is important for the universal realisation of human rights, however, in a system with weak enforcement mechanisms such as the UN human rights regime, it does not necessarily lead to change on the ground. Many states ratify human rights treaties, yet they continue to violate human rights. Therefore, the forum in which human rights can be most effectively enforced is in the national level context. That is why it is important to analyse the issue of access to medicines from a domestic perspective. ${ }^{40}$ Moreover, it must be mentioned that this study measures the realisation of human rights obligations with regard to access to medicines from a legal positive approach, namely addressing implementation within the national legislative and policy framework. However, no inferences are made whether such a rights is fulfilled in practice, i.e. de facto realisation. ${ }^{41}$

\subsection{The Selection of Countries}

The aim of the country studies is to provide insights and in-depth understanding with a view to identifying common problems and possible approaches and solutions rather than empirical generalisations. Therefore use has been made of a purposeful sampling strategy. ${ }^{42}$ These countries were not selected because they are similar; actually it is quite the opposite. Although there are similarities between these countries, for example all three countries suffer from a serious public health burden and operate in a resource constrained setting (although to varying degrees), there are many differences. It must also be mentioned that other countries would also provide interesting case studies, for example Brazil and China. However, due to practical considerations such as time limits, availability of materials and language barriers it was decided to limit the number of country studies to three, as choosing fewer countries would allow a more in-depth study of each country.

39 AUST, Modern Treaty Law and Practice, at 244; PAUWELYN, Conflict of Norms in Public International Law, at 252-253.

40 LANDMAN, Studying Human Rights, at 80-81.

$41 \quad$ Ibid. at 76.

42 As opposed to a probability sampling strategy which intends to derive generalisations from a sample country which could then be applied to other countries of the same category. See DENISE PRÉVOST, Balancing Trade and Health in the SPS-Agreement: The Development Dimension (Nijmegen: Wolf Legal Publishers, 2009) at 163. 
A number of selection criteria were used to determine which countries would provide good case studies: The focus of this research is on developing countries as there is a clear connection between a country's level of wealth and human rights protection (namely that wealthy countries have fewer violations of human rights and vice versa). ${ }^{43}$ This seems especially true for socio-economic rights, which require positive action and resources such as the right to health and access to medicines. Low-income status is therefore a first criterion. In that regard the World Bank Atlas Method was used to classify countries according to income. ${ }^{44}$ Secondly, the countries should be WTO members and states parties to at least a number of UN human rights treaties protecting economic, social and cultural rights, preferably the ICESCR. Here it must be noted that South Africa has signed but not ratified the ICESCR, yet due to its inclusion of similar language to the ICESCR provisions in its constitution it was considered to be a valuable country study. Thirdly, countries should be experiencing a public health crisis and struggling with providing access to medicines. Finally, a practical consideration is that all legal texts in the three countries should be in English, so that there would be no problems with translations. In addition, materials for South Africa and India were relatively accessible, which was not the case for Uganda. Each of these countries provides a unique set of circumstances that are interesting for the issue at hand.

South Africa ${ }^{45}$ is classified as an upper middle income country with a GNI per capita of US\$ 6.090 (2010); it has a poverty headcount ratio of $23 \%$ of the population, ${ }^{46}$ life expectancy of 52 years ${ }^{47}$ and an under-5 mortality rate of 56.6. ${ }^{48}$ Although it is one of the most developed and influential countries in sub-Saharan Africa, South Africa is experiencing one of the worst HIV/AIDS epidemics worldwide. It is a young democracy with a progressive constitution protecting the right to health. This is also shown by case law of the South African Constitutional Court which has deemed the right to health to be justiciable and enforceable. South Africa has been involved in a conflict with the pharmaceutical industry over the issue of access to medicines, which was one of the first instances this issue received

43 LANDMAN, Studying Human Rights, at 94-95.

44 The World Bank's main criterion for classifying economies is gross national income (GNI) per capita. Economies are divided according to 2010 GNI per capita, calculated using the World Bank Atlas Method. The groups are: low income, $\$ 1,005$ or less; lower middle income, $\$ 1,006-$ $\$ 3,975$; upper middle income, $\$ 3,976$ - $\$ 12,275$; and high income, $\$ 12,276$ or more. See http://data.worldbank.org/about/country-classifications last accessed 27 October 2011.

45 See http://data.worldbank.org/country/south-africa?display=graph last accessed 27 October 2011.

46 National poverty rate is the percentage of the population living below the national poverty line. National estimates are based on population-weighted subgroup estimates from household surveys.

47 Life expectancy at birth indicates the number of years a newborn infant would live if prevailing patterns of mortality at the time of its birth were to stay the same throughout its life.

48 Under-five mortality rate is the probability per 1,000 that a newborn baby will die before reaching age five, if subject to current age-specific mortality rates. 
public attention. Moreover, it is a good example of how an active civil society can reach tangible results in favour of access.

India ${ }^{49}$ is classified as a lower middle income country with a GNI per capita of US\$ 1.330 (2010); it has a poverty headcount ratio of $37,2 \%$ of the population, life expectancy of 65 years, and an under-five mortality rate of 63. Although still a developing country, India is an up-and-coming economic power house. For years it has made use of the lack of (product) patent protection for pharmaceuticals to copy and produce pharmaceuticals, resulting in it now being one of the largest producers and exporters of generic medicines. However, the end of the transitional periods of the TRIPS Agreement for India in 2005 has lead to significant changes in its patent law. In implementing its TRIPS obligations, it has in several instances tried to make use of the flexibilities available, such as for example section $3 \mathrm{~d}$ of its Patents Act which attempts to prevent ever-greening. ${ }^{50}$ Moreover, although the Indian Constitution protects health as a non-justiciable directive principle of state policy its extremely progressive judiciary has interpreted the right to life to include health rights indirectly making it a justiciable right.

Finally, Uganda ${ }^{51}$ is classified as a low income country with a GNI per capita of US\$ 500 (2010); it has a poverty headcount ratio of $24,5 \%$ of the population, life expectancy of 53 years and an under-five mortality rate of 98,9. Being a leastdeveloped country it has high poverty and morbidity and mortality levels. Even so, it is one of the few African countries that has had declining HIV rates and performs above expected in its response to HIV/AIDS. ${ }^{52}$ The costs of antiretroviral medicines to manage HIV have decreased in the last two decades, although these are still unaffordable for many Ugandans. Most medicines are imported from countries such as China and India, and with the TRIPS' transition period ending for India prices for second generation pharmaceuticals are likely to rise in the future. This is a serious problem as Uganda has a limited drug manufacturing capacity. Moreover, Uganda has until 2021 to implement the TRIPS standards yet it has already tabled a bill amending the Patents Act to bring it in line with the TRIPS Agreement. Finally, Uganda does not have a constitutional right to health, but it protects health through National Objectives and Directive Principles of State Policy.

Developing countries are far from homogeneous, a fact that is obvious but not always acknowledged. Differences between developing countries can be found regarding their inequalities of income and wealth, social and economic structures and technical and scientific capacities. Therefore, the determinants of poverty and

49 See http://data.worldbank.org/country/india?display=graph last accessed 27 October 2011.

50 With "ever-greening" is referred to the practice of the pharmaceutical industry to effectively extend the term of protection for patented pharmaceuticals by obtaining related patents for minor modifications made to the original product, new delivery systems for the pharmaceuticals, or new uses of the pharmaceutical etc.

51 See http://data.worldbank.org/country/uganda?display=graph last accessed at 27 October 2011.

52 See for example CHRIS DESMOND et al., 'Relative Response: Raking Country Responses to HIV/AIDS', Health and Human Rights, 10:2 (2008), 105-119. 
public health problems and the appropriate policies to address these will vary accordingly between countries. The same is true for policies on IPRs; their impact will vary according to socio-economic circumstances. ${ }^{53}$ Thus it is not possible to draw broad generalisations from the country studies as such, however, they do illustrate that there are certain common problems with regard to implementing TRIPS standards and protecting access to medicines.

\subsection{Limitations of the Study}

This sub-section will set out the limitations of this research, which are mostly of a practical nature. ${ }^{54}$ The most important of which is the limited time frame, and especially the limited time spent in the countries reviewed. In that regard the list of experts I have interviewed during my research visits is by no means an exhaustive list. I have contacted as many experts as possible from a range of different backgrounds, from lawyers to health workers. Yet, the selection of interviewees depended mostly on the willingness and time of experts to talk with me. In addition I am not legally trained in the legal systems reviewed, and finding and selecting all relevant information (especially in the case of Uganda) was not easy. This was exacerbated by the overload of information available on the topic making it near to impossible to have read every article and news item on the issue of access to medicines.

Furthermore, the focus here is on states' obligations under international law. Although it is interesting to examine the role of other actors regarding access to medicines especially pharmaceutical corporations, the choice was made to take a state-centred approach, specifically developing countries. The nature of international trade law and human rights law is that states are the primary duty bearers for the implementation of international obligations in the national context. Thus, state actors are the natural focus of this analysis. ${ }^{55}$ In addition, it must be noted that this research focuses on states' human rights obligations within their own national system as opposed to extra-territorial human rights obligations in the context of access to medicines, such as a possible duty for developed states to assist developing states in complying with their human rights obligations.

Finally, it must be noted that this research does not take account of any developments after April 2013.

53 CIPR, Integrating Intellectual Property Rights and Development Policy. Report of the Commission on Intellectual Property Rights, UK Commission on Intellectual Property Rights, (2002) at 2.

54 COOMANS, GRÜNFELD, and KAMMINGA, 'A Primer', at 15.

55 HARRISON, The Human Rights Impact of the WTO, at 61. 



\section{Chapter 2 Access to Medicines: the Problem}

\section{INTRODUCTION}

The problem dealt with in this dissertation concerns the issue of access to essential medicines by patients in the developing world. The core of the problem is that a great number of patients in developing countries do not have adequate access to essential medicines for a variety of reasons, resulting in a devastating effect on public health world-wide. The research question addressed here is the following: Does patent protection interfere with patients' access to essential medicines? And, how do we define "interfere", "access" and "essential medicines"?

The WHO considers adequate access to medicines a priority health issue and stated that improvement in access to essential medicines and vaccines for patients could result in saving more than 10 million lives within one year. ${ }^{56}$ The WHO estimates that the share of people lacking access to medicines has fallen since 1975, when half of the world's population lacked sufficient access to essential medicines to a third of the world's population in 1999. However, due to a rise in the world's population, the absolute number of people lacking access has not changed much and is still at around 1.7 billion. ${ }^{57}$ The majority of patients lacking access, around $80 \%$ (that is 1.3 billion people) live in low-income countries. Developing countries are disproportionately affected due to high disease burdens, lack of resources, poor health care systems, and no or insufficient research and development targeted at diseases mainly prevalent in developing countries. In the developing world, and especially Sub-Saharan Africa mortality rates are high due to the large number of people falling ill to infectious diseases, like AIDS which is responsible for $19 \%$ of all deaths. Other diseases like malaria, pneumonia, diarrhoea, measles and tuberculosis also claim many lives. Although life expectancy rates have increased in the last century, they vary greatly in different regions of the world. ${ }^{58}$ It is the developing world that suffers most from these kinds of infectious diseases. Therefore the focus of this dissertation is on access within the context of developing countries.

The WHO finds that there is a correlation between a state's wealth and the degree of access to medicines its population enjoys. This correlation between economic wealth and access to medicines relates to the broader, underlying problem

56 WHO, 'Equitable Access to Essential Medicines: A Framework for Collective Action', Policy Perspectives on Medicines, 8 (2004).

57 WHO, The World Medicines Situation 2004 (2004) at 61.

58 JÖRG SCHAABER, Keine Medikamente Für Die Armen? Hindernisse Auf Dem Weg Zu Einer Gerechten Arzneimittelversorgung Am Beispiel AIDS (Frankfurt am Main: Mabuse-Verlag, 2005) at $17-18$. 
of how national health systems are organised, financed and delivered. ${ }^{59}$ Improvement in living conditions, better sanitary conditions, clean water and sufficient nutritious food could prevent many people from falling ill to infectious diseases; but if people do fall sick, proper medical treatment is essential and can be life-saving. Good medical treatment is in many cases not possible without the use of medicines. Here the cost factor of medicines plays an important role in the degree of access enjoyed. ${ }^{60}$ This does not automatically entail that medicines are the easiest and most effective choice of treatment. Proper effective treatment requires the right medicinal substance at the right time, taking account of the patient's social and medical situation. But nowadays it commonly accepted that medicines are often a very useful component in the treatment of many diseases. ${ }^{61}$

The global HIV epidemic is an infectious diseases that has spread massively world-wide during the second half of the last century, and is still spreading. It has had a devastating effect on states and individuals alike. HIV/AIDS can be contracted through unprotected sexual intercourse, blood transfusions with contaminated blood and transmitted from a mother infected with the virus to her unborn child during pregnancy or while breastfeeding. ${ }^{62}$ To control the disease and give patients a chance at a dignified life, extensive therapy and medication is required. More than 20 years ago the diagnosis of HIV/AIDS would in most cases have meant a definite death sentence for the unlucky patient. Fortunately, today, through the development of new antiretroviral medicines it has become possible to live a relatively high-quality life with this diagnosis. HIV, or human immunodeficiency virus, is a retrovirus that attacks the human immune system weakening it in time, which will eventually result in AIDS, acquired immune deficiency syndrome. People infected with HIV/AIDS have such weak immune systems that they are vulnerable to infections which the immune system of healthy person would fight off easily, so-called opportunistic infections. These infections are fatal in most cases. There is no vaccine or cure for the disease; however, a variety of antiretroviral therapy is available. There are several groups of antiretroviral therapy which attack the virus in different ways, but the effect is the same, it stops the virus from replicating. A combination of ARVs (HAART) depending on the specific situation of the patient, taken regularly on a daily basis is generally the best way to treat the disease. The patient has to take medication for the rest of his or her life to make sure that the virus is contained. If treatment is interrupted this can lead to resistance of the AIDS virus to the ARVs. There are a variety of reasons why patients do not or cannot adhere to their ARV treatment, including the lack of access, whether physical or economic, to

59 WHO, The World Medicines Situation 2004, at 63.

60 SCHAABER, Keine Medikamente Für Die Armen?, at 24.

61 Ibid. at 33-34.

62 BBC NEWS, 'HIV', <http://news.bbc.co.uk/2/hi/health/medical_notes/4756660.stm>, accessed 12 March 2008. 
antiretroviral drugs. Currently, over 40 million people are living with HIV/AIDS globally. 63

It is difficult to determine what the exact long-term impact of the HIV/AIDS pandemic on a developing country will be. However, looking at the development and characteristics of this particular disease there are a number of logical consequences. Firstly, morbidity and mortality rates will rise; and secondly, it will have negative economic and social consequences. This is in part due to the fact that HIV/AIDS targets the relatively young, economically active section of the population. ${ }^{64}$ This has severe social and economic consequences, such as for example the loss of workforce but also the increase of orphaned children which, if lucky, are taken in by relatives (often grandparents) or are otherwise forced to fend for themselves. Sadly, in many cases children are also infected with HIV/AIDS which leads to a vicious circle.

The core problem is that although effective medication and treatment exists which increases life expectancy and the quality of life of patients dramatically, the majority of patients in the developing world, have no or insufficient access to existing antiretroviral therapy, let alone access to new and more effective medicines. When antiretroviral medicines were introduced, their treatment costs reached over US $\$ 10,000$ per patient per year. ${ }^{65}$ In 2001 the Indian generic manufacturer Cipla announced that it would produce and supply a generic version of the antiretroviral triple therapy that would be marketed at the cost of about US\$ 350 per patient per year. ${ }^{66}$ This was possible because India at that time did not allow for product patents for pharmaceuticals. Compared to the initial price of around the US\$10,000 this is an enormous reduction. Other pharmaceutical manufacturers also started producing antiretroviral medicines in generic form and prices for ARVs continued to fall further. ${ }^{67}$

Activists argue that patents have a significant negative effect on access, as they raise prices to an unaffordable level for poor patients and poor countries. ${ }^{68}$ The

63 Ibid.

64 BERGER, 'Tripping over Patents: AIDS, Access to Treatment and the Manufacturing of Scarcity', at 159.

65 WHO, 'Access to Medicines', WHO Drug Information, 19:3 (2005), 236-241.

66 UN HUMAN RIGHTS COUNCIL, Report of the Special Rapporteur on the Right of Everyone to the Enjoyment of the Highest Attainable Standard of Physical and Mental Health, Anand Grover (UN Doc. A/HRC/11/12; 2009) at §20.

67 BENJAMIN CORIAT, 'Introduction: A New Stage in the Fight against the HIV/AIDS Pandemic. An Economic Perspective', in Benjamin Coriat (ed.), The Political Economy of HIV/AIDS in Developing Countries. TRIPS, Public Health Systems and Free Access (Cheltenham: Edward Elgar, 2008) at 9-10.

68 See for example 3D, Switzerland. Missing Policy Coherence: Trade Interests Overriding Right to Health? Report Submitted to the CESCR Pre-Sessional Working Group, 3D $\rightarrow$ Trade Human Rights - Equitable Economy, (23-26 November 2009); BUKO PHARMAKAMPAGNE, Indien: Behandlung Von AIDS-Patientinnen Gefährdet, BUKO PharmaKampagne, Pharma-Brief Nr.3/2005, (April/May 2005); MSF, HIV/AIDS Treatment in Developing Countries: The Battle for Long-Term Survival Has Just Begun, Médecins Sans 
pharmaceutical industry, however, argues that patents are absolutely necessary to regain their expenditure for the research and development (R\&D) invested in new pharmaceuticals. This chapter will address this debate and set out the underlying aspects of the access issues. The question posed here is whether patents negatively impact access. Here, generic medicines must be distinguished from the originator or innovator branded products, the latter being innovative medicines often protected by patents (and/or the protection afforded in some instances by regulatory marketing exclusivity) and the former being copies of the originator products that are not (or no longer) protected by patents or marketing exclusivity. ${ }^{69}$ Genuine generic medicines are equivalent in composition to the originator product.

This chapter first addresses the issue of access to medicines from the perspective of developing countries (section 2), defining the concepts of "essential medicines" (section 2.1.) and "access" (section 2.2.). Secondly, the importance of the particularities of medicines as public goods and the nature of the pharmaceutical market is addressed in section 3. Section 4 continues with a brief description of what patents are, their historic origins (section 4.1.1.) and rationales (section 4.1.2), particularly focusing on their incentive to innovate function in section 4.2. Finally, section 5 addresses the research question: does patent protection interfere with access to medicines?

\section{Access to Essential Medicines}

This section will address the issue of access to essential medicines more in depth. It will first define what is meant by "essential medicines", and secondly it will examine the concept of "access." The issue is addressed from the perspective of developing countries, and it will be examined whether there is sufficient evidence to conclude that essential medicines are not adequately available and affordable in developing countries.

\subsection{Defining Essential Medicines}

The term essential medicines first appeared in the 1970s, when, in a 1975 resolution, the World Health Assembly (WHA) requested the WHO to assist with the development of national medicine policies. In 1977 the WHO developed the first model list of essential medicines. A year later, at the WHO/UNICEF Conference on Primary Health in Alma-Ata, essential medicines were considered part of the concept of primary health care. The WHO Action Program on Essential Drugs was

Frontière Campaign for Access to Essential Medicines, (2009); OXFAM, Investing for Life. Meeting Poor People's Needs for Access to Medicines through Responsible Business Practices, Oxfam International Oxfam Briefing Paper 109, (November 2007).

69 FREDERICK M. ABBOTT and GRAHAM DUKES, Global Pharmaceutical Policy. Ensuring Medicines for Tomorrow's World (Cheltenham: Edward Elgar, 2009) at 2. 
established in 1979. The First Model List of Essential Drugs identified 208 individual medicines that could provide safe and effective treatment for the majority of infectious and non-infectious diseases. ${ }^{70}$

Currently, the WHO defines the term essential medicines as those medicines that "satisfy the priority health care needs of the population." "71 This definition intends that essential medicines should be "available within a national context at all times, in all adequate amounts, in the appropriate dosage forms and with the assured quality and at an affordable price for individuals and the community." 72

The WHO considers the concept of essential medicines a global, forwardlooking concept. It finds that it should be flexible and adaptable to different domestic situations. Taking into account the recent spread of infectious diseases like, HIV/AIDS, tuberculosis and malaria, and the subsequent increase in medicine expenditure for states, the concept of essential medicines can play a crucial role. Effective and speedy medical treatment of infectious diseases is vital for a state's public health. The concept of essential medicines is of importance because no state has the capacity to make all necessary medicines and medical therapies publicly available. It is vital that countries spend their public resources as efficient as possible for the benefit of the whole population. This is especially the case for those countries with limited resources. Thus, a careful assessment of a state's public health situation leading to a selection of a number of medicines considered to be essential in the specific national context, will result in a better management of medicines, a higher quality of health care and a cost-effective use of resources. Here national or regional lists of essential medicines, including treatment guidelines, can be of great assistance to states. Finally, according the WHO, numerous studies have shown the positive impact on public health of the concept of essential medicines. ${ }^{73}$

As stated above, the WHO started developing its first Model List of Essential Medicines in 1977. Since then it has revised and updated the Model List every two years. The most significant addition to the WHO Model List has been the Essential Medicines List for Children in 2007. The Model List is intended as a guide for states to create their own national or regional lists of essential medicines. ${ }^{74}$ The WHO Model Lists assist states herewith by identifying cost-effective medicines for certain priority diseases and by stating the reasons for inclusion in the list based on scientific evidence and considered their value for money. It is important that states

70 SCHAABER, Keine Medikamente Für Die Armen?, at 37-39; WHO, 'Essential Medicines', <www.who.int/medicines/services/essmedicines_def/en/print.html>, accessed 28 January 2008. WHO, 'The Selection of Essential Medicines', Policy Perspectives on Medicines, 4 (2002).

Ibid. at 2.

Ibid; WHO, The World Medicines Situation 2011. Selection of Essential Medicines (2011).

The Model List consists of a core list and a complementary list. The core list includes the medicines needed for a basic health-care system, listing the most efficacious, safe and costeffective medicines for priority diseases and conditions. The complementary list presents essential medicines for priority diseases which are effective and safe, but for which specialized health-care facilities or experience may be needed. 
create their own list of essential medicines based on the specific public health needs of their country/region.

In the national context the selection of essential medicines should start with identifying the most common health problems in a country and developing evidence-based standard treatment guidelines to assist prescribers in deciding on the appropriate treatment for specific health problems. Medicines that are recommended in the national standard treatment guidelines should also then be listed in the country essential medicines list. $^{75}$ The main criterion for deciding if a medicine is essential is its effectiveness and according to the WHO the high cost of an effective medicine should not automatically bar its inclusion in the essential medicines list. $^{76}$ Yet considerations of cost-effectiveness are also of importance. Generally, regulatory market approval of medicines takes into account the safety and efficacy of a new medicine, but it rarely compares the new medicine's efficacy and cost to that of other already existing medicines. Therefore one should evaluate and compare new and existing medicines to come up with a list of essential medicines specific to the public health needs of a particular state taking into account efficacy, safety and cost. The WHO Expert Committee on the Selection and Use of Essential Medicines uses the following selection criteria:

- the existence of sound and adequate evidence of efficacy and safety of a certain medicine;

- relative cost-effectiveness;

- the availability of medicines in a form which guarantees adequate quality and stability under the anticipated conditions of storage and use; and

- local considerations. ${ }^{77}$

It is crucial that essential medicines lists are updated regularly, to reflect changing therapeutic needs, include newly developed medicines and therapies, and that they are concordant with local treatment guidelines and aligned with the logistics and budget of the national health system. ${ }^{78}$ When used correctly the concept of essential medicines is an important tool in a modern national health care system.

In addition to drawing up a national list of essential medicines, countries should also be aware of medicine use and its effects on public health. The WHO estimates that worldwide over half of all medicines are prescribed, dispensed or sold inappropriately, and half of all patients fail to take their medication as prescribed or dispensed. ${ }^{79}$ Irrational use of medicines is not only wasteful but can be harmful for the patient and society at large. For example, in extreme situations it may lead to the

\footnotetext{
75 WHO, The World Medicines Situation 2011. Selection of Essential Medicines, at 3.

76 Ibid. at 4.

77 SCHAABER, Keine Medikamente Für Die Armen?, at 40; WHO, 'The Selection of Essential Medicines' Policy Perspectives on Medicines, 4 (2002).

78 WHO, The World Medicines Situation 2011. Selection of Essential Medicines, at 6.

79 WHO, The World Medicines Situation 2011. Rational Use of Medicines (2011) at 2.
} 
death of the patient, inappropriate overuse (especially of antibiotics) may lead to resistance and the use of unsterile injections is associated with the spread of blood borne infections, such as hepatitis B and $\mathrm{C}$ and HIV/AIDS.

\subsection{Access}

The issue of access to medicines is a complex one. To guarantee sufficient access to medicines worldwide some major challenges need to be overcome, including the broader, underlying problems relating to the organisation and performance of national health systems, which make this issue so complex. Around a third of the world population is estimated to have inadequate access to essential medicines. The regions of Africa and Asia are hit the hardest; and in certain parts of these regions the percentage of people lacking access is even as high as $50 \% .{ }^{80}$ Subsequently, the question arises what can be understood by "access" to essential medicines; when does a patient have sufficient access to essential medicines?

The Committee on Economic, Social and Cultural Rights has interpreted the human right to health to include access to essential drugs in its General Comment No. 14 on the right to the highest attainable standard of health (article 12 ICESCR). The provision of essential drugs, as defined by the WHO Action Programme on Essential Drugs, is considered to be one of the core obligations of states parties to ensure that the right to health is fulfilled. ${ }^{81}$ The Committee finds that the right to health includes the availability of essential medicines, meaning that sufficient amounts of essential medicines must be present within the state party. Additionally accessibility of essential medicines must be ensured without discrimination, which entails both physical accessibility, all patients must be able to safely reach health facilities, and economic accessibility, entailing that health services and goods, such as medicines, are affordable for all. ${ }^{82}$ Finally, health facilities, services and goods must be acceptable, i.e. respectful of medical ethics and culturally appropriate, and of good quality. ${ }^{83}$

In addition, the WHO has developed a framework dealing with the concept of access. This framework intends to act as a guide. It consists of four medicinesspecific elements which need to be in place so as to guarantee that patients can access medicines whenever and wherever they need to:

1. Rational selection and use of essential medicines, based on national lists of essential medicines and treatment guidelines;

2. Affordable prices for governments, health care providers and individuals;

80 WHO, The World Medicines Situation 2004, at 61.

81 CESCR, General Comment No. 14. The Right to the Highest Attainable Standard of Health (UN Doc. E/C.12/2000/4; 2000) at $\S 43(d)$.

82 Ibid. at $\$ 12$.

83 Ibid. at $\$ 12(c) \&(d)$. 
3. Fair and sustainable financing of essential medicines as part of the national health care system through adequate funding levels and equitable prepayment systems, to ensure that the poor are not disproportionately affected by medicine prices; and

4. Reliable health and supply systems to ensure efficient and a locally-appropriate combination of public and private service providers. ${ }^{84}$

Firstly, states are bound by their limited resources and will not be able to supply their population with all necessary medicines and medical therapies. Rational selection and use of essential medicines, therefore, is vital for the success of a national drug policy and can be achieved by adopting a list of essential medicines and treatment guidelines according to the criteria proposed by the WHO. As stated above, a list of essential medicines should be developed with the specific health needs of a state/region, cost-effectiveness and safety of the concerned pharmaceutical product in mind. Institutionalising rational selection and use enables states to spend their limited resources efficiently but still respond to the health needs of the greater part of their population. ${ }^{85}$ Of course, practice rarely corresponds with theory; and merely having, but not using, such a list is not sufficient.

Secondly, medicines must be affordable both for states and individuals as this is essential for the issue of access to medicines. It is undesirable that states spend great amounts of their resources on medicines that can also be procured more cheaply. Additionally in many low- and middle-income countries medicines are paid for privately, by the patients themselves, and they are neither supplied nor refunded by the state.

Thirdly, states can make use of several strategies to influence medicine prices and obtain the best price: for example via the selection and purchasing process, price regulation, or establishing a differential pricing system. Also, focusing on (local) generic production of pharmaceuticals can lead to a decrease in medicine expenditure. Generic production is one of the best methods to increase competition within the pharmaceutical market and subsequently reduce prices. Price transparency is also an important tool for governments to negotiate the best price for medicines. The reduction of taxes and duties on pharmaceutical products can also have a marked impact on affordability. Some pharmaceutical corporations give voluntary discounts on a specific patented medicine to buyers in low-income countries; see for an example the "Accelerated Access Initiative." However the modest impact of such approaches and their voluntary nature are problematic. Alternatively, some pharmaceutical companies have offered patent waivers to allow generic production. The WHO encourages states to collaborate with the pharmaceutical industry to achieve a differential pricing framework. Such

\footnotetext{
84 WHO, 'Equitable Access to Essential Medicines: A Framework for Collective Action'; WHO, The World Medicines Situation 2004, at 64-65.

85 WHO, The World Medicines Situation 2004, at 65.
} 
differential pricing would relate medicine prices to governments' purchasing power. ${ }^{86}$

Finally, a reliable supply system entails a good distribution system, meaning that essential medicines are at all times and at all levels of the health system available and physically accessible for patients. According to the WHO, "distribution" is the process which delivers medicines from their origin to their destination, and "timely" entails that medicines are distributed within their expiry date. ${ }^{87}$ In lowincome countries, the physical accessibility of medicines is often problematic.

Thus, we can conclude that the term "access" has several dimensions and entails the availability of those medicines considered essential in the specific national context, affordability and physical accessibility on a non-discriminatory basis, as well as acceptability and quality.

\subsection{Availability and Affordability in Developing Countries}

As addressed above the concept of access includes physical accessibility, availability and affordability of medicines. The availability and prices of medicines are therefore key indicators of access to treatment. High medicine prices, especially in developing countries, may result in these medicines becoming unaffordable for patients, thus limiting access. So is there sufficient evidence to conclude that essential medicines are not adequately available and affordable in developing countries? Of course it is not possible to answer this question in general as availability and affordability of medicines differs greatly between regions and even within states. However, the purpose of this section is to approach the issue of access to medicines from the perspective of developing and least-developed countries that continuously struggle with a systematic lack of resources, also in the area of health.

The WHO together with the non-governmental, non-profit organisation Health Action International (HAI), as part of a request by the 2000 World Health Assembly resolution ${ }^{88}$ to formulate a global strategy for the prevention and control of noncommunicable diseases, has developed a methodology to collect data on medicine prices, availability and affordability of medicines. ${ }^{89}$

Availability of medicines is expressed by the percentage of health care facilities that are able to provide a particular medicine. Availability is considered very low

86 WHO, 'Equitable Access to Essential Medicines: A Framework for Collective Action'; WHO, The World Medicines Situation 2004, at 66-71.

87 WHO, The World Medicines Situation 2004, at 72.

88 WHA, Prevention and Control of Noncommunicable Diseases (Fifty-third World Health Assembly; WHA53.17; 2000).

89 WHO and HEALTH ACTION INTERNATIONAL, Medicine Prices. A New Approach to Measurement, WHO/HAI (2003). SUSANNE GELDERS et al., Price, Availability and Affordability. An International Comparison of Chronic Disease Medicines. Background Report Prepared for the WHO Planning Meeting on the Global Initiative for Treatment of Chronic Diseases Held in Cairo in December 2005, WHO/ Health Action International (2006). 
when the percentage of health care facilities that have the surveyed medicine is less than $30 \%$, availability is low if between $30-49 \%$, it is fairly high if it is between $50-80 \%$ and it is high if it is above $80 \% .^{90}$ In its 2011 report on the world's medicines situation the WHO, in cooperation with HAI International, reported on a number of such surveys carried out in developing countries to assess medicine availability and prices. ${ }^{91}$ It found that in all regions, public sector availability of generic medicines is not very high, on average it is less than $60 \%$. The availability of originator brands in the public sector is low, with most governments favouring to purchase and distribute lower-priced generic equivalents. Furthermore, in the private sector, availability of generic medicines is higher than in the public sector in all regions, yet median availability is still less than $60 \%$ in Africa, South-East Asia and the Western Pacific. The availability of originator brands in the private sector was consistently lower than that of generics in all regions with less than $25 \%$ (with the exception of the Eastern Mediterranean). ${ }^{92}$ Thus, according to the WHO report the availability of originator brands is lower than that of generics both in the public and private sector of the developing countries surveyed.

The pharmaceutical market is a highly in transparent market. Prices for the same pharmaceutical product can differ from country to country and whether it concerns a generic or branded originator medicine. Research suggests that there are great differences within developing countries with regard to prices of originator branded medicines. Interestingly though, with regard to medicine prices there is no North-South divide; one would assume that prices would be higher in the richer developed world compared to the developing word. Actually, in certain instances higher medicine prices are found in developing states than in OECD countries. ${ }^{93}$

The WHO finds that because medicine availability in the public sector - whether originator brands or generics - is generally low, many patients are forced to buy

90 GELDERS et al., Price, Availability and Affordability. An International Comparison of Chronic Disease Medicines, at 11, 19.

91 WHO, The World Medicines Situation 2011. Medicines Prices, Availability and Affordability (2011). The analysis presented was based on the results of a total of 53 surveys conducted between 2001 and 2008, including middle- and low-income countries from WHO regions (11 countries from Africa, 6 from the Americas, 4 from South-East Asia, 6 from Europe, 11 from the Eastern Mediterranean, and 5 from the Western Pacific).

92 Ibid. at $4-5$.

93 KEREN BRIGHT and LOIS MURAGURI, 'Access to Medicines: Intellectual Property Rights, Human Rights and Justice', in Aurora Voiculescu and Helen Yanacopulos (eds.), The Business of Human Rights (London: Zed Books, 2011) at 109; CIPR, Integrating Intellectual Property Rights and Development Policy, at 37; SCHAABER, Keine Medikamente Für Die Armen?, at 55. GELDERS et al., Price, Availability and Affordability. An International Comparison of Chronic Disease Medicines, at 3.

Contrary: OWEN LIPPERT, 'A Market Perspective on Recent Developments in the TRIPS and Essential Medicines Debate', in Brigitte Granville (ed.), The Economics of Essential Medicines (London: Royal Institute of International Affairs, 2002) at 20. He finds that typically the wealthier a country is, the higher is the price. Lower medicine prices are related with lower national incomes. 
medicines from the private sector often at prices they can ill afford. When comparing medicine prices it finds that, broadly speaking, medicine prices are higher in the private sector. ${ }^{94}$ Moreover, private sector prices for originator brands are much higher than the lowest-priced generic equivalent. ${ }^{95}$ For originator brand medicines, private sector prices were at least 10 times higher than international reference prices in all WHO regions, and they were up to 20 and 30 times higher in Africa. When originator brands are prescribed and dispensed for medicines that are also available in generic form, patients are paying four times more, on average, to purchase the branded medicine. ${ }^{96}$

For many patients, this difference between originator brands and generics could decide whether they are or are not able to buy the medicine and receive treatment. To assess the affordability of medicines the WHO/HAI methodology compared prices to patients' actual income. ${ }^{97}$ In its report the WHO found that for treatment of a respiratory infection, even when lower-priced generics are available, the cost of such treatment means that it is out of reach for many patients in developing countries. The situation is worse if generics are not available and treatment consists of originator brand medicines. See also, for example the situation in Uganda concerning malaria treatment, where the lack of first-line antimalarials in the public sector (where they are free) is forcing patients to turn to the private sector where up to 11 days of an average household income is required to buy the antimalarials necessary to treat a five year old child. Unaffordability is exacerbated where patients are suffering from chronic diseases, such as HIV, and they require lifelong treatment. ${ }^{98}$

Although the question of availability and affordability of medicines must be assessed independently for each country (or even country region), there is no doubt that the lack of access to affordable medicines is a serious problem in many developing countries. Evidence seems to suggest a systematic lack of access to

94 Furthermore it finds that in the public sector, which has generally low availability of originator brands, prices of such originator brands tend to be very high.

95 GELDERS et al., Price, Availability and Affordability. An International Comparison of Chronic Disease Medicines, at 48.

96 WHO, The World Medicines Situation 2011. Medicines Prices, Availability and Affordability, at $6-7$.

97 GELDERS et al., Price, Availability and Affordability. An International Comparison of Chronic Disease Medicines, at 11, 19. The indicator used is the number of working days necessary for the lowest paid unskilled government worker to be able to afford a 30 day treatment. A course of treatment that costs the equivalent of one day's salary is generally considered affordable; treatments that cost more than this are considered unaffordable. However, it should be noted that large sections of the populations in developing countries earn less than the lowest-paid government worker, and as such, the true degree of unaffordability is likely to be underestimated using this indicator.

98 See also ibid; LAURENS M. NIËNS et al., 'Quantifying the Impoverishing Effects of Purchasing Medicines: A Cross-Country Comparison of the Affordability of Medicines in the Developing World', PLoS Medicine, 7:8 (2010), 1-8 at 6; WHO, The World Medicines Situation 2011. Medicines Prices, Availability and Affordability, at 8-10. 
medicines in developing countries, partly due to high prices, potentially leading to the impoverishment of large numbers of people. ${ }^{99}$ The question is whether this can be linked to patent protection for medicines.

\subsection{Conclusion}

This section examined the issue of access to essential medicines in more detail. First the concept of "essential medicines" was defined as those medicines that satisfy the priority health care needs of a country's population, while "access" to essential medicines was defined as including the following elements: availability, affordability, and physical accessibility on a non-discriminatory basis, in addition to acceptability and good quality. The focus of this research is on the element of affordability of essential medicines. As such, this research approaches the issue of access to medicines from the perspective of developing countries since countries handling severe resources constraints, firstly, often struggle with serious public health problems such as the HIV/AIDS epidemic and, secondly, they are faced with many difficulties in providing (free) health care and medicines where necessary. As a result many patients in developing countries privately finance their medicine use, making the price of the medicine a determinative factor in whether the patient receives medical treatment.

\section{The Pharmaceutical Market}

To set out the context of the issue at hand this section will briefly look at the nature of medicines as a product, which is different compared to most other goods. First of all, medicines serve a public good. Moreover, research and development of new medicines is a long, risky and expensive enterprise, while the marketing of medicines is heavily regulated. The particular nature of the pharmaceutical market plays an important role in the issue of access to medicines. Theoretically, a free and competitive market is achieved through balancing the demand side (the patients as consumers of medicines) and the supply side (the pharmaceutical industry which produces medicines). However medicines, as products differ from other goods in a number of ways.

Firstly, demand for essential medicines is inelastic; patients are willing to pay almost any price for an essential medicine. Demand for a medicine will decrease therefore only once the financial resources of the consumer/patient are exhausted. The opposite is also true that demand for an essential medicine does not increase due to lower medicines prices. Unfortunately, especially in low-income countries,

99 See for example NIËNS et al., 'Quantifying the Impoverishing Effects of Purchasing Medicines: A Cross-Country Comparison of the Affordability of Medicines in the Developing World', PLoS Medicine, 7:8 (2010), 1-8. 
the majority of patients must pay for treatments themselves as opposed to the situation in many developed countries which have introduced health-care or social security systems. Other particularities also characterise the pharmaceutical market. For example, generally it is not the actual consumers of medicines (i.e. the patients) who decide on the method of treatment and which medicines to use, but their doctors who prescribe the necessary medicines. Patients are often in a vulnerable position and lack the knowledge to assess a specific medicine's full effect. It is difficult for consumers to educate themselves so as to question and verify information on a pharmaceutical product given or advised to them by their doctor/ pharmacist. Sometimes even the doctor prescribing the medication or the pharmacist advising a customer does not have the full knowledge of all the (side-) effects of a particular medicine. In addition, demand is heavily influenced by advertising and promotion targeted at medicine prescribers. A lack of knowledge by patients, doctors and pharmacists can thus lead to irrational use of medication. Moreover, the doctors prescribing medicines are not the ones actually paying for the medicine, nor are the patients in countries where the public health system provides medicines free of charge. In many countries patients receive treatment via health-insurance schemes which, in certain situations might require a co-payment by the patient, yet such a co-payment is often small as compared to the actual price of the medicine. ${ }^{100}$ Therefore, due to the consumers' unique position as patients, demand for pharmaceutical products may be based on other factors than mere considerations of value for money of the pharmaceutical product.

Secondly, on the supply side of the pharmaceutical market there are also irregularities; for example competition is curbed between pharmaceutical corporations as a result of the granting of patents prohibiting (generic) pharmaceutical corporations to produce the patented product for a minimum of 20 years. Often a pharmaceutical corporation is the only manufacturer of one specific medicine, making substitution between medicines near to impossible. ${ }^{101}$

The pharmaceutical market can be divided into a number of components: that of original brands (innovative medicines often protected by patents) and generics (copies of the originator products). Genuine generic medicines are equivalent in composition to the originator product, and they can be marketed either without the existence of a patent for the originator product, before patent expiry (legality depending on the patent laws of the concerned state), after patent expiry or with a licence from the patent holder. Generics are generally intended to be interchangeable with the originator brand products. Within the generic market, two sub-markets can be identified: generic pharmaceuticals with their own brand names manufactured by a single company, i.e. "other brand names" and unbranded, "commodity generics." This complexity in defining "generic medicines" can to lead to much confusion. ${ }^{102}$ A number of innovative, research-based pharmaceutical corporations

\footnotetext{
100 ABBOTT and DUKES, Global Pharmaceutical Policy, at 11.

101 SCHAABER, Keine Medikamente Für Die Armen?, at 51-52.

102 WHO, The World Medicines Situation 2004, at 34-35.
} 
have subsidiaries which produce an important share of the world's generic market. According to WHO data, the leading generic markets, including branded and unbranded medicines, can be found in high-income states. These generic markets have grown immensely in recent years as governments and insurers attempt to contain medicine expenditure. On the other hand, innovate pharmaceutical manufacturers have promoted sales of patented original brands to increase turnover. ${ }^{103}$

According to a WHO publication in 2004 concerning the world medicines situation, high-income countries dominate world pharmaceutical production. It classified the top 10 countries of pharmaceutical production as having a "sophisticated industry with significant research" and considers them to be the principal sources of new medical discoveries (among the top are the US, Japan, Germany, France and the UK). Thus, the countries with the largest pharmaceutical production are mostly located in high-income countries. ${ }^{104}$ Additionally, the WHO classified 16 countries $^{105}$ as having "innovative capability" referring to the fact that at least one new molecular entity was discovered and marketed by these countries in the period 1961 to 1990 . These include India and China. India's pharmaceutical biotechnology market has grown rapidly over the last years and is currently estimated to be worth over one billion US dollars. ${ }^{106}$ In addition to India and China, a number of other developing states were able to develop a local pharmaceutical industry over the last half century; these include Brazil, Thailand, and South Korea. In most of these countries patent protection on pharmaceutical products was minimal; however, this will change or has already changed with the implementation of TRIPS. 107

Therefore with respect to the production of medicines we see a noticeable distinction between developed and developing countries. This discrepancy is also reflected with regard to the consumers of medicines and medicine expenditure. For example, the WHO found that for the year $199990 \%$ of the produced medicines are estimated to be consumed by patients in high-income states, which amount to $15 \%$ of the world's population. ${ }^{108}$ Moreover, in its 2011 report on the world's medicine situation, the WHO finds that high-income countries spend far more on medicines than developing countries. Medicine expenditure is governed not only by the price of the medicine but also by the volume of medicines consumed. In that regard many factors contribute to medicine expenditures, such as the level of health insurance coverage for prescription medicines, physician prescribing practices, consumer

103 Ibid. at 35, 37-38.

104 Ibid. at 3-8.

105 Canada, Mexico, Argentina, Spain, Portugal, Ireland, Austria, Hungary, Yugoslavia, Finland, Russia, Israel, China, India, Australia, South Korea.

106 WHO, The World Medicines Situation 2004, at 5-6.

107 See for example ANAND NANDKUMAR, 'Was the TRIPS Worthwhile?', Forbes India, (2012); SCHAABER, Keine Medikamente Für Die Armen?, at 63.

108 The WHO has defined "consumption" as domestic production plus imports and minus exports. See WHO, The World Medicines Situation 2004, at 33. 
behaviour, and regulatory policies that apply to medicine pricing and reimbursement.

Many countries are faced with increasing expenditures on medicines and between 1995-2006 per capita spending on pharmaceuticals increased by approximately 50\%. In addition, since 1995, total pharmaceutical expenditure as a share of GDP has increased across all income groups, especially in low-income countries. ${ }^{109}$ However, expenditure on pharmaceuticals in the poorest countries is still a fraction of that in the high-income countries.

The cost of medicines are not the only costs associated with the management of disease and illness, ${ }^{110}$ but it does represent a significant part of health expenditure particularly in developing countries (in 2000 medicine expenditure accounted for around $15,2 \%$ of the total health spending worldwide). ${ }^{111}$ According to the WHO, it is evident that high-income countries spend a lot more on medicines than lowincome countries. It estimates that $16 \%$ of the world's population living in highincome countries accounts for over $78 \%$ of global expenditures on medicines. ${ }^{112}$ This disparity becomes even more evident if represented in per capita pharmaceutical expenditures: for example in 2005/2006 per capita pharmaceutical expenditures ranged from US\$ 7,61 in low-income countries to US\$ 431,6 in highincome countries (with considerable variation between income groups in each country). ${ }^{113}$ Moreover, WHO data on pharmaceutical spending confirms that it accounts for a significant share of all health expenditure; medicine expenditure as a percentage of the total health expenditure ranges from an average of $19.7 \%$ in highincome countries to a $30.4 \%$ in low-income countries. Thus it is clear that in general, developing countries spend proportionally more of their health budget on medicines than the wealthier countries. ${ }^{114}$

Moreover, the WHO finds that in high-income countries the majority of medicines are funded publicly, through public health insurance or social security systems. This is the opposite for low-and middle-income countries, where at least two-thirds of the medicine expenditure is financed privately, i.e. by the patients themselves. 115

\footnotetext{
109 WHO, The World Medicines Situation 2011. Medicine Expenditures (2011) at 13.

110 Other costs are for example for diagnostics, physician consultations, transport costs to clinics, loss of work time etc.

111 NIËNS et al., 'Quantifying the Impoverishing Effects of Purchasing Medicines', at 6; WHO, The World Medicines Situation 2011. Medicine Expenditures, at 2-3.

112 It finds that in 2006, high-income countries accounted for $78.5 \%$ of global medicine expenditures, while the upper middle-income, the lower middle-income and the low-income countries combined accounted for the remaining $21.5 \%$ of the total $(10.2 \%, 10.3 \%$ and $1.0 \%$, respectively). In other words, just $16 \%$ of the world's population in 46 countries was responsible for more than $78 \%$ of the world's total expenditures on pharmaceuticals, leaving the poorest $71 \%$ of the population distributed among 78 low-middle- and low-income countries with an $11 \%$ share of the world's medicines expenditure.

113 WHO, The World Medicines Situation 2011. Medicine Expenditures, at 3.

114 Ibid. at 6.

115 Ibid. at 7.
} 
Therefore with regard to medicine expenditure there is a great disparity between high- and low-income countries. Although global medicine expenditure has increased, the level of medicine expenditure in the poorest countries, in per capita terms, is still extremely low. Moreover, except in high-income countries, most medicines are paid for privately usually as out-of-pocket payments by patients. ${ }^{116}$ Therefore the WHO finds that in low- and middle-income countries increased public funding for pharmaceuticals is vital to improve access to affordable medicines. ${ }^{117}$ In that regard it is essential for countries with limited resources to fully utilize all possibilities available to bring down medicine prices.

\subsection{Regulatory Review: Marketing Approval for Medicines}

Due to the particular nature of medicines as goods the pharmaceutical market is not a free and competitive market where demand and supply are evenly balanced. In addition, the marketing of medicines is heavily regulated. All states require that medicines receive market approval by a national regulatory authority before being marketed to ensure that the products are safe and efficacious. For example in the US under the Federal Food, Drug and Cosmetic Act pharmaceutical companies applying for drug approval must submit test data to the US Food and Drug Administration (FDA) on the safety and efficacy of the medicine. ${ }^{118}$ This submission of data for regulatory approval is not a requirement everywhere; in some states the national authorities will grant approval by relying on the existence of such an approval in another country.

Such a regulatory drug review often proceeds in stages and can be lengthy and costly. Generally, a regulatory review process will look something like this: first, the newly developed medicine must undergo preclinical investigations to determine whether it is safe for trials with humans. If the relevant authority approves, the process can proceed to the next phase: testing the medicine on humans. Studies are conducted with a small number of test subjects expanding the group of patients in phases until enough information and evidence has been gathered to prepare a claim for approval. The national medicine approval authority then examines whether the pharmaceutical is effective and safe, and whether all legal requirements, for example with regard to manufacturing controls or labelling, are met. When approved the medicine may be marketed. ${ }^{119}$ In addition to ensuring that the product itself is safe, regulatory authorities must also ensure that pharmaceutical manufacturers maintain good manufacturing practices.

\footnotetext{
116 NIËNS et al., 'Quantifying the Impoverishing Effects of Purchasing Medicines', at 2.

117 WHO, The World Medicines Situation 2011. Medicine Expenditures, at 16.

118 SUDIP CHAUDHURI, The WTO and India's Pharmaceuticals Industry. Patent Protection, TRIPS and Developing Countries (New Delhi: Oxford University Press, 2005) at 77.

119 HOLGER HESTERMEYER, Human Rights and the WTO: The Case of Patents and Access to Medicines (Oxford: Oxford University Press, 2007) at 60-61.
} 
The objective of regulating market approval is to ensure that newly produced medicines are efficacious and will not harm the general public. Reality though is that, almost all medicines have some sort of side-effects. The aim of such a regulatory process is therefore to ensure that these side-effects are appropriately proportionate to the benefits of the medicines. What is noteworthy here is that, in most countries clinical trials are designed to compare the new medicine with a placebo, not with existing therapies for the same condition. Thus, a newly approved medicine is not necessarily more effective in treating the condition than older medicines. ${ }^{120}$

Such a medicine approval process affects the patent protection of a product in a couple of ways. On the one hand the patent holder cannot effectively enjoy its patent for the duration of the regulatory drug review, because it cannot market the new pharmaceutical until it is approved. On the other hand, the originator product often enjoys extended market exclusivity after the expiry of the patent, since competing generic pharmaceuticals must also apply for regulatory review before being allowed to market their generic version of the medicine. Since genuine generic medicines are equivalent in composition to the originator (branded) pharmaceutical, it is easiest for generic producers to refer to the test data used by the innovator pharmaceutical manufacturer during the regulatory review and demonstrate bioequivalence to obtain market approval for the generic version. However, the studies conducted by the innovator to obtain such market approval, are often protected under patent law and cannot be relied upon without the consent of the right holder. In that case, a generic producer can either conduct the clinical trials itself to demonstrate that its product is safe for marketing, which is an extremely expensive operation, or it will need to wait until expiration of the innovator's patent to be able to use its data for the regulatory review process. The latter entails that, even though the innovator's patent term has ended; he still enjoys market exclusivity for the time that the generic version of the pharmaceutical is awaiting regulatory approval. Once the generic version has been approved, it can be marketed and will compete with the originator pharmaceutical. ${ }^{121}$

120 ABBOTT and DUKES, Global Pharmaceutical Policy, at 7-8.

121 In the U.S. the 1984 Drug Price Competition and Patent Term Restoration Act intends to restore both these issues. First, by extending the patent term with the time lost as a result of the regulatory process from the date the patent was issued to drug market approval, to a maximum of 14 years extension. Secondly, for the purpose of applying for drug approval the Act explicitly allows traditionally infringing acts of making, using, offering for sale, selling, or importing a patented invention. This is the so-called "Bolar exception." Additionally the Act also simplifies the drug approval process for generic pharmaceuticals through allowing abbreviated new drug applications (i.e. ANDA): if the pharmaceutical generic producer is able to establish bioequivalence with an already approved and listed drug, this will be sufficient to obtain drug approval. However, such applications are not accepted for a period of five years for drugs no active ingredient of which has been approved before. CHAUDHURI, The WTO and India's Pharmaceuticals Industry, at 77-78; HESTERMEYER, Human Rights and the WTO, at 61-62. 


\subsection{Conclusion}

Medicines serve a public good; and as such pharmaceuticals, as marketable goods, have certain characteristics, which do not necessarily lead to a competitive market situation. Additionally, the marketing of medicines is heavily regulated. Furthermore, we see that with regard to the production and consumption of medicines there are considerable differences between high- and low-income countries. Most pharmaceuticals are developed and produced in high-income countries. Moreover, high-income countries spend far more on medicines than developing countries. Pharmaceutical expenditure accounts for a significant share of all health expenditure and, in general, developing countries spend proportionally more of their health budget on medicines than the wealthier countries. In highincome countries the majority of medicines are funded publicly, through public health insurance or social security systems. This is the opposite for low-and middleincome countries, where at least two thirds of the medicine expenditure is financed privately, i.e. by the patients themselves, which is why medicine prices are an important factor when countries attempt to ensure patients have adequate access to medicines.

\section{Patent Protection for Pharmaceuticals}

The research sub-question posed in this chapter is whether patent protection for pharmaceuticals interferes with access to medicines in developing countries. This section will therefore briefly describe what patents are and, the history and rationale underlying patents. The legal obligations regarding patent protection under international law will be set out in detail in chapter 4 . The focus of this section is on one unique particularity of medicines, namely the risks and costs associated with researching and developing medicines and the role of patents in that regard.

\subsection{What Are Patents?}

Patents are among a set of rights referred to as intellectual property rights. Intellectual property is "a form of knowledge which societies have decided can be assigned specific property rights." 122 IPRs are rights awarded by society to individuals or organisations principally for creative works such as inventions, literary and artistic works, symbols, names, images, and designs used in commerce. The creator is given a right to prevent others from making unauthorised use of their intellectual property for a limited period of time.

A patent is an exclusive right granted to an inventor to prevent third parties from making, selling, distributing, importing, or using their invention without

CIPR, Integrating Intellectual Property Rights and Development Policy, at 11. 
authorisation for a set period of time, generally 20 years (according to international standards). For an invention to be able to receive patent protection, it must fulfil three conditions: novelty, inventiveness and utility or industrial applicability. In return the right holder is obliged to disclose his invention to the public so as to increase the body of knowledge and further research. ${ }^{123}$

\subsubsection{Brief History of Patent Law}

The origin and history of patents stretches back more than 500 years. Privileges or favours were granted by the state ruler or monarch with the intention to attract foreigners who were skilled in arts not known in their territory. The grant of a privilege in the form of a limited period of exclusivity promoted competitiveness between technologies and thus provided an incentive for local inventiveness and the importation of knowledge from abroad. State rulers and monarchs would bestow a monopoly by granting "Letters Patent" (litterae patentes), so-called "open letters" because they had a seal at the bottom of the letter instead of being sealed closed. The letter acted as proof for the bestowed monopoly. Privileges existed in many different forms, for example they could provide an exemption from guild rules or taxation, allocation of land, naturalisation or even titles of nobility. They were not enforceable rights, but privileges granted at the discretion of the monarch. Such privileges were granted to a person who, in the eyes of the monarch, introduced a new and useful craft irrespective of whether that person actually invented, in the modern sense of the word, the technique.

The element of reciprocity, which also exists in modern day patent law, between the state or monarch granting the monopoly and the beneficiary are also found in the early days of patent-like privileges. That is, in return for the monopoly the beneficiary was commonly obliged to publicly disclose his knowledge and skills of the trade or craft he practised. However, the terms of this social contract have been subject to disagreements ever since its introduction. These privileges were intended to enable the introduction of new knowledge within a nation's territory, preferably with minimal disadvantages to society, since to encourage innovation within a nation's territory would promote national industries and economic growth. In addition to importing knowledge by attracting foreigners skilled in arts not known in their territory, the granting of patent-like privileges also encouraged innovative activity by local craftsmen. No distinction was made between inventions created in the territory and the importation of knowledge from abroad. ${ }^{124}$

The first place in which existing practices were included in a patent statute so as to attract tradesmen who could introduce new skills was Venice in 1474. This act

123 See chapter 4 for detailed information on patent protection for pharmaceutical under the TRIPS Agreement.

124 HESTERMEYER, Human Rights and the WTO, at 21-22; HECTOR MACQUEEN, CHARLOTTE WAELDE, and GRAEME LAURIE, Contemporary Intellectual Property. Law and Policy (Oxford: Oxford University Press, 2008) at 360. 
protected "new and ingenious devices" against others making the same or similar devices without consent of the patentee for 10 years. Herewith, the rulers of Venice intended to encourage people to invent articles for the common good. ${ }^{125}$ We can see that certain elements of the early history of patents still exist today: for example, the notion of a social contract between the state granting the patent and the patentee, a system of patents as an incentive to encourage innovation, the intent to strike a balance between society and the right holder, and the belief that a monopoly right should be granted to the inventor. ${ }^{126}$

Moving on, from 1760 onwards, as a result of the process of industrialisation, technological advancement and economic growth, the number of patents granted in England increased. The courts in England played an important role in the development from a system of privileges towards a system of grants based on procedural requirements, one of which was the requirement of a detailed specification. ${ }^{127}$ Over the years, the manner in which knowledge was transferred had shifted from face-to-face teachings to written specifications. One of the first statutes to legislate that in return for a patent the patentee must disclose his invention in a written specification was the 1790 US Patent Act. This is still required today and it is an essential justification of national patent laws worldwide. The 1790 US Patent Act also abolished importation patents, for knowledge known abroad but not in the US. Thus, an early requirement of novelty existed: the invention was not used nor known anywhere, not just within the territory of patent application. This has become the standard approach. ${ }^{128}$

At almost the same time, in 1791, France adopted its patent law. Until then the majority of countries did not consider patents to be enforceable rights granted to inventors, but they viewed the matter in a more discretionary manner. Obviously such practice did not find much support with inventors. Additionally, John Locke's teachings on every man's natural right to the fruits of his labour strengthened the development in favour of property rights. Consequently, the French revolution firmly rooted the theory that an inventor had a property right in his invention. This was clearly stated in France's 1791 Patent Act, which considered the patent itself to be purely declaratory. Interestingly, although inventors were considered to have a natural property right in their invention, the limited duration of that right remained. Although Locke's natural law rationale did not stand the test of time, the French act has had much influence on the further development of patent law.

During the $19^{\text {th }}$ century many countries followed the US and England's example, which were early proponents of the patent system, and they enacted their own

125 HESTERMEYER, Human Rights and the WTO, at 21-22; WORLD INTELLECTUAL PROPERTY ORGANISATION, Introduction to Intellectual Property. Theory and Practice (London: Kluwer Law International, 1997) at 17-18.

126 MACQUEEN, WAELDE, and LAURIE, Contemporary Intellectual Property. Law and Policy, at 361 .

127 WORLD INTELLECTUAL PROPERTY ORGANISATION, Introduction to Intellectual Property. Theory and Practice, at 18.

128 HESTERMEYER, Human Rights and the WTO, at 24-25. 
patent legislation. Although many monarchies still formally adhered to the principle of privileges, practice showed that the idea that inventors had a right to a patent was now generally accepted. By the 1880s the process of industrialisation had reached several European countries and the number of patents granted grew rapidly, especially in the US, France and England but also elsewhere. Additionally, the conditions for granting patents also underwent a number of changes. ${ }^{129}$

It is important to note that patents are territorial by nature; however, since their early history patents have had an international dimension. Part of the initial reasons for granting a monopoly was to prohibit foreigners from gaining a dominant position on the national market. In the $19^{\text {th }}$ century cross-border trade between countries was growing rapidly resulting in inventors attempting to patent their inventions abroad. This, however, proved to be difficult since patent legislation differed from country to country; important differences included the interpretation of novelty, the length of patent protection, exceptions to patentability, the treatment of foreigners, and local working requirements. Some countries for example did not grant patents to foreigners at all, while others, such as France required stringent working requirements. In addition, practical problems like the lack of knowledge of the different languages in which applications had to been drawn up and of the specifics of the different legal systems complicated the matter. As a result, the need grew for some form of international regulation. Initiatives were taken first on a bilateral level but this was soon considered inadequate. As the differences between domestic approaches were considerable, it seemed unlikely that harmonisation could be achieved through the adoption of a single convention, yet there was a general understanding to reach an agreement on a number of common principles and procedural aspects. ${ }^{130}$

Moreover, at the same time the notion grew that this development in favour of patents constituted a barrier to free international trade. From the late $18^{\text {th }}$ century and during most of the $19^{\text {th }}$ century most countries, in order to compete with the powerful industrialised England, had adopted a protectionist strategy as opposed to free trade. However, the free-trade movement, which was strongest during 18501875, almost led to an abandonment of the patent system in England. In Switzerland and the Netherlands resistance was strong. Both countries industrialised without a patent system but still achieved impressive economic and technical advancements. The inventors from most industrialised countries opposed the free-trade movement. In addition to the economic depression of 1873-1879, this eventually caused a retreat from the free-trade movement. The major European countries, except for England, responded with protectionist measures. Interestingly, the relationship

129 Ibid. at 25-26; WORLD INTELLECTUAL PROPERTY ORGANISATION, Introduction to Intellectual Property. Theory and Practice, at 19.

130 GRAHAM DUTFIELD, Intellectual Property Rights and the Life Science Industries. A Twentieth Century History. (Aldershot/Burlington: Ashgate, 2003) at 49-50; HESTERMEYER, Human Rights and the WTO, at 34; MACQUEEN, WAELDE, and LAURIE, Contemporary Intellectual Property. Law and Policy, at 363. 
between patents, protectionism and free trade and economic development was just as controversial a discussion at that time as it is now. ${ }^{131}$

The turning point in favour of patents and protectionism came with the Universal Exposition held in Vienna in 1873. These international expositions were extremely prestigious events, where countries would present their newest scientific and technological achievements to the world. At the same time, they also provided opportunities to copy the presented works. Reacting to concerns from governments and lobby groups, the Austro-Hungarian government introduced a temporary system of IP protection and agreed to organise an international patent conference, leading eventually to the adoption of the 1883 Paris Convention on the Protection of Industrial Property and 1886 Berne Convention on the Protection of Literary and Artistic Works. ${ }^{132}$ The Paris Convention set up a Union and an accompanying secretariat to administer the convention. In 1970 this task was taken over by the World Intellectual Property Organisation, an agency set up under the United Nations framework. Until the adoption of the Paris Convention countries were free to shape their IP systems as it suited them best, and even after the adoption of the Paris Convention the standards therein were rather flexible and allowed members considerable freedom. The Paris Convention was also the beginning of a new period of internationalisation of patent laws. ${ }^{133}$

In the second half of the last century, the number of patents granted increased dramatically. Particularly in developed countries patents became essential for the success of national industries and economies. The majority of patents were owned by companies settled in developed countries. This growing importance of not just patents, but IP protection in general led the developed world to argue that the existing international patent regime was inadequate. Four main arguments were stated: membership was far from universal under the Paris Convention; the Paris Convention lacked "teeth": international obligations with respect to patent laws were not effectively enforced; the international system made no statement with regard to the domestic enforcement of IP; and, finally, a lack of harmonisation on all aspects of patent legislation resulted in a lack of protection. ${ }^{134}$ Additionally, due

131 DUTFIELD, IPRs and the Life Science Industries, at 50, 52, 58.

132 Historically a distinction was drawn between "industrial property" which was relevant for business and referred mainly to patents and trademarks on the one hand, and works of authors and artists on the other hand, which generally were protected by copyright and related rights. This distinction is reflected by the two earliest agreements on IP: the 1883 Paris Convention on the Protection of Industrial Property and the 1886 Berne Convention on the Protection of Literary and Artistic Works. UNCTAD-ICTSD, Resource Book on TRIPS and Development (New York: Cambridge University Press, 2005) at 38.

133 CIPR, Integrating Intellectual Property Rights and Development Policy, at 18; DUTFIELD, IPRs and the Life Science Industries, at 55; HESTERMEYER, Human Rights and the WTO, at 27, 34; WORLD INTELLECTUAL PROPERTY ORGANISATION, Introduction to Intellectual Property. Theory and Practice, at 19.

134 CARLOS CORREA, Trade Related Aspects of Intellectual Property Rights: A Commentary on the TRIPS Agreement, eds Prof. Philip Alston, Prof. Vaughan Lowe, and Prof. Robert House (Oxford Commentaries on International Law - GATT/WTO Agreements; New York: Oxford 
to an increase in the importance of IP, especially for the entertainment industry, computer industry and the agricultural and pharmaceutical industry, in addition to important technological changes and the development of the world's trading system, an update of existing international IP rules was more than necessary. ${ }^{135}$ However, the developed world's proposition to strengthen the international IP system led, unsurprisingly, to resistance by the developing world. The developed world argued that those countries without an effective IP system were free-riding on the efforts and costs of countries with strong IP protection. Companies complained about the huge losses they made as a result of piracy in developing countries. Furthermore, the developed world argued that strong intellectual property systems was in the self-interest of all developing countries, as it would foster local creativity and research, resulting in more foreign direct investment and transfer of technology. This debate continues to this day. ${ }^{136}$ The developed world attempted to introduce changes via the WIPO setting. This was, however, far from successful. Consequently industrialised countries started pressuring developing nations to strengthen their weak IP systems. Both the EU and the US withheld trade benefits from developing countries for lack of effective IP protection. ${ }^{137}$

With the inclusion of the Agreement on Trade-Related Aspects of Intellectual Property Rights in the World Trade Organisation in 1994, protection of intellectual property is to a large degree regulated internationally. This is a crucial departure from the approach followed by previous IP treaties such as the Paris Convention in that TRIPS is the first international instrument to set out minimum standards for the protection of IPRs. Consequently all WTO members must at the very least implement the level of IP protection as provided for by the TRIPS Agreement into their national legal framework. Historically we see that countries have been able to adapt their IPR regimes to facilitate technological development and promote national industrial policy objectives. Because policies in one country encroach on the interests of others, there has always been an international dimension to IPRs. The Paris and Berne Conventions recognised this dimension, and the desirability of reciprocity, but they allowed considerable flexibility in the design of IP regimes. With the introduction of TRIPS, a large part of this flexibility has been removed.

University Press, 2007) at 15; HESTERMEYER, Human Rights and the WTO, at 36-37; JAYASHREE WATAL, Intellectual Property Rights in the WTO and Developing Countries. (The Hague/London/Boston: Kluwer Law International, 2001) at 22.

135 DANIEL GERVAIS, The TRIPS Agreement: Drafting History and Analysis (second edn.; London: Sweet \& Maxwell Ltd., 2003) at 10.

136 HESTERMEYER, Human Rights and the WTO, at 37-39.

137 Ibid. at 40. See for information on the evolution of tensions between developed and developing countries on matters related to IP regulation, CAROLYN DEERE-BIRKBECK, 'Developing Countries in the Global IP System before TRIPS: The Political Context for the Negotiations', in Carlos M. Correa (ed.), Research Handbooks on the Protection of Intellectual Property under WTO Rules. Intellectual Property in the WTO Volume 1 (Series Research Handbooks on the WTO; Cheltenham/Northampton: Edward Elgar, 2010). 


\subsubsection{Why We need Patents: Rationales of Patent Protection}

Since its inception the patent system has been criticised. It has often been questioned whether the patent system, by granting a market monopoly, is the best way to strike a fair balance between competing social interests. Thus, there has always been a need to justify its existence, even though its long existence seems to indicate that it must be serving some useful function(s).

There is not one worldwide accepted rationale for patent protection. There are a variety of different, sometimes historical, reasons why protection of intellectual property is deemed necessary. Historically, nations used patents to transfer knowledge and enhance their industrial development. In our time patent protection is justified by utilitarian ideas. The following sections will briefly discuss a number of rationales attempting to justify the existence of the patent system, starting with the most common justification: the incentive function.

\subsubsection{INCENTIVE FOR INNOVATION}

The most commonly used justification is the incentive to innovate function, which considers that the possibility of patent protection is essential as an incentive for (further) research and development in a particular field. Inventions are classic examples of so-called market failures, which the patent system intends to correct. The argument is that, without any form of protection, anyone would be able to copy and market the invention without the added cost of having to recoup the research and development costs put into developing the invention in the first place. As a result competitors would most probably be able to offer the invention for a lower price than the originator, ruining any market advantage of the originator. This would be a considerable disincentive for innovations in areas, which incur high research and development costs. The patent system is based on the assumption that the short-term losses to consumers as a result of monopoly pricing are offset by the long-term advantages of technological development and innovation. This justification has had much support and influence. ${ }^{138}$

Even this most widely-accepted rationale for patent protection has been criticised. For example, it assumes that the value of innovation outweighs the increased costs for consumers and that the benefits of patents justify their costs. However, the optimal degree of patent protection, where the social benefits are found to exceed the social costs, is difficult to determine and depends on multiple aspects such as the duration of the patent term, the scope of protection and innovative and manufacturing capacity. Moreover, especially difficult for developing counties, this rationale presumes that consumers are willing and able to

138 CIPR, Integrating Intellectual Property Rights and Development Policy, at 14; HESTERMEYER, Human Rights and the WTO, at 31-32; MACQUEEN, WAELDE, and LAURIE, Contemporary Intellectual Property. Law and Policy, at 365. 
pay higher prices, and that the country possesses the necessary infrastructure to facilitate further research. The UK Commission on IPRs found that in practice IPRs regimes are the outcome of a compromise, and striking the wrong compromise (whether too much or little protection) may be costly to society especially in the longer term. ${ }^{139}$

Patents function as an incentive for innovation, however, it is unlikely that the sole reason for inventors to invent is the prospect of patent protection; many do so because of an inner desire to achieve something novel within their field of expertise. It has been argued, therefore, that honour and prizes could be sufficient incentives to replace patents. It is also stated that one should not assume that patent monopolies will not be used to block innovation rather than encourage it. Reality is complex and this depends on the specific sector. For pharmaceuticals, R\&D costs are high and patents provide a good incentive, however, that incentive is, primarily for those medicines which can be marketed with profit. ${ }^{140}$ The question whether patent protection for pharmaceuticals actually leads to innovation within the pharmaceutical sector will be discussed in the next section.

In addition to the incentive function, it has been argued that there are other rationales justifying the existence of the patent system, which will shortly be touched upon to give a general overview.

\subsubsection{Social Contract}

As we have seen patents are often described as a social contract between the patent holder, who is obliged to disclose his invention to the public in such a manner that a person skilled in the art could reproduce it, and the state granting a time-bound monopoly right in return for disclosure. This public disclosure requirement has been an essential feature of the patent system since its inception and an important justification for patent protection. Namely a monopoly granted by patent protection does not take away from the public domain, rather it discloses something new that was not known before and therewith adds to the body of human knowledge and, upon expiry of the patent also to the public domain. If the invention is not adequately disclosed in the application this can be a reason to deny patent protection. ${ }^{141}$ However, it must be noted that intellectual property lawyers have become increasingly skilled in drafting patent claims in such a way as to disclose as little as possible but still qualify for patent protection.

Disclosure within patent specifications is not always necessary to reproduce an invention. Sometimes engineers are able to reproduce an invention by studying the device in detail until they, to put it simply, have figured out how it functions; a

139 CIPR, Integrating Intellectual Property Rights and Development Policy, at 15.

140 HESTERMEYER, Human Rights and the WTO, at 32; MACQUEEN, WAELDE, and LAURIE, Contemporary Intellectual Property. Law and Policy, at 365.

141 MACQUEEN, WAELDE, and LAURIE, Contemporary Intellectual Property. Law and Policy, at 366. 
process which is generally referred to as "reverse engineering". In situations where reverse engineering is possible, patents are not necessary to transfer the knowledge of the inventor to the public domain. If reverse engineering is not possible, patents are desirable for society to facilitate the transfer of knowledge. The inventor could also decide not to disclose his invention, if he believes this will be more advantageous for him, secrecy can be a useful way to keep competitors out of the market. Then there is no incentive for the inventor to apply for patent protection. Concluding, this justification is not very persuasive. ${ }^{142}$

\subsubsection{Natural LaW}

The natural law rationale is founded on John Locke's theory that individuals automatically have property rights in their own ideas. Natural law finds that intellectual property should be treated exactly the same as all other property. This natural law theory gained much support during the French revolution especially in continental Europe. Today it is still an important justification for the protection of copyright. However, regarding patents there are a number of aspects which contradict natural law. For example, the administrative process necessary to obtain patent protection for an invention, is not compatible with the natural law notion that every inventor has an automatic property right; or the fact that no patent is granted for parallel inventions once a patent is obtained by someone else. Most significantly, the time limited nature of patents is not compatible with the natural law notions. Thus, the natural law theory as a rationale for patent protection is not considered very strong, and is actually rejected among Anglo-American lawyers. ${ }^{143}$

Interestingly, the natural law theory has recently re-emerged in the international debate on IP protection via international human rights law. Specifically, it is argued that international human rights law protects the author's material and moral interests in his or hers intellectual creations.

\subsubsection{REWARD THEORY}

Another justification theory was developed by economists who believed that inventors should be rewarded for the act of inventing something new, and thus contributing to society. This rationale has been rejected, because in order to reward an inventor it is not necessary to grant him a monopoly right; inventors could also be rewarded with prizes or other benefits. Moreover, rewards in the form of patents are not always proportional to the social value of the invention. Additionally, the person obtaining the patent is not necessarily the inventor, or the sole inventor. ${ }^{144}$

\footnotetext{
142 HESTERMEYER, Human Rights and the WTO, at 30-31.

143 Ibid. at 29-30.

144 Ibid. at 31; MACQUEEN, WAELDE, and LAURIE, Contemporary Intellectual Property. Law and Policy, at 365.
} 
In conclusion, the first policy objective of patent protection is the creation of new technology, the second objective is the diffusion of technology, this explains the disclosure requirement of patents and why they are limited in time and nonrenewable. ${ }^{145}$

\subsection{Research and Development}

Patents are most commonly justified by providing an incentive to innovate. This is also true for patents for medicines. The question that follows is, do patents for pharmaceuticals lead to the innovation of new medicines. In this section I will, therefore, look at the role of patents in health-related research and development.

In a perfectly competitive and unregulated market the law of demand and supply results in the price of a product being set at the marginal cost, which is generally advantageous for consumers. However, a free and competitive market does not always lead to the most optimal situation. The case of inventions provides classic examples of the so-called market failures. An inventor invests time and resources into researching and developing a product. If he puts the product on the market, without any form of protection, free-riders are able to benefit from the efforts made by the inventor, by copying or reverse engineering the invention, without incurring the costs of R\&D. Not having to recoup any $R \& D$ costs, free-riders are able to set much lower prices than the inventor. Consequently, there is no incentive to invent because there is no or only limited return on investment. ${ }^{146}$

Research and development is an important part of the work and image of transnational pharmaceutical corporations, which distinguish themselves as the "research-based industry," as opposed to generic manufacturers. The research-based pharmaceutical industry considers its primary role in contributing to public health efforts to be innovation: the research and development of new, high quality, effective and safe medicines. The development of new medicines brings pharmaceutical corporations prestige, good PR and if all requirements are fulfilled, protection under patent law for newly developed pharmaceutical products and processes. ${ }^{147}$ As a result the research-based pharmaceutical industry strongly supports the strengthening of IPRs in both developed and developing states. Without the incentive of potential patent protection for newly developed pharmaceutical products or processes, it is said that health-related R\&D and consequently innovation would decrease dramatically. ${ }^{148}$

145 DANIEL GERVAIS, The TRIPS Agreement: Drafting History and Analysis (Third edn.; London: Thomson Reuters - Sweet \& Maxwell, 2008) at 205.

146 HESTERMEYER, Human Rights and the WTO, at 141-142.

147 WHO, The World Medicines Situation 2004, at 15-16. IFPMA, Principle Focus and Actions of the Research-Based Pharmaceutical Industry in Contributing to Global Health, International Federation of Pharmaceutical Manufacturers \& Associations, (27 February 2008) at 4.

148 IFPMA, Principle Focus and Actions of the Research-Based Pharmaceutical Industry in Contributing to Global Health, 2008, at 5. CIPR, Integrating Intellectual Property Rights and Development Policy, at 29-30. 
In addition to investments in $\mathrm{R} \& \mathrm{D}$, companies must also recoup their production costs, which are significant particularly in highly developed countries with rigorous regulatory standards. ${ }^{149}$ Activists, on the other hand, say that the protection granted under patent law is often too extensive. They argue that the actual costs of health R\&D are not at as high as maintained by the pharmaceutical industry and they do not correspond to the monopoly position patent protection provides. ${ }^{150}$

The pharmaceutical industry argues that the reason patents are so important in this particular industry is the high cost of researching and developing new medicines. The International Federation of Pharmaceutical Manufacturers \& Associations (IFPMA) claims that, on average the research and development of just one single new medicine takes up to 10-15 years and costs an average of over US\$ 800 million. ${ }^{151}$ This amount is also supported by the European Federation of Pharmaceutical Industries and Associations (EFPIA). The EFPIA bases its estimates on a 2003 study conducted by J.A. DiMasi, R.W. Hansen and H.G. Grabowski. ${ }^{152}$ A previous study by DiMasi in 1991 assessed the cost for the R\&D of one new drug to be US\$ 231 million. ${ }^{153}$

Both DiMasi studies use the same methodology to calculate the cost of R\&D, which has been heavily criticised by NGOs and activists. ${ }^{154}$ There does seem to be remarkable differences between the amounts spent globally on $\mathrm{R} \& \mathrm{D}$ and production

149 ABBOTT and DUKES, Global Pharmaceutical Policy, at 12.

150 See for example BOB YOUNG and MICHAEL SURRUSCO, Rx R\&D Myths: The Case against the Drug Industry's R\&D “Scare Card”, Public Citizen's Congress Watch, (2001) at.

151 IFPMA, 'Research \& Development. Position 2005-2008', <www.ifpma.org/Issues/index. php?id=421>, accessed 10 April 2008.

152 JOSEPH A. DIMASI, RONALD W. HANSEN, and HENRY G. GABROWSKI, 'The Price of Innovation: New Estimates of Drug Development Costs', Journal of Health Economics, 22 (2003), 151-185.

153 JOSEPH A. DIMASI et al., 'Cost of Innovation in the Pharmaceutical Industry', Journal of Health Economics, 10 (1991), 107-142.

154 SCHAABER, Keine Medikamente Für Die Armen?, at 81; YOUNG and SURRUSCO, Rx R\&D Myths, at. It has been argued that, firstly, in his 2003 study DiMasi only included medicines which were developed solely by the pharmaceutical industry without any governmental input. But this is not the norm. Public funding still plays an important part in the R\&D of new medicines. Secondly, the amount of US\$ 800 million is argued to be exaggerated as it includes "opportunity costs", which amount to almost half of the total sum. These are costs which have not actually been made, but which entail returns that could have been made if the money used for R\&D would have been invested elsewhere. Thirdly, tax returns were not taken into account. Under US federal tax laws $34 \%$ of pharmaceutical R\&D expenditure is tax deductible. Fourthly, DiMasi researched 68 new chemical entities (NCEs) to define the cost of R\&D to create a new pharmaceutical. NCEs are truly novel inventions which are generally the most expensive to develop, however, in the U.S. of all approved pharmaceuticals only about a third are NCEs. Finally, the data used by DiMasi in his study were voluntary contributions of pharmaceutical corporations, which cannot be objectively verified. In addition, it is alleged that the centre where both studies were conducted - the Tufts Centre for the Study of Drug Development (CSDD) at Tufts University - is funded primarily by external funds, $65 \%$ of which come from the pharmaceutical sector. 
of medicines, and the amounts paid for new pharmaceuticals. ${ }^{155}$ It is argued that a significant part of the costs involves marketing and promotion expenses. ${ }^{156}$

Clearly problematic here is that the pharmaceutical industry does not fully disclose their R\&D costs, which makes it difficult to verify this high number. Even if the figure of US\$ 800 million is an exaggeration of the actual R\&D costs, it cannot be maintained that the costs for developing a new medicine are insubstantial. The exact figure might not be known, yet, what we do know is that researching and developing new medicines is costly. ${ }^{157}$

\subsubsection{An Incentive to innovate? Neglected Diseases}

Proponents of strong IPRs and especially the pharmaceutical industry argue that patent protection for medicines is indispensable because they provide an incentive to innovate. In addition, IPRs are considered to be critical for creating a sound and sustainable climate essential for investments. ${ }^{158}$ Without patents, new medicines would not be researched and developed and therefore the debate on the affordability of medicines would be moot because, simply said, the medicine would not exist. ${ }^{159}$ In that line of reasoning, patents need to be protected to safeguard access to future (new) medicines.

Therefore, it must be asked whether patents really do provide an incentive to innovate and thus safeguard access to new medicines. If that is not so, then it would be hard to argue that patents for medicines are justified when they result in negative price impacts (if they really do result in higher medicine prices will be discussed below).

Research and development is an important element of improving public health globally, and funding for health-related R\&D has increased steadily over the last decades. Health-related R\&D can be funded either privately or publicly. Both the pharmaceutical industry and non-profit organisations contribute to health R\&D. In high-income states, public funding of health-related R\&D amounts to almost $50 \%$ of the total health-related R\&D. However, industry-funded R\&D has grown in the last decade when compared to the overall health related R\&D. This increase of private industry funded health-related $R \& D$ is apparent in all industrialised countries. ${ }^{160}$ According to the WHO, R\&D spending on health has tripled in the last decade of the $20^{\text {th }}$ century; but surprisingly the number of new medicines that received marketing approval in the US decreased from over 50 to 32 in $2000 .{ }^{161}$

155 ABBOTT and DUKES, Global Pharmaceutical Policy, at 12-13.

156 See further ibid. at 163 et seq; YOUNG and SURRUSCO, Rx R\&D Myths, at 19-20.

157 HESTERMEYER, Human Rights and the WTO, at 142.

158 See for example FELIX ROZANSKI, Developing Countries and Pharmaceutical Intellectual Property Rights: Myths and Reality, The Stockholm Network Experts' Series on Pharmaceutical Intellectual Property Rights, (2007) at 19.

159 LIPPERT, 'A Market Perspective on Recent Developments in the TRIPS and Essential Medicines Debate', at 4.

160 WHO, The World Medicines Situation 2004, at 11-14.

161 Ibid. at 16. 
Thus, it seems that increased funding for health-related R\&D does not necessarily lead to an increase in the number of new medicines developed. ${ }^{162}$

Firstly, it is becoming more and more difficult and time and resource consuming to develop truly innovative pharmaceutical products. Secondly, like any other industry, the pharmaceutical industry aims its research at making a profit. As such there are a number of areas which are particularly attractive with probable returns on investments: for example minor but patentable improvements on existing medicines for which the patents are running out to effectively prolong the patent term of an existing medicines and save the already established market (so-called 'ever-greening'); and so-called 'life-style medicines' which are medicines marketed to a large share of the population, but they do not target serious diseases. ${ }^{163}$

More importantly, developing countries are generally not the principal market for pharmaceutical products. Most global pharmaceutical corporations that significantly invest in R\&D for new medicines (not those focusing on producing generic medicines) market their products and gain their profits from patients in the developed world, not in developing countries although there is sufficient demand in developing countries. For their R\&D strategy the research-based pharmaceutical industry is therefore unlikely to be dependent on the profits it makes in developing countries. Therefore, even without patents in developing countries R\&D into new medicines that affect patients globally would still be carried out. ${ }^{164}$

Yet the situation is more complex with respect to diseases that do not affect patients globally but are mainly prevalent in developing countries. Although the cost of health research and development has increased over the last decades, a worrying trend can be observed. Certain medicines, intended for the treatment of poverty-related and tropical diseases are slowly disappearing from the pharmaceutical market. Furthermore, very few novel medicines to treat such diseases have been developed and marketed during the last couple of decades. For example, regarding tuberculosis, no new anti-TB medicines has been developed in over 30 years. ${ }^{165}$ Much of the global health-related R\&D is directed towards the most profitable markets, the richer western world. Therefore these diseases, which affect a large number of patients the majority of which live in the developing world, are referred to as "neglected diseases". 166

162 See also ELLEN F.M. 'T HOEN, The Global Politics of Pharmaceutical Monopoly Power. Drug Patents, Access, Innovation and the Application of the WTO Doha Declaration on TRIPS and Public Health (Diemen: AMB, 2009) at 80 et seq.

163 JOHANNA VON BRAUN and MEIR P. PUGATCH, 'The Changing Face of the Pharmaceutical Industry and Intellectual Property Rights', The Journal of World Intellectual Property, 8:5 (2005), 599-623 at 605 et seq; HESTERMEYER, Human Rights and the WTO, at 160.

164 HESTERMEYER, Human Rights and the WTO, at 162. CIPR, Integrating Intellectual Property Rights and Development Policy, at 30.

165 CIPR, Integrating Intellectual Property Rights and Development Policy, at 33.

166 Neglected tropical diseases are diseases such as sleeping sickness, dengue fever, leishmaniasis, leprosy, rabies among others. See also www.who.int/neglected_diseases/diseases/en/. In 
This trend of abandoning research for neglected diseases has been branded as the 10/90 gap, because it is estimated that only $10 \%$ of health-related research and development is spent on diseases and health problems which affect $90 \%$ of the people world-wide. This trend has especially grave consequences for the developing world where infectious diseases affect great number of very poor people, people with little to no purchasing power.

This trend can be portrayed by the numbers of medicines targeted at neglected tropical diseases. In the period 1975-1999 only 13 from a total of 1,393 new chemical entities (NCEs) granted market authorisation were directed towards a neglected disease. ${ }^{167}$ During 2000-2004 another 163 NCEs were marketed worldwide, of which 4 NCEs targeted neglected diseases. If malaria and tuberculosis (both poverty-related diseases) are included then over the past 30 years, 21 medicines were marketed specifically for neglected diseases, representing only $1 \%$ of all NCEs (1556) marketed in that period..$^{168}$

The reason for this trend is relatively simple: production for markets with low purchasing power is simply not profitable. ${ }^{169}$ Furthermore, increasing stringent safety regulations to obtain market approval also lead to higher costs for clinical development. The lack of patent protection for pharmaceuticals and the consequent rise of a generic industry during the second half of the previous century in certain developing countries, such as India, have also made the research-based industry hesitant to invest heavily in neglected diseased. The risks are just too great,

addition, neglected diseases are also often considered to include poverty-related diseases such as HIV/AIDS, malaria and tuberculosis.

Neglected diseases should not be confused with rare or orphan diseases, which affect a very small numbers of patients, wherever in the world. In the USA, they are defined as a disorder affecting less than 200000 people, while in Europe a prevalence rate of less than 5 per 10000 is used. Most of these disorders are of genetic origin and children account for $50 \%-75 \%$ of patients with rare diseases. There is also a lack of R\&D targeted at such rare diseases. These are often not very high on the priority list of pharmaceutical corporations, since these diseases only affect small number of patients world-wide. However, it is important to distinguish between rare diseases that affect small number of patients and neglected diseases that affect large number of patients. UN COMMISSION ON HUMAN RIGHTS, Report of the Special Rapporteur on the Right of Everyone to the Enjoyment of the Highest Attainable Standard of Physical and Mental Health, Paul Hunt, Submitted in Accordance with Commission Resolution 2002/31 (UN Doc. E/ CN.4/2003/58; 2003) at $\$ 73$ et seq; UN COMMISSION ON HUMAN RIGHTS, Report of the Special Rapporteur on the Right of Everyone to the Enjoyment of the Highest Attainable Standard of Physical and Mental Health, Paul Hunt. Addendum. Mission to Uganda (UN Doc. E/CN.4/2006/48/Add.2; 2006) at §4 et seq.

167 Defined here as parasitic diseas (malaria, African trypanosomiasis, Chagas' disease, leishmaniasis, schistosomiasis, lymphatic filariasis, onchocerciasis, intestinal nematode infections), leprosy, dengue, Japanese encephalitism trachoma and infectious diarrhoeal diseases. See PATRICE TROUILLER et al., 'Drug Development for the Neglected Diseases: A Deficient Market and a Public-Health Policy Failure', The Lancet, 359 (2002), 2188-94 at 2189.

168 PIERRE CHIRAC and ELS TORREELE, 'Global Framework on Essential Health R\&D', The Lancet, 367 (2006), 1560-1561.

169 HESTERMEYER, Human Rights and the WTO, at 162. CIPR, Integrating Intellectual Property Rights and Development Policy, at 32 et seq. 
especially since not every $R \& D$ investment will successfully result in a new profitable pharmaceutical product.

The question then is whether the introduction of a patent system in developing countries would rectify this situation; that seems unlikely. As long as there is no real profit to be made with treatments targeted at currently neglected diseases, even the introduction of a (more stringent) patent system for pharmaceuticals will most probably not be incentive enough to produce more health $\mathrm{R} \& \mathrm{D}$ targeted at developing countries' needs. ${ }^{170}$

In addition, the contention that a stronger patent system will encourage local R\&D in neglected diseases also seems doubtful, at least in the short term. The developing countries that have pharmaceutical manufacturing capacity, which are few, do not have a strong innovative research-based pharmaceutical industry but focus mainly on generic production. If they do have R\&D capacity it is still questionable whether they would focus their efforts on neglected diseases, as was stated above, there is little profit to be made. The introduction of a (product) patent system for pharmaceutical products would not significantly change that. ${ }^{171}$

On the other hand, in more general terms, it is argued that improved protection for intellectual property will bring long-term economic gains. There is evidence that in developed countries intellectual property is important for the promotion of innovation in certain industrial sectors, for example the pharmaceutical and biotechnology sector. In low-income countries, developing local scientific and technological capacity is essential for sustainable development and a distinctive factor here is the success of technology transfer. ${ }^{172}$ Therefore, a crucial question is whether the introduction and strengthening of intellectual property systems will assist developing countries in facilitating technology transfer and achieve economic and social development. ${ }^{173}$ The impact of stronger IP systems on economic growth

170 CIPR, Integrating Intellectual Property Rights and Development Policy, at 33. TROUILLER et al., 'Drug Development for the Neglected Diseases', at 2191-2192; JEAN O. LANJOUW and MARGARET MACLEOD, Statistical Trends in Pharmaceutical Research for Poor Countries, Commission on Intellectual Property Rights, Innovation and Public Health, WHO, (2005) at 19-20; F.M. SCHERER and JAYASHREE WATAL, Post-TRIPS Options for Access to Patented Medicines in Developing Countries, Commission on Macroeconomics and Health, Working Paper Series, Paper No. WG4:1, (2001) at 11-12.

171 CIPR, Integrating Intellectual Property Rights and Development Policy, at 33; HESTERMEYER, Human Rights and the WTO, at 163. See further CHAUDHURI, The WTO and India's Pharmaceuticals Industry, at 153 et seq; SUDIP CHAUDHURI, Is Product Patent Protection Necessary in Developing Countries for Innovation? R\&D by Indian Pharmaceutical Companies after TRIPS, Indian Institute of Management Calcutta, Working Paper Series, WPS No. 614, (2007) at 6 et seq.

172 CIPR, Integrating Intellectual Property Rights and Development Policy, at 11, 20 et seq.

173 Ibid. at 12. See also MICHAEL BLAKENEY and GETACHEW MENGISTIE, 'Intellectual Property and Economic Development in Sub-Saharan Africa', The Journal of World Intellectual Property, 14:3 (2011), 1-27. 
largely depends on the level of development and will therefore differ among countries. ${ }^{174}$

In general, developing countries are the net importers of technology, most of which is provided by developed countries. Moreover, the vast majority of patent rights are held by corporations and organisations in developed countries. ${ }^{175}$ It is recognised that increasing IP protection comes with losses due to potential higher medicine prices. However, "the welfare cost of limited increases in drug prices should be offset by the dynamic gains", including increased foreign direct investment, increased licensing and technology transfer, local innovation and enhanced institutional performance. ${ }^{176}$

On the other hand, according to the UK Commission on IPRs "it can safely be said that the effect of applying patent rights globally will be to benefit very considerably the holders of patent rights, mainly in developed countries, at the expense of the users of protected technologies and goods in developing countries." 177 It finds that there is no strong evidence to suggest that IPRs promote economic growth in developing, low-income countries. It concludes that in developing countries with weak scientific and technological capacities, IP protection at the levels required by the TRIPS Agreement is not a significant determinant for economic growth; actually quite the opposite is true in that increasing growth is more often associated with weaker forms of IP protection. ${ }^{178}$ This is contrary to technologically advanced developing countries, where some evidence does suggest that IP protection becomes important at a stage of development. ${ }^{179}$ Furthermore, there is no real evidence that in most developing countries (those that are not technologically advanced) foreign investment and increased trade is positively associated with IP protection. ${ }^{180}$

For developing countries, just as was the case in developed countries, developing local technological capacity is an essential component for sustainable economic development. Technological capacity determines to what extent developing

174 See ROD FALVEY, NEIL FOSTER, and DAVID GREENAWAY, 'Intellectual Property Rights and Economic Growth', Review of Development Economics, 10:4 (2006), 700-719. This study concludes that IPR protection encourages innovation in high-income countries and technology flows to low-income countries, but middle-income countries may have offsetting losses from reduced scope for imitation. In that regard it emphasises though that there is no evidence that stronger IPR protection reduces growth for middle-income countries. Consequently, developing countries joining the WTO should be able to reap the broad benefits of freer trade without sacrificing growth in order to meet the accompanying TRIPs obligations.

175 CIPR, Integrating Intellectual Property Rights and Development Policy, at 21.

176 LIPPERT, 'A Market Perspective on Recent Developments in the TRIPS and Essential Medicines Debate', at 23-26, 28.

177 CIPR, Integrating Intellectual Property Rights and Development Policy, at 21.

178 Ibid. at 22. See further NAGESH KUMAR, 'Intellectual Property Rights, Technology and Economic Development: Experiences of Asian Countries', Economic and Political Weekly, 38:3 (2003), 209-226.

179 CIPR, Integrating Intellectual Property Rights and Development Policy, at 22.

180 Ibid. at 24. 
countries can assimilate and apply foreign technology to ensure successful technology transfer. Therefore, a crucial question with regard to IP protection is whether it promotes or hinders technology transfer to developing countries. ${ }^{181}$ The determinants for successful transfer of technology are many and various. The ability to absorb foreign knowledge and adapt it to local conditions depends on the development of local capacity, R\&D, education and the development of institutional performance among others. The introduction of TRIPS does not seem to have led developed countries to take additional measures to encourage technology transfer. ${ }^{182}$

In conclusion, this dissertation cannot provide the solution to the economic problem of patenting in the developing world. However, the question addressed in this section is whether introducing patents for medicines in developing countries will create an incentive to innovate new medicines, also for those diseases which are mainly prevalent in the developing world. It seems unlikely that introducing a strong patent system in developing countries will lead to significantly more R\&D targeted at neglected diseases, yet evidence on this issue is not conclusive. Thus, the argument by proponents of IPRs that patents are essential for innovation and the availability of new medicines might not be as persuasive as it seems at first glance.

\subsection{Conclusion}

As we have seen the most common justification for a patent system is that it provides an incentive to innovate. The question posed in this section is whether patents lead to more innovation in the area of health. There are many that criticise the patent system and challenge the contention that patents provide incentives to innovate especially in the context of neglected diseases affecting mainly developing countries. Moreover, it is questioned whether the innovations created because of patents compensates for the welfare losses due to high medicine prices. There does not seem to be conclusive evidence on this issue; there are numerous studies supporting both sides of the argument. ${ }^{183}$ It is outside of the scope of this study to determine merits of the patent system as a whole and whether it truly provides an incentive to innovate. But it is generally accepted that researching and developing new medicines requires a substantial investment and that there needs to be a system

181 See for example MEIR P. PUGATCH, RACHEL DIAMANT, and HELEN DAVISON, Promoting Technology Transfer in Developing Countries: Lessons from Public-Private Partnerships in the Field of Pharmaceuticals, The Stockholm Network, Expert Series on Pharmaceutical IPRs, (2007). This study suggests that there is a growing body of evidence that IPRs are important for the promotion of innovative, inventive and technology transfer activities in developing countries, including in industrial sectors like pharmaceuticals. Moreover, the evidence suggests that such activities allow developing countries to better address domestic health concerns.

182 CIPR, Integrating Intellectual Property Rights and Development Policy, at 26.

183 HESTERMEYER, Human Rights and the WTO, at 159. 
in place that allows pharmaceutical companies to recoup their R\&D costs and make a profit. The patent system fulfils these aims. The issue therefore does not concern whether the patent system is necessary - it is - but in what form to ensure that both medicines are available and accessible in the short term (i.e. that existing medicines are affordable for patients that need them now) and in the long term (i.e. ensure that there are sufficient incentive for $R \& D$ for new medicines for the future). The question is whether the patent system as it is currently organised (and the focus of this research is on the system introduced by TRIPS in the WTO context) is able to balance these two aims.

\section{Patents - Access: Interference?}

The research question addressed in this chapter is whether patent protection for pharmaceuticals interferes with patients' access to essential medicines. As addressed earlier access includes the availability, physical and economic accessibility of those medicines that are necessary to satisfy the priority health care needs of a country's population. Interference is interpreted here as the question whether patents negatively affect access, particularly the affordability of essential medicines, due to the fact that they are argued to result in higher medicine prices. Thus, does patenting of medicines lead to higher medicine prices?

In a competitive market without patents the law of demand and supply will set the price for a product. However, as was shown, the pharmaceutical market, and the nature of the pharmaceutical products, distinguishes itself from other markets in goods in a number of ways. Demand for medicines is inelastic in the sense that consumers/patients are willing to pay almost any price for the product, especially if it as a life-saving medicine. As a result, for such medicines demand only decreases once the available financial means of the patients/consumers are exhausted. ${ }^{184}$ On the other side, lower prices for essential medicines do not increase the demand for those medicines, because patients/consumers do not buy significantly more medicines than they need just because they are cheap.

Moreover, most newly developed medicines are protected by patents. The justification given here is that patents are vital to ensure that innovators are able to recoup their research and development costs. Patents therefore provide an incentive to innovate, without which the pharmaceutical industry would not be able to continue $\mathrm{R} \& \mathrm{D}$ in future medicines. But we have also seen that although there is no doubt that developing new medicines implies significant resources on the part of the innovator, the system of patents is not at its most effective in situations where there is no market, i.e. with regard to neglected diseases. Unfortunately it is exactly with respect to these diseases that many patients in developing countries are lacking access.

Patents provides right holders with the right to prevent third parties from making, using, offering for sale, selling, or importing for these purposes the patent protected 
product. Thus, the patent holder has a monopoly position on the market, i.e. there is only one supplier of a good that is lacking close substitutes. The lack of competition means that the monopoly supplier can set the price for its product and the quantity it will market to achieve the highest profit. Economic theory suggests that a monopolist sells a lower quantity of goods than would be sold in a competitive market at a higher price to maximise its profit. ${ }^{185}$ Thus monopoly positions lead to higher prices and fewer quantities sold. Furthermore, competition leads to more efficient production processes, which in a monopoly position often remain unchanged. ${ }^{186}$

However, do patents always confer a monopoly position? Not necessarily, because they strictly do not prevent new inventions from entering the market. Patented pharmaceuticals may still face competition by substitutes such as other chemical entities with the same or similar effects. In such a situation there is no real monopoly position and prices for the patented pharmaceutical will be set competitively. ${ }^{187}$ On the other hand, it is clear that patents do limit the number of competitors in the market, and as a result prices are higher than in a truly competitive setting. ${ }^{188}$

Economic and empirical studies have confirmed the negative impact of patents on medicine prices. ${ }^{189}$ Generic production often stimulates competition. ${ }^{190}$ Ending the threat of generics by introducing (product) patents for medicines and thus

185 Ibid. at 144. See for a discussion on IP protection and competition BEATRIZ CONDE GALLEGO, 'Intellectual Property Rights and Competition Policy', in Carlos M. Correa (ed.), Research Handbook on the Protection of Intellectual Property under WTO Rules. Intellectual Property in the WTO Volume 1 (Research Handbooks on the WTO; Cheltenham/Northampton: Edward Elgar, 2010) at 226 et seq.

186 HESTERMEYER, Human Rights and the WTO, at 144.

187 LIPPERT, 'A Market Perspective on Recent Developments in the TRIPS and Essential Medicines Debate', at 8.

188 CIPR, Integrating Intellectual Property Rights and Development Policy, at 34; HESTERMEYER, Human Rights and the WTO, at 145.

189 CIPR, Integrating Intellectual Property Rights and Development Policy, at 36 et seq; SCHERER and WATAL, Post-TRIPS Options for Access to Patented Medicines in Developing Countries, at 5 et seq.

See also JOAN-RAMON BORRELL, 'Pricing and Patent of HIV/AIDS Drugs in Developing Countries', Applied Economics, 39:4 (2007), 505-518; XUAN LI, 'The Impact of Higher Standards in Patent Protection for Pharmaceutical Industries under the TRIPS Agreement: A Comparative Study of China and India', The World Economy, (2008), 1367-1382; KEITH E. MASKUS, 'A Review of the Economic Literature', in Ricardo Meléndez-Ortiz and Pedro Roffe (eds.), Intellectual Property and Sustainable Development. Development Agendas in a Changing World (Cheltenham: Edward Elgar Publishing, 2009).

Contrary: AMIR ATTARAN, 'How Do Patents and Economic Policies Affect Access to Essential Medicines in Developing Countries?', Health Affairs, 23:3 (2004), 155-166. According to Attaran the settled assumptions regarding access to medicines and patent protection for such medicines must be reexamined. He finds that patents cannot cause essential medicines to be inaccessible in "many" developing countries because they do not exist 98.6 percent of the time; similarly, patents cannot be a "global" necessity of pharmaceutical business because companies forgo them 69 percent of the time.

190 GELDERS et al., Price, Availability and Affordability. An International Comparison of Chronic Disease Medicines, at 3-4. 
limiting competition has been estimated to result in price increases, particularly if substitution is low and a loss of variety for consumers due to the elimination of domestic (generic) versions. ${ }^{191}$ Furthermore, the market entry of generics, for example due to patent expiry or compulsory licensing, has been shown to reduce average medicine prices substantially. ${ }^{192}$

Local generic production has been possible in countries that have not, granted patents for pharmaceutical products until recently. For example in India, patent protection was only granted for pharmaceutical processes not products, which encouraged the development of a strong domestic generic pharmaceutical industry. Brazil is also an example where local generic production has made a remarkable reduction in prices for antiretroviral medicines possible. ${ }^{193}$ The impact of introducing a patent system (for medicines) is therefore likely to be felt most strongly in countries with a developed generic pharmaceutical industry and a degree of competition keeping prices low. On the other hand developing countries with a strong generic industry developing innovative $R \& D$ capacities might benefit from patent protection. ${ }^{194}$

Thus, in general, patent protection for pharmaceuticals results in higher medicines prices; and higher prices reduces access to medicines for patients and states with limited resources. ${ }^{195}$ Developed countries have the resources to assist their population with health care costs through national health care systems. They have a human rights obligation to do so. Developing countries are also obliged to realise the right to health progressively, however, only to their maximum available resources. ${ }^{196}$ Many developing countries do not have sufficient financial resources to ensure that those individuals who cannot pay their health costs receive free medicines. Countries are struggling to find the resources for generic medicines, let alone patented medicines. ${ }^{197}$ Consequently, we must conclude that patents for

191 See for further information SUDIP CHAUDHURI, P.K. GOLDBERG, and P. JIA, 'Estimating the Effects of Global Patent Protection in Pharmaceuticals: A Case Study of Quinolones in India', American Economic Review, 96:5 (2006), 1477-1514; EUROPEAN COMMISSION, Pharmaceutical Sector Inquiry, (8 July 2009); CARSTEN FINK, 'Patent Protection, Transnational Corporations, and Market Structure: A Simulation Study of the Indian Pharmaceutical Industry', Journal of Industry, Competition and Trade, 1:1 (2001), 101-121.

See further R.B FRANK and D.S. SALKEVER, 'Generic Entry and the Pricing of Pharmaceuticals', Journal of Economics and Management Strategy, 6:1 (1997), 75-90; H.G. GRABOWSKI and J.M. VERNON, 'Brand Loyalty, Entry and Price Competition in Pharmaceuticals after the 1984 Drug Act', Journal of Law and Economics, 35:2 (1992), 331-350; D. REIFFEN and M.R. WARD, 'Generic Drug Industry Dynamics', The Review of Economics and Statistics, 87:1 (2005), 37-49; SCHERER and WATAL, Post-TRIPS Options for Access to Patented Medicines in Developing Countries, at 5 et seq. SCHAABER, Keine Medikamente Für Die Armen?, at 63-66.

194 CIPR, Integrating Intellectual Property Rights and Development Policy, at 37-38.

195 See also TINA S. BHATT, 'Amending TRIPS: A New Hope for Increased Access to Essential Medicines', Brooklyn Journal of International Law, 33 (2007-2008), 597-628 at 602 et seq.

196 See further chapter 3.

197 HESTERMEYER, Human Rights and the WTO, at 149. 
pharmaceuticals interfere with patients' access to essential medicines particularly within developing and underdeveloped contexts. ${ }^{198}$

However, it has been argued that the impact of patents on medicines prices is minimal compared to other factors that impact access. The Special Rapporteur on the Right of Everyone to the Highest Attainable Standard of Physical and Mental Health has also examined this issue. Based on the input of a variety of stakeholders, he considers the main determinants of access to medicines to be: investing in local production in order to ensure the availability of medicines particularly in developing and least-developed countries; ${ }^{199}$ ensuring that medicines are priced fairly and equitably so as to not disproportionately burden the poor which is of particular significance in developing countries where the majority of expenditure on medicines is individually financed through out-of-pocket payments; ${ }^{200}$ identifying the medicines required to address the priority health needs of a population through the adoption of a national essential medicines list; ${ }^{201}$ efficient and transparent procurement of medicines; ${ }^{202}$ functioning distribution systems; ${ }^{203}$ rational and appropriate use of medicines; ${ }^{204}$ and quality assurance for medicines. ${ }^{205}$

Moreover, not all essential medicines are patented, their patent term might have expired or they are not patented in developing countries. ${ }^{206}$ Obviously, for those medicines that have never been patented or are no longer patented, the debate on the impact of patent protection on prices does not hold true. However, the majority of newly developed medicines are patented; and the medicines, the patens for which have expired, are older medicines which might be less effective or have more side effects (see for example with regard to the newer second-line HIV/AIDS medicines, which are becoming more and more important due to increasing resistance within HIV infected patients). With regard to medicines that are not patented in developing countries, this does not automatically imply that patents have no impact on prices. The reason for this is that many developing countries do not have the manufacturing capacity to benefit from the fact that a medicine is not patented within their legal

198 See also UN SUB-COMMISSION ON HUMAN RIGHTS, Report of the High Commissioner on the Impact of the Agreement on Trade-Related Aspects of Intellectual Property Rights on Human Rights (UN Doc. E/CN.4/Sub.2/2001/13; 2001) at $\$ 42$ et seq; UN SUB-COMMISSION ON THE PROMOTION AND PROTECTION OF HUMAN RIGHTS, Progress Report Submitted by J. Oloka-Onyango and Deepika Udagama, in Accordance with Sub-Commission Resolution 1999/8 and Commission on Human Rights Decision 2000/102 on Globalisation and Its Impact on the Full Enjoyment of Human Rights (UN Doc. E/CN.4/Sub.2/2001/10; 2001) at \$24.

UN HUMAN RIGHTS COUNCIL, Report of the Special Rapporteur on the Right of Everyone to the Highest Attainable Standard of Physical and Mental Health, Anand Grover, on Access to Medicines (UN Doc. A/HRC/23/42; 2013) at §11-19. Ibid. at $\$ 20-39$.

Ibid. at $\$ 40-46$.

Ibid. at $\$ 47-53$.

Ibid. at $\$ 54-56$.

Ibid. at $\$ 57-60$.

Ibid. at $\$ 61-66$.

HESTERMEYER, Human Rights and the WTO, at 150. 
system. Thus many developing countries are dependent on imports. In a country like Uganda, without any substantial manufacturing capacity, patenting is not necessary as the product cannot be produced within that country. Only in countries that have (some) manufacturing capacity, such as for example India and South Africa, do innovative pharmaceutical companies patent their medicines to prevent third parties form producing them. ${ }^{207}$

Furthermore it is argued that the impact of patents on medicine prices is not the crucial problem here, poverty is. In most developed countries national health systems are able to provide patients with the most essential medicines, but this is not true for many developing countries. A key reason for this is that developing states, and especially least developed states, do not have the financial capacity to provide all patients with the necessary medical treatment. Many people in developing countries live in severe poverty and lack basic amenities, like sufficient nutritious food, clean water, basic sanitary facilities, and access to hospitals and health clinics. Poverty contributes to existing public health problems. The pharmaceutical industry argues that such severe poverty, inadequate healthcare and health infrastructure are far more important reasons why patients lack access to quality health care and medicines and not medicine prices per se, as is often argued by activists. ${ }^{208}$ It is said that in many developing countries the situation is aggravated by high medicine distribution costs as a result of import tariffs, port charges, importers' margins, value added taxes on medicines and high margins for wholesalers and retailers (the so-called domestic add-on). ${ }^{209}$ Additionally it is argued that generic version of patented medicines may be of sub-standard quality or even hazardous. ${ }^{210}$

These arguments put forward by the pharmaceutical industry are definitely relevant; however, the issue concerning the lack of access to medicines is multifaceted and complicated. Poverty in developing states has, without a doubt, a negative effect on public health in those countries; this does not entail, however, that high medicines prices do not also contribute to the problem too. The effect of patents should not be underestimated. Consider the example of the HIV/AIDS epidemic and the difference between prices of originator branded antiretrovirals and subsequent generic products. When medicines are priced at the initial high costs, developing states with limited resources simply cannot afford to provide patients with the medicines they so desperately need. The focus in this dissertation is on the effect that patents have on medicine prices; and the question whether

207 CIPR, Integrating Intellectual Property Rights and Development Policy, at 35; HESTERMEYER, Human Rights and the WTO, at 150.

208 CIPR, Integrating Intellectual Property Rights and Development Policy, at 38; BRYAN MERCURIO, 'Resolving the Public Health Crisis in the Developing World: Problems and Barriers of Access to Essential Medicines', Northwestern Journal of International Human Rights, 5:1 (2006).

209 IFPMA, Principle Focus and Actions of the Research-Based Pharmaceutical Industry in Contributing to Global Health, 2008, at 2-3, 6.

210 CIPR, Integrating Intellectual Property Rights and Development Policy, at 38. 
patents impede access is not negated by the fact that other factors impede access even more. ${ }^{211}$

\section{Conclusion}

This research examines the interface between patent and human rights law with regard to access to essential medicines in the context of developing countries. The argument that is often made is that patents negatively impact patients' access to medicines, as patent protection for medicines results in higher prices. It is exactly this contention that is under review in this chapter. Therefore the research question addressed here is whether patent protection for medicines interferes with patients' access to essential medicines. As addressed in this chapter "access" in the context of this research refers to medicines being available, physically accessible and affordable on a non-discriminatory basis (in addition to being culturally acceptable and of good quality). The focus here is on the element of "affordability" of essential medicines within a developing country context. Namely, for countries operating in a resource constrained setting it is a continuous struggle to find and allocate the resources necessary to maintain and improve the public health care system. Medicine expenditure accounts for a significant share of all health expenditure and developing countries spend proportionally more of their health budget on medicines than wealthier countries. As a result of inadequate public health systems, many patients in developing countries are forced to finance medicine use privately. Moreover, it is especially developing countries with poor public health systems which suffer disproportionately from widespread public health problems such as HIV/AIDS, tuberculosis and malaria. It is therefore crucial that developing countries ensure that medicine prices are as low as is realistically possible.

The question posed in this chapter was to what extent patent protection for medicines negatively impact access by resulting in higher medicine prices, i.e. can we identify an interference? As was shown, both economic theory (the fact that patent protection in the majority of situations leads to a monopoly position) and empirical studies find that in general patent protection for medicines goes hand-inhand with higher medicine prices. These higher prices are then argued, particularly by the pharmaceutical industry, to be justified due to the fact that patents are essential in order to enable pharmaceutical corporations to recoup their substantial research and development costs. Thus, it is argued that without patent protection companies would have no incentive to invest in innovation. Although the incentive to innovate function of patent protection is not contested here, an important observation must be made. Patent protection only provides an incentive to innovate in situations where the innovator has a real possibility to recoup his investment, i.e. a profitable market. Unfortunately though, the majority of patients in developing countries, lacking resources, do not provide such a profitable market. As a result the

HESTERMEYER, Human Rights and the WTO, at 151. 
largest part of health-related research and development is invested in diseases that either affect patients worldwide (such as cancer or diabetes) or at least affect patients in the developed world. Lacking, however, is the research and development targeted at diseases mainly prevalent in developing countries, also referred to as neglected and poverty-related diseases.

Thus, the problem with regard to access to medicines is two-fold:212

- Patients lack access to essential medicines that are available but for a variety of reasons they do not reach the patient in need (short term needs of the patient);

- Lack of research \& development of new medicines targeted at diseases especially prevalent in developing countries which could lead to a decline of available medicines in the future (long term needs of the patient).

212 See also GALLEGO, 'Intellectual Property Rights and Competition Policy', at 253. 



\section{Part II}

\section{International FramewORK}





\section{Chapter 3 \\ A Human Right of Access to Medicines?}

\section{INTRODUCTION}

During the last decade, there has been much debate both within the international and domestic context on the issue of patients' access, or lack thereof, to essential medicines. This issue has been especially relevant for developing countries, where pandemics like HIV/AIDS have taken hold, with devastating results for their populations, and who are in dire need of good quality medication. Within the human rights field it is often argued that patients have a right of access to essential medicines. ${ }^{213}$ Although such a right of access to medicines is not explicitly mentioned in any of the international or regional human rights treaties, it is deduced from the codified human right to health. Moreover, accessibility of medicines is argued to include affordability of medicines. As was shown in chapter 2, in developing countries, which are the focus of this research, high medicine prices curtail patients' access to essential medicines. In part, these high, and as such possibly unaffordable, medicine prices are ascribed to the 20-year monopoly enjoyed by pharmaceutical corporations patenting new medicines. This link between the patent protection of medicines and patients' access to such medicines became a topic of much debate and research, particularly after the negotiation and entry into force of the Agreement on Trade-related aspects of Intellectual Property Rights as an annex to the Agreement establishing the World Trade Organisation. Namely, the TRIPS Agreement provides for minimum standards of intellectual property rights, including patents. Not only activists, ${ }^{214}$ but also international organisations started to further examine the link between patients' (lack of) access to medicines as a human rights issue with regard to the minimum patent standards as required by TRIPS. ${ }^{215}$

Before being able to examine the legal relationship between patents and patients' possible right of access to medicines, the latter issue must first be situated within

213 See for example DANWOOD MZIKENGE CHIRWA, 'The Right to Health in International Law: Its Implications for the Obligations of State and Non-State Actors in Ensuring Access to Essential Medicines', South African Journal of Human Rights, 19 (2003), 541-566.

214 See for example some of the few NGOs active campaigning for adequate access to essential medicines for all patients: Essential Action's Access to Medicines Project (www.essentialaction. org/access/); Health Action International (www.haiweb.org); Médicins Sans Frontières' Access to Essential Medicines Campaign (www.accessmed-msf.org/); Oxfam International (www.oxfam.org/); and the Consumer Project on Technology (www.cptech.org/ip/health/). In addition there have also been regional campaigns, see for example the Treatment Action Campaign in South Africa (www.tac.org.za) and India's Peoples Health Movement (www.phm-india.org).

215 See for example WHO, 'Globalisation, TRIPS and Access to Pharmaceuticals.', Policy Perspectives on Medicines, 3 (2001). 
the broader context of international human rights protection. The research question addressed in this chapter is therefore whether, and if so how, access to (essential) medicines is protected under international human rights law. The focus of this research is on international human rights law within the framework of the United Nations, which will be introduced first (section 2). Following this, the question posed is whether a right of access to medicines can identified within a number of different sources: the most obvious starting point being the right to health (section 3 ), but also the right to life (section 4), the right to benefit of science (section 5) and within customary international law (section 6).

\section{The International Human Rights Framework}

This section aims to put the research question - is access to medicines protected under international human rights law? - into context by briefly discussing the origins of the concept of human rights (section 2.1), the perceived traditional dichotomy between civil and political and economic, social and cultural rights (section 2.2) and the framework in which to place the main developments in the area of the standard-setting and monitoring of human rights, i.e. the UN human rights framework (section 2.3).

\subsection{Brief History of the Concept of Human Rights}

There is much debate on the history and origins of human rights. ${ }^{216}$ The notion of human rights has been connected to religious, moral and philosophical origins in biblical and classical history. It is sometimes believed that the 1215 Magna Carta is one of the first documents which speaks of subjective rights of men, and as such, is inappropriately labelled the forerunner of modern-day human rights texts. ${ }^{217}$ However, only after the Middle Ages do we see the development of the concept of natural or human rights take off as part of the Enlightenment Movement and later with the emergence of the modern state. ${ }^{218}$ The most notable documents in that

216 See for a discussion on the history and origins of the concept of human rights MICHAEL FREEMAN, Human Rights. An Interdisciplinary Approach (Cambridge: Polity Press, 2002); MICHELINE R. ISHAY, The History of Human Rights. From Ancient Times to the Globalisation Era (second edn.; Berkeley/Los Angeles/London: University of Califorina Press, 2008). CHRISTIAN TOMUSCHAT, Human Rights: Between Idealism and Realism, eds Marise Cremona et al. (second edn., The Collected Courses of the Academy of European Law; New York: Oxford University Press, 2008) at 7 et seq.

218 Ibid. at 18-23; TOMUSCHAT, Human Rights, at 7 et seq. Jurists and philosophers like Hugo Grotius, Thomas Hobbes, Jean-Jacques Rousseau and John Locke played an important part in the development of the concept of natural rights. For example Hobbes (1588-1679) stressed the rights of the sovereign power of the state (i.e. the person of the ruler) over all the members of the common polity. He thought to free state power from any constraints which could possibly justify 
regard are the 1776 American Declaration of Independence which provides "as self evident" that "all men are created equal, that they are endowed by their creator with certain unalienable rights, that among these are life, liberty and the pursuit of happiness", and the 1789 French Déclaration des Droits de l'Homme et du Citoyen which also proclaims the freedom of man. The French Declaration set the tone for Europe and, after the fall of the Napoleonic Empire in 1815 a constitutional movement emerged in all neighbouring states. ${ }^{219}$

The rationale behind such individual rights is the protection of human beings against abuses of power by states. ${ }^{220}$ In none of these documents, though, do we find obligations for the state to provide anything more for its citizens than physical security and a functioning judicial system. This ideology, that the reference to human rights in national constitutions was confined to the classical freedoms, prevailed during the $18^{\text {th }}$ and $19^{\text {th }}$ century. It was not until the $20^{\text {th }}$ century that we see a shift towards incorporating economic and social rights in national constitutions. From then on, there was a growing awareness within states (and their constitutions) of the usefulness of socio-economic rights, in addition to the protection of classical freedoms. ${ }^{221}$ Unfortunately, however, there is no agreement on the manner in which socio-economic rights should be guaranteed, as we will see below.

The protection of human rights was originally confined to the domestic context as rights included within national constitutions. Protection of human rights on the international level is what Tomuschat calls a "latecomer in history" and it is not until the $20^{\text {th }}$ century that the notion of human rights acquired a distinctive international character. ${ }^{222}$ Traditionally, international law was, as the wording

a right of resistance. In his perception man, following his instincts, would attack his neighbours if not restrained by public authority. Locke (1632-1704) on the other hand had a totally opposite view to Hobbes. He believed that men were by nature all free, equal and independent. Every individual had a responsibility to God and must observe the law of nature. Each individual, as a rational being, had a natural right to freedom, limited to the extent that he should respect the natural rights of others. Furthermore, each individual has a property in himself and his labour. The influence of Locke can be found in the 1776 American Declaration of Independence.

TOMUSCHAT, Human Rights, at 14; DAVID WEISSBRODT and CONNIE DE LA VEGA, International Human Rights Law. An Introduction, ed. Jr. Bert. B Lockwood (Pennsylvania Studies in Human Rights; Philadelphia: University of Pennsylvania Press, 2007) at 17.

220 FREEMAN, Human Rights. An Interdisciplinary Approach, at 15; TOMUSCHAT, Human Rights, at 8 .

221 CHRISTIAN TOMUSCHAT, Human Rights. Between Idealism and Realism, eds Philip Alston, Gráinne De Búrca, and Bruno De Witte (The Collected Courses of the Academy of European Law; New York: Oxford University Press, 2003) at 27-28.

222 TOMUSCHAT, Human Rights, at 8 et seq. It must be mentioned here that a first indication of development to the international protection of human rights already took place in 1815 with the adoption of the Declaration on the Abolition of Slave Trade. Although one could question the real intention behind the Declaration - considering that it abolished the slave trade, but not slavery, and the argument made was that the ban was essentially intended to serve the economic interests of England - it is the first international instrument prohibiting a practice which was profoundly at odds with the concept of human dignity. 
makes clear, the law of nations. Its main functions concerned primarily with regulating the relationships and interactions between states. Individuals were merely subjects of the state, without any legal personality within international law. As a result, a state's treatment of its own population was considered a solely internal matter of consequence only for the concerned state. International law, to a limited extent, did regulate the treatment of individuals, for example with regard to the treatment of (non-)combatants during armed conflict, the protection of aliens abroad and the protection of minorities. ${ }^{223}$ The first treaties that came into existence before World War I aimed at protecting the individual, yet none of these treaties addressed the relationship between a state and its citizens. ${ }^{224}$

The situation changed after WW I ended in 1919 with the Paris Peace Conference and Versailles Treaty. ${ }^{225}$ At that time, the League of Nations was established as the first organisation with the mandate to ensure international peace and security, therewith preventing war as the greatest threat to human life and physical and spiritual integrity. Yet, nowhere does the League's Covenant make reference to human rights. ${ }^{226}$ At the same time, in 1919, the International Labour Organisation was set up, the first international organisation in which individuals were represented. However, it was World War II and the horrors of the Nazi's regime treatment of its own subjects that brought about a fundamental change. The mass violations of human rights and infringements of territorial sovereignty provided the turning point which led to the development of contemporary international human rights law and the acceptance that the treatment of individuals at home (within their own state) was no longer a purely internal matter, but a matter of international law and concern. ${ }^{227}$ This is reflected in the statement that in addition to ensuring international peace and security, the promotion of and encouragement of respect for human rights and fundamental freedoms is one of the core purposes of, at that time newly created, United Nations. ${ }^{228}$

The UN Charter was the first international legal document to recognise the concept of human rights. During its 1945 founding conference in San Francisco the initial lack of any human rights references met with strong protests especially from some Latin American countries. This led to the inclusion of human rights within the Charter as one of the core purposes of the UN. ${ }^{229}$ Once the UN came into being,

223 HESTERMEYER, Human Rights and the WTO, at 79-80; WEISSBRODT and VEGA, International Human Rights Law, at 16.

224 TOMUSCHAT, Human Rights, at 15-16.

225 See also ISHAY, The History of Human Rights, at 199 et seq.

226 WEISSBRODT and VEGA, International Human Rights Law, at 17-18.

227 HESTERMEYER, Human Rights and the WTO, at 80; TOMUSCHAT, Human Rights, at 22-24; WEISSBRODT and VEGA, International Human Rights Law, at 20-21.

228 See the Preamble and article 1.3. of the UN Charter, which reads as follows: To achieve international co-operation in solving international problems of an economic, social, cultural, or humanitarian character, and in promoting and encouraging respect for human rights and for fundamental freedoms for all without distinction as to race, sex, language, or religion. 
the newly created Commission on Human Rights was charged with the task to draft a complete list of human rights and thus define the general human rights obligations as established by the Charter, which it did so very effectively. ${ }^{230}$ The draft was adopted during the Commission's third session in 1948 and via the Economic and Social Council, it was passed on to the General Assembly which adopted the Universal Declaration of Human Rights on December $10^{\text {th }} 1948$ by a vote of 48 to none (with 8 abstentions). ${ }^{231}$ This was the first time in history that a document was created which defined every human being's rights, independent of his or her race, colour, sex, language or other condition. ${ }^{232}$ In that regard it was rather remarkable that there was consensus among the UN members, which was probably also partly due to the fact that the document was adopted in form of a declaration, not intended to be legally binding. ${ }^{233}$ Yet as we will see below the UDHR has gained substantial importance in international human rights law as it is an authoritative interpretation of the human rights references in the UN Charter and is now (partly) considered to represent customary international law. ${ }^{234}$

\subsection{Civil \& Political Rights vs. Economic, Social \& Cultural Rights}

Since the beginning of the international development of human rights, there has been a dichotomy between two sets, or generations, of human rights: civil and political rights on the one hand - so-called first generation rights; and economic, social and cultural rights (or ESC rights) on the other - so-called second generation rights. ${ }^{235}$ As a result of the growing interdependence of states and issues of global importance, a third generation of human rights emerged, that of collective or solidarity rights. The right to development, peace or a clean environment are illustrations thereof. ${ }^{236}$ This distinction between first generation and second generation rights can be found from the early development of human rights. ESC rights developed later than civil and political rights, in the late $19^{\text {th }}$ and early $20^{\text {th }}$ century. It was only when the notion of economic and social justice came to the forefront that economic, social and cultural rights were created and developed. Internationally, the formation of the International Labour Organisation, after World War I, was an important point in time in the development of ESC rights. Also, US President Roosevelt's famous 1941 speech in which he states that individual freedom

\footnotetext{
230 TOMUSCHAT, Human Rights, at 23; ISHAY, The History of Human Rights, at 218 et seq.

231 See JAVAID REHMAN, International Human Rights Law (Second edn.; Essex: Pearson Education Ltd, 2010) at 75 et seq.

232 WEISSBRODT and VEGA, International Human Rights Law, at 24 et seq.

233 REHMAN, International Human Rights Law, at 78-79.

234 See further section 6 of this chapter.

235 See also PHILIP ALSTON and GERARD QUINN, 'The Nature and Scope of States Parties' Obligations under the International Covenant on Economic, Social and Cultural Rights', Human Rights Quarterly, 9 (1987), 156-229 at 159 et seq.

236 TOMUSCHAT, Human Rights, at 24.
} 
cannot exist without economic security and independence ("freedom from want"). ${ }^{237}$ The increasing attention and recognition of ESC rights eventually led to their inclusion in the 1948 Universal Declaration of Human Rights, which comprises civil and political and ESC rights. However, the two sets of rights were still considered to be fundamentally different, an attitude strengthened by the political climate during the 1950s leading up to the Cold War and visible through the adoption of two separate human rights covenants in $1966 .{ }^{238}$ Even though civil and political rights and ESC rights were adopted in two separate treaties, both international documents are binding and thus create legal obligations for states parties to the Covenants.

The conceptual distinction between these two sets of rights is argued to be relatively simple. Civil and political rights are considered first to guarantee personal liberties, ensuring individuals' freedom and protection from interference by the state. They are thus categorised as negative rights, i.e. rights obliging the state not to interfere with one's personal freedom and bodily integrity. Classic examples are the right to life, prohibition of torture, the right of free expression etc. Economic, social and cultural rights, however, demand economic and social equality and concern rights pertaining to the social position of the individual within society. They are thus categorised as positive rights, i.e. rights that require states to intervene, to act. ${ }^{239}$ Requiring a state to act often involves the commitment of financial resources. Examples of economic, social and cultural rights are the right to education, the right to food and clean drinking water, the right to health and the right to work.

This distinction is oversimplified and outdated. ${ }^{240}$ Both sets of rights require action by the state for their realisation, and they have an impact on the enjoyment of all human rights. For example, the right to a fair trial requires the state to put in place a fully functioning judicial system, to take full advantage of the right to freedom of expression a decent education is necessary, or, the right to free elections cannot be meaningful in a society where the majority of people live in dire social conditions, without adequate housing, food and clean drinking water. Human rights are therefore found to be universal, indivisible, interdependent, and interrelated. ${ }^{241}$

237 J.K. MAPULANGA-HULSTON, 'Examining the Justiciability of Economic, Social and Cultural Rights', The International Journal of Human Rights, 6:4 (2002), 29-48 at 34. See further ALSTON and QUINN, 'The Nature and Scope of States Parties' Obligations under the ICESCR', at 181 et seq; ISHAY, The History of Human Rights, at 225 et seq.

239 TOMUSCHAT, Human Rights, at 24.

240 CHRISTIAN COURTIS, Courts and the Legal Enforcement of Economic, Social and Cultural Rights Comparative Experiences of Justiciability. (Geneva: International Commission of Jurists, 2008) at 10; REHMAN, International Human Rights Law, at 142-143.

241 UN WORLD CONFERENCE ON HUMAN RIGHTS, Vienna Declaration and Programme of Action (UN Doc. A/CONF.157/23; 1993) at §5; TOMUSCHAT, Human Rights, at 25. There has been an ongoing debate over the universality of human rights. Does the content and scope of rights vary according to regional, religious and political backgrounds, or is there a single set of human rights applicable to every individual? Proponents of universalism take the stance that human rights are global in nature and belong to every individual irrespective of gender, colour, race, ethnicity, religion or regional background. Proponents of regionalism advocate for establishing distinct systems (see for example some Islamic States who have advanced their own 
This universal character is based on the belief that human rights are intrinsically linked to human dignity and fundamental to all civilised societies. Human rights are rights which a person enjoys simply because of the fact that he or she is human, without requiring any supplementary conditions. ${ }^{242}$

Concluding, the two sets of rights are not fundamentally different in nature. The difference lies in the degree of state action necessary for full realisation which depends on the right in question, irrespective of what category this right belongs to. It is correctly thought that, on average, socio-economic rights are more dependent on positive state action for their full realisation than civil and political rights. ${ }^{243}$

\subsection{The UN Human Rights Framework}

The international development of state obligations with regard to human rights has mainly taken place within the UN framework. ${ }^{244}$ The Preamble to the UN Charter states that the UN is determined "to reaffirm faith in fundamental human rights, in the dignity and worth of the human person, in the equal rights of men and women and of nations large and small", "to promote social progress and better standards of life" and resolves to combine efforts to accomplish these aims. Article 1.3 of the UN Charter states that solving international problems of an economic, social and cultural or humanitarian character, and promoting and encouraging respect for human rights and fundamental freedoms, is one of the core purposes of the UN. Thus, human rights and the improvement of social and economic conditions have a prominent place within the UN system. This is reaffirmed by article 55 of the UN Charter which reads as follows:

With a view to the creation of conditions of stability and well-being which are necessary for peaceful and friendly relations among nations based on respect for the principle of equal rights and self-determination of peoples, the United Nations shall promote:

1) higher standards of living, full employment, and conditions of economic and social progress and development;

standards of human rights which in certain instances may conflict with modern international human rights law).

242 TOMUSCHAT, Human Rights, at 3.

243 ALSTON and QUINN, 'The Nature and Scope of States Parties' Obligations under the ICESCR', at 184.

244 See the following major human rights documents adopted in the UN framework: the 1948 Universal Declaration of Human Rights (UDHR); the 1965 International Convention on the Elimination of All Forms of Racial Discrimination (ICERD); the 1966 International Covenant on Civil and Political Rights (ICCPR) \& International Covenant on Economic, Social and Cultural Rights (ICESCR); the 1979 Convention on the Elimination of All Forms of Discrimination against Women (CEDAW); the 1984 Convention against Torture and Other Cruel, Inhuman or Degrading Treatment or Punishment (CAT); and the 1989 Convention on the Rights of the Child (CRC). 
2) solutions of international economic, social, health, and related problems; and international cultural and educational cooperation; and

3) universal respect for, and observance of, human rights and fundamental freedoms for all without distinction as to race, sex, language, or religion.

Article 56 of the Charter states that all UN members pledge themselves to take joint and individual action in cooperation with the UN to achieve the abovementioned goals. Articles 55 and 56 must be read together and clearly formulate a legal obligation flowing from the Charter on all UN members to promote and respect human rights, both fundamental freedoms and socio-economic rights. The UDHR is seen as an authoritative interpretation of members' legal obligations with respect to human rights under the UN Charter. This is substantiated by the travaux préparatoires and the reference to articles 55 and 56 in the UDHR's preamble. ${ }^{245}$

Following the adoption of the Universal Declaration of Human Rights in 1948, the Commission on Human Rights embarked on drafting an international Bill of Human rights. Despite continuous calls for the indivisibility of human rights, an ongoing dispute between members of the Commission over the relationship between civil and political rights and economic, social and cultural rights, including the appropriate means to implement, supervise and protect the different rights, led to the development of two separate Covenants both adopted by the General Assembly in 1966: the International Covenant on Civil and Political Rights and the International Covenant on Economic, Social and Cultural Rights. Both Covenants entered into force on January $3^{\text {rd }}, 1976 .^{246}$

The 1948 UDHR and the two 1966 Covenants together are often referred to as the International Bill of Human Rights. However, many more treaties, declarations and instruments on human rights have been drafted and adopted during the last century. In that regard, the international community has been very successful in creating norms to promote and protect human rights, yet, it has not been able to provide truly effective international monitoring and enforcement mechanisms. ${ }^{247}$ This unfortunately manifests itself through the many instances of human rights violations worldwide.

There is a range of human rights bodies intended to monitor states' performance in complying with their human rights obligations based either on the UN Charter,so-called Charter-based bodies,- or on a human rights treaty,- so-called treatybased bodies.

Charter-based mechanisms refer to the work of the political bodies of the UN. Both the General Assembly (GA) ${ }^{248}$ and the Economic and Social Council

\footnotetext{
245 REHMAN, International Human Rights Law, at 29.

246 ISHAY, The History of Human Rights, at 223.

247 See for more information SARAH JOSEPH and JOANNA KYRIAKAKIS, 'The United Nations and Human Rights', in Sarah Joseph and Adam Mcbeth (eds.), Research Handbook on International Human Rights Law (Cheltenham: Edward Elgar, 2010). 
$(\mathrm{ECOSOC})^{249}$ have been granted competencies in the field of human rights. Furthermore, the UN Charter required the ECOSOC to set up a commission in the economic and social field for the promotion of human rights. ${ }^{250}$ In its first meeting in 1946 ECOSOC established two functional commissions, one in the area of human rights, i.e. the Commission on Human Rights (HRCion). ${ }^{251}$ The initial mandate of the HRCion was to submit proposals, recommendations and reports to ECOSOC concerning a range of human rights issues. ${ }^{252}$ The first 20 years the HRCion focused primarily on standard-setting mechanisms. It had no powers to take action with regard to complaints concerning specific human rights situations. This attitude, however, started changing from the 1960s onwards: the political environment with respect to colonialism and racial discrimination was changing; the membership of the UN increased which led to an almost doubling of the HRCion's members. As a result the mandate of the HRCion was further extended empowering it to deal with communications relating to human rights violations. ${ }^{253}$

The HRCion has made a significant contribution to the development of human rights law, particularly regarding standard-setting through its preparation of human rights instruments, and more recently to the monitoring and implementation of human rights obligations. In addition, it authorised the establishment of various working groups and Special Rapporteurs. However, in time the political nature and controversial membership of the HRCion led to a lack of objectivity in its approaches towards human rights. ${ }^{254}$ As a result, in 2006, the Human Rights Council (HRC) was set up to replace the HRCion. ${ }^{255}$

The HRC is responsible for "promoting universal respect for the protection of all human rights and fundamental freedoms for all, without distinction of any kind and

249 Article 62.2 of the UN Charter.

250 Article 68 UN Charter.

251 The other commission set up was the Commission on the Status of Women. The membership of the Commission of Human Rights consisted of government representatives of UN members allocated on a geographical basis. At the time of its abolition it consisted of 53 representatives. Other states would send representatives to the proceedings, but they could not vote. The HRCion met annually for six weeks in March - April, and reported its proceedings to the General Assembly via ECOSOC. The HRCion also had a subsidiary organ: the Sub-Commission on the Promotion and Protection of Human rights which consisted of 26 expert members who served in their individual capacity independent of their government.

252 See ECOSOC Resolutions 5(2) of 16 February 1946 and 5(11) 21 June 1946.

253 See ECOSOC Resolution 1235 (XLII) of 6 June 1967 and resolution 1503 (XLVIII) of 17 May 1970. REHMAN, International Human Rights Law, at 46 et seq.

254 Ibid. at 49.

255 UN GENERAL ASSEMBLY, Resolution 60/251. Human Rights Council (UN Doc. A/ RES/60/251; 2006). The HRC is a subsidiary body of the UN General Assembly (as opposed to the HRCion which was a subsidiary body of ECOSOC) and reports directly to the GA. The HRC consists of 47 members allocated regionally. Members are elected for a three year period and cannot be re-elected after been a HRC member for more than two consecutive terms. In situations where a member commits gross and systematic violations of human rights, the GA may suspend membership with a two-third vote of members present. The Sub-Commission on HRs has been replaced by an Advisory Committee which main task is to support the HRC's work. 
in a fair and equal manner". ${ }^{256}$ The Council will also address situations of human rights violations and make recommendations thereon, in addition to promoting and co-ordinating the mainstreaming of human rights in the UN framework. ${ }^{257}$ To achieve this goal, the HRC will undertake a universal periodic review of each of the UN member states. ${ }^{258}$ The HRC also provides for a complaint procedure which allows individuals and groups to report human rights abuses in a confidential setting. ${ }^{259}$

As stated, the HRCion set up a number of mechanisms such as working groups, independent experts and Special Rapporteurs dealing with thematic issues relating to human rights violations or country-specific situations. These are referred to as Special Procedures. ${ }^{260}$ The HRC has continued this system and is reviewing all mandates. ${ }^{261}$ Special Rapporteurs are independent experts serving in their personal capacity conducting in-depth and on-the-ground research relating to their thematic or country mandate and reporting their findings to the HRC (previously HRCion) and GA. Thematic mandates, which last for three years and may be extended, allow Special Rapporteurs to analyse a particular human rights issue globally. The Special Procedures are considered the most flexible and effective mechanisms within the UN human rights framework. They have done very valuable work to promote and encourage respect for human rights, yet they do not have any enforcement tools and are therefore dependent on the goodwill and cooperation of the member states and governments. $^{262}$ This dissertation will also look at the work of the Special Rapporteur on the Right of everyone to the enjoyment of the highest attainable standard of physical and mental health set up in $2002 .{ }^{263}$

In addition to Charter-based mechanisms, international human rights treaties provide for independent expert bodies to monitor the implementation of the rights enshrined in that particular human rights treaty, the so-called treaty-based mechanisms. For example the Human Rights Committee (HRCee) is charged with

256 Ibid. at $\$ 2$.

257 Ibid. at $\$ 3$.

258 Ibid. at §5; UN HUMAN RIGHTS COUNCIL, Resolution 5/1. Institution-Building of the United Nations Human Rights Council (UN Doc. A/HRC/RES/5/1; 2007).

259 UN HUMAN RIGHTS COUNCIL, Resolution 5/1, (UN Doc. A/HRC/RES/5/1) at $\S 85$ et seq. See also REHMAN, International Human Rights Law, at 55 et seq.

260 REHMAN, International Human Rights Law, at 58 et seq. Special Procedures are either individuals (referred to as Special Rapporteurs, Special Representative of the SecretaryGeneral, Representative of the Secretary-General, or Independent Expert) or working groups (usually composed of five members, one of each region). UN HUMAN RIGHTS COUNCIL, Resolution 5/1, (UN Doc. A/HRC/RES/5/1) at §54 et seq. REHMAN, International Human Rights Law, at 65-66.

263 UN COMMISSION ON HUMAN RIGHTS, Resolution 2002/31. The Right of Everyone to the Enjoyment of the Highest Attainable Standard of Physical and Mental Health (UN Doc. E/ CN.4/2002/31; 2002); UN HUMAN RIGHTS COUNCIL, Resolution 6/29. The Right of Everyone to the Enjoyment of the Highest Attainable Standard of Physical and Mental Health (UN Doc. A/HRC/RES/6/29; 2009). The current mandate holder is Mr. Anand Grover from India. See further section 3.5 of this chapter. 
monitoring state compliance with the ICCPR. ${ }^{264}$ Contrary to other international human rights treaties within the UN framework, the ICESCR initially did not provide for an independent expert body to monitor its implementation by states parties, but referred this task to the ECOSOC. ${ }^{265}$ As the ECOSOC is a political body consisting not of independent experts but UN members, ${ }^{266}$ it seems that at the time of the ICESCR's adoption the task of monitoring socio-economic rights was considered a political task. ${ }^{267}$ This attitude changed, though, in the $1980 \mathrm{~s}$ when ECOSOC adopted resolution 1985/17 establishing the Committee on Economic, Social and Cultural Rights (CESCR). The CESCR consists of 18 independent experts who serve in their individual capacity, and it is assigned the task of monitoring the implementation of the ICESCR. ${ }^{268}$

Monitoring the implementation of human rights treaties can take place through a number of mechanisms such as state reporting, complaint procedures and factfinding. ICESCR requires states parties to submit periodic reports on the measures adopted to give effect to the Covenant's rights. ${ }^{269}$ The CESCR then assesses these state reports and issues Concluding Observations in which it addresses both positive developments and issues of concern and recommendations. ${ }^{270}$ States parties to the ICESCR are obliged to progressively realise the Covenant's economic, social and cultural rights and must, therefore, identify the progress made in realising these rights (since ratifying the ICESCR or a previous report) when reporting to the

264 See article articles 28-45 ICCPR. See also the Committee on the Elimination of Racial Discrimination (articles 8-16 of the International Convention on the Elimination of Racial Discrimination); the Committee on the Elimination of Discrimination against Women (articles 17-22 of the International Convention on the Elimination of all forms of Discrimination against Women); the Committee against Torture (articles 17-24 of the Convention against Torture and Other Cruel, Inhuman and Degrading Treatment and Punishment); the Committee on the Rights of the Child (articles 43-45 of the Convention on the Rights of the Child); the Committee on the Rights of all Migrant Workers and Members of their Families (articles 72-78 of the International Convention on the Protection of the Rights of all Migrant Workers and Members of their Families); the Committee on the Rights of Persons with Disabilities (articles 34-39 of the Convention on the Rights of Persons with Disabilities); and the Committee on Enforced Disappearances (articles 26-36 of the International Convention for the Protection of All Persons from Enforced Disappearance).

265 Article 16 ICESCR.

266 See article $61-68$ of the UN Charter.

267 TOMUSCHAT, Human Rights, at 140-141.

268 UN ECONOMIC AND SOCIAL COUNCIL, Resolution 1985/17. Review of the Composition, Organisation and Administrative Arrangements of the Sessional Working Group of Governmental Experts on the Implementation of the International Covenant on Economic, Social and Cultural Rights (1985).

269 Articles 16-25 ICESCR.

270 See for an extensive discussion on the development and current reporting system at UN level, TOMUSCHAT, Human Rights, at 140 et seq. And specifically with regard to the ICESCR and the right to health, see BIRGIT C.A. TOEBES, The Right to Health as a Human Right in International Law (School of Human Rights Research Series, Vol. 1; Antwerpen/Groningen/ Oxford: Intersentia, 1999) at 90 et seq. 
CESCR. ${ }^{271}$ The main difficulty with the state reporting system is that many states are severely lacking in complying with their reporting obligations: reports submitted to the CESCR are often overdue and excessively brief. ${ }^{272}$

In addition to adopting Concluding Observations with regard to a specific state report, expert monitoring bodies also issue General Comments and General Recommendations. These General Comments and General Recommendations function as explanatory documents for states parties aiding them with the implementation of the obligations found in a particular human rights treaty and are therefore also examined when analysing the different rights in the following sections. ${ }^{273}$ These documents are "comments" or "recommendations" and, therefore, cannot be binding on states parties to the relevant international human rights treaty. However, that does not render these documents meaningless; they are authoritative interpretations of the obligations laid down in the relevant human rights treaty. ${ }^{274}$ Some argue that especially the General Comments published by the CESCR enjoy a significant degree of authority and acceptance by state parties. ${ }^{275}$

After having briefly set out the context in which to place the topic addressed in this chapter - the origins of the concept of human rights, the perceived traditional dichotomy between civil and political and ESC rights and the framework in which to place the main developments in the area of the standard-setting and monitoring of human rights, i.e. the UN - the following sections will turn to the essential question addressed here: is access to medicines protected by international human rights law?

\section{The Human Right to Health: Introduction}

Protecting public health and controlling the spread of disease has historically always been an important duty of monarchs and rulers. The concept of a health as a human right did not appear until after World War II with the establishment of the UN and an explicit reference in its Charter to health as a human right and goal of the UN, and with the establishment of the World Health Organisation in 1946, as a specialised agency ${ }^{276}$ of the UN. The Constitution of the $\mathrm{WHO}^{277}$ was the first

271 REHMAN, International Human Rights Law, at 166 et seq; TOEBES, The Right to Health as a Human Right in International Law, at 139.

272 REHMAN, International Human Rights Law, at 172.

273 See further TOMUSCHAT, Human Rights, at 156-158.

274 TOMUSCHAT, Human Rights, at 190-191.

275 MATTHEW C. R. CRAVEN, The International Covenant on Economic, Social and Cultural Rights: A Perspective on Its Development (New York: Oxford University Press, 1995) at 91; M. MAGDALENA SEPÚLVEDA, The Nature of the Obligations under the International Covenant on Econonomic, Social and Cultural Rights (School of Human Rights Research, Vol. 18; Antwerpen/Oxford/New York: Intersentia, 2003) at 42.

277 The WHO Constitution was adopted by the International Health Conference held in New York from 19 June to 22 July 1946, signed on 22 July 1946 and entered into force on 7 April 1948. 
international legal document to recognise the "enjoyment of the highest attainable standard of health" as "one of the fundamental rights of every human being". 278 Two years later, the Universal Declaration of Human Rights laid the foundation for the legal framework with respect to the right to health. Article 25 UDHR states that "[e]veryone has the right to a standard of living adequate for the health and wellbeing of himself and of his family, including food, clothing, housing and medical care and necessary social services". The right to health was then taken up by a number of international legal documents, most notably the ICESCR.

The human right to health in international law can be found in a number of different international declarations and treaties: most prominent among these are article 25 of the 1948 Universal Declaration of Human Rights and article 12 of the 1966 International Covenant on Economic, Social and Cultural Rights (hereinafter the ICESCR or Covenant). In addition, health-related rights are also found in a number of international treaties specifically focused on vulnerable groups, for example article 11.1(f), 12 and 14(2)b of the 1979 Convention on the Elimination of All Forms of Discrimination against Women, article 24 of the 1989 United Nations Convention on the Rights of the Child and article 5(e)iv of the 1965 International Convention on the Elimination of All Forms of Racial Discrimination. The right to health as found in article 12 ICESCR is further developed by the Committee on Economic, Social and Cultural Rights (CESCR or Committee) in its General Comment No. 14. ${ }^{279}$ Since 2002, the Special Rapporteur on the right to health and the World Health Organisation have further contributed to the development of this specific right.

In the regional context, one will also find human rights instruments which recognise health rights, such as article 11 of the revised 1961 European Social Charter, article 16 of the 1981 African Charter on Human and Peoples' Rights, article 14 of the 1999 African Charter on the Rights and Welfare of the Child and article 10 of the 1988 Additional Protocol to the American Convention on Human Rights in the Area of Economic, Social and Cultural Rights (also known as the "Protocol of San Salvador").

The main question addressed in this chapter is whether access to medicines is protected under international human rights law. The right to health is the most obvious starting point in that regard. Thus, this section asks whether access to medicines is protected under the right to health. The right to health will be analysed making use of relevant treaty law, particularly the ICESCR, in accordance with customary rules of treaty interpretation, as well as soft law and interpretations by treaty monitoring bodies. The first step will be to examine the content of the right

Amendments adopted by the Twenty-sixth, Twenty-ninth, Thirty-ninth and Fifty-first World Health Assemblies (resolutions WHA26.37, WHA29.38, WHA39.6 and WHA51.23) came into force on February $3^{\text {rd }}, 1977$, January $20^{\text {th }}$, 1984, July $11^{\text {th }}$, 1994 and September $15^{\text {th }}, 2005$ respectively.

278 See the preamble of the WHO.

279 CESCR, General Comment No. 14, (UN Doc. E/C.12/2000/4). 
to health to determine whether access to medicines falls within its scope. Secondly, the states parties' obligations under ICESCR will be set out.

\subsection{Treaty Law: Article 12 ICESCR}

The International Covenant on Economic, Social and Cultural Rights protects a range of economic, social and cultural rights and counts 160 state parties. ${ }^{280}$ The majority of WTO members are bound by the ICESCR. Notable exceptions are the Republic of South Africa and the United States of America, both of which are signatories to the ICESCR but have not ratified it. As signatories, however, they are obliged to refrain from any acts which would defeat the object and purpose of the treaty. ${ }^{281}$

The object and purpose of the ICESCR is relatively simple: to promote universal respect for, and observance of, the rights enshrined in the Covenant, while recognising that these rights derive from the inherent dignity of the human person and are essential (in addition to civil and political rights) to achieve the ideal of free human beings enjoying freedom from fear and want. ${ }^{282}$ Consequently, the ICESCR sets out a list of economic, social and cultural rights and states parties' obligations in that regard. ${ }^{283}$

Article 2 of the ICESCR is the central provision of the Covenant with respect to states parties' obligations and reads as follows: ${ }^{284}$

1. Each State Party to the present Covenant undertakes to take steps, individually and through international assistance and co-operation, especially economic and technical, to the maximum of its available resources, with a view to achieving progressively the full realization of the rights recognized in the present Covenant by all appropriate means, including particularly the adoption of legislative measures.

Article 2.1 requires states parties to progressively realise, to the maximum of its available resources, the rights laid down in the Covenant. As such it recognises that the realisation of the rights protected by the ICESCR requires time and (financial) resources. It would be unreasonable to expect states parties to fully realise the

280 That is at the time of writing (April 2013). See also http://treaties.un.org/Pages/ViewDetails. aspx?src=TREATY\&mtdsg_no=IV-3\&chapter=4\&lang=en.

281 Article 18(a) of the Vienna Convention on the Law of the Treaties.

282 See preamble to the ICESCR.

283 While states are the primary duty bearers with regard to human rights, the Special Rapporteur on the Right to Health, Paul Hunt, has noted that all actors, individuals, local communities, inter-governmental and non-governmental organisations, health professional, private enterprises etc., have responsibilities regarding the realisation of the right to health. UN COMMISSION ON HUMAN RIGHTS, Report of the Special Rapporteur on the Right to Health, (UN Doc. E/ CN.4/2003/58) at $\S 30$.

284 For more information on the nature of states parties' obligations under the ICESCR see ALSTON and QUINN, 'The Nature and Scope of States Parties' Obligations under the ICESCR', Human Rights Quarterly, 9 (1987), 156-229. 
ICESCR's rights immediately upon ratification or even within a short period of time. $^{285}$ However, this does not entail that states parties are not required to act, sometimes even immediately, to realise the ICESCR's rights. The nature of states parties' obligations under article 2 ICESCR and in particular with regard to the right to health will be discussed below. ${ }^{286}$

The right to health is codified in article 12 of the ICESCR. It is a fundamental human right ${ }^{287}$ recognising "the right of everyone to the enjoyment of the highest attainable standard of physical and mental health." 288 Determining the scope of this provision is difficult because of the broad wording and subjective nature of the term "health". ${ }^{289}$ The WHO Constitution declares that "health is a state of complete physical, mental and social well-being and not merely the absence of disease or infirmity." This is a rather broad and vague interpretation. A comprehensive definition of the term health will not be given here as this dissertation focuses on one aspect of the right to health: access to medicines. ${ }^{290}$ Whatever the exact meaning of "health", it is clear from the wording of article 12 ICESCR that the right to health does not entail a right to be healthy. ${ }^{291}$ Instead, it grants every human being a set of freedoms and entitlements enabling them to realise the highest attainable standard of health. ${ }^{292}$ In that sense the wording used here ("a right to health") is misleading. The wording used by the CESCR in its General Comment No. 14 is better, in which it is stated that individuals have a right to the highest attainable standard of physical and mental health, taking into account the individuals biological and socio-economic preconditions and the state's available resources. Thus, the use of the term "right to health" in this dissertation should be seen as a short form of the longer term (right to the highest attainable standard of health).

285 CESCR, General Comment No. 3. The Nature of States Parties Obligations (UN Doc. E/1991/23; 1990) at §9; AUDREY R. CHAPMAN and SAGE RUSSELL (eds.) Core Obligations: Building a Framework for Economic, Social and Cultural Rights (Antwerp/Oxford/New York: Intersentia, 2002) at 5.

286 See section 3.2.2. of this chapter.

287 See the Preamble to the UDHR and CESCR, General Comment No. 14, (UN Doc. E/C.12/2000/4) at $\S 1$.

288 Article 12.1 ICESCR.

289 TOEBES, The Right to Health as a Human Right in International Law, at 20 et seq. When is a person considered to be "healthy"? Does "health" include only physical, or physical and mental well-being, or maybe even include social well-being? Moreover, descriptions vary from health being the "absence of disease" to the "ability to function in society" to the total package of "well-being".

290 Moreover, it has been argued that a definition of health would not necessarily contribute to a better understanding of the right to health. But that it is more useful to review the application of the right to health in practice than look for the abstract meaning of the term "health". See for a discussion on the many attempts to define "health" and the need for such a definition. Ibid. at 20-25.

291 See also CESCR, General Comment No. 14, (UN Doc. E/C.12/2000/4) at $§ 8$.

292 Ibid. at §8-9; UN COMMISSION ON HUMAN RIGHTS, Report of the Special Rapporteur on the Right to Health, (UN Doc. E/CN.4/2003/58) at $\$ 24$. 
Chapter 3

Article 12.2 lists a number of elements which are explicitly included in the international right to health:

The steps to be taken by the State Parties to the present Covenant to achieve the full realisation of this right shall include those necessary for:

a) The provision for the reduction of the stillbirth-rate and of infant mortality and for the healthy development of the child;

b) The improvement of all aspects of environmental and industrial hygiene;

c) The prevention, treatment and control of epidemic, endemic, occupational and other diseases;

d) The creation of conditions which would assure to all medical service and medical attention in the event of sickness.

Paragraph 2 lists the steps states parties must take to achieve the full realisation of the right to health, yet the wording also makes it clear that this list is not exhaustive. Examining the prescribed steps to be taken by states parties to achieve the full realisation of the right to health, it becomes clear that access to medicines is especially relevant in the event of preventing, treating and controlling epidemic, endemic, occupational and other diseases (article 12.2(c)) and in creating conditions which assure that everyone enjoys medical service and attention in the event of sickness (article 12.2(d)). Today the use of medicines is an essential and indispensable part of the treatment of most diseases, and access to and provision of such medicines is therefore a vital element in enabling individuals to attain their highest attainable standard of health. ${ }^{293}$ Such a conclusion is in line with the text of article 12, the context and object and purpose of the Covenant.

\subsubsection{The Principle of Non-Discrimination}

In addition to the prescribed steps to achieve the full realisation of the right to health, the principle of non-discrimination is another essential element not only of the right to health but all rights enshrined in the Covenant. Article 2.2 of the ICESCR reads:

The States Parties to the present Covenant undertake to guarantee that the rights enunciated in the present Covenant will be exercised without discrimination of any kind as to race, colour, sex, language, religion, political or other opinion, national or social origin, property, birth or other status.

Article 3 of the ICESCR furthermore confirms that both men and women have equal rights to the enjoyment of the rights under the Covenant. ${ }^{294}$ Both articles clearly entail that any discrimination with respect to access to health care and underlying

293 HESTERMEYER, Human Rights and the WTO, at 104.

294 See specifically for the right to health, CESCR, General Comment No. 14, (UN Doc. E/C.12/2000/4) at $\$ 20-21$. 
determinants of health on the abovementioned grounds is prohibited, as corroborated by the CESCR. Non-discrimination and equal treatment is an essential component of a human rights-based approach to health. ${ }^{295}$ The CESCR has, furthermore, stressed that measures intended to eliminate health-related discrimination can be taken with few costs, and can even be adopted in times of serious resource constraints. ${ }^{296}$

\subsubsection{Limitations}

Lastly it must be mentioned briefly that the ICESCR also provides for the possibility to impose limitations on its rights, yet it does not provide for a derogation clause similar to article 4 ICCPR, which allows for the suspension of civil and political rights in times of public emergency threatening the life of the nation. Article 4 ICESCR authorises states parties to impose limitations on the rights in the Covenant, while ensuring that the rights are still protected by limiting the purposes for which limitations may be imposed and the manner in which that may be done legitimately. ${ }^{297}$ Thus, states parties' intending to limit rights under the Covenant must first ensure that such a limitation is "determined by law", is sufficiently clear, publicly accessible, and has been reached through a participatory and transparent decision-making process. Furthermore, the limitation should not infringe upon the nature of ESC rights which entails that the limitation does not conflict with the minimum core content of the Covenant's rights. This interpretation is in line with the Committee's approach regarding the concept of non-derogable core obligations. 298 Finally, the limitation must be necessary for the "purpose of promoting general welfare" and thus also respect the principle of proportionality.

The question to what extent states parties may impose limitations is intrinsically linked to the question of the exact scope of states parties' obligations under article 2.1 of the Covenant. The CESCR evaluates so-called retrogressive measures, limitations to the Covenant's rights based on a lack of resources, according to article 2.1, and the concept of progressive realisation. Accordingly, there has been little debate, also by the Committee, on the question of legitimate limitations to and derogations from the Covenant's rights under article 4 ICESCR. 299

295 UN COMMISSION ON HUMAN RIGHTS, Report of the Special Rapporteur on the Right to Health, (UN Doc. E/CN.4/2003/58) at $\$ 26$.

296 CESCR, General Comment No. 14, (UN Doc. E/C.12/2000/4) at $\$ 18$.

297 Article 4 ICESCR reads as follows: The States Parties to the present Covenant recognize that, in the enjoyment of those rights provided by the State in conformity with the present Covenant, the State may subject such rights only to such limitations as are determined by law only in so far as this may be compatible with the nature of these rights and solely for the purpose of promoting the general welfare in a democratic society.

See further ALSTON and QUINN, 'The Nature and Scope of States Parties' Obligations under the ICESCR', at 192 et seq.

298 See CESCR, General Comment No. 3, (UN Doc. E/1991/23).

299 See further The Limburg Principles on the Implementation of the International Covenant on Economic, Social and Cultural Rights, (2-6 June 1986) at §46-57; AMREI MÜLLER, 


\subsection{Soft Law: The Committee on Economic, Social and Cultural Rights}

The Committee on Economic, Social and Cultural Rights has issued several explanatory documents on a range of rights included in the Covenant, referred to as General Comments. It has also done so with respect to the right to health under article 12 ICESCR: General Comment No. 14 on the right to the highest attainable standard of health. As noted above, General Comments are not formally binding on states parties. However, as authoritative interpretations by an expert treaty monitoring body, they are especially relevant and should be taken into account when interpreting the ICESCR's provisions. ${ }^{300}$ The following sections will therefore examine the Committee's analysis of the scope and consequent obligations for states parties regarding the right to health, to assess whether it considers access to medicines to be within the ambit of article 12 ICESCR.

\subsubsection{Scope of the Right to Health}

As stated above, the international right to health does not entail a right for individuals to be healthy, but it encompasses a number of freedoms and entitlements to enable individuals to attain the highest standard of health possible. The CESCR interprets the right to health in its General Comment No. 14 as an inclusive right comprising of two broad components: a right to "health care" and the "underlying preconditions for health". 301 The first component, timely and appropriate health care, includes medical care both preventative and restorative in nature, directed at the individual; while the second component concerns the traditional areas of public health: access to safe and potable water, adequate supply of safe food and nutrition, a clean environment, safe and sanitary living conditions, sewage systems, control of communicable diseases through vaccination, and education on health risks. ${ }^{302}$ Thus, the right to health is intrinsically linked and dependent on the realisation of a number of other human rights, like the right to housing, food and clean water among others. ${ }^{303}$

As was shown above, article 12.2 of the ICESCR gives a set of four steps to be taken by state parties to achieve full realisation. The Committee confirms that this

'Limitations to and Derogation from Economic, Social and Cultural Rights', Human Rights Law Review, 9:4 (2009), 557-601.

300 TOMUSCHAT, Human Rights, at 190-191.

301 CESCR, General Comment No. 14, (UN Doc. E/C.12/2000/4) at §11; TOEBES, The Right to Health as a Human Right in International Law, at 245-246; UN COMMISSION ON HUMAN RIGHTS, Report of the Special Rapporteur on the Right to Health, (UN Doc. E/CN.4/2003/58) at $\$ 23$.

302 CESCR, General Comment No. 14, (UN Doc. E/C.12/2000/4) at §11; TOEBES, The Right to Health as a Human Right in International Law, at 245-246.

303 CESCR, General Comment No. 14, (UN Doc. E/C.12/2000/4) at §3; UN COMMISSION ON HUMAN RIGHTS, Report of the Special Rapporteur on the Right to Health, (UN Doc. E/ CN.4/2003/58) at $\$ 31$. 
list is non-exhaustive and intends to provide states parties with guidance when identifying action to be taken to fulfil the right to health. ${ }^{304}$ For example, the CESCR finds that the right to prevention, treatment and control of diseases (article 12.2(c) ICESCR) includes the creation of a system of urgent medical care in cases of accidents, epidemics and similar health hazards, and the provision of disaster relief and humanitarian assistance in emergency situations. The right to health facilities, goods and services (Article 12.2(d) ICESCR) includes appropriate treatment of prevalent diseases and the provision of essential drugs. ${ }^{305}$

The Committee interprets the right to health as having four interrelated and essential elements, the application of which will depend on the specific situation within a state party. ${ }^{306}$ These elements include:

Availability. According to the CESCR, availability entails that "[f]unctioning public health and health care facilities, goods and services, as well as programmes, have to be available in sufficient quantity within the State Party", the precise nature of which depends on various factors within that state party, including its developmental level. Such facilities, though, will include underlying determinants of health such as safe drinking water, adequate sanitation facilities, hospitals, clinics, trained medical and profession personnel, and essential drugs as defined by the WHO Action Programme on Essential Drugs. ${ }^{307}$

Accessibility. "Health facilities, goods and services have to be accessible to everyone without discrimination, within the jurisdiction of the State Party." Accessibility, according to the CESCR, has four overlapping dimensions: firstly, accessibility must be ensured on the principle of non-discrimination; secondly, accessibility includes physical accessibility, meaning that both health facilities, goods and services and underlying determinants of health must be within in safe physical reach, also for rural areas; thirdly, accessibility also entails economic accessibility, or affordability, requiring that health facilities, goods and services must be affordable for all; and, fourthly, accessibility entitles everyone to seek, receive and impart information and ideas with regard to health issues. ${ }^{308}$

Acceptability. "All health facilities, goods and services must be respectful of medical ethics and culturally appropriate".309

Quality. Finally, "health facilities, goods and services must also be scientifically and medically appropriate and of good quality." 310

With respect to the focus of this dissertation - the interface between access to medicines and patent protection - the third dimension of accessibility that health facilities, services and goods must be affordable is of special interest here. Namely,

\footnotetext{
304 CESCR, General Comment No. 14, (UN Doc. E/C.12/2000/4) at $§ 13$.

305 Ibid. at $\$ 17$.

306 Ibid. at $\$ 12$.

307 Ibid. at $\$ 12(\mathrm{a})$.

308 Ibid. at $\$ 12(\mathrm{~b})$.

309 Ibid. at $\$ 12$ (c).

310 Ibid. at $\$ 12(d)$.
} 
as shown in chapter 2, granting a 20-year monopoly in the form of a patent for medicines generally leads to higher medicine prices which, in the context of developing countries faced with resource constraints, often result in the unaffordability of these medicines.

Consequently, in line with the interpretation by the Committee, we can conclude that access to essential medicines is an important element of the right to health under article 12 ICESCR. This entails that essential medicines must be sufficiently available and accessible, which means that essential medicines must not only be physically accessible but also affordable to all sections of the population, in addition to being culturally acceptable and of good quality.

Now that we have determined that the scope of the international right to health includes access to essential medicines, the following question is to assess states parties' obligations in that respect.

\subsubsection{States Parties' Obligations}

States parties are obliged to implement ICESCR's standards; however, the manner of implementation is left open and can differ from state to state. The ICESCR leaves state parties a margin of discretion in determining which measures are most appropriate in implementing the Covenant's rights within the domestic context. ${ }^{311}$

As we have seen article 2 ICESCR is of particular importance to the full understanding of the Covenant as it describes the nature of the general legal obligations undertaken by states parties. It introduces the concept of progressive realisation in fulfilling their obligations under the Covenant, although this does not imply the Covenant does not contain any obligations of immediate effect. The CESCR has interpreted the nature of states parties' obligations under article 2 ICESCR in its General Comment No. $3^{312}$ and finds these obligations to include both obligations of conduct and obligations of result. ${ }^{313}$ Furthermore, it makes a link with regard to states parties' obligations under article 2 ICCPR $^{314}$ and states that although much emphasis has been placed on the difference between the two articles, there are also significant similarities, particularly with regard to obligations of immediate effect. Two obligations of immediate effect are of particular

311 Ibid. at $\$ 53$.

312 See also The Limburg Principles, at \$16-34.

313 The obligation of conduct requires action reasonably calculated to realise the enjoyment of a specific right, while the obligation of result requires states to achieve specific targets to satisfy a detailed substantive standard. See The Maastricht Guidelines on Violations of Economic, Social and Cultural Rights, (22-26 January 1997) at §7.

314 Article 2.1 of the International Covenant on Civil and political Rights reads as follows: Each State Party to the present Covenant undertakes to respect and to ensure to all individuals within its territory and subject to its jurisdiction the rights recognized in the present Covenant, without distinction of any kind, such as race, colour, sex, language, religion, political or other opinion, national or social origin, property, birth or other status. 
importance in understanding the precise nature of states parties' obligations: the principle of non-discrimination and the obligation "to take steps". 315

According to article 2.1 states parties must undertake to take steps, to the maximum of its available resources, by all appropriate means, including particularly the adoption of legislative measures. Therefore, although the full realisation of the rights may be achieved progressively, "steps towards that goal must be taken within a reasonably short time after the ICESCR's entry into force." 316 Such steps should be deliberate, concrete and targeted as clearly as possible towards realising the rights. ${ }^{317}$ Furthermore, article 2.1 provides the means which should be used to satisfy the obligation to take steps, namely "all appropriate means, including particularly the adoption of legislative measures". According to the Committee, this entails that in many instances legislation will be highly desirable and sometimes even indispensable. ${ }^{318}$ However, only adopting legislation might not be sufficient to comply with the Covenant's obligations and the CESCR states that the phrase "by all appropriate means" must be given its full and natural meaning. States parties have considerable freedom to decide which means are the most appropriate within their national context, however, the final determination as to whether all appropriate measures have been taken remains one for the Committee to make. ${ }^{319}$ Among the measures which might be considered appropriate, in addition to legislation, is the provision of judicial remedies with respect to rights which may, in accordance with the national legal system, be considered justiciable. ${ }^{320}$ The justiciability of socio-economic rights will be discussed below. ${ }^{321}$ Other measures which may also be considered appropriate include, but are not limited to, administrative, financial, educational, and social measures. ${ }^{322}$

The principle obligation of result under article 2.1 is the obligation for states parties to take steps "with a view to achieving the progressive realisation of the rights recognised" in the Covenant. The concept of progressive realisation reflects the reality that economic, social and cultural rights will generally not be fully realised within a short period of time. However, this should not be interpreted as depriving the obligation of all meaningful content. ${ }^{323}$ It rather means that, as put by the CESCR, "[s]tates parties have a specific and continuing obligation to move as expeditiously and effectively as possible towards the full realisation" of socioeconomic rights. ${ }^{324}$ In that line, the Committee has found that there is a strong

315 CESCR, General Comment No. 3, (UN Doc. E/1991/23) at $\$ 1$.

316 The Limburg Principles, at \$21; CESCR, General Comment No. 3, (UN Doc. E/1991/23) at $\$ 2$.

317 CESCR, General Comment No. 3, (UN Doc. E/1991/23) at $\$ 2$.

318 Ibid. at $\$ 3$.

319 Ibid. at $\$ 4$

320 Ibid. at \$5. See also CESCR, General Comment No. 9. The Domestic Application of the Covenant (UN Doc. E/C.12/1998/24; 1998) at $§ 5$.

321 See section 3.4.2. of this chapter.

322 CESCR, General Comment No. 3, (UN Doc. E/1991/23) at §7.

323 Ibid. at \$9. CESCR, General Comment No. 14, (UN Doc. E/C.12/2000/4) at \$31.

324 CESCR, General Comment No. 14, (UN Doc. E/C.12/2000/4) at §31. See also CESCR, General Comment No. 3, (UN Doc. E/1991/23) at \$9. There the Committee stated that the concept of 
presumption that retrogressive measures, that is measures which take a step back in fulfilling the ICESCR's rights, are not permissible under the ICESCR. ${ }^{325}$ If any such retrogressive measures, for example regarding the right to health, are taken deliberately, the state party is strictly obliged to prove that any alternatives have been carefully considered and that such retrogressive measures are duly justified by reference to the other rights under the Covenant and the full use of the state party's maximum available resources. ${ }^{326}$

Article 2.1 obliges each state party to take the necessary steps "to the maximum of its available resources". However, even in times of severe resource constraints, the Committee underlines that states parties are still obliged to "strive to ensure the widest possible enjoyment of the relevant rights under the prevailing circumstances." 327 Furthermore it developed the concept of "minimum core content", i.e. the obligation of states parties to ensure satisfaction of, at the very least, minimum essential levels of each of the rights enshrined in the Covenant. ${ }^{328}$ The Committee's reasoning for establishing a minimum core obligation is that if the Covenant would be interpreted to not include such an obligation, it would be largely deprived of its raison d'être.

From the above, we see that the concept of progressive realisation complicates monitoring states parties' compliance, since under this concept states parties' obligations are neither uniform nor universal, and they are dependent on the state party's level of development and availability of resources. ${ }^{329}$

The CESCR has further set out states parties' obligations specifically with regard to the right to health in its General Comment No. 14. States parties' obligations under article 2 ICESCR include both obligations of conduct and obligations of result. Consequently, with respect to the right to health, the CESCR made use of the tripartite typology of obligations as it has also done with respect to other rights. The right to health has three levels of state obligations: firstly, the obligation to respect, that is to abstain from interfering directly or indirectly with individuals' enjoyment of the right to health; secondly, the obligation to protect, by preventing third parties from interfering with right to health; and, thirdly, the

progressive realisation should be interpreted in the light of the overall objective, the raison d'être of the Covenant, namely the establishment of clear obligations for states parties to fully realise the rights under the Covenant.

CESCR, General Comment No. 14, (UN Doc. E/C.12/2000/4) at \$32. CESCR, General Comment No. 3, (UN Doc. E/1991/23) at $\S 9$.

CESCR, General Comment No. 14, (UN Doc. E/C.12/2000/4) at $\$ 32$.

CESCR, General Comment No. 3, (UN Doc. E/1991/23) at \$11.

Ibid. at $\$ 10$.

CHAPMAN and RUSSELL (eds.), Core Obligations: Building a Framework for Economic, Social and Cultural Rights at 5; VICTOR DANKWA, CEES FLINTERMAN, and SCOTT LECKIE, 'Commentary to the Maastricht Guidelines on Violations of Economic, Social and Cultural Rights', Human Rights Quarterly, 20 (1998), 705-730 at 706. See further ROBERT E. ROBERTSON, 'Measuring State Compliance with the Obligation to Devote the "Maximum Available Resources" to Realising Economic, Social and Cultural Rights', Human Rights Quarterly, 16 (1994), 693-714. 
obligation to fulfil the right to health requiring the state to adopt appropriate measures, whether legislative, administrative, budgetary or judicial, towards the full realisation of the right to health. ${ }^{330}$ The right to health, therefore, contains both positive and negative duties for states parties.

\subsubsection{Core Obligations}

As we have seen above, in addition to states parties' obligations to respect, protect and fulfil the right to health, the Committee has interpreted the Covenant's rights to have a minimum core content without which the rights would be devoid of any meaning and relevance. Consequently, the CESCR developed the concept of "core obligations". 331 The Committee noted, though, that determining whether a state party has complied with its minimum core obligation must also take account of resource constraints. Therefore, "in order for a state party to be able to attribute its failure to meet at least its minimum core obligations to a lack of available resources it must demonstrate that every effort has been made to use all resources that are at its disposition in an effort to satisfy, as a matter of priority, those minimum obligations." ${ }^{32}$ Yet in its General Comment No. 14, the Committee went a step further and stressed that "a state party cannot, under any circumstances whatsoever, justify its non-compliance with the core obligations [...] which are non-derogable." 333

States parties must, thus, at the very least ensure the satisfaction of a minimum essential level with regard to the right to health. Guided by the Alma-Ata Declaration $^{334}$ the CESCR finds that state parties' core obligations with regard to the right to health include the obligation to:

- ensure the right of access to health facilities, goods and services without any form of discrimination, especially regarding vulnerable and marginalised groups;

- ensure access to the minimum essential level of food necessary to ensure freedom from hunger;

- ensure access to basic shelter, housing and sanitation and adequate supply of safe drinking water;

- ensure equitable distribution of health facilities, goods and services;

- adopt and implement a national public health strategy and plan of action; and

- ensure the provision of essential medicines as defined by the WHO Action Programme on Essential Drugs. ${ }^{335}$

CESCR, General Comment No. 14, (UN Doc. E/C.12/2000/4) at \$33.

See for different approaches to the minimum core of ESC rights, KATHERINE G. YOUNG, 'The Minimum Core of Economic and Social Rights: A Concept in Search of Content', Yale Journal of International Law, 33 (2008), 113-175.

CESCR, General Comment No. 3, (UN Doc. E/1991/23) at §10.

CESCR, General Comment No. 14, (UN Doc. E/C.12/2000/4) at \$47.

WHO, Declaration of Alma-Ata. International Conference on Primary Health Care (1978).

CESCR, General Comment No. 14, (UN Doc. E/C.12/2000/4) at §43. 
The CESCR also lists a number of other obligations considered to be of comparable priority. ${ }^{336}$

A closer look at the concept of the minimum core content and corresponding core duties for each of the rights protected by the ICESCR leads to a degree of conceptual confusion. ${ }^{337}$ Questions arise for example as to whether the core content of a right should be determined by reference to those elements of rights which are essential to survival or should go a step further and not only focus on what is strictly required for existence but emphasise human dignity. With regard to the latter, the question then arises what aspects of, for example, the right to health would not be considered the core content of such a right? Furthermore the fact that the Committee considers these core obligations to be of a non-derogable nature is problematic, meaning that non-compliance cannot be justified under any circumstance. ${ }^{338}$ In relation to the right to health and the provision of essential medicines this seems a step too far, especially since - as will be seen in chapter 5 there is no evidence to suggest that the international community considers access to medicines an internationally prioritised norm. ${ }^{339}$

\subsubsection{InTERNATIONAL OBLIGATIONS}

Essentially the realisation of economic, social and cultural rights within a state party's territory is primarily the duty of that particular state party. As such, the ICESCR's scope is principally territorial in nature. ${ }^{340}$ However, due to the process of globalisation and the growing international interaction between an increasing number of actors, the need for international cooperation has come to the forefront.

\footnotetext{
336 Ibid. at $\$ 44$.

337 Consequently the list of obligations considered to be core obligations by the CESCR has been subject to criticism; for example it is difficult to determine whether the Committee designated these obligations as core because of their immediate practicability or because of their greater moral nature. See BENJAMIN MASON MEIER, 'Employing Health Rights for Global Justice: The Public Health Response to the Insalubrious Ramifications of Globalisation', Cornell International Law Journal, 39 (2006), 711-777 at 735-736; YOUNG, 'The Minimum Core of Economic and Social Rights', at 157.

338 CESCR, General Comment No. 14, (UN Doc. E/C.12/2000/4) at $\$ 47$.

339 See section 4.1. of chapter 5.

340 However, the ICESCR - unlike the ICCPR - does not refer to territory or jurisdiction as the criteria for demarcation of the scope and application of the Covenant. Article 2.1 ICESCR refers to the obligation to take steps individually and through international assistance and cooperation. Furthermore, the preamble to the Covenant also refers to the international dimension of the realisation of ESC rights. Consequently, it is argued that the ICESCR has an international, or otherwise referred to, extraterritorial scope. See FONS COOMANS, 'The Extraterritorial Scope of the International Covenant on Economic, Social and Cultural Rights in the Work of the United Nations Committee on Economic, Social and Cultural Rights', Human Rights Law Review, 11:1 (2011), 1-35 at 5 et seq.
} 
Consequently, the realisation of economic, social and cultural rights has increasingly international dimensions. ${ }^{341}$

The CESCR also recognises that in the spirit of article 56 of the UN Charter, the provisions of the ICESCR (specifically articles 2.1, 12, $22^{342}$ and $23^{343}$ ) and the Alma-Ata Declaration, ${ }^{344}$ states parties' obligations under the right to health are not confined to the domestic context. States parties should recognise the importance of international assistance and cooperation and observe their commitment to take joint and separate action to fully achieve not just the right to health but all the Covenant's rights. ${ }^{345}$ See in that regard also the 2012 Maastricht Principles on Extraterritorial Obligations of States in the area of Economic, Social and Cultural rights which defines extraterritorial obligations as "(a) obligations relating to the acts and omissions of a State, within or beyond its territory, that have effects on the enjoyment of human rights outside of that State's territory; and (b) obligations of a global character that are set out in the Charter of the United Nations and human rights instruments to take action, separately, and jointly through international cooperation, to realize human rights universally."346

Article 2 ICESCR states that all state parties must take steps, individually and through international and assistance and cooperation to progressively realise the Covenant's rights. Those states parties unable to comply with their obligation to progressively realise the right to health, for example due to a lack of resources, must seek assistance from the international community. ${ }^{347}$ Moreover, the reference to "through international assistance and cooperation" has sparked the debate as to whether developed countries have not merely a moral, but also a legal obligation to provide assistance to least-developed and/or developing countries. ${ }^{348}$ The

341 See further FONS COOMANS, 'Application of the International Covenant Onf Economic, Social and Cultural Rights in the Framework of International Organisations', Max Planck Yearbook of United Nations Law, 11 (2007), 359-390.

342 Article 22 ICESCR: The Economic and Social Council may bring to the attention of other organs of the United Nations, their subsidiary organs and specialized agencies concerned with furnishing technical assistance any matters arising out of the reports referred to in this part of the present Covenant which may assist such bodies in deciding, each within its field of competence, on the advisability of international measures likely to contribute to the effective progressive implementation of the present Covenant.

343 Article 23 ICESCR: The States Parties to the present Covenant agree that international action for the achievement of the rights recognized in the present Covenant includes such methods as the conclusion of conventions, the adoption of recommendations, the furnishing of technical assistance and the holding of regional meetings and technical meetings for the purpose of consultation and study organized in conjunction with the Governments concerned.

344 WHO, Declaration of Alma-Ata.

345 CESCR, General Comment No. 14, (UN Doc. E/C.12/2000/4) at \$38. CESCR, General Comment No. 3, (UN Doc. E/1991/23) at §13-14.

346 The Maastricht Principles on Extraterritorial Obligations of States in the Area of Economic, Social and Cultural Rights, (29 February 2012f) at $\S 8$.

347 See also ibid. at $\$ 34$.

348 Many, especially Western, states have disputed that the ICESCR contains any extraterritorial legal obligations. See for example the negotiations on the Optional Protocol to the ICESCR 
Committee has stated that "core obligations give rise to national responsibilities for all States and international responsibilities for developed States, as well as others that are "in a position to assist'." 349 It is unclear whether "responsibilities" is equal to an (enforceable) obligation for developed states. That would seem unlikely. 350 Furthermore it is problematic how one would determine whether a state is "in a position to assist". ${ }^{351}$ Consequently, it is difficult to maintain the argument that the commitment to international cooperation is a legally binding obligation upon any state party to provide any particular form of assistance. However, this cannot entail that this part of article 2 ICESCR is meaningless; rather such international obligations by other states should be viewed as of a complementary nature. ${ }^{352}$

establishing a complaints procedure; or the statement of the US representative chastising the UN Special Rapporteur on the Right to Food for his "irresponsible and unfounded statements" on the topic. UN COMMISSION ON HUMAN RIGHTS, Sixtieth Session. Summary Record of the 51st Meeting (UN Doc. E/CN.4/2004/SR.51; 2004) at §84.

On the other hand, see in that regard also the The Maastricht Principle on Extraterritorial Obligations of States in the Area of ESC Rights, at \$28-33. Particularly, principle 33 which states that "[a]s part of the broader obligation of international cooperation, States, acting separately and jointly, that are in a position to do so, must provide international assistance to contribute to the fulfilment of economic, social and cultural rights in other States". Furthermore, principle 29 states: "States must take deliberate, concrete and targeted steps, separately, and jointly through international cooperation, to create an international enabling environment conducive to the universal fulfilment of economic, social and cultural rights, including in matters relating to bilateral and multilateral trade, investment, taxation, finance, environmental protection, and development cooperation"; and principle 31 states: "A State has the obligation to fulfil economic, social and cultural rights in its territory to the maximum of its ability. Each State must separately and, where necessary, jointly contribute to the fulfilment of economic, social and cultural rights extraterritorially, commensurate with, inter alia, its economic, technical and technological capacities, available resources, and influence in international decision-making processes. States must cooperate to mobilize the maximum of available resources for the universal fulfilment of economic, social and cultural rights."

See further ALSTON and QUINN, 'The Nature and Scope of States Parties' Obligations under the ICESCR', at 186 et seq.

349 CESCR, Statement Adopted by the Committee on Economic, Social and Cultural Rights on 4 May 2001. Substantive Issues Arising in the Implementation of the ICESCR: Poverty and the ICESCR (UN Doc. E/C.12/2001/10; 2001) at \$15-18.

350 MAGDALENA SEPÚLVEDA CARMONA, 'The Obligations of 'International Assistance and Cooperation' under the International Covenant on Economic, Social and Cultural Rights. A Possible Entry Point to a Human Rights-Based Approach to Millennium Development Goal 8', The International Journal of Human Rights, 13:1 (2009), 86-109 at 93.

351 COOMANS, 'The Extraterritorial Scope of the ICESCR', at 23.

352 ALSTON and QUINN, 'The Nature and Scope of States Parties' Obligations under the ICESCR', at 191; COOMANS, 'The Extraterritorial Scope of the ICESCR', at 23; MANISULI SSENYONJO, 'Economic, Social and Cultural Rights: An Examination of State Obligations', in Sarah Joseph and Adam Mcbeth (eds.), Research Handbook on International Human Rights Law (Cheltenham: Edward Elgar, 2010) at 60 et seq. See for more information SIGRUN I. SKOGLY, 'Extraterritoriality: Universal Human Rights without Universal Obligations?', in Sarah Joseph and Adam Mcbeth (eds.), Research Handbook on International Human Rights Law (Cheltenham: Edward Elgar, 2010). 
The CESCR interprets the right to health to include a number of international obligations: for example it finds that state parties must respect individuals' enjoyment of the right to health in other countries, prevent, to the extent possible, third parties from violating the right to health in other countries, and, facilitate, wherever possible, access to essential health facilities, goods and services in other countries and provide the necessary aid when required. ${ }^{353}$

Of particular relevance for the issue addressed here, the Committee finds that "States parties should ensure that the right to health is given due attention in international agreements." 354 "Similarly, States parties have an obligation to ensure that their actions as members of international organizations take due account of the right to health." 355 The language used by the Committee with regard to the former duty - "should ensure" - brings about some confusion as to the precise nature of these obligations. It seems that it is not strictly mandatory for states parties to ensure that the right to health is given due account in international agreements. Of course, once a state party has concluded an international agreement, for example in the area of trade and/or IPRs, this does not in any way detract from its obligations under the ICESCR. Yet, states parties are under an obligation to ensure that their actions as members of international organisations take due account of the right to health. It seems unlikely that a state party would be obliged take due account of the right to health as a member of an international organisation, yet is not obliged to do so when concluding a treaty which could negatively impact the right to health. Consequently, it is argued here that state parties are under an obligation to give due account to the right to health both when concluding international agreements and when taking actions as members of international organisations. Therefore, the ICESCR obliges states parties to ensure that when negotiating and ratifying agreements in the area of IPRs, these agreements do not curtail or inhibit a state's capacity to fulfil the right to health including access to medicines. ${ }^{356}$ This would be of particular relevance for (bilateral) agreements demanding higher standards of

353 CESCR, General Comment No. 14, (UN Doc. E/C.12/2000/4) at $\$ 39$.

354 Ibid. See also The Maastricht Principle on Extraterritorial Obligations of States in the Area of ESC Rights, at \$17. "States must elaborate, interpret and apply relevant international agreements and standards in a manner consistent with their human rights obligations. Such obligations include those pertaining to international trade, investment, finance, taxation, environmental protection, development cooperation, and security."

355 CESCR, General Comment No. 14, (UN Doc. E/C.12/2000/4) at \$39. See also The Maastricht Principle on Extraterritorial Obligations of States in the Area of ESC Rights, at §15. "As a member of an international organization, the State remains responsible for its own conduct in relation to its human rights obligations within its territory and extraterritorially. A State that transfers competences to, or participates in, an international organization must take all reasonable steps to ensure that the relevant organization acts consistently with the international human rights obligations of that State."

356 SEPÚLVEDA CARMONA, 'The Obligations of 'International Assistance and Cooperation' under the ICESCR', at 91. See also COOMANS, 'The Extraterritorial Scope of the ICESCR', at 24; EMILY A. MOK, 'International Assistance and Cooperation for Access to Essential Medicines', Health and Human Rights, 12:1 (2010), 73-81. 
protection for IPRs than required by the TRIPS Agreement - so called TRIPS-plus Agreements - which might interfere with patients' access to essential medicines. It is difficult though, to determine whether a state party has given "due regard" to the right to health. A state party could comply with this obligation, for example, by conducting a right to health, or more generally, human a rights impact assessment or explicit recognition by the parties to the (trade) agreement of the flexibilities within the TRIPS Agreement to balance IPRs and the right to health. ${ }^{357}$

\subsubsection{CONCLUSION}

We can conclude here that the nature of states parties' obligations under ICESCR is twofold: ${ }^{358}$ firstly, states parties have immediate obligations under the Covenant, such as for example the prohibition of discrimination (as can be found in articles 2.2 and 3 ICESCR) ${ }^{359}$ or the obligation to take deliberate, concrete and targeted steps towards realising the right to health; secondly, states parties are obliged to progressively realise the fulfilment of the Covenant's rights. ${ }^{360}$ With respect to the latter, states parties have a margin of discretion as long as they do so by all appropriate means and to the maximum of their available resources. Consequently, states parties' obligations to progressively realise the Covenant's rights are not uniform and will depend on their level of development.

In General Comment No. 14 the CESCR has further elaborated states parties' obligations under article 12 ICESCR. States parties must respect, protect and fulfil individuals' right of access to essential medicines within the scope of the right to health. The Committee considers the provision of essential medicines a core component of the right to health and therefore a non-derogable core obligation of state parties; ${ }^{361}$ however, the non-derogable nature of such core obligations is questionable considering that fulfilment of the minimum core content, particular in relation to the obligation to provide essential medicines, is intimately linked to a state party's availability of resources. In that regard, developing and leastdeveloped states parties unable to realise the right to health due to a lack of resources are under an obligation to seek international assistance. Yet this does not automatically lead to the conclusion that developed state parties are under an obligation to provide assistance to less developed countries. However, all states

357 See also UN COMMISSION ON HUMAN RIGHTS, Report of the Special Rapporteur on the Right of Everyone to the Enjoyment of the Highest Attainable Standard of Physical and Mental Health, Paul Hunt. Addendum. Mission to the WTO (UN Doc. E/CN.4/2004/49/add.1; 2004) at $\S 82$. 
parties must recognise the importance of international assistance and cooperation in achieving the full realisation of the right to health, respect the right to health in other countries and, to the extent possible, prevent third parties from violating the right to health in other countries. This also entails that states parties must take due account of the right to health when concluding international agreements and when acting within the framework of an international organisation of which they are a member.

\subsection{Other Treaties protecting the Right to Health}

Article 12 ICESCR, although the most logical starting point, is not the only provision in international human rights law that safeguards the right to health. There are other provisions protecting health-related interests which could provide a basis for determining whether access to medicines is guaranteed under international human rights law. Moreover, the ICESCR does not enjoy universal membership and some WTO members are not party to the Covenant. For example South Africa - see the case study in chapter 6 - has not ratified the ICESCR but is party to the Convention on the Rights of the Child and the Convention on the Elimination of All Forms of Discrimination against Women. This section will therefore briefly examine other sources for a right of access to medicines within the scope of the right to health.

Firstly the right to health of children, which is explicitly contained in the Convention on the Rights of the Child, will be addressed. ${ }^{362}$ Health is mentioned in a number of articles in the CRC but here I will focus primarily on article 24, which is one of the most elaborate and specific provisions on the right to health and provides that:

1. States Parties recognize the right of the child to the enjoyment of the highest attainable standard of health and to facilities for the treatment of illness and rehabilitation of health. States Parties shall strive to ensure that no child is deprived of his or her right of access to such health care services. ${ }^{363}$

362 See also AOIFE NOLAN, 'The Child's Right to Health and the Courts', in John Harrington and Maria Stuttaford (eds.), Global Health and Human Rights. Legal and Philosophical Perspectives (Abingdon: Routledge, 2010).

363 Article $24 \mathrm{CRC}$ reads further:

2. States Parties shall pursue full implementation of this right and, in particular, shall take appropriate measures:

(a) To diminish infant and child mortality;

(b) To ensure the provision of necessary medical assistance and health care to all children with emphasis on the development of primary health care;

(c) To combat disease and malnutrition, including within the framework of primary health care, through, inter alia, the application of readily available technology and through the provision of adequate nutritious foods and clean drinking-water, taking into consideration the dangers and risks of environmental pollution; 
There is a degree of overlap between the right to health and states parties' obligations under the ICESCR and the CRC. For example the CRC also makes use of the concept of progressive realisation; see paragraph 4 of article 24 which states that "states parties undertake to promote and encourage international co-operation with a view to achieving progressively the full realisation" of the Convention's rights. Article 4 CRC states that with regard to the socio-economic rights enshrined in the Convention states parties shall take measures "to the maximum extent of their available resources". 364

The Committee on the Rights of the Child has also addressed the right to health in its General Comments. ${ }^{365}$ There it has referred to CESCR's General Comment No. 14 and the framework established therein that health goods, services and facilities should be available, accessible, acceptable and of quality. ${ }^{366}$ Particularly concerning the issue of access to medicines and HIV/AIDS, the Committee has found that states parties are obliged under the Convention to ensure that children have sustained and equal access to comprehensive treatment and care, including necessary HIV-related drugs, goods and services on a basis of non-discrimination. ${ }^{367}$ Regarding mother-tochild transmission, states parties are required to take steps to prevent the transmission of the HIV virus to the child, by for example providing essential medicines (e.g. antiretrovirals). ${ }^{368}$ The Committee recognises the cost factor of many medicines as a barrier to access and compels states parties to negotiate with the pharmaceutical industry in order to ensure that the necessary medicines are available

(d) To ensure appropriate pre-natal and post-natal health care for mothers;

(e) To ensure that all segments of society, in particular parents and children, are informed, have access to education and are supported in the use of basic knowledge of child health and nutrition, the advantages of breastfeeding, hygiene and environmental sanitation and the prevention of accidents;

(f) To develop preventive health care, guidance for parents and family planning education and services.

3. States Parties shall take all effective and appropriate measures with a view to abolishing traditional practices prejudicial to the health of children.

4. States Parties undertake to promote and encourage international co-operation with a view to achieving progressively the full realization of the right recognized in the present article. In this regard, particular account shall be taken of the needs of developing countries.

Article 4 CRC reads as follows: States Parties shall undertake all appropriate legislative, administrative, and other measures for the implementation of the rights recognized in the present Convention. With regard to economic, social and cultural rights, States Parties shall undertake such measures to the maximum extent of their available resources and, where needed, within the framework of international co-operation.

365 See CRC, General Comment No. 3. HIVIAIDS and the Rights of the Child (UN Doc. CRC/ GC/2003/3; 2003); CRC, General Comment No. 4. Adolescent Health and Development in the Context of the Convention on the Rights of the Child (UN Doc. CRC/GC/2003/4; 2003); CRC, General Comment No. 7. Implementing Child Rights in Early Childhood (UN Doc. CRC/C/ GC/7/Rev.1; 2005) at §27; CRC, General Comment No. 9. The Rights of Children with Disabilities (UN Doc. CRC/C/GC/9; 2006) at §51-61. 
locally at the lowest possible price. ${ }^{369}$ Concluding, the right to health under the CRC requires states parties to ensure children have access to essential medicines.

Secondly, we see that international human rights law also guarantees a right to health for women in the Convention on the Elimination of All Forms of Discrimination against Women. The right to health of women is not only a question of eliminating discrimination and gender inequality but also the right of a human being to receive adequate health care in the first place. The right to health specifically for women is protected in article 12 of the CEDAW, which reads as follows: ${ }^{370}$

\section{States Parties shall take all appropriate measures to eliminate discrimination against women in the field of health care in order to ensure, on a basis of equality of men and women, access to health care services, including those related to family planning. \\ 2. Notwithstanding the provisions of paragraph I of this Article, States Parties shall ensure to women appropriate services in connection with pregnancy, confinement and the post-natal period, granting free services where necessary, as well as adequate nutrition during pregnancy and lactation.}

Firstly, CEDAW intends to eliminate all forms of discrimination against women. ${ }^{371}$ Women, whether rich or poor, have a human right to health, but poor women are

369 Ibid. at $\$ 28$.

370 The right to health is also mentioned in Article 11 of the CEDAW which states that all state parties should take all appropriate measures to eliminate discrimination against women in the field of employment in order to ensure, on a basis of equality of men and women, the same rights, including "the right to protection of health and to safety in working conditions, including the safeguarding of the function of reproduction." Furthermore, Article 14 CEDAW requires that states parties take particular account of the problems faced by rural women, and should take all appropriate measures to ensure the application of the rights protected under the Convention to women in rural areas, including the right to have access to adequate health care facilities, including information, counselling and services in family planning.

371 Article 1 CEDAW defines "discrimination" as: any distinction, exclusion or restriction made on the basis of sex which has the effect or purpose of impairing or nullifying the recognition, enjoyment or exercise by women, irrespective of their marital status, on a basis of equality of men and women, of human rights and fundamental freedoms in the political, economic, social, cultural, civil or any other field.

CEDAW obliges all state parties to "condemn discrimination against women in all its forms", and "agree to pursue by all appropriate means and without delay a policy of eliminating discrimination against women". Article 2 goes on to state a number of actions a State party is required to take:

(a) To embody the principle of the equality of men and women in their national constitutions or other appropriate legislation if not yet incorporated therein and to ensure, through law and other appropriate means, the practical realization of this principle;

(b) To adopt appropriate legislative and other measures, including sanctions where appropriate, prohibiting all discrimination against women;

(c) To establish legal protection of the rights of women on an equal basis with men and to ensure through competent national tribunals and other public institutions the effective protection of women against any act of discrimination; 
often at greater risk of suffering the negative consequences of high health care costs and more likely to face inadequate or insufficient health services. Existing gender inequality in income and lesser autonomy with regard to participation in economic opportunities also means that women are more likely to be poor - a situation that is being described as the "feminization of poverty". ${ }^{372}$ Furthermore, women usually bear a disproportionate responsibility of care-giving in families and in many cultural contexts, also a low prioritization of their own health needs. Thus, in situations of ill-health in the family, the burden of increased health care costs in terms of labour and health care cost-cutting is usually borne by women. Furthermore, the added physical vulnerability of women and girls due to their reproductive role adds another dimension to women's health issues. ${ }^{373}$

Secondly, CEDAW safeguards women's right of access to health care, including reproductive health, as a basic, fundamental right. This has been confirmed by the Committee on the Elimination of All Forms of Discrimination against Women in its General Recommendation No. 24 on article 12 of the Convention on the Elimination of All Forms of Discrimination against Women: Women and Health. ${ }^{374}$ The Committee here also makes use of the tripartite typology of obligations for states parties to ensure, on a basis of equality between men and women, access to health care services, information and education, which implies an obligation to respect, protect and fulfil women's rights to health care. ${ }^{375}$ The Committee makes a number of recommendations for state action which encompasses implementing a comprehensive national strategy to promote women's health throughout their life, including interventions to prevent and treat diseases and conditions affecting women, responding to violence against women and ensuring universal access to a wide range of high quality affordable health care services. ${ }^{376}$ To this end, States parties must allocate adequate budgetary, human and administrative resources so as

(d) To refrain from engaging in any act or practice of discrimination against women and to ensure that public authorities and institutions shall act in conformity with this obligation;

(e) To take all appropriate measures to eliminate discrimination against women by any person, organization or enterprise;

(f) To take all appropriate measures, including legislation, to modify or abolish existing laws, regulations, customs and practices which constitute discrimination against women;

(g) To repeal all national penal provisions which constitute discrimination against women.

SAKIKO FUKUDA-PARR, 'What Does Feminization of Poverty Mean? It Isn't Just Lack of Income', Feminist Economics, 5:2 (1999), 99-103; VALENTINE M. MOGHADAM, The 'Feminization of Poverty' and Women's Human Rights, UNESCO, SHS Papers in Women Studies/Gender Research, (2005).

UN HUMAN RIGHTS COUNCIL, Resolution 11/8. Preventable Maternal Mortality and Morbidity and Human Rights (UN Doc. A/HRC/RES/11/8; 2009).

374 CEDAW, General Recommendation No. 24. Article 12 of the Convention on the Elimination of All Forms of Discrimination against Women: Women and Health (UN Doc. CEDAW/GR 24; 1999) at $\$ 1$. 
to ensure that women's health needs take an equal share to that of men's needs of the overall budget. ${ }^{377}$

Although less clearly set out, here we see that the key elements as determined by the CESCR, namely that all health facilities, services and goods, including medicines, should be available, accessible, acceptable and of quality, are also elements of women's right to health recognized under the CEDAW. As such, it would be reasonable to conclude that the right to health under the CEDAW requires states parties to ensure that women have access to essential medicines on a non-discriminatory basis.

The CESCR has also addressed women's position regarding the right to health and although it only compasses two paragraphs of the 65 paragraph long General Comment, it recommends that states parties include a gender perspective in their health-related policies, planning, programmes and research. ${ }^{378}$ The context of having a right to health under the CEDAW highlights the special health needs of women and can thus be used to further enhance the understanding of the gender dimension of the right to health as expressed in the ICESCR.

In the regional context one also finds human rights instruments which recognise the right to health, such as article 11 and 13 of the 1996 (revised) European Social Charter, ${ }^{379}$ article 16 of the 1981 African Charter on Human and Peoples' Rights, ${ }^{380}$

377 Ibid. at $\$ 30$.

378 Ibid. at $\$ 20$.

379 Article 11 of the European Social Charter:

With a view to ensuring the effective exercise of the right to protection of health, the Parties undertake, either directly or in co operation with public or private organisations, to take appropriate measures designed inter alia:

1. to remove as far as possible the causes of ill health;

2. to provide advisory and educational facilities for the promotion of health and the encouragement of individual responsibility in matters of health;

3. to prevent as far as possible epidemic, endemic and other diseases, as well as accidents.

Article 13 of the European Social Charter:

With a view to ensuring the effective exercise of the right to social and medical assistance, the Parties undertake:

1. to ensure that any person who is without adequate resources and who is unable to secure such resources either by his own efforts or from other sources, in particular by benefits under a social security scheme, be granted adequate assistance, and, in case of sickness, the care necessitated by his condition;

2. to ensure that persons receiving such assistance shall not, for that reason, suffer from a diminution of their political or social rights;

3. to provide that everyone may receive by appropriate public or private services such advice and personal help as may be required to prevent, to remove, or to alleviate personal or family want;

4. to apply the provisions referred to in paragraphs 1,2 and 3 of this article on an equal footing with their nationals to nationals of other Parties lawfully within their territories, in accordance with their obligations under the European Convention on Social and Medical Assistance, signed at Paris on 11 December 1953.

380 Article 16 of the African Charter on Human and Peoples' Rights:

1. Every individual shall have the right to enjoy the best attainable state of physical and mental health. 
article 14 of the 1999 African Charter on the Rights and Welfare of the Child, ${ }^{381}$ and article 10 of the 1988 Additional Protocol to the American Convention on Human Rights in the Area of Economic, Social and Cultural Rights (also known as the "Protocol of San Salvador"), ${ }^{382}$ which will not be discussed here.

\subsection{Monitoring and Accountability}

During the previous century, the international human rights framework has been very successful in creating and developing human rights norms, however, it has

2. States Parties to the present Charter shall take the necessary measures to protect the health of their people and to ensure that they receive medical attention when they are sick.

381 Article 14 of the African Charter on the Rights and Welfare of the Child:

1. Every child shall have the right to enjoy the best attainable state of physical, mental and spiritual health.

2. States Parties to the present Charter shall undertake to pursue the full implementation of this right and in particular shall take measures:

(a) to reduce infant and child mortality rate;

(b) to ensure the provision of necessary medical assistance and health care to all children with emphasis on the development of primary health care;

(c) to ensure the provision of adequate nutrition and safe drinking water;

(d) to combat disease and malnutrition within the framework of primary health care through the application of appropriate technology;

(e) to ensure appropriate health care for expectant and nursing mothers;

(f) to develop preventive health care and family life education and provision of service;

(g) to integrate basic health service programmes in national development plans;

(h) to ensure that all sectors of the society, in particular, parents, children, community leaders and community workers are informed and supported in the use of basic knowledge of child health and nutrition, the advantages of breastfeeding, hygiene and environmental sanitation and the prevention of domestic and other accidents;

(i) to ensure the meaningful participation of non-governmental organizations, local communities and the beneficiary population in the planning and management of a basic service programme for children;

(j) to support through technical and financial means, the mobilization of local community resources in the development of primary health care for children.

382 Article 10 of the Protocol of San Salvador:

1. Everyone shall have the right to health, understood to mean the enjoyment of the highest level of physical, mental and social well-being.

2. In order to ensure the exercise of the right to health, the States Parties agree to recognize health as a public good and, particularly, to adopt the following measures to ensure that right:

a. Primary health care, that is, essential health care made available to all individuals and families in the community;

b. Extension of the benefits of health services to all individuals subject to the State's jurisdiction;

c. Universal immunization against the principal infectious diseases;

d. Prevention and treatment of endemic, occupational and other diseases;

e. Education of the population on the prevention and treatment of health problems, and

f. Satisfaction of the health needs of the highest risk groups and of those whose poverty makes them the most vulnerable. 
been less successful in providing effective enforcement mechanisms to hold states accountable for not complying with their obligations under international human rights law. The European Court of Human rights is a notable exception in that regard. Moreover, with respect to socio-economic rights, the adoption of an Optional Protocol to the ICESCR, allowing individuals to bring a complaint before the CESCR, is an encouraging development. ${ }^{383}$ Unfortunately, as was shown above, the system in place to monitor implementation of international human rights law within the framework of the UN, for example through state reporting, is very weak. The consequence is that states wanting to avoid international human rights obligations simply ignore those human rights obligations that are inconvenient to them and they do not cooperate in good faith, for example by failing to (timely) submit reports to the human rights monitoring bodies. ${ }^{384}$

Accountability is a central feature of a human rights-based approach to health and effective monitoring is a crucial precondition for accountability. Without accountability, human rights are not more than mere declarations of intent. The Special Rapporteur on the Right to Health finds that monitoring and accountability is an integral feature of the right to health analytical framework. ${ }^{385}$ Since the right to health is subject to progressive realisation and limited resources, monitoring state compliance with its obligations under ICESCR may prove difficult. Scholars have proposed an effective approach to the progressive realisation standard for assessing state compliance: the violations approach. ${ }^{386}$ Moreover, the Special Rapporteur has elaborated on this approach and dedicated part of his work to a human rights-based approach to the use of indicators and benchmarks to assess state compliance with the standard of progressive realisation in the area of health. ${ }^{387}$

383 UN GENERAL ASSEMBLY, Optional Protocol to the International Covenant on Economic, Social and Cultural Rights (UN Doc. A/RES/63/117; 2008).

384 ED BATES, 'Avoiding Legal Obligations Created by Human Rights Treaties', International and Comparative Law Quarterly, 57 (2008), 751-788 at 787-788.

385 PAUL HUNT and SHELDON LEADER, 'Developing and Applying the Right to the Highest Attainable Standard of Health. The Role of the UN Special Rapporteur (2002-2008)', in John Harrington and Maria Stuttaford (eds.), Global Health and Human Rights. Legal and Philosophical Perspectives (Abingdon: Routledge, 2010) at 37 et seq.

386 See The Maastricht Guidelines on Violations of Economic, Social and Cultural Rights, at. AUDREY R. CHAPMAN, 'A "Violations Approach" for Monitoring the International Covenant on Economic, Social and Cultural Rights', Human Rights Quarterly, 18 (1996), 23-66; DANKWA, FLINTERMAN, and LECKIE, 'Commentary to the Maastricht Guidelines on Violations of Economic, Social and Cultural Rights', at 707-708.

See for a more critical view on the violations approach EVA BREMS, 'Human Rights: Minimum and Maximum Perspectives', Human Rights Law Review, 9:3 (2009), 349-372.

387 UN COMMISSION ON HUMAN RIGHTS, Report of the Special Rapporteur on the Right to Health, (UN Doc. E/CN.4/2003/58) at \$36. See also CESCR, General Comment No. 14, (UN Doc. E/C.12/2000/4) at $\$ 57-58$. 


\subsubsection{Violations of the Right to Health}

According to the Limburg Principles on the Implementation of the International Covenant on Economic, Social and Cultural rights and the Maastricht Guidelines on Violations of Economic, Social and Cultural Rights "[a] failure by a state party to comply with an obligation contained in the Covenant is, under international law, a violation of the Covenant." 388 The concept of progressive realisation complicates monitoring states parties' compliance, since under this concept states parties' obligations are neither uniform nor universal, and tey are dependent on the state party's level of development and availability of resources. ${ }^{389}$ In that regard states parties have a margin of appreciation in selecting the means for implementing their obligations under the Covenant, yet it should not be used as an excuse for noncompliance. The burden of proof is on the state to demonstrate that it is progressively realising the right to health. ${ }^{390}$ Moreover, violations of the right to health are in principle imputable to the state within which the violations occur and, as such, the state being the primary duty bearer, is responsible for establishing mechanisms to correct such violations. ${ }^{391}$

State parties to the ICESCR can violate the rights enshrined therein through acts of commission (for example deliberate retrogressive measures such as noncompatible budgetary cuts or reallocations regarding minimum core content of a Covenant right) or acts of omission (for example the failure to take steps, failure to enforce laws or design and implement policies for the realisation of ESC rights and failure to regulate private actors). ${ }^{392}$

The CESCR noted, in its General Comment No. 14 on the right to health that, when determining whether a state has violated the right to health, one must distinguish between a state party's inability from its unwillingness to comply with its obligations under the ICESCR. ${ }^{393}$ For example, a state party that is unwilling to assign its maximum available resources to realising the right to health violates its obligations under article 12 and 2.1 of the ICESCR, while a state party faced with severe resource constraints might not be able to comply fully with its obligations but can justify its non-compliance by demonstrating that every effort was taken to use all available resources to progressively realise the right to health. ${ }^{394}$ Moreover, according to the CESCR, regardless of the circumstances, a state party has a non-

388 The Limburg Principles, at $§ 70$. The Maastricht Guidelines on Violations of Economic, Social and Cultural Rights, at $\$ 5$.

389 CHAPMAN and RUSSELL (eds.), Core Obligations: Building a Framework for Economic, Social and Cultural Rights at 5; DANKWA, FLINTERMAN, and LECKIE, 'Commentary to the Maastricht Guidelines on Violations of Economic, Social and Cultural Rights', at 706. 
derogable obligation to comply with the aforementioned core obligations and meet the minimum essential levels of the right to health; non-compliance with these core obligations, including the provision of essential medicines, cannot be justified under any circumstances, irrespective of the availability of resources. ${ }^{395}$

In its General Comment No. 14 the CESCR categorises violations of the right to health using its tripartite typology of states parties' obligations under the Covenant. ${ }^{396}$ Accordingly it identifies the following violations:

\subsubsection{Violations OF THE OBLIGATION TO RESPECT}

Violations of this type are "those State actions, policies or laws that contravene the standards set out in article 12 of the Covenant and are likely to result in bodily harm, unnecessary morbidity and preventable mortality."397 Examples include denial of access to health facilities, goods and services as a result of discrimination; the suspension of legislation or the adoption of laws or policies that interfere with any of the components of the right to health; and the failure of the state to take into account its legal obligations regarding the right to health when entering into bilateral or multilateral agreements with other States, international organisations and other entities, such as multinational corporations. ${ }^{398}$

Interesting here is the phenomenon of TRIPS-plus (bilateral) trade agreements $^{399}$ and to what extent the conclusion of such agreements might conflict with states parties' obligation to respect every individual's right to health and access to medicines. As we have seen, state parties are under an obligation to give due account to the right to health both when concluding international agreements and when taking actions as members of international organisations. ${ }^{400}$ Therefore, the ICESCR obliges states parties to ensure that when they are negotiating and ratifying agreements in the area of IPRs these agreements do not curtail or inhibit a state party's capacity to fulfil the right to health and particularly the provisions of access to essential medicines as a core obligation. In that regard, the conclusion of (bilateral) trade agreements without conducting a right to health or human rights impact assessment and consequent interference with access to affordable medicines, would be a breach of the right to health. That would certainly hold true for the

395 The Maastricht Guidelines on Violations of Economic, Social and Cultural Rights, at \$9-10; CESCR, General Comment No. 14, (UN Doc. E/C.12/2000/4) at \$47.

396 See also The Maastricht Guidelines on Violations of Economic, Social and Cultural Rights, at $\S 6$.

397 Ibid. at §11; CESCR, General Comment No. 14, (UN Doc. E/C.12/2000/4) at 550.

398 See further AUDREY R. CHAPMAN, 'Conceptualising the Right to Health: A Violations Approach', Tennessee Law Review, 65 (1997-1998), 389-418 at 399-404.

399 These are considered TRIPS-plus, because they go above and beyond the level of intellectual property protection as provided for by TRIPS. This can be particular problematic with regard to standards of patent protection for pharmaceuticals, curtailing patients' access to essential medicines even further, especially for developing countries.

400 See also The Maastricht Guidelines on Violations of Economic, Social and Cultural Rights, at §19. 
(developing) state obliging itself to protect higher standards of IPRs without due regard to the possible negative impact on access to medicines. It is questionable, though, to what extent the (developed) state pushing for such stronger IPRs in its negotiations with developing states would also be considered as not taking due regard of the right to health and is thus in violation of its obligations under ICESCR.

\subsubsection{ViOLATIONS OF THE OBLIGATION TO PROTECT}

Violations of this type follow from "the failure of a State to take all necessary measures to safeguard persons within their jurisdiction from infringements of the right to health by third parties." ${ }^{201}$ For example the failure to regulate (pharmaceutical) corporations so as to prevent them from violating individuals' right to health would be a violation of the obligation to protect. ${ }^{402}$

\subsubsection{VIOLATIONS OF THE OBLIGATION TO FULFIL}

Violations of this type "occur through the failure of States parties to take all necessary steps to ensure the realisation of the right to health" including state party's failure to fulfil its minimum core obligations. ${ }^{403}$ Examples include the failure to provide essential medicines; adopt or implement a national health policy to ensure the right to health for all; insufficient expenditure or misallocation of public resources; the failure to monitor the realisation of the right to health at the national level; and the failure to take measures to reduce the inequitable distribution of health facilities, goods and services.

\subsubsection{Justiciability}

According to the CESCR "[a]ny person or group victim of a violation of the right to health should have access to effective judicial or other appropriate remedies at both national and international levels. All victims of such violations should be entitled to adequate reparation, which may take the form of restitution, compensation, satisfaction or guarantees of non-repetition." ${ }^{404}$ However, since the international human rights framework does not provide any truly effective means of enforcing human rights obligations, monitoring and accountability mechanisms should be established at the national level. ${ }^{405}$ The extensive nature and complexity of the right

401 Ibid. at §18; CESCR, General Comment No. 14, (UN Doc. E/C.12/2000/4) at §51.

402 See further CHAPMAN, 'Conceptualising the Right to Health', at 404-409.

403 CESCR, General Comment No. 14, (UN Doc. E/C.12/2000/4) at \$52. See further CHAPMAN, 'Conceptualising the Right to Health', at 409-414.

404 The Maastricht Guidelines on Violations of Economic, Social and Cultural Rights, at §22-23; CESCR, General Comment No. 14, (UN Doc. E/C.12/2000/4) at §59.

405 MEIER, 'Employing Health Rights for Global Justice: The Public Health Response to the Insalubrious Ramifications of Globalisation', at 737. 
to health requires a range of effective, accessible, transparent and independent accountability mechanisms, for example human rights institutions, public hearings, patients' committees, impact assessments and judicial proceedings. In that regard the media and civil society play an important role. ${ }^{406}$

This thesis will focus mainly on judicial accountability mechanisms, as they provide individuals with concrete options to hold a state accountable for human rights violations. In this regard, recourse to the court system can ensure that the interests of the poor and disadvantaged are given due consideration. Moreover, the CESCR has stated that the provision of judicial remedies with respect to rights which may, in accordance with the national legal system, be considered justiciable, are among the measures which could be considered appropriate under article 2 ICESCR. ${ }^{407}$ However, holding a state accountable for a violation of the right to health is not as straightforward as it may seem. Namely, as a socio-economic right, it has been contended to be non-justiciable. This section will therefore briefly examine the justiciability of socio-economic rights.

Since the beginning of the international development of human rights, there has been a dichotomy between two sets of human rights: civil and political rights on the one hand and economic, social and cultural rights on the other. ${ }^{408}$ The distinction between these two sets of rights is based mainly on the argument that civil and political rights are considered to be negative rights, i.e. rights obliging the state not to interfere with one's personal freedom and bodily integrity, while economic, social and cultural rights are categorised as positive rights, i.e. rights that require states to intervene, to act.

Directly linked with the categorisation of human rights into negative and positive rights is the issue of justiciability. ${ }^{409}$ Broadly speaking, justiciability entails the degree to which an alleged violation of a social, economic or cultural right can be reviewed before a judicial or quasi-judicial body at the domestic level. ${ }^{410}$ The ability to claim a legal remedy allowing effective access to a (quasi-) judicial body and adequate reparation to the victim in case of a violation is a defining aspect of a

406 HUNT and LEADER, 'Developing and Applying the Right to the Highest Attainable Standard of Health', at 37.

407 CESCR, General Comment No. 3, (UN Doc. E/1991/23) at §5.

408 In addition to this dichotomy, and as a result of the growing interdependence of states and issues of global importance, a third generation of human rights emerged, that of collective or solidarity rights. The right to development, peace or a clean environment are illustrations thereof. TOMUSCHAT, Human Rights, at 24.

409 In this regard a distinction must be made between 'enforcement' and 'justiciability' of human rights, although both concepts are closely related. Enforceability identifies the entitlements and duties created by a legal system which must be maintained and executed, while justiciability refers to "the ability to claim a remedy before an independent and impartial body when a violation of a right has occurred or is likely to occur." See COURTIS, Courts and the Legal Enforcement of ESC Rights, at 6.

410 FONS COOMANS (ed.), Justiciability of Economic and Social Rights. Experiences from Domestic Systems (Antwerpen/Oxford: Intersentia, 2006); MAPULANGA-HULSTON, 'Examining the Justiciability of Economic, Social and Cultural Rights', at 37. 
fully fledged right. ${ }^{411}$ Such possibilities of legal remedies are especially relevant when it concerns violations of human rights. ${ }^{412}$

A number of objections have been raised against the justiciability of economic, social and cultural rights. The main objections are that ESC rights (i.e. positive rights) are fundamentally different from civil and political rights (i.e. negative rights) and that it is the specific characteristics of ESC rights which makes them unsuitable for (quasi-) judicial review. ${ }^{413}$ It is argued that it would be inappropriate for courts to decide on budget allocation and that this power should belong exclusively to the executive. ${ }^{414}$ Granting ESC rights justiciability would seriously endanger the notion of separation of powers and democracy. Socio-economic issues are considered core elements of political policy. Therefore, it is argued, that it is not the place for the judiciary, as an unelected body, to determine the exact content and scope of socioeconomic rights. There is a general distrust of the process of constitutional review and the power judges would have if they are expected to review ESC rights. ${ }^{415}$

This argument, that ESC rights are fundamentally different from civil and political rights, is not convincing. Economic, social and cultural rights also possess "negative" elements, that is, their implementation does not require state resources. ${ }^{416}$ The prohibition to discriminate, which also applies to ESC rights, provides a most clear example. Thus, the judicial review of ESC rights does not necessarily involve resource expenditure, but it can consist of the determination of a violation of ESC rights, leaving the manner of remedy to the public authority. On the other hand, civil and political rights also have certain "positive" elements, requiring resource expenditure. ${ }^{417}$ For example, the right to free and democratic elections cannot be enjoyed without establishing a cost-expensive electoral system, nor can the right to a fair trial be guaranteed without maintaining a court system

411 COURTIS, Courts and the Legal Enforcement of ESC Rights, at 6.

412 In that sense a number of international human rights instruments have incorporated a right to a remedy in case of human rights violations. See for example article 8 UDHR, article 2.3 ICCPR, article 13 CAT and article 6 ICERD.

413 MAPULANGA-HULSTON, 'Examining the Justiciability of Economic, Social and Cultural Rights', at 40.

414 COURTIS, Courts and the Legal Enforcement of ESC Rights, at 73; MAPULANGA-HULSTON, 'Examining the Justiciability of Economic, Social and Cultural Rights', at 40; ELLEN WILES, 'Aspirational Principles or Enforceable Rights? The Future for Socio-Economic Rights in National Law', American University of International Law Review, 22 (2006-2007), 35-64 at 45.

415 WILES, 'Aspirational Principles or Enforceable Rights? The Future for Socio-Economic Rights in National Law', at 43.

416 DANIE BRAND, 'Socio-Economic Rights and Courts in South Africa: Justiciability on a Sliding Scale', in Fons Coomans (ed.), Justiciability of Economic and Social Rights. Experiences from Domestic Systems. (Antwerpen/Oxford: Intersentia, 2006) at 225; HESTERMEYER, Human Rights and the WTO, at 90; MAPULANGA-HULSTON, 'Examining the Justiciability of Economic, Social and Cultural Rights', at 40.

417 BRAND, 'Socio-Economic Rights and Courts in South Africa', at 226; HESTERMEYER, Human Rights and the WTO, at 90; MAPULANGA-HULSTON, 'Examining the Justiciability of Economic, Social and Cultural Rights', at 40-41; WILES, 'Aspirational Principles or Enforceable Rights? The Future for Socio-Economic Rights in National Law’, at 46. 
and providing legal aid if necessary. However, it is asserted that ESC rights are more resource-intensive than civil and political rights, which does hold true although the extent depends on the specific circumstances of the case. Yet, even in those cases in which resource expenditure is necessary to remedy the violation of an ESC right - or a civil or political right for that matter - this does not mean that the judiciary is not aware of its position and sensitive to the role of the government and the fact that resources are not limitless. ${ }^{418}$

Moreover, it is often said that in a welfare state enforceable socio-economic rights are not necessary since issues like housing, nutrition, health and social security are generally regulated by national law and policy. Justiciability of ESC rights would lead to an increase in litigation, which would be considered undesirable since most judiciaries are already overworked as it is. Of course a strong welfare system limiting litigation with regard to these issues is absolutely advisable. However, this does not entail that a system guaranteeing justiciability of ESC rights is thus superfluous. ${ }^{419}$

Other objections raised against the justiciability of ESC rights are the complexity of cases involving such rights, the lack of expertise of judges to analyse such cases and the alleged vagueness of ESC rights concerning their exact content and scope. ${ }^{420}$ It seems unjustified to argue that judges would not be able to deal with complex matters; on the contrary it is in the job description of a judge to be able to analyse a great variety of different and complex legal cases. ${ }^{421}$ Furthermore, as we have seen the CESCR has issued a series of General Comments, including a General Comment on the right to health, ${ }^{422}$ in order to clarify the content of the rights protected in the ICESCR. ${ }^{423}$ Moreover, increased litigation will further add to clarifying the scope of the ESC rights, a development that was also seen at an earlier stage with regard to civil and political rights. ${ }^{424}$

With regard to states parties' duty to give effect to the ICESCR, the Committee has elaborated this issue in its General Comment No. 9 on the Domestic Application of the Covenant. ${ }^{425}$ Although the ICESCR does not prescribe the manner in which state parties must implement the Covenant, the methods applied must be

\footnotetext{
418 WILES, 'Aspirational Principles or Enforceable Rights? The Future for Socio-Economic Rights in National Law', at 47.

419 Ibid. at 40

420 COOMANS (ed.), Justiciability of Economic and Social Rights. Experiences from Domestic Systems at 5.

421 WILES, 'Aspirational Principles or Enforceable Rights? The Future for Socio-Economic Rights in National Law', at 54-55.

422 CESCR, General Comment No. 14, (UN Doc. E/C.12/2000/4).

423 WILES, 'Aspirational Principles or Enforceable Rights? The Future for Socio-Economic Rights in National Law', at 50-51.

424 See for more information SHIVANI VERMA, Justiciability of Economic, Social and Cultural Rights. Relevant Case Law, The International Council on Human Rights Policy. Review Meeting, (2005).

425 CESCR, General Comment No. 9, (UN Doc. E/C.12/1998/24).
} 
appropriate, meeting their obligations. ${ }^{426}$ The Committee considers implementation in light of two principles of international law: ${ }^{427}$ First, states parties must modify their domestic legal order as necessary to give effect to treaty obligations ${ }^{428}$ and, second, the right to an effective remedy by competent national tribunals for acts violating fundamental rights granted by constitution or law. ${ }^{429}$

The ICESCR itself, however, does not contain a provision explicitly obliging state parties to provide judicial remedies. ${ }^{430}$ The Committee is of the view that not providing any domestic legal remedies for violations of ESC rights can only be justified if such remedies are not "appropriate means" within the meaning of article 2.1 ICESCR or, considering the other means available, unnecessary. According to the Committee this will be difficult to demonstrate. ${ }^{431}$

The notion that socio-economic rights are justiciable rights is further strengthened by a recent development within the international sphere: the adoption, by the UN General Assembly, of an Optional Protocol to the International Covenant on Economic, Social and Cultural Rights ${ }^{432}$ on December $10^{\text {th }}, 2008$ establishing a new quasi-judicial function for the CESCR. ${ }^{433}$ The Optional Protocol allows the Committee to receive and consider communications by individuals claiming to be a victim of a violation of any economic, social and cultural right protected under the ICESCR. ${ }^{434}$ The preamble to the Optional Protocol reaffirms the principle that all human rights and fundamental freedoms are universal, indivisible, interdependent and interrelated, and it also recalls that states are under the obligation to progressively realise the rights contained in the ICESCR.

This is the first international document to provide a standard of review for ESC rights. See article 8 of the Optional Protocol, which was influenced by the South African Constitutional Court's jurisprudence, ${ }^{435}$ stating that:

426 Ibid. at $\$ 5$.

427 Ibid. at $\$ 3$.

428 See also article 27 of the Vienna Convention on the Law of Treaties: A party may not invoke the provisions of its internal law as justification for its failure to perform a treaty.

429 Article 8 UDHR.

430 See for example article 2.3 of the ICCPR.

431 CESCR, General Comment No. 9, (UN Doc. E/C.12/1998/24) at \$3.

432 UN GENERAL ASSEMBLY, Optional Protocol to the ICESCR, (UN Doc. A/RES/63/117). At the time of writing (April 2013) 42 states have signed the Optional Protocol and 10 states have become party to the OP. See http://treaties.un.org/Pages/ViewDetails. aspx?src=TREATY\&mtdsg_no=IV-3-a\&chapter=4\&lang=en.

433 See for more information CHRISTOPHE GOLAY, The Optional Protocol to the International Convention on Economic, Social and Cultural Rights, Europe - Third World Centre, Critical Report No. 2, (November 2008); CLAIRE MAHON, 'Progress at the Front: The Draft Optional Protocol to the International Covenant on Economic, Social and Cultural Rights', Human Rights Law Review, 8:4 (2008), 617-646 at 628; REHMAN, International Human Rights Law, at 177 et seq.

434 Article $1 \& 2$ OP-ICESCR.

435 MAHON, 'Progress at the Front: The Draft Optional Protocol to the International Covenant on Economic, Social and Cultural Rights', at 637. See for more information BRIAN GRIFFEY, "The "Reasonableness" Test: Assessing Violations of State Obligations under the Optional 
[w] hen examining communications under the present Protocol, the Committee shall consider the reasonableness of the steps taken by the State Party in accordance with part II of the Covenant. In doing so, the Committee shall bear in mind that the State Party may adopt a range of possible policy measures for the implementation of the rights set forth in the Covenant. ${ }^{436}$

The impact and effectiveness of the Optional Protocol with regard to adjudicating violations of economic, social and cultural rights on the international level will show itself in time. The fact that only 10 states have become party to the OP-ICESCR seems to reflect the reluctance of states to acknowledge the justiciable nature of ESC rights. ${ }^{437}$

In conclusion, for human rights to be truly effective, they must be enforceable and justiciable. From a conceptual viewpoint, the rigid approach that socio-economic rights are by definition not justiciable, while civil and political rights are, is no longer tenable. This traditional approach is incompatible with the principle that all human rights are indivisible and interdependent. Both sets of rights encompass positive and negative duties, requiring different types of state measures and variable degrees of resources to fully realise these rights within a national setting. Thus, with regard to the justiciability of socio-economic rights, it is better to make use of a contextual approach where all rights - whether civil, political, socio-economic or cultural - are located somewhere along a "justiciability spectrum". 438 In addition, there are indications that international human rights bodies and states are increasingly recognising the justiciability of ESC rights. For example, as seen above international treaty monitoring bodies and particularly the CESCR have, through General Comments, continually interpreted and concretised states parties' obligations with respect to the right to health. Very few states parties have publicly protested against these efforts of treaty monitoring bodies. Although only a small number of states have ratified the Optional Protocol to the ICESCR, the very fact that it was adopted by the General Assembly signifies a strengthening of the recognition of the justiciable nature of ESC rights. ${ }^{439}$

\subsubsection{Case Law}

At the national level, an increasing number of constitutions recognise and protect economic and social rights, including the right to health. ${ }^{440}$ However, in many cases

Protocol to the International Covenant on Economic, Social and Cultural Rights', Human Rights Law Review, 11:2 (2011), 275-327.

436 Article 8.4 OP-ICESCR.

437 The 10 states party to the OP-ICESCR are: Argentina, Bolivia, Bosnia and Herzegovina, Ecuador, El Salvador, Mongolia, Portugal, Slovakia, Spain and Uruguay.

438 See BRAND, 'Socio-Economic Rights and Courts in South Africa', at 226.

439 YUVAL SHANY, 'Stuck in a Moment in Time: The International Justiciability of Economic, Social and Cultural Rights', in Daphne Barak-Erez and Aeyal M. Gross (eds.), Exploring Social Rights: Between Theory and Practice (Oxford: Hart Publishing, 2007) at 104.

440 See further GUNILLA BACKMAN et al., 'Health Systems and the Right to Health: An Assessment of 194 Countries', The Lancet, 372 (2008); COURTIS, Courts and the Legal 
these rights are not considered justiciable in the national context mainly for the reasons touched upon above. ${ }^{41}$ Yet in the last couple of decades we see a development towards recognition of the justiciable nature of socio-economic rights. ${ }^{442}$ In a study conducted by the Department of Medicines Policy and Standards of the WHO into the enforceability of access to essential medicines, as part of the right to health through the court system in low- and middle-income countries, over 70 cases were identified in which access to medicines was claimed with reference to the right to health; more than $90 \%$ of these cases came from Central and Latin America. ${ }^{443}$

Enforcement of ESC Rights, at 4; HANS V. HOGERZEIL, MELANIE SAMSON, and JAUME VIDAL CASANOVA, Ruling for Access. Leading Court Cases in Developing Countries on Access to Essential Medicines as Part of the Fulfilment of the Right to Health, World Health Organisation - Dept. of Essential Drugs and Medicines Policy, (November 2004); S.K. PEREHUDOFF, R.O. LAING, and H.V. HOGERZEIL, 'Access to Essential Medicines in National Constitutions', Bulletin World Health Organisation, 88:11 (2010) at 800; UN GENERAL ASSEMBLY, Report of the Special Rapporteur on the Right of Everyone to the Enjoyment of the Highest Attainable Standard of Physical and Mental Health (UN Doc. $\mathrm{A} / 59 / 422 ; 2004)$ at $\S 15$.

441 LISA FORMAN, 'Justice and Justiciability: Advancing Solidarity and Justice through South Africans' Right to Health in Jurisprudence', Medicine and Law, 27 (2008), 661-683 at 665. See for an interesting discussion on the justiciability of economic and social rights within domestic systems, COOMANS (ed.), Justiciability of Economic and Social Rights. Experiences from Domestic Systems; COURTIS, Courts and the Legal Enforcement of ESC Rights.

442 See also HUNT and LEADER, 'Developing and Applying the Right to the Highest Attainable Standard of Health', at 39 et seq; DANIEL WANJAU MURIU, 'The Imperial - Emancipatory Paradox of International Human Rights: How Useful Is the Right to Health in Sub-Saharan Africa?', International Community Law Review, 9:4 (2007), 387-403 at 399 et seq.

The African Commission on Human and Peoples' Rights has also considered the right to health. In Social and Economic Rights Action Centre and Centre for Economic and Social Rights $v$. Nigeria (Communication No. 155/96), members of the Ogoni community in Nigeria alleged that the operations of an oil consortium contaminating the environment and resulting in widerspread health problems led to a violation of their rights to health and a clean environment. The African Commission held that the Ogoni's human rights had indeed been violated as a result of the government's failure to prevent pollution. In Purohit and Moore v. Gambia (Communication No. 241/2001), health advocates witnessed inhuman treatment of mental health patients. The applicants submitted a complaint on behalf of the patients arguing that national legislation was seriously deficient from a human rights perspective. The African Commission found that the national legislation was indeed lacking and treatment for mental health patients was inadequate. See further a petition brought before a High Court in Kenya (Constitutional Petition No. 2 of 2011 (Garissa)) by a large group of individuals who were evicted from their homes. The High Court ruled for the petitioners recognising the interdependence of civil and political and economic, social and cultural rights, highlighting the justiciability of the latter. The Court stressed that any treaty ratified by Kenya is part of Kenyan law, basing its decision not only on the new Kenyan Constitution but also on articles 11 and 26 of the International Covenant on Economic, Social and Cultural Rights and articles 16 and 18 of the African Charter on Human and People's Rights.

443 HANS V. HOGERZEIL et al., 'Is Access to Essential Medicines as Part of the Fulfilment of the Right to Health Enforceable through the Courts?', The Lancet, 368 (2006), 305-311. 
Thus, this section will study this development by examining case law from a number of national legal systems. It must be mentioned that an in-depth study of the national context in South Africa, India and Uganda can be found in the country studies and will not be discussed here. Moreover, this section is in no way exhaustive but it intends to illustrate some samples of state practice on the issue of justiciability of the right to health and access to medicines in particular.

In Venezuela, for example, the 1999 Constitution considers the right to health a fundamental social right and the responsibility of the state. Moreover, the right to health is a right of the highest legal order, as international treaties are considered to have constitutional rank. ${ }^{444}$ In addition, each citizen may file a claim for the protection of his constitutional rights before all courts. ${ }^{445}$ The N.A., Y.F. et al. vs Ministerio de Sanidad y Asistencia Social ${ }^{446}$ case is the first in a series of cases challenging the Ministry of Health for failing to ensure coverage for ARVs through the public health care system for those who were not eligible under the social security scheme. The Supreme Court linked the fundamental duty of the state to preserve life with the obligation to adopt public health measures against the HIV epidemic. It ruled that the provision of ARVs is a state obligation. It based its decision on the interdependence of the right to life, the right to an adequate standard of health and the right to benefit from scientific advances. In later similar cases, the Supreme Court maintained this standpoint ordering the Ministry to comply with its legal obligations and provide ARVs, in addition to granting the petitioners' request to extend the effect of the decision to all patients in the same circumstances. ${ }^{447}$

Another example is the case of Colombia. ${ }^{448}$ The Colombian Constitution recognises health as a fundamental right and it is the responsibility of the state to ensure that this right is not infringed while also taking steps to implement the right to health through national laws. ${ }^{449}$ It established that international human rights treaties

444 Article 23 of the Venezuelan Constitution:

The treaties, pacts and conventions relating to human rights which have been executed and ratified by Venezuela have a constitutional rank, and prevail over internal legislation, insofar as they contain provisions concerning the enjoyment and exercise of such rights that are more favorable than those established by this Constitution and the laws of the Republic, and shall be immediately and directly applied by the courts and other organs of Public Power. (Not legally binding translation).

445 Article 27 of the Venezuelan Constitution:

Everyone has the right to be protected by the courts in the enjoyment and exercise of constitutional rights and guarantees, including even those inherent individual rights not expressly mentioned in this Constitution or in international instruments concerning human rights. (Not legally binding translation.).

446 N.A., Y.F. et al. vs Ministerio de Sanidad y Asistencia Social, Supreme Court, expediente no. 14625, 14 August 1998, Venezuela.

447 See Cruz del Valle Bermúdez et al. vs Ministerio de Salud y Acción Social, Supreme Court, expediente no. 15789, 15 July 1999; Glenda López et al. vs Instituto Venezolano de Seguros Sociales, Supreme Court, expediente no. 00-1343, 6 April 2001, Venezuela.

448 HOGERZEIL, SAMSON, and CASANOVA, Ruling for Access, at 21 et seq.

449 Article 49 of the Colombian Constitution:

It is the responsibility of the State to organize, direct, and regulate the delivery of health services 
ratified by Colombia rank higher than national law, may not be restricted in a state of emergency, and that the rights and duties enshrined in the Colombian Constitution shall be interpreted in accordance with such international human rights treaties. ${ }^{450}$ There are a number of cases in the Colombian context with regard to access to medicines. In Alonso Muñoz Ceballos vs Instituto de Seguros Sociales (ISS), ${ }^{451}$ a person infected with HIV, receiving free treatment through the Public Social Security Scheme (ISS), was informed that free medical treatment would no longer be provided to him. The Constitutional Court found that this HIV-infected employee had a right of access to (certain) health services. The Court explained that the right to health had two functions: first, it is a fundamental right to be protected from health threats, linking health to the right to life (Article 11 Colombian Constitution); secondly, it also constitutes a social right, which implies positive obligations binding on the State. In Diego Serna Gómez vs Hospital Universitario del Valle ${ }^{452}$ the plaintiff, who was HIV infected and financially unstable, challenged the hospital's decision to refuse him free medical care, claiming that the refusal violated his right to health in relation to the right to non-discrimination (article 13 Colombian Constitution). The Constitutional Court ruled that the right to health is a fundamental right, particularly when connected to the right to life. It also found that the state has limited resources and is therefore not required to provide free health care to all. Yet, article 13 does require special protection in situations where a lack of economic resources prevents a person from reducing the suffering, discrimination and social risks involved in being afflicted by a terminal, infectious and incurable disease. In $X$ vs Instituto de Seguros Sociales (ISS) ${ }^{453}$ the plaintiff, who was also HIV infected and receiving treatment through the Public Social Security Scheme, challenged the ISS for refusing to provide him with the mix

and of environmental protection to the population in accordance with the principles of efficiency, universality, and cooperation, and to establish policies for the provision of health services by private entities and to exercise supervision and control over them. In the area of public health, the state will establish the jurisdiction of the nation, territorial entities, and individuals, and determine the shares of their responsibilities within the limits and under the conditions determined by law. Public health services will be organized in a decentralized manner, in accordance with levels of responsibility and with the participation of the community.

The law will determine the limits within which basic care for all the people will be free of charge and mandatory. Every person has the obligation to attend to the integral care of his/her health and that of his/her community. (Not legally binding translation).

450 Article 93 of the Colombian Constitution:

International treaties and agreements, which have been ratified by Congress, which recognize human rights and which prohibit their restriction during states of emergency shall take precedence over internal law. These fundamental constitutional rights must be interpreted in the context of the public human rights treaties ratified by Colombia. (Not legally binding translation).

451 Alonso Muñoz Ceballos vs Instituto de Seguros Sociales (ISS), Constitutional Court Judgement no. T-484, 11 August 1992, Colombia.

452 Diego Serna Gómez vs Hospital Universitario del Valle, Constitutional Court, Judgement no. T-505, 28 August 1992, Colombia.

$453 X$ vs Instituto de Seguros Sociales (ISS), Constitutional Court, Judgement no. T-271 of 23 June 1995, Colombia. 
of ARVs necessary to avoid further deterioration of his health. The ISS argued that it could not provide these particular ARVs because they were not included in the Official Medicines List due their high cost. The Constitutional Court finding that the right to health is a fundamental right when connected, even indirectly, to the right to life, ruled that the state (through the ISS) had the obligation to provide treatment to alleviate the condition of people living with serious illnesses. We see here that the Constitutional Court takes into account the particularly vulnerable position of HIV-infected persons. In $X$ vs Secretaríia de Salud Pública Municipal de Cali ${ }^{454}$ it noted that HIV positive patients needed special protection by the state and that providing free treatment to all HIV patients was a priority. Moreover, the Colombian Constitutional Court has also enforced the right to health with regard to private health entities. ${ }^{455}$

A further example is the case of the Philippines. ${ }^{456}$ According to article II of the 1987 Philippine Constitution - a Declaration of Principles and States Policies - section 15 of that article prescribes that the "state shall protect and promote the right to health of the people". 457 It further states that the Philippines adopts the generally accepted principles of international law as part of the law of the land. ${ }^{458}$ In the Del Rosario $v$. Bengzon case, ${ }^{459}$ the constitutionality of some provisions of the 1988 Generics Act, which sought to make medicines more available and accessible particularly to the poor, was challenged. The Supreme Court declared the law constitutional stating that it was "unable to find any constitutional infirmity in the Generics Act." On the contrary, the Act implements the national mandate for the state "to protect and promote the right to health" and "to make essential goods, health and other social services available to all the people at affordable cost" as found in Articles II(15) and XIII(11).

Another particularly interesting case from the perspective of the interface between access to medicines and intellectual property rights is the 2012 ruling of a Kenyan High Court in Patricia Asero Ochieng and 2 Others v. the Attorney General \& Another. ${ }^{460}$ The petitioners, three Kenyan citizens infected with HIV/AIDS and

454 Xvs Secretariia de Salud Pública Municipal de Cali, Constitutional Court, Judgement no. T-177, 18 March 1999, Colombia.

455 See for example Mrs Diana María Pinilla Sandoval vs Salud Colpatria EPS, Constitutional Court, Judgement no. 170, 8 March 2002, Colombia.

456 GILBERT SEMBRANO, 'Mechanisms and Avenues for Judicial and Quasi-Judicial Implementation of ESC Rights: The Philippine Experience', in Fons Coomans (ed.), Justiciability of Economic and Social Rights (Antwerpen/Oxford: Intersentia, 2006).

457 See also article XIII(11) of the Philippine Constitution:

The State shall adopt an integrated and comprehensive approach to health development which shall endeavour to make essential goods, health and other social services available to all the people at affordable cost. There shall be priority for the needs of the underprivileged, sick, elderly, disabled, women, and children. The State shall endeavour to provide free medical care to paupers.

458 Article II(2) of the Philippines Constitution.

459 Del Rosario v. Bengzon, Supreme Court Judgment 180 SCRA 521, 21 December 1989, the Philippines.

460 Nairobi High Court, Patricia Asero Ochieng and Others v the Attorney General \& Another, 20 April 2012, Petition No. 409 of 2009. 
receiving (generic) antiretroviral medicines, petitioned the High Court challenging the 2008 Anti-Counterfeit Act. They argued that section 2 of that Act confused generic medicines with counterfeit medicines and if implemented would significantly restrict access to affordable medicines by imposing civil and criminal penalties on generic pharmaceutical manufacturers. ${ }^{461}$ This, as the petitioners contended, would constitute a violation of their right to life, health and human dignity under articles 26(1), 28 and 43 of the Constitution ${ }^{462}$ and Article 12 of the International Covenant on Economic, Social and Cultural Rights. ${ }^{463}$ In ruling on this issue the High Court referred to the CESCR's General Comment No. 14 holding that the state's failure to promote conditions in which its citizens can lead a healthy life means that it has violated, or is likely to violate, their right to health. ${ }^{464}$ Continuing the Court referred to General Comments No. 17 - in which the ICESCR stated that states parties have a duty to prevent unreasonably high costs for access to essential medicines - and case law by the South African Constitutional Court. Consequently it found that "[ $\mathrm{t}]$ he state's obligation with regard to the right to health therefore encompasses not only the positive duty to ensure that its citizens have access to health care services and medication but must also encompass the negative duty not to do anything that would in any way affect access to such health care services and essential medicines. Any legislation that would render the cost of essential drugs unaffordable to citizens would thus be in violation of the state's obligations under the Constitution." 465

461 Section 2 of the 2008 Kenyan Anti-Counterfeit Act provides as follows: "counterfeiting" means taking the following actions without the authority of the owner of intellectual property right subsisting in Kenya or elsewhere in respect of protected goods-

(a) the manufacture, production, packaging, re-packaging, labelling or making, whether in Kenya or elsewhere, of any goods whereby those protected goods are imitated in such manner and to such a degree that those other goods are identical or substantially similar copies of the protected goods;

(b) the manufacture, production or making, whether in Kenya or elsewhere, the subject matter of that intellectual property, or a colourable imitation thereof so that the other goods are calculated to be confused with or to be taken as being the protected goods of the said owner or any goods manufactured, produced or made under his licence;

(c) the manufacturing, producing or making of copies, in Kenya or elsewhere, in violation of an author's rights or related rights;

(d) in relation to medicine, the deliberate and fraudulent mislabelling of medicine with respect to identity or source, whether or not such products have correct ingredients, wrong ingredients, have sufficient active ingredients or have fake packaging.

Article 26(1) of the Kenyan Constitution grants every person the right to life; article 28 respects and protects every person's inherent dignity; and article 43(1)a states that every person has the right "to the highest attainable standard of health, which includes the right to health care services, including reproductive health care". ratified by Kenya shall form part of the law of Kenya under this Constitution." 
The Nairobi High Court agreed with the petitions declaring several of the Act's sections unconstitutional holding that the Act's definition of "counterfeit" would likely be read as including generic medication and was therefore likely to adversely affect the manufacture, sale, and distribution of generic drugs. ${ }^{466}$ According to the Court, the Anti-Counterfeit Act prioritises enforcement of IPRs when dealing with the problem of counterfeit medicines. ${ }^{467}$ Consequently, it stated that:

Should the Act be implemented as it is, the danger that it poses to the right of the petitioners to access essential medicine which they require on a daily basis in order to sustain life is far greater and more critical than the protection of the intellectual property rights that the Act seeks to protect. The right to life, dignity and health of the petitioners must take precedence over the intellectual property rights of patent holders. ${ }^{468}$

Lastly, the Court ordered the Kenyan parliament to review the Act and amend the unconstitutional sections. ${ }^{469}$

Some constitutions do no not contain a right to health explicitly; even so, courts have found a way to adjudicate health cases and guarantee access to medicines, such as in the case of Argentina. ${ }^{470}$ Although the Argentine Constitution does not contain an express provision recognising health as a human right, the 1994 constitutional reform opened the way for individuals (and groups) to directly invoke human rights treaty provisions before national courts by adopting a clear monist position towards human rights treaties. ${ }^{471}$ The Argentine courts have ruled on the

466 Ibid. at $\$ 78$.

467 Ibid. at $\$ 83$.

468 Ibid. at $\$ 85$.

469 Ibid. at $\$ 88$.

470 See VICTOR ABRAMOVICH and LAURA PAUTASSI, 'Judicial Activism in the Argentine Health System: Recent Trends', Health and Human Rights, 10:2 (2008), 53-65; CHRISTIAN COURTIS, 'Socio-Economic Rights before the Courts of Argentina', in Fons Coomans (ed.), Justiciability of Economic and Social Rights (Antwerpen/Oxford: Intersentia, 2006) at 323-331; HOGERZEIL, SAMSON, and CASANOVA, Ruling for Access, at 17 et seq.

471 See article 75 of the Argentine Constitution which grants constitutional status to 11 declarations and international human rights treaties. It reads:

Congress is empowered:

22. To approve or reject treaties concluded with other nations and international organizations, and concordats with the Holy See. Treaties and concordats have a higher hierarchy than laws.

The American Declaration of the Rights and Duties of Man; the Universal Declaration of Human Rights; the American Convention on Human Rights; the International Pact on Economic, Social and Cultural Rights; the International Pact on Civil and Political Rights and its Empowering Protocol; the Convention on the Prevention and Punishment of Genocide; the International Convention on the Elimination of all Forms of Racial Discrimination; the Convention on the Elimination of all Forms of Discrimination against Women; the Convention against Torture and other Cruel, Inhuman or Degrading Treatments or Punishments; the Convention on the Rights of the Child; in the full force of their provisions, they have constitutional hierarchy, do not repeal any section of the First Part of this Constitution and are to 
right to health demanding both positive and negative action by the government. In Asociación Benghalensis, ${ }^{472}$ a coalition of NGOs sued the National Ministry of Health and Social Welfare for the failure to supply medicines to people living with HIV/AIDS as guaranteed under the national AIDS law (law no. 23798). The Supreme Court challenged all arguments from the Ministry and reaffirmed strongly that the Ministry was responsible for ensuring the effective implementation of the AIDS programme. In Campodónico de Beviacqua,${ }^{473}$ regarding a demand for medicine coverage for a disabled child, the Supreme Court upheld an appeal and ordered the national government to continue providing medicine to a child with a disability, basing its decision mainly on international provisions, including article 3 of the CRC, article 25 of the UDHR, and articles 10 and 12 of ICESCR. In this case the Supreme Court set out an important precedent indicating (among others) that the right to preservation of health (included in the right to life) has constitutional status based on international human rights treaties specified in the Argentine Constitution; that the scope of the state's obligations regarding the provision and continuity of treatment is such that the right to health must be guaranteed with positive actions; and that state parties have obligated themselves through ratification of ICESCR to progressively realise the right to health to the maximum of their available resources. ${ }^{474}$ The Supreme Court has followed this precedent ruling, for example, by granting medical coverage to HIV/AIDS infected persons and granting interim relief in order to ensure access to medication and treatment in situations of extreme urgency. Similarly, the lower courts have frequently decided cases of access to medical coverage in favour of the claimants. ${ }^{475}$

Another example of indirectly protecting the right to health is the case of Costa Rica. ${ }^{476}$ The Costa Rican Constitution does not expressly recognise the right to health, however, it includes norms that guarantee the right to health and the protection of human rights in general. ${ }^{477}$ It has ratified the main international

be understood as complementing the rights and guarantees recognized herein. (Not legally binding translation).

Asociación Benghalensis y Otros c. Ministerio de Salud y Acción Social, Supreme Court, File No A.186.XXXIV, June 1, 2000, Argentina.

473 Ana Carina v. Ministerio de Salud y Acción Social, Supreme Court, File No. C.823.XXXV, October 24, 2000, Argentina.

474 NOLAN, 'The Child's Right to Health and the Courts', at 148-149.

475 ABRAMOVICH and PAUTASSI, 'Judicial Activism in the Argentine Health System', at 57.

476 HOGERZEIL, SAMSON, and CASANOVA, Ruling for Access, at 25 et seq.

477 See for example Article 50 of the Costa Rican Constitution:

The State shall procure the greatest welfare of all inhabitants of the country, organizing and promoting production and the most adequate distribution of wealth. Every person has the right to a healthy and ecologically balanced environment, being therefore entitled to denounce any acts that may infringe said right and claim redress for the damage caused.

The State shall guarantee, defend and preserve that right. The Law shall establish the appropriate responsibilities and penalties. (Not legally binding translation). 
human rights treaties and these take precedence over national law. ${ }^{478}$ In Sidonia Vargas vs Hospital San Juan de Dios ${ }^{479}$ the hospital refused to provide the patient with medicines for administrative and safety reasons. Here the Constitutional Court referred to the right to health as an essential component of the right to life, and thus linked collective and individual rights. The refusal to provide free medication, in the case of an HIV patient, due to the fact that these ARVs were at that time not included in the official national medicines list was challenged in William Garcia Álvarez vs Caja Costarricense de Seguro Social. ${ }^{480}$ The patient was unable to afford the medication in the private sector and based its claim on an imminent violation of the right to life. The Court ruled in favour of the plaintiff and ordered the National Health Care System to provide him with the ARVs free of charge. The Court based its decision on the right to life and health as enshrined in the Cost Rican Constitution and as endorsed by Costa Rica in international treaties. The Constitutional Court continued this line of reasoning also in other cases regarding access to medicines. ${ }^{481}$

A similar line of reasoning can be found in a case in El Salvador, in which a HIV-positive person filed an action against the Social Security Institution for the refusal to provide him with free ARVs, alleging that this violated his right to life and health. ${ }^{482}$ HIV treatment was available at that time in El Salvador, but patients had to finance treatment themselves. The Constitutional Court accepted the petition, but continuously postponed its decision. Consequently, the plaintiff and 25 other HIV-infected persons supported by health advocacy NGOs, filed a complaint before the Inter-American Commission of Human Rights. As a provisory measure, the Commission implored El Salvador to comply with its regional obligations and provide the needed medications. It admitted the petition, yet before the hearings started, the Salvadoran Constitutional Court came to a decision. It ruled in favour of the plaintiff, ordering the Social Security Institution to provide the required ARV treatment, basing its ruling on the right to life and health as enshrined in the Salvadoran Constitution and international treaties ratified by the state.

Finally, brief mention must also be made of the developments within the European context. The European Court of Human Rights has increasingly started to assess social security norms on their compatibility with fundamental human

478 Article 7 of the Costa Rican Constitution:

Official treaties, international agreements and concordats that have been duly approved by the Legislative Assembly shall, from the date of their promulgation or the date designated by them, have precedence over laws. (Not legally binding translation.).

479 Sidonia Vargas vs Hospital San Juan de Dios, Constitutional Court, File no. 2390-C-94, 7 September 1994, Costa Rica.

480 William García Álvarez vs Caja Costarricense de Seguro Social, Constitutional Court, File no. 5778-V-97, 23 September 1997, Costa Rica.

481 See for example Ombudsman for Mrs Ledi Orellana Martínez vs Caja Costarricense de Seguro Social (CCSS), Constitutional Court, File no. 02-007871, 24 September 2002, Costa Rica.

482 See Jorge Odir Miranda Cortez vs la Directora del Instituto Salvadoreño del Seguro Social, Constitutional Court, File no. 348-99, 4 April 2001, El Salvador. 
rights, even though the right to social security, social assistance or access to health care are not included in the European Convention for the Protection of Human Rights. ${ }^{483}$ See for example the case of $D v$. $U K$, in which the ECHR found that expelling the applicant, an irregular migrant diagnosed with HIV/AIDS and seriously ill, would expose him to a real risk of dying under very disturbing circumstances, resulting in a violation of article 3 of the Convention prohibiting inhuman treatment. ${ }^{484}$ This was a rather extreme situation and, as such, it is an exceptional case. See for example a later case which also concerned an HIV positive and seriously ill applicant facing expulsion to her home country Uganda where the required medication was available yet at a considerable cost. The Court ruled that this particular case does not disclose very exceptional circumstances as in $D v$. UK and would therefore not result in a violation of article 3 of the Convention. ${ }^{485}$

Concluding, from the above discussed examples it can be concluded firstly that courts are able and willing to adjudicate right to health cases, and the contention that socio-economic rights by definition are not justiciable is no longer tenable. Broadly speaking, there are three possibilities through which the right to health and access to medicines is recognised in the national legal framework: incorporation into the constitution, constitutional recognition that international treaties ratified by the state override or acquire the status of national law, and inclusion of health rights in national legislation. Secondly, states increasingly recognise a right of access to medicines either as an essential element of the right to health or right to life.

\subsubsection{Conclusion}

Monitoring states parties' compliance with their international human rights obligations and holding them accountable for violations of human rights is an essential component of a human rights-based approach to health. However, the international human rights framework does not provide any truly effective means of enforcing human rights obligations. Therefore, monitoring and accountability mechanisms should be established at the national level. There are different ways to ensure accountability of the state; the focus here, however, is on judicial mechanisms. Namely, to be truly effective human rights must be justiciable and enforceable. ${ }^{486}$ Consequently, it is argued here that the rigid traditional approach that socio-economic rights are not justiciable, while civil and political rights are justiciable is no longer tenable. States should apply a contextual approach to the

483 See futher PAUL SCHOUKENS, 'The Right to Access Health Care: Health Care According to European Social Security Law Instruments', Medicine and Law, 27 (2008), 501-533 at 526 et seq.

484 D. v. the United Kingdom, Judgment of the European Court of Human Rights, Application No. 30240/96, 2 May 1997.

485 N. v. the United Kingdom, Judgment of the European Court of Human Rights, Application No. 26565/05, 27 May 2008.

486 See also Article 8 of the UDHR grants every individual a right to an effective remedy in case of violations of his or her fundamental rights granted by the national constitution or law. 
justiciability of human rights; all rights hold a position along a sliding scale of justiciability, which is redefined every time a right is enforced before a (quasi-) judicial body. ${ }^{487}$

Furthermore, case law from different legal systems suggests that recourse to the court system can play a significant part in the promotion and protection of healthrelated rights. In that regard, a study aimed at identifying, analysing and summarising court cases in developing countries, where individuals or groups have challenged the government successfully claiming access to essential medicines based (partly) on international human rights law and the right to health, found a number of success factors such as: constitutional provisions on the right to health, or with defined state obligations regarding health care services and social welfare; constitutional provisions stating that international (human rights) treaties rank higher than national law; linking the right to health with the right to life; and legal, moral and financial support by civil society and public interest NGOs. ${ }^{488}$

\subsection{Special Rapporteur on the Right to Health}

An analysis of the right to health with respect to access to medicines would be incomplete without reference to the work of the Special Rapporteur (SR) on the Right of Everyone to the Enjoyment of the Highest Attainable Standard of Physical and Mental Health established within the framework of the UN Charter. This section will therefore provide an overview of the Special Rapporteur's work on this particular issue. In 2002 the Commission on Human Rights established the position of Special Rapporteur on the Right of Everyone to the Enjoyment of the Highest Attainable Standard of Physical and Mental Health. ${ }^{489}$ The first SR on the right to health was Paul Hunt (New Zealand) who served two terms until 2008, after which Anand Grover (India) took over. The question addressed in this section is whether the Special Rapporteur's analysis of the right to health contains a right of access to medicines.

In his preliminary report, Special Rapporteur Paul Hunt outlined his general approach to the mandate, identifying three primary objectives for the mandate: to promote - and encourage others to promote - the right to health as a fundamental human right; to clarify the contours and content of the right to health; and to identify good practices for the operationalisation of the right to health at community, national and international levels. ${ }^{490}$ In clarifying the contours and content of the right to health, the Special Rapporteur made some initial remarks in line with the

\footnotetext{
487 BRAND, 'Socio-Economic Rights and Courts in South Africa', at 226.

488 See HOGERZEIL, SAMSON, and CASANOVA, Ruling for Access.

489 UN COMMISSION ON HUMAN RIGHTS, Resolution 2002/3, (UN Doc. E/CN.4/2002/31); UN HUMAN RIGHTS COUNCIL, Resolution 6/29, (UN Doc. A/HRC/RES/6/29).

490 UN COMMISSION ON HUMAN RIGHTS, Report of the Special Rapporteur on the Right to Health, (UN Doc. E/CN.4/2003/58).
} 
interpretation of the CESCR. ${ }^{491}$ He finds that the right to health is a broad concept that can be broken down into more specific entitlements such as the prevention, treatment and control of diseases, including access to essential medicines. ${ }^{492}$

The SR has also addressed the issue of "neglected diseases" and the 10/90 gap concluding that these are human rights issues. ${ }^{493}$ Following up on this, in his 2004 report, the Special Rapporteur pointed out one of the human rights dimensions of "neglected diseases", namely the need for international assistance and cooperation to promote the development of new medicines (and vaccines and diagnostic tools) for diseases causing a heavy burden in developing countries. ${ }^{494}$ In addition, he found that there is a need to make existing medicines for "neglected diseases" more accessible to patients in need of them and in that regard welcomes the Canadian initiative of introducing legislation in line with the 2003 Decision of the WTO General Council allowing for the compulsory licensing of patented medicines for the purposes of export. Furthermore he has focused his attention on the human rights responsibility of international assistance and cooperation in health of high-income countries. ${ }^{495}$ In practice, the realisation of the right to health is dependent on international assistance and cooperation, particularly for developing and least-developed countries. In his 2008 report the SR sets out the contours and context of the human rights responsibility of international assistance and cooperation. Thus, international assistance and cooperation includes a responsibility to seek appropriate assistance and cooperation particularly for those states with limited available resources, and a responsibility on states in a position to assist (mainly high-income states) in providing appropriate assistance and cooperation; the responsibility to assist is supplementary and does not qualify, limit or condition in any way the primary responsibility to realise the right to health of the country seeking assistance; international assistance and cooperation may not be limited to financial assistance but states should ensure that international policies, including trade policies, support the realisation of the right to health; states must ensure that their actions respect the right to health in other countries, so far as possible, protect against third parties undermining the right to health in other countries, and depending on resource availability, fulfil the right to health (i.e. facilitate access to essential health facilities and services) in other countries; and the

\footnotetext{
491 Ibid. at $\$ 22$ et seq.

492 Ibid. at $\$ 25$.

493 Ibid. at $\S 81$.

494 UN COMMISSION ON HUMAN RIGHTS, Report of the Special Rapporteur on the Right of Everyone to the Enjoyment of the Highest Attainable Standard of Physical and Mental Health, Paul Hunt (Un Doc. E/CN.4/2004/49; 2004) at \$79-80. See also UN COMMISSION ON HUMAN RIGHTS, Report of the Special Rapporteur on the Right to Health. Addendum. Mission to Uganda, (UN Doc. E/CN.4/2006/48/Add.2).

495 UN GENERAL ASSEMBLY, Report of the Special Rapporteur on the Right to Health, (UN Doc. A/59/422) at \$32-35; UN HUMAN RIGHTS COUNCIL, Report of the Special Rapporteur on the Right of Everyone to the Enjoyment of the Highest Attainable Standard of Physical and Mental Health. Addendum: Missions to the WB and the IMF in Washington, D.C. And Uganda (UN Doc. A/HRC/7/11/Add.2; 2008).
} 
international right to health must be applied consistently and coherently across all relevant national and international policymaking processes. ${ }^{496}$

In a 2006 report, the Special Rapporteur focused particularly on the human right to medicines stating that medical care in the event of sickness, as well as the prevention, treatment and control of diseases - all features depending upon access to medicines - are central aspects of the right to health. Consequently, access to medicines forms an indispensable part of the right to health. ${ }^{497}$ The Special Rapporteur continues by defining states' responsibilities in that regard in line with the interpretation of CESCR: i.e. states are responsible for ensuring that existing medicines are available within their borders while also taking reasonable measures to ensure that much-needed new medicines are developed and thereby become available; that available medicines are accessible (physical accessibility, economic accessibility, the principle of non-discrimination, accessibility of information); that medicines must be culturally acceptable and respectful of medical ethics; and that medicines must also be of good quality. ${ }^{498}$ The Special Rapporteur emphasises the crucial importance of all states having an essential medicines list, an up-to-date national medicines policy and a detailed implementation plan. Finally it also dedicates a section to the responsibility of pharmaceutical companies with regard to a right of medicines. ${ }^{499}$ Furthermore, following an expert consultation on access to medicines as a fundamental component of the right to health in 2011, the Special Rapporteur issued a report concluding firstly that access to medicines is an integral and fundamental part of the right to health and that states and the international community as a whole have the responsibility to provide access to medicines for all. ${ }^{500}$ Secondly, it finds that more research and development is required to promote the availability of new drugs for neglected diseases disproportionately affecting developing countries and refers to the role of IPRs in stimulating innovation while also pushing up medicine prices. ${ }^{501}$ The Special Rapporteur concludes that, on the basis of the expert consultation, states should establish an adequate legal framework for the realisation of the right of access to medicines. ${ }^{502}$ Lastly the Special

496 UN HUMAN RIGHTS COUNCIL, Report of the Special Rapporteur on the Right to Health. Addendum: Missions to the WB and the IMF in Washington, D.C. And Uganda, (UN Doc. A/ HRC/7/11/Add.2) at \$20-30.

497 UN GENERAL ASSEMBLY, Report of the Special Rapporteur on the Right of Everyone to the Enjoyment of the Highest Attainable Standard of Physical and Mental Health (UN Doc. $\mathrm{A} / 61 / 338 ; 2006)$ at $\S 40$.

498 Ibid. at $\$ 47$ et seq.

499 Ibid. at $\$ 82$ et seq.

500 UN HUMAN RIGHTS COUNCIL, Report of the Special Rapporteur on the Right of Everyone to the Enjoyment of the Highest Attainable Standard of Physical and Mental Health. Expert Consultation on Access to Medicines as a Fundamental Component of the Right to Health (UN Doc. A/HRC/17/43; 2011).

$501 \quad$ Ibid. at $\$ 46-47$.

502 Ibid. at $\$ 49$.

On the basis of the presentations and discussions, the Special Rapporteur believes the expert consultation suggests that States should: 
Rapporteur addressed the issue of access to medicines, excluding issues relating to intellectual property rights, in its 2013 report. ${ }^{503}$ Again he reiterated the fundamental nature of access to medicines as an integral component of the right to health under article 12 ICESCR. ${ }^{504} \mathrm{He}$ found there is a "need to shift the dominant marketoriented paradigm on access to medicines towards a right-to-health paradigm and reaffirm that access to affordable and quality medicines and medical care in the event of sickness, as well as the prevention, treatment and control of diseases, are central elements of the enjoyment of the right to health." 505 He concluded by recommending that with respect to long-term security and affordability of medicines states should (a) develop a policy framework on local production of medicines to ensure long-term accessibility and affordability, (b) strengthen the regulatory framework to increase competitiveness of the local industry, and (c) use the flexibilities under the TRIPS Agreement to promote regional collaboration to pool resources and facilitate competitiveness of local production. ${ }^{506}$

In conclusion, under the Special Rapporteur's analysis of the right to health access to medicines forms an indispensable part of this right. And in order for a

(a) Establish an adequate legal framework for the realization of the right to access to medicines;

(b) Ensure that medicine-related health priorities are not weakened in favour of investment or industrial priorities;

(c) Take measures to ensure equality for all individuals and groups, such as disadvantaged minorities;

(d) In formulating national health and medicines policies and programmes, ensure the active and informed participation of all concerned - not only of professional organizations and universities, but rural communities, civil society organizations and patients' and consumer organizations as well;

(e) Establish a regulatory system to ensure the safety and quality of medicines;

(f) Establish a national medicine supply system that includes programmes specifically tailored to reach vulnerable groups;

(g) Establish monitoring and accountability mechanisms for access to medicines;

(h) Ensure price and quality control of medicines, and establish dosage standards and ensure the efficacy of medicines;

(i) Ensure that procurement practices and procedures are transparent, fair and competitive;

(j) Establish mechanisms to limit the impact of intellectual property rights and protect unhindered access to medicines;

(k) Ensure that countries are able to take full advantage of TRIPS flexibilities, and to comply with them;

(1) Enhance the transfer of technology and investment in research and development to developing countries;

(m) Strengthen the effectiveness of national and international measures to ensure access to medicines for all.

UN HUMAN RIGHTS COUNCIL, Report of the Special Rapporteur on the Right to Health on Access to Medicines, (UN Doc. A/HRC/23/42).

Ibid. at $\$ 3$.

Ibid. at $\$ 7$.

With regard to the affordability of medicines the Special Rapporteur further recommends that states:

(a) Adopt price control measures in pricing and reimbursement policies with a view to ensuring access of the population, and vulnerable groups particularly, to affordable medicines; 
state to comply with its obligations under such a right it must, at least, draw up an essential medicines list, national medicines policy and detailed implementation plan.

\subsection{Conclusion: Is there a Right of Access to Essential Medicines within the Right to Health?}

This section posed the question whether access to (essential) medicines is protected under the right to health. A textual interpretation of article 12 ICESCR leads to the conclusion that the scope of the right to health includes a right of access to essential medicines. This is confirmed by the CESCR's interpretation of the right to health in its General Comment No. 14, which determined that the provision of essential medicines is part of the minimum core content of the right to health, as well as the Special Rapporteur's analysis of the right to health in his various reports. Such a right of access to medicines requires, firstly, that access is guaranteed on a nondiscriminatory basis and, secondly, entails the following elements: availability, physically accessibility, affordability, cultural acceptability, and good quality of essential medicines.

Consequently, states parties to the ICESCR have the obligation to progressively realise the right to health and a core obligation to provide essential medicines. The concept of progressive realisation brings with it a margin of discretion when complying with the Covenant's obligations. As such states parties are free to determine the exact manner in which to implement the right to health, as long as they take all appropriate measures to the maximum of their available resources in order to ensure that the right to health and access to medicines is respected, protected and fulfilled. In addition to the obligation to progressively realise the right to health, the ICESCR also imposes obligations which must be complied with immediately limiting states parties' margin of discretion in that regard. These

(b) Select countries with a similar level of economic development to that of the State concerned as reference countries in order to secure the lowest price medicines through external reference pricing;

(c) Monitor and regulate, if necessary, manufacturers' selling prices as well as distribution mark-ups in the supply chain, while ensuring incentives for wholesalers and retailers for sustainable distribution;

(d) Resist trade policies that undermine the ability of States to reimburse the price of essential medicines to local pharmaceutical companies;

(e) Eliminate import tariffs on medicines, except when considered to be strategic to the promotion of local production of essential medicines;

(f) Remove taxes on all medicines, especially essential medicines, and consider other revenue options for health, such as excise taxes on socially harmful goods such as tobacco, alcohol and junk foods;

(g) Adopt competition laws and policies to prevent pharmaceutical companies from indulging in anti-competitive practices and promote competitive pricing of medicines together with strong enforcement.

Ibid. at $§ 70-71$. 
include particularly the prohibition of discrimination and the obligation to take deliberate, concrete and targeted steps towards the full realisation of the right to health and access to medicines. Moreover, the CESCR interprets core obligations to be of a non-derogable nature entailing that non-compliance can never be justified, also not with reference to lacking resources. Such an interpretation of core obligations raises a number of issues. Firstly the question arises how to determine the minimum core content; in relation to those elements of the right to health essential for survival or more broadly in relation to human dignity. In case of the latter, the scope of the minimum core content of the right to health would be significant as it is difficult to determine elements of the right to health which are not relevant for a life with dignity. Moreover, the realisation of the right to health and the core obligation to provide essential medicines is intimately linked with the availability of resources, which the ICESCR recognises by obliging states parties to progressively realise the Covenant's rights. This is at odds with the Committee's interpretation that the availability of resources is not determinative of compliance with the ICESCR's core obligations. Elevating the minimum core content to nonderogable rights, i.e. impossibility of justifying non-compliance, would entail elevating these to prioritised norms under the Covenant for which no basis can be found within the ICESCR itself. However, this should not lead to the conclusion that the concept of minimum core obligations is meaningless; rather it should be interpreted to mean that the margin of appreciation with respect to the minimum core content of the right to health, and thus also the provision of essential medicines, is tightened. Finally, states parties obligations under the Covenant are not confined to the national context but also have an international dimension. Consequently, states parties must take due account of the right of access to medicines when concluding international agreements and as members of international organisations, such as the WTO.

As we have seen above, there are other sources guaranteeing access to medicines in addition to the right to health. Moreover, many constitutions which do not contain a (justiciable) right to health do protect the right to life which has been interpreted to include access to life-saving or essential medicines. The right to the enjoyment of the benefits of scientific progress has also been used as an additional source to guarantee a right of access to medicines. Thus, the following sections will first discuss the right to life and, secondly, the right to benefit from scientific progress with a view to determining whether these support the conclusion that access to medicines is protected under international human rights law.

\section{The Human Right to Life: Article 6 ICCPR}

The analysis of the research question - whether, and if so, how access to medicines is protected under international human rights law - has until now been conducted from the perspective of the right to health, which is the most logical starting point. And as has been shown, the right to health under article 12 ICESCR does indeed 
include a right of access to medicines. However, are there any additional sources which would protect such a right of access? The first possibility will be addressed here: the right to life.

As opposed to the right to health, the right to life is categorised as a civil and political right, enshrined in a number of international legal documents, most notably article 3 of the Universal Declaration of Human Rights and article 6 of the International Covenant on Civil and Political Rights. The ICCPR protects a range of civil and political rights and counts 167 states parties. ${ }^{507}$ Unlike the ICESCR, the ICCPR included an Optional Protocol establishing an individual complaints mechanism from the moment of its adoption in 1966. The Optional Protocol has been ratified by 114 states, with the exception of the United States of America, India and China among others. ${ }^{508}$

Similar to the ICESCR, article 2 of the ICCPR specifies states parties' obligations with respect to the rights enumerated in the ICCPR. It reads as follows:

Each State Party to the present Covenant undertakes to respect and to ensure to all individuals within its territory and subject to its jurisdiction the rights recognized in the present Covenant, without distinction of any kind, such as race, colour, sex, language, religion, political or other opinion, national or social origin, property, birth or other status. ${ }^{509}$

The right to life is contained in article 6 of the ICCPR:

1. Every human being has the inherent right to life. This right shall be protected by law. No one shall be arbitrarily deprived of his life.

507 That is at the time of writing (April 2013). See also http://treaties.un.org/Pages/ViewDetails. aspx?src=TREATY\&mtdsg_no=IV-4\&chapter=4\&lang=en. The United States of America and the Republic of South Africa, which are signatories to the ICESCR but have not ratified it, are state parties to the ICCPR.

508 See also http://treaties.un.org/Pages/ViewDetails.aspx?src=TREATY\&mtdsg_no=IV-5\&chapter $=4 \&$ lang $=$ en. That is at the time of writing (April 2013).

509 Article 6 ICCPR further reads:

2. Where not already provided for by existing legislative or other measures, each State Party to the present Covenant undertakes to take the necessary steps, in accordance with its constitutional processes and with the provisions of the present Covenant, to adopt such laws or other measures as may be necessary to give effect to the rights recognized in the present Covenant.

3. Each State Party to the present Covenant undertakes:

(a) To ensure that any person whose rights or freedoms as herein recognized are violated shall have an effective remedy, notwithstanding that the violation has been committed by persons acting in an official capacity;

(b) To ensure that any person claiming such a remedy shall have his right thereto determined by competent judicial, administrative or legislative authorities, or by any other competent authority provided for by the legal system of the State, and to develop the possibilities of judicial remedy;

(c) To ensure that the competent authorities shall enforce such remedies when granted. 
The right to life is one of the most basic and fundamental human rights. It is a nonderogable right; without it all other human rights would lose their significance. ${ }^{510}$ The text of the Covenant also strengthens the fundamental nature of this right by referring to an "inherent" right to life. Academics have, therefore, argued the right to life to be an international norm of jus cogens: a norm which is recognised and accepted by the international community of states as a norm of which no derogation is allowed. ${ }^{511}$

The question here is to what extent access to medicines could fall within the ambit of the right to life. A traditional interpretation of the right to life would impose a negative duty on states parties not to interfere with an individual's right to life and not positive duties with respect to socio-economic elements necessary to guarantee a minimum standard of living. However, such a traditional interpretation is outdated. Article 2 ICCPR refers to states parties' obligations to respect and to ensure for all individuals the rights recognized in the Covenant, while the second paragraph obliges states parties "to take the necessary steps, in accordance with its constitutional processes and with the provisions of the present Covenant, to adopt such laws or other measures as may be necessary to give effect to the rights recognized in the present Covenant." Article 6 explicitly provides that the right to life "shall be protected by law." It would seem that "to ensure" and "take steps" would not merely entail negative duties for states parties. Moreover, taking into account that all human rights are universal, indivisible, interdependent and interrelated and find their basis in ensuring human dignity, the right to life - to be truly effective - should extend to the basic necessities of life required for survival, even if these partly overlap with economic, social and cultural rights. ${ }^{512}$

The Human Rights Committee in its General Comment No. 6 has also argued for a less strict interpretation of the right to life including not merely negative but also positive duties on states parties:

[T]he Committee has noted that the right to life has been too often narrowly interpreted. The expression "inherent right to life" cannot properly be understood in a restrictive manner, and the protection of this right requires that States adopt

510 HESTERMEYER, Human Rights and the WTO, at 115-116.

See article 4 of the ICCPR which reads as follows:

1. In time of public emergency which threatens the life of the nation and the existence of which is officially proclaimed, the States Parties to the present Covenant may take measures derogating from their obligations under the present Covenant to the extent strictly required by the exigencies of the situation, provided that such measures are not inconsistent with their other obligations under international law and do not involve discrimination solely on the ground of race, colour, sex, language, religion or social origin.

2. No derogation from article[s] $6[\ldots]$ may be made under this provision.

3. $[\ldots]$.

511 FRANS VILJOEN, International Human Rights Law in Africa (New York: Oxford University Press, 2007) at 28.

512 HESTERMEYER, Human Rights and the WTO, at 116 et seq; ALICIA ELY YAMIN, 'Not Just a Tragedy: Access to Medications as Right under International Law', Boston University International Law Journal, 21 (2003), 325-371 at 331 et seq. 
positive measures. In this connection, the Committee considers that it would be desirable for States parties to take all possible measures to reduce infant mortality and to increase life expectancy, especially in adopting measures to eliminate malnutrition and epidemics. ${ }^{513}$

Consequently, such an interpretation of the right to life entails a positive duty for states parties. However, what the precise scope would be of such positive duties is unclear. Although the HRCee does not make use of the tripartite typology with regard to states parties' obligations as developed by the CESCR, this approach could be usefully applied to the right life: state parties would then have the duty to respect, protect, and fulfil the right to life. With regard to the latter, states parties' obligation to fulfil the right to life, it is justified to argue that the state is required to create a legal order in which access to life-saving medicines as a basic necessity to ensure human life and dignity is guaranteed. ${ }^{514}$ Following such an interpretation, the right to life would include a right of access to medicines, although it would be limited to life-saving medicines.

\section{The Human Right to the Benefits of Science: Article 15 ICESCR}

A third source to support the conclusion that access to (essential) medicines is protected under international human rights law is the right to the enjoyment of the benefits of science as enumerated in article 27 of the UDHR and article 15.1(b) of the ICESCR. Article 27 UDHR states that everyone has the right "to share in scientific advancement and its benefits." It prescribes a two-pronged standard in that it protects the rights of those benefitting from science in addition to the rights of the scientists themselves ("the right to the protection of the moral and material interests resulting from any scientific, literary or artistic production of which he is the author"). Article 15 ICESCR follows a similar structure and reads as follows: ${ }^{515}$

513 HRCee, General Comment No. 6. The Right to Life (Article 6 of the International Covenant on Civil and Political Rights) (UN Doc. HRC/GC/6; 1982) at §5.

514 HESTERMEYER, Human Rights and the WTO, at 119.

515 Article 15 ICESCR further reads:

1. $[\ldots]$

(a) to take part in cultural life;

$[\ldots]$

2. The steps to be taken by the States Parties to the present Covenant to achieve the full realization of this right shall include those necessary for the conservation, the development and the diffusion of science and culture.

3. The States Parties to the present Covenant undertake to respect the freedom indispensable for scientific research and creative activity.

4. The States Parties to the present Covenant recognize the benefits to be derived from the encouragement and development of international contacts and co-operation in the scientific and cultural fields. 


\section{The States Parties to the present Covenant recognize the right of everyone:}

[...]

(b) to enjoy the benefits of scientific progress and its applications;

(c) to benefit from the protection of the moral and material interests resulting from any scientific, literary or artistic production of which he is the author.

The focus here is on article 15.1(b): the right to the enjoyment of the benefits of scientific progress and its applications, which in short is referred to as the right to the benefits of science. The right to benefit from science does not have a very prominent place within international human rights law. As such, there has been little (academic) debate on the scope and consequent obligations for states parties with regard to the right to benefit from science. The CESCR has not yet addressed the right to benefit from science in one of its general comments. It has, however, issued a general comment with regard to article 15.1(c) on the right to the protection of interests in one's intellectual creations. ${ }^{516}$ Determining the minimum core content of the right to benefit from science - and particularly whether it could include access to medicines - is therefore a difficult task. The most logical starting point is the text of article 15.1(b) ICESCR. In addition to the text, the drafting process of article 15 ICESCR also provides guidance in interpreting this right. The drafting process of the ICESCR was inspired by the human rights standards as protected in the UDHR. The Commission on Human Rights was, therefore, assigned with the difficult task of translating the relatively broad formulated standards of the UDHR into specific legal obligations for states. ${ }^{517}$

There is a slight textual difference between article 27 UDHR, which protects everyone's right to share in scientific advancement and its benefits, and article 15 ICESCR, which states that everyone should enjoy the benefits of scientific progress and its applications. The text of article 15.1(b) has been argued to contain at least the following core elements. Firstly, the right to enjoy the benefits of science requires an environment of freedom without undue interference by the state. In that respect this right is closely connected to other rights, such as the right free speech, access to information, participation, assembly, and association. Secondly, the wording referring to everyone's right to enjoy the benefits of scientific progress and its applications indicates that it should further socially beneficial applications of science and protect people from applications that could be harmful and violate their human rights. Thirdly, the reference to everyone's right has a further implication in that the right must be linked to principles of equality and non-discrimination, as

516 CESCR, General Comment No. 17. The Right of Everyone to Benefit from the Protection of the Moral and Material Interests Resulting from Any Scientific, Literary or Artistic Production of Which He or She Is the Author (Article 15, Paragraph 1(c), of the Covenant) (UN Doc. E/C.12/ $\mathrm{GC} / 17$; 2005).

517 RICHARD PIERRE CLAUDE, 'Scientists' Rights and the Human Right to the Benefits of Science', in Audrey Chapman and Sage Russel (eds.), Core Obligations: Building a Framework for Economic, Social and Cultural Rights (Antwerp/Oxford/New York: Intersentia, 2002) at 252. 
also confirmed in articles 2.2 and 3 of the ICESCR. Fourthly, the right to enjoy the benefits of science will not be very effective in especially least-developed and developing countries without (much) scientific progress. Thus, this right can only be fully realised with national and international co-operative efforts. ${ }^{518}$ This links in with article 2.1 which states that every state party must take steps, individually and through international assistance and co-operation, to achieve the full realisation of the Covenant's rights. Consequently, one could argue that medicines, in particular newly invented pharmaceuticals, fall within the definition of "scientific progress and its applications" and that article 15.1(b) therefore grants every individual a right to enjoy the benefits from scientific progress in the field of pharmaceuticals.

Just as with other human rights, making use of the tripartite typology can help in identifying states parties' obligations: the state is obliged to respect, protect and fulfil the right to the enjoyment of the benefits of science. ${ }^{519}$ The second paragraph of article 15 ICESCR states that states parties should take steps to fully realise the rights mentioned including those "necessary for the conservation, the development and the diffusion of science and culture." During the drafting process much debate took place on states parties' responsibilities with regard to implementing rights relating to science. It was warned against including ideological references in the Covenant because the article on science (and culture) was especially delicate. This stance is reflected in the structure of article 15.2, which specifies the steps to be taken by the states parties; namely those steps necessary for first, the conservation of science as in safeguarding the integrity of science which is closely related to the right of academic freedom; second, ensuring the development of science, which is closely connected to the right to education but also guarantees equal access for everyone to the scientific community; and, lastly, safeguarding the diffusion of science, which entails that all members of the scientific community have the right to freely communicate and publish their research without any form of censorship. ${ }^{520}$

Considering the above, it can be argued that states parties to the ICESCR have an international responsibility to co-operate internationally to ensure that the benefits of scientific and technological progress are shared on a global basis. ${ }^{521}$ However, it is not only states parties to the ICESCR that have committed themselves to realising this goal, as the General Assembly in 1975 adopted a Declaration in which it stated that "[a]11 States shall promote international co-operation to ensure that the results of scientific and technological developments are used in the interests

518 Ibid. at 254-255. See also AUDREY R. CHAPMAN, 'A Human Rights Perspective on Intellectual Property, Scientific Progress, and Access to the Benefits of Science', Intellectual Property and Human Rights. A Panel Discussion to Commemorate the 50th Anniversary of the Universal Declaration of Human Rights (Geneva: World Intellectual Property Organisation Office of the United Nations High Commissioner for Human Rights, 1999) at 136 et seq.

For an overview of examples of violations of the right to respect, protect and fulfil the right to the enjoyment of the benefits of science see CLAUDE, 'Scientists' Rights and the Human Right to the Benefits of Science', at 271-277.

520 Ibid. at $258-259$

521 Ibid. at 265. 
of strengthening international peace and security, freedom and independence, and also for the purpose of the economic and social development of peoples and the realization of human rights and freedoms in accordance with the Charter of the UN." 522 Moreover, the 1975 Declaration also affirms respect for the principle of non-discrimination with regard to enjoying the benefits of scientific and technological progress. ${ }^{523}$ In the field of access to medicines we can also identify issues of discrimination disadvantaging developing countries. For example, with regard to research and development of new pharmaceuticals, it has been demonstrated that only $10 \%$ of health research and development is spent on diseases and health problems which affect $90 \%$ of the population worldwide, most of them in the developing world. 524 The 1975 Declaration also addressed this inequality between developed and developing countries in the field of science by stating that "[a]11 States shall co-operate in the establishment, strengthening and development of the scientific and technological capacity of developing countries with a view to accelerating the realization of the social and economic rights of the peoples of those countries." 525

In conclusion, the interpretation of the right to the enjoyment of the benefits of science does not guarantee individuals a right of access to medicines, as such, but does support the conclusion that individuals have a right of access to (essential) medicines under the ICESCR.

\section{Access to Medicines under Customary International Law}

In addition to the above discussed rights enshrined in treaty law, the next section will examine whether a right of access to medicines can be identified within customary law as a source of international law in the meaning of article 38.1 of the Statute of the International Court of Justice. There is no inherent hierarchy between treaty law and customary law. Both sources of law are based on the consent of states, whether explicit or implicit, and thus they have the same binding force. ${ }^{526}$ The added value of examining customary law with regard to access to medicines is that treaty law only binds states parties to that particular treaty, while customary international law binds all states.

Simply said, customary law is the hardening of a practice into a legally binding norm. Therefore the development of customary law is a process: "through repetition acts give rise to a usage, usage begins to raise expectations of a certain behavioural

522 UN GENERAL ASSEMBLY, Resolution 30/3384. Declaration on the Use of Scientific and Technological Progress in the Interests of Peace and for the Benefit of Mankind (UN Doc. A/ RES/30/3384; 1975) at $\$ 1$. The resolution was adopted by 97 votes to 0 , with 20 abstentions. 
pattern, and ultimately what was a mere fact hardens to soft and then hard law." 527 Customary international law, as opposed to treaty law, binds all states except for those states that from the beginning have persistently objected to a rule of customary law. ${ }^{528}$

Considering the wording of article 38.1(b) of the ICJ Statute, "international custom, as evidence of a general practice accepted as law", a norm only constitutes a rule of customary international law if it fulfils two requirements: it must reflect state practice, which is the objective component, and the states concerned must believe that the norm amounts to a binding legal obligation, the subjective component also known as opinio juris sive necessitatis. This has been confirmed by the ICJ in the North Sea Continental Shelf cases where it stated that: ${ }^{529}$

[F]or, in order to achieve this result [mandatory rule of customary international law], two conditions must be fulfilled. Not only must the acts concerned amount to a settled practice, but they must also be such, or be carried out in such a way, as to be evidence of a belief that this practice is rendered obligatory by the existence of a rule of law requiring it. The need for such a belief, i.e., the existence of a subjective element, is implicit in the very notion of the opinio juris sive necessitatis. The States concerned must therefore feel that they are conforming to what amounts to a legal obligation.

As stated above, for a norm to become a rule of customary international law it must firstly constitute a state practice. State practice must be of a certain duration, consistency and generality for it to harden into customary law. ${ }^{530}$ It is not necessary that all states participate in the practice; the requirement is that of generality not universality. ${ }^{531}$ Moreover, the ICJ, in the North Sea Continental Shelf cases, has recognised that even without the passage of any considerable period of time, a very widespread and representative participation in a convention might suffice in itself to cause a norm-creating treaty rule to become customary law. It has even been argued that, considering the quick pace of developments in international law and relations, it might be possible to accept the creation of "instant customary law". 532

As stated above, state practice alone is not sufficient to become a norm of customary international law. It merely indicates a usage of states. For such a usage to become customary law there must be something more; an element which elevates the practice from a usage of states to a rule with a normative character, something that states must do. This second element of customary international law is referred to as opinio juris sive necessitatis. There has been and still is much debate on what

\footnotetext{
527 HESTERMEYER, Human Rights and the WTO, at 134.

528 Fischeries Case, at 131.

529 North Sea Continental Shelf Cases, at §77. See also US Supreme Court, Sosa v. AlvarezManchain Et Al, (2004) 542 US 692.

530 See further, International Court of Justice, Asylum Case (Colombia v. Peru), 20 November 1950.

531 REHMAN, International Human Rights Law, at 22.

532 HESTERMEYER, Human Rights and the WTO, at 123; SHAW, International Law, at 73-74.
} 
this concept actually entails, which will not be discussed here. The majority view has been expressed in the North Sea Continental Shelf cases, in which the ICJ stated that "states must therefore feel that they are conforming to what amounts to a legal obligation." 533

Proving the existence of a rule of customary international law is an extremely difficult and time-consuming process. This is also partly due to the fact that there is still disagreement on what acts of state constitute state practice (for the purpose of determining customary law) and demonstrate opinio juris. Many examples, whether paper practice or verbal practice, may be used to demonstrate the existence of both elements. ${ }^{534}$ A strong indicator of state practice is the approach taken by state representatives in UN organs, such as the Security Council and General Assembly. Declarations and resolutions of other international organisations and conferences as statements of intent may also indicate evolving rules under customary law, and treaties may act as de facto evidence of state practice. ${ }^{535}$ Furthermore, judgments and opinions of national and international courts, documents by quasi-judicial human rights treaty bodies and scholarly works may have great persuasive force. ${ }^{536}$ In addition, moral considerations, especially considering the topic under review, will also be of relevance..$^{537}$

Taking this all into account, it will be difficult to reliably determine what constitutes state practice in the field of access to medicines. This is complicated by the fact that, more than in any other field of law, international human rights law is inextricably linked to morality. Many states are hesitant to reject rules of international human rights law, being afraid of negative public attention if they behave ethically and morally wrong. In such situations they mostly tend to argue that they have not breached any rule, rather than refuse to accept the existence of a human rights norm as such.

It is outside the scope of this dissertation to conduct a full review of the question whether access to medicines is protected under general international law. The following sections will therefore examine whether there is any indication that states believe that access to medicines, whether as an independent right, as part of the right to health or the right life, is an emerging norm of customary international law. Therefore the extent to which access to medicines has been, maybe even a prioritised issue within different international for a will be examined. The focus will mainly be on state practice within the UN framework.

533 North Sea Continental Shelf Cases, at $\$ 77$.

534 HESTERMEYER, Human Rights and the WTO, at 123, 134; SHAW, International Law, at 78-80.

535 VILJOEN, International Human Rights Law in Africa, at 28-30; REHMAN, International Human Rights Law, at 22-23.

536 BHATT, 'Amending TRIPS: A New Hope for Increased Access to Essential Medicines', at 621.

537 HESTERMEYER, Human Rights and the WTO, at 134. See futher JAN WOUTERS and CEDRIC RYNGAERT, The Impact of Human Rights and International Humanitarian Law on the Process of the Formation of Customary International Law, Katholieke Universiteit Leuven, Faculty of Law. Institute for International Law, Working Paper No. 121, (February 2008). 


\subsection{The International Bill of Rights}

In examining the existence of a possible customary right of access to medicines, this section examines whether the UDHR, which includes the right to life and health, has reached the status of customary law. Moreover, a treaty norm may give rise to a rule of customary law. ${ }^{538}$ Consequently, the question would be whether the right life and/or the right health, as incorporated in the UDHR and further set out in the ICCPR and ICESCR respectively, have reached the status of customary international law and are, thus, binding on all states.

It is argued that the UDHR, or at least a number of its provisions, represents customary international law in that it is an authoritative statement of states' obligations under article 55 and 56 of the Charter of the United Nations. This interpretation has been strengthened by the fact that the UDHR - and the ICESCR and ICCPR - have been repeated, cited and reaffirmed many times without opposition by the GA, in international instruments, bilateral agreements and multilateral (including regional) human rights treaties. ${ }^{539}$ This is further supported by the widespread and representative participation in the mentioned human rights treaties. ${ }^{540}$ However, it would be too easy to conclude that, simply because of its widespread and representative participation, the International Bill of Rights has become customary law and is now also binding on those states that decided against ratifying these treaties. Moreover, many of the numerous documents repeating and reaffirming the international human rights have been made in a non-binding form. It is very possible that the non-binding nature of these documents is an important reason they enjoy such widespread recognition and acceptance by states. If states agreed to them fully aware that they were not legally bound to them, it is dubious to use these documents in support of state practice. Moreover, these documents are what would be considered "paper practice". If we look at the actual deeds of states, as in its non-paper practice, with regard to human rights, the picture is gloomy: states violate human rights on a daily basis. However, violations of human rights provisions, especially if they have been condemned by the international community, do not prevent the development of a norm becoming part of customary law. ${ }^{541}$

The right to health is incorporated in article 12 ICESCR and has been further developed by the CESCR in its General Comment No. 14. In addition, the right to health has been incorporated in a considerable number of constitutions, up to 60, but non-paper practice on the right to health is sparse. ${ }^{542}$ Although some national

\footnotetext{
538 HESTERMEYER, Human Rights and the WTO, at 122-123; REHMAN, International Human Rights Law, at 22.

539 CLAUDE, 'Scientists' Rights and the Human Right to the Benefits of Science', at 251-252; REHMAN, International Human Rights Law, at 79-81; HESTERMEYER, Human Rights and the WTO, at 125.

$540 \quad$ North Sea Continental Shelf Cases, at $\$ 73$.

541 HESTERMEYER, Human Rights and the WTO, at 125-127.

542 Ibid. at 127.
} 
legal systems have recognised the justiciable nature of the right to health, and other socio-economic rights for that matter, there is still an ongoing debate on the legal value and content of these rights. ${ }^{543}$ Many governments are ambivalent and unreceptive towards socio-economic rights in general because they believe they are not justiciable and enforceable rights. Although the CESCR has done a good job conceptualising the scope of the right and states parties' obligations under the Covenant, the very nature of the right to health is its broad and relatively vague scope encompassing a range of elements from the underlying preconditions for health, such as a minimum essential level of food, basic shelter, sanitation and safe drinking water to adopting and implementing a national public health strategy and ensuring the provision of essential medicines. ${ }^{544}$ Concluding, there is no international consensus to justify claiming that the right to health, as such, is a norm under customary international law. ${ }^{545}$

This might be different, though, with regard to the right to life as incorporated in article 6 ICCPR. Namely state practice concerning the right to life can be found in abundance and consists of numerous treaties mentioning the right to life, resolutions of international bodies, national constitutions and national and international case law. Although there are also ample examples of violations of the right to life by states, these violations are often condemned by the international community of states. As such, the right to life is commonly accepted as being part of customary international law. However, it is questionable whether the scope of the right to life under customary international law would extend to a positive duty for states to protect and ensure access to life-saving medicines. ${ }^{546}$

Thus, there is insufficient evidence to conclude that the right to health, as incorporated in the UDHR and ICESCR, and interpreted by the CESCR, is a rule of customary international law. The right to life on the other hand is generally considered to be part of customary law, although its precise scope is unclear. Therefore, the next section will focus the analysis further and assess whether one element of the right to health and life - i.e. access to essential and life-saving medicines - has reached the status of customary international law.

\subsection{A Customary Right of Access to Medicines?}

There is considerable state practice with regard to access to medicines, particularly in the context of access to life-saving medicines in pandemics such as HIV/AIDS, tuberculosis and malaria. ${ }^{547}$ Access to essential and life-saving medicines is not a controversial issue within the international community. Thus, it has been argued

\footnotetext{
543 REHMAN, International Human Rights Law, at 82.

544 CESCR, General Comment No. 14, (UN Doc. E/C.12/2000/4) at $§ 43$.

545 See also BHATT, 'Amending TRIPS: A New Hope for Increased Access to Essential Medicines', at 608 .

546 HESTERMEYER, Human Rights and the WTO, at 128.

547 Ibid. at 129.
} 
that a right of access to essential or, more specific, life-saving medicines in the context of pandemics has reached the status of customary law. ${ }^{548}$

The United Nations General Assembly has frequently stressed the importance of making anti-retroviral medicines available at an affordable cost to fight the HIV/ AIDS epidemic. In a special session on HIV/AIDS in 2001, government representatives stated their political commitment to "address factors affecting the provision of HIV-related drugs, including anti-retroviral drugs, inter alia, affordability and pricing, including differential pricing, and technical and healthcare system capacity" and "make every effort to provide progressively and in a sustainable manner, the highest attainable standard of treatment for HIV/AIDS." 549 Moreover, HIV/AIDS was specifically addressed as a human rights issue. ${ }^{550}$ In its 2006 resolution 60/262, the UN General Assembly reaffirmed its political commitment to halt and begin to reverse the spread of HIV/AIDS, malaria and other major diseases. ${ }^{551}$ Reviewing its progress achieved in realising the 2001 and 2006 Declarations on HIV/AIDS, the General Assembly adopted the Political Declaration on HIV/AIDS in a resolution on 8 July 2011, in which it explicitly recognises that access to safe, effective, affordable and good-quality medicines in the context of epidemics such as HIV is fundamental to the full realisation of the right to health. ${ }^{552}$ It recognises that affordable medicines, including generics, are of critical importance in scaling up access to affordable HIV treatment and also refers to the role of IPRs in that regard. ${ }^{553}$ The General Assembly commits itself to remove before 2015, where feasible, obstacles that limit the capacity of low- and middle-income countries to provide affordable and effective HIV prevention and treatment products, including medicines. ${ }^{554}$ In that regard it also commits itself to work towards closing the global HIV/AIDS resource gap to enable countries to access predictable and sustainable financial resources. ${ }^{555}$

The General Assembly firstly recognised that access to medicines in the context of pandemics is a fundamental element of the right to health in its Resolution 58/179 in $2004 .{ }^{556}$ It called upon states to develop and implement national strategies, to

\footnotetext{
548 See for example BHATT, 'Amending TRIPS: A New Hope for Increased Access to Essential Medicines'; HESTERMEYER, Human Rights and the WTO, at 121 et seq.

549 UN GENERAL ASSEMBLY, Resolution S-26/2. Declaration of Commitment on HIV/AIDS (UN Doc. A/RES/S-26/2; 2001) at $§ 55$. The resolution was adopted without a vote.

550 Ibid. at $\$ 58-61$.

551 UN GENERAL ASSEMBLY, Resolution 60/262. Political Declaration on HIV/AIDS (UN Doc. A/RES/60/262; 2006). The resolution was adopted without a vote.

552 UN GENERAL ASSEMBLY, Resolution 65/277. Political Declaration on on HIV/AIDS: Intensifying Our Efforts to Eliminate HIV/AIDS (UN Doc. A/RES/65/277; 2011) at §32. The resolution was adopted without a vote.

553 Ibid. at $\$ 35$.

554 Ibid. at $\$ 71$.

555 Ibid. at $\$ 86$ et seq.

556 UN GENERAL ASSEMBLY, Resolution 58/179. Access to Medication in the Context of Pandemics Such as HIV/AIDS, Tuberculosis and Malaria (UN Doc. A/RES/58/179; 2004. The resolution was adopted 181 votes to one; the United States being the sole dissenter.
} 
establish and strengthen national health and social infrastructures and health-care systems to progressively realise access to prevention-related goods and services, treatment, care and support for patients infected and affected by HIV/AIDS, tuberculosis and malaria. ${ }^{557}$ Further, it called upon states to pursue policies which promote the availability in sufficient quantities, the accessibility and affordability without discrimination, and the scientific and medical appropriateness and quality of pharmaceutical products or medical technologies used to treat pandemics such as HIV/AIDS, tuberculosis and malaria. ${ }^{558}$ This mirrors the four elements included in the right to health as interpreted by the CESCR in its General Comment No. 14. In the same vein, the General Assembly resolution also implicitly refers to states' obligations under the international right to health as set out by the CESCR: to respect ("to refrain from taking measures that would deny or limit equal access for all persons to preventive, curative or palliative pharmaceutical products or medical technologies"); to protect ("to adopt and implement legislation or other measures $[\ldots]$ to safeguard access to such [...] pharmaceutical products or medical technologies from any limitations by third parties") and fulfil the right to health ("to adopt all appropriate positive measures, to the maximum of the resources allocated for this purpose, to promote effective access to such [...] pharmaceutical products or medical technologies"). ${ }^{559}$ The resolution also recognizes states' extra-territorial obligations and responsibility as members of international organisations, which would include the World Trade Organisation. States are called upon to take steps, individually and/ or through international cooperation, in accordance with applicable international law, including international agreements acceded to, ensuring that their actions, as members of international organisations, take due account of the right to health and that the application of international agreements is supportive of public health policies that promote broad access to safe, effective and affordable preventive, curative or palliative pharmaceutical products or medical technologies. ${ }^{560}$ Additionally, the resolution calls upon states to take all appropriate measures to promote research and development of new and more effective pharmaceutical products; ${ }^{561}$ calls upon the international community, in particular the developed countries, to continue to assist developing countries in the fight against pandemics, ${ }^{562}$ and invites the CESCR to give attention to the issue of access to medication in the context of pandemics. ${ }^{563}$

The General Assembly reaffirmed its commitment to the Millennium Development Goals in its resolution 65/1 adopted 19 October 2010. ${ }^{564}$ It reiterated

\footnotetext{
557 Ibid. at $\$ 4-5$.

558 Ibid. at $\$ 6$.

559 Ibid. at $\$ 7$.

560 Ibid. at $\$ 10$.

561 Ibid. at $\$ 9$.

562 Ibid. at $\$ 15$.

563 Ibid. at $\$ 16$.

564 UN GENERAL ASSEMBLY, Resolution 65/1. Keeping the Promise: United to Achieve the Millennium Development Goals (UN Doc. A/RES/65/1; 2010). The resolution was adopted without a vote.
} 
its commitment to promoting global public health for all, including by realising the values and principle of primary health care, as well as strengthening international cooperation, inter alia, through improving access to medicines, encouraging the development of technology and the transfer of technology, the production of affordable, safe, effective and good quality medicines, and fostering the production of innovative medicines, generics, vaccines and other health commodities. ${ }^{565}$ In that line it reiterated its commitment to reducing child mortality, 566 improve maternal health, ${ }^{567}$ and also combat HIV/AIDS, malaria and other diseases by redoubling efforts to achieve universal access to HIV/AIDS prevention, treatment, care and support services as an essential step in achieving the MDGs. ${ }^{568}$

In addition to the General Assembly, the UN Commission on Human Rights (HRCion) has also addressed the issue of access to life-saving medicines in the context of pandemics. See for example its resolution 2001/33 in which the Commission recognised "that access to medication in the context of pandemics such as HIV/AIDS is one fundamental element for achieving progressively the full realization of the right of everyone to the enjoyment of the highest attainable standard of physical and mental health". ${ }^{569}$ Mirroring the language of General Comment No. 14 it called upon states to pursue policies so as to promote: (a) the availability of medicines and medical technologies for the treatment pandemics such as HIV/AIDS and the opportunistic infections that accompany them; (b) the accessibility of such medicines to all without discrimination, and affordability for all; and (c) that such medicines are scientifically and medically appropriate and of

565 Ibid. at $\$ 73(\mathrm{a}) \&(\mathrm{~m})$.

566 Ibid. at $\$ 74$. See for example $\$ 74($ a): We commit ourselves to accelerating progress in order to achieve Millennium Development Goal 4, including by

(a) Scaling up efforts to achieve integrated management of childhood illnesses, particularly actions to address and prevent the main causes of child mortality, including newborn and infant mortality, these being, inter alia, pneumonia, diarrhoea, malaria and malnutrition. This can be achieved by developing, implementing and evaluating appropriate national strategies, policies and programmes for child survival, preventive pre-natal, para-natal and post-natal measures, vaccinations and immunization and by working to ensure that medicines, medical products and technologies are affordable and available.

567 Ibid. at $\$ 75$.

568 Ibid. at $\$ 76$. See for example: We commit ourselves to accelerating progress in order to achieve Millennium Development Goal 6, including by (j) Increasing efforts to achieve universal access to HIV prevention, treatment, care and support, strengthening the fight against malaria, tuberculosis and other diseases, including by providing adequate funding for the Global Fund to Fight AIDS, Tuberculosis and Malaria and through the agencies, funds and programmes of the United Nations system and other multilateral and bilateral channels, strengthening innovative financing mechanisms, as appropriate, and contributing to the long-term sustainability of the response.

See further PHILIP ALSTON, 'Ships Passing in the Night: The Current State of the Human Rights and Development Debate Seen through the Lens of the Millennium Development Goals', Human Rights Quarterly, 27 (2005), 755-829 at 771 et seq.

569 UN COMMISSION ON HUMAN RIGHTS, Resolution 2001/33. Access to Medication in the Context of Pandemics Such as HIV/AIDS (UN Doc. E/CN.4/RES/2001/33; 2001) at $§ 1$. 
good quality. ${ }^{570}$ Continuing, it called upon states, at the national level, to refrain from taking measures which would deny or limit equal access for all, to adopt legislation or other measures in accordance with international law to safeguard access, and adopt all appropriate positive measures to the maximum of their resources allocated here to promote effective access to medicines for the treatment of pandemics. ${ }^{571}$ At the international level, the Commission called upon states to take steps, individually and/or through international cooperation, in accordance with international law, to facilitate, wherever possible, access in other countries particularly in times of emergency, and to ensure that their actions as members of international organisations take due account of, and the application of international agreements is supportive of the right to health. ${ }^{572}$ Finally, it called upon the international community and developed countries in particular to continue to assist through financial and technical support developing countries in their fight against pandemics such as HIV/AIDS. ${ }^{573}$ The Commission has reiterated this several times in later resolutions recognising the role of intellectual property rights and the TRIPS Agreement by welcoming the Doha Declaration on TRIPS and Public Health. ${ }^{574}$

The Human Rights Council (HRC) continued the work of the Commission recognising that access to medicine is one of the fundamental elements of the right to health. ${ }^{575}$ It stressed "the responsibility of States to ensure access to all, without discrimination, of medicines, in particular essential medicines, that are affordable, safe, effective and of good quality." 576 Further, it called upon states to take due account of the right to health as members of international agreements and regarding the application of international agreements, specifically referring to IPRs, TRIPS and the Doha Declaration. ${ }^{577}$ See also later resolutions where the Council urges states to "ensure full and unimpeded access for all [...] to HIV prevention, treatment, care and support, in a public health environment free from

\footnotetext{
$570 \quad$ Ibid. at $\$ 2$.

571 Ibid. at $\$ 3$.

572 Ibid. at $\$ 4$.

573 Ibid. at $\$ 5$.

574 See UN COMMISSION ON HUMAN RIGHTS, Resolution 2002/32. Access to Medication in the Context of Pandemics Such as HIV/AIDS (UN Doc. E/CN.4/RES/2002/32; 2002); UN COMMISSION ON HUMAN RIGHTS, Resolution 2003/29. Access to Medication in the Context of Pandemics Such as HIV/AIDS, Tuberculosis and Malaria (UN Doc. E/CN.4/ RES/2003/29; 2003); UN COMMISSION ON HUMAN RIGHTS, Resolution 2004/26. Access to Medication in the Context of Pandemics Such as HIV/AIDS, Tuberculosis and Malaria (UN Doc. E/CN.4/RES/2004/26; 2004); UN COMMISSION ON HUMAN RIGHTS, Resolution 2005/23. Access to Medication in the Context of Pandemics Such as HIV/AIDS, Tuberculosis and Malaria (UN Doc. E/CN.4/RES/2005/23; 2005).

575 UN HUMAN RIGHTS COUNCIL, Resolution 12/24. Access to Medicines of the Right of Everyone to the Enjoyment of the Highest Attainable Standard of Physical and Mental Health (UN Doc. A/HRC/RES/12/24; 2009). The resolution was adopted without a vote.

576 Ibid. at $\$ 2$.

577 Ibid. at \$3-6.
} 
discrimination"578 and recognises that the progressive realisation of the right to health is one of the central aspects of the process of development. ${ }^{579}$

Moreover, the Secretary General has also affirmed the fundamental importance of access to medicines in the context of pandemics in realising the right to health. In its reports he summarizes contributions received from states, intergovernmental and non-governmental organisations on the steps they have taken to improve access. ${ }^{580}$ In addition, the Special Rapporteur on the Right of Everyone to the Highest Attainable Standard of Physical and Mental Health stated that "[a]t the international level, legal and political commitments have been made to improve access to essential drugs for all, particularly in the context of the TRIPS Agreement and the Declaration of Commitment on HIV/AIDS. ${ }^{581}$

In addition to state practice on access to medicines within the framework of the United Nations, a brief look will be taken at developments within the World Health Organisation. In May 2001 the 54 ${ }^{\text {th }}$ World Health Assembly approved two resolutions of relevance here. In the resolution "Scaling up the Response to HIV/ AIDS" it considers that the progressive realisation of the right to health in the context of HIV/AIDS should involve access, on a non-discriminatory basis, to health facilities, prevention, care, treatment, and support and further acknowledges that the lack of affordable medicines continues to hinder an effective response to

578 UN HUMAN RIGHTS COUNCIL, Resolution 16/28. The Protection of Human Rights in the Context of Human Immunodeficiency Virus (HIV) and Acquired Immunodeficiency Sydrome (AIDS) (UN Doc. A/HRC/RES/16/28; 2011). The resolution was adopted without a vote.

579 UN HUMAN RIGHTS COUNCIL, Resolution 17/14. The Right of Everyone to the Enjoyment of the Highest Attainable Standard of Physical and Mental Health in the Context of Development and Access to Medicines (UN Doc. A/HRC/RES/17/14; 2011). The resolution was adopted without a vote.

580 See UN COMMISSION ON HUMAN RIGHTS, Report of the Secretary-General on Access to Medication in the Context of Pandemics Such as HIV/AIDS (UN Doc. E/CN.4/2003/48; 2003); UN COMMISSION ON HUMAN RIGHTS, Report of the Secretary General on Access to Medication in the Context of Pandemics Such as HIV/AIDS, Tuberculosis and Malaria (UN Doc. E/CN.4/2004/39; 2003); UN COMMISSION ON HUMAN RIGHTS, Report of the Secretary General on Access to Medication in the Context of Pandemics Such as HIV/AIDS, Tuberculosis and Malaria (UN Doc. E/CN.4/2005/38; 2005); UN COMMISSION ON HUMAN RIGHTS, Report of the Secretary General on Access to Medication in the Context of Pandemics Such as HIV/AIDS, Tuberculosis and Malaria (UN Doc. E/CN.4/2006/39; 2006); UN HUMAN RIGHTS COUNCIL, Implementation of the General Assembly Resolution 60/251 of 15 March Entitled "Human Rights Council". Report of the Secretary-General on the Protection of Human Rights in the Context of Human Immunodeficiency Virus (HIV) and Acquired Immunodefiency Syndrome (AIDS) (UN Doc. A/HRC/4/110; 2007); UN HUMAN RIGHTS COUNCIL, Annual Report of the UN High Commissioner for Human Rights and Reports of the Office of the High Commissioner and the Secretary-General on Access to Medication in the Context of Pandemics Such as HIV/AIDS, Tuberculosis and Malaria (UN Doc. A/HRC/7/30; 2008); UN HUMAN RIGHTS COUNCIL, Report of the Secretary-General on the Protection of Human Rights in the Context of Human Immunodeficiency Virus (HIV) and Acquired Immunodefiency Syndrome (AIDS) (UN Doc. A/HRC/16/69; 2010).

581 UN GENERAL ASSEMBLY, Interim Report of the Special Rapporteur of the Commission on Human Rights on the Right of Everyone to the Highest Attainable Standard of Physical and Mental Health, Mr. Paul Hunt (UN Doc. A/58/427; 2003) at $§ 65$. 
HIV/AIDS in many countries, especially for the poor. ${ }^{582}$ It urges member states to scale up their responses to HIV/AIDS and "to make every effort to provide, progressively and in a sustainable manner, the highest standard of treatment for HIV/AIDS". ${ }^{583}$ The World Health Assembly has reiterated the importance of scaling up the response to HIV/AIDS in later resolutions. ${ }^{584}$

In the second resolution on the WHO's medicines strategy, the WHA, bearing in mind the WHO global framework for expanding access to essential drugs and its components (the rational selection and use of medicines, reliable health and supply systems, sustainable financing, and affordable prices), takes account of the fact that access to medicines is particularly price sensitive, especially for patients in developing countries who often pay for medication themselves, and that it will take the commitment of governments, the organisations of the UN, the private sector and civil society in order to achieve universal access. ${ }^{585}$ It urges member states:

1) to reaffirm their commitment to ensuring public health interests and to make every effort to promote equitable access to medicines, and to undertake the necessary action within their national health policies, including for priority diseases and pandemics, as an important element for progressively achieving the highest attainable standard of health;

2) to take effective measures in accordance with international law and international agreements acceded to in order to ensure improved access to medicines;

3) to cooperate with respect to resolution 2001/33 of the United Nations Commission on Human Rights;

4) to pursue measures directed to expanding access of their populations to essential drugs [...];

5) in order to increase access to medicines, and in accordance with the health needs of people, especially those who can least afford the costs, and recognizing the efforts of Member States to expand access to drugs and promote domestic industry, cooperate constructively in strengthening pharmaceutical policies and practices, including those applicable to generic drugs, and intellectual property regimes in order further to promote innovation and the development of domestic industries, consistent with applicable international law;

6) to provide financial support and technical cooperation to enable Member States in need to expand access of their populations to essential drugs.

582 WHA, Scaling up the Response to HIV/AIDS (Fifty-Fourth World Health Assembly. WHA54.10; 2001).

583 Ibid. at $\$ 3 \& 5$.

584 WHA, Global Health-Sector Strategy for HIVIAIDS (Fifty-Sixth World Health Assembly. WHA56.30; 2003); WHA, Scaling up Treatment and Care within a Coordinated and Comprehensive Response to HIVIAIDS (Fifty-Seventh World Health Assembly. WHA57.14; 2004); WHA, WHO HIVIAIDS Strategy for 2011-2015 (Sixty-Third World Health Assembly. WHA63.19; 2010); WHA, Global Health Sector Strategy on HIV/AIDS, 2011-2015 (Sixty-Fourth World Health Assembly. WHA64.14; 2011).

WHA, WHO Medicines Strategy (Fifty-Fourth World Health Assembly. WHA54.11; 2001). 
Furthermore, in May 2002 the 55 $5^{\text {th }}$ World Health Assembly firstly welcomed the Doha Declaration on TRIPS and Public Health and reaffirmed its medicines strategy. ${ }^{586}$ It urged members to "reaffirm their commitment to increasing access to medicines, and to translate such commitment into specific regulation within countries" 587 and continue "monitoring the implications on access to medicines of recent patent-protection laws and compliance with WTO's Agreement on TradeRelated Aspects of Intellectual Property Rights". 588

These resolutions and declarations adopted within the UN and WHO framework are examples of paper practice on access to medicines in the context of pandemics. There is also evidence of increasing non-paper practice of states on this particular issue. For example, states have indicated their willingness to take responsibility in the fight against public health pandemics through the establishment of a Global Fund to Fight AIDS, Tuberculosis and Malaria (hereinafter the Global Fund) in January 2002. The Global Fund was first conceived of at a G8 meeting in Japan in July 2000. African leaders meeting in Abuja in 2001 voiced their support, as did UN Secretary General Kofi Annan. The United Nations Special Session on AIDS, in June 2001, called for the formal creation of the Global Fund. ${ }^{589}$ A transitional working group was then formed to establish its structures, and the Secretariat opened its doors in Geneva in January 2002. The first grants were made in March 2002. The purpose of the Global Fund is "to attract, manage and disburse additional resources through a new public-private partnership that will make a sustainable and significant contribution to the reduction of infections, illness and death, thereby mitigating the impact caused by HIV/AIDS, tuberculosis (TB) and malaria in countries in need, and contributing to poverty reduction as part of the Millennium Development Goals." ${ }^{590}$ It is a financial instrument, not an implementing entity. ${ }^{591}$ The Global Fund is a public-private partnership and thus includes representatives from donor and recipient countries, civil society and the private sector in the central administration and in the implementation of programmes. The Global Fund relies on voluntary contributions from all sectors of society, yet government funding represents its largest source of income. According the Global Fund's website, for the period 2002-2015, "54 donor governments have pledged US\$ 28.8 billion and

586 WHA, Ensuring Accessibility of Essential Medicines (Fifty-Fifth World Health Assembly. WHA55.14; 2002).

587 Ibid. at $\$ 1$.

588 Ibid. at $\$ 5$.

589 UN GENERAL ASSEMBLY, Resolution $S-26 / 2$, (UN Doc. A/RES/S-26/2) at $\$ 79$.

590 THE GLOBAL FUND, The Framework Document. Global Fund Governance and Core Documents, The Global Fund to Fight AIDS, Tuberculosis and Malaria, (2001) at section II.

591 It is further guided by the following principles: make available and leverage additional financial resources; support programs that evolve from national plans and priorities; operate in a balanced manner in terms of different regions, diseases and interventions; pursue an integrated and balanced approach to prevention and treatment; evaluate proposals through independent review processes; and operate with transparency and accountability. See ibid. at section III. 
paid in US\$ 24 billion." $59295 \%$ of all public sector contributions were made by 17 OECD countries. Private sector donors include, among others, the Bill \& Melinda Gates Foundation, the UN Foundations and several multinational corporations such as Chevron, the Coca-Cola Company and Standard Bank. In its 2012-2016 Strategy, it commits to a set of goals and actions for contributing to the collective fight against the three diseases, including the promotion and protection of human rights. 593

Within the World Trade Organisation the severity of public health problems, such as HIV/AIDS, tuberculosis and malaria, affecting developing and leastdeveloped countries has also been recognised, namely with the adoption of the Doha Declaration on the TRIPS Agreement and Public Health. ${ }^{594}$ The Doha Declaration stresses that the TRIPS Agreement needs to be part of the wider national and international action to address these problems. ${ }^{595}$ Moreover, it recognises that intellectual property is important for the development of new medicines, but it also notes the concerns intellectual property has on prices. ${ }^{596}$ In paragraph 4 of the Doha Declaration it states that the WTO members "agree that the TRIPS Agreement does not and should not prevent Members from taking measures to protect public health." The Doha Declaration also identified a shortcoming within the TRIPS Agreement regarding the requirement that a compulsory license must be granted predominantly for the supply of the domestic market, making the use of compulsory licenses practically pointless for countries with no or limited manufacturing capacity, referred to as the "paragraph 6 problem". Moreover, developing countries with a growing generic pharmaceutical industry could not issue a compulsory license for exporting medicines to those countries without the ability to produce their own generic medicines. Consequently the WTO General Council adopted a Decision on 30 August 2003 implementing a system to allow WTO members with insufficient or no manufacturing capacities in the pharmaceutical sector to make effective use of compulsory licensing under the TRIPS Agreement. ${ }^{597}$ The decision is a temporary waiver to the limitation within TRIPS that the use of a compulsory license should predominantly pertain to supplying the domestic market. Finally, according to a decision by the WTO

592 THE GLOBAL FUND, 'Government Doners', <www.theglobalfund.org/en/donors/public/>, accessed 18 January 2013.

593 See THE GLOBAL FUND, The Global Fund Strategy 2012-2016: Investing for Impact, The Global Fund to Fight AIDS, Tuberculosis and Malaria, (2011).

594 WTO, Doha Declaration on the TRIPS Agreement and Public Health Adopted at the Doha Ministerial Conference, Fourth Session (WT/MIN(01)/DEC/2; 2001) at $\$ 1$. See for an in-depth discussion of the Doha Declaration on the TRIPS Agreement and Public Health section 5.1 of chapter 5 .

595 Ibid. at $\$ 2$.

596 Ibid. at $\$ 3$.

597 WTO GENERAL COUNCIL, Decision of 30 August 2003 on the Implementation of Paragraph 6 of the Doha Declaration on the TRIPS Agreement and Public Health (WT/L/540; 2003); HESTERMEYER, Human Rights and the WTO, at 261 et seq. 
General Council in 2005 the TRIPS Agreement shall be amended to implement the system introduced by the 30 August 2003 Decision. 598 At the time of writing (January 2013), 45 members have accepted the amendment. ${ }^{599}$ Until two-thirds of the WTO members accept the amendment to TRIPS, the waiver introduced by the 2003 Decision will continue to apply. The 2005 amendment decision is unprecedented and it will be the first amendment to the TRIPS Agreement. The TRIPS amendment takes a very concrete and specific position on the issue of public health and TRIPS and is the result of considerable negotiation and deliberation. Although there are insufficient ratifications as of yet to formally amend TRIPS, it has been approved by the WTO General Council, which consists of representatives of all WTO members. Consequently, the amendment to TRIPS, in addition to the Doha Declaration (and the 2003 Decision), constitute a very powerful statement of state practice: namely support for the promotion and protection of public health and access to medicines especially in the area of HIV/AIDS, TB and malaria. ${ }^{600}$ The UN General Assembly has also reaffirmed the right to fully use the flexibilities contained in the TRIPS Agreement and Doha Declaration on TRIPS and Public Health in order to protect public health, particularly to promote access to medicines for all, and encourage the provision of assistance to developing countries in this regard. ${ }^{601}$

In conclusion, it seems justified to assert that states recognise that access to medicines in the context of pandemics is a fundamental element of the right to health. Moreover, taking into account the numerous documents and initiatives where states have explicitly stated their intention to undertake efforts to guarantee access to (life-saving) medicines in the context of pandemics, it seems there is an increasing degree of state practice recognising their responsibility in ensuring access to (life-saving) medicines in the context of pandemics. It is however unclear whether this recognition follows from the belief that it constitutes a legal obligation, i.e. opinio juris, or merely from a moral obligation.

\section{Conclusion: A Human Right of Access to Medicines?}

This chapter addressed the research question whether and how international human rights law protects a right of access to (essential) medicines. This question can be answered in the affirmative and as such we can speak of a "right of access to

\footnotetext{
598 WTO GENERAL COUNCIL, Amendment of the TRIPS Agreement (WT/L/641; 2005).

599 See WTO COUNCIL FOR TRADE-RELATED ASPECTS OF INTELLECTUAL PROPERTY RIGHTS, Annual Review of the Decision on the Implementation of Paragraph 6 of the Doha Declaration on TRIPS and Public Health $(\mathrm{IP} / \mathrm{C} / 63 ; 2012)$ at $\S 7$. See for up to date information the website of the WTO.

600 BHATT, 'Amending TRIPS: A New Hope for Increased Access to Essential Medicines', at 623624. See for a more detailed discussion on the Doha Declaration on TRIPS and Public Health and the proposed amendment to the TRIPS Agreement chapter 5, section 5.1.

601 UN GENERAL ASSEMBLY, Resolution 65/1, (UN Doc. A/RES/65/1) at §78(t).
} 
medicines". There are a number of sources which protect access to essential medicines in varying degrees. The most obvious and logical starting point is article 12 ICESCR, which includes a right of access to essential medicines as part of the minimum core content of the right to health. In addition to ICESCR, other international human rights treaties containing health rights have also been interpreted to include access to medicines. The conclusion that access to medicines is a right under international human rights law is supported by the analysis of other sources, particularly the right to life, the right to benefit from science and customary international law. However, the exact scope of a right of access to medicines differs depending on the source. For example under the right to health states parties to the ICESCR are obliged to ensure access to essential medicines, while under the right to life the scope is narrowed down to access to life-saving medicines. Under a possibly emerging customary right, state practice is mainly concerned with access to medicines in the context of pandemics such as HIV/AIDS, tuberculosis and malaria. 


\section{Chapter 4 \\ The TRIPS AgReEMENT: \\ Patent Protection for Pharmaceuticals}

\section{INTRODUCTION}

The previous chapter examined the issue of access to medicines from the perspective of human rights. We concluded that access to essential medicines is indeed protected under international human rights law, most notably under the right to health. Access was shown to have different dimensions: availability, physical accessibility, affordability, acceptability, and quality. It is particularly with regard to the element of affordability of essential medicines that this dissertation focuses on. Namely, as was shown in chapter 2, patent protection for medicines interferes with patients' access to such medicines. This is argued on the basis that patents negatively affect access due to the fact that they in many cases result in higher medicine prices, and consequently the unaffordability of medicines in the context of developing countries facing severe resource constraints.

With respect to the problem of lack of access to medicines, countries, in essence, have two options. They can either assist individuals in buying the medicines they need, for example by granting financial aid, financing the health care system or providing certain medicines free of charge, or they can ensure the that the price of medicines is a low as possible. Ideally states should use both options in order to ensure patients have adequate access, yet the first option is resource intensive which is particularly problematic for developing and least-developed countries. The second option is therefore more feasible. One manner in which medicine prices can be regulated is by curtailing patent protection for such medicines.

This chapter will therefore take a closer look at the patenting of pharmaceutical products and processes. The focus here is on the Agreement on Trade-Related Aspects of Intellectual Property Rights within the framework of the World Trade Organisation. The reason for focusing primarily on the TRIPS Agreement is that it is one of the most recent and far-reaching international agreements within the field of intellectual property protection. It is the first international instrument to comprehensively set out substantive minimum standards for protection of intellectual property rights. The inclusion of intellectual property into the multilateral trading system has had far-reaching consequences. Except for least-developed members, all members of the WTO are required to implement the TRIPS Agreement and its minimum standards of IP protection, which has greatly influenced domestic developments in the field of patent protection for pharmaceuticals. ${ }^{602}$ Moreover, the

602 The TRIPS Agreement contains a number of transitional arrangements, particularly for developing and least-developed WTO members (see articles 65 and 66 of the TRIPS Agreement); 
WTO has widespread membership throughout the world, making the TRIPS one of the most influential agreements in the area of IP protection. At the time of writing (April 2013) the WTO had 159 members. ${ }^{603}$ Furthermore, contrary to previous conventions dealing with intellectual property, the agreements concluded within the WTO framework are subject to a robust dispute settlement mechanism.

The research question addressed in this chapter is the following: what standards, with respect to the patenting of pharmaceuticals, does the TRIPS Agreement require WTO members to implement in their national legal system; and what flexibility exists within the scope of the TRIPS Agreement for members to balance patent protection for pharmaceuticals and a right of access to medicines?

\section{The World Trade Organization}

The inclusion of intellectual property within the framework of the WTO is one of the most significant developments in the area of IP protection. Therefore this section aims to set out the context and background in which to put the TRIPS Agreement and the minimum standards it requires members to implement. The negotiation of TRIPS started from two opposing standpoints; developed countries aimed at more effective international regulation of IP while developing countries attempted to lower existing standards of IP protection (see section 2.1.). A second crucial consequence of the inclusion of IPRs into the WTO is that the WTO set up a robust dispute settlement mechanism (see section 2.2) - a marked difference compared to the weak and ineffective monitoring system within the UN human rights framework.

International regulation of IP protection already occurred in the late $19^{\text {th }}$ century with the adoption of the 1883 Paris Convention for the Protection of Industrial Property and 1886 Berne Convention for the Protection of Literary and Artistic Works. However, more than half a century later developed countries started voicing their concerns about the effectiveness of the international IP framework arguing that the existing IP conventions were inadequate. The Paris and Berne Conventions do not contain minimum standards and lack detailed rules on domestic enforcement of IPRs, nor was there an effective system of dispute settlement to deal with disputes between member states under the conventions. ${ }^{604}$ Moreover membership under the Paris Convention was far from universal, and a lack of harmonisation on all aspects of patent legislation resulted in a lack of protection. Due to these

moreover, as a result of the 2001 Doha Declaration on the TRIPS Agreement and Public Health, the TRIPS Council extended the transitional period for least-developed members in the area of patenting of pharmaceuticals to 2016. More recently, the TRIPS Council further extended the transition period under article 66.1 TRIPS for least-developed members to 1 July 2021. See for more information section 3.3 of this chapter.

603 See www.wto.org/english/thewto_e/whatis_e/tif_e/org6_e.htm.

604 GERVAIS, The TRIPS Agreement: Drafting History and Analysis, at 10. 
perceived shortcomings of the existing international IP framework, many developed countries desired to strengthen the international IP system.

However, progress within the World Intellectual Property Organisation - the most obvious forum to achieve such a goal - was slow due to the difficulty to reach an agreement. Consequently, developed countries turned to another forum: the General Agreement on Tariffs and Trade (GATT). Similar to the developments in international human rights law, the development of international economic law took off after World War II. The severe economic crisis in the late 1920s is seen to be a leading factor of the outbreak of World War II. Once the war ended, international action was taken: institutions were set up to ensure that such a tragedy would never repeat itself again. A number of these institutions were set up with the intention to safeguard the world economic order and included the International Monetary Fund, the International Bank for Reconstruction and Development and the International Trade Organisation. The first two were established in 1944 during the Bretton Woods Conference. Although the latter never made it into existence, agreement was found for the conclusion of the GATT Agreement, adopted in 1947 with the intention to promote free, non-discriminatory trade in goods. The 1947 GATT was founded on the "theory of comparative advantage" which argues that free trade benefits all nations. In addition to provisions on tariffs and import barriers to free up global trade, it also contained a dispute resolution mechanism. ${ }^{605}$

The 1947 GATT's main focus was free trade in goods, although a few intellectual property provisions were also incorporated. ${ }^{606}$ Traditionally IPRs were regarded as impediments to free trade. This view corresponds to the notion of IPRs as found in article XX(d) of the 1947 GATT Agreement: under the heading "General Exceptions" it states that members are allowed to restrict free trade in goods in certain instances, for example to protect intellectual property rights. Thus, IPRs were considered an acceptable impediment to free trade. ${ }^{607}$ It is therefore rather remarkable that IP protection was included at the Tokyo and Uruguay Round negotiations of the former GATT system, which in 1995 led to the establishment of the WTO - an international organisation committed to liberalising trade worldwide with a view to promoting sustainable economic development.

605 Ibid. at 4; HESTERMEYER, Human Rights and the WTO, at 41-42.

606 GERVAIS, The TRIPS Agreement: Drafting History and Analysis, at 5 et seq.

607 CARLOS M. CORREA, Trade-Related Aspects of Intellectual Property Rights: A Commentary on the TRIPS Agreement, eds Prof. Philip Alston, Prof. Vaughan Lowe, and Prof. Robert House (Oxford Commentaries on International Law. GATT/WTO Agreements; New York: Oxford University Press, 2007) at 2; KATHARINA GAMHARTER, Access to Affordable Medicines: Developing Responses under the TRIPS Agreement and EC Law (Europainstitut Wirtschaftsuniversität Wien Publication Series, Vol. 25; Vienna: SpringerWienNewYork, 2004) at 7; HESTERMEYER, Human Rights and the WTO, at 43; JAYASHREE WATAL, Intellectual Property Rights in the WTO and Developing Countries (The Hague/London/Boston: Kluwer Law International, 2001) at 14; GERVAIS, The TRIPS Agreement: Drafting History and Analysis, at 8. 
This process of including IPRs in the WTO framework through the negotiation of the TRIPS Agreement will be briefly set out in the following section. There has been much criticism about the negotiation process, especially with respect to the relatively weak negotiation position of developing countries.

\subsection{Negotiation Process of the TRIPS Agreement}

Emerging competition during the 1970s and 80s particularly from East Asia and Latin America gave rise to concerns in the developed world; such as in the US which was particularly concerned about the growing international trade in counterfeit trademarked products and its effect on trade revenues. During the Tokyo Round (1973-1979) developed countries proposed the introduction of an anticounterfeiting treaty into the GATT framework. ${ }^{608}$ However, no agreement could be reached. On the initiative of the US and Japan, the possibility of including IPRs in the GATT setting was introduced. The US concerned about the increasing competitiveness of developing countries both in traditional and high technology markets pushed for the integration of developing countries in the world trading system, wanting them to give up their special and differential position and adopt reciprocity in international trade. ${ }^{609}$ A number of developing countries, directed by Brazil, India and Argentina, objected strongly to this development. ${ }^{610}$ They argued that the WIPO setting was the correct place to discuss IP protection, not the GATT. 611 However, this argument did not take hold. Developing countries had been trying to negotiate a revision of the Paris Convention within the WIPO setting to lower standards of IP protection since the mid-70s. However, they had been unsuccessful in that regard. In effect, this was the end of any attempts to lower or weaken international standards of IP protection. ${ }^{612}$

Subsequently, the 1986 GATT "Ministerial Declaration on the Uruguay Round of Multilateral Trade Negotiations" included a mandate for negotiating "TradeRelated Aspects of Intellectual Property Rights". The basic assumption for the negotiation of such an Agreement was the desire "to reduce distortions and impediments to international trade, and taking into account the need to promote effective and adequate protection of intellectual property rights, and to ensure that measures and procedures to enforce intellectual property rights do not themselves become barriers to legitimate trade, the negotiations shall aim to clarify GATT

608 GERVAIS, The TRIPS Agreement: Drafting History and Analysis, at 8-9.

609 WATAL, IPRs in the WTO and Developing Countries, at 19.

610 GERVAIS, The TRIPS Agreement: Drafting History and Analysis, at 11.

611 ALFREDO ILARDI and MICHAEL BLAKENEY, International Encyclopaedia of Intellectual Property Treaties (Oxford: Oxford University Press, 2004) at 166.

612 ADRONICO O. ADEDE, 'Origins and History of the TRIPS Negotiations', in Christophe Bellmann, Graham Dutfied, and Ricardo Meléndez-Ortiz (eds.), Trading in Knowledge. Development Perspective on TRIPS, Trade and Sustainability (London: Earthscan Publications,

146 2003) at 24-25; GAMHARTER, Access to Affordable Medicines, at 8-9; WATAL, IPRs in the WTO and Developing Countries, at 15-17. 
provisions and elaborate as appropriate new rules and disciplines." ${ }^{\prime 13}$ This initial mandate was rather limited, and fact that it resulted in the TRIPS Agreement in the end is remarkable. ${ }^{614}$

Between 1987 and 1989 negotiations progressed slowly. ${ }^{615}$ It became apparent that some countries ${ }^{616}$ wanted a far-reaching agreement, while a number of developing countries ${ }^{617}$ expressed concerns about high levels of IP protection, possibly hindering technology transfer and increasing the cost of, among others, pharmaceutical products. The 1989 mid-term ministerial conference in Geneva reflected the broadened scope of the Punta del Este Declaration to encompass the following in the negotiations: the applicability of the basic principles of the GATT and relevant international IP conventions; providing adequate standards and principles concerning all substantive aspects of IPRs such as availability, scope and use; providing effective and appropriate means for the enforcement of IPRs; providing effective and expeditious procedures for the multilateral prevention and settlement of disputes; and transitional arrangements aiming at the fullest participation in the results of the negotiations. Furthermore, "Ministers agree that in the negotiations consideration will be given to concerns raised by participants related to the underlying public policy objectives of their national systems for the protection of intellectual property, including development and technological objectives." $" 618$

Both developed and developing countries tabled opposing proposals trying to influence the end product. ${ }^{619}$ It became quickly obvious that the historical divide between north and south with regard to IP protection still existed, and it would not be easily resolved during the negotiations. ${ }^{620}$ In the first half of 1990 the European Communities tabled a proposal which was the beginning of the work towards a TRIPS Agreement which covered all aspects of IPRs. Soon after, the US tabled a very similar proposal. ${ }^{621}$ Eventually the main structure found in both proposals would serve as the basis for the agreement under negotiation. An additional three proposals were tabled, from Japan, Switzerland and a group of developing countries. ${ }^{622}$ However the developing countries were unable to agree on a detailed

613 GATT, Punta Del Este Ministerial Declaration (20 September 1986). As confirmed by the Preamble of the TRIPS.

614 GERVAIS, The TRIPS Agreement: Drafting History and Analysis, at 11-12.

615 Ibid. at 14.

616 Mostly developed countries, including the US, Switzerland, EC and Japan.

617 I.e. Thailand, Mexico and Brazil.

618 GATT TRADE NEGOTIATIONS COMMITTEE, Multilateral Trade Negotiations. The Uruguay Round. Meeting at Level of High Officials, (Geneva, 5-8 April 1989).

619 GAMHARTER, Access to Affordable Medicines, at 10-11.

620 HESTERMEYER, Human Rights and the WTO, at 45.

621 It is said that the similarity of EC and US proposal seems to suggest that there had been consultations between the EC and the US before tabling both proposals. See GERVAIS, The TRIPS Agreement: Drafting History and Analysis, at 17.

622 These developing countries included: Argentina, Brazil, Chile, China, Colombia, Cuba, Egypt, India, Nigeria, Pakistan, Peru, Tanzania, Uruguay, and Zimbabwe. See ADEDE, 'Origins and 
common text and submitted a compromise text far too general to really be able to oppose the strong submissions made by the developed countries. ${ }^{623}$

Developed countries argued that due to weak IP systems in developing countries, an additional form of trade distortions existed. Innovators intending to export their product to foreign markets with such a weak IP system might be deterred from doing so since piracy in developing countries was quite common. In addition, they were concerned about the fact that some of those pirated products found their way back into developed markets, where they were offered at very low prices destroying any incentive patent protection provided. Thus, it was argued that the benefits secured through the 1947 GATT Agreement were negated because of the lack of strong IP protection in the developing world. Developed countries did not only object to the lack of adequate IP protection, especially in developing countries, but they also objected to the lack of appropriate enforcement mechanisms. ${ }^{624}$ Although developed countries regulated IP issues differently within their own national context, they were able to unite on this issue and determined to reach an acceptable result. An effort fundamentally supported by the concerns of industry within those countries, including the pharmaceutical sector which had become largely dependent on IP protection. ${ }^{625}$

Developing countries feared that implementing higher levels of IP protection would unduly strengthen the right-holders position, limit access to, and transfer of knowledge to their country. They argued that including substantive IP standards would entail giving up part of their sovereign power to decide on national developmental goals and deny them the chance to develop. It was argued that such issues should be discussed in the WIPO forum, not the GATT. They were able to oppose the inclusion of substantive IP issues for a short period of time but their strategy was much less coordinated and certainly not as effective as that of the developed countries. ${ }^{626}$ Developing countries demanded that pharmaceutical patents were excluded from the agreement under negotiation due to public health reasons. They argued that even industrialised countries did not introduce patent protection for pharmaceuticals until the late $20^{\text {th }}$ century enabling them to develop a strong local pharmaceutical industry. The inclusion of patents for pharmaceuticals would thus remove the opportunity for developing countries to develop their own local industry. This argument, however, was not regarded by the developed world. ${ }^{627}$

In return for the inclusion of IP protection within the WTO negotiations, the developed world offered the developing world trade concessions by increasing

History of the TRIPS Negotiations', at 28; GERVAIS, The TRIPS Agreement: Drafting History and Analysis, at 17. 
market access, especially for agricultural products and textiles. This would not have been possible within the WIPO setting. Moreover, the strong negotiation position of developed countries in the GATT setting cannot be underestimated. ${ }^{628}$ In the US particularly the pharmaceutical and entertainment industries were very much involved in strengthening IPRs in trade relations; and a strong industrial lobby convinced the US government of the linkage between IPRs and trade. ${ }^{629}$ In 1984, the US made an amendment to section 301 of the its 1974 Trade Act, permitting the US president to demand action against unjustifiable or unreasonable trade practices, specifically including IP issues. The US Trade Representative (USTR) annually reviews all US' trading partners, and those that do not provide adequate and effective IP protection are included on a so-called "watch list", and if these trade practices are considered especially serious in nature they are on the "priority watch list". Countries listed on the "watch list" are closely monitored; and those listed on the "priority watch list" are contacted directly to conduct bilateral negotiations in order to remedy the weak or ineffective domestic system of IP protection. Nonagreement on this matter can result in further investigations and even trade sanctions in the form of increased duties or import restrictions. During such investigations, the USTR relies heavily on information provided to it by US industry associations, like the International Intellectual Property Alliance (IIPA) or the Pharmaceutical Research and Manufacturers of America (PhRMA). Particularly, the lack of patent protection for pharmaceutical products in a number of developing countries led to investigations and/or the adoption of trade sanctions, for example in Brazil in 1985, Argentina in 1988 and Thailand in 1989. This was (and still is) a very effective strategy employed by the US and strengthened its position during the Uruguay Round negotiations. ${ }^{630}$ As a result, developing countries increasingly accepted that a multilateral system providing for an objective dispute settlement mechanism to resolve any trade conflicts with respect to IPRs would probably be more beneficial in the long-run. ${ }^{631}$

Consequently, developing countries accepted the inclusion of IP protection in the negotiations, yet progress was still slow due to the all or nothing nature of the process of negotiation. The breakthrough came in June 1990 when Lars Anell, Chairman of the negotiation group, distributed his paper which identified the main proposals tabled and the substantive differences between them. The formal document reflected the position's of both the developed countries (the " $\mathrm{A}$ " approach) and developing countries (the "B" approach). The "A" approach adopted the structure found in the EC' and US' proposals and covered all aspects of IPRs,

\footnotetext{
628 CORREA, Trade-Related Aspects of IPRs: A Commentary on the TRIPS Agreement, at 52; HESTERMEYER, Human Rights and the WTO, at 45-47.

629 CORREA, Trade-Related Aspects of IPRs: A Commentary on the TRIPS Agreement, at 16, 91.

630 HESTERMEYER, Human Rights and the WTO, at 40; ILARDI and BLAKENEY, International Encyclopaedia of Intellectual Property Treaties, at 168-169; WATAL, IPRs in the WTO and Developing Countries, at 18, 24-26.

631 ADEDE, 'Origins and History of the TRIPS Negotiations', at 31.
} 
including acquisition, enforcement and application of GATT principles like the national treatment and most favoured nation treatment principles. Differences between proposals tabled by industrialised countries were indicated by squarebrackets and became known as "North - North" issues. The "B" approach favoured by developing countries was fundamentally different. Instead of a single agreement covering all IP issues, they envisaged two agreements: one on trade in counterfeit and pirated goods and a second on the availability, scope and use of IPRs. ${ }^{632}$

The negotiations continued both in a formal and informal setting, and by the end of 1990 negotiations were advancing swiftly in time for the Brussels Ministerial meeting. ${ }^{633}$ Negotiations in other sectors of the Round, however, did not proceed as quickly and as a result the Brussels meeting failed to conclude the Round. When the Round restarted there were still a great number of IP issues open to debate. Four major issues emerged: patent protection for pharmaceutical products, dispute settlement, transitional arrangements for developing countries, and protection of geographical indications. ${ }^{634}$ At the end of 1991 the Director General of the GATT, Dunkel, intended to conclude the negotiations by drafting a Final Act, including a proposal for an Agreement on Trade-related Aspects of Intellectual Property Rights. ${ }^{635}$ Reactions were mostly positive. However, the US pharmaceutical industry were concerned by the transitional arrangements and demanded "pipeline" or retroactive protection in developing countries during the transitional periods for new pharmaceutical and agricultural products. India, on the other hand was concerned about restrictions on compulsory licensing despite the transitional arrangements. Until the last minute both the US and India pushed for amendments to the draft expressing their concerns yet without avail. As such the Dunkel draft, with some minor modifications, became the basis for the TRIPS Agreement which was finally adopted. ${ }^{636}$ The negotiations to establish the WTO were based on the idea of a "single undertaking" meaning that the WTO Agreement could only be adopted by members in a "single package approach". Thus potential members either had to adopt all agreements or not become a member to the WTO: "a take-it-orleave-it" approach. And so, the Uruguay Round ended in 1994 in Marrakech with the establishment of the World Trade Organisation. The WTO is a single undertaking, firstly on a political level referring to the method of negotiation, i.e. nothing is agreed until everything is agreed, and secondly from a legal perspective referring to the fact that the results of the negotiations form a single package to be implemented as one treaty. ${ }^{637}$ The WTO includes not only rules on free trade in goods (GATT 1994) but also rules on the free trade in services (GATS), intellectual

GERVAIS, The TRIPS Agreement: Drafting History and Analysis, at 18-20.

See further ibid. at 20-23.

Ibid. at 23.

ILARDI and BLAKENEY, International Encyclopaedia of Intellectual Property Treaties, at 169-170; WATAL, IPRs in the WTO and Developing Countries, at 35-36.

GERVAIS, The TRIPS Agreement: Drafting History and Analysis, at 26-27.

GABRIELLE MARCEAU, 'WTO Dispute Settlement and Human Rights', European Journal of International Law, 13:4 (2002), 753-814 at 772. 
property rights (TRIPS), dispute settlement and a trade policy review mechanism. The TRIPS Agreement entered into force on the January $1^{\text {st }}, 1995$ as an annex to the WTO Agreement; it contains a number of transitional arrangements, particularly for developing and least-developed WTO members (see articles 65 and 66 of the TRIPS Agreement). ${ }^{638}$

\subsection{Dispute Settlement}

A key reason for the inclusion of IPRs within the WTO framework, especially for developed countries, was the lack of enforcement mechanisms within existing IP conventions. Nor did these conventions require any form of domestic enforcement of IPRs. The TRIPS Agreement remedies this shortcoming and obliges members to provide domestic enforcement procedures. ${ }^{639}$ In addition, the TRIPS Agreement in article 64 states that articles XXII and XXIII of the 1994 GATT, as elaborated by the Understanding on Rules and Procedures for the Settlement of Disputes (DSU), are applicable. ${ }^{640}$ The following section will give a brief description of the WTO Dispute Settlement Mechanism and the effects of WTO membership for developing countries particularly in relation to enforcement of their obligations under the TRIPS Agreement. ${ }^{641}$

The WTO agreements are based on the notion of reciprocal and mutually advantageous economic benefits through trade liberalisation. As such, the principal objective of the WTO dispute settlement mechanism is to reinstall a situation in

638 See for more information section 3.3 of this chapter.

639 UNCTAD-ICTSD, Resource Book on TRIPS and Development, at 578. See further section 3.6. of this chapter regarding the minimum standards prescribed by the TRIPS Agreement with respect to the enforcement of IPRs covered by the Agreement.

640 Article 64 of the TRIPS Agreement reads as follows:

1. The provisions of Articles XXII and XXIII of GATT 1994 as elaborated and applied by the Dispute Settlement Understanding shall apply to consultations and the settlement of disputes under this Agreement except as otherwise specifically provided herein.

2. Subparagraphs 1(b) and 1(c) of Article XXIII of GATT 1994 shall not apply to the settlement of disputes under this Agreement for a period of five years from the date of entry into force of the WTO Agreement.

3. During the time period referred to in paragraph 2, the Council for TRIPS shall examine the scope and modalities for complaints of the type provided for under subparagraphs $1(\mathrm{~b})$ and 1(c) of Article XXIII of GATT 1994 made pursuant to this Agreement, and submit its recommendations to the Ministerial Conference for approval. Any decision of the Ministerial Conference to approve such recommendations or to extend the period in paragraph 2 shall be made only by consensus, and approved recommendations shall be effective for all Members without further formal acceptance process.

641 See for more information MOHAMED OMAR GAD, 'TRIPS Dispute Settlement and Developinc Country Interests', in Carlos M. Correa and Abdulqawi A. Yusuf (eds.), Intellectual Property and International Trade: The TRIPS Agreement (Aphen aan den Rijn: Kluwer Law International, 2008). 
which every member can fully enjoy the benefits it is entitled to under WTO law. ${ }^{642}$ The jurisdiction of the WTO dispute settlement mechanism is compulsory, ${ }^{643}$ exclusive $^{644}$ and only for contentious cases. ${ }^{645}$ The DSU provides a detailed and rules-based procedure consisting of different phases, each subject to mandatory timeframes. ${ }^{646}$

The first phase of this procedure is the consultation phase: preference is given to resolving disputes amicably without recourse to adjudication. Therefore, WTO dispute settlement proceedings start with the members involved in the dispute entering into consultations (or at least attempting to have consultations) with a view of reaching a mutually satisfactory solution. ${ }^{647}$ If a mutually agreed solution cannot be reached within 60 days, or the responding party refuses to engage in consultations, the complainant may request the WTO's Dispute Settlement Body (DSB) to establish a dispute settlement panel. ${ }^{648}$ The request must contain an identification of the specific measure(s) complained of, as well as the legal basis for such a complaint. ${ }^{649}$

Herewith the parties to the dispute enter the second phase of the procedure: examination by a panel. ${ }^{650}$ A panel usually consists of three independent and highly qualified trade experts. ${ }^{651}$ Selecting the panellists is often a time-consuming

642 See also Article 3.7 DSU, which reads as follows: Before bringing a case, a Member shall exercise its judgement as to whether action under these procedures would be fruitful. The aim of the dispute settlement mechanism is to secure a positive solution to a dispute. A solution mutually acceptable to the parties to a dispute and consistent with the covered agreements is clearly to be preferred. In the absence of a mutually agreed solution, the first objective of the dispute settlement mechanism is usually to secure the withdrawal of the measures concerned if these are found to be inconsistent with the provisions of any of the covered agreements. The provision of compensation should be resorted to only if the immediate withdrawal of the measure is impracticable and as a temporary measure pending the withdrawal of the measure which is inconsistent with a covered agreement. The last resort which this Understanding provides to the Member invoking the dispute settlement procedures is the possibility of suspending the application of concessions or other obligations under the covered agreements on a discriminatory basis vis-à-vis the other Member, subject to authorization by the DSB of such measures. 
exercise since both parties must agree on the selected individuals. ${ }^{652}$ If one of the parties to the dispute is a developing country, the developing country member may request to include at least one panellist to be from a developing country. ${ }^{653}$ The Panel will examine the dispute according to the terms of reference, which are important in that they define the scope of the panel's mandate. ${ }^{654}$ The panel is only authorised to rule on the provisions explicitly mentioned in the terms of reference. ${ }^{655}$ The panel's function is to assist the DSB in discharging its functions under the DSU and covered agreements. Consequently, "a panel should make an objective assessment of the matter before it, including an objective assessment of the facts of the case and the applicability of and conformity with the relevant covered agreements". ${ }^{656}$ In line herewith panels should consult regularly with the parties to the dispute and give them adequate opportunity to develop a mutually satisfactory solution. Once the panel has examined the dispute ${ }^{657}$ and reached a conclusion it will issue an interim report to the parties including both the descriptive sections and the panel's findings and conclusions. The parties may submit comments and request a review of precise aspects of the interim report, after which the panel issues the final report to the parties and, once it is available in the three working languages of the WTO, circulates it to the DSB. 658 "Within 60 days after the date of circulation of a panel report to the Members, the report shall be adopted at a DSB meeting" unless one of the parties to the dispute has signalled its intention to appeal or the DSB decides by consensus not to adopt report. 659

If a party decides to appeal the panel report, the process proceeds to the third phase, the appellate phase. ${ }^{660}$ A party to the dispute may appeal the decision of the panel, however, only on issues of law and legal interpretation, not fact. ${ }^{661}$ The appeal is heard by the standing WTO Appellate Body (AB), whose members are persons of recognised authority, with demonstrated expertise in law, international trade and the subject matter of the covered agreements generally. ${ }^{662}$ As a general rule, the appellate review is not supposed to exceed 60 days from the date the party to the dispute formally notifies its decision to appeal to the date the $\mathrm{AB}$ circulates

\footnotetext{
652 Article 8.6 and 8.7 DSU.

653 Article 8.10 DSU.

654 Article 7 DSU.

655 WTO Appellate Body Report, India - Patent Protection for Pharmaceutical and Agricultural Chemical Products, adopted 16 January 1998, WT/DS50/AB/R at $\S 92$.

656 Article 11 DSU.

657 See for the panel procedures article 12 and Appendix 3 of the DSU.

658 Article 15 DSU.

659 Article 16.4 which further reads: If a party has notified its decision to appeal, the report by the panel shall not be considered for adoption by the DSB until after completion of the appeal. This adoption procedure is without prejudice to the right of Members to express their views on a panel report.

660 See further VAN DEN BOSSCHE and ZDOUC, The Law and Policy of the World Trade Organisation, at 283 et seq.

661 Article 17.6 DSU.

662 Article 17.1 and 17.3 DSU.
} 
its report; furthermore, even in exceptional circumstances the proceedings shall in no case exceed 90 days. ${ }^{663}$ The AB's final report must be unconditionally accepted by the parties to the dispute unless the DSB decides by consensus not to adopt the report. ${ }^{664}$ Although the DSU provides limited time periods for each step of the process experience shows that cases do take much longer than the possible 18-20 months. ${ }^{665}$

The DSU defines the mandate (jurisdiction) of the WTO judicial bodies (panels and the Appellate Body) with reference to the allegations of WTO violations by complaining members, the specific type of remedies and conclusions the judicial bodies may recommend, and the prohibition on adding to or diminishing WTO law. ${ }^{666}$ The starting point is article $3.2 \mathrm{DSU}$, which mandates the WTO dispute settlement system "to clarify the existing provisions of those agreements in accordance with customary rules of interpretation of public international law."667 Furthermore it states that "the DSB cannot add to or diminish the rights and obligations provided in the covered agreements." 668 WTO jurisprudence has confirmed that the DSU requires the WTO adjudicative bodies to clarify existing provisions within WTO law in accordance with customary rules of interpretation of public international law. ${ }^{669}$

The competence or jurisdiction of the WTO adjudicative bodies is distinct of the concept of 'applicable law' within the WTO dispute settlement system. ${ }^{670}$ Jurisdiction of international adjudicative bodies is generally limited to specific types of disputes, or disputes arising from certain treaties. The jurisdiction of the WTO judicial bodies is limited to disputes arising from the WTO covered agreements. ${ }^{671}$ The concept of applicable law is the system of legal rights and

\section{Article 17.5 DSU.}

664 Article 17.14 DSU.

665 WATAL, IPRs in the WTO and Developing Countries, at 60-63.

666 MARCEAU, 'WTO Dispute Settlement and Human Rights', at 762.

667 Article 3.2 DSU reads as follows: The dispute settlement system of the WTO is a central element in providing security and predictability to the multilateral trading system. The Members recognize that it serves to preserve the rights and obligations of Members under the covered agreements, and to clarify the existing provisions of those agreements in accordance with customary rules of interpretation of public international law. Recommendations and rulings of the DSB cannot add to or diminish the rights and obligations provided in the covered agreements.

668 See also Article 19.2 DSU: In their findings and recommendations panels and the Appellate Body cannot add to or diminish the rights and obligations provided in the covered agreements.

669 See further VAN DEN BOSSCHE and ZDOUC, The Law and Policy of the World Trade Organisation, at 184 et seq.

670 MARCEAU, 'WTO Dispute Settlement and Human Rights', at 766.

671 See articles 1.1, 3.2 and 11 of the DSU. INTERNATIONAL LAW COMMISSION, Fragmentation of International Law, (UN Doc. A/CN.4/L.682) at §45; PAUWELYN, Conflict of Norms in Public International Law, at 443 et seq; VAN DEN BOSSCHE and ZDOUC, The Law and Policy of the World Trade Organisation, at 163.

Marceau ask the question whether the violation of a human rights provision, although not a breach of WTO law, could nullify and impair the benefits resulting from the covered agreement, 
obligations binding on WTO members, as WTO members, which can be enforced before the WTO judicial bodies who have the exclusive jurisdiction over WTO matters. ${ }^{672}$ The limited jurisdiction of the WTO dispute settlement system - to claims arising from the covered agreements only - does not necessarily imply a limited scope of the applicable law in the interpretation and application of the covered agreements. ${ }^{673}$ Moreover, as opposed to for example article 38 of the Statute of the ICJ, there is no explicit provision within the WTO DSU identifying the scope of applicable law. ${ }^{674}$

Only WTO members have access to the WTO dispute settlement mechanism and according to article 1.1 DSU only disputes arising under the covered agreements, including the TRIPS Agreement, are subject to the WTO dispute settlement system. Article 64.1 TRIPS states: "[t]he provisions of Articles XXII and XXIII of GATT 1994 as elaborated and applied by the Dispute Settlement Understanding shall apply to consultations and the settlement of disputes under this Agreement except as otherwise specifically provided herein." 675

Article XXIII:1 of the GATT 1994 provides a WTO Member recourse to the dispute settlement mechanism if it considers "any benefit accruing to it directly or indirectly under this Agreements is being nullified or impaired or that the attainment of any objective of the Agreement is being impeded" as a result of three types of actions: ${ }^{676}$

a) The first cause of action is a complaint which alleges that a member has violated a provision of a covered agreement, including a TRIPS obligation, resulting in the nullification or impairment of benefits and thus harming the complainant

and thus form the basis of a WTO non-violation claim? She finds that most doubtful. See MARCEAU, 'WTO Dispute Settlement and Human Rights', at 768.

672 Ibid., at 755.

673 INTERNATIONAL LAW COMMISSION, Fragmentation of International Law, (UN Doc. A/ CN.4/L.682) at \$45; PAUWELYN, Conflict of Norms in Public International Law, at 460. See further section 5.2. of chapter 5 .

674 INTERNATIONAL LAW COMMISSION, Fragmentation of International Law, (UN Doc. A/ CN.4/L.682) at §45; PAUWELYN, Conflict of Norms in Public International Law, at 465.

675 See further CORREA, Trade-Related Aspects of IPRs: A Commentary on the TRIPS Agreement, at 479 et seq; VAN DEN BOSSCHE and ZDOUC, The Law and Policy of the World Trade Organisation, at 172 et seq.

676 Article XXIII GATT 1994:

1. If any Member should consider that any benefit accruing to it directly or indirectly under this Agreement is being nullified or impaired or that the attainment of any objective of the Agreement is being impeded as the result of

(a) the failure of another Member to carry out its obligations under this Agreement, or

(b) the application by another Member of any measure, whether or not it conflicts with the provisions of this Agreement, or

(c) the existence of any other situation,

the Member may, with a view to the satisfactory adjustment of the matter, make written representations or proposals to the other Member or Members which it considers to be concerned. 
(the violation cause of action). ${ }^{677}$ The claimant does not have to demonstrate nullification or impairment of a benefit; it is presumed that when a WTO Member violates a WTO obligation the result is nullification or impairment. ${ }^{678}$

b) Secondly, a complaint may allege that although a member has not violated a specific provision its actions nullified or impaired the benefits provided by the covered agreements (the non-violation cause of action). The DSU limits the possible remedies in case of a non-violation cause of action: the defendant member may not be obliged to withdraw or amend a non-violating national measure. It could, however, be faced with the withdrawal of concessions by the complaining member. ${ }^{679}$ There have only been very few non-violation complaints brought to the WTO, none of which were successful. ${ }^{680}$

c) Finally, a complaint may allege that nullification or impairment of benefits is "the result of the existence of any other situation". This third and last cause of action, the so-called situation cause of action, has never been the basis of a dispute. ${ }^{681}$

Regarding the latter two, the TRIPS Agreement provides in article 64.2 that, for five years after entry into force of the Agreement, non-violation or situation complaints shall not be applicable in the TRIPS context. ${ }^{62}$ Article 64.3 further stated that the TRIPS Council should make a recommendation on these types of actions to the Ministerial Conference. At the 2001 Doha Ministerial Conference it was decided that the TRIPS Council must continue its work on this recommendation for the fifth Ministerial Conference and until that time no such causes of actions were allowed. Since then, the members have not been able to reach consensus and the moratorium has been extended from one ministerial conference to the next, the latest being the extension from the 2011 Geneva Ministerial Conference to the next meeting, which ministers agreed to hold in 2013. Developing members have opposed the possibility of non-violation complaints as they fear it would result in a widely increased range of complaints brought against them. ${ }^{683}$

UNCTAD-ICTSD, Resource Book on TRIPS and Development, at 664 et seq.

See article 3.8 DSU: In cases where there is an infringement of the obligations assumed under a covered agreement, the action is considered prima facie to constitute a case of nullification or impairment. This means that there is normally a presumption that a breach of the rules has an adverse impact on other Members parties to that covered agreement, and in such cases, it shall be up to the Member against whom the complaint has been brought to rebut the charge.

Article 26 DSU.

VAN DEN BOSSCHE and ZDOUC, The Law and Policy of the World Trade Organisation, at 175.

Ibid.

See further CORREA, Trade-Related Aspects of IPRs: A Commentary on the TRIPS Agreement, at 488; UNCTAD-ICTSD, Resource Book on TRIPS and Development, at 668 et seq.

FREDERICK M. ABBOTT, 'Dispute Settlement', in UN Conference on Trade And Development (ed.), World Trade Organisation. 3.14 TRIPS (New York/Geneva: United Nations, 2003) at 36-37. 
According to article 64.1 TRIPS violation complaints are applicable to the TRIPS Agreement. Thus, TRIPS is justiciable and fully enforceable before the WTO dispute settlement system. Following GATT practice, the underlying rationale for violation complaints is to protect members' expectation as to the competitive relationship between their own and foreign products. When the competitive relationship is upset this leads to a nullification or impairment of the benefits accruing to that member whose nationals, products or services suffer due to a deterioration of competitive conditions. This competitive relationship is reflected in the legal obligations as set up by the WTO and is upset if: one member violates (one of) its WTO obligations, the violation cannot be justified (for example through article 30 or 31 TRIPS), and has an adverse impact on the member whose rights have been violated. ${ }^{684}$

In order for a member to establish that the competitive relationship is upset, the complainant must prove the existence of a violation of a WTO obligation. If it is able to do so, it is prima facie presumed that the respondent has nullified or impaired benefits accruing to the complainant without requiring the complainant to provide evidence as to the adverse impact of respondent's actions. ${ }^{685}$ The only way for the respondent to rebut the presumption of nullification or impairment is by demonstrating that there is no violation of a WTO obligation or that the violation can be justified.

If a national measure is considered to be inconsistent with a WTO obligation, the panel or Appellate Body will recommend that the member bring its measure into conformity with WTO requirements. They may also recommend ways in which the inconsistency can be remedied. ${ }^{686}$ The member must comply with these recommendations immediately, ${ }^{687}$ if this is not possible a reasonable time frame for completion of the recommendations is set. ${ }^{68}$ If the recommendations and rulings adopted by the DSB are not implemented by the violating member within a reasonable period of time, the parties to the dispute shall enter into negotiations with a view to coming to mutually acceptable compensation. In case no agreement can be reached, the complainant may request authorisation from the DSB to withdraw trade or other concessions. These measures, however, are temporary remedies which can be applied awaiting the withdrawal or modification of the WTO inconsistent measure(s). ${ }^{689}$ Thus, the application of the DSU allows for measures of

\footnotetext{
684 UNCTAD-ICTSD, Resource Book on TRIPS and Development, at 664-665.

685 Article 3.8 DSU.

686 Article 19 DSU. See further VAN DEN BOSSCHE and ZDOUC, The Law and Policy of the World Trade Organisation, at 194 et seq and 291 et seq.

687 Article 21.1 DSU.

688 Article 21.3 DSU. "Where there is disagreement as to the existence or consistency with a covered agreement of measures taken to comply with the recommendations and rulings such dispute shall be decided through recourse to these dispute settlement procedures, including wherever possible resort to the original panel." See article 21.5 DSU. 
commercial retaliation for a violation of WTO law, including cross-retaliation. ${ }^{690}$ In such cases, the breach of a TRIPS obligation by one member may result in the withdrawal of concessions in another sector of essential importance to its own industries, such as exports of certain goods such as textiles or agricultural products. Therefore, from the developed members' perspective the possibility of crossretaliation is a very powerful tool to ensure that developing members comply with their TRIPS obligations. Yet this sword cuts both ways in that developed members are equally obliged to comply with their WTO obligations and may be subject to dispute settlement under the DSU initiated by a developing member. There are limitations though to the use of the dispute settlement system by developing members against an economically stronger developed member. Practically, because of a lack of domestic human resources, developing countries tend to turn to foreign experts for the purpose of dispute settlement thereby incurring high costs. More importantly, however, is the limited value of cross-retaliation for developing members. As a result of developing members' comparative economic weakness visà-vis developed members, the DSB's authorisation to suspend concessions to a developed member will likely have a more adverse effect on the developing members' economy than on that of the developed member. ${ }^{691}$ It is therefore argued that the DSB should put pressure on developed members to pay compensation which would represent an actual benefit to the developing member. ${ }^{692}$

Furthermore, and of particular relevance for developing members is article 23 of the DSU which stipulates that members cannot take unilateral measures or countermeasures if a member allegedly breaches a WTO obligation, but they must have recourse to the WTO dispute settlement system. ${ }^{693}$ Accordingly, developing

690 UNCTAD-ICTSD, Resource Book on TRIPS and Development, at 667-668.

691 VAN DEN BOSSCHE and ZDOUC, The Law and Policy of the World Trade Organisation, at 203.

692 UNCTAD-ICTSD, Resource Book on TRIPS and Development, at 688-689.

693 Article 23 DSU reads as follows:

1. When Members seek the redress of a violation of obligations or other nullification or impairment of benefits under the covered agreements or an impediment to the attainment of any objective of the covered agreements, they shall have recourse to, and abide by, the rules and procedures of this Understanding.

2. In such cases, Members shall:

(a) not make a determination to the effect that a violation has occurred, that benefits have been nullified or impaired or that the attainment of any objective of the covered agreements has been impeded, except through recourse to dispute settlement in accordance with the rules and procedures of this Understanding, and shall make any such determination consistent with the findings contained in the panel or Appellate Body report adopted by the DSB or an arbitration award rendered under this Understanding;

(b) follow the procedures set forth in Article 21 to determine the reasonable period of time for the Member concerned to implement the recommendations and rulings; and

(c) follow the procedures set forth in Article 22 to determine the level of suspension of concessions or other obligations and obtain DSB authorization in accordance with those procedures before suspending concessions or other obligations under the covered 
members should no longer be confronted with unilateral assessment by developed members of their domestic implementation of TRIPS standards, although this is still a recurring practice. ${ }^{694}$

The value of the WTO dispute settlement system to the security and predictability of the world trading system is uncontested. If the success of the system is determined by the frequency of use, we can conclude that the system established by the DSU has done rather well. Yet if one disaggregates the users of the system it becomes clear that developed countries are in the majority partly due to the limitations for developing members as mentioned above; although it must be mentioned here that there is great disparity among developing members and it would be too simple to group all developing members into one category. For example, some developing members, such as Brazil, Mexico, India, China, Argentina, Thailand and Chile, have increasingly made use of the system and have also been successful. ${ }^{695}$ Moreover, it has also been argued that the participation of developing members in the systems is a reflection of a broad range of factors and that the major challenge for developing countries to use the system effectively are linked to their domestic governance. ${ }^{696}$

Consequently developing members could strengthen their position within the WTO by bringing allegations as to TRIPS violations before the WTO dispute settlement system where they will be assessed on the basis of the law by the impartial WTO adjudicatory bodies contributing to the predictability and transparency of the dispute settlement system. ${ }^{697}$

\section{The Agreement on Trade-Related Aspects of Intellectual Property Rights}

Chapter 2 of this dissertation demonstrated the manner in which the patenting of medicines may interfere with patients' access to such medicines. Moreover, with the adoption of the TRIPS Agreement within the WTO framework - being the first international instrument to set out minimum standards of protection for IP - all

\footnotetext{
agreements in response to the failure of the Member concerned to implement the recommendations and rulings within that reasonable period of time.

694 Unfortunately we see that particularly the US still makes use of this strategy via its section 301 of the 1974 Trade Act. See further chapter 5, section 6.

695 JAN BOHANES and FERNANDA GARZA, 'Going Beyond Stereotypes: Participation of Developing Countries in WTO Dispute Settlement', Trade, Law and Development, 4:1 (2012), 45-124 at 56; VAN DEN BOSSCHE and ZDOUC, The Law and Policy of the World Trade Organisation, at 299.

696 BOHANES and GARZA, 'Going Beyond Stereotypes', at 116-117.

697 UNCTAD-ICTSD, Resource Book on TRIPS and Development, at 686. See further MELISSA BLUE SKY, 'Developing Countries and Intellectual Property Enforcement Measures: Improving Access to Medicines through WTO Dispute Settlement', Trade, Law and Development, 3:2 (2011), 407-440 at 425 et seq.
} 
WTO members, subject to the transitional periods, are obliged to implement TRIPS' standards within their domestic legislative framework. Consequently, the manoeuvring room to adapt the national IP system to the needs of the WTO member in question has been significantly limited. This might prove problematic particularly for developing countries. It is continuously asserted, particularly by the pharmaceutical industry, that a strong patent system is essential for the pharmaceutical sector since it provides an incentive to innovate by allowing innovators to recoup their substantial research and development costs. On the other hand, as long as there is no real profit to be made with treatments targeted at diseases mainly prevalent in developing countries, even the introduction of a (more stringent) patent system for pharmaceuticals will not necessarily be incentive enough to produce more health R\&D targeted at developing countries' needs. ${ }^{698}$ Furthermore, it is questioned whether in low-income countries, without significant technological and scientific capacities, increased IP protection leads to increased foreign investment and trade, technology transfer, and economic growth. However, it is not the aim of this research to determine the merits of a patent system. The fact of the matter is that with the adoption of TRIPS, WTO members have a legal obligation under international law to incorporate the minimum standards provided for by TRIPS. Therefore, the research question posed is the following: what standards, with respect to the patenting of pharmaceuticals, does the TRIPS Agreement require WTO members to implement in their national legal system; and what flexibility exists within the scope of the TRIPS Agreement for members to balance patent protection for pharmaceuticals and a right of access to medicines?

First of all, TRIPS is an agreement established within the framework of the WTO, the objectives of which are to reduce barriers and discrimination in trade in order to promote economic development and improve standards of living, with attention to sustainable development, and with special attention to the needs of developing countries. ${ }^{699}$ The preamble to the TRIPS Agreement, which closely follows the 1986 Punta del Este Declaration, lists a number of principles and objectives that underline TRIPS. Firstly it states one of the main objectives for adopting the TRIPS Agreement: to reduce international trade distortions and impediments by introducing strong IP protection. It expresses the need for adequate standards and principles concerning the availability, scope and use of IPRs; the need for appropriate and effective means for the enforcement of IPRs; that IPRs are private rights, and it strengthens the commitments to resolve disputes in a multilateral context. Yet it also maintains that, although strong protection of IPRs is necessary, over-protection of IP can have the opposite effect leading to distortions

698 HESTERMEYER, Human Rights and the WTO, at 163; CIPR, Integrating Intellectual Property Rights and Development Policy, at 33; TROUILLER et al., 'Drug Development for the Neglected Diseases', at 2191-2192; SCHERER and WATAL, Post-TRIPS Options for Access to Patented Medicines in Developing Countries, at 11-12.

See the preamble to the Agreement Establishing the World Trade Organisation. 
and barriers in international trade. ${ }^{700}$ As such it reflects the contentious nature of the negotiation process. ${ }^{701}$ Consequently, it recognises the necessity to find a balance: a balance between free trade and IP protection, between the needs of highly developed and still developing and least-developed countries, and between the private rights of the right holders and underlying public policy objectives, including technological and developmental objectives of national systems of IP protection..$^{702}$ Of course the protection of IP is itself a matter of public interest ${ }^{703}$ and it is only justified to restrict IPRs when the level of IP protection has become excessive and no longer serves the objectives as outlined in the preamble. In line with article 31.2 of the VCLT the preamble is an essential and integral part of the TRIPS Agreement and a source of interpretative guidance in the process of implementation and dispute settlement. ${ }^{704}$

The TRIPS Agreement provides minimum standards of IP protection in the field of copyright and related rights, trademarks, geographical indications, industrial designs, patents, layout designs of integrated circuits, protection of undisclosed information, and control of anti-competitive practices in contractual licences. For the issue discussed here, section 5 of part II of the TRIPS Agreement on patents is essential. In addition to these minimum standards TRIPS also covers enforcement, acquisition and maintenance of IPRs, dispute prevention and settlement, transitional arrangements and institutional arrangements.

\subsection{General Provisions and Basic Principles}

Article 1 TRIPS sets out the nature and scope of WTO members obligations under TRIPS and states the following:

Members shall give effect to the provisions of this Agreement. Members may, but shall not be obliged to, implement in their law more extensive protection than is required by this Agreement, provided that such protection does not contravene the provisions of this Agreement. Members shall be free to determine the appropriate method of implementing the provisions of this Agreement within their own legal system and practice.

As such, it first implicitly reiterates the international legal obligation to perform an agreement in good faith. ${ }^{705}$ Secondly, it permits members - but does not oblige

700 See the first paragraph of the Preamble to the TRIPS Agreement: Desiring to reduce distortions and impediments to international trade, and taking into account the need to promote effective and adequate protection of intellectual property rights, and to ensure that measures and procedures to enforce intellectual property rights do not themselves become barriers to legitimate trade. UNCTAD-ICTSD, Resource Book on TRIPS and Development, at 2 et seq.

702 GAMHARTER, Access to Affordable Medicines, at 69; GERVAIS, The TRIPS Agreement: Drafting History and Analysis, at 158.

703 GAMHARTER, Access to Affordable Medicines, at 70.

704 GERVAIS, The TRIPS Agreement: Drafting History and Analysis, at 154 et seq.

705 The obligation to perform in good faith or "pacta sunt servanda" is a rule of customary international law codified in article 26 of the VCLT. CORREA, Trade-Related Aspects of IPRs: 
them - to provide more extensive protection than required by TRIPS, provided that such higher standards of protection do not contravene the Agreement's provisions. ${ }^{706}$ The wording of article 1.1 TRIPS is very clear that more extensive protection is optional. Thirdly, it leaves the manner of implementation up to the discretion of the members; and as such members have a degree of flexibility to implement and interpret TRIPS in line with national legal systems and policy objectives, as long as TRIPS' minimum standards are guaranteed and implementation is "appropriate" within the national context. ${ }^{707}$ In that regard, developing countries have argued that they "should be free to implement the TRIPS Agreement in ways that best accommodate the protection of health policies in national legislation." 708

It must be clearly stated that the TRIPS Agreement does not provide for a harmonised system of IP protection. However, it does oblige all WTO members, irrespective of their degree of development, to apply the same minimum standards, which has received much criticism..$^{709}$ The implementation of TRIPS has been, and still is, a difficult task, especially for developing countries, since it may require an extensive reform of a substantial part of domestic IP legislation in a relatively short period of time. ${ }^{710}$ For developing countries, the minimum standards required by TRIPS limits the possibility to benefit from weak(er) intellectual property standards until they reached a higher level of development, as for example industrialised countries did in the years before introducing strict standards for IPRs. ${ }^{711}$ Moreover, TRIPS limits members' sovereign powers in areas of economic policy of importance when it comes to the issue of access to medicines. ${ }^{712}$

A Commentary on the TRIPS Agreement, at 22; UNCTAD-ICTSD, Resource Book on TRIPS and Development, at 17.

706 More extensive protection of intellectual property is within the literature often referred to as TRIPS-plus standards. See for example UNCTAD-ICTSD, Resource Book on TRIPS and Development, at 17.

707 CORREA, Trade-Related Aspects of IPRs: A Commentary on the TRIPS Agreement, at 24, 27; GERVAIS, The TRIPS Agreement: Drafting History and Analysis, at 164; UNCTAD-ICTSD, Resource Book on TRIPS and Development, at 18. See with regard to the "appropriate method of implementing" the TRIPS Agreement also the Appellate Body Report in the India - Patent Protection for Pharmaceutical and Agricultural Chemical Products case, WT/DS50/AB/R, where the AB found that India's freedom to decide on the appropriate manner of implementation is not equal to a right to self-certify compliance with TRIPS obligations.

708 WTO COUNCIL FOR TRADE-RELATED ASPECTS OF INTELLECTUAL PROPERTY RIGHTS, Submission by the African Group, Barbados, Bolivia, Brazil, Cuba, Dominican Republic, Ecuador, Honduras, India, Indonesia, Jamaica, Pakistan, Paraguay, Philippines, Peru, Sri Lanka, Thailand and Venezuela (IP/C/W/296; 2001) at 8.

CORREA, Trade-Related Aspects of IPRs: A Commentary on the TRIPS Agreement, at 8.

710 Ibid. at $23-24$.

711 UNCTAD-ICTSD, Resource Book on TRIPS and Development, at 35.

712 GAMHARTER, Access to Affordable Medicines, at 17. See for a discussion on the relationship between free trade agreements that go beyond the level of protection required by TRIPS (TRIPS-plus) and the potential impact thereof on states' sovereignty to decide their own health priorities, FONS COOMANS, 'Sovereignty Fading Away? Prioritising Domestic Health Needs 
The TRIPS Agreement was the first agreement to substantively set out minimum standards for protecting IP, but it was not the first agreement concluded in the area of IP protection. Not all WTO members had contracted to earlier IP treaties though. TRIPS refers to a number of such earlier IP treaties, obliging members to comply with or not derogate from certain obligations laid down in those treaties, even if they had not initially contracted to that agreement. ${ }^{713}$ As a result, the substantive provisions established by the 1883 Paris Convention for the Protection of Industrial Property (Paris Convention), have been incorporated within the TRIPS framework and are binding for WTO members. ${ }^{714}$ As such, TRIPS has been described as a "Paris/Berne-plus" agreement. ${ }^{715}$ Furthermore, article 2.2 TRIPS ensures that state parties to the Paris Convention comply with the obligations set out therein, even if they go beyond TRIPS' minimum standards. ${ }^{716}$

Article 3 and 4 of the TRIPS Agreement reiterate two basic principles which are both cornerstones of the WTO legal system and thus also TRIPS: the national treatment and most-favoured nation treatment principle. First, the national treatment principle - article 3 TRIPS - is a non-discrimination principle establishing that members must treat nationals of other members at least as favourable as it treats its own nationals with respect to the protection of IP. Although as a basic principle it is not absolute but it is subject to a number of exceptions already provided in earlier IP treaties. ${ }^{717}$ Fundamentally, this provision prohibits members from discriminating

Versus Promoting Free Trade', in Ineke Boerefijn and Jenny Goldschmidt (eds.), Changing Perceptions of Sovereignty and Human Rights: Liber Amicorum Cees Flinterman (Antwerp: Intersentia, 2008).

713 See article 2 TRIPS:

1. In respect of Parts II, III and IV of this Agreement, Members shall comply with Articles 1 through 12, and Article 19, of the Paris Convention (1967).

2. Nothing in Parts I to IV of this Agreement shall derogate from existing obligations that Members may have to each other under the Paris Convention, the Berne Convention, the Rome Convention and the Treaty on Intellectual Property in Respect of Integrated Circuits.

See also WTO Apellate Body Report, United States - Section 211 Omnibus Appropriations Act of 1998, adopted 1 February 2002, WT/DS176/AB/R at $\$ 125$.

714 In addition, nothing in the TRIPS Agreement with regard to basic principles, substantive standards, acquistion, maintenance and enforcement of IPRs shall derogate from existing obligations that Members may have to each other under the Paris Convention, the Berne Convention, the Rome Convention and the Treaty on Intellectual Property in Respect of Integrated Circuits. Important obligations in the area of patents are found in articles $4 \& 5$ of the Paris Convention for the Protection of Industrial Property. Article 4A sets out the principle of priority for a period of 12 months, and article 4 bis the principle of independence. Article 5 lays down the rules, among others, with regard to forfeiture and compulsory licensing.

715 GERVAIS, The TRIPS Agreement: Drafting History and Analysis, at 175; HESTERMEYER, Human Rights and the WTO, at 52.

716 UNCTAD-ICTSD, Resource Book on TRIPS and Development, at 50.

717 See article 3 TRIPS which reads as follows:

1. Each Member shall accord to the nationals of other Members treatment no less favourable than that it accords to its own nationals with regard to the protection of intellectual property, subject to the exceptions already provided in, respectively, the Paris Convention (1967), the Berne Convention (1971), the Rome Convention or the Treaty on Intellectual Property in 
against nationals from other WTO members and has been a foundation of international IP law, such as the Paris and Berne Convention, long before TRIPS was concluded. ${ }^{718}$ Article 3 encompasses both de jure as well as de facto discrimination. ${ }^{719}$ Second, the most-favoured-nation treatment (MFN) principle article 4 TRIPS - is a founding principle of the GATT system, although it is new to the IP framework. ${ }^{720}$ Unlike the national treatment principle, the MFN principle is not found in pre-TRIPS IP conventions, but it originates from the GATT framework and was initially applied to trade in goods. It is a fundamental principle of the world trading system and with the conclusion of TRIPS, it now also applies to the field of IPRs. ${ }^{721}$ It establishes that "any advantage, favour, privilege or immunity granted by a Member to the nationals of any other country shall be accorded immediately and unconditionally to the nationals of all other members", subject to the exceptions provided for in article $4 .{ }^{722}$ It intends to ensure that WTO members are accorded no less favourable treatment compared to nationals of any other member, and so ensure uniformity within the international trading system. In both articles, the prohibition

Respect of Integrated Circuits. In respect of performers, producers of phonograms and broadcasting organizations, this obligation only applies in respect of the rights provided under this Agreement. Any Member availing itself of the possibilities provided in Article 6 of the Berne Convention (1971) or paragraph 1(b) of Article 16 of the Rome Convention shall make a notification as foreseen in those provisions to the Council for TRIPS.

2. Members may avail themselves of the exceptions permitted under paragraph 1 in relation to judicial and administrative procedures, including the designation of an address for service or the appointment of an agent within the jurisdiction of a Member, only where such exceptions are necessary to secure compliance with laws and regulations which are not inconsistent with the provisions of this Agreement and where such practices are not applied in a manner which would constitute a disguised restriction on trade.

United States - Section 211 Omnibus Appropriations Act of 1998, at \$237-241; CORREA, Trade-Related Aspects of IPRs: A Commentary on the TRIPS Agreement, at 52; GERVAIS, The TRIPS Agreement: Drafting History and Analysis, at 179 et seq.

UNCTAD-ICTSD, Resource Book on TRIPS and Development, at 75 et seq.

Ibid. at 77 et seq.

United States - Section 211 Omnibus Appropriations Act of 1998, at \$297; CORREA, TradeRelated Aspects of IPRs: A Commentary on the TRIPS Agreement, at 66; GERVAIS, The TRIPS Agreement: Drafting History and Analysis, at 188 et seq.

722 See article 4 TRIPS:

With regard to the protection of intellectual property, any advantage, favour, privilege or immunity granted by a Member to the nationals of any other country shall be accorded immediately and unconditionally to the nationals of all other Members. Exempted from this obligation are any advantage, favour, privilege or immunity accorded by a Member:

(a) deriving from international agreements on judicial assistance or law enforcement of a general nature and not particularly confined to the protection of intellectual property;

(b) granted in accordance with the provisions of the Berne Convention (1971) or the Rome Convention authorizing that the treatment accorded be a function not of national treatment but of the treatment accorded in another country;

(c) in respect of the rights of performers, producers of phonograms and broadcasting organizations not provided under this Agreement;

(d) deriving from international agreements related to the protection of intellectual property which entered into force prior to the entry into force of the WTO Agreement, provided that 
on discrimination relates to a broad range of issues, including the availability and scope of IPRs and their acquisition, use, maintenance, and enforcement; furthermore, they were not subject to the transitional periods and article 3 and 4 TRIPS came into force for all WTO members, including developing and leastdeveloped, on January $1^{\text {st }}, 1996 .{ }^{723}$

Problematic with respect to the MFN principle is the question whether IPRs exceeding the level of protection required by TRIPS, established through the conclusion of bilateral or regional trade agreements (so-called TRIPS-plus standards), are also subject to the MFN principle. Must a member who has adopted a bilateral or regional TRIPS-plus agreement accord the same TRIPS-plus standards of IP protection to WTO members not party to that bilateral agreement? In case the bilateral TRIPS-plus agreement was concluded after the entry into force of the WTO Agreement, the exception of article 4(d) TRIPS does not apply and this would seem to be the case. ${ }^{724}$ That would mean, for example, that a developing country that has concluded a FTA with a developed country, both WTO members, committing itself to TRIPS-plus standards must accord the same treatment, that is apply the TRIPS-plus provisions to all WTO members leading to the a global development of ever increasing standards of IP protection, referred to as the IP upward ratchet. ${ }^{725}$

Last to be addressed in this section is article 6 of the TRIPS Agreement which gives members the freedom, subject to articles 3 and 4 TRIPS, to decide freely how to address the issue of exhaustion of IPRs. ${ }^{726}$ It specifically states that for the purposes of dispute settlement the issue of exhaustion of IPRs is excluded. This does not mean though, that the issue of exhaustion of IPRs cannot be the subject of an action brought before a national court. ${ }^{727}$ The principle of exhaustion essentially entails that once a good or service protected by an IPR has legally been sold or

such agreements are notified to the Council for TRIPS and do not constitute an arbitrary or unjustifiable discrimination against nationals of other Members.

Furthermore, what exactly constitutes an "advantage" regarding the protection of intellectual property is not entirely clear. See CORREA, Trade-Related Aspects of IPRs: A Commentary on the TRIPS Agreement, at 72; UNCTAD-ICTSD, Resource Book on TRIPS and Development, at 78.

723 See footnote 3 to articles 3 \& 4 TRIPS; and articles 65 \& 66 TRIPS.

724 UNCTAD-ICTSD, Resource Book on TRIPS and Development, at 88. However, authors like Correa argue that such an interpretation would be "troublesome", since rights and advantages granted in bilateral agreements would be extended to WTO members not party to the bilateral agreement, without any trade concessions in concern. He, moreover, argues that the mostfavoured nation treatment principle is limited by the coverage of the TRIPS Agreement. See CORREA, Trade-Related Aspects of IPRs: A Commentary on the TRIPS Agreement, at 69-70.

725 See for more information SUSAN K. SELL, The Global IP Upward Ratchet, Anti-Counterfeiting and Piracy Enforcement Efforts: The State of Play (2008).

726 Article 6 TRIPS: For the purposes of dispute settlement under this Agreement, subject to the provisions of Articles 3 and 4 nothing in this Agreement shall be used to address the issue of the exhaustion of intellectual property rights.

727 CORREA, Trade-Related Aspects of IPRs: A Commentary on the TRIPS Agreement, at 78; UNCTAD-ICTSD, Resource Book on TRIPS and Development, at 105. 
marketed (with the consent of the right holder), the right holder's exclusive rights are exhausted, i.e. his control over the good or service is terminated, permitting the free transfer of the good or service.

The exclusion of exhaustion of IPRs from the scope of dispute settlement was a compromise solution between developed countries (particularly the US and Switzerland) which wanted the TRIPS to establish a national exhaustion regime and other mostly developing countries (particularly Australia, Brazil, India, New Zealand) which wanted an international regime. ${ }^{728}$ This principle of 'exhaustion of rights' is readily accepted in the national context, meaning that for example a patented product which is legally placed on the domestic market exhausts the patent holder's rights with regard to that product nationally, however not in other legal systems. Thus, according to the principle of national exhaustion, placing a protected good on the market exhausts the right holder's rights but only in the legal system where the protected good has been marketed. As such, this principle gives right holders the power to prevent the movement of protected goods and as such segregates markets. ${ }^{729}$ Yet, there is a second doctrine: ${ }^{730}$ the principle of international exhaustion which entails that once a protected product is placed on any market worldwide, the intellectual property right is exhausted. ${ }^{731}$ This latter doctrine allows for so-called parallel imports $;{ }^{732}$ that is the possibility to import a product protected by an IPR into a country, without the authorisation of the right holder, once that product has been legally placed on any foreign market. This international principle of exhaustion has sparked some controversy especially regarding possible parallel importation of patented pharmaceuticals, which will be further discussed below.

728 LUIS MARIANO GENOVESI, 'The TRIPS Agreement and Intellectual Property Rights Exhaustion', in Carlos M. Correa (ed.), Research Handbook on the Protection of Intellectual Property under WTO Rules. Intellectual Property in the WTO Volume 1 (Research Handbooks on the WTO; Cheltenham/Northampton: Edward Elgar, 2010) at 218; GERVAIS, The TRIPS Agreement: Drafting History and Analysis, at 199.

729 An IPR can have the same effect as a quota. A system of national exhaustion of IPRs, allowing right holders to block importation of goods, could thus be considered in breach with article XI of the 1994 GATT Agreement. Article 6 TRIPS is clear that it precludes the issue of exhaustion of IPRs to be subject to dispute settlement under this agreement, i.e. the TRIPS Agreement. This interpretation would allow a GATT panel to address the issue. However, a different view contends that the TRIPS Agreement is a lex specialis, preventing a GATT panel of examining the issue of exhaustion. No WTO jurisprudence exists on this matter, so the issue is still open. UNCTAD-ICTSD, Resource Book on TRIPS and Development, at 94, 104-105.

730 In fact there is also a third type of exhaustion: regional exhaustion, which exists in specific regions, for example free trade regions like NAFTA and the EU.

731 Some authors argue that the recognition of a principle of international exhaustion of IPRs is a "logical reflection of the globalisation of the economy." See CORREA, Trade-Related Aspects of IPRs: A Commentary on the TRIPS Agreement, at 79; UNCTAD-ICTSD, Resource Book on TRIPS and Development, at 94.

732 See CORREA, Trade-Related Aspects of IPRs: A Commentary on the TRIPS Agreement, at 78; UNCTAD-ICTSD, Resource Book on TRIPS and Development, at 93. 
The TRIPS Agreement: Patent Protection for Pharmaceuticals

\subsection{Objectives and Principles}

The objectives and purpose of the TRIPS Agreement can be firstly found in the preamble to the Agreement: namely to reduce international trade distortions and impediments by introducing IP protection. Yet it also states that although strong protection or IPRs is necessary, over-protection of IP can have the opposite effect leading to distortions and barriers in international trade. ${ }^{733}$ Thus, it recognises the need to find a balance between the protection of intellectual property, as private rights, and public policy objectives and the special needs of least-developed countries regarding maximum flexibility. In addition to the preamble, articles 7 and 8 TRIPS set out the objectives and principles underlying the Agreement. Together they attempt to find a compromise between the sometimes conflicting positions of developed and developing countries. ${ }^{734}$ This is reflected in the wording of article 7 TRIPS, which was one of the main proposals made by developing countries and reads as follows:

The protection and enforcement of intellectual property rights should contribute to the promotion of technological innovation and to the transfer and dissemination of technology, to the mutual advantage of producers and users of technological knowledge and in a manner conducive to social and economic welfare, and to a balance of rights and obligations.

This provision contains a number of elements, namely that the objective of protecting and enforcing IPRs is to promote innovation, transfer and dissemination of technology, to benefit social and economic welfare and that a balance between rights and obligations should be achieved. It again enforces the justification of strong IPRs as incentives for technological innovation but also refers to the initial concerns brought forward by developing countries with regard to dissemination and transfer of technologies and knowledge.

The wording of article 7 - "protection and enforcement of IPRs should contribute to" - could be interpreted to mean that this provision is of a more promotional nature and does not have a significantly higher status than any clause in the preamble. However, as this provision is incorporated in the first part of TRIPS titled "General Provision and Basic Principles" and not in the preamble, this interpretation seems unjustified. The placement of this provision does indicate a

733 See the first paragraph of the Preamble to the TRIPS Agreement: Desiring to reduce distortions and impediments to international trade, and taking into account the need to promote effective and adequate protection of intellectual property rights, and to ensure that measures and procedures to enforce intellectual property rights do not themselves become barriers to legitimate trade.

734 CORREA, Trade-Related Aspects of IPRs: A Commentary on the TRIPS Agreement, at 91. For an overview of the negotiation history with regard to articles $7 \& 8$ TRIPS see UNCTADICTSD, Resource Book on TRIPS and Development, at 118 et seq. 
heightening of its legal status. ${ }^{735}$ That said, its placement does not change the wording of article 7 and whether it may be used to curtail the scope of a "shall" or equivalent provision is questionable. ${ }^{736}$ Moreover, the use of the term "should" also seems to indicate that IPRs do not automatically contribute to technological innovation and the dissemination and transfer thereof, but in the overall context of TRIPS it should do so. ${ }^{737}$ Thus, the promotion of technological innovation in itself should not be the sole aim of the TRIPS Agreement; the diffusion of knowledge gained through innovation and access thereto is equally important objective. ${ }^{738}$ In that line of reasoning, article 7 further states that IPRs should work to enhance "social and economic welfare", referring to higher societal values and to a "balance of rights and obligations". This explicit mention of the need to balance the rights and obligations under TRIPS indicates that IPRs are not considered as an end in themselves, but the means to the above stated objectives. ${ }^{739}$ Nor are IPRs absolute and a fair balance should be found. ${ }^{740}$

As opposed to article 7, article 8 TRIPS is formulated more strongly in that it provides members with the possibility to take action to protect and promote certain public policy objectives. It reads as follows: ${ }^{741}$

\section{Members may, in formulating or amending their laws and regulations, adopt measures necessary to protect public health and nutrition, and to promote the public interest in sectors of vital importance to their socio-economic and technological development, provided that such measures are consistent with the provision of this Agreement.}

With regard to the issue at hand - assessing whether TRIPS contains sufficient manoeuvring room for developing members to adapt their IP framework to their domestic needs, particularly the need to enhance access to affordable medicines this permission to take measures is of importance because it explicitly refers to the protection of public health. It does set out a number of requirements the measure must meet: first, the measure(s) must be taken in the form of laws or regulations; second, it must be "necessary" for the protection or promotion of the mentioned objectives; and, third, it must be consistent with the provisions of TRIPS. Paragraph 2 of article 8 is a more permissive provision in that it mandates measures of a

CORREA, Trade-Related Aspects of IPRs: A Commentary on the TRIPS Agreement, at 93. GAMHARTER, Access to Affordable Medicines, at 71; GERVAIS, The TRIPS Agreement: Drafting History and Analysis, at 203.

UNCTAD-ICTSD, Resource Book on TRIPS and Development, at 126. CORREA, Trade-Related Aspects of IPRs: A Commentary on the TRIPS Agreement, at 97. UNCTAD-ICTSD, Resource Book on TRIPS and Development, at 125-126.

CORREA, Trade-Related Aspects of IPRs: A Commentary on the TRIPS Agreement, at 101. Article 8.2 TRIPs reads further: Appropriate measures, provided that they are consistent with the provisions of this Agreement, may be needed to prevent the abuse of intellectual property rights by right holders or the resort to practices which unreasonably restrain trade or adversely affect the international transfer of technology. 
preventative or defensive nature in order to prevent abuse of IPRs by right holders, such as the failure to work a patent within a period of time not justified by legitimate reasons, ${ }^{742}$ and to prevent practices which unreasonably restrain trade and adversely affect the international transfer of technology. ${ }^{743}$ Both paragraphs are subject to the limitation that measures must be "consistent with the provisions" of TRIPS and as such does not provide a basis for broader exceptions not included in the TRIPS Agreement. ${ }^{74}$ Yet, where the TRIPS Agreement is silent or ambiguous, article 8.1 TRIPS can be useful for developing members as it can serve as a basis for adopting measures aimed at mitigating the adverse effects of IPRs on public health as long as these are consistent with TRIPS. ${ }^{745}$ In essence, article 8 confirms that the TRIPS Agreement does not, and should not, prevent members from taking measures to protect societal values such as public health and promoting access to medicines for all, which has been reiterated by the 2001 Doha Declaration on the TRIPS Agreement and Public Health. ${ }^{746}$

Consequently, both articles 7 and 8 are promising in that they provide developing members the flexibility to take those measures necessary to guarantee access to affordable medicines. However, although one should not underestimate the importance of both provisions, they cannot be interpreted as general exception clauses or a safeguard measure comparable to article XX GATT (or article XIV GATS) ${ }^{747}$ These articles were never intended to serve as exceptions, as can be seen by the use of wording such as "should" and "may". Thus, the importance of articles 7 and 8, and the preamble too, lies in the fact that they set out the Agreement's objectives and principles, and thus they provide the context for interpreting and implementing the TRIPS Agreement. ${ }^{748}$ This is a principle clearly established by customary rules of treaty interpretation and an approach also followed by the WTO adjudicative bodies in dispute settlement procedures although at times rather restrictively. ${ }^{749}$ The adoption of the Doha Declaration on the TRIPS Agreement and Public Health and its reference to articles 7 and 8 indicates a strengthening of the status of these provisions in that they reflect the importance of the interpretative value of the Agreement's objectives and principles and the need to

742 See article 5.A of the Paris Convention.

743 GALLEGO, 'Intellectual Property Rights and Competition Policy', at 234.

744 GERVAIS, The TRIPS Agreement: Drafting History and Analysis, at 209; HESTERMEYER, Human Rights and the WTO, at 58.

745 GAMHARTER, Access to Affordable Medicines, at 72-73; WATAL, IPRs in the WTO and Developing Countries, at 293-294.

746 WTO, Doha Declaration on TRIPS and Public Health, (WT/MIN(01)/DEC/2) at $\$ 4$.

747 HESTERMEYER, Human Rights and the WTO, at 58.

748 GERVAIS, The TRIPS Agreement: Drafting History and Analysis, at 209.

749 See Article 31 of the Vienna Convention on the Law of Treaties (1969) which reads:

1. A treaty shall be interpreted in good faith in accordance with the ordinary meaning to be given to the terms of the treaty in their context and in the light of its object and purpose.

2. The context for the purpose of the interpretation of a treaty shall comprise, in addition to the text, including its preamble and annexes: (a) any agreement relating to the treaty which was made between all the parties in connexion with the conclusion of the treaty; (b) any 
find a balance. ${ }^{750}$ Thus, in the context of developing countries attempting to take full advantage of TRIPS' flexibility to protect public health and guarantee access to affordable medicines, TRIPS' objectives and principles are of particular importance in interpreting the scope of existing obligations and exceptions under TRIPS, and they may therefore be of use when defending a member's use of the TRIPS flexibilities. ${ }^{751}$ It is also interesting as to what extent international human rights standards could, or maybe even should be taken into consideration when interpreting TRIPS' provisions. ${ }^{752}$

\subsection{Transitional Arrangements}

The TRIPS agreement attempts to strike a balance between different objectives promotion of technological innovation and the diffusion of knowledge gained through innovation and access thereto - and between the needs of developed and developing members. With regard to the latter, TRIPS takes the special needs of developing and least-developed members into account by providing differing transitional periods: the time period available for a WTO member to comply fully with the obligations set out by an Agreement, in this context the TRIPS Agreement. These transitional arrangements are automatically applicable, and prior notification or declaration by a state is not required. Moreover, the transitional arrangements are of particular importance for developing and least-developed members as a tool for special and differential treatment in favour of developing countries and LDCs. This is so because TRIPS, as the first WTO Agreement to the address protection of intellectual property, required a substantial effort from developing and leastdeveloped countries with regard to the implementation of TRIPS' obligations, especially since these countries often did not have the same tradition of IP protection as developed countries. ${ }^{753}$ In this section those provisions pertaining to

instrument which was made by one or more parties in connexion with the conclusion of the treaty and accepted by the other parties as an instrument related to the treaty.

See for example WTO Panel Report, Canada-Patent Protection for Pharmaceutical Products, adopted 7 April 2000, WT/DS114/R at \$7.26. See further CORREA, Trade-Related Aspects of IPRs: A Commentary on the TRIPS Agreement, at 93; GERVAIS, The TRIPS Agreement: Drafting History and Analysis, at 209; ILARDI and BLAKENEY, International Encyclopaedia of Intellectual Property Treaties, at 9-10; PETER K. YU, 'The Objectives and Principles of the TRIPS Agreement', in Carlos M. Correa (ed.), Research Handbook on the Protection of Intellectual Property under WTO Rules. Intellectual Property in the WTO Volume 1 (Research Handbooks on the WTO; Cheltenham/Northampton: Edward Elgar, 2010) at 171 et seq.

CORREA, Trade-Related Aspects of IPRs: A Commentary on the TRIPS Agreement, at 109; GERVAIS, The TRIPS Agreement: Drafting History and Analysis, at 207; WTO, Doha Declaration on TRIPS and Public Health, (WT/MIN(01)/DEC/2) at $\S 4 \& 5(\mathrm{a})$.

752 This issue will be further addressed in chapter 5. UNCTAD-ICTSD, Resource Book on TRIPS and Development, at 130.

753 Ibid. at 706-707. 
the transitional arrangements relevant for developing countries relating to the patenting of pharmaceuticals will be addressed. ${ }^{754}$

Article 65.1 of the TRIPS Agreement provides for a general one year implementation period from the date of entry into force (1 January 1995) of the Agreement for all members. ${ }^{755}$ Additionally, TRIPS provides for the possibility to extend the implementation periods for developing members, except with regards to articles 3, 4 and 5 TRIPS, for another four years. ${ }^{756}$ So, developed WTO members had until 1 January 1996 to incorporate all of TRIPS' obligations, while from that moment onwards all members must apply the obligations set forth in articles 3, 4 and 5 of the TRIPS Agreement. The exclusion of articles 3, 4 and 5 (relating to National Treatment, Most-Favoured Nation and Multilateral Agreements on Acquisition or Maintenance of IPRs respectively) from the transitional arrangements is an important exception to the rule. From the perspective of developed countries, direct implementation (that is after the general one year implementation period) of articles 3 and 4 TRIPS ensures a level playing field for right holders of IP (from developed countries) in developing countries and LDCs. ${ }^{757}$ Intellectual property right holders from developed countries may, thus, not be treated less favourable than domestic right holders, nor may they be treated less favourable compared to nationals from other WTO members.

In addition to the general one year implementation period which all states enjoyed, TRIPS provided three transitional periods especially for developing countries and least-developed countries: (1) Developing countries ${ }^{758}$ were allowed an additional four years from the date of entry into force of the TRIPS Agreement, until 1 January 2000, except for articles 3, 4 and 5 TRIPS as stated above. ${ }^{759}$ (2) Particularly important for pharmaceuticals is article 65.4 TRIPS, ${ }^{760}$ which allowed for an additional period of five years for developing members to introduce product

754 See further CORREA, Trade-Related Aspects of IPRs: A Commentary on the TRIPS Agreement, at 491 et seq.

755 See article 65.1 TRIPS: Subject to the provisions of paragraphs 2, 3 and 4, no Member shall be obliged to apply the provisions of this Agreement before the expiry of a general period of one year following the date of entry into force of the WTO Agreement.

756 See article 65.2 TRIPS: A developing country Member is entitled to delay for a further period of four years the date of application, as defined in paragraph 1, of the provisions of this Agreement other than Articles 3, 4 and 5.

757 UNCTAD-ICTSD, Resource Book on TRIPS and Development, at 713.

758 And "[a]ny other member [not necessarily a developing country] which is in the process of transformation from a centrally-planned into a market, free-enterprise economy and which is undertaking structural reform of its intellectual property system and facing special problems" in this regard may also benefit from this 4 year additional implementation period. See article 65.3 TRIPS.

759 Article 65.2 TRIPS.

760 Article 65.4 TRIPS reads as follows: To the extent that a developing country Member is obliged by this Agreement to extend product patent protection to areas of technology not so protectable in its territory on the general date of application of this Agreement for that Member, as defined in paragraph 2, it may delay the application of the provisions on product patents of Section 5 of Part II to such areas of technology for an additional period of five years. 
patents in areas of technology that formerly did not benefit from protection by product patents in that country, subject to the requirement to introduce a so-called "mail-box" or "black-box" system. ${ }^{761}$ Developing members that did not grant product patents for pharmaceuticals before the implementation of TRIPS would, thus, receive a total of ten years (until 1 January 2005) before being obliged to adapt their national legislation to incorporate product patents for pharmaceuticals. This transitional period could only be invoked by developing countries and only for products within areas of technology that before the application of TRIPS were excluded from product patent protection. (3) The final transitional period provided for by TRIPS is specifically targeted at least-developed countries and recognises their special needs by granting them a ten year period from the date of entry into force (until 1 January 2006) to implement all obligations under the TRIPS Agreement, except for articles 3, 4 and 5 TRIPS as stated above. ${ }^{762}$ In 2005 this transition period was extended to 1 July $2013 ;{ }^{763}$ and only recently (June 2013) to 1 July 2021. ${ }^{764}$ As a result of the 2001 Doha Declaration on the TRIPS Agreement and Public Health ${ }^{765}$ the TRIPS Council also decided to extend the transitional period further for least-developed countries in the area of patenting pharmaceuticals until 1 January 2016. ${ }^{766}$

761 Article 70.8 and 9 TRIPS.

762 See article 66.1 TRIPS which reads as follows: In view of the special needs and requirements of least-developed country Members, their economic, financial and administrative constraints, and their need for flexibility to create a viable technological base, such Members shall not be required to apply the provisions of this Agreement, other than Articles 3, 4 and 5, for a period of 10 years from the date of application as defined under paragraph 1 of Article 65. The Council for TRIPS shall, upon duly motivated request by a least-developed country Member, accord extensions of this period.

Additionally, article 65.5 TRIPS does not apply to article 66, and, thus also not to leastdeveloped countries, which left them free to roll back their level of IP protection and make full use of the transition periods. See also HESTERMEYER, Human Rights and the WTO, at 72; UNCTAD-ICTSD, Resource Book on TRIPS and Development, at 715.

763 See WTO COUNCIL FOR TRADE-RELATED ASPECTS OF INTELLECTUAL PROPERTY RIGHTS, Extension of the Transition Period under Article 66.1 for Least-Developed Country Members (IP/C/40; 2005).

764 Or until such a date on which they cease to be a least-developed country member, whichever date is earlier. See WTO COUNCIL FOR TRADE-RELATED ASPECTS OF INTELLECTUAL PROPERTY RIGHTS, Extension of the Transition Period under Article 66.1 for Least Developed Members (IP/C/64; 2013).

765 WTO, Doha Declaration on TRIPS and Public Health, (WT/MIN(01)/DEC/2) at §7.

766 WTO COUNCIL FOR TRADE-RELATED ASPECTS OF INTELLECTUAL PROPERTY RIGHTS, Extension of the Transition Period under Article 66.1 of the TRIPS Agreement for Least-Developed Country Members for Certain Obligations with Respect to Pharmaceutical Products (IP/C/25; 2002). Both the 2005 (IP/C/40) and 2013 (IP/C/64) decisions of the TRIPS Council to extend the transition period for least-developed members state that these decisions are without prejudice to the 2002 decision (IP/C/25) and to the right of least developed country Members to seek further extensions of the period provided for in paragraph 1 of Article 66 TRIPS. 
Although the term "developing country" is not defined by the WTO and categorisation occurs on the basis of self-selection, it is generally accepted that two thirds of all WTO members fall within this category, including countries like Brazil, India, South Africa and Thailand which are important providers of generic pharmaceuticals. With regard to categorising "least-developed countries", the WTO traditionally accepts that members designated as such by the United Nations fall within this category, including for example Uganda.

With respect to the patenting of pharmaceuticals these transitional periods were actually not as useful as they may have seemed to be at first glance. First, it must be shortly remarked that multinationals rarely obtain patents for products in countries that do not have the manufacturing capacity to produce such a product. Especially least-developed countries do not have the manufacturing capacity to produce pharmaceuticals and are thus no threat to pharmaceutical corporations. Without any competition there is little reason to obtain patent protection for pharmaceuticals in LDCs. ${ }^{767}$ Secondly, article 65.5 TRIPS prevents members from "rolling back" during the transition periods; therefore, if a developing member granted patents for pharmaceuticals before the implementation of TRIPS this could not be rolled back for the duration of the transitional period. ${ }^{768}$ More importantly, though, are the additional obligations provided for by the TRIPS Agreement notwithstanding the transitional periods applicable to the patenting of pharmaceuticals. ${ }^{769}$ That is, in case a member did not provide for patent protection for pharmaceutical and agricultural chemical products from the date of entry into force of the TRIPS Agreement, as required by article 27, that member shall, notwithstanding the transitional arrangements, "provide as from the date of entry into force of the WTO Agreement a means by which applications for patents for such inventions [of pharmaceutical and agricultural chemical products] can be filed". 770 This provision

767 HESTERMEYER, Human Rights and the WTO, at 72-73.

768 Article 65.5 TRIPS: A Member availing itself of a transitional period under paragraphs 1, 2, 3 or 4 shall ensure that any changes in its laws, regulations and practice made during that period do not result in a lesser degree of consistency with the provisions of this Agreement.

769 HESTERMEYER, Human Rights and the WTO, at 73.

770 Article 70.8 TRIPS reads as follows:

Where a Member does not make available as of the date of entry into force of the WTO Agreement patent protection for pharmaceutical and agricultural chemical products commensurate with its obligations under Article 27, that Member shall:

(a) notwithstanding the provisions of Part VI, provide as from the date of entry into force of the WTO Agreement a means by which applications for patents for such inventions can be filed;

(b) apply to these applications, as of the date of application of this Agreement, the criteria for patentability as laid down in this Agreement as if those criteria were being applied on the date of filing in that Member or, where priority is available and claimed, the priority date of the application; and

(c) provide patent protection in accordance with this Agreement as from the grant of the patent and for the remainder of the patent term, counted from the filing date in accordance with Article 33 of this Agreement, for those of these applications that meet the criteria for protection referred to in subparagraph (b). 
Chapter 4

established the so-called "mail box" or "black box" system, ${ }^{771}$ which requires members:

- to provide from the date of entry into force (so from 1 January 1995 onwards) for a means of filing applications for patents for pharmaceuticals and agricultural chemical inventions; 772

- "apply to these applications, as of the date of application of this [i.e. the TRIPS] Agreement, the criteria for patentability" as found in article 27, "as if those criteria were being applied on the date of filing in that Member", or if applicable, the priority date of the application; ${ }^{773}$ and

- provide patent protection for those inventions that fulfil the criteria for patentability "as from the grant of the patent and for the remainder of the patent term, counted from the filing date in accordance with article 33" TRIPS. ${ }^{774}$

As confirmed by the WTO Appellate Body, this obligation entails that members must provide a mechanism to "allow the filing of applications for patents for pharmaceutical and agricultural chemical products from 1 January 1995 and preserve the dates of filing and priority of those applications, so that the criteria for patentability may be applied as of those dates, and so that the patent protection eventually granted is dated back to the filing date". ${ }^{775}$ Additionally, article 70.9 TRIPS requires that notwithstanding the transitional arrangements:

[w] here a product is the subject of a patent application in the Member in accordance with paragraph 8(a) [the mailbox system], exclusive marketing rights shall be granted [...] for a period of 5 years after obtaining marketing approval in that member or until a product patent is granted or rejected, in that member, whichever period is shorter, provided that, subsequent to the entry into force of the WTO Agreement a patent application has been filed and a patent granted for that product in another member and marketing approval obtained in such other member.

From the wording of this article it seems that the grant of exclusive marketing rights (EMRs) must enable the right holder to exclude third parties from advertising, offering or selling the product similarly to the rights granted to right holders under a patent. 776

Both paragraph 8 and 9 of article 70 explicitly state that they must be applied notwithstanding the transitional arrangements from the moment the WTO

771 CORREA, Trade-Related Aspects of IPRs: A Commentary on the TRIPS Agreement, at 514 et seq; UNCTAD-ICTSD, Resource Book on TRIPS and Development, at 766 et seq.

772 Article 70.8(a) TRIPS.

773 Article 70.8(b) TRIPS.

774 Article 70.8(c) TRIPS.

775 India-Patent Protection for Pharmaceutical and Agricultural Chemical Products, at $\$ 56$.

776 HESTERMEYER, Human Rights and the WTO, at 73-74. UNCTAD-ICTSD, Resource Book on TRIPS and Development, at 774. 
Agreement entered into force, that is, 1 January 1995. This was also confirmed by the WTO Appellate Body. ${ }^{777}$ However, because least-developed members were experiencing problems in trying to balance their obligations under TRIPS and also having to deal with a public health crisis, the TRIPS Council decided to extend the transitional periods for LDCs with regard to TRIPS obligations concerning pharmaceuticals and waived their obligations under article 70.9 TRIPS (with regard to the grating of EMRs) until $2016 .{ }^{778}$

Peculiarly, a number of WTO members did not make full use of these provisions and incorporated the TRIPS obligations in their domestic framework before the expiration of the, to their situation applicable, transitional periods. ${ }^{779}$ Why especially developing countries did not take full advantage of the possibilities is unclear. But it is argued that the pressure put on them by some developed countries was an important factor. ${ }^{780}$ Furthermore, with respect to the patenting of pharmaceuticals (and chemical agricultural products), TRIPS did not give developing members the freedom to totally exclude the patenting of pharmaceuticals for the transitional period. Firstly, articles 3 and 4 TRIPS were excluded from the transitional arrangements entailing that once patent standards were implemented, patent holders from another WTO member could not be treated less favourably than domestic or right holders from other members. In addition, TRIPS prevents members from "rolling back" patents standards for the duration of the transitional periods. Thirdly, developing members were under an obligation to establish a "mail box" system to register patent applications for pharmaceutical products and grant exclusive marketing rights. Finally, at this point in time the transitional periods for developing countries have lapsed entailing that they are obliged to fully implement TRIPS' standards including the provision of patent protection for pharmaceutical products. LDCs, however, have been exempted (or until such time they are no longer a least-developed member) from implementing TRIPS' standards (except for

777 India-Patent Protection for Pharmaceutical and Agricultural Chemical Products, at $\$ 53,82$.

778 CORREA, Trade-Related Aspects of IPRs: A Commentary on the TRIPS Agreement, at 13; HESTERMEYER, Human Rights and the WTO, at 74-75; WTO COUNCIL FOR TRADERELATED ASPECTS OF INTELLECTUAL PROPERTY RIGHTS, Extension of the Transition Period under Article 66.1 of the TRIPS Agreement for Least-Developed Country Members for Certain Obligations with Respect to Pharmaceutical Products, (IP/C/25); WTO GENERAL COUNCIL, Least-Developed Country Members. Obligations under Article 70.9 of the TRIPS Agreement with Respect to Pharmaceutical Products (WT/L/478; 2002). To make use of this flexibility, LDCs must implement the TRIPS Council's Decision in their national law. However, there is some uncertainty to what extent LDCs can make use of this decision with regard to patents already granted for pharmaceutical products. See SISULE F. MUSUNGU and CECILIA $\mathrm{OH}$, The Use of Flexibilities in TRIPS by Developing Countries: Can They Promote Access to Medicines?, Commission on Intellectual Property Rights, Innovation and Public Health, Study $4 \mathrm{C}$, (August 2005) at 8.

779 MUSUNGU and OH, The Use of Flexibilities in TRIPS by Developing Countries, at 8.

780 CORREA, Trade-Related Aspects of IPRs: A Commentary on the TRIPS Agreement, at 24. 
articles 3, 4 and 5 TRIPS) including the obligation to grant patents for pharmaceuticals until July $2021 .^{781}$

\subsection{Patents}

After having set out the general provisions and basic principles, object and purpose and transitional arrangements of TRIPS, this section will focus on the substantive provisions of TRIPS to, firstly, determine the standard of protection required by TRIPS and, secondly, examine possible exceptions to patent rights under TRIPS. Section 5 of Part II of the TRIPS Agreement contains the minimum standards with respect to patents including provisions on patentable subject matter, criteria for patentability, rights conferred to the right-holder through the grant of a patent, exceptions to those rights, the period of protection and the possibility of revocation. Also of relevance for the access to medicines debate is the protection of undisclosed information, set out in section 7 of Part II of the TRIPS Agreement, and the procedures for acquisition, maintenance, and enforcement of IPRs set out in Part III and IV of the TRIPS Agreement. All these elements will be discussed in the following sections.

\subsubsection{Article 27 TRIPS: Patentable Subject Matter}

Article 27 TRIPS is the first provision to internationally set out substantive patent provisions with respect to patentable subject matter and conditions for patentability. ${ }^{782}$ In that regard it remedied one of the main weaknesses of the Paris

781 WTO COUNCIL FOR TRADE-RELATED ASPECTS OF INTELLECTUAL PROPERTY RIGHTS, Extension of the Transition Period under Article 66.1 for Least Developed Members, (IP/C/64).

782 Article 27 TRIPS reads as follows:

1. Subject to the provisions of paragraphs 2 and 3, patents shall be available for any inventions, whether products or processes, in all fields of technology, provided that they are new, involve an inventive step and are capable of industrial application. 5 Subject to paragraph 4 of Article 65, paragraph 8 of Article 70 and paragraph 3 of this Article, patents shall be available and patent rights enjoyable without discrimination as to the place of invention, the field of technology and whether products are imported or locally produced.

2. Members may exclude from patentability inventions, the prevention within their territory of the commercial exploitation of which is necessary to protect ordre public or morality, including to protect human, animal or plant life or health or to avoid serious prejudice to the environment, provided that such exclusion is not made merely because the exploitation is prohibited by their law.

3. Members may also exclude from patentability:

(a) diagnostic, therapeutic and surgical methods for the treatment of humans or animals;

(b) plants and animals other than micro-organisms, and essentially biological processes for the production of plants or animals other than non biological and microbiological processes. However, Members shall provide for the protection of plant varieties either by patents or by an effective sui generis system or by any combination thereof. The 
The TRIPS Agreement: Patent Protection for Pharmaceuticals

Convention by, instead of relying on national law, defining the scope of a patent. ${ }^{783}$ However, it must be clearly stated that it does not constitute a harmonised system. The first sentence of article 27.1 TRIPS provides the following:

\begin{abstract}
1. Subject to the provisions of paragraphs 2 and 3, patents shall be available for any inventions, whether products or processes, in all fields of technology, provided that they are new, involve an inventive step and are capable of industrial application. ${ }^{784}$
\end{abstract}

We see that article 27 TRIPS requires patent protection for products and processes. Product patents refer to the product itself, a technological device or chemical compound, which are therefore tangible. Process patents, on the other hand, refer to a course of action or proceeding by which a product is made. With respect to the latter, if the same result is achieved but by different proceedings the process patent is not infringed, unlike a product patent, which is infringed by any reproduction of the product regardless of the manner it was produced, as long as it falls within the claims of the patent. ${ }^{785}$

The question has been raised whether article 27 TRIPS obliges members to protect uses as such; for example claims made for patent protection of subject matter which results in a "new, second or subsequent use" of a known substance not suggested by the prior art. ${ }^{786}$ Such claims are relevant for pharmaceutical products.

\footnotetext{
provisions of this subparagraph shall be reviewed four years after the date of entry into force of the WTO Agreement\}.

GERVAIS, The TRIPS Agreement: Drafting History and Analysis, at 337. Article 27.1 (first sentence) TRIPS.

See also article 28 TRIPS; CORREA, Trade-Related Aspects of IPRs: A Commentary on the TRIPS Agreement, at 271; HESTERMEYER, Human Rights and the WTO, at 64.

Within the European context claims for patenting a known product for a new specific purpose is allowed under article 54.5 European Patent Convention, which reads: "[t]he provisions of paragraphs 1 to 4 [with regard to the requirement of novelty for patentability] shall not exclude the patentability of any substance or composition, comprised in the state of the art, for use in a method referred to in Article 52, paragraph 4, [i.e. therapeutic or diagnostic methods for treatment of the human or animal body] provided that its use for any method referred to in that paragraph is not comprised in the state of the art." So, the first medical indication of a known product may allow patenting of the product. The second or subsequent uses of existing compounds for medical treatment were initially not patentable. However this changed in the 1980s when the European Patent Office allowed a claim on second medical indications of a known product if it was formulated in a specific manner: the "use of substance $X$ in the manufacture of a medicament for the treatment of condition Y". This is the so-called Swiss-type claim, because the Swiss Federal Intellectual Property Office was the first to adopt such an approach.

The US has explicitly allowed claims for patenting of a "method of use" in its Patent Act, see 35 USC $\S 100(b)$ which reads: "[t]he term "process" means process, art, or method, and includes a new use of a known process, machine, manufacture, composition of matter, or material."

CORREA, Trade-Related Aspects of IPRs: A Commentary on the TRIPS Agreement, at 273-274; HESTERMEYER, Human Rights and the WTO, at 65; MACQUEEN, WAELDE, and LAURIE, Contemporary Intellectual Property. Law and Policy, at 401; UNCTAD-ICTSD, Resource Book on TRIPS and Development, at 356-357.
} 
The obvious example is Aspirin which was initially introduced as a painkiller, but later it was found to also have blood-thinning properties. The substance or product, here the chemical substance which is known to relieve pain, is already part of the state of the art. However, the new use it is put to, the fact that the substance can also be used for preventing blood clots is not. This new use of the known substance could be considered an innovative process warranting patent protection. This is not addressed by the TRIPS Agreement. It is argued that an interpretation of article 27.1, obliging members to allow patent protection for subsequent use, is contrary to the Agreement, since it only explicitly refers to products and processes. ${ }^{787}$ Additionally, discovering an unknown property of a known substance cannot always be considered an invention. State practice on this issue is very inconsistent. Moreover, as will be seen below, a method of treating humans or animals may be excluded from patentability under article 27.3(a) TRIPS. Thus, members are free to decide within their own national context the patentability of such subsequent indications. Whether or not new uses of pharmaceuticals may be granted patent protection is relevant for a domestic public health policy, since expanding patent protection in such a manner could negatively affect patients' access to medicines. ${ }^{788}$

One of the major changes introduced by the TRIPS Agreement, especially for developing countries attempting to safeguard access to medicines by taking full advantage of a weak patent system, was the extension of patent protection to all fields of technology. As a result, members are obliged to incorporate patent protection for pharmaceuticals into their legislative framework. Pre-TRIPS, though, this was not the standard approach in quite a few developing and also developed countries. ${ }^{789}$ See for example the case study on India, which initially only allowed for patent protection for pharmaceutical processes but not products. Moreover, the Paris Convention allowed excluding fields of technology from patentability, for example concerning pharmaceutical products and/or processes, and did not establish any patentability criteria. ${ }^{790}$ The availability of patents for pharmaceutical products was an important discussion point during the TRIPS negotiations and heavily lobbied for by the pharmaceutical industry which argued that, in line with the incentive rationale for protection of IP, patents were absolutely essential for the

787 CARLOS M. CORREA, A Guide to Pharmaceutical Patents. Vol. I, South Centre, (July 2008) at 130-131; UNCTAD-ICTSD, Resource Book on TRIPS and Development, at 357.

788 CORREA, Trade-Related Aspects of IPRs: A Commentary on the TRIPS Agreement, at 273-274; CORREA, A Guide to Pharmaceutical Patents. Vol. I, at 128; HESTERMEYER, Human Rights and the WTO, at 64-65.

789 According to a 2005 UNCTAD \& ICTSD publication about 50 states did not grant patent protection to pharmaceutical products at the start of the Uruguay Round, while some excluded pharmaceutical processes from patent protection too. See CORREA, Trade-Related Aspects of IPRs: A Commentary on the TRIPS Agreement, at 275; GAMHARTER, Access to Affordable Medicines, at 21; HESTERMEYER, Human Rights and the WTO, at 55; UNCTAD-ICTSD, Resource Book on TRIPS and Development, at 353. 
industry to recover their high R\&D costs. A number of developing countries, that had excluded (product) patents for pharmaceuticals within their legal system, objected strongly to the inclusion of an obligation to provide patent protection for pharmaceutical processes and products. However, their efforts were in vain; now TRIPS obliges all members to implement patent protection for inventions, whether products or processes, in all fields of technology and without discrimination (i.e. also with respect to medicines), provided that they are new, involve an inventive step and are capable of industrial application. ${ }^{791}$

Generally, to determine whether a product or process should be granted patent protection a Patent Office will take the following approach: when examining an application for patent protection the patent examiner will first consider what is not deemed to be an invention or not entitled to patent protection under national patent law. Secondly, the examiner will test the invention against the following three criteria: novelty, inventiveness or non-obviousness and usefulness or capability of industrial application. ${ }^{792}$ A similar approach will be applied here, addressing the subject matter excluded from patentability followed by an examination of the patentability criteria as established by TRIPS. However, the next section will discuss the principle of non-discrimination.

\subsubsection{NON-DISCRIMINATION}

The principle of non-discrimination is a central element of the patent standards under TRIPS, incorporated in the second sentence of article 27.1 TRIPS which reads as follows:

Subject to paragraph 4 of article 65, paragraph 8 of article 70 and paragraph 3 of this article, patents shall be available and patents rights enjoyable without discrimination as to the place of invention, the field of technology and where the products are imported or locally produced.

The non-discrimination obligation included in article 27.1 TRIPS is a hotly debated provision. The application of this non-discrimination principle is subject to three provisions: first article 65.4 TRIPS, concerning the transitional arrangement which permits developing countries until 1 January 2005 to discriminate with regard to those areas of technology that did not enjoy patent protection on the date application of the Agreement. Secondly, article 70.8 TRIPS obliging all members that did not allow for patent protection of pharmaceuticals on the date of entry into force of the Agreement to establish a mailbox system for the filing of applications for inventions in the field of pharmaceuticals and agrochemicals. Thirdly, article 27.3 TRIPS which allows certain subject matter to be excluded from patentability.

\footnotetext{
791 Ibid. at 356.

792 MACQUEEN, WAELDE, and LAURIE, Contemporary Intellectual Property. Law and Policy, at 408-409.
} 
The non-discrimination principle applies to the availability of patents, (i.e. patentability) and the enjoyment of patents (i.e. the rights conferred by a patent). It specifically prohibits three types of discrimination: discrimination with regard to the place of invention, field of technology and whether products are imported or produced locally. Thus, not providing patent protection for pharmaceuticals would be a clear violation of the principle of non-discrimination with regard to the field of technology, which - as has been stated above - has been considered one of the greatest achievements of the TRIPS Agreement. ${ }^{793}$

The question then arises, what is considered to be discrimination under the TRIPS Agreement. In the Canada - Patent Protection for Pharmaceutical Products case the panel found that discrimination is "a normative term, pejorative in connotation, referring to results of the unjustified imposition of differentially disadvantageous treatment." 794 It went on to distinguish between de jure and de facto discrimination and held that not all de facto differential treatment is discrimination. ${ }^{795}$ Unfortunately, the panel did not give a more precise definition of non-discrimination and its exact scope thus remains unclear. ${ }^{796}$ One of the most controversial elements of the Canada - Patent Protection for Pharmaceutical Products case is that the Panel dismissed Canada's argument that the nondiscrimination requirement of article 27.1 TRIPS was itself subject to the exception of article 30 TRIPS. Canada maintained that it could discriminate making limited exceptions under article 30 and, as such, establish separate rules with regard to pharmaceuticals. ${ }^{797}$ The panel disagreed and ruled that the non-discrimination requirement also applied to measures taken under articles 30 and 31 of the TRIPS Agreement. ${ }^{798}$ This interpretation is also found in the travaux préparatoires showing that the adoption of the non-discrimination requirement intended to

793 CORREA, Trade-Related Aspects of IPRs: A Commentary on the TRIPS Agreement, at 281-282; GAMHARTER, Access to Affordable Medicines, at 26; HESTERMEYER, Human Rights and the WTO, at 59.

794 Canada-Patent Protection for Pharmaceutical Products, at \$7.94. See for more information GERVAIS, The TRIPS Agreement: Drafting History and Analysis, at 353 et seq. Canada - Patent Protection for Pharmaceutical Products, at \$7.101.

796 See ibid. at $\$ 7.98$. Here the Panel stated the following: In considering how to address these conflicting claims of discrimination, the Panel recalled that various claims of discrimination, de jure and de facto, have been the subject of legal rulings under GATT or the WTO. These rulings have addressed the question whether measures were in conflict with various GATT or WTO provisions prohibiting variously defined forms of discrimination. As the Appellate Body has repeatedly made clear, each of these rulings has necessarily been based on the precise legal text in issue, so that it is not possible to treat them as applications of a general concept of discrimination. Given the very broad range of issues that might be involved in defining the word "discrimination" in Article 27.1 of the TRIPS Agreement, the Panel decided that it would be better to defer attempting to define that term at the outset, but instead to determine which issues were raised by the record before the Panel, and to define the concept of discrimination to the extent necessary to resolve those issues. 
prevent automatic compulsory licenses on pharmaceuticals and thus should apply to article 31 and consequently also to article 30 TRIPS. This reasoning of the Panel has been contested. ${ }^{799}$ It is argued that exceptions generally apply to the obligations they are meant to except, an opposite intention should be contained in the rule itself, in this case article 27. In addition, article 32 of the Vienna Convention states clearly that recourse to the travaux préparatoires is a subsidiary means of treaty interpretation. However, the Panel did not condemn all discrimination with regard to the field of technology where it distinguished between permissible differential treatment and impermissible discrimination. In that regard it stated that article 27 "does not prohibit bona fide exceptions to deal with problems that may exist only in certain product areas. Moreover, to the extent the prohibition of discrimination does limit the ability to target certain products in dealing with certain of the important national policies referred to in articles 7 and 8.1, that fact may well constitute a deliberate limitation rather than a frustration of purpose." 800

Consequently it has been argued that differential treatment aimed at preserving TRIPS' objectives (see articles 7 and 8), such as public health in line with the Doha Declaration on TRIPS and Public Health, would be more easily justified. ${ }^{801}$ For example, with regard to protecting public health and access to affordable medicines, the question arises whether the non-discrimination principle also applies to the conditions for compulsory licensing under article 31 TRIPS. This could be problematic since it would mean that compulsory licenses could not be granted for public policy interests in certain fields of technology, for example pharmaceuticals. In Canada - Patent Protection for Pharmaceutical Products, the panel confirmed that both articles 30 and 31 were subject to the non-discrimination clause of article 27.1 TRIPS. ${ }^{802}$ However, such an interpretation has been criticised; it being illogical to forcedly apply compulsory licenses to fields where these are not necessary. In addition, "problem areas", like public health, may be considered distinct from fields of technology. ${ }^{803}$

\subsubsection{Excluded Subject Matter}

Article 27 TRIPS states that all members are obliged to allow for the granting of patents for any inventions, including processes and products in all technological fields. This, however, does not mean that everything made by man can be patented;

\footnotetext{
799 See for example HANS MORTEN HAUGEN, 'Human Rights and TRIPS Exclusion and Exception Provision', The Journal of World Intellectual Property, 11:5/6 (2009), 345-374 at 357. Canada - Patent Protection for Pharmaceutical Products, at $\$ 7.92$.

801 CORREA, Trade-Related Aspects of IPRs: A Commentary on the TRIPS Agreement, at 26, 282; HESTERMEYER, Human Rights and the WTO, at 59-60; GAMHARTER, Access to Affordable Medicines, at 30-33; UNCTAD-ICTSD, Resource Book on TRIPS and Development, at 370 et seq. 802 Canada-Patent Protection for Pharmaceutical Products, at $\$ 7.91$.

803 CORREA, Trade-Related Aspects of IPRs: A Commentary on the TRIPS Agreement, at 284.
} 
there are boundaries to what is considered patentable subject matter under the TRIPS Agreement.

Article 27 TRIPS is designed to protect inventions. However, it does not provide for a legal definition of the term "invention". ${ }^{804}$ Thus members have considerable room to decide how to define this term within their national legal context, subject to customary rules of treaty interpretation. ${ }^{805}$ The ordinary meaning of "invention" would suggest that it is a product of original thought, ingenuity or imagination. In general it is accepted that discoveries do not fall within the ambit of the term 'invention' and can therefore not be patented. For example substances found (discovered) in nature with medicinal properties would then be excluded from patentability. 806

Furthermore, the following is also often considered not patentable: scientific theories and mathematical methods; aesthetic creations; schemes, rules and methods for performing mental acts, playing games or doing business, and programmes for computers; and presentations of information. ${ }^{807}$ Just like discoveries, scientific theories and mathematical methods are regarded as being too abstract, indistinct or intellectual to be subject to patent protection. This also applies to schemes, rules and methods for performing mental acts, playing games and doing business. The patentability, or better said the lack thereof, of computer programmes has been a controversial issue; it has been argued that a computer programme is no more than the mathematical application of a logical series of steps without any technical effect. Although computer programmes as such are excluded from patent protection, software-related inventions can in the European context be patented. ${ }^{808}$ Aesthetic creations are generally not considered technical nor include a technical contribution to the state of the art to warrant patent protection. However, they sometimes can be protected by another form of intellectual property rights, for example copyright. ${ }^{809}$

804 Like the TRIPS Agreement, many national legal systems do not elaborate on what constitutes an invention. In the UK the approach is to ask whether an invention makes a technical contribution (i.e. produces a technical effect) to the state of the art. If so it can be patentable as long as the matter is not specifically excluded from patentability. In the US a contrasting approach is taken where, although this is slightly overstated, everything under the sun made by man is considered patentable. It is true, though, that patentability of subject matter is interpreted much wider in the US than within the European context. MACQUEEN, WAELDE, and LAURIE, Contemporary Intellectual Property. Law and Policy, at 411, 413.

CORREA, Trade-Related Aspects of IPRs: A Commentary on the TRIPS Agreement, at 272; GAMHARTER, Access to Affordable Medicines, at 21; UNCTAD-ICTSD, Resource Book on TRIPS and Development, at 357. HESTERMEYER, Human Rights and the WTO, at 54-55; MACQUEEN, WAELDE, and LAURIE, Contemporary Intellectual Property. Law and Policy, at 413-414.

807 See for example in the European context, article 52.2. of the final and revised version of the 2000 European Patent Convention.

808 MACQUEEN, WAELDE, and LAURIE, Contemporary Intellectual Property. Law and Policy, at $413,416,509$. 


\subsubsection{Exemptions to Patentability}

In addition to subject matter excluded from patentability due to the fact that it is not considered an invention, the TRIPS Agreement provides for the possibility to exclude certain inventions (not categories of inventions) from patentability in order to protect public goals. First, article 27.2 TRIPS states the following:

2. Members may exclude from patentability inventions, the prevention within their territory of the commercial exploitation of which is necessary to protect ordre public or morality, including to protect human, animal or plant life or health or to avoid serious prejudice to the environment, provided that such exclusion is not made merely because the exploitation is prohibited by their law.

It is important here to note that members may exclude inventions from patentability on the stated grounds, however, they are not obliged to do so. In addition, there is no internationally accepted interpretation of the terms 'ordre public' and 'morality' as used in paragraph 2, although the deliberate choice to use the term 'ordre public' seems to suggest a narrower concept than 'public order' or 'public interest'. In general 'ordre public' encompasses the protection of public security and the physical integrity of the individuals as part of society, while morality depends more on the culture of a country. ${ }^{810}$ The reference to the protection of human, animal or plant life and health is not a separate ground for exclusion but is included as a subcategory or example to the first mentioned 'ordre public' and 'morality' grounds for exception. ${ }^{811}$ Article 27.2 has not been clarified yet by the WTO dispute settlement mechanism, which leaves the exact interpretation of this provision uncertain. ${ }^{812}$ Consequently, the concepts of ordre public and morality are of a vague and culturally dependent nature that members have substantial flexibility in defining the situations that would fall within both concepts. ${ }^{813}$

However, the usefulness of this provision with regard to public health will be limited, due to the fact that the patentability of inventions may only be excluded if

810 HAUGEN, 'Human Rights and TRIPS Exclusion and Exception Provision', at 349; UNCTADICTSD, Resource Book on TRIPS and Development, at 379.

811 Although some commentators disagree and find that the inclusion of the phrases "seriously prejudice the environment" and "protect human, animal or plant life or health" show that these are two distinct and additional bases for exclusion from patentability. See for example HAUGEN, 'Human Rights and TRIPS Exclusion and Exception Provision', at 349; UNCTADICTSD, Resource Book on TRIPS and Development, at 380.

812 The wording of article 27.2 TRIPS seems to suggest a "necessity test" in order to exclude inventions from patentability; a requirement similar to the one under article XX(b) GATT. Thus it is argued that the "necessity test" as developed in the GATT jurisprudence should also be taken into account when interpreting article 27.2 TRIPS.

GAMHARTER, Access to Affordable Medicines, at 81-82; HAUGEN, 'Human Rights and TRIPS Exclusion and Exception Provision', at 351; UNCTAD-ICTSD, Resource Book on TRIPS and Development, at 378.

813 CORREA, Trade-Related Aspects of IPRs: A Commentary on the TRIPS Agreement, at 287-290. 
the commercial exploitation of such inventions are contrary to 'ordre public' or 'morality' within the territory of the member, not the invention as such. Denying the grant of a patent, however, would not entail that the contentious invention cannot be used, it could only act as a disincentive. The mere fact that the exploitation of an invention is prohibited by law does not suffice to deny the grant of a patent. To increase patients' access to medicines preventing the commercial exploitation (i.e. the marketing and sale) of pharmaceutical products would not be functional. Rather the desire is to enable generic pharmaceutical products to have access the market. Therefore article 27.2 cannot be employed as a general exception to patentability in order to protect public health. ${ }^{814}$

Secondly, article 27.3 TRIPS further provides that:

\section{Members may also exclude from patentability:}

(a) diagnostic, therapeutic and surgical methods for the treatment of humans or animals;

(b) plants and animals other than micro-organisms, and essentially biological processes for the production of plants or animals other than non-biological and microbiological processes.

Equivalent to article 27.2, paragraph three of article 27 is a facultative clause. As was shown article 27.1, TRIPS only requires the protection of products and processes, however, some members have extended patentability to inventions consisting of methods of use. In that regard, article 27.3(a) applies specifically with respect to methods of treatment, i.e. the way inventions are used in order to heal humans or animals may be excluded from patentability. Diagnostic, therapeutic and surgical methods for the treatment of humans are excluded from patent protection in most countries, often because of a lack of industrial capability. However, this exception does not include pharmaceuticals as such, since they are not methods of treatment but patented as products, nor does it include any kind of devices or products for diagnostic or treatment. 815

Finally, within limits, members may exclude plants and animals from patent protection as stated in article $27.3(\mathrm{~b}) .{ }^{816}$

814 GAMHARTER, Access to Affordable Medicines, at 82; HESTERMEYER, Human Rights and the WTO, at 56-57; MACQUEEN, WAELDE, and LAURIE, Contemporary Intellectual Property. Law and Policy, at 425.

815 HESTERMEYER, Human Rights and the WTO, at 57; UNCTAD-ICTSD, Resource Book on TRIPS and Development, at 384 et seq.

816 Article 27.3(b) TRIPS will not be discussed here. See for more information CORREA, TradeRelated Aspects of IPRs: A Commentary on the TRIPS Agreement, at 292; GRAHAM DUTFIELD, LOIS MURAGURI, and FLORIAN LEVERVE, 'Exploring the Flexibilities of TRIPS to Promote Biotechnology in Developing Countries', in Carlos M. Correa (ed.), Research Handbook on the Protection of Intellectual Property under WTO Rules. Intellectual Property in the WTO Volume 1 (Research Handbooks on the WTO; Cheltenham/Northanmpton: Edward Elgar, 2010) at 569 et seq; UNCTAD-ICTSD, Resource Book on TRIPS and Development, at 388 et seq. 


\subsubsection{Patentability CRiteria}

From the foregoing it becomes clear that members have considerable flexibility to determine what subject matter may be patentable under national patent legislation. Once an invention is deemed patentable, the actual grant of a patent depends on three criteria provided for in article 27.1 TRIPS: novelty, inventiveness and capability of industrial application. These criteria, in one form or another, are found in most domestic patent laws. These conditions aim to ensure that only truly innovative, previously unknown and socially beneficial inventions receive a monopoly right in the form of a patent. Since patent law is inherently domestic law, TRIPS is the first to internationally address such substantive patent provisions. There has been little practice and case law in the international context, and as such, there is no internationally accepted approach regarding the interpretation of these three criteria. Thus, the exact definition of these criteria is left to the discretion of the WTO members. Developing members may therefore, as long as they respect the basic definition of these criteria, implement these according to what is most appropriate for their specific level of development. ${ }^{817}$

\section{Novelty}

The first condition is the universal requirement of novelty. This condition requires that at the time of application the invention must not have been made available within the public domain, either in written form or any other way, anywhere in the world and, thus, does not constitute part of the state of the art (or prior art). This requirement aims to prevent re-inventions, ensures that knowledge already available within the public domain is not subject to monopoly rights and attempts to encourage true innovation. ${ }^{818}$

To assess whether an invention applying for patent protection is part of the public domain, it must first be determined what is contained in the 'public domain' or 'state of the art'. It can be a difficult task to assess the amount of information necessary within the public domain to squash an invention's novelty. ${ }^{819}$ Generally, to defeat novelty the information disclosed must be such that the invention can be

817 CORREA, Trade-Related Aspects of IPRs: A Commentary on the TRIPS Agreement, at 292-293; GAMHARTER, Access to Affordable Medicines, at 22-23; HESTERMEYER, Human Rights and the WTO, at 53; MACQUEEN, WAELDE, and LAURIE, Contemporary Intellectual Property. Law and Policy, at 376, 433; UNCTAD-ICTSD, Resource Book on TRIPS and Development, at 358 .

818 HESTERMEYER, Human Rights and the WTO, at 66; MACQUEEN, WAELDE, and LAURIE, Contemporary Intellectual Property. Law and Policy, at 433; UNCTAD-ICTSD, Resource Book on TRIPS and Development, at 359.

819 Within the European context, article 54 EPC states a relatively wide definition of the "state of the art" as "everything made available to the public by means of a written or oral description, by use or in any other way, before the date of filing". Thus, at the exact moment a piece of information is made public anywhere in the world, in any language it is part of the state of the 
worked by a person skilled in the art without additional explanation. A mere published statement of the existence of the invention, will not be sufficient to defeat novelty. The patent applicant must be careful not to make his invention public by accident before securing the priority date, ${ }^{820}$ as it is irrelevant who discloses the information. Importantly, novelty will only be tested against the state of the art as it exists prior to the priority date. ${ }^{821}$

\section{Inventive Step}

The second requirement to be fulfilled is the need of an invention to involve an inventive step. Again, the TRIPS Agreement does not provide a definition of 'inventiveness', but it does state in a footnote that this term is considered to be equal to 'non-obviousness', a term used within the US. In general, an invention considered being a simple and obvious improvement to the state of the art in the view of a person skilled in the art cannot warrant patent protection. Members are here also free to adopt their own level of inventiveness necessary to receive patent protection. ${ }^{822}$ Approaches can vary widely in different countries. ${ }^{823}$ The requirement that the invention must involve an inventive step intends to justify the strong monopoly right granted in this respect, and ensure that trivial improvements do not enjoy the same level of protection and are kept out of the public domain.

art. It is not necessary that the public actually knows about the piece of information, as long as it can have (if necessary paid) access to it.

The priority date is normally the filing date of the patent application with a patent office. MACQUEEN, WAELDE, and LAURIE, Contemporary Intellectual Property. Law and Policy, at $433-434$.

CORREA, Trade-Related Aspects of IPRs: A Commentary on the TRIPS Agreement, at 276; HESTERMEYER, Human Rights and the WTO, at 66.

In the European context an invention is inventive if "having regard to the state of the art, it is not obvious to a person skilled in the art", see article 56 EPC. Thus, to assess inventiveness of an invention the following questions must be asked: what is comprised within the state of the art; what is meant with a person skilled in the art; and finally when do we know that something is "obvious" to a person skilled in the art? First, it must be noted that the state of the art with regard to assessing inventiveness is the same as for determining the novelty of an invention. Here, however, combining different pieces of prior art in order to test an invention's inventiveness is permissible as long as this is something a person skilled in the art would do; this process is referred to as mosaicing. Inventiveness depends therefore also on the specific field of technology. Common knowledge, whether general or specific, must also be taken into account. Secondly, with a person skilled in the art is meant and ordinary member of the specific field of technology, who is aware of the state of the art, but has no imaginative or inventive capacity. As is the same with novelty, the skilled person must assess inventiveness at the time of the priority date and must not take into account information publicised afterwards. Thirdly, inventiveness is defeated if the invention is the next logical, obvious step within a specific field of technology. Required to fulfil this condition is a leap forward in a manner which would not be obvious for most others working in the same field of technology. See further MACQUEEN, WAELDE, and LAURIE, Contemporary Intellectual Property. Law and Policy, at 444-447. 
Inventiveness also entails a certain societal advantage brought about by the invention. $^{824}$

Particularly in the pharmaceutical sector, many patent applications do not concern truly new and innovative chemical entities, but they relate to (minor) adjustments, new manufacturing processes or formulations of already existing pharmaceuticals, a development referred to as "ever-greening". 825 The TRIPS Agreement does not provide members any guidance here and members are free, within the boundaries of the rules of treaty interpretation, to adopt their own definition of what is considered to be novel and inventive in the domestic context. ${ }^{826}$

\section{Industrial Application}

Thirdly, the TRIPS Agreement requires the invention to be capable of industrial application, referring to the industrial or technical nature of the invention. Although TRIPS does not give a definition of the term, it does consider the capability of an industrial application to be synonymous with 'useful', another term often found in US terminology. ${ }^{827}$ In addition 'industrial' is defined in the Paris Convention in the 'broadest sense and shall apply not only to industry and commerce proper, but likewise to agricultural and extractive industries and to all manufactured or natural products (...) ${ }^{828}$ In general, if the invention is intellectual, aesthetic, or artistic in nature, it can be held that this requirement is not fulfilled. ${ }^{829}$

\section{Article 29: Disclosure}

In addition to the three requirements specifically stated in article 27.1 of the TRIPS Agreement, article 29 provides that to attain patent protection the applicant must 'disclose the invention in a manner sufficiently clear and complete for the invention to be carried out by a person skilled in the art'. Members may, however are not obliged

824 GAMHARTER, Access to Affordable Medicines, at 24; MACQUEEN, WAELDE, and LAURIE, Contemporary Intellectual Property. Law and Policy, at 444.

825 See for more information HENNING GROSSE RUSE-KAHN, Policy Space for Domestic Public Interest Measures under TRIPS, South Centre, Research Papers 22, (2009).

826 CORREA, Trade-Related Aspects of IPRs: A Commentary on the TRIPS Agreement, at 275-276; GAMHARTER, Access to Affordable Medicines, at 23-24; UNCTAD-ICTSD, Resource Book on TRIPS and Development, at 360.

827 See footnote 5 to article 27.1 TRIPS. "Utility" in the US context implies that the invention must accomplish an intended purpose not in contrast with morality and the law to the benefit of society. In the European context it is assumed that if an invention can be "made or used in any kind of industry, including agriculture" it is considered to be capable of industrial application; see article 57 EPC. It must be noted here, that the invention must only be capable of industrial application; there is no requirement of actually proving effective use.

828 Article 1.3 of the Paris Convention.

829 HESTERMEYER, Human Rights and the WTO, at 66-67; MACQUEEN, WAELDE, and LAURIE, Contemporary Intellectual Property. Law and Policy, at 453. GAMHARTER, Access to Affordable Medicines, at 24-25. 
to, 'require the applicant to indicate the best mode of carrying out the invention known to the inventor'. 830 This trade-off is a fundamental element of the patent system: granting patent protection in return for the disclosure of an invention which otherwise could have remained secret. ${ }^{831}$ In practice though many patent applicants draw up their patent claims very restrictively revealing as little information as possible, so as to hinder competitors using the information for follow-up inventions. ${ }^{832}$

\subsubsection{Article 28: Rights Conferred}

In addition to setting out standards with regard to patentable subject matter, article 28 TRIPS guarantees patent holders a minimum standard of exclusive rights; these will be discussed here. ${ }^{833}$

Article 28 distinguishes between product patents and process patents. The patent holder of a product patent can prevent third parties from making, using, offering for sale, selling, or importing for these purposes the patented product without his consent. ${ }^{834}$ As such a product patent confers on the patent holder the right to exclude others from these actions irrespective of the manner or process with which such a product was obtained. Therefore, a third party, without knowledge of the existing product patent, who independently reaches the same result as the patent holder may be excluded from working the patent. ${ }^{835}$ The set of actions a patent holder can prevent as stated in TRIPS are exhaustive. ${ }^{836}$

If it concerns a process patent, the patent holder can prevent third parties from using the process and using, offering for sale, selling or importing for these purposes at least the product obtained directly by the patented process without his consent. ${ }^{837}$ This provision went further than many national patent laws at the time

830 Article 29.1 TRIPS.

831 GERVAIS, The TRIPS Agreement: Drafting History and Analysis, at 378.

832 CORREA, Trade-Related Aspects of IPRs: A Commentary on the TRIPS Agreement, at 301; HESTERMEYER, Human Rights and the WTO, at 67; UNCTAD-ICTSD, Resource Book on TRIPS and Development, at 448 et seq.

833 Article 28 TRIPS reads as follows:

1. A patent shall confer on its owner the following exclusive rights:

(a) where the subject matter of a patent is a product, to prevent third parties not having the owner's consent from the acts of: making, using, offering for sale, selling, or importing6 for these purposes that product;

(b) where the subject matter of a patent is a process, to prevent third parties not having the owner's consent from the act of using the process, and from the acts of: using, offering for sale, selling, or importing for these purposes at least the product obtained directly by that process.

2. Patent owners shall also have the right to assign, or transfer by succession, the patent and to conclude licensing contracts. 
of adoption and strengthened process patents considerably. ${ }^{838}$ The TRIPS Agreement also recognises the difficulty for patentees to prove that their process patent has been infringed and allows for the reversal of the burden of proof in civil proceedings. The judicial authorities may "order the defendant to prove that the process to obtain an identical product is different from the patented process" ${ }^{839}$ In that regard article 34 TRIPS establishes, under certain circumstances, a presumption that without any proof to the contrary any identical product manufactured without consent of the patent holder is deemed to be obtained by the patented process. Here it must concern an identical product, not merely a product similar in composition or functioning. ${ }^{840}$

Patent holders, irrespective of whether it concerns product or process patents, also have the right to assign, or transfer by succession the patent itself and conclude licensing contracts with third parties. ${ }^{841}$

A patent grants the right holder a negative right: to exclude third parties without the right holder's consent from the actions mentioned above. It does not, therefore, grant the patent holder a positive right to use or market the invention. Specifically, for pharmaceuticals the grant of patent does not entail that the manufacturer can place the pharmaceutical on the market; to be able to do so it must first have received approval of the national regulatory authority responsible. This right to exclude others from working the patent is independent from the purpose with which the third party uses, makes and/or sells the patented product. Thus it is not necessary that the third party's intentions are of a commercial nature. ${ }^{842}$

838 GAMHARTER, Access to Affordable Medicines, at 43; UNCTAD-ICTSD, Resource Book on TRIPS and Development, at 414, 421.

839 Article 34 TRIPS reads as following:

1. For the purposes of civil proceedings in respect of the infringement of the rights of the owner referred to in paragraph 1(b) of Article 28, if the subject matter of a patent is a process for obtaining a product, the judicial authorities shall have the authority to order the defendant to prove that the process to obtain an identical product is different from the patented process. Therefore, Members shall provide, in at least one of the following circumstances, that any identical product when produced without the consent of the patent owner shall, in the absence of proof to the contrary, be deemed to have been obtained by the patented process:

(a) if the product obtained by the patented process is new;

(b) if there is a substantial likelihood that the identical product was made by the process and the owner of the patent has been unable through reasonable efforts to determine the process actually used.

2. Any Member shall be free to provide that the burden of proof indicated in paragraph 1 shall be on the alleged infringer only if the condition referred to in subparagraph (a) is fulfilled or only if the condition referred to in subparagraph (b) is fulfilled.

3. In the adduction of proof to the contrary, the legitimate interests of defendants in protecting their manufacturing and business secrets shall be taken into account.\}.

See further CORREA, Trade-Related Aspects of IPRs: A Commentary on the TRIPS Agreement, at 298, 345; UNCTAD-ICTSD, Resource Book on TRIPS and Development, at 496 et seq.

841 Article 28.2 TRIPS. CORREA, Trade-Related Aspects of IPRs: A Commentary on the TRIPS Agreement, at 299.

842 Ibid. at 295; HESTERMEYER, Human Rights and the WTO, at 68. 
The right to exclude competitors gives patent holders a monopoly position for the patent permitting him to exploit fully an invention and recoup any research and development costs. However, once the patent holder has legally marketed the patented product (i.e. the first sale) his exclusive rights in respect of the use, sale, importation or other distribution of that specific product are exhausted. From then on, that product can be used, offered for sale, resold or imported without requiring consent by the patent holder first. This doctrine has become known as the 'exhaustion of IPRs'. ${ }^{843}$ As we have seen, this principle is readily accepted for the national market, but it has sparked some controversy if interpreted as resulting in exhaustion once a protected product is placed on any market anywhere in the world, the principle of international exhaustion. This latter doctrine allows for so-called parallel imports; ${ }^{844}$ that is the possibility to import a product protected by an IPR into a country, without authorisation of the right holder, once that product has been legally placed on any foreign market. This is controversial since TRIPS explicitly grants the patent holder the right to prevent third parties from importing the patented product for the purpose of using, offering for sale and selling it. However, with regard to patents a footnote to article 28 TRIPS states that the exclusive right of the right holder to prevent third parties from importing the protected product, "in respect of the use, sale, importation or other distribution of goods, is subject to the provisions of Article 6." Moreover, under the international principle of exhaustion, parallel importation is allowed with regard to "legitimate" products: products that are legally placed on a foreign market. What exactly is considered to be legitimate marketing of a product and whether it requires consent of the right holder can vary and depends on the national context. It is controversial to what extent compulsory licenses (without consent of the right holder) may be a basis for exhaustion. ${ }^{845}$ The Doha Declaration on the TRIPS Agreement and Public Health has explicitly confirmed members' right to freely establish their own regime with regard to the exhaustion of IPRs, subject to articles 3 and 4 TRIPS. ${ }^{846}$ Consequently, the TRIPS Agreement does not prohibit parallel imports under the international doctrine of exhaustion of rights.

For developing countries, applying the international principle of exhaustion of rights and allowing parallel importation of patented pharmaceutical products, can be a useful tool for meeting their public health needs, since it would permit them to purchase the cheapest drugs offered anywhere in the world. ${ }^{847}$ Especially

\footnotetext{
843 See section 3.1. of this chapter.

844 See CORREA, Trade-Related Aspects of IPRs: A Commentary on the TRIPS Agreement, at 78; GAMHARTER, Access to Affordable Medicines, at 36-37; UNCTAD-ICTSD, Resource Book on TRIPS and Development, at 93.

845 See further CORREA, Trade-Related Aspects of IPRs: A Commentary on the TRIPS Agreement, at 82-86; GERVAIS, The TRIPS Agreement: Drafting History and Analysis, at 199; UNCTADICTSD, Resource Book on TRIPS and Development, at 106-107.

846 WTO, Doha Declaration on TRIPS and Public Health, (WT/MIN(01)/DEC/2) at §5(d).

847 CORREA, Trade-Related Aspects of IPRs: A Commentary on the TRIPS Agreement, at 80; HESTERMEYER, Human Rights and the WTO, at 231; WTO COUNCIL FOR TRADERELATED ASPECTS OF INTELLECTUAL PROPERTY RIGHTS, Submission by the African
} 
developing countries without pharmaceutical manufacturing capacity would benefit from parallel importation as the use of compulsory licensing is ineffective without the ability to manufacture. On the contrary, one could argue that adopting an international exhaustion regime is actually harmful for developing countries. The reason therefore would be that allowing protected goods to move freely from developing countries to developed countries, could prevent manufacturers from demanding lower prices specifically for developing countries, so-called 'price discrimination or differentiation', because they fear that the lower priced products would leak into higher priced markets. ${ }^{848}$ However this view has been challenged. ${ }^{849}$ Nevertheless, to take advantage of parallel importing it is desirable that markets are segmented. Developed countries and developing countries should provide for measures to prevent imports of low priced pharmaceuticals originating from developing countries to be exported to developed countries.

Price discrimination provides an option enabling the pharmaceutical sector to recoup their $R \& D$ investment costs but still guarantee affordable prices for patients in poor countries. ${ }^{850}$ This would entail pharmaceutical corporations charging discriminatory prices for medicines: higher prices in rich developing states which allow the pharmaceutical sector to recover their R\&D costs, and lower prices in developing states that cannot afford the current high prices. In establishing a differential pricing system, two factors are of importance: markets with different price ranges must be segmented, so that lower-priced products cannot enter higher priced markets; and price decisions in higher priced markets must not be made with reference to prices in the lower priced markets. ${ }^{851}$ Unfortunately creating such an environment might not be as easy as it may seem. The pharmaceutical sector therefore may be hesitant about such a system for a number of reasons. For example, reducing prices in lower-income countries could lead to discussion and protest within high-income countries concerning the high costs of medicines. In reality, pharmaceutical markets are not strictly separated, and a reduction of medicine prices in developing countries could lead to re-importation of the cheaper products in developed states, destroying profits. There is not much of a profit margin in providing developing states with cheaper medicines and it could be so that it is more profitable

Group, Barbados, Bolivia, Brazil, Cuba, Dominican Republic, Ecuador, Honduras, India, Indonesia, Jamaica, Pakistan, Paraguay, Philippines, Peru, Sri Lanka, Thailand and Venezuela, (IP/C/W/296) at 6-7.

848 HESTERMEYER, Human Rights and the WTO, at 231; UNCTAD-ICTSD, Resource Book on TRIPS and Development, at 117. See also A. BRYAN BAER, 'Price Controls through the Back Door: The Parallel Importation of Pharmaceuticals', Journal of Intellectual Property Law, 9 (2001-2002), 109-136.

849 See for example CORREA, Trade-Related Aspects of IPRs: A Commentary on the TRIPS Agreement, at 89; UNCTAD-ICTSD, Resource Book on TRIPS and Development, at 117.

850 See also SCHERER and WATAL, Post-TRIPS Options for Access to Patented Medicines in Developing Countries, at 35 et seq; UN SUB-COMMISSION ON HUMAN RIGHTS, Report of the High Commissioner on the Impact of the TRIPS Agreement on Human Rights (UN Doc. E/ CN.4/Sub.2/2001/13) at $\S 47$.

851 CIPR, Integrating Intellectual Property Rights and Development Policy, at 41. 
to offer medicines at high prices to the rich minority in a developing state. ${ }^{852}$ To what extent this argument is correct and parallel imports really do harm developing countries' interests is questionable. ${ }^{853}$ However, concerns by the pharmaceutical sector in achieving effective market segmentation, preventing unlawful (re-)entry of the lower-priced medicines in the higher-priced markets, of political and regulatory nature and little pressure by developed countries have, consequently, resulted in not fully exploiting price discrimination in the field of pharmaceuticals in order to guarantee access to affordable medicines in developing countries. ${ }^{854}$

\subsubsection{Article 33 TRIPS: Patent Term}

The TRIPS Agreement states that the term of protection provided for by a patent must be a minimum of 20 years from the date of filing. ${ }^{855}$ Different patent terms depending on the field of technology or any other grounds are prohibited. In some cases patent holders cannot fully exploit their patent term, as is the case with regard to pharmaceuticals which cannot be marketed before regulatory approval has been obtained. TRIPS does not state though, whether this term of protection is a purely formal term or whether a patent holder should be granted an effective 20 year term of protection. In Canada - Term of Patent Protection, ${ }^{856}$ the Appellate Body stated that article 33 clearly imposes a minimum term of 20 years patent protection. There seems to be no indication that this minimum term of 20 years should provide effective protection. Consequently, members cannot be forced to grant longer patent terms to compensate for the time lost as a result of a lengthy regulatory approval processes. ${ }^{857}$ Several members, though, attempt to achieve an effective patent term of at least 20 years through the conclusion of bilateral free trade agreements. The actual duration of a patent is of great practical importance, especially with regard to the issue of access to medicines, as every day longer a product is patented a patent holder can maintain high asking prices making the patented pharmaceutical inaccessible to the poor. ${ }^{858}$

852 SCHAABER, Keine Medikamente Für Die Armen?, at 60; HESTERMEYER, Human Rights and the WTO, at 146-147.

853 See for example CORREA, Trade-Related Aspects of IPRs: A Commentary on the TRIPS Agreement, at 89; UNCTAD-ICTSD, Resource Book on TRIPS and Development, at 117.

854 BRIGHT and MURAGURI, 'Access to Medicines: Intellectual Property Rights, Human Rights and Justice', at 109; CIPR, Integrating Intellectual Property Rights and Development Policy, at 41-42.

856 WTO Appellate Body Report, Canada - Term of Patent Protection, adopted 18 September 2000, WT/DS170/AB/R at $\$ 85$.

857 GAMHARTER, Access to Affordable Medicines, at 48; UNCTAD-ICTSD, Resource Book on TRIPS and Development, at 424.

858 CORREA, Trade-Related Aspects of IPRs: A Commentary on the TRIPS Agreement, at 343; HESTERMEYER, Human Rights and the WTO, at 69. 


\title{
3.4.4. Articles $30 \& 31$ TRIPS: Exceptions
}

As we have seen in the previous section, the grant of patent confers a number of exclusive rights on the right holder. These exclusive rights granted to the patent owner are, however, not absolute; and in certain specified situations, the use of the patented invention without authorisation of the right holder is justified. ${ }^{859}$ Most national patent laws include the possibility to derogate from the exclusive rights conferred by a patent to the right holder. However, the scope and content of such exceptions will differ significantly from country to country. ${ }^{860}$

The TRIPS Agreement provides a number of exceptions with regard to the above mentioned rights conferred to the right holder. However, it does not contain a safeguard measure comparable to article XX GATT (or article XIV GATS). These exceptions to the exclusive rights of patent owners should not be confused with the exemptions from patentability as found in article 27.2 and 27.3 TRIPS. In the latter case, inventions which fall within one of the categories of article 27.2 or 27.3 TRIPS are not considered patentable, while in the first case an invention has already been granted patent protection and as such the right holder enjoys a number of exclusive rights which may be subject to the exceptions found in article 30 or 31 TRIPS.

The first, more general, exception to the exclusive rights of patent owner is found in article 30 TRIPS, which reads:

\begin{abstract}
Members may provide limited exceptions to the exclusive rights conferred by a patent, provided that such exceptions do not unreasonably conflict with a normal exploitation of the patent and do not unreasonably prejudice the legitimate interests of the patent owner, taking account of the legitimate interests of third parties.
\end{abstract}

The second exception is more specific and can be found in article 31 TRIPS which states that under a considerable number of conditions a Member may "allow[s] for other use [which refers to use other than allowed under article 30] of the subject matter of a patent without the authorization of the right holder" ${ }^{861}$ The general

859 UNCTAD-ICTSD, Resource Book on TRIPS and Development, at 430.

860 A comparative analysis of national patent laws regarding terms of exceptions that are most commonly provided for in domestic legislation include, but are not limited to the following: (1) the Bolar exception; (2) an exception for research or experimental use of an invention; and (3) an exception for individual prescriptions. See MUSUNGU and OH, The Use of Flexibilities in TRIPS by Developing Countries., at 31-32; UNCTAD-ICTSD, Resource Book on TRIPS and Development, at 431.

861 Article 31 TRIPS reads as follows:

Where the law of a Member allows for other use of the subject matter of a patent without the authorization of the right holder, including use by the government or third parties authorized by the government, the following provisions shall be respected:

(a) authorization of such use shall be considered on its individual merits;

(b) such use may only be permitted if, prior to such use, the proposed user has made efforts to obtain authorization from the right holder on reasonable commercial terms and conditions and that such efforts have not been successful within a reasonable period of time. This 
requirement may be waived by a Member in the case of a national emergency or other circumstances of extreme urgency or in cases of public non-commercial use. In situations of national emergency or other circumstances of extreme urgency, the right holder shall, nevertheless, be notified as soon as reasonably practicable. In the case of public noncommercial use, where the government or contractor, without making a patent search, knows or has demonstrable grounds to know that a valid patent is or will be used by or for the government, the right holder shall be informed promptly;

(c) the scope and duration of such use shall be limited to the purpose for which it was authorized, and in the case of semi-conductor technology shall only be for public noncommercial use or to remedy a practice determined after judicial or administrative process to be anti-competitive;

(d) such use shall be non-exclusive;

(e) such use shall be non-assignable, except with that part of the enterprise or goodwill which enjoys such use;

(f) any such use shall be authorized predominantly for the supply of the domestic market of the Member authorizing such use;

(g) authorization for such use shall be liable, subject to adequate protection of the legitimate interests of the persons so authorized, to be terminated if and when the circumstances which led to it cease to exist and are unlikely to recur. The competent authority shall have the authority to review, upon motivated request, the continued existence of these circumstances;

(h) the right holder shall be paid adequate remuneration in the circumstances of each case, taking into account the economic value of the authorization;

(i) the legal validity of any decision relating to the authorization of such use shall be subject to judicial review or other independent review by a distinct higher authority in that Member;

(j) any decision relating to the remuneration provided in respect of such use shall be subject to judicial review or other independent review by a distinct higher authority in that Member;

(k) Members are not obliged to apply the conditions set forth in subparagraphs (b) and (f) where such use is permitted to remedy a practice determined after judicial or administrative process to be anti-competitive. The need to correct anti-competitive practices may be taken into account in determining the amount of remuneration in such cases. Competent authorities shall have the authority to refuse termination of authorization if and when the conditions which led to such authorization are likely to recur;

(1) where such use is authorized to permit the exploitation of a patent ("the second patent") which cannot be exploited without infringing another patent ("the first patent"), the following additional conditions shall apply:

(i) the invention claimed in the second patent shall involve an important technical advance of considerable economic significance in relation to the invention claimed in the first patent;

(ii) the owner of the first patent shall be entitled to a cross-licence on reasonable terms to use the invention claimed in the second patent; and

(iii) the use authorized in respect of the first patent shall be non-assignable except with the assignment of the second patent.

Article 31 TRIPS applies in cases of use by governments, or third parties authorised by governments, which will be elaborated in the next section. Article 30 would for example apply to situations of non-commercial research. 
Both provisions provide members with the possibility to allow for exceptions to the rights conferred to a right holder through the grant of a patent, without the right holder's authorisation. As with many other TRIPS provisions, the wording is vague in places, and there is no such thing as a generally accepted approach. Moreover, members have the freedom to determine the appropriate method of implementation within the constraints of TRIPS. The following sections will address TRIPS' conditions and determine whether articles 30 and 31 provide the flexibility for developing members to balance the patent standards as required by TRIPS and public health concerns, particularly with respect to a right of access to medicines.

\subsubsection{Article 30 TRIPS: Exceptions to Rights Conferred}

The purpose and scope of exceptions to patent rights vary significantly among national laws, and may apply to non-commercial and commercial acts. Article 30 TRIPS does not intend to restrict members' freedom to determine the grounds of the possible exceptions, however, it establishes the substantive conditions for the admissibility of such exceptions. Examples of exceptions include: use of the invention for teaching and research; commercial experimentation on the invention to test or improve on it; experiments carried out for the purposes of seeking regulatory approval for the marketing of a product after the expiration of a patent (the so-called Bolar, early working or regulatory review exception). ${ }^{863}$ Such exceptions to patent rights operate automatically, which entails that a party making use of an exception does not need to obtain a specific authorisation from a governmental body or judicial body beforehand, as opposed to compulsory licenses under article 31 TRIPS. The exceptions may therefore be invoked as a defence in case of an alleged infringement by any third party during the patent term. ${ }^{864}$

In the Canada - Patent Protection for Pharmaceutical Products case, the EC challenged Canada's Patent Act which provided exceptions to the exclusive rights of patent owners so as to enable competitors to obtain regulatory medicine approval as required by law and manufacture and stockpile the patented invention (the so-called Bolar or regulatory review exception, and stockpiling exception) ${ }^{865} \mathrm{~A}$ competitor (generic) pharmaceutical manufacturer would be allowed to use the patented

863 See also CORREA, Trade-Related Aspects of IPRs: A Commentary on the TRIPS Agreement, at 303.

864 UNCTAD-ICTSD, Resource Book on TRIPS and Development, at 430.

865 The Bolar exception is sometimes also referred to as the regulatory review exception or the early working exception. See section 55.2(1) of Canada's Patent Act: It is not an infringement of a patent for any person to make, construct, use or sell the patented invention solely for uses reasonably related to the development and submission of information required under any law of Canada, a province or a country other than Canada that regulates the manufacture, construction, use or sale of any product.

See for the stockpiling exception section 55.2(2) of Canada's Patent Act: It is not an infringement of a patent for any person who makes, constructs, uses or sells a patented invention in accordance with subsection (1) to make, construct or use the invention, during the applicable 
innovative pharmaceutical before the expiry of the patent to obtain regulatory approval. This provision enabled the manufacturer to market the generic version directly once the patent term for the innovative pharmaceutical patent expired. Otherwise competing pharmaceutical producers could be prevented from using the patented invention to receive market approval which would result in an extended term of monopoly for the patent holder. In addition, the competitor who invoked the regulatory review exception could stockpile the thus manufactured goods for a certain period before the patent expired, but they still had to wait for the expiration of the patent before they could actually market and sell the generic pharmaceutical.

The EC argued that these provisions were inconsistent with the nondiscrimination requirement as stated in article 27.1 TRIPS, because pharmaceutical inventions were treated unfavourably compared to inventions in other fields of technology. This argument was unsuccessful. ${ }^{866}$ The EC also argued that the provisions are inconsistent with the rights conferred on right holders in article 28 and the minimum patent term of 20 years as required by article 33 TRIPS. Canada replied that both provisions were justifiable limited exceptions as allowed by article 30 TRIPS. The panel found that the Bolar or regulatory review exception is not inconsistent with article 28 since it was justified by the exception of article 30 TRIPS; ${ }^{867}$ while the stockpiling exception was found to be inconsistent with article 28.1 and unjustifiable under the exception of article 30 TRIPS. ${ }^{868}$

As stated in article 30 TRIPS and confirmed by the Panel's ruling in the Canada - Patent Protection for Pharmaceutical Products case, three criteria must be fulfilled so as to qualify for an exception under article 30:

1) the measure must be "limited";

2) the measure must not "unreasonably conflict with a normal exploitation of the patent", and

3) the measure must not "unreasonably prejudice the legitimate interests of the patent owner, taking account of the legitimate interests of third parties".

According to the panel "the three conditions are cumulative, each being a separate and independent requirement that must be satisfied." 869 All three conditions will be discussed in turn.

period provided for by the regulations, for the manufacture and storage of articles intended for sale after the date on which the term of the patent expires. 
The TRIPS Agreement: Patent Protection for Pharmaceuticals

\section{Limited Exception}

The first requirement is that the measure must be "limited", meaning that it is confined within definite limits; i.e. subject to certain boundaries for example regarding the acts involved, the purpose of the use, the persons that may invoke the exception, or its duration. ${ }^{870}$ In Canada - Patent Protection for Pharmaceutical Products the Panel interpreted this exception rather narrowly, reasoning that an exception in itself is a limited derogation which is narrowed even further by expressing that it must be a limited exception. ${ }^{871}$ It concluded that, in the absence of other indications, "it would be justified in reading the text literally, focusing on the extent to which legal rights have been curtailed, rather than the size or extent of the economic impact." 872

In the Canada - Patent Protection for Pharmaceutical Products case, the EC challenged Canadian legislation allowing for a Bolar and stockpiling exception. Canada replied that both provisions were justifiably limited exceptions as allowed by article 30 TRIPS. The Panel considered the Bolar exception to be sufficiently limited as it only permitted a few acts of making and using of the patented invention for a specific purpose, that of obtaining regulatory drug approval. ${ }^{873}$ Contrary to this, the stockpiling exception, which allowed a competitor to 'make' and 'use' the patented invention during the last six months of the patent term, was considered not to be 'limited'. ${ }^{874}$ The Panel stated that the stockpiling exception consisted of a

870 CORREA, Trade-Related Aspects of IPRs: A Commentary on the TRIPS Agreement, at 306307; UNCTAD-ICTSD, Resource Book on TRIPS and Development, at 433.

871 Canada - Patent Protection for Pharmaceutical Products, at \$7.30; GERVAIS, The TRIPS Agreement: Drafting History and Analysis, at 243.

872 It further stated: In support of this conclusion, the Panel noted that the following two conditions of Article 30 ask more particularly about the economic impact of the exception, and provide two sets of standards by which such impact may be judged.

Canada - Patent Protection for Pharmaceutical Products, at §7.31; GERVAIS, The TRIPS Agreement: Drafting History and Analysis, at 243; UNCTAD-ICTSD, Resource Book on TRIPS and Development, at 434.

873 'In the Panel's view, however, Canada's regulatory review exception is a 'limited exception' within the meaning of TRIPS Article 30. It is 'limited' because of the narrow scope of its curtailment of Article 28.1 rights. As long as the exception is confined to conduct needed to comply with the requirements of the regulatory approval process, the extent of the acts unauthorized by the right holder that are permitted by it will be small and narrowly bounded." Canada-Patent Protection for Pharmaceutical Products, at $\$ 7.45$.

874 "The right to exclude 'making' and 'using' provides protection, additional to that provided by the right to exclude sale, during the entire term of the patent by cutting off the supply of competing goods at the source and by preventing use of such products however obtained. With no limitations at all upon the quantity of production, the stockpiling exception removes that protection entirely during the last six months of the patent term, without regard to what other, subsequent, consequences it might have. By this effect alone, the stockpiling exception can be said to abrogate such rights entirely during the time it is in effect." Ibid. at §7.34; HESTERMEYER, Human Rights and the WTO, at 235. 
"substantial curtailment of the exclusionary rights required to be granted to patent owners under Article 28.1 of the TRIPS Agreement." 875

This narrow interpretation of the term "limited" in article 30 TRIPS has been criticised as being "unduly narrow". 876 It is argued that the Panel should have taken the objectives and principles of TRIPS and thus also health-related interests into account and allowed exceptions which are limited and pursue the purposes laid down in article 7 and 8.877

\section{Not unreasonably conflict with normal exploitation}

Secondly, the limited exception must not "unreasonably conflict with a normal exploitation" of the patent, which requires a determination of what is "unreasonable" in certain circumstances and when there is a "conflict" with the "normal" exploitation of a patent. In the Canada - Patent Protection for Pharmaceutical Products case the Panel did not address the "unreasonable" requirement, since it concluded that there was no conflict with the normal exploitation of a patent and it was therefore not necessary to elaborate further. The Panel did, however address what it considers "normal exploitation". According to the Panel, "exploitation" refers to the commercial activity of a patent owner in order to extract economic value from the patent. Adding the term "normal" defines the kind of commercial activity article 30 seeks to protect. As such, it refers to both normative standards and empirical data. 878 Thus, "normal exploitation" includes at the very least a patent owner's right to exclude competition during the patent term. ${ }^{879}$

This interpretation has been criticised to be very one-sided in that it focuses only on what a patent owner would consider to be "normal". 880 This could be remedied by considering public health interests and a right of access to medicines as a factor and/or by defining "unreasonably" with these in mind. Measures that do conflict with the "normal exploitation" of a patent are permissible as long as this is not unreasonable. In that sense, the right of access to the medicines should be taken into account by a panel or the $\mathrm{AB}$ in its considerations which is in line with the objectives and principles of TRIPS and the Doha Declaration. ${ }^{881}$

875 Canada-Patent Protection for Pharmaceutical Products, at $\$ 7.36$.

876 See for example HESTERMEYER, Human Rights and the WTO, at 235.

877 GAMHARTER, Access to Affordable Medicines, at 91; HESTERMEYER, Human Rights and the WTO, at 235-236.

878 Canada-Patent Protection for Pharmaceutical Products, at $\$ 7.54$.

879 Ibid. at \$7.55; GERVAIS, The TRIPS Agreement: Drafting History and Analysis, at 243.

880 GAMHARTER, Access to Affordable Medicines, at 93. See also, CORREA, Trade-Related Aspects of IPRs: A Commentary on the TRIPS Agreement, at 308.

881 HESTERMEYER, Human Rights and the WTO, at 236; CORREA, Trade-Related Aspects of IPRs: A Commentary on the TRIPS Agreement, at 310; UNCTAD-ICTSD, Resource Book on TRIPS and Development, at 435-436. 


\section{Not unreasonably prejudice legitimate interests}

The final and third element necessary for a permissible exception under article 30 TRIPS is that the concerned national measure "must not unreasonably prejudice the legitimate interests of the patent owner", in addition to taking into account the "legitimate interests of third parties". The Panel stated that "legitimate interests" are not purely legal interests, as was contested by the EC, but referred to "a normative claim calling for protection of interests that are 'justifiable' in the sense that they are supported by relevant public policies or other social norms." ${ }^{882}$ Furthermore, it considered the interests of a patent owner in receiving compensation for the time lost because of the necessity to obtain regulatory approval, especially where competitors did not lose such time, not so compelling nor widely recognised to warrant them to be "legitimate interests". ${ }^{883}$ However, the Panel's view was criticised in that the discussion on "legitimate interests" should have incorporated considerations with regard to a right of access to medicines and the objectives contained in articles 7 and 8 TRIPS. 884

Moreover, the Panel did not clarify the term "third parties" since it was not considered necessary to do so as the interpretation of "legitimate interests" led to the finding that all tree requirements of article 30 had been met by Canada. ${ }^{885}$ Neither party appealed the decision, so the Appellate Body did not judge on the matter itself. This does leave us with uncertainty about the meaning of this term. Do these include only competitors of the patent holder or also the users of the patented products or processes? The EC argued that "third parties" referred solely to other patent holders while Canada held that "general societal interests and particularly interests connected with health policy", were also within the ambit of the term "third parties". ${ }^{886}$ The Panel did not explicitly state that third parties only included other patent holders, nor did it argue against Canada's statement that general societal interests would fall within the ambit of this term. Interpreting "third parties" to include general societal interests, the interests of the users of patented products and processes, would be a legitimate interpretation in line with the object and purpose of the TRIPS Agreement and the Doha Declaration on TRIPS and Public Health. ${ }^{887}$ Such an interpretation would indicate a more balanced test in determining the scope of exclusive rights.

In conclusion, there are a number of exceptions members could introduce under article 30 TRIPS with a view to enhancing access to medicines, particularly the Bolar exception. However, the relative narrow interpretation of article 30 in the Canada - Patent for Pharmaceutical Products decision suggests that, as the law

\footnotetext{
882 Canada-Patent Protection for Pharmaceutical Products, at $\$ 7.69$.

883 Ibid. at $\$ 7.82$.

884 HESTERMEYER, Human Rights and the WTO, at 236-237.

885 HAUGEN, 'Human Rights and TRIPS Exclusion and Exception Provision', at 356.

886 Canada - Patent Protection for Pharmaceutical Products, at \$7.62, 7.67.

887 HAUGEN, 'Human Rights and TRIPS Exclusion and Exception Provision', at 357.
} 
stands today, article 30 provides only a limited number of measures available for developing members to enhance access to medicines. ${ }^{888}$

\subsubsection{Article 31 TRIPS: Other Use Without Authorisation of the Right HOLDER}

TRIPS provides for another possibility for (developing) WTO members to lower medicine prices and provide patients with increased access to such medicines: the grant of a non-voluntary or compulsory license. This was a fiercely debated matter during the TRIPS negotiations, where developing countries argued for broad governmental powers with regard to the grant of compulsory licenses as opposed to the restrictive views taken by developed countries and especially the US. A compromise had to be struck and this can be found in the wording and complexity of article 31 TRIPS. Many Western developed countries allow for the possibility of compulsory licensing, although the actual use of it is quite rare. ${ }^{889}$

In essence, a compulsory license is a license granted by the government without the authorisation of the right holder to a third party or government agency allowing the patented product or process to be produced or used. A compulsory license is always directed at a single patented process or product and authorises an identified party to use or produce the patented process or product, even without authorisation by the right holder. The use of compulsory licensing is a useful tool for developed and developing countries to tackle public health issues or other public interests. The public interest for allowing broader access to the patented inventions is, thus, considered of a higher importance than retaining the right holder's exclusive rights. ${ }^{890}$ Of course a patent holder, like for example a pharmaceutical corporation, can always grant a third party a voluntary license to produce or use its patented product or process. However, in cases in which such a pharmaceutical corporation is unwilling, a compulsory license or merely the threat thereof can be a useful tool to increase generic production, importation and/or domestic competition and reduce medicine prices. In addition to promoting domestic competition, a compulsory license can also serve other purposes: to ensure that the domestic market is supplied with the patented product, and to promote the growth of a domestic industry. ${ }^{891}$

Article 31 TRIPS reads as follows:

888 See also MOR BAKHOUM, TRIPS, Patent Rights and Right to Health: "Price" or "Prize" for Better Access to Medicine?, Max Planck Institute for Intellectual Property, Competition and Tax Law, 10-07, (2007) at 11.

889 HESTERMEYER, Human Rights and the WTO, at 239-240.

890 MUSUNGU and OH, The Use of Flexibilities in TRIPS by Developing Countries, at 15.

891 CORREA, Trade-Related Aspects of IPRs: A Commentary on the TRIPS Agreement, at 313 et seq; HESTERMEYER, Human Rights and the WTO, at 239. 
Where the law of a member allows for other use of the subject matter of a patent without the authorisation of the right holder, including use by the government or third parties authorised by the government, the following shall be respected: ...

The TRIPS Agreement indicates in a footnote that 'other use' refers to use other than under article 30 TRIPS. This indicates clearly the close relationship between both articles. Article 31 states a great number of provisions $(\mathrm{a}-1)$ that need to be respected when issuing a compulsory license. ${ }^{892}$ This section will discuss the requirement with regard to compulsory licenses starting with the grounds on which a compulsory license may be granted, and then the procedure of a grant and finally the scope of rights granted under a compulsory license will be addressed.

\section{Grounds for a compulsory license}

Article 31 TRIPS does not entail an explicit list of grounds permissible or necessary for the issuance of a compulsory license. Article 5.A (2) of the Paris Convention allows members to grant compulsory licenses to prevent patent abuses, mentioning as an example the failure to work the patent. ${ }^{893}$ However, nowhere does it suggest that patent abuses would be the only permissible ground for issuing a compulsory licensing. Similarly, from article 8 TRIPS it cannot be deduced that it limits members' freedom to take measures, on the contrary, it purposefully clarifies that TRIPS does not prevent members from taking certain measures in the light of public interest. Furthermore, the Doha Declaration on TRIPS and Public Health clearly states that the TRIPS Agreement does not limit the grounds for which compulsory licenses may be granted. ${ }^{894}$ Thus, members could grant a compulsory license for a pharmaceutical product patent to allow a domestic generic manufacturer to produce cheaper generic medicines and consequently lower medicine prices. ${ }^{895}$

892 See further GERVAIS, The TRIPS Agreement: Drafting History and Analysis, at 390 et seq.

893 Article 5.A(2) of the Paris Convention reads as follows:

Each country of the Union shall have the right to take legislative measures providing for the grant of compulsory licenses to prevent the abuses which might result from the exercise of the exclusive rights conferred by the patent, for example, failure to work.

894 WTO, Doha Declaration on TRIPS and Public Health, (WT/MIN(01)/DEC/2) at §5(b); CORREA, Trade-Related Aspects of IPRs: A Commentary on the TRIPS Agreement, at 314-315; HESTERMEYER, Human Rights and the WTO, at 241-242.

895 In their study for CIPIH Sisule F. Musungu (South Centre) \& Cecilia Oh (WHO) have found seven possible grounds for the grant of compulsory licenses based on an analysis of current state practice around the world: (1) the patent holder's refusal to license (in a reasonable period of time and on reasonable commercial terms); (2) public interest; (3) public health and nutrition, including availability and affordability of medicines; (4) situations of national emergency or extreme urgency; (5) to correct anti-competitive practices; (6) enabling the use of a dependent patent for working a new invention; (7) failure to (sufficiently) work a patent locally. MUSUNGU and $\mathrm{OH}$, The Use of Flexibilities in TRIPS by Developing Countries, at 16-17. 
The Panel in Canada - Patent Protection for Pharmaceutical Products held that the non-discrimination requirement of article 27.1 TRIPS also applies to articles 30 and 31 TRIPS and thus also to the grant of a compulsory license. This would suggest that the non-discrimination requirement prohibits grounds for compulsory licenses which discriminate as to the place of invention, the field of technology and as to whether products are imported or produced locally. Such a reading, though, would first of all limit a member's possibility to create technology specific rules, for example specifically for pharmaceutical products. Secondly, it would also prohibit so-called "local working requirements". In that regard article 5.A (2) of the Paris Convention states that the "failure to work" a patent is considered to be an abuse of such a patent and thus an acceptable ground for granting a compulsory license. ${ }^{896}$ The grant of a compulsory license shall be refused unless if the patent holder justifies his inaction by legitimate reasons. ${ }^{897}$ A legitimate reason not to work, a pharmaceutical patent, for example, would be the process of regulatory market approval for the patented pharmaceutical product. The concept of a "local working requirement", is broader than just requiring that the patent is worked, but it adds the condition that it is worked locally. Such a requirement would therefore not be satisfied by merely importing the patented product; and, for instance, a pharmaceutical manufacturer could be held to produce the patented pharmaceutical in that country or risk the grant of a compulsory license. Such an interpretation, however, is contested on the basis of the non-discrimination principle. ${ }^{898}$ Of course, if a patent is not worked at all (so not produced domestically nor imported), the grant of a compulsory license is still possible, although it is constrained by the limits of article 5.A of the Paris Convention. On the one hand, this interpretation of the non-discrimination requirement to compulsory licensing is supported by the Canada - Patent Protection for Pharmaceutical Products decision. On the other hand, such an interpretation would have a strange practical result; in that a national patent law which allows for the grant of a compulsory license if a patent has not been worked locally violates TRIPS, while a much broader patent law allowing a compulsory license to be issued on any ground would not. Additionally, the failure to work a patent as is found in article 5.A of the Paris Convention was traditionally considered to entail working the patent industrially, by manufacturing the product not by importing it.

Local working requirements used to be a common feature of national patent laws and were used to introduce new knowledge and technologies into a territory, an object

896 See also article 5.A(4) of the Paris Convention: A compulsory license may not be applied for on the ground of failure to work or insufficient working before the expiration of a period of four years from the date of filing of the patent application or three years from the date of the grant of the patent, whichever period expires last; it shall be refused if the patentee justifies his inaction by legitimate reasons. Such a compulsory license shall be non-exclusive and shall not be transferable, even in the form of the grant of a sub-license, except with that part of the enterprise or goodwill which exploits such license.

898 HESTERMEYER, Human Rights and the WTO, at 242. 
of the TRIPS Agreement as found in article 7 TRIPS. In that sense, a local working requirement and especially the threat or use of a compulsory license if such a requirement is not complied with, can be a useful tool for developing members trying to encourage technology transfer and the growth of the domestic pharmaceutical industry, or any other technological industry for that matter. The legality of local working requirements has been the subject of a dispute under WTO law in 2000. The United States requested consultations with Brazil concerning Brazil's industrial property law which established a local working requirement. The local working requirement stipulated that a patent shall be subject to compulsory licensing if the subject matter of the patent is not worked - meaning here the failure to manufacture of incomplete manufacture of the product or the failure to make full use of the patented process - in the territory of Brazil. According to the US this was inconsistent with Brazil's obligations under article 27 and 28 of the TRIPS Agreement. ${ }^{899}$ The case attracted quite some attention especially by international civil society which feared it could have detrimental effects on Brazil's successful HIV/AIDS programme. ${ }^{900}$ It was not brought before a panel since the parties came to a mutually satisfactory solution that if the US withdrew its WTO panel, Brazil would agree, in cases of non-fulfilment of the local working requirement, to hold prior talks with the US before granting compulsory licenses on patents held by US companies. Interestingly, the US explicitly stated that it concerns were never directed at Brazil's "bold and effective" HIV/AIDS programme. ${ }^{901}$ Consequently, there is no decision by a panel and the TRIPS compatibility of local working requirements remains uncertain. ${ }^{902}$

\section{Procedure for granting a compulsory license}

The TRIPS Agreement does not provide for a limited set of grounds on which a compulsory license may be granted, it does, however, set a number of procedural requirements, which will briefly be discussed in turn here:

- Authorisation on individual merits ${ }^{903}$

The first requirement the TRIPS Agreement sets out is that authorisation of such use, that is use without the authorisation of the right holder, shall be considered on its individual merits. It is not possible for a member to include in its domestic law a

899 WTO, Brazil - Measures Affecting Patent Protection. Request for Consultations by the United States (WT/DS199/1; 2000).

900 'T HOEN, The Global Politics of Pharmaceutical Monopoly Power, at 22.

901 WTO, Brazil-Measures Affecting Patent Protection. Notification of Mutually Agreed Solution (WT/DS199/4; 2001). See for more information GERVAIS, The TRIPS Agreement: Drafting History and Analysis, at 359-361.

902 HESTERMEYER, Human Rights and the WTO, at 243-244; MUSUNGU and OH, The Use of Flexibilities in TRIPS by Developing Countries, at 17; UNCTAD-ICTSD, Resource Book on TRIPS and Development, at 482.

903 Article 31(a) TRIPS: authorization of such use shall be considered on its individual merits. 
regulation for automatic compulsory licensing for pharmaceuticals. However, this provision is not absolute. Specifically concerning a right of access to medicines, the provision does not preclude a member from creating a domestic regulation establishing, for example, a presumption supportive of compulsory licensing for pharmaceuticals in the public interest, as long as the authority granting the compulsory license considers the actual grant on its individual merits. ${ }^{904}$

- Prior negotiations $^{905}$

A further requirement stipulated by TRIPS entails that the use of a patent's subject matter without the authorisation of the right holder "may only be permitted if, prior to such use, the proposed user has made efforts to obtain authorisation from the right holder on reasonable commercial terms and conditions and that such efforts have not been successful within a reasonable period of time." This requirement of prior negotiations is inherently flexible since reasonableness of the commercial terms and period of time depend on context. In that regard it allows the granting authority to take into account the circumstances of a specific case and thus also considerations of public health and a right of access to medicines. The interpretation of reasonableness however, could prove to be problematic. ${ }^{906}$

The requirement to engage in prior negotiations is waived in three situations: (1) in the case of a "national emergency or other circumstances of extreme urgency" the prior negotiation requirement is waived. However, in such case the right holder shall "be notified as soon as reasonably practicable"; (2) the prior negotiation requirement is also waived in "cases of public non-commercial use". Here the right holder "shall be informed promptly"; (3) finally, the prior negotiation requirement is

904 HESTERMEYER, Human Rights and the WTO, at 245; CORREA, Trade-Related Aspects of IPRs: A Commentary on the TRIPS Agreement, at 320; UNCTAD-ICTSD, Resource Book on TRIPS and Development, at 468.

905 Article 31(b) TRIPS: such use may only be permitted if, prior to such use, the proposed user has made efforts to obtain authorization from the right holder on reasonable commercial terms and conditions and that such efforts have not been successful within a reasonable period of time. This requirement may be waived by a Member in the case of a national emergency or other circumstances of extreme urgency or in cases of public non-commercial use. In situations of national emergency or other circumstances of extreme urgency, the right holder shall, nevertheless, be notified as soon as reasonably practicable. In the case of public non-commercial use, where the government or contractor, without making a patent search, knows or has demonstrable grounds to know that a valid patent is or will be used by or for the government, the right holder shall be informed promptly.

Article 31(k) TRIPS: Members are not obliged to apply the conditions set forth in subparagraphs (b) and (f) where such use is permitted to remedy a practice determined after judicial or administrative process to be anti-competitive. The need to correct anti-competitive practices may be taken into account in determining the amount of remuneration in such cases. Competent authorities shall have the authority to refuse termination of authorization if and when the conditions which led to such authorization are likely to recur.

906 GAMHARTER, Access to Affordable Medicines, at 98; HESTERMEYER, Human Rights and the WTO, at 246; UNCTAD-ICTSD, Resource Book on TRIPS and Development, at 469-470. 
waived where a compulsory license "is permitted to remedy a practice determined after judicial or administrative process to be anticompetitive."907

These exceptions simplify and speed up the process of granting a compulsory license and as such enhance the usefulness of compulsory licensing for public health purposes. The first possibility (an emergency situation and circumstances of extreme urgency) which allows for compulsory licensing without first requiring that the user attempts to obtain the prior authorisation of the right holder pertains to situations where a speedy reaction is required to prevent possible severe consequences. Both cases imply that there is no time to engage in prior negotiations with patent holders. This provision can be read either in favour or against compulsory licensing of pharmaceuticals aiming to enhance access to medicines. The broader interpretation in favour implies that (certain) diseases have grave consequences for a country's population and need a speedy reaction to contain them and prevent further harmful effects. That would entail that a country would classify its situation as one of emergency, which is not always a favourable option as it could dissuade possible investors and/or tourists. Conversely, it could be argued that these provisions never intended to provide tools for long-term problems like public health pandemics, and as such, warrant a narrow interpretation of this provision excluding (long-term) public health issues, such as situations of emergency or extreme urgency. ${ }^{908}$ However, it has been explicitly confirmed in the Doha Declaration on TRIPS and Public Health that each member has the right to determine what constitutes a national emergency or other circumstances of extreme urgency, it being understood that public health crises, including those relating to HIV/AIDS, tuberculosis, malaria and other epidemics, can represent a national emergency or other circumstances of extreme urgency. ${ }^{909}$

The second possibility which is that of public non-commercial use, is also a potentially useful tool for developing countries in the field of public health. Public non-commercial use is the use of the subject matter of a patented invention, for example a pharmaceutical, by a government entity or a private contractor of a government entity. The term "non-commercial" indicates that the use occurs outside a commercial setting, and therefore not for profit. A narrow reading of this term would suggest that no entity may be involved in the act for the purpose of making a profit, which could result in preventing any private companies from participating. It has been argued that such a narrow interpretation would make this provision totally ineffective for governments, since most governments do not have

907 Article 31(b) \& (k) TRIPS.

908 HESTERMEYER, Human Rights and the WTO, at 246-247. In 2002 Zimbabwean's Minister of Justice declared an initial 6 month period of emergency with regard to the domestic HIV/AIDS epidemic, enabling the state or a by the stated authorised party to make or use any patented drug, and/or import any generic drug used in the treatment of HIV/AIDS infected people. This period of emergency was extended for another 5 years from January 2003 to December 2008. GERVAIS, The TRIPS Agreement: Drafting History and Analysis, at 54; MUSUNGU and OH, The Use of Flexibilities in TRIPS by Developing Countries, at 22-23. 
the capacity to manufacture patented (pharmaceutical) products themselves. A better understanding of the term would therefore entail that the intention or purpose which underlies the public use must be of a non-commercial nature. ${ }^{910}$ Thus, the exploitation of a patented product by a private entity for the benefit of the public, for example purchasing or producing anti-retroviral medicines and distributing them to public hospitals without profit, would fall within the ambit of this provision. Clearly, it cannot be that the public use of a patented invention intends to create a profit for the government. In the light of enhancing access to medicines for patients in developing countries, the broader view that the purpose for which the public use exception is used must be non-commercial is more favourable. ${ }^{911}$

Thirdly, if a compulsory license is granted to remedy an anti-competitive practice, the member is waived from the obligation to engage in prior negotiations and the obligation that use of a compulsory license is predominantly for the supply of the domestic market. ${ }^{912}$ The difficulty here is of course, what constitutes an anticompetitive practice, since patents by their very nature intend to exclude competition from the market. TRIPS does not give a definition of the term "anti-competitive practice", however article $31(\mathrm{k})$ does state that a judicial or administrative process must determine the practice to be anti-competitive. Thus, it would seem that members have the freedom to interpret this term as in the way that suits their interests best. ${ }^{913}$

\section{- Adequate remuneration 914}

The TRIPS Agreement further requires that "the right holder shall be paid adequate remuneration". Each case must be considered on its individual circumstances and shall take into account the economic value of the authorisation. If the compulsory

$910 \quad$ Ibid. at 317.

911 HESTERMEYER, Human Rights and the WTO, at 247; MUSUNGU and OH, The Use of Flexibilities in TRIPS by Developing Countries, at 20. In 2003 Malaysia authorised a local company to import three anti-retroviral medicines from India for the sole purpose to supply to public hospitals. The reason for this authorisation was the government's lack of success in the price negotiations with the patent holding corporations. It is reported that the introduction of generic ARVs has led to significant reductions in the cost of treatment of HIV/AIDS infected people. See ibid. at 24-26.

912 Article 31(k) TRIPS.

913 BERGER, 'Tripping over Patents: AIDS, Access to Treatment and the Manufacturing of Scarcity', at 202; GALLEGO, 'Intellectual Property Rights and Competition Policy', at 246.

914 Article 31(h) TRIPS: the right holder shall be paid adequate remuneration in the circumstances of each case, taking into account the economic value of the authorization.

Article 31(k) TRIPS: Members are not obliged to apply the conditions set forth in subparagraphs (b) and (f) where such use is permitted to remedy a practice determined after judicial or administrative process to be anti-competitive. The need to correct anti-competitive practices may be taken into account in determining the amount of remuneration in such cases. Competent authorities shall have the authority to refuse termination of authorization if and when the conditions which led to such authorization are likely to recur. 
license is a result of anti-competitive practice, this fact may be taken into account when determining the amount of remuneration. ${ }^{915}$

This requirement could prove problematic with a view to enhancing access to medicines, as the intention underlying the use of a compulsory license is to allow (generic) pharmaceutical manufacturers to produce generic medicines, creating competition and thus lower prices. Compulsory licensing would be rendered totally useless if the (generic) manufacturer producing under a compulsory license had to pay too high a remuneration. The essence comes down to the following question: what level of remuneration is adequate? ${ }^{916}$ The textual interpretation seems to indicate that 'full compensation' for the right holder of the patented product is not required. ${ }^{917}$ Factors that need to be taken into account when considering the amount of remuneration are: interests of the patent holder and the interests of the public and the economic situation of the country granting the compulsory license. Here public health concerns and a right of access to medicines may be of value as an interpretative guide. For example, a developing or least-developed country with an extensive HIV/AIDS epidemic should reward a lower amount of compensation than a fully developed country not facing a public health crisis. ${ }^{918}$

\section{- Review ${ }^{919}$}

A final procedural requirement stipulated by TRIPS concerning the grant of a compulsory license is the obligation that "the legal validity of any decision relating to the authorisation of such use [under a compulsory license] shall be subject to judicial review or other independent review by a distinct higher authority". This possibility of review must also exist for the decision relating to the amount of remuneration provided. Since legal systems and procedures of members will differ substantially, the requirements for review are set out in general terms providing members with considerable discretion in implementation. ${ }^{920}$ Finally, these provisions must be read in conjunction with article 44.2 TRIPS which addresses injunctions and provides that remedies may be limited to the payment of remuneration. ${ }^{921}$

915 GALLEGO, 'Intellectual Property Rights and Competition Policy', at 245.

916 CORREA, Trade-Related Aspects of IPRs: A Commentary on the TRIPS Agreement, at 322-323; HESTERMEYER, Human Rights and the WTO, at 248; UNCTAD-ICTSD, Resource Book on TRIPS and Development, at 475-476.

917 GAMHARTER, Access to Affordable Medicines, at 101.

918 HESTERMEYER, Human Rights and the WTO, at 248-249.

919 Article 31(i) TRIPS: the legal validity of any decision relating to the authorization of such use shall be subject to judicial review or other independent review by a distinct higher authority in that Member.

Article 31(j) TRIPS: any decision relating to the remuneration provided in respect of such use shall be subject to judicial review or other independent review by a distinct higher authority in that Member.

920 UNCTAD-ICTSD, Resource Book on TRIPS and Development, at 477.

921 Article 44.2 reads as follows: Notwithstanding the other provisions of this Part and provided that the provisions of Part II specifically addressing use by governments, or by third parties 
Chapter 4

Scope of rights granted under a compulsory license

In addition to the above mentioned procedural conditions, article 31 TRIPS also stipulates a number of requirements with regard to the scope of the rights granted under a compulsory license.

\section{- Limited by the purpose $e^{922}$}

Article 31 TRIPS states clearly that the "scope and duration of the compulsory license "shall be limited to the purpose for which it was authorised". Furthermore, it stipulates that a compulsory license shall be liable to be terminated once the "circumstances which led to it cease to exist and are unlikely to recur." However, such a possibility to terminate a compulsory license must be "subject to adequate protection of the legitimate interests of the persons so authorised". This is relevant since if a compulsory license would be granted to a pharmaceutical corporation allowing for the production of a generic version of a patented drug, that pharmaceutical corporation would make certain investments beforehand. For example, it would need to ready its manufacturing capacity to be able to produce this type of drug. If the compulsory license is liable to be terminated at any given time, it is likely not to be a very lucrative investment. ${ }^{923}$

\section{- Non-exclusive \& non-assignable 924}

The use of a patent's subject matter under a compulsory license must be nonexclusive entailing that after the grant of a compulsory license a right holder can still work its patent. And a compulsory license "shall be non-assignable, except with that part of the enterprise or goodwill which enjoys such use".

authorized by a government, without the authorization of the right holder are complied with, Members may limit the remedies available against such use to payment of remuneration in accordance with subparagraph (h) of Article 31. In other cases, the remedies under this Part shall apply or, where these remedies are inconsistent with a Member's law, declaratory judgments and adequate compensation shall be available.

Article 31(c) TRIPS: the scope and duration of such use shall be limited to the purpose for which it was authorized, and in the case of semi-conductor technology shall only be for public noncommercial use or to remedy a practice determined after judicial or administrative process to be anti-competitive.

Article 31(g) TRIPS: authorization for such use shall be liable, subject to adequate protection of the legitimate interests of the persons so authorized, to be terminated if and when the circumstances which led to it cease to exist and are unlikely to recur. The competent authority shall have the authority to review, upon motivated request, the continued existence of these circumstances.

924 Article 31(d) TRIPS: such use shall be non-exclusive.

Article 31(e) TRIPS: such use shall be non-assignable, except with that part of the enterprise or goodwill which enjoys such use. 


\section{- Territoriality ${ }^{925}$}

Firstly, the principle of territoriality entails that the use of the subject matter of a patent without authorisation under a compulsory license is effective only within the territory of the country where the compulsory license is granted. Secondly, article 31 TRIPS specifies that use under a compulsory license must be "predominately for the supply of the domestic market" of the country issuing the compulsory license. This condition is not required if the compulsory license is intended to remedy an anti-competitive situation..$^{926}$

In this context determining the exact meaning of the term "predominantly" is of course essential. Several options are possible: firstly it could entail that more than $50 \%$ of the use has to occur for the supply of the domestic market; a second option is that the domestic market must be the most important market for which the use is intended. However, this could mean that less than $50 \%$ of the use goes to the supply of the domestic market depending on the number of other, foreign markets the use supplies; and thirdly, instead of referring to the actual production it could refer to the "intent" of the country issuing the compulsory license. In interpreting the term predominantly it has been argued that a right of access to medicines should be taken into account to adopt the most flexible approach, leaving ample room for least-developed and developing countries to manoeuvre and handle their public health issue domestically. ${ }^{927}$

This requirement of article 31 TRIPS has some dramatic consequences for the ability of developing members' to ensure access to medicines and as such it has caused much controversy and heated debate. The problem is that, especially leastdeveloped members, but also developing countries seldom have a pharmaceutical industry with the manufacturing capacity to make use of the possibility of compulsory licensing effectively. Developing members that do have sufficient domestic manufacturing capacity, like for example India and Brazil, are able to authorise the production of cheaper generic drugs under a compulsory license, but they do this predominately for the supply of the domestic market and not for export to those least-developed or developing countries without sufficient domestic manufacturing capacity. This has especially grave consequences for those countries facing a severe public health crisis.

Additionally, TRIPS' transitional periods for developing countries expired on January, $1^{\text {st }}, 2005$, although the transitional periods for least-developed countries

925 Article 31(f) TRIPS: any such use shall be authorized predominantly for the supply of the domestic market of the Member authorizing such use.

Article 31(k) TRIPS: Members are not obliged to apply the conditions set forth in subparagraphs (b) and (f) where such use is permitted to remedy a practice determined after judicial or administrative process to be anti-competitive. The need to correct anti-competitive practices may be taken into account in determining the amount of remuneration in such cases. Competent authorities shall have the authority to refuse termination of authorization if and when the conditions which led to such authorization are likely to recur.

926 See above under the heading prior negotiations.

927 HESTERMEYER, Human Rights and the WTO, at 251. 
have been extended to 2021. Before the end of the transitional period, a number of (developing) countries did not allow patents for pharmaceutical products. Notably India was one of those countries that did not allow the patenting of pharmaceuticals and which also had a domestic manufacturing capacity enabling it to produce generic medicines, and as such, acquired the label of being the 'pharmacist of the poor'. However, a least-developed or developing country without domestic manufacturing capacity will find it more difficult to import cheaper generic versions of a medicine, because all WTO members, except for least-developed members, must allow for the patenting of pharmaceutical products. A member willing to export generic medicines to members lacking manufacturing capacity, must either provide for an exception from patent protection for pharmaceuticals under article 30 TRIPS or grant a compulsory license under article 31 TRIPS, allowing the use of the patented pharmaceutical for the purpose of export. Both approaches clash with the general interpretation of TRIPS. The first interpretation is prohibited by the Panel's, argued by some, unduly interpretation of article 30 TRIPS in the CanadaPatent Protection for Pharmaceutical Products case, while the latter is impermissible because article 31(f) demands that use under a compulsory license is predominantly for the supply of the domestic market. ${ }^{928}$

This issue has caught the attention of the WTO Ministerial Conference and as a result it adopted a Decision on August 30 3003 waiving the obligations under article 31(f) TRIPS for an exporting member under a number of conditions. Moreover, an amendment to the TRIPS Agreement is foreseen resulting in the addition of article 31 bis. ${ }^{929}$

\subsubsection{CONCLUSION}

The previous section has addressed TRIPS' conditions to determine whether articles 30 and 31 provide the flexibility for developing members to balance the patent standards as required by TRIPS with public health concerns, particularly with respect to a right of access to medicines. Both provisions provide members with options to limit patent rights in favour of public health interests. Article 30 TRIPS for example, would allow members to implement a Bolar exception. However, the relatively narrow interpretation of article 30 in the Canada-Patent for Pharmaceutical Products decision suggests that article 30 does not provide an extremely useful flexibility for developing members to enhance access to medicines.

Article 31 TRIPS, which allows members to grant compulsory licenses, might therefore prove to be a more useful tool for developing members. ${ }^{930}$ Since article 31

\footnotetext{
928 Ibid. at 251-252.

929 See further section 5.1 of chapter 5.

930 Contrary: RICHARD A. EPSTEIN and A. SCOTT KIEFF, Questioning the Frequency and Wisdom of Compulsory Licensing for Pharmaceutical Patents, The University of Chicago Law School John M. Olin Law \& Economic Working Papers, WP No. 527, (2010).
} 
does not explicitly list the grounds on which one may grant compulsory licenses, this leaves developing members with considerable freedom to use this tool for public health purposes. Furthermore, the requirement that prior negotiations must be undertaken before a compulsory license may be granted is waived in situations of national emergencies and situations of extreme urgency. Consequently, in recent years a number of developing countries have made use of, or have threatened to make use of compulsory licensing procedures which in some instances have led to agreements with major pharmaceutical companies, for example, Brazil (in 2003 \& 2007), Indonesia (2004 \& 2008), Malaysia (2004), Zambia (2004), Zimbabwe (2004), Thailand (2006-07), and India (2012). ${ }^{931}$ On the other hand, the value of compulsory licensing has been questioned, especially since few developing countries that have made use of this tool in order to enhance access to medicines. The reasons for this are: the many conditions required by TRIPS makes compulsory licensing a complex, cumbersome and long winded procedure; it requires an administrative and legal infrastructure that is lacking in many developing countries; developing countries fear possible (trade) sanctions by countries with a strong pharmaceuticals lobby; under the TRIPS system compulsory licenses are nonexclusive and for a limited period, which tends to make them less attractive for compulsory license holders; and TRIPS requires compulsory licenses to be predominantly for the supply of the domestic market. ${ }^{932}$ This last reason is particularly problematic for least-developed members, as they rarely have the local capacity to manufacture generic pharmaceuticals. Consequently, the WTO General Council has introduced a waiver system allowing members to produce under compulsory license for export which is intended to be incorporated into the TRIPS Agreement as article 31bis.

\subsubsection{Article 32 TRIPS: Revocation}

The TRIPS Agreement also allows for the revocation or forfeiture of a patent as long as there is "an opportunity for judicial review of any decision to revoke or

931 JEROME H. REICHMAN, 'Compulsory Licensing of Patented Pharmaceutical Inventions: Evaluating the Options', in Carlos M. Correa (ed.), Research Handbook on the Protection of Intellectual Property under WTO Rules. Intellectual Property in the WTO Volume 1 (Research Handbooks on the WTO; Cheltenham/Northampton: Edward Elgar, 2010) at 596-597. See also 'T HOEN, The Global Politics of Pharmaceutical Monopoly Power, at 44 et seq; CRISTINA D'ALMEIDA et al., 'New Antiretroviral Treatments and Post-2005 TRIPS Constraints: First Moves Towards IP Flexibilisation in Developing Countries', in Benjamin Coriat (ed.), The Political Economy of HIVIAIDS in Developing Countries. TRIPS, Public Health Systems and Free Access (Cheltenham: Edward Elgar, 2008) at 38 et seq.

932 S.K. VERMA, 'The Doha Declaration and Access to Medicines by Countries without Manufacturing Capacity', in Carlos M. Correa (ed.), Research Handbook on the Protection of Intellectual Property under WTO Rules. Intellectual Property in the WTO Volume 1 (Research Handbooks on the WTO; Cheltenham/Northampton: Edward Elgar, 2010) at 640. 
forfeit a patent". 933 National patent law generally includes the possibility to revoke a patent for different reasons, for example when the conditions for a patent were not fulfilled at the time of granting the patent. The TRIPS Agreement, however, does not mention anything with regard to the grounds on which a patent may be revoked. ${ }^{934}$ Therefore, a patent could, theoretically, be revoked on public health grounds, for example that patent protection would lead to an increase in medicine prices. However, such an interpretation of article 32 TRIPS is unlikely and undesirable. If revocation of a patent would be possible on any ground without any safeguard for the right holder's interests, all patent-related provisions of the TRIPS Agreement would be rendered virtually useless. This would also not be in line with the extensive procedure under article 31 which is simply to grant a compulsory license. ${ }^{935}$

Furthermore, article 5.A (3) of the Paris Convention states the following:

Forfeiture of the patent shall not be provided for except in cases where the grant of compulsory licenses would not have been sufficient to prevent the said abuses [i.e. abuses which might result from the exercise of the exclusive rights conferred by the patent]. ${ }^{936}$ No proceedings for the forfeiture or revocation of a patent may be instituted before the expiration of two years from the grant of the first compulsory license.

Some commentators find that the Paris Convention does not rule out revocation or forfeiture of a patent based on public interest, instead of just abuse, and in such a case the conditions of article 5.A(3) Paris Conventions would not apply. However, a decision based on strong public interest considerations would be easier to justify if abuse of the said patent was involved. If a state adheres to the interpretation that article 5.A (3) of the Paris Convention only applies when revocation or forfeiture is based on abuse, then one could argue that basing a decision to revoke or forfeit on strong public interest reasons, as opposed to abuse, would enable it to circumvent the two year requirement, which in urgent public health situations, where access to life-saving medicines are at stake, might be vital. Such a strategy would only be possible, if compulsory licensing would be ineffective in mitigating the situation, and the forfeiture or revocation of the patent is the most appropriate measure under the circumstances. ${ }^{937}$

Article 32 TRIPS reads as follows: An opportunity for judicial review of any decision to revoke or forfeit a patent shall be available. 
The TRIPS Agreement: Patent Protection for Pharmaceuticals

\subsection{Protection of Undisclosed Information}

In addition to patents, undisclosed information is one of the categories of intellectual property included in the framework of TRIPS: section 7 of Part II of the TRIPS Agreement consisting of a single article. The TRIPS Agreement is the first international instrument to specifically include obligations regarding undisclosed information including test data. ${ }^{938}$

Article 39 TRIPS does not provide a definition of "undisclosed information" but it would include any secret information of commercial value, such as technical know-how, data of commercial value and of particular importance for the discussion with regards to pharmaceuticals test data and other data submitted for the regulatory approval of pharmaceutical (and agro-chemical) products. ${ }^{939}$ Protecting clinical test data prevents regulatory authorities for a certain period from relying on the test data submitted by originator pharmaceutical manufacturers in order to grant regulatory approval to generic versions of the already approved originator (patented) pharmaceutical. Data exclusivity therefore adds an additional term of protection which, from the viewpoint of the right to health could be problematic for developing countries aiming at ensuring the rapid entry of generic competition once the patent term has expired.

Article 39.1 TRIPS provides the main rule applicable with regard to undisclosed information and the context for interpreting the second and third paragraph of the article: members must protect undisclosed information against unfair competition as provided in article 10bis(1) of the Paris Convention. ${ }^{940}$ Paragraph 2 of article 39 TRIPS ensures that natural and legal persons "have the possibility of preventing information lawfully within their control from being disclosed to, acquired by, or

938 CARLOS M. CORREA, 'Data Exclusivity for Pharmaceuticals: TRIPS Standards and Industry's Demand in Free Trade Agreements', in Carlos M. Correa (ed.), Research Handbook on the Protection of Intellectual Property under WTO Rules. Intellectual Property in the WTO Volume 1 (Cheltenham/Northampton: Edward Elgar, 2010) at 718; GERVAIS, The TRIPS Agreement: Drafting History and Analysis, at 424; UNCTAD-ICTSD, Resource Book on TRIPS and Development, at 522.

939 UNCTAD-ICTSD, Resource Book on TRIPS and Development, at 521.

940 Article 39.1 TRIPS: In the course of ensuring effective protection against unfair competition as provided in Article 10bis of the Paris Convention (1967), Members shall protect undisclosed information in accordance with paragraph 2 and data submitted to governments or governmental agencies in accordance with paragraph 3.

Article 10bis of the Paris Convention reads as follows:

(1) The countries of the Union are bound to assure to nationals of such countries effective protection against unfair competition.

(2) Any act of competition contrary to honest practices in industrial or commercial matters constitutes an act of unfair competition.

(3) The following in particular shall be prohibited:

1. all acts of such a nature as to create confusion by any means whatever with the establishment, the goods, or the industrial or commercial activities, of a competitor;

2. false allegations in the course of trade of such a nature as to discredit the establishment, the goods, or the industrial or commercial activities, of a competitor; 
used by others without their consent in a manner contrary to honest commercial practices" specifying the conditions that such information needs to meet to be deemed undisclosed and thus protectable. ${ }^{941}$

Of particular importance for the discussion here is article 39.3 TRIPS, which reads as follows:

3. Members, when requiring, as a condition of approving the marketing of pharmaceutical or of agricultural chemical products which utilize new chemical entities, the submission of undisclosed test or other data, the origination of which involves a considerable effort, shall protect such data against unfair commercial use. In addition, Members shall protect such data against disclosure, except where necessary to protect the public, or unless steps are taken to ensure that the data are protected against unfair commercial use.

A basic premise for the application of paragraph 3 of this article is that the member imposes an obligation to submit data as a condition in order to obtain marketing approval for pharmaceutical (or agrochemical) products. This condition the submission of data is not a requirement everywhere however; in some states the national regulatory authority will grant marketing approval by relying on the existence of such approval in another country. In such cases article 39.3 is not applicable.

The subject matter protected by article 39.3 relates to undisclosed information, test or other data, contained in written material detailing the results of the clinical trials. Furthermore, such data must relate to "new chemical entities", a concept not defined by the TRIPS Agreement. From the ordinary meaning it would seem though that article 39.3 does not apply to new uses or new forms of known products as these do not relate to new chemical entities. ${ }^{942}$

3. indications or allegations the use of which in the course of trade is liable to mislead the public as to the nature, the manufacturing process, the characteristics, the suitability for their purpose, or the quantity, of the goods.

941 Article 39.2 TRIPS: Natural and legal persons shall have the possibility of preventing information lawfully within their control from being disclosed to, acquired by, or used by others without their consent in a manner contrary to honest commercial practices10 so long as such information:

(a) is secret in the sense that it is not, as a body or in the precise configuration and assembly of its components, generally known among or readily accessible to persons within the circles that normally deal with the kind of information in question;

(b) has commercial value because it is secret; and

(c) has been subject to reasonable steps under the circumstances, by the person lawfully in control of the information, to keep it secret.

See further GERVAIS, The TRIPS Agreement: Drafting History and Analysis, at 424-425; UNCTAD-ICTSD, Resource Book on TRIPS and Development, at 528-530.

942 CORREA, 'Data Exclusivity for Pharmaceuticals', at 718; UNCTAD-ICTSD, Resource Book on TRIPS and Development, at 530. 
Article 39.3 TRIPS does not impose any substantive standard for granting protection but only commands protection when obtaining data involved "a considerable effort". What type of effort, and when such an effort is deemed considerable is left open. Reasonably, the effort involved should be significant both in economic terms and from a technical and scientific perspective. 943

The standard required under article 39 TRIPS is limited to obliging members to protect undisclosed information against unfair competition. The obligation under article 39.3 TRIPS requires protection to be granted in two cases: against unfair commercial use and against disclosure of the relevant protected information. Regarding the latter, the standard of protection is subject to two exceptions: when disclosure is necessary to protect the public, and when steps have been taken to ensure that the data will not be used in a commercially unfair manner.

There has been much controversy as to the extent of the obligation to protect data against unfair commercial use under the TRIPS Agreement. ${ }^{944}$ Some have argued that the most effective way to protect such data is by granting the originator of the data a period of exclusive use. That would entail that national regulatory authorities could not, during the period of exclusivity, rely on already received clinical test data by the originator pharmaceutical corporation in order to assess subsequent applications by other companies for marketing approval of generic equivalents of the original pharmaceutical. This is the prevailing view in a number of developed countries and supported by the pharmaceutical research-based industry. It is argued that it is of fundamental importance to protect clinical test data because pharmaceutical corporations invest heavily in the research necessary in order to develop the relevant data. Furthermore, where patent laws fail to provide protection (for example when the active component was shortly off-patent, or the pharmaceutical was based on a combination of known substances used in a new way which may not satisfy patent requirements) exclusivity of clinical test data is the only way in which to prevent generic producers from quickly producing and registering a generic equivalent of the original pharmaceutical. ${ }^{945}$

On the other hand, it is argued that article 39.3 TRIPS does not prescribe exclusivity but that undisclosed information, such as clinical test data, must be protected against unfair commercial use. ${ }^{946}$ The question then of course is what is considered to be "unfair commercial use" and would it prevent national regulatory authorities from relying on already received clinical test data to grant marketing approval to generic equivalents? The ordinary meaning of unfair competition entails market behaviour not equitable, honest, impartial or according to rules. ${ }^{947}$

\footnotetext{
943 GERVAIS, The TRIPS Agreement: Drafting History and Analysis, at 428; UNCTAD-ICTSD, Resource Book on TRIPS and Development, at 531.

944 GAMHARTER, Access to Affordable Medicines, at 50-51; GERVAIS, The TRIPS Agreement: Drafting History and Analysis, at 428-429.

945 UNCTAD-ICTSD, Resource Book on TRIPS and Development, at 531.

946 CORREA, 'Data Exclusivity for Pharmaceuticals', at 718-719.

947 UNCTAD-ICTSD, Resource Book on TRIPS and Development, at 527.
} 
This clarifies little and will depend on the kind of practices trade secret laws have traditionally classified as unfair. Arguably, the reliance of national regulatory authorities on already received clinical test data in approving generic versions of an already approved (originator) pharmaceutical is not considered "unfair commercial use" and, as such, is outside the scope of article 39.3 TRIPS. ${ }^{948}$ Furthermore, requiring generic manufacturers to generate their own data for marketing approval would be wasteful as it entails repetitive clinical investigation and would be ethically questionable. Particularly from a public health perspective ensuring the swift entry of generic competition and thus allowing for more affordable medicines is an important public policy objective. ${ }^{949}$ It is this view that has been advocated by many developing countries. ${ }^{950}$

Consequently, with respect to pharmaceutical products the protection of undisclosed information supplements the protection granted to such products via patents. However it seems that, unlike patent protection for pharmaceuticals, article 39 TRIPS does not necessarily entail the granting of exclusive rights. The ambiguity of the TRIPS Agreement has been argued to have been a catalyst for developed countries, particularly the US, to seek establishment and implementation of strong(er) data exclusivity standards via free-trade agreements and other trade relations tools, such as the USTR's "(priority) watch list."951

\subsection{Enforcement of Intellectual Property Rights}

Part III of the TRIPS Agreement sets out the minimum standards for the enforcement of intellectual property rights, and Part IV does the same for the acquisition and maintenance of such rights. As with the substantive standards regarding patents, the TRIPS Agreement does not harmonise national laws regarding enforcement; it merely sets out minimum standards which must be

948 HESTERMEYER, Human Rights and the WTO, at 62-63; JEROME H. REICHMAN, 'The International Legal Status of Undisclosed Clinical Trial Data: From Private to Public Goods?', in Pedro Roffe, Geoff Tansey, and David Vivas-Eugui (eds.), Negotiating Health. Intellectual Property and Access to Medicines (London: Earthscan, 2006) at 143-144.

949 UNCTAD-ICTSD, Resource Book on TRIPS and Development, at 538.

950 WTO COUNCIL FOR TRADE-RELATED ASPECTS OF INTELLECTUAL PROPERTY RIGHTS, Submission by the African Group, Barbados, Bolivia, Brazil, Cuba, Dominican Republic, Ecuador, Honduras, India, Indonesia, Jamaica, Pakistan, Paraguay, Philippines, Peru, Sri Lanka, Thailand and Venezuela, (IP/C/W/296) at 8-9.

See further BROOK K. BAKER, 'Ending Drug Registration Apartheid: Taming Data Exclusivity and Patent/Registration Linkage', American Journal of Law \& Medicine, 34 (2008), 303-344.

951 MEIR P. PUGATCH, 'Intellectual Property, Data Exclusivity, Innovation and Market Access', in Pedro Roffe, Geoff Tansey, and David Vivas-Eugui (eds.), Negotiating Health. Intellectual Property and Access to Medicines (London: Earthscan, 2006) at 122. See further section 6 of chapter 5 . 
implemented by members in a manner deemed appropriate for the member's legal system and practice in line with article 1 of the TRIPS Agreement.

One of the key reasons for the inclusion of IPRs within the WTO framework, especially for developed countries, was the lack of enforcement mechanisms within existing IP conventions. These conventions also did not require any form of domestic enforcement of IPRs. For right holders, the existence of substantive minimum rights is of no value when these cannot be enforced. The TRIPS Agreement therefore remedies this shortcoming and obliges members to provide domestic enforcement procedures. As such, Part III and IV complement the substantive minimum standards laid down in the second part of the Agreement.

The scope of the standards relating to enforcement contained in Part III is broad; they apply to all rights, thus also to patents. It consists of five sections: general obligations applying to all provisions of Part III (article 41), standards relating to civil and administrative procedures and remedies (articles 42-49), standards relating to provisional measures (article 50), special requirements related to border measures (articles 51-60), and standards relating to criminal procedures (article 61). Some of these provisions establish outright obligations, while many others require members to empower their judicial authorities or other competent or relevant authorities to take certain actions.

Article 41.1 of the TRIPS sets out the general obligation relating to enforcement and states the following:

\begin{abstract}
Members shall ensure that enforcement procedures as specified in this Part are available under their law so as to permit effective action against any act of infringement of intellectual property rights covered by this Agreement, including expeditious remedies to prevent infringements and remedies which constitute a deterrent to further infringements. These procedures shall be applied in such a manner as to avoid the creation of barriers to legitimate trade and to provide for safeguards against their abuse.
\end{abstract}

Article 41.1 applies to all types of intellectual property rights covered by the Agreement; it applies to judicial as well as administrative procedures and sets out the basic obligation relating to enforcement: to establish procedures that permit "effective action" against an infringement. This leaves members considerable leeway as to the interpretation and implementation of this obligation, given that national legal systems will have different standards as to what constitutes effectiveness. ${ }^{952}$ At the very least, members must comply with the TRIPS Agreement and make available the procedures as required by Part III, yet it would not oblige members to introduce any further enforcement measures not laid down

952 See also the Preamble to the TRIPS Agreement: recognising the need for "effective and appropriate means for the enforcement of trade-related intellectual property rights, taking into account differences in national legal systems". 
in the TRIPS Agreement. ${ }^{953}$ Article 41.1, furthermore, provides for two types of remedies: "expeditious remedies to prevent infringements" and "remedies which constitute a deterrent to further infringements". 954 Finally, it establishes the need to balance the interests of right holders, alleged infringers and the public interest. Namely, enforcement procedures must be applied in such a manner as "to avoid the creation of barriers to legitimate trade". Consequently, in line with the Preamble and objectives and principles of the TRIPS Agreement, members must ensure that the adoption and application of enforcement measures will not constitute a barrier to legitimate trade. Moreover, it indicates the need to strike a balance between protecting IPRs while also taking account of the interests of third parties and the public. In that regard, article 41.1 TRIPS specifically requires members to provide safeguards in order to avoid abuses by right holders of enforcement procedures. ${ }^{955}$

Article 41.2 of the TRIPS Agreement provides that the standards relating to enforcement set out by TRIPS are subject to the general principle of fairness and equality, specifying that procedures "shall not be unnecessarily complicated or costly, or entail unreasonable time-limits or unwarranted delays."956 Article 41.3 TRIPS establishes further procedural requirements namely that a decision on the merits of a case "shall preferably be in writing and reasoned" and "based only on evidence in respect of which parties were offered the opportunity to be heard", in addition to providing for a transparency obligation (such decisions "shall be made available at least to the parties to the proceeding without undue delay"). ${ }^{957}$ Article 41.2 and 41.3 also apply to procedures concerning the acquisition and maintenance of IPRs. ${ }^{958}$ Furthermore, article 41.4 provides that administrative decisions shall be subject to review by a judicial authority. ${ }^{959}$

Lastly article 41.5 TRIPS states that:

[i]t is understood that this Part does not create any obligation to put in place a judicial system for the enforcement of intellectual property rights distinct from that

953 CORREA, Trade-Related Aspects of IPRs: A Commentary on the TRIPS Agreement, at 410; UNCTAD-ICTSD, Resource Book on TRIPS and Development, at 580.

954 See further CORREA, Trade-Related Aspects of IPRs: A Commentary on the TRIPS Agreement, at 411; GERVAIS, The TRIPS Agreement: Drafting History and Analysis, at 441.

955 See also article 48.1 of the TRIPS Agreement. See further CORREA, Trade-Related Aspects of IPRs: A Commentary on the TRIPS Agreement, at 412; UNCTAD-ICTSD, Resource Book on TRIPS and Development, at 597-599.

956 See also article 42 TRIPS. See further CORREA, Trade-Related Aspects of IPRs: A Commentary on the TRIPS Agreement, at 413-415.

957 See further ibid. at 415.

958 See article 62.4 of the TRIPS Agreement.

959 Article 41.4 of the TRIPS Agreement: Parties to a proceeding shall have an opportunity for review by a judicial authority of final administrative decisions and, subject to jurisdictional provisions in a Member's law concerning the importance of a case, of at least the legal aspects of initial judicial decisions on the merits of a case. However, there shall be no obligation to provide an opportunity for review of acquittals in criminal cases. See further CORREA, Trade-Related Aspects of IPRs: A Commentary on the TRIPS Agreement, at 416. 
for the enforcement of law in general, nor does it affect the capacity of members to enforce their law in general. Nothing in this Part creates any obligation with respect to the distribution of resources as between enforcement of intellectual property rights and the enforcement of law in general.

Paragraph 5 of article 41 was introduced by a proposal of India and is one of the few provisions in Part III which specifically addresses the concerns of developing countries. 960

The second section of Part III contains standards concerning civil and administrative procedures and remedies. Article 42 TRIPS clarifies the general obligation enshrined in article 41 TRIPS, however, only in relation to civil judicial procedures. It applies to all IPRs covered by the Agreement and obliges members to "make available to right holders civil judicial procedures" concerning the enforcement IPRs. It continues stating the elements such procedures must provide for: 961

- defendants shall have the right to timely written notice containing sufficient detail, including the basis of the claims;

- parties shall be allowed to be represented by independent legal counsel;

- procedures shall not impose overly burdensome requirements concerning mandatory personal appearances;

- all parties shall be duly entitled to substantiate their claims and to present all relevant evidence; and finally

- the procedure shall provide a means to identify and protect confidential information, unless this would be contrary to existing constitutional requirements.

Section two of Part III further sets out standards regarding remedies in the case of an infringement of IPRs. Article 44 TRIPS deals with injunctions and obliges members to grant the judicial system "the authority to order a party to desist from an infringement". 962 Paragraph 2 of article 44 explicitly allows members to exclude the granting of injunctions for cases of government use and other uses without the authorisation of the right holder, for example for compulsory licensing as long as it complies with the conditions of article 31, stating that "members may limit the remedies available against such use to payment of remuneration". 963 Here members

960 Ibid. at 417; GERVAIS, The TRIPS Agreement: Drafting History and Analysis, at 442-443; UNCTAD-ICTSD, Resource Book on TRIPS and Development, at 585.

961 See further CORREA, Trade-Related Aspects of IPRs: A Commentary on the TRIPS Agreement, at 418; GERVAIS, The TRIPS Agreement: Drafting History and Analysis, at 444-446; UNCTAD-ICTSD, Resource Book on TRIPS and Development, at 585-587.

962 See further CORREA, Trade-Related Aspects of IPRs: A Commentary on the TRIPS Agreement, at 422 et seq.

963 Article 44 TRIPS:

1. The judicial authorities shall have the authority to order a party to desist from an infringement, inter alia to prevent the entry into the channels of commerce in their 
have substantial freedom to determine what level of payment would be adequate. Since this provision refers to "payment of remuneration", as opposed to compensation for damage, it is safe to assume that a reasonable royalty, as payable under a freely negotiated contract, would be adequate. ${ }^{964}$ Article 45 TRIPS deals with damages and obliges members to grant the judicial authorities "the authority to order the infringer to pay the right holder damages". As such, article 45.1 TRIPS mandates damages as an available remedy within members' national legal systems, yet it leaves the members the freedom to decide the amount as long as it is "adequate to compensate for the injury the right holder has suffered". ${ }^{965}$ Lastly, article 46 TRIPS obliges members to grant judicial authorities additional powers "to create an effective deterrent to infringement" taking into account "the need for proportionality between the seriousness of the infringement and the remedies ordered as well as the interests of third parties". 966 Finally, article 49 TRIPS extends

jurisdiction of imported goods that involve the infringement of an intellectual property right, immediately after customs clearance of such goods. Members are not obliged to accord such authority in respect of protected subject matter acquired or ordered by a person prior to knowing or having reasonable grounds to know that dealing in such subject matter would entail the infringement of an intellectual property right.

2. Notwithstanding the other provisions of this Part and provided that the provisions of Part II specifically addressing use by governments, or by third parties authorized by a government, without the authorization of the right holder are complied with, Members may limit the remedies available against such use to payment of remuneration in accordance with subparagraph (h) of Article 31. In other cases, the remedies under this Part shall apply or, where these remedies are inconsistent with a Member's law, declaratory judgments and adequate compensation shall be available.

UNCTAD-ICTSD, Resource Book on TRIPS and Development, at 592. See further CORREA, Trade-Related Aspects of IPRs: A Commentary on the TRIPS Agreement, at 425-426; GERVAIS, The TRIPS Agreement: Drafting History and Analysis, at 450-453.

Article 45.1 TRIPS states the following: The judicial authorities shall have the authority to order the infringer to pay the right holder damages adequate to compensate for the injury the right holder has suffered because of an infringement of that person's intellectual property right by an infringer who knowingly, or with reasonable grounds to know, engaged in infringing activity. See further CORREA, Trade-Related Aspects of IPRs: A Commentary on the TRIPS Agreement, at $426-427$.

Article 46 TRIPS: In order to create an effective deterrent to infringement, the judicial authorities shall have the authority to order that goods that they have found to be infringing be, without compensation of any sort, disposed of outside the channels of commerce in such a manner as to avoid any harm caused to the right holder, or, unless this would be contrary to existing constitutional requirements, destroyed. The judicial authorities shall also have the authority to order that materials and implements the predominant use of which has been in the creation of the infringing goods be, without compensation of any sort, disposed of outside the channels of commerce in such a manner as to minimize the risks of further infringements. In considering such requests, the need for proportionality between the seriousness of the infringement and the remedies ordered as well as the interests of third parties shall be taken into account. In regard to counterfeit trademark goods, the simple removal of the trademark unlawfully affixed shall not be sufficient, other than in exceptional cases, to permit release of the goods into the channels of commerce. See further ibid. at 428-429. 
the application of the standards set out in the second section of Part III to administrative procedures. ${ }^{967}$

The standards prescribed here tend to use the format of obliging members to grant their judicial system a certain authority without defining the nature of the measure to be adopted.

The third section of Part III deals with provisional measures, ${ }^{968}$ section 4 deals with special requirements relating to border measures, ${ }^{969}$ and section 5 addresses criminal procedures. ${ }^{970}$ Regarding the latter two, the standards set out are optional with respect to patent protection.

Part IV relates to a further important procedural aspect of intellectual property rights, namely the acquisition and maintenance of such rights. ${ }^{971}$ Article 62.1 TRIPS allows members to require, as a condition for the acquisition and maintenance of IPRs covered by the Agreement, compliance with reasonable procedures and formalities. ${ }^{972}$ It safeguards members' sovereignty in determining the procedures and formalities, such as registration, required for the acquisition of IPRs, while ensuring that such procedures and formalities do not prejudice the effective protection of IPRs. The standard prescribed by article 62.1 is that such procedures and formalities must be "reasonable", without defining it. Thus, members have a degree of flexibility when implementing this provision. Generally, reasonable would entail procedures and formalities that are adequate to their purpose without being overly restrictive on the applicant. Restrictions on the availability of IPRs are only permitted as long as these are in accordance with the substantive standards of the TRIPS Agreement. ${ }^{973}$ Furthermore, article 62.2 aims at preventing overly extensive examination or registration procedures. ${ }^{974}$ This is of particular importance for patent protection for pharmaceuticals, as article 33 TRIPS stipulates a patent term of at least 20 years from the date of filing. Consequently, the

967 See further ibid. at 432.

968 See further ibid. at 433 et seq; UNCTAD-ICTSD, Resource Book on TRIPS and Development, at 601-608.

969 See further CORREA, Trade-Related Aspects of IPRs: A Commentary on the TRIPS Agreement, at 439 et seq; UNCTAD-ICTSD, Resource Book on TRIPS and Development, at 608-619.

970 See further ibid., at 448 et seq; UNCTAD-ICTSD, Resource Book on TRIPS and Development, at 619-621.

971 See further GERVAIS, The TRIPS Agreement: Drafting History and Analysis, at 495 et seq.

972 Article 62.1 TRIPS: Members may require, as a condition of the acquisition or maintenance of the intellectual property rights provided for under Sections 2 through 6 of Part II, compliance with reasonable procedures and formalities. Such procedures and formalities shall be consistent with the provisions of this Agreement.

973 CORREA, Trade-Related Aspects of IPRs: A Commentary on the TRIPS Agreement, at 467468; UNCTAD-ICTSD, Resource Book on TRIPS and Development, at 622.

974 Article 62.2 TRIPS: Where the acquisition of an intellectual property right is subject to the right being granted or registered, Members shall ensure that the procedures for grant or registration, subject to compliance with the substantive conditions for acquisition of the right, permit the granting or registration of the right within a reasonable period of time so as to avoid unwarranted curtailment of the period of protection. See further CORREA, Trade-Related Aspects of IPRs: A Commentary on the TRIPS Agreement, at 468-470. 
time examining the application is deducted from the effective term of protection once a patent is granted to the detriment of the right holder. Article 62.2 therefore seeks to avoid any "unwarranted curtailment of the period of protection". Particularly with respect to pharmaceutical products and with a view to protecting public health, this provision, however, should not discourage patent offices from thoroughly examining patent applications as to whether they fulfil all conditions before granting a patent. In such cases, a detailed and time-consuming procedure could be justified as long as it is reasonable with a view to achieving the public policy objective. ${ }^{975}$ Article 62.4 stipulates that the basic principles applicable to enforcement procedures - fairness, equality and reasoned decisions - are also applicable to procedures concerning the acquisition and maintenance of IPRs. ${ }^{976}$ Additionally, article 62.5 imposes the possibility of (quasi-) judicial review of a final administrative decision in any of the procedures referred to in paragraph $4 .{ }^{977}$

In conclusion, in addition to the minimum substantive standards with regards to patents, the TRIPS Agreement also provides minimum procedural standards in relation to the acquisition, maintenance and enforcement of IPRs. The importance of the procedural standards must not be underestimated as the value of a substantive right, such as a patent, depends on the ability to effectively enforce such a right. Yet members must also take care to ensure that a balance is struck between the interests of the right holder, third parties and the public. The TRIPS Agreement ensures to do this by leaving members considerable freedom in implementing its requirements while also specifically addressing the issue of possible abuses by right holders. ${ }^{978}$

\section{Conclusion}

The question posed in this chapter is the following: what standards, with respect to the patenting of pharmaceuticals, does the TRIPS Agreement oblige WTO members to implement in their national legal system; and what flexibility exists within the scope of the TRIPS Agreement for members to adapt their national IP systems to their domestic needs. The focus here is on the TRIPS Agreement as it is one of the

\footnotetext{
975 UNCTAD-ICTSD, Resource Book on TRIPS and Development, at 623.
}

976 Article 62.4 TRIPS: Procedures concerning the acquisition or maintenance of intellectual property rights and, where a Member's law provides for such procedures, administrative revocation and inter partes procedures such as opposition, revocation and cancellation, shall be governed by the general principles set out in paragraphs 2 and 3 of Article 41. See further CORREA, Trade-Related Aspects of IPRs: A Commentary on the TRIPS Agreement, at 470-471. Article 62.5 TRIPS: Final administrative decisions in any of the procedures referred to under paragraph 4 shall be subject to review by a judicial or quasi-judicial authority. However, there shall be no obligation to provide an opportunity for such review of decisions in cases of unsuccessful opposition or administrative revocation, provided that the grounds for such procedures can be the subject of invalidation procedures. See further ibid. at 471-472. UNCTAD-ICTSD, Resource Book on TRIPS and Development, at 635-636. 
most recent and far-reaching international agreements within the field of intellectual property protection. Furthermore, the TRIPS Agreement was concluded within the framework of the World Trade Organisation making it subject to its extremely effective dispute settlement mechanism.

The question addressed in this chapter is twofold. The first question pertains to the minimum standards with regard to patent protection for pharmaceuticals which TRIPS requires developing members to implement within their national legal system. Article 27 TRIPS has introduced one of the major changes for developing members, namely the extension of patent protection to all fields of technology. As a result, members are now obliged to incorporate patent protection for pharmaceuticals into their legislative framework. TRIPS obliges members to grant patent holders a set of exclusive rights for a minimum period of 20 years. Furthermore the obligation of members to protect undisclosed information from unfair commercial use is of relevance for pharmaceutical products. However, unlike patents article 39 TRIPS does not necessarily entail the granting of exclusive rights. Moreover, the value for right holders of TRIPS' minimum substantive standards depends on the ability to effectively enforce such a right. Consequently the TRIPS Agreement sets out a minimum procedural standard in relation to the acquisition, maintenance and enforcement of IPRs.

The second question posed in this chapter is whether the TRIPS Agreement provides the flexibility for members to balance patent protection for pharmaceuticals with public health objectives, particularly the right of access to medicines. The objective and purpose of the TRIPS Agreement as can be found in its preamble and articles 7 and 8 and confirmed by the Doha Declaration does not limit itself to the protection of intellectual property rights, but it recognises the necessity to find a balance: a balance between free trade and IP protection, between the needs of highly developed and developing and least-developed countries, and between the private rights of the right holders and underlying public policy objectives, including technological and developmental objectives of national systems of IP protection. Furthermore, TRIPS allows members a degree of freedom when implementing and interpreting TRIPS in line with national legal systems and policy objectives. In that regard, many TRIPS provisions, such as the terms "novelty" and "inventiveness" found in article 27 TRIPS, allow a degree of interpretative flexibility and can be interpreted in a manner conducive to social welfare and public health.

TRIPS also takes account of the special needs of developing and least-developed countries by providing for transitional periods. With regard to patent protection for pharmaceuticals, developing countries (if they did not previously provide for patent protection) had to fully implement TRIPS by 2005, while least-developed members have been granted an extension until 2021. Yet it is questionable, however, whether the ten year period to introduce patent protection for pharmaceuticals was adequate considering that this required a substantial effort on the part of many developing countries who previously provided for far weaker standards of protection, especially 
since, notwithstanding the transitional periods, developing members were obliged to introduce the so-called "mail box" system allowing for patent applications for pharmaceuticals and the grating of EMRs.

In addition to the flexibility inherent in TRIPS' objective to balance patent protection with access, it also provides a number of concrete options for developing members to balance patent protection with the right of access to medicines, particularly articles 30 and 31 TRIPS. Consequently, within the limits of TRIPS, developing members can incorporate a number of tools to ensure an adequate balance is struck, such as a Bolar exception, compulsory licensing, government use and parallel importation. Finally, though, the value of the flexibility within TRIPS will depend much on the manner in which it is actually implemented by the WTO members. 


\section{Chapter 5 \\ The Interface between Patents and Human Rights in the Context of Access to Medicines}

\section{INTRODUCTION}

This chapter addresses the interface between international trade law and intellectual property law with international human rights law in the context of patent protection for pharmaceuticals and a right of access to medicines. The issue of access to medicines sits on the cross-point between the three systems and is one illustrative example of how these systems interact. ${ }^{979}$ The starting point for this discussion is that international trade law (which includes patents) can have significant benefits for the protection and promotion of human rights. ${ }^{980}$ This thesis adopts a legal approach to assess how international patent law and international human rights law interact in order to determine potential conflicts between both systems. It must be recognised however, that the debate takes place against the background of broader social, economic and political discussions.

International trade law and intellectual property law have historically been isolated from international human rights law. Human rights have not been very prominent in the World Trade Organisation. For a long time, international trade law was considered a very technical subject dealing with mainly economic analysis and beyond the scope of general international lawyers. ${ }^{981}$ Furthermore, some of the members within the WTO political bodies have shown concern in including human rights within WTO deliberations. ${ }^{982}$ In that sense the debate within the WTO on the possible impact of intellectual property rights on access to medicines, which resulted in the 2001 Doha Declaration on TRIPS and Public Health and a proposed amendment to the TRIPS Agreement, is remarkable in that it, although not explicitly, addresses human rights concerns within the WTO framework. See for example the debate preceding the adoption of the Doha Declaration in which a number of WTO members, mainly developing members, refer to the right of access to medicines, the right to health and the right to life as the context for the discussion

979 See also WOLFGANG BENEDEK, 'The World Trade Organisation and Human Rights', in Wolfgang Benedek, Koen De Feyter, and Fabrizio Marrella (eds.), Economic Globalisation and Human Rights (New York: Cambridge University Press, 2007); AUDREY R. CHAPMAN, 'The Human Rights Implication of Intellectual Property Protection', Journal of International Economic Law, 5:4 (2002), 861-882; HOE LIM, 'Trade and Human Rights. What's at Issue?', Journal of World Trade, 35:2 (2001), 275-300.

980 HARRISON, The Human Rights Impact of the WTO, at 137.

981 Ibid. at 34.

982 HAUGEN, 'Human Rights and TRIPS Exclusion and Exception Provision', at 362; VALENTINA VADI, 'Balancing the Human Right to Health and Intellectual Property Rights after Doha', Italian Yearbook of International Law, XIV (2004), 195-223 at 216-217. 
of TRIPS and public health. ${ }^{983}$ Consequently it is only in the last decade and a half that the links between human rights and international trade are being fully recognised.

In recent years there has been a continuous expansion of intellectual property rights, both in their subject matter and scope. Part of this is due to the development of new technologies in the last decades and the, therefore, growing demand for new forms of legal protection by the content owners and business. ${ }^{984}$ With the linking of intellectual property to trade through the adoption of the TRIPS Agreement, intellectual property protection has been brought within the framework of the WTO, a framework with robust enforcement procedures through its Dispute Settlement Mechanism. The move to link intellectual property with trade has been criticised. ${ }^{985}$

Not only the international intellectual property system but also the international human rights system has experienced expansion. Although the ICESCR was adopted at the same time as the ICCPR, namely in 1966, economic, social and cultural rights for a long time did not receive the same form of recognition as civil and political rights. ${ }^{986}$ The work done conceptualising and clarifying socioeconomic rights, through for example the adoption of General Comments by treaty monitoring bodies but also within academia, has led to a refinement of the rights of individuals and obligations for states under international human rights law. For example, a human right of access to medicines is not explicitly codified in any treaty on international human rights but, as explained in chapter 3 , it is a fundamental element under the right to health as found in article 12 ICESCR and, as such, deserves protection as a human right within the parameters of the right to health.

This recent expansion of the fields of international intellectual property law and international human rights law has led to a blurring of the demarcation between the two fields, creating dense policy spaces where previously unrelated sets of principles, norms and rules increasingly overlap in incoherent and inconsistent ways. ${ }^{987}$ There has been an increasing recognition from a human rights perspective

983 WTO COUNCIL FOR TRADE-RELATED ASPECTS OF INTELLECTUAL PROPERTY RIGHTS, Special Discussion on Intellectual Property and Access to Medicines. Held in the Centre William Rappard During the Meeting of the Council from 18 to 22 June 2001 (IP/C/M/31; 2001); WTO COUNCIL FOR TRADE-RELATED ASPECTS OF INTELLECTUAL PROPERTY RIGHTS, Submission by the African Group, Barbados, Bolivia, Brazil, Cuba, Dominican Republic, Ecuador, Honduras, India, Indonesia, Jamaica, Pakistan, Paraguay, Philippines, Peru, Sri Lanka, Thailand and Venezuela, (IP/C/W/296).

984 LAURENCE R. HELFER, 'Toward a Human Rights Framework for Intellectual Property', University of California, Davis Law Review 40:3 (2007), 971-1020 at 973.

985 See for example VALBONA MUZAKA, 'Developing Countries and the Struggle on Access to Medicines Front: Victories Won and Lost', Third World Quarterly, 30:7 (2009), 1343-1361 at 1343.

986 See also section 2.2 of chapter 3.

987 See for a discussion on such regime expansion, HELFER, 'Toward a Human Rights Framework for Intellectual Property', at 980-982; INTERNATIONAL LAW COMMISSION, Fragmentation of International Law, (UN Doc. A/CN.4/L.682). 
of the impact of the WTO regime on issues going beyond trade, such as economic, social and environmental concerns. ${ }^{988}$ This, however, is a recent phenomenon. Within the international trade community, human rights are considered of little relevance for trade law. Moreover, issues of social justice are rarely discussed in WTO bodies, and if they are, reference is not made to the human rights discourse. ${ }^{989}$ It is only in the last couple of years that an increasing awareness can be seen among academics, NGOs and international bodies of the different intersections of trade, intellectual property and human rights. ${ }^{990}$

Furthermore, the idea of framing intellectual property rights within a human rights framework was uncharted territory, even though the 1948 Universal Declaration of Human Rights and the ICESCR include a right on the protection of the moral and material interests of authors and inventors in addition to a right to benefit from scientific progress. ${ }^{991}$ Both instruments seek to find a balance between guaranteeing protection for one's intellectual labour and assuring that the public can benefit from the scientific and cultural progress these by IPRs protected products may induce. ${ }^{92}$ Moreover, it is increasingly recognised that the international trading system (of which patent protection is an element through the TRIPS Agreement) is only legitimate as long as it promotes social justice and human welfare as a central objective of the system. ${ }^{993}$ However, this leaves unanswered the question how human rights norms interface with rules on patent protection stemming from multilateral agreements within the framework of the WTO or from bilateral or regional trade and investment agreements.

Under international human rights law, states have an obligation to ensure that essential medicines are available, accessible, affordable, and of adequate quality. That would include ensuring medicines are priced reasonably; for example, by ensuring the national production or parallel importation of generic medicines would enable a national health system to procure medicines against a cheaper price compared to patented medicines. Although medicine prices are not the only factor

988 HARRISON, The Human Rights Impact of the WTO, at 36. See further GROSSE RUSE-KAHN, Policy Space for Domestic Public Interest Measures under TRIPS.

989 HARRISON, The Human Rights Impact of the WTO, at 36; FRANTZESKA PAPADOPOULOU, 'TRIPS and Human Rights', in Annette Kur and Marianne Levin (eds.), Intellectual Property Rights in a Fair World Trade System. Proposals for Reform of TRIPS (Cheltenham: Edward Elgar, 2011) at 271.

990 See for example FREDERICK M. ABBOTT, 'TRIPS and Human Rights: Preliminary Reflections', in Frederick M. Abbott, Christine Breining-Kaufmann, and Thomas Cottier (eds.), International Trade and Human Rights. Foundations and Conceptual Issues (Studies in International Economics. The World Trade Forum, Volume 5: The University of Michigan Press, 2006.

991 See article 27 UDHR and article 15 ICESCR.

992 HELFER, 'Toward a Human Rights Framework for Intellectual Property', at 976.

993 HARRISON, The Human Rights Impact of the WTO, at 36-37. See also PETER SUTHERLAND et al., The Future of the WTO. Addressing Institutional Challenges in the New Millennium. Report by the Consultative Board to the Director-General Supachai Panitchpakdi, World Trade Organisation, (2004) at 10 et seq. 
impacting patients' access to such medicines, the ability to procure much cheaper medicines would, especially for developing countries having to cope with resource constraints, be one step in the right direction to ensure nationwide access to essential medicines. However, since essential medicines may be protected by patents, ensuring national production or parallel importation of generic versions might prove problematic. States must consider either not granting patents for medicines or overriding or curtailing existing patents. However, states do not have unlimited freedom to establish a national regime of IP protection, at least not as members of the World Trade Organisation since the TRIPS Agreement, which is part of the WTO single undertaking, establishes minimum standards for IP protection. Thus, we see that the majority of WTO members are faced with these seemingly contrasting legal duties.

The relationship between IP protection and human rights is not only relevant for the issue of access to affordable medicines, but it also plays a role in a number of other issues, such as access to cultural and educational materials, patented seeds and food products, and the protection of traditional knowledge and indigenous materials. Therefore, human rights implications of IP protection relate to a variety of different rights and not only the right to health, but for example also the right to food, the right to education, the right to self-determination, the right to freedom of expression, the right to privacy, the right to cultural participation and development, and the right to benefit of scientific progress. ${ }^{994}$ Although these issues may not necessarily concern "life and death" matters, as is often the case with respect to access to medicines, they are still of importance and should not be ignored.

With respect to the IP and human rights interface, there are two distinct conceptual approaches: the conflict and coexistence approach. ${ }^{995}$ Some find that IPRs and human rights are in fundamental conflict with each other. This view sees strong IP protection as undermining a range of human rights obligations, especially with respect to economic, social and cultural rights. ${ }^{996}$ The Sub-Commission on the Protection and Promotion of Human Rights (Sub-Commission) stated that "there are apparent conflicts between the intellectual property rights regime embodied in the TRIPS Agreement, on the one hand, and international human rights law, on the other." 997 In the case of access to medicines, patent protection for pharmaceutical products is seen to undermine the right to health and life. Proponents of this

994 See for example South African Constitutional Court, Laugh It Off Promotions $v$ South African Breweries, 27 May 2005, Case CCT 42/04.

995 HANS MORTEN HAUGEN, 'Patent Rights and Human Rights: Exploring Their Relationships', The Journal of World Intellectual Property, 10:2 (2007), 97-124 at 102; LAURENCE R. HELFER, 'Human Rights and Intellectual Property: Conflict or Coexistence?', Minnesota Journal of Law, Science \& Technology, 5 (2003), 47-61 at 47-48; PETER K. YU, 'Ten Common Questions About Intellectual Property and Human Rights', Georgia State University Law Review, 23 (2007), 709-753 at 709-710. Rights and Human Rights (UN Doc. E/CN.4/SUB.2/RES/2000/7; 2000) at 2 . 
approach argue that to resolve this conflict the normative primacy of human rights law over intellectual property law must be recognised in situations where specific treaty obligations conflict. ${ }^{998}$ Others disagree and consider human rights and intellectual property rights to be essentially compatible. They see "both areas of law as concerned with the same fundamental question: defining the appropriate scope of private monopoly power that gives authors and inventors sufficient incentive to create and innovate, while ensuring that the consuming public has adequate access to the fruits of their efforts." 999 In short, the question is how to strike the balance between incentives on the hand and access on the other. Thus, human rights law and intellectual property law can be considered to be compatible; although there are differing views on how exactly the balance between the two should be struck. ${ }^{1000}$

The question posed in this chapter is whether the right of access to essential medicines within the framework of international human rights law conflicts with patent standards for pharmaceuticals as required by TRIPS (section 2). If a conflict is identified, the question then turns to how to resolve such a conflict (section 3). Within international law, it is generally accepted that there is no formal hierarchy between sources of international law (i.e. treaties, customary law and general principles of law). ${ }^{1001}$ As a result, in case of a conflict of norms, simply referencing the respective source of the norm does not allow a conflict to be resolved. ${ }^{1002} \mathrm{~A}$

998 See further PHILLIPPE CULLET, 'Patents and Medicines: The Relationship between TRIPS and the Human Right to Health', International Affairs, 79:1 (2003), 139-160 at 157-159; CAROLINE DOMMEN, 'Raising Human Rights Concerns in the World Trade Organisation: Actors, Processes and Possible Strategies', Human Rights Quarterly, 24 (2002), 1-50; EBENEZER DUROJAYE, 'Compulsory Licensing and Access to Medicines in Post Doha Era: What Hope for Africa?', Netherlands International Law Review, 55:1 (2008), 33-71 at 69; MEIER, 'Employing Health Rights for Global Justice: The Public Health Response to the Insalubrious Ramifications of Globalisation', at 729 et seq.

999 HELFER, 'Human Rights and Intellectual Property: Conflict or Coexistence?', at 48.

1000 See the response received by the World Trade Organisation to the UN Sub-Commission for the Promotion and Protection of Human Rights' Resolution 2000/7 (Intellectual Property and Human Rights) in UN SUB-COMMISSION ON THE PROMOTION AND PROTECTION OF HUMAN RIGHTS, Report of the Secretary General on Intellectual Property Rights and Human Rights (UN Doc. E/CN.4/Sub.2/2001/12; 2001); and the response received by the World Intellectual Property Organisation in UN SUB-COMMISSION ON THE PROMOTION AND PROTECTION OF HUMAN RIGHTS, Report of the Secretary General on Intellectual Property Rights and Human Rights. Addendum (UN Doc. E/CN.4/Sub.2/2001/12/Add.1; 2001). See further HELFER, 'Human Rights and Intellectual Property: Conflict or Coexistence?', at 49; LAURENCE R. HELFER and GRAEME W. AUSTIN (eds.) Human Rights and Intellectual Property: Mapping the Global Interface (New York: Cambridge University Press, 2011) at 73; PETER K. YU, 'Reconceptualising Intellectual Property Interests in a Human Rights Framework', University of California, Davis, Law Review, 40 (2006-2007), 1039-1150 at 1077.

1001 INTERNATIONAL LAW COMMISSION, Fragmentation of International Law, (UN Doc. A/ CN.4/L.682) at §85, 324 et seq; PAUWELYN, Conflict of Norms in Public International Law, at 147.

1002 This as opposed to the situation of domestic law, where the hierarchy of norms is determined by whom and how the norm was enacted. PAUWELYN, Conflict of Norms in Public International Law, at 95-96, 147. 
clear situation of a hierarchical relationship between norms of international law is if it concerns jus cogens or so-called peremptory norms. A norm reflecting jus cogens will not only prevail over but will invalidate another norm that is not part of jus cogens, irrespective of the source from which it is derived. ${ }^{1003}$ Therefore, the second question posed is whether the right to health and/or right of access to medicines is a superior norm under international law (section 4). If so, a possible conflict between norms relating to patent protection and a right of access to medicines may easily be resolved in favour of the superior norm. If not, the following question to be asked is whether both allegedly conflicting norms may be interpreted harmoniously in order to strike a balance (section 5). Finally, brief attention will also be paid to a phenomenon outside the framework of the WTO with added consequences for the ability of developing countries to ensure access to affordable medicines: TRIPS-plus developments (section 6).

\section{ICESCR - TRIPS: CONFLICT?}

Integrating and balancing diverging interests on the global level is particularly difficult due to the absence of a central authority in international relations. As such, one faces a multitude of regimes, institutions and actors, all addressing different elements of the whole picture. Consequently, the absence of a central authority and the rapid normative development by different and uncoordinated legal regimes may lead to conflicts between norms and/or regimes and diverging institutional practices. The International Law Commission issued a report, finalised by Martti Koskenniemi, addressing exactly this issue: the fragmentation of international law. ${ }^{1004}$

This fragmentation is also visible with respect to the issue of access to affordable medicines. On the one hand, international human rights law (most notably under the right to health enshrined in ICESCR) ${ }^{1005}$ prescribes the obligation to

1003 See article 53 of the Vienna Convention on the Law of Treaties which reads as follows: A treaty is void if, at the time of its conclusion, it conflicts with a peremptory norm of general international law. For the purposes of the present Convention, a peremptory norm of general international law is a norm accepted and recognized by the international community of States as a whole as a norm from which no derogation is permitted and which can be modified only by a subsequent norm of general international law having the same character.

See article 64 of the Vienna Convention on the Law of Treaties: If a new peremptory norm of general international law emerges, any existing treaty which is in conflict with that norm becomes void and terminates.

1004 INTERNATIONAL LAW COMMISSION, Fragmentation of International Law, (UN Doc. A/ CN.4/L.682).

1005 A right of access to affordable medicines is argued to exist as part of the right to health (article 12 ICESCR) and supported by the right to enjoy the benefits of scientific progress and its applications (article 15.1(b) ICESCR), the right to life (article 6 ICCPR) and state practice regarding access to life-saving medicines in national health emergencies, like pandemics such as HIV/AIDS, tuberculosis and malaria. See chapter 3. 
(progressively) realise adequate access to affordable medicines, while on the other hand the minimum patent standards introduced by the TRIPS Agreement within the framework of the WTO have interfered with, particularly, the economic accessibility of patented medicines. Thus, there is a clear link between prohibitively high medicines prices leading to inadequate access and standards of patent protection for medicines as required by the TRIPS Agreement. ${ }^{1006}$ The UN SubCommission on the Protection and Promotion of Human Rights has also referred to the link between access and patents in a resolution adopted in 2000 in which it declared that "apparent conflicts" existed between the IP regime embodied in the TRIPS Agreement and international human rights law. ${ }^{1007}$

This section will therefore address whether it is possible to identify a conflict between a right of access to essential medicines - within the framework of international human rights law - with patent standards for pharmaceuticals - within the framework of the TRIPS Agreement. Before being able to answer this question, though, "conflict" must be defined first. ${ }^{1008}$ Furthermore, it is necessary to identify the relevant norms and ensure all preconditions are met.

The report of the International Law Commission raised the question of what is a conflict. That report examined four types of relationships implicated in normative conflicts: relationships between special and general law, between prior and subsequent law, between laws at different hierarchical levels, and relationships of law to its "normative environment" more generally. ${ }^{1009}$ It found that conflict can be interpreted strictly and more widely. A strict definition of conflict presumes "that conflict exists if it is possible for a party to two treaties to comply with one rule only by thereby failing to comply with another rule."1010 Such a strict direct incompatibility of treaty terms is the traditional understanding of conflict, setting a rather high threshold for finding a conflict between treaties and thus rightly considered unduly narrow. ${ }^{1011}$ The ILC report, however, also finds that there are "looser understandings" of what constitutes a conflict. ${ }^{1012}$ Even though there is no strict incompatibility between treaty provisions, a treaty may frustrate the goals of another treaty. Therefore the report adopts a wide notion of conflict "as the situation where two rules or principles suggest different ways of dealing with a problem."1013

\footnotetext{
1006 See also chapter 2.

1007 See UN SUB-COMMISSION ON HUMAN RIGHTS, Resolution 2000/7. Intellectual Property Rights and Human Rights, (UN Doc. E/CN.4/SUB.2/RES/2000/7) at §2.

1008 Here the term "conflict" is used interchangeably with inconsistent, incompatible or contradictory norms. See for a discussion of how conflict of norms is defined in doctrinal writings PAUWELYN, Conflict of Norms in Public International Law, at 166 et seq.

1009 INTERNATIONAL LAW COMMISSION, Fragmentation of International Law, (UN Doc. A/ CN.4/L.682) at $\$ 18$.

1010 Ibid. at $\$ 24$.

1011 HAUGEN, 'Patent Rights and Human Rights: Exploring Their Relationships', at 102; HESTERMEYER, Human Rights and the WTO, at 175.

1012 INTERNATIONAL LAW COMMISSION, Fragmentation of International Law, (UN Doc. A/ CN.4/L.682) at $\$ 24$.

1013 Ibid. at $\$ 25$.
} 
The International Court of Justice has rarely addressed the issue of what constitutes a conflict of norms in international law, yet in the Jurisdictional Immunities of the State case the Court did state that there can be no conflict when two norms regulate different matters. ${ }^{1014}$ Therefore it must be assessed whether the allegedly conflicting norms address the same subject matter (ratione materiae), in addition to both applying to a state party at the same time (ratione personae, ratione temporis). ${ }^{1015}$

Here this dissertation is limited to examining the relationship between those provisions of the TRIPS Agreement dealing with the protection of patents and the provisions of ICESCR protecting a right of access to medicines. The strongest legal basis for a right of access to medicines is the right to health as set out in ICESCR and further developed in General Comments by the Committee on Economic, Social and Cultural Rights. In addition, as shown in the previous chapter, there are a range of provisions in TRIPS which are relevant for access to medicines, particularly those requiring all members to grant exclusive rights to patent holders for a minimum of 20 years and possible exceptions to such rights. ${ }^{1016}$ Considering that the TRIPS Agreement is the first international instrument to set out minimum standards of IPRs and that it has widespread membership as an agreement within the WTO framework, it was decided to address the question of a possible conflict from the perspective of the TRIPS Agreement and ICESCR. Possibly conflicting with TRIPS are the obligations under ICESCR to progressively realise the rights of the Covenant, ensure medicines are available, accessible, affordable, and of adequate quality and, particularly, as determined by the CESCR to constitute a minimum core obligation, ensure the provision of essential medicines (as defined by the WHO). ${ }^{1017}$

A conflict between two (or more) norms can only arise if at least one state is bound by both norms at the same time. The majority of WTO members (more than $80 \%$ ) are also parties to the ICESCR and therefore faced with possible conflicting norms between the TRIPS Agreement and ICESCR. Although the two treaties at a first glance seem to address different subject matters (protection of human rights vs. protection of intellectual property rights) it has been shown that there are clear links between access to medicines, the right to health and the right to life, and intellectual property rights, particularly patents for pharmaceuticals. The ILC finds that terms such as "human rights law", "trade law" or "environmental law" are arbitrary labels on forms of specialisation. It would be absurd to conclude that a WTO norm and a human rights norm cannot conflict because the first norm refers

\footnotetext{
1014 International Court of Justice, Jurisdictional Immunities of the State (Germany v. Italy: Greece Intervening), 2012, at $\$ 93$.

1015 HAUGEN, 'Patent Rights and Human Rights: Exploring Their Relationships', at 104; HESTERMEYER, Human Rights and the WTO, at 174; PAUWELYN, Conflict of Norms in Public International Law, at 165 .

1016 Most notably: articles 6, 27, 28, 30, 31 and 33 TRIPS.

1017 Most notably: articles 2 and 12 ICESCR.
} 
to trade and the second to human rights, and they therefore do not address the same subject matter. Thus the ILC states that to assess whether two treaties cover the "same subject matter" the question is "whether the fulfilment of the obligation under one treaty affects the fulfilment of the obligation of another. This 'affecting' might then take the form of either strictly preventing the fulfilment of the other obligation or undermining its object and purpose in one or another way."1018 The obligation to provide patent protection for pharmaceuticals for a minimum of 20 years has affected the ability of developing countries to provide adequate access to affordable medicines. TRIPS has significantly curtailed developing members' regulatory flexibility in dealing with patents for pharmaceuticals and ensuring adequate access to them. We can thus conclude that both TRIPS and ICESCR address the same subject matter with respect to access to medicines.

The next sections will address the matter of conflict between TRIPS and ICESCR in more detail focusing on the strict definition of conflict first and applying a wider definition of conflict second.

\subsection{Narrow Definition of Conflict: Inconsistent Obligations?}

Firstly, there may be a strict conflict on the level of inconsistent obligations. If obligations are mutually exclusive this would entail that the implementation of TRIPS' obligations regarding patents makes it impossible to implement ICESCR's obligations regarding a right of access to medicines or vice versa. This is the traditional understanding of conflict and refers to a direct incompatibility of treaty terms, setting a rather high threshold for finding a conflict between treaties and thus rightly considered unduly narrow. ${ }^{1019}$

In the case of TRIPS and the ICESCR, one would have to demonstrate that compliance with TRIPS necessitates violating the ICESCR, or vice versa. From the previous chapters it is clear that the treaties do not contain mutually exclusive obligations. ${ }^{1020}$ The ICESCR and the TRIPS Agreement oblige states parties to take measures so as to ensure the full realisation of the rights protected under ICESCR and the implementation of the minimum standards of protection for intellectual property as set by TRIPS respectively. However, both - although the ICESCR more so than TRIPS - allow states parties flexibility in the manner of implementation.

1018 INTERNATIONAL LAW COMMISSION, Fragmentation of International Law, (UN Doc. A/ CN.4/L.682) at \$254; XAVIER SEUBA, 'Mainstreaming the TRIPS and Human Rights Interactions', in Carlos M. Correa (ed.), Research Handbook on the Protectioin of Intellectual Property under WTO Rules. Intellectual Property in the WTO Volume 1 (Research Handbooks on the WTO; Cheltenham/Northampton: Edward Elgar, 2010) at 211.

1019 HAUGEN, 'Patent Rights and Human Rights: Exploring Their Relationships', at 102; HESTERMEYER, Human Rights and the WTO, at 175; PAPADOPOULOU, 'TRIPS and Human Rights', at 286-287; PAUWELYN, Conflict of Norms in Public International Law, at 170. See for more information why authors do adopt a strict definition of conflict, ibid. at 172-175.

1020 HAUGEN, 'Patent Rights and Human Rights: Exploring Their Relationships', at 103; PAPADOPOULOU, 'TRIPS and Human Rights', at 287. 
Adopting a narrow, technical definition of conflict therefore leads to the conclusion that there is no conflict between the ICESCR and TRIPS. Yet this would be too easy a conclusion. Simply focusing on a technical definition of conflict ignores the complexity of the interface between TRIPS and ICESCR. As Pauwelyn has put it, "one essentially solves part of the problem by ignoring it." ${ }^{1021}$ Therefore it is unwarranted to apply such a strict conflict definition because it would prejudice the question how to address the alleged tension between TRIPS and the ICESCR. ${ }^{1022}$ Consequently, in order to examine TRIPS and ICESCR more closely, a broader definition of conflict is required.

\subsection{Broad Definition of Conflict: Tension?}

Above the question was addressed whether it is possible to identify a strict conflict between provisions of the ICESCR and TRIPS regarding access to medicines. There is no evidence of a strict conflict between provisions regarding the right of access to medicines (ICESCR) and patent protection for pharmaceuticals (TRIPS). Yet as was stated, there are "looser understandings" of what constitutes a conflict. ${ }^{1023}$ Even though there is no strict incompatibility between treaty provisions, a treaty may frustrate the goals of another treaty. Therefore a wider notion of conflict is adopted here, referred to as possible tension between the TRIPS Agreement and the ICESCR, in that both suggest different, arguably even contradictory, ways of dealing with the issue of access to medicines.

The primary objective of the TRIPS agreement is - obviously - the protection of trade-related intellectual property rights, but it is also striking a balance between the interests of holders of IPRs and other societal values. The context, set within the WTO framework and TRIPS' preamble, firmly positions it within the international trade regime, the main objective of which is to facilitate and promote international trade with a view to achieving sustainable economic development and the integration of developing countries in the world trading system. ${ }^{1024}$ Reflected in the

1021 PAUWELYN, Conflict of Norms in Public International Law, at 170-171.

1022 Contrary, Marceau finds that there is no need to expand the concept of conflict as other rules of international law guarantee the respect of provisions allowing for rights (for example human rights treaties) over other provisions imposing obligations (for example provisions of WTO law). She suggests that "'conflicts' should continue to be interpreted narrowly. An expanded definition of conflicts would lead to providing a third party (an adjudication body or an interpreter) with the power to set aside provisions that have been voluntarily negotiated by states." Furthermore, "[e]ven if one agrees with a broad definition of conflict [...] one must recognise that the identification of which of the two conflict provisions is to supersede the other is not a simple exercise.” See MARCEAU, 'WTO Dispute Settlement and Human Rights', at 794.

1023 HAUGEN, 'Patent Rights and Human Rights: Exploring Their Relationships', at 103; HESTERMEYER, Human Rights and the WTO, at 174 et seq; INTERNATIONAL LAW COMMISSION, Fragmentation of International Law, (UN Doc. A/CN.4/L.682) at §24.

1024 VAN DEN BOSSCHE and ZDOUC, The Law and Policy of the World Trade Organisation, at 83. 
preamble and several of the TRIPS provisions is the need to balance protection for intellectual property, as private rights, with public policy objectives and the special needs of least-developed countries regarding maximum flexibility. See for example articles 7 and 8 of the TRIPS Agreement and the transitional provisions for developing and least-developed countries. The ICESCR, on the other hand, focuses primarily on the progressive realisation of the rights protected by the Covenant. In that regard it considers access an essential element of many socio-economic rights including the right to health. As stated in the preamble of the ICESCR, human rights are derived from the inherent dignity of the human person which is the main underlying objective of all human rights. So it seems that the object and purpose of both treaties are different, although they are not strictly incompatible. ${ }^{1025}$ Simply put the ICESCR focuses on human rights and human dignity and, in that regard, on access as a crucial element for the realisation of the right to health, while TRIPS focuses on striking a balance between access and protection within the framework of intellectual property rights. Setting the two treaties in the context of their respective regimes, it is seen that the underlying values of the international trade regime and the international human rights regime are distinct. Both have different starting points and principal characteristics. ${ }^{1026}$ With respect to the interface between the TRIPS Agreement and ICESCR the High Commissioner for Human Rights has noted that there remain "fundamental differences of approach" between the two. ${ }^{1027}$ The Special Rapporteur on the right to health has further noted that TRIPS bears upon crucial elements of the right to health. ${ }^{1028}$

Moreover, an element of crucial importance in this discussion is enforcement. There are stark differences between the enforcement of TRIPS and ICESCR. The TRIPS Agreement is part of the WTO framework and thus falls under the WTO dispute settlement mechanism. If a member is found to be in violation of its WTO obligations, the DSB may authorise the complainant to withdraw trade or other concessions against the violator. ${ }^{1029}$ The possibility of cross-retaliation is a powerful incentive, particularly for developing members, to comply with their TRIPS obligations. ${ }^{1030}$ The ICESCR on the other hand does not have a strong enforcement mechanism and, even if human rights are considered morally superior, the lack of legal recognition and enforcement gives them a weaker position compared to WTO

\footnotetext{
1025 HAUGEN, 'Patent Rights and Human Rights: Exploring Their Relationships', at 102.

1026 PAPADOPOULOU, 'TRIPS and Human Rights', at 270.

1027 UN SUB-COMMISSION ON HUMAN RIGHTS, Report of the High Commissioner on the Impact of the TRIPS Agreement on Human Rights (UN Doc. E/CN.4/Sub.2/2001/13) at §22.

1028 UN COMMISSION ON HUMAN RIGHTS, Report of the Special Rapporteur on the Right to Health, (UN Doc. E/CN.4/2003/58) at $\S 86$.

1029 See further section 2.2 of chapter 4.

1030 HARRISON, The Human Rights Impact of the WTO, at 10; VADI, 'Balancing the Human Right to Health and Intellectual Property Rights after Doha', at 202. It must be mentioned here though that to date cross-retaliation has been rarely authorised. See VAN DEN BOSSCHE and ZDOUC, The Law and Policy of the World Trade Organisation, at 201.
} 
rules. ${ }^{1031}$ Because the WTO and international human rights law are generally considered independently from another, this fragmentation within international law establishes a factual hierarchy, independent of any normative hierarchy. ${ }^{1032}$

Commentators have also looked at the concept of conflict with respect to WTO law and human rights. For example, Pauwelyn states that "[e]ssentially, two norms are [...] in a relationship of conflict if one constitutes, had led to, or may lead to, a breach of the other."1033 This approach equates conflict with breach or violation. Consequently the question addressed must be: when is there a breach of a certain norm? According to Pauwelyn, an added advantage of this approach is that determining a breach of a norm is a more concrete and objective question than defining the abstract relationship between the two norms. ${ }^{1034} \mathrm{He}$ specifies this definition of conflict to inherent normative conflicts, i.e. one norm breaching in and of itself another norm, which can be equated with the strict definition of conflict discussed above - for example the emergence or existence of a norm in violation of jus cogens would constitute an inherent conflict - and conflicts in applicable law, where the implementation of or compliance with, one norm breaches another norm. ${ }^{1035}$

Applying this approach, the question essentially comes down to whether a member is able to comply with and implement the obligations with respect to patent standards set out in the TRIPS Agreement without violating the right to health; and/ or whether a state party can comply with and implement the right of access to medicines as required by the ICESCR without violating the TRIPS Agreement. As set out in the Maastricht Guidelines, the failure by a state party to comply with an obligation under ICESCR is considered a violation of the ICESCR. ${ }^{1036}$

Article 2.1 and 12 ICESCR requires states to progressively realise the right to health to the maximum of their available resources by all appropriate means including particularly the adoption of legislative measures. The TRIPS Agreement imposes a number of minimum standards with regard to patent protection. Members must allow for patent protection in all fields of technology, including

1031 This as opposed to the situation in Europe where human rights enshrined in the European Convention on Human Rights are effectively enforced by the European Court of Human Rights. Here human rights have been invoked in a number of intellectual property conflicts although not frequently. See further LAURENCE R. HELFER, 'The New Innovation Frontier? Intellectual Property and the European Court of Human Rights', Harvard International Law Journal, 49:1 (2008), 1-52; PAPADOPOULOU, 'TRIPS and Human Rights', at 274 et seq.

1032 HESTERMEYER, Human Rights and the WTO, at 170; PAPADOPOULOU, 'TRIPS and Human Rights', at 289.

1033 PAUWELYN, Conflict of Norms in Public International Law, at 175-176.

1034 Ibid. at 176.

1035 Ibid. at 176-177. Pauwelyn makes the distinction between necessary conflicts (in cases where the breach occurs necessarily, when either of the two norms is complied with as required, thus mutually exclusive obligations) and potential conflicts (in cases where there is a margin of discretion and the breach therefore only arises when a state decides to exercise a right, a permission or exemption).

1036 The Maastricht Guidelines on Violations of Economic, Social and Cultural Rights, at §5. 
pharmaceuticals, granting right holders a number of exclusive rights for a minimum patent term of 20 years. Furthermore, it has considerably limited the means in which WTO members may restrict patent holders' rights. The difficulty here is that unlike the TRIPS Agreement, which sets out some very clear and straightforward obligations for WTO members, the ICESCR leaves states parties a considerable degree of discretion as to the manner of implementation. Moreover, the exact scope of a state party's obligations under the ICESCR is dependent on its level of development and availability of resources, as such states parties' obligations under the Covenant are neither uniform nor universal. This is inherent in the nature of the obligation to progressively realise the right to health. Yet this does not mean that states parties' obligations under the Covenant are meaningless; nor should it be used as an excuse for non-compliance. Moreover, this margin of discretion is limited with regard to those elements of a right which are considered to be the core content of a right. Since the provision of essential medicines is a core obligation of the right to health, states parties have less freedom and time when it comes to the implementation of this obligation. Moreover, it would also entail that states parties must take full advantage of the transitional provisions and flexibilities of the TRIPS Agreement.

Additionally, it is argued that a norm that gives states a permission - an option to take certain actions - would conflict with a norm that prohibits or commands those particular actions. Under a strict definition of conflict, there would not be a conflict, since a state bound by both norms could comply with both by adhering to the strictest norm, i.e. the command or prohibition. That would, however, make the permission irrelevant and meaningless which would go against the principle of effective interpretation. ${ }^{1037}$ The TRIPS Agreement grants members such permission, i.e. the TRIPS flexibilities. For example, it allows WTO members to make exceptions to exclusive rights of patent holders, such as compulsory licensing or parallel importing. This is an option for members, whether or not to grant a compulsory license or parallel import. However, under ICESCR, states are commanded to fulfil their obligations with regard to the right to health. Thus, states parties must ensure access to affordable medicines, one element of which entails that medicines are affordable. Yet the options to do so are limited by the requirements of TRIPS. If applying the general rule under TRIPS, namely that all pharmaceutical products must be patentable for a minimum of 20 years, this severely curtails members' option to introduce generic competition and bring

1037 FRANÇOIS BOUDREAULT, 'Idenitfying Conflicts of Norms: The ICJ Approach in the Case of the Jurisdictional Immunities of the State Germany (Germany v. Italy: Greece Intervening)', Leiden Journal of International Law, 25 (2012), 1003-1012 at 1008-1009; HESTERMEYER, Human Rights and the WTO, at 175; PAUWELYN, Conflict of Norms in Public International Law, at 247 et seq.

The principle of effective treaty interpretation (ut res magis valeat quam pereat): when a treaty is open to two interpretations one of which does and the other does not enable the treaty to have appropriate effects, good faith and the objects and purposes of the treaty demand that the former interpretation should be adopted. 
medicine prices down. Therefore, in order not to violate their obligations under international human rights law, they must make use of the TRIPS flexibilities. Therefore, the permission TRIPS grants (i.e. the flexibilities) no longer constitute a permission or option, as such, but a must. Consequently, Hestermeyer finds that "the obligation to use the exception nullifies the aspect of the norm granting members a right not to use the exception". 1038

Concluding, there is no strict or inherent normative conflict between TRIPS and ICESCR. Yet tension does exist between states' obligations with respect to the right of access to medicines - within the framework of ICESCR - and patent standards for pharmaceutical products - within the framework of TRIPS. Namely compliance with and national implementation of the right of access to medicines may breach TRIPS' patent standards, although this situation seems less likely to occur than the opposite - the implementation of TRIPS' standards leading to a violation of members human rights obligations - since TRIPS may be enforced far more effectively through the WTO dispute settlement mechanisms compared to the weak enforcement mechanisms in international human rights law. ${ }^{1039}$

The following step therefore is to determine how to resolve such tension. If one can prove that the right to health and/or access to medicines has reached a position of superiority in international law then any tension is easily resolved in favour of the superior norm. ${ }^{1040}$ Yet, if this is not so, the question must be whether this tension between TRIPS and ICESCR is a "real" or genuine conflict in that it cannot be resolved through conflict avoidance techniques, for example, through interpretation. ${ }^{1041}$

\section{How to Resolve the Tension?}

It has been shown that when applying a broad definition of conflict, it is possible to conclude tension exists between norms relating to patent protection for pharmaceuticals under TRIPS and norms relating to the right of access to medicines under ICESCR. There are a number of ways in which such tension can be dealt with: avoid a conflict through treaty interpretation and if this does not prove

1038 HESTERMEYER, Human Rights and the WTO, at 176.

1039 See also PRABHASH RANJAN, 'International Trade and Human Rights: Conflicting Obligations', in Thomas Cottier, Joost Pauwelyn, and Elisabeth Bürgi (eds.), Human Rights and International Trade (New York: Oxford University Press, 2005) at 313-314.

1040 The question whether the right to health might have attained the status of superiority in international law will be discussed in section 4.1 of this chapter.

1041 PAUWELYN, Conflict of Norms in Public International Law, at 179 et seq. Finally, he finds there are four conflict situations:

- conflicting commands (necessary conflicts, except where the conflicting commands are merely different but not mutually exclusive, then it would be a potential conflict);

- conflict between a command and a prohibition (necessary conflicts);

- conflict between a command and a right that is an exemption (potential conflicts);

- conflict between a prohibition and a right that is a permission (potential conflicts). 
possible resolve the conflict with the aid of conflict resolution techniques under international law.

Firstly, in international law there is a presumption against conflict. Thus one way in order to avoid tension between the obligation to implement the right to health under ICESCR and ensuring access to essential medicines and also implementing the minimum standards with respect to patent protection for pharmaceuticals is through treaty interpretation. ${ }^{1042}$ In this way one interprets one norm in the light of another norm in order to avoid a conflict. For example, where TRIPS leaves members room as to the exact manner in which to implement their obligations or where it contains vague terms that need clarification, human rights may be resorted to in order to inform policy choices and balance both obligations. ${ }^{1043}$ If treaty interpretation cannot lead to avoiding the conflict, the conflict is no longer just apparent but genuine. In that case, a conflict must be resolved through a series of conflict resolution techniques.

The first of these is the so-called lex superior derogat legi inferori rule, which simply put means that the norm with the superior status under international law prevails over a norm of inferior status. This would for example be the case if the right to health and/or access to medicines would be of a jus cogens character, i.e. a peremptory norm.

Secondly, there is the so-called lex posterior derogat legi priori rule. In the case of no relationship of hierarchy, sources of international law have the same legal status; in such a situation, a later expression of state will logically prevails over an earlier expression. ${ }^{1044}$ This is referred to as the lex posterior rule, which is also found in article 30 of the VCLT, although that does not mean this rule only applies to conflicts of treaty norms. ${ }^{1045}$ Yet it might be difficult to apply to other sources

\footnotetext{
1042 Ibid. at 244.

1043 SEUBA, 'Mainstreaming the TRIPS and Human Rights Interactions', at 201.

1044 INTERNATIONAL LAW COMMISSION, Fragmentation of International Law, (UN Doc. A/ CN.4/L.682) at $\$ 226$.
}

1045 See article 30 of the Vienna Convention on the Law of Treaties:

1. Subject to Article 103 of the Charter of the United Nations, the rights and obligations of States Parties to successive treaties relating to the same subject matter shall be determined in accordance with the following paragraphs.

2. When a treaty specifies that it is subject to, or that it is not to be considered as incompatible with, an earlier or later treaty, the provisions of that other treaty prevail.

3. When all the parties to the earlier treaty are parties also to the later treaty but the earlier treaty is not terminated or suspended in operation under article 59, the earlier treaty applies only to the extent that its provisions are compatible with those of the later treaty.

4. When the parties to the later treaty do not include all the parties to the earlier one:

(a) as between States Parties to both treaties the same rule applies as in paragraph 3;

(b) as between a State party to both treaties and a State party to only one of the treaties, the treaty to which both States are parties governs their mutual rights and obligations.

5. Paragraph 4 is without prejudice to article 41 , or to any question of the termination or suspension of the operation of a treaty under article 60 or to any question of responsibility which may arise for a State from the conclusion or application of a treaty the provisions of which are incompatible with its obligations towards another State under another treaty. 
than treaties, as, for example, it is practically impossible to determine the exact date a custom or general principle of law came into existence. The lex posterior rule finds that a later expression of state will prevails over an earlier expression, yet in that regard it assumes that the conflicting norms emanate from the same law-maker which is often not the case. The decentralised and fragmented nature of international law and its divergent sources, therefore, reduces the value of the lex posterior rule and as such is rarely applied. ${ }^{1046}$ The ILC finds that it is often more useful to refer directly to the will of the parties than to the lex posterior rule which would only apply if nothing else follows from party intent. ${ }^{1047}$

The third conflict resolution technique is the lex specialis derogat legi generali rule. The lex specialis rule was not included in the VCLT (as opposed to the lex posterior rule), but it was mentioned as a conflict resolution method during the drafting process. ${ }^{1048}$ Within the system of international law there is a division between general international law and more specific or particular international law. The relationship between special and general international law can be regarded in two ways: ${ }^{1049}$ first, the specific rule may be considered an application of the general rule. ${ }^{1050}$ Both the specific and general rule point in the same direction, but the former is, for example, an elaboration, updating or specification of the latter. ${ }^{1051}$ Secondly, the specific rule can modify, overrule or set aside a general rule and in such situations, the lex specialis rule is used as a method of conflict resolution. ${ }^{1052}$ States, through for example the adoption of treaties, can contract out of general international law, except for those norms representing jus cogens. ${ }^{1053}$ In that regard, general international law (again except for jus cogens) is considered to be residual law or law which has a "fall back" function in cases where specific international law does not address a matter. Distinguishing between the two situations is difficult and more importantly not necessary, because in both situations the special rule prevails over the general rule. ${ }^{1054}$

1046 BENEDETTO CONFORTI, 'Consistency among Treaty Obligations', in Enzo Cannizzaro (ed.), The Law of Treaties Beyond the Vienna Convention (New York: Oxford University Press, 2011) at 188; INTERNATIONAL LAW COMMISSION, Fragmentation of International Law, (UN Doc. A/CN.4/L.682) at $\$ 234$ et seq; PAUWELYN, Conflict of Norms in Public International Law, at 97.

1047 INTERNATIONAL LAW COMMISSION, Fragmentation of International Law, (UN Doc. A/ CN.4/L.682) at $\$ 243,252$.

1048 Ibid. at $\$ 65$.

1049 Ibid. at $\$ 56-57$.

1050 Ibid. at $\S 88,98$ et seq.

1051 Some consider such a situation as not being one of normative conflict. PAUWELYN, Conflict of Norms in Public International Law, at 386.

1052 INTERNATIONAL LAW COMMISSION, Fragmentation of International Law, (UN Doc. A/ CN.4/L.682) at $\S 88,103$ et seq.

1053 PAUWELYN, Conflict of Norms in Public International Law, at 149.

1054 INTERNATIONAL LAW COMMISSION, Fragmentation of International Law, (UN Doc. A/ CN.4/L.682) at $\$ 91-92$. 
Thus, in a situation of conflict between a norm of general law and a norm of special law, the latter will prevail over the former which is referred to as the lex specialis rule. ${ }^{1055}$ Special rules are clearer, more definite and concrete than general rules; and therefore the need to comply with the special rule is often considered more pressing. Furthermore, special rules are argued to be better suited to expressing state will. ${ }^{1056}$ However, the general rule is not displaced in its entirety, but it stays in the background as an interpretative guide. ${ }^{1057}$ See for example the case of international humanitarian law which is often stated to be lex specialis in relation to international human rights law. ${ }^{1058}$ Yet, as affirmed by the ICJ, international human rights law continues to apply during armed conflicts. ${ }^{1059}$

How to determine what is general and what is specific (or particular) international law is problematic. ${ }^{1060}$ The ILC finds that generality and speciality are relational and can register on two levels: with regard to the subject matter or with regard to the number of actors whose actions are regulated by it. ${ }^{1061}$ Here the following distinction is made: general international law is binding on all states, while specific international law is binding on only some states. ${ }^{1062}$ Thus, general international law consists of: general customary international law (in terms of membership), general principles of law and jus cogens. ${ }^{1063}$ Rules of general customary international law are, by their very nature, binding on all states and include for example rules on state responsibility, the law of treaties, the use of force, genocide, and (certain) human rights. ${ }^{1064}$ For example, the 1948 Universal Declaration of Human Rights represents, although not necessarily in its entirety, general customary international law. As opposed to general international law, specific international law is binding on only some states and consists of: treaties, special customary international law (in terms of membership), unilateral acts of

1055 See also article 55 of the articles on Responsibility of States for Internationally Wrongful Acts: These articles do not apply where and to the extent that the conditions for the existence of an internationally wrongful act or the content or implementation of the international responsibility of a State are governed by special rules of international law.

International case law also provides evidence for accepting the lex specialis rule. See ibid. at $\S 68$ et seq.

Ibid. at $\$ 60$.

1057 Ibid. at $\$ 102$.

1058 Ibid. at $\$ 103$.

1059 International Court of Justice, Advisory Opinion on the Legality of the Threat or Use of Nuclear Weapons, 8 July 1996d, at $\$ 25$.

1060 INTERNATIONAL LAW COMMISSION, Fragmentation of International Law, (UN Doc. A/ CN.4/L.682) at $\$ 58,111$.

1061 Ibid. at $\$ 112$.

1062 PAUWELYN, Conflict of Norms in Public International Law, at 148, 155.

1063 Ibid. at 148.

1064 This does not entail that states cannot "contract out" of general international law. "Persistent objectors" against a rule of general customary law would not be bound by the rule they have persistently objected to. Yet such a rule would still be part of general international law, and cannot be contracted out of unless persistently objected to. See Fisheries Case, at 131. 
states, and acts of international organisations. ${ }^{1065}$ The TRIPS Agreement and the ICESCR, being binding only on WTO members and states parties respectively, are part of specific or particular international law. Within the WTO context, the adjudicative bodies have only occasionally referred to the lex specialis principle in interpreting the covered agreements. It appears to have a limited role as a subsidiary means in conflict resolution only applying when harmonious interpretation proves unsuccessful. ${ }^{1066}$

Moreover, the relationship between conflict resolution techniques is problematic: for example, should the lex specialis principle overrule the lex posterior principle or vice versa? ${ }^{1067}$ According to the ILC, both approaches cannot be applied in an absolute way, and there is a need to balance both. ${ }^{1068}$ In the case at hand, a further limitation of the lex posterior and lex specialis rules is the specific nature of human rights treaties in that they do not protect states' interests but human beings' fundamental interests. In that regard, they set out obligations of an objective nature excluding reciprocity. ${ }^{1069}$ Finally, irrespective of how special a norm's subjectmatter is or how limited the number of states bound by it, it cannot be applied in a vacuum. ${ }^{1070}$ It applies in a normative environment and must be considered in the light of the wider corpus of public international law, including both general international law and other sub-systems. ${ }^{1071}$

Concluding, the simplest way to resolve the tension between TRIPS and ICESCR is first to assess whether one of the two norms has a superior status under international law. Therefore section 4 of this chapter will address to what extent the right to health or access to essential medicines may be considered a superior norm under international law. As will be seen, there is little evidence to support the contention that the right to health or access to essential medicines is a norm of superior character in international law. Consequently, section 5 of this chapter will examine whether it is possible to interpret TRIPS' provisions in light of human rights standards to achieve a harmonious reading and thus avoid any tension.

\section{The Principle of Human Rights Primacy}

The UN human rights system first addressed the interface between IP and human rights at the turn of the century. In a resolution adopted in 2000, the SubCommission on the Protection and Promotion of Human Rights (Sub-Commission)

\footnotetext{
1065 PAUWELYN, Conflict of Norms in Public International Law, at 155.

1066 INTERNATIONAL LAW COMMISSION, Fragmentation of International Law, (UN Doc. A/ CN.4/L.682) at $\$ 75,88$.

1067 Ibid. at $\$ 58$.

1068 Ibid. at $\$ 62,67,225$.

1069 SEUBA, 'Mainstreaming the TRIPS and Human Rights Interactions', at 210-214.

1070 INTERNATIONAL LAW COMMISSION, Fragmentation of International Law, (UN Doc. A/ CN.4/L.682) at $\$ 120$.

1071 Ibid. at $\$ 119$ et seq; PAUWELYN, Conflict of Norms in Public International Law, at 201.
} 
The Interface between Patents and Human Rights in the Context of Access to Medicines

was critical of the high level of intellectual property protection required by the TRIPS Agreement declaring that:

since the implementation of the TRIPS Agreement does not adequately reflect the fundamental nature and indivisibility of all human rights, including the right of everyone to enjoy the benefits of scientific progress and its applications, the right to health, the right to food and the right to self-determination, there are apparent conflicts between the intellectual property rights regime embodied in the TRIPS Agreement, on the one hand, and international human rights law, on the other. ${ }^{1072}$

Consequently, it reminds all governments of the "primacy of human rights obligations over economic policies and agreements". ${ }^{1073}$ It further requested all governments to take international human rights obligations and principles fully into account in international economic policy formulation and to integrate into legislation, policies, practices and operations provisions, in accordance with international human rights obligations and principles that protect the social function of intellectual property. ${ }^{1074}$ It requested the WTO to take full account of international human rights obligations during its ongoing review of the TRIPS Agreement. ${ }^{1075}$

This statement by the Sub-Commission, however, does not have legal force since it is a non-binding instrument, but it did set out an ambitious new agenda for addressing IP issues within the UN human rights system, based on the idea of human rights primacy over IPRs in general and TRIPS more specifically. ${ }^{1076}$

In 2001 the Sub-Commission received a progress report submitted by Mr. J. Oloka-Onyango and Ms. Deepika Udagama, appointed as Special Rapporteurs to undertake a study on the impact of globalisation on human rights. ${ }^{1077}$ In their preliminary report they were very critical of the WTO stating that "the assumptions on which the rules of WTO are based are grossly unfair and even prejudiced."1078

1072 UN SUB-COMMISSION ON HUMAN RIGHTS, Resolution 2000/7. Intellectual Property Rights and Human Rights, (UN Doc. E/CN.4/SUB.2/RES/2000/7) at §2. See for more information DAVID WEISSBRODT and KELL SCHOFF, 'Human Rights Approach to Intellectual Property Protection: The Genesis and Application of Sub-Commission Resolution 2000/7', Minnesota Intellectual Property Review, 5:1 (2003), 1-46; DAVID WEISSBRODT and KELL SCHOFF, 'The Sub-Commission's Initiative on Human Rights and Intellectual Property', Netherlands Quarterly of Human Rights, 22:2 (2004), 181-215.

1073 UN SUB-COMMISSION ON HUMAN RIGHTS, Resolution 2000/7. Intellectual Property Rights and Human Rights, (UN Doc. E/CN.4/SUB.2/RES/2000/7) at $\$ 3$.

1074 Ibid. at $\$ 4-6$.

1075 Ibid. at $\$ 8$.

1076 HELFER, ‘Toward a Human Rights Framework for Intellectual Property', at 986.

1077 UN SUB-COMMISSION ON THE PROMOTION AND PROTECTION OF HUMAN RIGHTS, Progress Report Submitted by J. Oloka-Onyango and Deepika Udagama on Globalisation and Its Impact on the Full Enjoyment of Human Rights, (UN Doc. E/CN.4/Sub.2/2001/10).

1078 UN SUB-COMMISSION ON HUMAN RIGHTS, Prelimiary Report Submitted by J. OlokaOnyango and Deepika Udagama, in Accordance with Sub-Commission Resolution 1999/8 on 
Consequently what is required, according to the Special Rapporteurs, is a more balanced approach ensuring that human rights principles are integrated into the rule-making processes from the outset; namely, primacy of international human rights law - based on article 103 of the UN Charter - over all other regimes of international law is a basic and fundamental principle that should not be departed from. ${ }^{1079}$ In that regard they contended that although the primary obligation to comply with international human rights law lies with the individual state, intergovernmental organisations such as the WTO are essentially creatures of the international legal system and, therefore, cannot be exempt from fundamental principles of international law such as the obligation to respect universal human rights norms. ${ }^{1080}$ Consequently, the Special Rapporteurs reiterated "that the WTO qua an international organization, created and functioning under general principles of international law, is bound to respect fundamental principles of international human rights law which form part of those general principles of law."1081 Concerning IP protection the Special Rapporteurs were of the opinion that "the argument for stringent patent protection as essential to the promotion of innovation and invention is one that over-privileges the owners of capital."1082

The WTO reacted to the criticisms of the Special Rapporteurs' preliminary report. In a letter to the High Commissioner for Human Rights, Mrs. Mary Robinson, the WTO Deputy Director-General Miguel Rodriguez Mendoza expressed the WTO's deep concern with the language, methodology and main conclusions of the report, virtually unsubstantiated by any empirical evidence. ${ }^{1083}$ Although the he Sub-Commission's resolution was more balanced in its analysis it was still critical of the TRIPS Agreement and its impact on human rights, specifically socio-economic rights, and of the more general development of a global expansion of IPRs. However, it fails to provide a detailed textual analysis of a human rights framework for intellectual property and how that framework interfaces with existing intellectual property protection standards in national and international law. ${ }^{1084}$ The WTO disagrees with the SubCommission's criticism and views the interface of IPRs and public interest as

Globalisation and Its Impact on the Full Enjoyment of Human Rights (UN Doc. E/CN.4/ Sub.2/2000/13; 2000) at $\S 14$.

1079 Ibid. at $\$ 63$.

1080 UN SUB-COMMISSION ON THE PROMOTION AND PROTECTION OF HUMAN RIGHTS, Progress Report Submitted by J. Oloka-Onyango and Deepika Udagama on Globalisation and Its Impact on the Full Enjoyment of Human Rights, (UN Doc. E/CN.4/Sub.2/2001/10) at §58.

083 See for example CHAKRAVARTHI RAGHAVAN, 'WTO Concerned over Human Rights Appraisal Report', <www.twnside.org.sg/title/appraisal.htm>, accessed 1 March; SOMESHWAR SINGH, 'UN Human Rights Commissioner', <www.globalpolicy.org/ component/content/article/209/43850.html>, accessed 1 March 20142014.

1084 HELFER, 'Toward a Human Rights Framework for Intellectual Property', at 987. 
complementary rather than mutually exclusive, as is reflected in articles 7 and 8 of the TRIPS Agreement. ${ }^{1085}$

Within the UN framework, other human rights bodies and experts have also examined this interface approaching IPRs from the perspective of human rights. These will be set out in section 5 of this chapter, however, the following section will first examine whether the Sub-Commission's claim of human rights primacy over IPRs has any foundation in international law.

\subsection{The Right to Health as a Superior Norm in International Law?}

International law recognises that certain norms are superior to others. In that regard, there are three sources of hierarchically superior norms: jus cogens, article 103 of the Charter of the United Nations and to a certain extent obligations erga omnes. Jus cogens are peremptory norms and the only norms within international law recognised to be superior to all other norms. Article 103 UN establishes that the Charter of the United Nations takes precedence over all other obligations. Obligations erga omnes or "duties owed to all" are obligations which are considered to be so important that states owe these duties to the international community as a whole. Currently, human rights in general or the right to health specifically are not universally recognised as prioritised norms within international law. ${ }^{1086}$ However, it has been argued that it would not be impossible to include health-related interests in the concept of prioritised international norms. ${ }^{1087}$

Article 53 of the VCLT states that a treaty is void if, at the time of its conclusion, it conflicts with a peremptory norm of general international law. ${ }^{1088}$ It further defines peremptory norms as "a norm accepted and recognised by the international community of states as a whole as a norm from which no derogation is permitted". The concept of peremptory norms firstly ensures that any treaty in conflict with jus cogens is void, and secondly it obliges every state to comply with peremptory norms irrespective of consent by the state. Thus, if human rights norms are considered to be peremptory they would override any WTO or TRIPS obligations.

\footnotetext{
1085 UN SUB-COMMISSION ON THE PROMOTION AND PROTECTION OF HUMAN RIGHTS, Report of the SG on IPRs and Human Rights, (UN Doc. E/CN.4/Sub.2/2001/12) at 7.

1086 LISA FORMAN, 'An Elementary Consideration of Humanity? Linking Trade-Related Intellectual Property Rights to the Human Right to Health in International Law', The Journal of World Intellectual Property, 14:2 (2011), 155-175 at 157; PAPADOPOULOU, 'TRIPS and Human Rights', at 290-291.

1087 See FORMAN, 'An Elementary Consideration of Humanity?', at 157.

1088 Article 53 VCLT reads: A treaty is void if, at the time of its conclusion, it conflict with a peremptory norm of general international law. For purposes of the present Convention, a peremptory norm of general international law is a norm accepted and recognised by the international community of states as a whole as a norm from which no derogation is permitted and which can be modified only by a subsequent norm of general international law having the same character.

See also Article 64 VCLT: If a new peremptory norm of general international law emerges, any existing treaty which is in conflict with that norm becomes void and terminates.
} 
The concept of jus cogens is recognised in international practice, international and domestic jurisprudence and legal doctrine, however, there is disagreement about its application and content. ${ }^{1089}$

The non-consensual element of jus cogens is contradictory to the traditional underlying notion of general international law being based on consent. However, it is also partly limited by the fact that the content of jus cogens is based on international consensus as defined by the VCLT, which states that a peremptory norm must be recognised as such by the whole international community. Thus, peremptory norms are binding irrespective of consent, but their actual content is determined by consent. This adds another dimension to the concept of jus cogens that although these are norms superior to other rules of international law, they may also be subject to contestation, realpolitik and political or cultural bias as it is the international community which determines what norm is considered to have a peremptory character. As such, the concept of jus cogens has some inherent limitations which may prevent international consensus in identifying new peremptory norms or classifying existing conduct to fall within the ambit of existing norms. ${ }^{1090}$

There are few norms that are considered to have such a peremptory character by the international community. Generally accepted as having the status of jus cogens are: the prohibition of aggressive use of force, the right to self-defence, the prohibition of genocide, the prohibition of torture, crimes against humanity, the prohibition of slavery and slave trade, the prohibition of piracy, the prohibition of racial discrimination and apartheid, and the prohibition of hostilities directed at civilian population (basic rules of international humanitarian law). ${ }^{1091}$ Others have added the right to life, liberty and security. ${ }^{1092}$

However, the current list of peremptory norms cannot be absolute and the fact that health-related prohibitions are absent from jus cogens rules is no bar to their inclusion. Forman argues that "the circumscribed list of accepted peremptory norms is itself reflective of normative priorities within international law that could reasonably be interpreted to include health-related interests."1093 See, for example, the International Law Commission's commentary on the VCLT in which it stated that it is not the form but the particular nature of the subject matter that gives the norm its jus cogens character. ${ }^{1094}$ The International Court of Justice has been hesitant to refer to the concept of jus cogens. Yet, its repeated reference to general

\footnotetext{
1089 INTERNATIONAL LAW COMMISSION, Fragmentation of International Law, (UN Doc. A/ CN.4/L.682) at $\$ 363$.

1090 FORMAN, 'An Elementary Consideration of Humanity?', at 157-158.

1091 Ibid. at 157; INTERNATIONAL LAW COMMISSION, Fragmentation of International Law, (UN Doc. A/CN.4/L.682) at \$374-376.

1092 VILJOEN, International Human Rights Law in Africa, at 28.

1093 FORMAN, 'An Elementary Consideration of Humanity?', at 158.

1094 INTERNATIONAL LAW COMMISSION, Draft Articles of the Law of Treaties with Commentaries (Yearbook of the International Law Commission. Vol. II; 1966) at 248.
} 
and fundamental principles such as "elementary considerations of humanity"1095 as "intransgressible principles of international law"1096 leads the ILC to assume that the ICJ has, in substance, affirmed the concept. ${ }^{1097}$

Thus, the fundamental nature of existing peremptory norms lies in their subject matter. As such it does not seem unjustified to argue that they would include the prohibition of acts that violate human rights to dignity, life and bodily integrity to such a gross extent that the essential content of all human rights are negated. ${ }^{1098}$ One could interpret this to include elements of the right to health since the rights to life, bodily integrity and human dignity are intimately linked with the right to health, as is recognised in international law and practice. For example, the right to life under article 6 ICCPR has been interpreted to include positive obligations with respect to increasing life-expectancy by, for example, eliminating epidemics. ${ }^{1099}$ Furthermore, state practice indicates an increasing recognition of states' responsibility in ensuring access to (life-saving) medicines in the context of pandemics. ${ }^{1100}$ It is unlikely, though, that the right to life comprehensively would fall within the ambit of peremptory norms. Moreover, the CESCR finds the right to health to be a fundamental right indispensible for the exercise of other human rights. ${ }^{101}$ More particularly it considered access to essential medicines as part of the core content of the right to health which, as such, is considered to be nonderogable. ${ }^{1102}$ However, it is questionable whether this determination by the CESCR - the core content of a right being non-derogable - would lead to the conclusion that such core content is a prioritised norm under international law. ${ }^{1103}$ Firstly, the ICESCR does not formally prioritise certain elements of a right above others nor does it include a provision similar to the ICCPR prohibiting derogation from the rights enshrined in the ICESCR. Secondly, the CESCR's General Comment No. 14 on the right to health, although an authoritative interpretation, is a non-binding instrument.

Moreover, it has been argued that a jus cogens norm relating to the rights to life, bodily integrity and human dignity would imply that any gross violations of these or similar rights would be prohibited if it led to the negation of the essential content

\footnotetext{
1095 International Court of Justice, Corfu Channel Case (United Kingdom of Great Britain and Northern Ireland v. Albania), 9 April 1949, at 22.

1096 Advisory Opinion on the Legality of the Threat or Use of Nuclear Weapons, at $\$ 79$.

1097 INTERNATIONAL LAW COMMISSION, Fragmentation of International Law, (UN Doc. A/ CN.4/L.682) at \$378-379.

1098 FORMAN, 'An Elementary Consideration of Humanity?', at 158.

1099 HRCee, General Comment 6, (UN Doc. HRC/GC/6) at $\$ 5$.

1100 See also section 6 of chapter 3 .

1101 CESCR, General Comment No. 14, (UN Doc. E/C.12/2000/4) at $\$ 1$.

1102 Ibid. at $\$ 43$.

1103 INTERNATIONAL LAW COMMISSION, Draft Articles of the Law of Treaties with Commentaries, (Yearbook of the International Law Commission. Vol. II) at 248. Here the ILC stated that it would not "be correct to say that a provision in a treaty possesses the character of jus cogens merely because the parties have stipulated that no derogation from that provision is permitted, so that another treaty which conflicted with that provision would be void."
} 
of all human rights. ${ }^{1104}$ Would such an interpretation mean that all human rights violations of a scale and intent to be considered gross would be prohibited as a peremptory norm?

The right to health, with its fundamental nature and interrelation with the right to life, is more than capable of being grossly violated. According to the Maastricht Guidelines a state would violate the right to health if it pursues, by action or omission, a policy which deliberately contravenes or ignores the Covenant's obligations or fails to achieve the required standard of conduct or result, ${ }^{1105}$ for example by causing large-scale deaths by denying patients access to life-saving medicines, such as was the case in South Africa under President Thabo Mbeki's policy refusing to provide ARV treatment to HIV-infected people and declining to accept freely donated ARVs and grants from the Global Fund. ${ }^{1106}$

However, international practice seems to suggest that a restrictive approach is applied to the concept of jus cogens. Considering the still controversial nature of socio-economic rights, it seems very unlikely that the current list of accepted peremptory norms includes the right to health or a right of access to essential or even life-saving medicines. ${ }^{1107}$ This does not automatically mean that health-related interests are irrelevant when it comes to jus cogens norms. Rather it suggests that the absence of health "reflects the skewed and culturally specific nature of those norms identified as peremptory". ${ }^{1108}$ It is indeed questionable what the value of the concept of jus cogens is if it is applied so restrictively that it would not include gross violations of fundamental aspects of the human right to health, or other socioeconomic rights for that matter, such as access to essential life-saving medicines.

Although all human rights are considered indivisible, the right to health (and socio-economic rights in general) are de facto still inferior to the traditional civil

1104 FORMAN, 'An Elementary Consideration of Humanity?', at 159.

1105 The Maastricht Guidelines on Violations of Economic, Social and Cultural Rights, at $\$ 11$.

1106 The intentional deprivation of access to food and medicines, with the intent to bring about the destruction of a population is a crime against humanity under the Rome Statute of the International Criminal Court (article 7). Questionable is whether this definition would include acts (or maybe even failures to act) depriving populations of access to medicines, however, without the intent to bring about their destruction. The Rome Statute defines intent as (a) meaning to engage in conduct or (b) meaning to cause a consequences or being aware that the consequence will occur in the ordinary course of events (article 30(2) a and b). Under this definition, where policy makers deny access to life-saving medicines and are aware of its consequences in that it will lead to avoidable and foreseeable deaths, one could argue such state action to be covered by the definition of intent and therefore a crime against humanity. According to a study of the Harvard School of Public Health AIDS Initiative the absence of a HIV/AIDS prevention and treatment programme in South Africa between 2000-2005 is estimated to have cost approximately 330.000 lives and resulted in 35.000 newborns infected with the virus. See PRIDE CHIGWEDERE et al., 'Estimating the Lost Benefits of Antiretrovial Drug Use in South Africa', Journal of Acquired Immune Deficiency Syndroms, 49:4 (2008), 410-415.

1107 HARRISON, The Human Rights Impact of the WTO, at 58; PAPADOPOULOU, 'TRIPS and Human Rights', at 290-291.

1108 FORMAN, 'An Elementary Consideration of Humanity?', at 160. 
and political rights. A change in their standing has been seen in recent years though. The CESCR's authoritative interpretation of the right to health in its General Comment No. 14, the creation of a permanent post for a UN Special Rapporteur on the Right to Health, the establishment of an individual complaint mechanism under the ICESCR, and the increase in domestic enforcement and jurisprudence allows us to delineate and clarify the scope and content of the right to health, thus being far better able to identify violations. Further legal development of socio-economic rights and specifically the right to health may in due time lead to a more coherent integration of these rights into international human rights theory and practice. Yet it must be remembered that for a norm to be elevated to jus cogens there must be consensus among the international community of states, and it may therefore be unlikely that health-related interests will be considered peremptory in the near future. However, jus cogens also has a certain evolutionary nature and further legal and doctrinal development of the right to health and arguments in favour of its inclusion into the category of jus cogens will shape public opinion and thus also state practice. 1109

Jus cogens, however, is not the only form of hierarchy of norms in international law. Article 103 of the Charter of the United Nations reads that:

[i]n the event of a conflict between the obligations of the members of the United National under the present Charter and their obligations under any other international agreement, their obligations under the present Charter shall prevail.

Article 103 UN denotes that obligations under the UN Charter enjoy priority within international law. These obligations not only include those expressed in the Charter but also obligations emanating from binding decisions by UN bodies; most importantly here is article 25 of the UN Charter which obliges members to accept and carry out the decisions adopted by the Security Council under chapter VII of the Charter. ${ }^{110}$ As a result, treaty obligations which conflict with binding Charter

1109 SEUBA, 'Mainstreaming the TRIPS and Human Rights Interactions', at 210.

1110 See International Court of Justice, Questions of Interpretation and Application of the 1971 Montreal Convention Arising from the Aerial Incident at Lockerbie (Libyan Arab Jamahiriya $v$. United States of America). Order for Provisional Measures, 14 April 1992, at \$42. Here the ICJ stated "whereas both Libya and the United States, as Members of the United Nations, are obliged to accept and carry out the decisions of the Security Council in accordance with Article 25 of the Charter; whereas the Court, which is at the stage of proceedings on provisional measures, considers that prima facie this obligation extends to the decision contained in resolution 748 (1992); and whereas, in accordance with Article 103 of the Charter, the obligations of the Parties in that respect prevail over their obligations under any other international agreement, including the Montreal Convention. See also International Court of Justice, Separate Opinion of Judge Ad Hoc Lauterpach in the Case Concerning the Application of the Convention on the Prevention and Punishment of the Crime of Genocide (Bosnia and Herzegovina v. Serbia and Montenegro). Further Requests for the Indication of Provisional Measures, Order of 13 September 1993, at §99. INTERNATIONAL LAW COMMISSION, Fragmentation of International Law, (UN Doc. A/CN.4/L.682) at §331; PAUWELYN, Conflict of Norms in Public International Law, at 99. 
obligations are set aside. ${ }^{1111}$ This, however, does not equate Charter obligations with having jus cogens standing and, if a Charter norm would be found in breach of jus cogens, the Charter obligation would be invalid. ${ }^{1112}$ Moreover, non-binding resolutions adopted by UN bodies, such as by human rights bodies, are not covered by article $103 \mathrm{UN}$ and therefore do not prevail over other treaty obligations. ${ }^{113}$

Finally discussed here is the concept of integral or erga omnes obligations ${ }^{111}$ obligations owed to the international community as a whole - a concept developed by the International Court of Justice in the Barcelona Traction case. ${ }^{1115}$ The ICJ distinguished between obligations of states towards another state (reciprocal/ bilateral) and obligations owed to the international community as a whole (integral/ erga omnes). ${ }^{1116}$ It found that certain rights are so important that all states can be held to have a legal interest in protecting them and that these include duties arising from the "basic rights of the human person." 1117 A breach of obligations erga omnes is therefore a breach against all states.

Norms of jus cogens nature are always obligations erga omnes and, as such, both concepts often coincide. Although in practice obligations erga omnes represent interests of importance in international law, they do not have the same status as jus cogens or Charter obligations under article 103 UN. ${ }^{1118}$ Nor can one equate obligations erga omnes with norms of jus cogens status. ${ }^{1119}$ Jus cogens prohibits

1111 Although article 103 UN reads "obligations under any other international agreement" implying that it only applies to treaty obligations, it is now accepted that article $103 \mathrm{UN}$ must be read extensively in affirmation that Charter obligations prevail also over customary law obligations. See INTERNATIONAL LAW COMMISSION, Fragmentation of International Law, (UN Doc. A/CN.4/L.682) at \$344-345.

1112 As opposed to the Charter and consequent obligations, which can be amended, jus cogens norms cannot be derogated from, but can only be modified by a subsequent norm of jus cogens. Ibid. at $\S 346,360$; PAUWELYN, Conflict of Norms in Public International Law, at 99.

1113 INTERNATIONAL LAW COMMISSION, Fragmentation of International Law, (UN Doc. A/ CN.4/L.682) at $\$ 331$.

1114 Here mention must also be made of obligations erga omnes partes, which are obligations that are not owed to the international community but to all parties to a multilateral treaty, i.e. a particular regime. See ibid. at \$399-403; PAUWELYN, Conflict of Norms in Public International Law, at 62.

See article 48 of the Articles on State Responsibility:

Any state other than an injured state is entitled to invoke the responsibility of another [...] if:

(a) The obligation breached is owed to a group of states including that state, and is established for the protection of a collective interest of the group, or

(b) The obligation breached is owed to community as a whole.

1115 International Court of Justice, Barcelona Traction, Light and Power Company, Limited Case (Belgium v. Spain), 5 February 1970.

1116 Ibid. at $\$ 33$.

1117 Ibid. at $\$ 34$. See also INTERNATIONAL LAW COMMISSION, Fragmentation of International Law, (UN Doc. A/CN.4/L.682) at \$387.

1118 INTERNATIONAL LAW COMMISSION, Fragmentation of International Law, (UN Doc. A/ CN.4/L.682) at §380; PAUWELYN, Conflict of Norms in Public International Law, at 61, 100.

1119 INTERNATIONAL LAW COMMISSION, Fragmentation of International Law, (UN Doc. A/ CN.4/L.682) at $\$ 404$. 
states from acting in violation of peremptory norms, while obligations erga omnes concern only the duties regarding the interests themselves. ${ }^{1120}$ Thus, an obligation erga omnes confers general standing on all states to make a claim in the event of a breach. Consequently, obligations erga omnes do not directly relate to conflict of norms.

The integral nature of obligations erga omnes is not based on the concerned interests themselves but on the structure and origin of the commitment made by a state, whether this is an obligation made to the collective conscience of states and may be invoked by any state in case of a breach not just the beneficiary. ${ }^{1121}$ That said, defining the common conscience of states involves a subjective value judgment and in that regard they provide an indication of which obligations are considered more important than others within the international community. ${ }^{1122}$

Initially it was found that obligations erga omnes arose from basic human rights, however, now it is argued that obligations erga omnes arise from all human rights since all human rights are universal, indivisible, interdependent and interrelated. ${ }^{1123}$ Human rights obligations are not bilateral obligations, but rather they are a promise made to the collective or common conscience of all states involved, namely human rights primary intent is to ensure governments do not mistreat their own nationals. ${ }^{124}$ Respect for human rights is therefore mainly a national matter, but the underlying values are of a collective and universal nature. ${ }^{1125}$ The violation of a human right principally does not impact one state more than another, but it is a breach against the community as a whole. ${ }^{1126}$ Unlike human rights, most trade obligations (allowing market access to another state, which is multilateralised through the MFN principle) are a collection of reciprocal/bilateral obligations. They are promises made to each WTO member individually rather than the international community as a whole. ${ }^{1127}$ See also for example the manner in which WTO obligations are enforced, which is exclusively bilateral. ${ }^{1128}$ However, this view must

1120 FORMAN, 'An Elementary Consideration of Humanity?', at 161; PAUWELYN, Conflict of Norms in Public International Law, at 63.

1121 See for more information on distinction between reciprocal/bilateral and integral/erga omnes obligations PAUWELYN, Conflict of Norms in Public International Law, at 67 et seq.

1122 Ibid. at 101.

1123 YORAM DINSTEIN, 'The Erga Omnes Applicability of Human Rights', Archiv des Völkerrechts, 30:1 (1992), 16-21 at 17; FORMAN, 'An Elementary Consideration of Humanity?', at 161.

1124 PAUWELYN, Conflict of Norms in Public International Law, at 65.

1125 Ibid. at 72

1126 INTERNATIONAL LAW COMMISSION, Fragmentation of International Law, (UN Doc. A/ CN.4/L.682) at \$391-393.

1127 HARRISON, The Human Rights Impact of the WTO, at 60; PAUWELYN, Conflict of Norms in Public International Law, at 65-66, 69 et seq.

1128 PAUWELYN, Conflict of Norms in Public International Law, at 76-78. Suspension of obligations as a form of retaliation, as is the case in the WTO, is possible for reciprocal/bilateral obligations, yet not for integral/erga omnes obligations. Thus human rights obligations of an integral nature cannot be suspended in case of a breach, as this would affect not only the 
be nuanced. Non-discrimination obligations under WTO law are not merely reciprocal/bilateral, they are owed to all WTO members and as such can be termed as obligations erga omnes partes; i.e. "obligations arising out of a treaty and designed to protect the "collective interests' of the treaty parties." 1129 Additionally, trade is not a value as for example human rights, it is a tool. It is a tool to achieve the WTO's primary objective to increase global economic welfare. ${ }^{1130}$

Concluding, under international law certain interests are prioritised over others which, arguably, would include the prohibition of gross violations of human rights and conduct which would render human rights meaningless. Similarly international human rights law also considers certain elements of human rights - the core content of a particular right - to be non-derogable. However, this non-derogable nature of the core content is questionable and would not lead to the conclusion that such core content is a prioritised norm under international law. There is no evidence that the international community currently considers access to essential medicines, either as an element of the right to health or life, as part of internationally prioritised norms. A norm can only reach the status of jus cogens if there is consensus among the international community of states, and it seems clear that there is no such consensus at this time and unlikely that health-related interests will be considered peremptory in the near future.

\section{Harmonious Interpretation: The Principle of Systemic INTEGRATION}

In international law there is a strong presumption against conflict. It is assumed that when states create new obligations under international law, they do not derogate

violating state but all other contracting parties. It can therefore be criticised that state-to-state suspension is also allowed under TRIPS, an agreement which might also include integral obligations.

1129 INTERNATIONAL LAW COMMISSION, Fragmentation of International Law, (UN Doc. A/ CN.4/L.682) at $\$ 390$.

1130 See for example the preamble to the Agreement establishing the World Trade Organisation: Recognizing that their relations in the field of trade and economic endeavour should be conducted with a view to raising standards of living, ensuring full employment and a large and steadily growing volume of real income and effective demand, and expanding the production of and trade in goods and services, while allowing for the optimal use of the world's resources in accordance with the objective of sustainable development, seeking both to protect and preserve the environment and to enhance the means for doing so in a manner consistent with their respective needs and concerns at different levels of economic development;

Recognizing further that there is need for positive efforts designed to ensure that developing countries, and especially the least developed among them, secure a share in the growth in international trade commensurate with the needs of their economic development;

Being desirous of contributing to these objectives by entering into reciprocal and mutually advantageous arrangements directed to the substantial reduction of tariffs and other barriers to trade and to the elimination of discriminatory treatment in international trade relations.

See also ibid. at §389; PAUWELYN, Conflict of Norms in Public International Law, at 73. 
from their already existing obligations. ${ }^{1131}$ Consequently, where possible, WTO norms should be interpreted in a manner so as to avoid any conflict or tension with other rules of international law. The assumption therefore is that the tension between TRIPS and ICESCR is an apparent tension, not a genuine conflict. Yet if a harmonious reading (between the norms regarding the right of access to medicines and protection of patents for pharmaceuticals) is not possible, the presumption against conflict is rebutted and a genuine conflict must be acknowledged. ${ }^{1132}$

Every sub-system of international law must be considered in the light of the wider corpus of general international law, including general international law and other sub-systems. ${ }^{1133}$ Such a "fall-back" on other norms of international law can take the form of interpretation (giving meaning to the terms of a particular norm) and application of TRIPS and ICESCR in the context and together with other norms of international law. Article 31.3(c) of the VCLT states that, together with the context, taken into account shall be: "any relevant rules of international law applicable in the relation between the parties." This reflects a "principle of systemic integration" emphasising the unity of international law, where treaties are contextually interpreted taking into account a broader normative environment within international law. ${ }^{1134}$ In that regard article 31.3(c) VCLT is seen as a linking device between disparate bodies of international law, and it is argued that it will enable the recognition of the right to health within TRIPS. ${ }^{1135}$

The principal way, therefore, in which to avoid a genuine conflict between TRIPS and ICESCR is in interpreting the TRIPS Agreement in a manner conducive to promoting and protecting human rights, in this case public health and a right of access to medicines. ${ }^{1136}$ Marceau finds that "a good faith interpretation of the relevant WTO and human rights provisions should lead to a reading of WTO law coherent with human rights law" of which the Doha Declaration is a good

1131 International Court of Justice, Right of Passage over Indian Territory - Preliminary Objections (Portugal v. India), 26 November 1957, at 142; INTERNATIONAL LAW COMMISSION, Fragmentation of International Law, (UN Doc. A/CN.4/L.682) at \$37; PAUWELYN, Conflict of Norms in Public International Law, at 207. Here the ICJ found that "it is a rule of interpretation that a text emanating from a government must, in principle, be interpreted as producing and intended to produce effects in according with existing law and not in violation of it."

1132

PAUWELYN, Conflict of Norms in Public International Law, at 251.

Ibid. at 201.

INTERNATIONAL LAW COMMISSION, Fragmentation of International Law, (UN Doc. A/ CN.4/L.682) at $\$ 413$ et seq; PAUWELYN, Conflict of Norms in Public International Law, at 253. See for a discussion on the role of article 31.3(c) VCLT with respect to the interpretation of the TRIPS Agreement in light of broader societal interests, such as public health chapter 5 , section 5.2 .

1135 FORMAN, 'An Elementary Consideration of Humanity?', at 163.

1136 See for example PAPADOPOULOU, 'TRIPS and Human Rights', at 293-294; PATRICK L. WOJAHN, 'A Conflict of Rights: Intellectual Property under TRIPS, the Right to Health, and AIDS Drugs', UCLA Journal of International Law \& Foreign Affairs, 6 (2001-2002), 463-497 at 491 et seq. 
example. ${ }^{137}$ The WTO itself states that the TRIPS Agreement promotes values essential for the realisation of human rights and that TRIPS aims at striking an appropriate balance between intellectual property protection and human rights standards. ${ }^{1138}$

The idea of balancing incentives with access is not something unknown within international human rights law. General Comment No. 17 on the right of everyone to benefit from the protection of the moral and material interests resulting from any scientific, literary or artistic production of which he or she is the author (article 15(1)c ICESCR) discusses the content and states' obligations regarding this right and also examines its relationship with systems of IPRs. Unfortunately, like many other UN human rights documents addressing the IP - human rights interface, the CESCR here also does not give a lot of guidance on how states parties should achieve a balanced, human rights compliant system of intellectual property protection. ${ }^{1139}$ It gives insight however into how a state party should strike a balance between authors' private rights to the protection of interests in their intellectual creations and the wider public interest in the right to enjoy access to their productions in paragraph 35 of its General Comment No. 17. There it firstly states that the rights of authors under article 15.1(c) ICESCR cannot be recognised in isolation of the other rights enshrined in the Covenant and that states parties are therefore obliged to strike an adequate balance between the rights of authors and the other provisions of the Covenant. ${ }^{1140}$ Moreover:

[i]n striking this balance, the private interests of authors should not be unduly favoured and the public interest in enjoying broad access to their productions should be given due consideration. States parties should therefore ensure that their legal or other regimes for the protection of the moral and material interests resulting from one's scientific, literary or artistic productions constitute no impediment to their ability to comply with their core obligations in relation to the rights to food, health and education, as well as to take part in cultural life and to enjoy the benefits of scientific progress and its applications, or any other right enshrined in the Covenant.

Here the CESCR indirectly acknowledges the difficulty states may have in reconciling treaty-based obligations regarding IPRs especially with the ICESCR's non-core obligations. ${ }^{1141}$ The CESCR offers some specific recommendations to achieve a balance, stating that ultimately IP is a social product and has a social function. Therefore, states parties have a "duty to prevent unreasonably high costs for access to essential medicines, plant seeds or other means of food production, or

1137 MARCEAU, 'WTO Dispute Settlement and Human Rights', at 755.

1138 See CESCR, Protection of Intellectual Property under the TRIPS Agreement. Background Paper Submitted by the Secretariat of the WTO (UN Doc. E/C.12/2000/18; 2000a) at $\$ 13$ et seq.

1139 HELFER, 'Toward a Human Rights Framework for Intellectual Property', at 997.

1140 CESCR, General Comment No. 17, (UN Doc. E/C.12/GC/17) at $\$ 35$.

1141 HELFER, 'Toward a Human Rights Framework for Intellectual Property', at 997. 
for schoolbooks and learning materials, [from] undermining the rights of large segments of the population to health, food and education"; states parties "should prevent the use of scientific and technical progress for purposes contrary to human rights and dignity, including the rights to life, health and privacy, e.g. by excluding inventions from patentability whenever their commercialization would jeopardize the full realization of these rights"; and that states parties "should, in particular, consider to what extent the patenting of the human body and its parts would affect their obligations under the Covenant or under other relevant international human rights instruments." 1142 Thus, the CESCR recommends that states parties undertake human rights impact assessments at the moment of adoption and after a period of implementation of legislation for protecting authors' rights to benefit from the interests of their intellectual creations. ${ }^{1143}$

Following a request by the Sub-Commission on the Promotion and Protection of Human Rights, the High Commissioner for Human Rights examined the relationship between the TRIPS Agreement and the right to health in her 2001 report. ${ }^{144}$ She found that the starting point for a human rights analysis of the TRIPS Agreement is article 27 of the UDHR and article 15 of the ICESCR which recognises the right of everyone to the moral and material interests resulting from any scientific, literary or artistic production of which he or she is the author and the right of everyone to enjoy the benefits of scientific progress and its applications. As such, the ICESCR identifies the need to balance promoting general public interests in accessing new knowledge and protecting the interests of authors and inventors in such knowledge and binds states parties to achieve such balance when designing an IP system. ${ }^{1145}$

Balancing public and private interests is also not unfamiliar to intellectual property laws. For example, with respect to patents, the monopoly position granted to a right holder is for a limited period and non-renewable, intended to provide inventors with the ability to recoup research and development costs; in return inventors must disclose their inventions, which has been a fundamental element of patent laws since its inception. As such, patents aim to ensure access to the knowledge in the short term and access to the actual (patented) invention, and future inventions, in the long-term.

Consequently, the High Commissioner found a degree of compatibility between article 15 and traditional IP systems, yet posed that the essential question is "where to strike the right balance." 1146 In order to analyse the TRIPS Agreement from a human rights perspective two preconditions must be kept in mind: the publicprivate balance should be struck with the primary objective of promoting and

\footnotetext{
1142 CESCR, General Comment No. 17, (UN Doc. E/C.12/GC/17) at §35.

1143 Ibid.

1144 UN SUB-COMMISSION ON HUMAN RIGHTS, Report of the High Commissioner on the Impact of the TRIPS Agreement on Human Rights (UN Doc. E/CN.4/Sub.2/2001/13).

1145 Ibid. at $\$ 10$.

1146 Ibid. at $\$ 12$.
} 
protecting human rights and the difference in characteristics of IPRs (a limited right granted by the state according to well-defined criteria which may be licensed, assigned, or revoked) and human rights (inalienable and universal). ${ }^{1147}$ The High Commissioner found that there are a number potential links between human rights and TRIPS, such as TRIPS' objectives and principles recognising the need to strike a balance and TRIPS' flexibilities allowing members to take concrete measures to do so. ${ }^{148}$ However, she also found that recognising potential links between human rights and TRIPS does not lead to the conclusion that TRIPS takes a human rights approach to IP protection. Actually she found that there remain fundamental differences in approach. ${ }^{149}$ Although both suggest different approaches, much will depend on the actual implementation and interpretation of the TRIPS Agreement by states, but also for example within the WTO dispute settlement mechanism.

The High Commissioner concluded that "members should therefore implement the minimum standards of the TRIPS Agreement bearing in mind both their human rights obligations as well as the flexibility inherent in the TRIPS Agreement, and recognizing that 'human rights are the first responsibility of Governments'."1150 Consequently, the implementation of TRIPS should be characterised by the following objectives: the promotion of article 15 ICESCR in order achieve a balance between public - private interests; the promotion of the right of everyone to the enjoy the benefits of scientific progress and its applications and prevention of abuse of IPRs taking into consideration the increasing tendency to grant patents for "me-too" medicines which may run counter to the primary objective of IP systems to promote innovation; the promotion of the right to health and access to affordable medicines by taking full advantage of TRIPS' flexibilities such as compulsory licensing and parallel importation; and the promotion of international cooperation in the implementation of the TRIPS Agreement. ${ }^{1151}$

In his preliminary report, Special Rapporteur Paul Hunt touched upon the relationship of TRIPS and human rights, stating that both Agreements (including GATS) bear upon crucial elements of the right to health. ${ }^{1152}$ As a result the Special Rapporteur undertook a mission at the World Trade Organisation in order to examine trade rules and policies and set out the ways in which these impact the right to health. ${ }^{1153} \mathrm{He}$ stated that international human rights law takes a position neither for nor against any particular trade rule or policy, subject to two conditions: first, the rule or policy must in practice actually enhance the enjoyment of human

\footnotetext{
1147 Ibid. at $\$ 13-14$.

1148 Ibid. at $\$ 16-19$.

1149 Ibid. at $\$ 21-22$.

1150 Ibid. at $\$ 60$.

1151 Ibid. at $\$ 61$ et seq.

1152 UN COMMISSION ON HUMAN RIGHTS, Report of the Special Rapporteur on the Right to Health, (UN Doc. E/CN.4/2003/58) at $\S 86$ et seq.

1153 UN COMMISSION ON HUMAN RIGHTS, Report of the Special Rapporteur on the Right to Health. Addendum. Mission to the WTO, (UN Doc. E/CN.4/2004/49/add.1).
} 
rights and, second, the process by which the rule or policy is formulated, implemented and monitored must be consistent with democratic and human rights principles. ${ }^{154}$

Continuing Hunt's work on TRIPS and human rights, Special Rapporteur Anand Grover submitted a report to the Human Rights Council in 2009 exploring the impact of the TRIPS Agreement on access to affordable medicines in the broader framework of the right to health. ${ }^{1155}$ There he stated that "from a right to health perspective, developing countries and LDCs should be enabled to use TRIPS flexibilities." $" 156 \mathrm{He}$ referred to the following flexibilities which members should incorporate into their national laws: make full use of the transition periods; define the criteria of patentability; issue compulsory licences and provide for government use; adopt the international exhaustion principle to facilitate parallel importation; create limited exceptions to patent rights; and allow for opposition and revocation procedures.

The Commission on Human Rights has followed the same approach and urged states to enact, where necessary, national legislation in order to take full advantage of the TRIPS flexibilities, in addition to encouraging states to take note of the TRIPS flexibilities and to conduct impact assessments when entering into trade agreements. ${ }^{1157}$ It, furthermore, stressed the importance of monitoring and analysing the pharmaceutical and public health implications of (trade) agreements, so that states can effectively assess and subsequently develop pharmaceutical and health policies and regulatory measures addressing their specific needs, to be able to maximise the positive and mitigate the negative impact of such agreements, while complying with their international obligations. ${ }^{1158}$

What the (legal) consequences are of these resolutions, reports and recommendations for states parties to the ICESCR that are WTO members and thus bound to the TRIPS Agreement is unclear. As has been stated before, General Comments are authoritative interpretations of the rights enshrined in the Covenant, however, being non-binding they do not have any formal legal force. Therefore, it would not be unreasonable for states to view these recommendations simply as such: suggestions for states to consider, guidelines for implementation. However, this does not mean that the General Comments, and reports by other human rights expert bodies for that matter, will have no effect whatsoever regarding the interface between IP and human rights and more particularly the issue of access to

\footnotetext{
1154 Ibid. at $\S 11$.

1155 UN HUMAN RIGHTS COUNCIL, Report of the Special Rapporteur on the Right to Health, (UN Doc. A/HRC/11/12).

1156 Ibid. at $\$ 27$.

1157 UN COMMISSION ON HUMAN RIGHTS, Resolution 2004/26, (UN Doc. E/CN.4/ RES/2004/26) at §11; UN COMMISSION ON HUMAN RIGHTS, Resolution 2005/23, (UN Doc. E/CN.4/RES/2005/23) at $\$ 13-14$.

1158 UN COMMISSION ON HUMAN RIGHTS, Resolution 2004/27. The Right of Everyone to the Enjoyment of the Highest Attainable Standard of Physical and Mental Health (UN Doc. E/CN.4/ $\mathrm{RES} / 2004 / 27 ; 2004)$ at 3.
} 
medicines. ${ }^{1159}$ Although it will probably be a long and slow process, these recommendations could lead to political and legal change by opening up the debate, questioning government officials on specific issues during the process of state reporting, providing guidance for states wishing to implement a more human rightsfriendly IP system and might even influence the jurisprudence of WTO dispute settlement panels. ${ }^{1160}$

Finally, many areas of coexistence between human rights and IPRs have been analysed by commentators from a variety of different perspectives. ${ }^{1161}$ The aim here is to determine whether it is possible to strike a balance between patents and access to medicines by interpreting the TRIPS Agreement in light of human rights standards, particularly the right to health. In that regard, use will made of the customary rules of treaty interpretation as set out in the methodology chapter. The starting point therefore is the TRIPS Agreement itself, taking into account its objective to promote innovation, transfer and dissemination of technology, to benefit social and economic welfare and that a balance between rights and obligations should be achieved. ${ }^{1162}$ As was set out in chapter 4, the TRIPS Agreement contains a number of flexibilities in that it leaves members a degree of freedom to determine the manner of implementation and allows members to take some concrete measures to enhance access to medicines. Furthermore of importance here, as an important interpretative document, is the 2001 Doha Declaration on TRIPS and Public Health which will be discussed in the next section.

\subsection{The Doha Declaration on the TRIPS Agreement and Public Health \& Article 31bis TRIPS}

The Declaration on the TRIPS Agreement and Public Health was adopted by consensus on November $14^{\text {th }}, 2001$ by the Fourth Ministerial Conference in Doha,

1159 HARRISON, The Human Rights Impact of the WTO, at 133-135; HELFER, 'Toward a Human Rights Framework for Intellectual Property', at 999.

1160 HELFER, 'Toward a Human Rights Framework for Intellectual Property', at 999-1000.

1161 See for example ANDERSON and WAGER, 'Human Rights, Development, and the WTO: The Cases of Intellectual Property and Competition Policy', Journal of International Economic Law, 9:3 (2006), 707-747; SHARON E. FOSTER, 'Prelude to Compatibility between Human Rights and Intellectual Property', Chicago Journal of International Law, 9 (2008), 171-211; DANIEL GERVAIS, 'The Relationship between Intellectual Property and Human Rights', in Paul L.C. Torremans (ed.), Intellectual Property and Human Rights. Enhanced Edition of Copyright and Human Rights (Alphen aan den Rijn: Kluwer Law International, 2008); DUNCAN MATTHEWS, 'Intellectual Property Rights, Human Rights and the Right to Health', in Willem Grosheide (ed.), Intellectual Property Rights and Human Rights: A Paradox (Cheltenham: Edward Elgar, 2010).

1162 See further ALISON SLADE, 'Article 7 and 8 of the TRIPS Agreement: A Force for Convergence within the International IP System', The Journal of World Intellectual Property, $14: 6$ (2011), 413-440 at 430-432. 
Qatar. ${ }^{1163}$ It was a proposal by a group of developing countries, supported by an international access to medicines campaign coordinated by an alliance of NGOs from both the North and the South. ${ }^{164}$ The adoption of the Doha Declaration was the result of the strength of the developing country coalition in addition to the NGO alliance and the simple fact that because of the prevalent political climate the time was right. ${ }^{1165}$ A number of events leading up to the adoption of the Doha Declaration highlighted the importance of this issue, particularly the need to clarify the flexibility within TRIPS as regards public health. ${ }^{1166}$ Firstly, in 1997, South Africa amended its legislation permitting compulsory licensing, parallel importation and price regulation in order to increase access to medicines. The amendment was challenged by the pharmaceutical industry with the backing of the US and EU on the ground that it violated the TRIPS Agreement. The case was eventually withdrawn after an international campaign in support of South Africa. ${ }^{1167}$ In 2001, the US requested consultations with Brazil within the WTO dispute settlement system over legislation allowing for compulsory licensing if a patent was not worked locally. The Brazilian government had threatened to invoke this law in order to ensure access to HIV/AIDS medicines for its citizens. This dispute was resolved bilaterally. ${ }^{168}$ Moreover, the negotiation position of developed countries was compromised when in the fall of 2001, shortly after the 9/11 attacks, mysterious letters containing anthrax surfaced in the US. Both the US and Canada did not hesitate in threatening to break Bayer's patent on the only available treatment for anthrax, Cipro. ${ }^{1169}$ It demonstrated that public health is a problem common to all states and that under certain circumstances patent protection should be curtailed in favour of public health concerns. ${ }^{1170}$ At the same time, the UN General Assembly in

1163 WTO, Doha Declaration on TRIPS and Public Health, (WT/MIN(01)/DEC/2).

1164 DAVINIA OVETT, 'Making Trade Policies More Accountable and Human Rights Consistent: A NGO Perspective of Using Human Rights Instruments in the Case of Access to Medicines', in Wolfgang Benedek, Koen De Feyter, and Fabrizio Marrella (eds.), Economic Globalisation and Human Rights (New York: Cambridge University Press, 2007) at 176. See for a discussion on the negotiation history of the Doha Declaration, GERVAIS, The TRIPS Agreement: Drafting History and Analysis, at 50 et seq; HESTERMEYER, Human Rights and the WTO, at 256 et seq. HESTERMEYER, Human Rights and the WTO, at 256; OVETT, 'Making Trade Policies More Accountable and Human Rights Consistent', at 176; WTO COUNCIL FOR TRADE-RELATED ASPECTS OF INTELLECTUAL PROPERTY RIGHTS, Submission by the African Group, Barbados, Bolivia, Brazil, Cuba, Dominican Republic, Ecuador, Honduras, India, Indonesia, Jamaica, Pakistan, Paraguay, Philippines, Peru, Sri Lanka, Thailand and Venezuela, (IP/C/W/296).

1166 See for more information 'T HOEN, The Global Politics of Pharmaceutical Monopoly Power, at 19 et seq.

1167 See also section 4.2. of chapter 6.

1168 VERMA, 'The Doha Declaration and Access to Medicines by Countries without Manufacturing Capacity', at 629.

1169 HESTERMEYER, Human Rights and the WTO, at 16-17.

1170 VADI, 'Balancing the Human Right to Health and Intellectual Property Rights after Doha', at 208-209. 
a special session on HIV/AIDS adopted a Declaration of Commitment ${ }^{1171}$ and a number of African leaders adopted the Abuja Declaration on HIV/AIDS and other related diseases. ${ }^{1172}$

In its introductory paragraphs, the Doha Declaration recognises "the gravity of the public health problems afflicting many developing and least-developed countries, especially those resulting from HIV/AIDS, tuberculosis, malaria and other epidemics." 1173 It stresses the need for the TRIPS Agreement to be part of the wider national and international action to address these problems. ${ }^{1174}$ It goes on to state that it recognises the importance of IP protection for the development of new medicines, in addition to the concerns about its effects on prices. ${ }^{1175}$ The latter comment is crucial since it is an explicit acknowledgment that IP protection may have an effect on medicine prices and therefore hamper access.

Paragraph 4 of the Doha Declaration then states that:

We agree that the TRIPS Agreement does not and should not prevent Members from taking measures to protect public health. Accordingly, while reiterating our commitment to the TRIPS Agreement, we affirm that the Agreement can and should be interpreted and implemented in a manner supportive of WTO Members' right to protect public health and, in particular, to promote access to medicines for all. In this connection, we reaffirm the right of WTO Members to use, to the full, the provisions in the TRIPS Agreement, which provide flexibility for this purpose.

The first part is clearly a compromise between the position of developing countries, that health concerns should override IPRs, and the position of developed countries, that members should not depart from the TRIPS Agreement because it benefits public health instead of impeding it. The wording of this paragraph, though, clearly does not override TRIPS' obligations. Actually it is a restatement of the law as maintained in the TRIPS Agreement, namely that public health concerns especially access to medicines must be taken into account when interpreting TRIPS. ${ }^{1176}$ The Doha Declaration, however, now makes clear that the TRIPS should be interpreted and implemented in a manner supportive of members' right to protect public health. While maintaining their commitment to the TRIPS Agreement, the Doha Declaration recognises the following flexibilities within TRIPS. ${ }^{1177}$ Other Related Infectious Diseases. African Summit on HIV/AIDS, Tuberculosis and Other Related Infectious Diseases in Abuja, Nigeria from 24-27 April 2001 (OAU/SPS/ABUJA/3; 2001).

1173 WTO, Doha Declaration on TRIPS and Public Health, (WT/MIN(01)/DEC/2) at $\$ 1$.

1174 Ibid. at $\$ 2$.

1175 Ibid. at $\$ 3$.

1176 HESTERMEYER, Human Rights and the WTO, at 258; VERMA, 'The Doha Declaration and Access to Medicines by Countries without Manufacturing Capacity', at 641.

1177 WTO, Doha Declaration on TRIPS and Public Health, (WT/MIN(01)/DEC/2) at §5. 
- Applying the customary rules of interpretation of public international law, the provisions of the TRIPS Agreement shall be read in the light of the object and purpose of TRIPS as expressed, in particular, in its articles 7 and 8 ;

- Each Member has the right to grant compulsory licences and the freedom to determine the grounds upon which such licences are granted.

- Each Member has the right to determine what constitutes a national emergency or other circumstances of extreme urgency, it being understood that public health crises, including those relating to HIV/AIDS, tuberculosis, malaria, and other epidemics, can represent a national emergency or other circumstances of extreme urgency.

- The effect of the provisions in the TRIPS Agreement that are relevant to the exhaustion of intellectual property rights is to leave each Member free to establish its own regime for such exhaustion without challenge, subject to the MFN and national treatment provisions of Articles 3 and 4.

The Doha Declaration is a political commitment. Its exact legal status is unclear, however. ${ }^{1178}$ Its language suggests that it is intended to interpret TRIPS. Therefore it has been argued that as an authoritative legal interpretation, it should be considered to have legal force in a dispute settlement case. ${ }^{1179}$ However, in order to be considered by the WTO adjudicative bodies in a dispute, the legal status of the Doha Declaration needs to be clarified. Since the Doha Declaration does not form part of the TRIPS Agreement, it can only give rise to rights and obligations of WTO members in certain specifically defined situations. In the alternative, it must be examined whether the Doha Declaration can be considered under the rules of interpretation contained within article 31 VCLT.

Some acts of WTO bodies give rise to rights and obligations of the WTO members, which are enforceable through the dispute settlement system, such as, authoritative interpretations under article IX:2 $2^{1180}$ and waivers under article IX:31181 of the Marrakesh Agreement. However, the Doha Declaration does not specify its

1178 GERVAIS, The TRIPS Agreement: Drafting History and Analysis, at 58; VERMA, 'The Doha Declaration and Access to Medicines by Countries without Manufacturing Capacity', at 644 .

1179 OVETT, 'Making Trade Policies More Accountable and Human Rights Consistent', at 176.

1180 Article IX:2 of the Agreement establishing the World Trade Organisation: The Ministerial Conference and the General Council shall have the exclusive authority to adopt interpretations of this Agreement and of the Multilateral Trade Agreements. In the case of an interpretation of a Multilateral Trade Agreement in Annex 1, they shall exercise their authority on the basis of a recommendation by the Council overseeing the functioning of that Agreement. The decision to adopt an interpretation shall be taken by a three-fourths majority of the Members. This paragraph shall not be used in a manner that would undermine the amendment provisions in Article X.

1181 Article IX:3 of the Agreement establishing the World Trade Organisation: In exceptional circumstances, the Ministerial Conference may decide to waive an obligation imposed on a Member by this Agreement or any of the Multilateral Trade Agreements, provided that any such decision shall be taken by three fourths of the Members unless otherwise provided for in this paragraph. 
legal basis, nor does it state it is an authoritative interpretation, a waiver or an amendment to the TRIPS Agreement. According to article IX:2 of the Marrakesh Agreement, any interpretation of TRIPS must be made on the recommendation of the TRIPS Council. This is not the case here. Therefore the Doha Declaration cannot be considered an "authoritative interpretation" in the sense of article IX:2 of the Marrakesh Agreement. ${ }^{1182}$

Yet, other acts of the WTO bodies can also be sources of WTO law although it is not clear yet whether such other acts provide for enforceable rights and obligations of the WTO members. ${ }^{1183}$ In US - Clove Cigarettes (2012) the Appellate Body ruled that "a decision adopted by members, other than a decision adopted pursuant to article IX:2 of the WTO Agreement, may constitute a 'subsequent agreement' on the interpretation of a provision of a covered agreement under article 31.3(a) of the Vienna Convention [on the Law of Treaties]." 1184 This case dealt with the interpretation of a term of the Agreement on Technical Barriers to Trade (TBT Agreement) found in the Doha Ministerial Decision on Implementation Related Issues and Concerns. ${ }^{1185}$ The same matter arose in US - Tuna II (Mexico) but here it concerned a decision by a technical committee, the TBT Committee. ${ }^{1186}$ Here the AB stated that "the TBT Committee Decision can be considered a 'subsequent agreement' within the meaning of article 31.3(a) of the Vienna Convention. The extent to which this Decision will inform the interpretation and application of a term or provision of the TBT Agreement in a specific case, however, will depend on

(a) A request for a waiver concerning this Agreement shall be submitted to the Ministerial Conference for consideration pursuant to the practice of decision-making by consensus. The Ministerial Conference shall establish a time-period, which shall not exceed 90 days, to consider the request. If consensus is not reached during the time-period, any decision to grant a waiver shall be taken by three fourths of the Members.

(b) A request for a waiver concerning the Multilateral Trade Agreements in Annexes 1A or 1B or $1 \mathrm{C}$ and their annexes shall be submitted initially to the Council for Trade in Goods, the Council for Trade in Services or the Council for TRIPS, respectively, for consideration during a time-period which shall not exceed 90 days. At the end of the time-period, the relevant Council shall submit a report to the Ministerial Conference.

1182 See also WTO Appellate Body Report, United States - Measures Affecting the Production and Sale of Clove Cigarettes, adopted 24 April 2012, WT/DS406/AB/R at $\$ 254$.

1183 VAN DEN BOSSCHE and ZDOUC, The Law and Policy of the World Trade Organisation, at 53-54.

1184 United States - Measures Affecting the Production and Sale of Clove Cigarettes, at \$260.

1185 See WTO, Implementation-Related Issues and Concerns Adopted at the Doha Ministerial Conference, Fourth Session (WT/MIN(01)/17; 2001).

1186 See WTO COMMITTEE ON TECHNICAL BARRIERS TO TRADE, Decision of the Committee on Principles for the Development of International Standards, Guides and Recommendations with Relation to Articles 2, 5 and Annex 3 of the Agreement, in Decisions and Recommendations Adopted by the TBT Committee since 1 January 1995 (G/TBT/1/Rev.10; 2011). 
the degree to which it 'bears specifically' on the interpretation and application of the respective term or provision." 1187

An act of a WTO body other than a decision adopted pursuant to article IX:2 is a "subsequent agreement" in the sense of article 31.3(a) of the VCLT if, firstly, "the decision is, in a temporal sense, adopted subsequent to the relevant covered agreement" and, secondly, "the terms and content of the decision express an agreement between Members on the interpretation or application of a provision of WTO law." 1188 Consequently, and although the above mentioned rulings concerned decisions, the same reasoning would apply to the Doha Declaration on TRIPS and Public Health. Firstly, the Doha Declaration (same as the Doha Ministerial Decision on Implementation-related Issues and Concerns) was adopted on November $14^{\text {th }}$, 2001 at the Fourth Ministerial Conference of the WTO. Thus, there is no doubt that it was adopted subsequently to the relevant WTO Agreement, the TRIPS Agreement.

Secondly, the question is whether the Doha Declaration expresses an agreement between members on the interpretation or application of provisions of WTO law. According to the reasoning of the $\mathrm{AB}$ this would be so if the Doha Declaration bears specifically upon the interpretation of the TRIPS Agreement. ${ }^{1189}$ The language of the Doha Declaration suggests so, even if the Doha Declaration does not (always) refer to specific articles of the TRIPS Agreement; see for example the statement that the TRIPS Agreement "can and should be interpreted and implemented in a manner supportive of WTO members' right to protect public health" and repeated references to WTO members "rights". Additionally, the Doha Declaration must be an agreement in the sense of article 31.3(a) VCLT. The AB has stated that article 31.3(a) VCLT "refers, fundamentally, to substance rather than to form." 1190 Thus, although the Doha Declaration was formally adopted as a declaration, it could be characterised as a "subsequent agreement" as long as "it clearly expresses a common understanding and an acceptance of that common understanding among Members" with regard to the TRIPS Agreement and the issue of public health. ${ }^{1191}$ Again, the language of the Doha Declaration seems to do so by stating that "[w]e agree that the TRIPS Agreement does not and should not prevent Members from taking measures to protect public health", "we affirm that the Agreement can and should be interpreted and implemented in a manner supportive of WTO Members' right to protect public health", "we reaffirm the right of WTO Members to use, to the full, the provisions in the TRIPS Agreement, which provide flexibility for this purpose" and "we recognize that these flexibilities include (a)...".

\footnotetext{
1187 WTO Appellate Body Report, United States - Measures Concerning the Importation, Marketing and Sale of Tuna and Tuna Products, adopted 13 June 2012, WT/DS381/AB/R at $\$ 372$.

1188 United States - Measures Affecting the Production and Sale of Clove Cigarettes, at $\$ 262$.

1189 Ibid. at $\$ 265$.

1190 Ibid. at \$267.

1191 Ibid.
} 
Moreover, the Doha Declaration was agreed by all WTO members in the form of a Ministerial Conference, the highest ranking body of the WTO.

As a result, here the Doha Declaration is considered a "subsequent agreement" in the sense of article 31.3(a) of the VCLT and therefore must, together with the context, be taken into account when interpreting a treaty. As such the value of the Doha Declaration on TRIPS and Public Health lies in the fact that it is an interpretative tool to determine and clarify the meanings of the TRIPS provisions.

Since the adoption of the Doha Declaration, developing countries have issued or threatened to issue compulsory licenses or government use orders for pharmaceutical products, for example Zimbabwe in 2002, Malaysia in 2003 and Indonesia, Mozambique and Zambia in 2004. ${ }^{1192}$ Moreover, the ability to issue a compulsory license, and the threat thereof, strengthens the government's position when negotiating a voluntary license with pharmaceutical companies; a strategy which was used for example by Brazil. ${ }^{1193}$ Brazil, with its research capabilities and the development of public sector manufacturing capacity, has been able to use the threat of compulsory licensing in negotiations with pharmaceutical corporations, for example by using estimates of its own production costs under compulsory licensing when negotiating prices. ${ }^{1194}$ However, the threat of compulsory licensing is only truly effective if the country has the required manufacturing capacity, and the licensee has the technical capacity to reverse engineer patented drugs without the cooperation of the patent holder.

Moreover, with respect to using compulsory licenses to reduce the cost of medicines in developing countries, the TRIPS regime had one major shortcoming, namely that it required use without the authorisation of the right holder to be predominantly for the supply of the domestic market. ${ }^{1195}$ This requirement proved problematic for developing countries without manufacturing capacity, mostly leastdeveloped countries. Under this requirement, developing countries with a growing generic pharmaceutical industry could not issue a compulsory license for exporting medicines to those countries without the ability to produce their own generic medicines. This problem was acknowledged in paragraph 6 of the Doha Declaration and since then termed the "paragraph 6 problem". To solve this problem the Doha Declaration instructed the TRIPS Council to find an expeditious solution.

Consequently, preceded by a statement by its Chairperson, the WTO General Council adopted a Decision on August 30 ${ }^{\text {th }}, 2003$ implementing a system to allow WTO Members with insufficient or no manufacturing capacities in the pharmaceutical sector to make effective use of compulsory licensing under the

\footnotetext{
1192 MUSUNGU and OH, The Use of Flexibilities in TRIPS by Developing Countries; REICHMAN, 'Compulsory Licensing of Patented Pharmaceutical Inventions', at 596-597.

1193 OVETT, 'Making Trade Policies More Accountable and Human Rights Consistent', at 177.

1194 CIPR, Integrating Intellectual Property Rights and Development Policy, at 43.

1195 Article 31(f) TRIPS.
} 
TRIPS Agreement. ${ }^{1196}$ The decision is a temporary waiver to the limitation of article 31(f) TRIPS that the use of a compulsory license should predominantly pertain to supplying the domestic market. It sets out a detailed mechanism under which one country - the "eligible importing member" - may issue a compulsory license in order to import medicines from another country - the "exporting member" - which must also issue a compulsory license specifically for the purpose of exporting the required medicines.

Paragraph 1(a) of the 2003 Decision defines "pharmaceutical product" as "any patented product, or product manufactured through a patented process, of the pharmaceutical sector needed to address the public health problems as recognized in paragraph 1 of the [Doha] Declaration. It is understood that active ingredients necessary for its manufacture and diagnostic kits needed for its use would be included". This definition refers to the underlying purpose of the Decision, namely to allow members to address their public health problems, and as such it is sufficiently broad. ${ }^{1197}$ Although the Doha Declaration explicitly refers to the public health problems resulting from HIV/AIDS, tuberculosis, malaria it should not be read as limiting the reach of the Doha Declaration or the 2003 Decision to only those particular public health issues. Paragraph 1 further sets out that any leastdeveloped member and any other member which has notified the TRIPS Council of its intention to use the system is considered an "eligible importing member". ${ }^{1198}$ In a footnote to paragraph 1(b) it is stated that the use of the system is not dependent on approval by the TRIPS Council. An "exporting member" is defined as "a member using the system set out in this Decision to produce pharmaceutical products for, and export them to, an eligible importing member".

1196 WTO GENERAL COUNCIL, 2003 Decision on the Implementation of Paragraph 6 of the Doha Declaration, (WT/L/540). See further CARLOS M. CORREA, Implementation of the WTO General Council Decision on Paragraph 6 of the Doha Declaration on the TRIPS Agreement and Public Health, World Health Organisation, (April 2004); HESTERMEYER, Human Rights and the WTO, at 243-244, 261 et seq; DUNCAN MATTHEWS, 'WTO Decision on Implementation of Paragraph 6 of the Doha Declaration on the TRIPS Agreement and Public Health: A Solution to the Access to Essential Medicines Problem?', Journal of International Economic Law, 7:1 (2004), 73-107; CORREA, Trade-Related Aspects of IPRs: A Commentary on the TRIPS Agreement, at 325 et seq; UNCTAD-ICTSD, Resource Book on TRIPS and Development, at 485 et seq.

1197 VERMA, 'The Doha Declaration and Access to Medicines by Countries without Manufacturing Capacity', at 645.

1198 See WTO GENERAL COUNCIL, 2003 Decision on the Implementation of Paragraph 6 of the Doha Declaration, (WT/L/540) at §1(b). It reads as follows: "eligible importing Member" means any least-developed country Member, and any other Member that has made a notification to the Council for TRIPS of its intention to use the system as an importer, it being understood that a Member may notify at any time that it will use the system in whole or in a limited way, for example only in the case of a national emergency or other circumstances of extreme urgency or in cases of public non-commercial use. It is noted that some Members will not use the system set out in this Decision as importing Members and that some other Members have stated that, if they use the system, it would be in no more than situations of national emergency or other circumstances of extreme urgency. 
The 2003 Decision establishes a detailed process for the use of the mechanism. Paragraph 2 states that the obligation under article 31(f) TRIPS that the use of a compulsory license should predominantly pertain to supplying the domestic market shall be waived for the exporting member on the following conditions:

- Firstly, the eligible importing member must notify the TRIPS Council of the names and expected quantities of the product(s) required. Where the eligible importing member is not a least-developed member but intends to use the system it must establish that it has no or insufficient manufacturing capacity in the pharmaceutical sector for the product(s) required. If the pharmaceutical product(s) are patented in the territory of the importing member it must confirm that it has granted or intends to grant a compulsory license in line with article 31 TRIPS and the Decision. ${ }^{1199}$

- Secondly, the compulsory license issued by the exporting member may only be issued for the production of the amount necessary to meet the needs of the eligible importing member and the entirety of this production shall be exported to that member. The products manufactured under the license must be clearly identified as such through specific labelling or marking. The quantities, destination and distinguishing features of the product(s) produced under the system must be posted on a publicly accessible website by the licensee. ${ }^{1200}$

- Finally, the exporting member shall notify the TRIPS Council of the grant of the compulsory license and its conditions, providing the name and address of the licensee, the product(s) and the quantities of that product which shall be manufactured under the license, the country to which the product(s) shall be supplied, the duration of the license and the address of the website referred to above. $^{1201}$

Once a compulsory license has been granted by the exporting member, the 2003 Decision sets out that adequate remuneration shall be paid to the patent holder pursuant to article 31(h) TRIPS. Where a compulsory license has been granted for the same product(s) in the importing member, the obligation of that member to pay remuneration is waived. ${ }^{1202}$

Paragraphs 4 and 5 of the 2003 Decision address the fears, particularly of developed members, that the system might encourage trade diversion. It states that an importing member must take reasonable measures within their means and proportionate to their administrative capacities to prevent that products manufactured under the system are re-exported to other members. ${ }^{1203}$ Moreover, all

1199 Ibid. at \$2(a).

1200 Ibid. at $\$ 2$ (b).

1201 Ibid. at $\$ 2$ (c).

1202 Ibid. at $\$ 3$.

1203 Ibid. at $\$ 4$. 
WTO members must make available effective legal means to prevent the importation into, and sale of, produces produced under the system. ${ }^{1204}$

According to paragraph 6 of the 2003 Decision, the obligation under article 31(f) TRIPS shall also be waived to the extent necessary to enable a pharmaceutical product, produced or imported under a compulsory licence in a member party to a regional trade agreement, to be exported to the markets of other country parties to that trade agreement that share the same health problem, as long as at least half of the current members to the trade agreement are considered least-developed countries. This possibility has been included in order to harness economies of scale for the purposes of enhancing purchasing power for, and facilitating the local production of, pharmaceutical products. ${ }^{1205}$ Moreover, the 2003 Decision recognises and encourages the desirability of promoting the transfer of technology and capacity building in the pharmaceutical sector in order to overcome public health problems. ${ }^{1206}$

Finally, the 2003 Decision reiterates that the Decision operates without prejudice to the obligations and flexibilities that Members have under the TRIPS Agreement, other than paragraphs (f) and (h) of Article 31, including those reaffirmed by the Declaration, and to their interpretation. ${ }^{1207}$ In addition it states that no member shall challenge any measure taken in conformity with the 2003 Decision. ${ }^{1208}$ The 2003 Decision will terminate for each Member on the date on which an amendment to the TRIPS Agreement replacing its provisions takes effect for that Member. ${ }^{1209}$

The 2003 Decision was accompanied by the Chairperson's Statement at the General Council meeting on August $30^{\text {th }}$ in which the Chairperson presented several key shared understandings of the WTO members as to the interpretation and implementation of the 2003 Decision mechanism. ${ }^{1210}$ Firstly, the members recognised that the mechanism should be "used in good faith to protect public health and [...] not be an instrument to pursue industrial or commercial policy objectives." Secondly, it reiterated the importance of ensuring that products produced and supplied under the system are not diverted from the markets for which they are intended as this would defeat the whole purpose of the system. At the same time it acknowledged that the duty to ensure that products, or active ingredients, produced or supplied under the system are clearly marked as such should not have a significant impact on the price. ${ }^{1211}$ "Best Practices" Guidelines

\footnotetext{
1204 Ibid. at $\$ 5$.

1205 Ibid. at $\$ 6$.

1206 Ibid. at $\$ 7$.

1207 Ibid. at $\$ 9$.

1208 Ibid. at $\$ 10$.

1209 Ibid. at $\$ 11$.

1210 See WTO GENERAL COUNCIL, General Council Chairperson's Statement. Excerpt of the Minutes of the General Council Meeting 30 August 2003 (Paragraph No. 29) (WT/GC/M/82; 2003).

1211 See also WTO GENERAL COUNCIL, 2003 Decision on the Implementation of Paragraph 6 of the Doha Declaration, (WT/L/540) at \$2(b)ii.
} 
drawing upon the past experience of companies in preventing trade diversion are attached as an annex to the Chairperson's Statement. Thirdly, the Chairperson affirmed the importance that members resolve any issue arising from the use and implementation of the 2003 Decision expeditiously and amicably. ${ }^{1212}$ Fourthly, and finally, it listed those members who have agreed to opt out of using the system as importers $^{1213}$ and those members who have agreed to only use the system as importers in situations of national emergency or other circumstances of extreme urgency. ${ }^{1214}$

The implementation of the mechanism is fully voluntary and only a few countries have passed legislation to implement the system, including Canada, the EU, Norway, Switzerland, China and India. ${ }^{1215}$ India was one of the first to amend its patent laws in order to give effect to the 2003 Decision and introduced the mechanism through the 2005 Patents (Amendment) Act. ${ }^{1216}$

It has been argued that the mechanism introduced by the 2003 Decision is "too complex to have an effective impact on price." 1217 The mechanism is too burdensome especially for least-developed but also developing countries to be a truly effective tool in removing barriers to access to affordable medicines. The many administrative conditions required to make use of the system will obstruct the very purpose underlying it. As such, the system has been criticised. ${ }^{1218}$ The

1212 In that regard the Chairperson's Statement specifies the following:

- To promote transparency and avoid controversy, notifications under paragraph 2(a)(ii) of the Decision would include information on how the Member in question had established, in accordance with the Annex, that it has insufficient or no manufacturing capacities in the pharmaceutical sector.

- In accordance with the normal practice of the TRIPS Council, notifications made under the system shall be brought to the attention of its next meeting.

- Any Member may bring any matter related to the interpretation or implementation of the Decision, including issues related to diversion, to the TRIPS Council for expeditious review, with a view to taking appropriate action.

- If any Member has concerns that the terms of the Decision have not been fully complied with, the Member may also utilize the good offices of the Director-General or Chair of the TRIPS Council, with a view to finding a mutually acceptable solution.

These include: Australia, Austria, Belgium, Canada, Denmark, Finland, France, Germany, Greece, Iceland, Ireland, Italy, Japan, Luxembourg, The Netherlands, New Zealand, Norway, Portugal, Spain, Sweden, Switzerland, the United Kingdom and the United States.

1214 These include: Hong Kong, China, Israel, Korea, Kuwait, Macao China, Mexico, Qatar, Singapore, the Separate Customs Territory of Taiwan, Penghu, Kinmen and Matsu, Turkey and the United Arab Emirates. In addition: Czech Republic, Cyprus, Estonia, Hungary, Latvia, Lithuania, Malta, Poland, the Slovak Republic and Slovenia until their accession to the European Union after which they will opt out of using the system as importers.

1215 See WTO, 'Intellectual Property: TRIPS and Public Health. Members' Laws Implementing the 'Paragraph 6' System', <www.wto.org/english/tratop_e/trips_e/par6laws_e.htm>, accessed 18 May 2013.

1216 See section 4 of Chapter 7.

1217 OVETT, 'Making Trade Policies More Accountable and Human Rights Consistent', at 178.

1218 CHAUDHURI, The WTO and India's Pharmaceuticals Industry, at 113; OVETT, 'Making Trade Policies More Accountable and Human Rights Consistent', at 178; UN HUMAN RIGHTS 
system has only been used once by Rwanda to import generic HIV/AIDS medicines from Canada and the process took around three years. ${ }^{1219}$ Concern about the value of the mechanism has also been voiced within the WTO framework. Although some members have stated that it is a useful tool and that the limited use so far was not an appropriate way to measure its success, ${ }^{1220}$ the value of the system will most probably lie mainly in the improved negotiation strength of importing members with respect to patent holders of pharmaceutical products. ${ }^{1221}$

Finally, in 2005 the WTO members approved an amendment of the TRIPS Agreement in the form of article 31 bis in order to implement the system introduced by the 2003 Decision. ${ }^{122}$ The TRIPS agreement will be formally amended once two-thirds of the members have accepted the change. At the time of writing (January 2013), 45 members have accepted the amendment. ${ }^{122}$ Until the TRIPS amendment enters into force the waiver introduced by the 2003 Decision will continue to apply.

In conclusion, the Doha Declaration is the first public acknowledgment by the WTO that there is a "problem" with regard to the TRIPS Agreement and public health. See for example the reference to the concerns about IP protection about its effects on prices in paragraph 3 and the explicit reference to the problem with respect to members with no or insufficient manufacturing capacity in the pharmaceutical sector in paragraph 6. It is explicit in the manner in which members

COUNCIL, Report of the Special Rapporteur on the Right to Health, (UN Doc. A/HRC/11/12) at $\S 41$; VERMA, 'The Doha Declaration and Access to Medicines by Countries without Manufacturing Capacity', at 647-648.

1219 WTO, "TRIPS: TRIPS and Public Health "Paragraph 6" System. Notifications by Importing WTO Members', <www.wto.org/english/tratop_e/trips_e/public_health_notif_import_e.htm>, accessed 18 May 2013.

1220 See for example WTO COUNCIL FOR TRADE-RELATED ASPECTS OF INTELLECTUAL PROPERTY RIGHTS, Minutes of Meeting. Held in the Centre William Rappard on 27-28 October and 6 November 2009 (IP/C/M/61; 2010) at $\$ 100$ et seq; WTO COUNCIL FOR TRADE-RELATED ASPECTS OF INTELLECTUAL PROPERTY RIGHTS, Minutes of Meeting. Held in the Centre William Rappard on 26-27 October 2010 (IP/C/M/64; 2011) at $\$ 68$ et seq; WTO COUNCIL FOR TRADE-RELATED ASPECTS OF INTELLECTUAL PROPERTY RIGHTS, Minutes of Meeting. Held in the Centre William Rappard on 24-25 October and 17 November 2011 (IP/C/M/67; 2012) at $\$ 172$ et seq. See further JAKOB CORNIDES, 'European Union Adopts Regulation on Compulsory Licensing of Pharmaceutical Products for Export', The Journal of World Intellectual Property, 10:1 (2007), 70-77; ANDREW D. MITCHELL and TANIA VOON, 'Patents and Public Health in the WTO, FTAs and Beyond: Tension and Conflict in International Law', Journal of World Trade, 43:3 (2009), 571-601 at 585 et seq.

1221 VERMA, 'The Doha Declaration and Access to Medicines by Countries without Manufacturing Capacity', at 666.

1222 WTO GENERAL COUNCIL, Amendment of the TRIPS Agreement, (WT/L/641). See further GERVAIS, The TRIPS Agreement: Drafting History and Analysis, at 396 et seq.

1223 See WTO COUNCIL FOR TRADE-RELATED ASPECTS OF INTELLECTUAL PROPERTY RIGHTS, Annual Review of the Decision on the Implementation of Paragraph 6 of the Doha Declaration on TRIPS and Public Health, (IP/C/63) at $\$ 7$. See for up to date information the website of the WTO. 
should reconcile the tension between the interests of IP right holders' and users of IP protected subject matter; ${ }^{1224}$ namely that the TRIPS Agreement "can and should be interpreted and implemented in a manner supportive of WTO members' right to protect public health and, in particular, to promote access to medicines for all" in paragraph 4. This reference suggests that the Doha Declaration refers, although implicitly, to the promotion and protection of human rights. ${ }^{1225}$ See for example the Special Rapporteur on the right to health who stated that "[i]n this way, the Declaration reflects human rights perspectives, especially the right to health and the right to enjoy the benefits of scientific progress." 1226

\subsection{WTO Dispute Settlement Mechanism: Interpreting TRIPS in Light of Human Rights Standards?}

The TRIPS Agreement, interpreted in light of the Doha Declaration, takes other interests such as public health into account in order to achieve a balance between producers and users of IP protected subject matter. However, whether these "other interests" can be considered to refer to human rights is questionable. There is a lack of explicit human rights references in the WTO Agreement, the TRIPS Agreement and the Doha Declaration, as well as in cases decided by the WTO dispute settlement mechanism. ${ }^{122}$ Moreover, the WTO dispute settlement mechanism has not yet elucidated the impact of human rights on the interpretation of TRIPS. ${ }^{122}$ And among commentators and scholars, there is no broadly accepted view of the status human rights have in the TRIPS or, more broadly, the WTO context. ${ }^{122}$ However, this does not imply that in the WTO context human rights are isolated from TRIPS. ${ }^{1230}$

The principal source of WTO law is the Marrakesh Agreement Establishing the WTO, which includes the TRIPS Agreement as an annex. ${ }^{1231}$ In addition to the

1224 GROSSE RUSE-KAHN, Policy Space for Domestic Public Interest Measures under TRIPS, at 8.

1225 FREDERICK M. ABBOTT, 'TRIPS and Human Rights: Preliminary Reflections', in Frederick M. Abbott, Christine Breining-Kaufmann, and Thomas Cottier (eds.), International Trade and Human Rights. Foundations and Conceptual Issues (Studies in International Economics. The World Trade Forum, 5; Ann Arbor: University of Michigan Press, 2006) at 153; SEUBA, 'Mainstreaming the TRIPS and Human Rights Interactions', at 214.

1226 UN COMMISSION ON HUMAN RIGHTS, Report of the Special Rapporteur on the Right to Health, (UN Doc. E/CN.4/2003/58) at $§ 87$.

1227 PAPADOPOULOU, 'TRIPS and Human Rights', at 271.

1228 HAUGEN, 'Human Rights and TRIPS Exclusion and Exception Provision', at 361.

1229 HARRISON, The Human Rights Impact of the WTO, at 56-57; HAUGEN, 'Human Rights and TRIPS Exclusion and Exception Provision', at 362. See for more information on the debate of human rights and the World Trade Organisation THOMAS COTTIER, JOOST PAUWELYN, and ELISABETH BÜRGI (eds.) Human Rights and International Trade, ed. John H. Jackson (International Economic Law Series, New York: Oxford University Press, 2005).

1230 HAUGEN, 'Human Rights and TRIPS Exclusion and Exception Provision', at 361.

1231 VAN DEN BOSSCHE and ZDOUC, The Law and Policy of the World Trade Organisation, at 40 . 
WTO covered agreements there are also other sources of WTO law, although they are not of the same nature and legal standing, such as dispute settlement reports, acts of the WTO bodies and also - of importance here - international law. ${ }^{1232}$ The WTO, being a sub-system of international law, must be considered within the overall context of international law and its relationship with other sub-systems such as international human rights law. ${ }^{1233}$ The WTO covered agreements are creations of and interact with other norms of international law. ${ }^{1234}$ According to the ILC report on the fragmentation of international law there is "little reason of principle to depart from the view that general international law supplements WTO law unless it has been specifically excluded and that so do other treaties which should, preferably, be read in harmony with the WTO covered treaties." 1235 The WTO Appellate Body has confirmed that the WTO covered agreements, and thus also the TRIPS Agreement, cannot be read in "clinical isolation from public international law". 1236

Article 3.2 DSU mandates the WTO dispute settlement bodies "to clarify the existing provisions of those agreements in accordance with customary rules of interpretation of public international law" with the express limitation that "the DSB cannot add to or diminish the rights and obligations provided in the covered agreements."1237 As such, the DSU cautions against any form of judicial activism on the part of the WTO adjudicative bodies. ${ }^{1238}$ WTO jurisprudence has confirmed that the DSU requires the WTO adjudicative bodies to clarify existing provisions within WTO law in accordance with customary rules of interpretation of public

1232 PETROS C. MAVROIDIS, 'No Outsourcing of Law? WTO Law as Practiced by WTO Courts', American Journal of International Law, 102 (2008), 421-474 at 422, 427 et seq.

1233 HARRISON, The Human Rights Impact of the WTO, at 14; MARCEAU, 'WTO Dispute Settlement and Human Rights', at 755; PAUWELYN, Conflict of Norms in Public International Law, at 38, 40 .

1234 INTERNATIONAL LAW COMMISSION, Fragmentation of International Law, (UN Doc. A/ CN.4/L.682) at $\S 45$.

1235 Ibid. at $\$ 169$.

1236 WTO Appellate Body Report, United States - Standards for Reformulated and Conventional Gasoline, adopted 20 May 1996, WT/DS2/AB/R at 17.

1237 Article 3.2 DSU reads as follows: The dispute settlement system of the WTO is a central element in providing security and predictability to the multilateral trading system. The Members recognize that it serves to preserve the rights and obligations of Members under the covered agreements, and to clarify the existing provisions of those agreements in accordance with customary rules of interpretation of public international law. Recommendations and rulings of the DSB cannot add to or diminish the rights and obligations provided in the covered agreements.

See also Article 19.2 DSU: In their findings and recommendations panels and the Appellate Body cannot add to or diminish the rights and obligations provided in the covered agreements.

1238 See further ISABELLE VAN DAMME, 'Treaty Interpretation by the WTO Appellate Body', European Journal of International Law, 21:3 (2010), 605-648; VAN DEN BOSSCHE and ZDOUC, The Law and Policy of the World Trade Organisation, at 184 et seq. 
international law. ${ }^{1239}$ Yet in Korea - Government Procurement the Panel went a step further and stated that:

the relationship of the WTO Agreements to customary international law is broader than this. Customary international law applies generally to the economic relations between the WTO members. Such international law applies to the extent that the WTO treaty agreements do not "contract out" from it. To put it another way, to the extent that there is no conflict or inconsistency, or an expression in a covered WTO agreement that applies differently, we are of the view that the customary rules of international law apply to the WTO treaties and to the process of treaty formation under the WTO. ${ }^{1240}$

The mandate or jurisdiction of the WTO adjudicative bodies is distinct from the concept of "applicable law" within the WTO dispute settlement system. ${ }^{1241}$ The jurisdiction of international judicial bodies is generally limited to specific types of disputes, or disputes arising from certain treaties. The jurisdiction of the WTO judicial bodies is limited to disputes arising from the WTO covered agreements. ${ }^{1242}$ The concept of applicable law is the system of legal rights and obligations binding on WTO members, as WTO members, which can be enforced before the WTO judicial bodies that have the exclusive jurisdiction over WTO matters. ${ }^{1243}$ The limited jurisdiction of the WTO dispute settlement system - to claims arising from the covered agreements only - does not necessarily imply a limited scope of the applicable law in the interpretation and application of the covered agreements. ${ }^{1244}$

1239 See for example India - Patent Protection for Pharmaceutical and Agricultural Chemical Products, at $\$ 46$.

1240 See WTO Panel Report, Korea - Measures Affecting Government Procurement, adopted 19 June 2000, WT/DS163/R at \$7.96. See further PAUWELYN, Conflict of Norms in Public International Law, at 211. Pauwelyn criticised that the panel should not have limited itself to customary international law, but should have referred to general international law (includes both general customary international law and general principles of law). It should also have specified that only general customary international law applies, not all customary law.

1241 MARCEAU, 'WTO Dispute Settlement and Human Rights', at 766; SEUBA, 'Mainstreaming the TRIPS and Human Rights Interactions', at 205-206.

1242 See articles $1.1,3.2$ and 11 of the DSU. INTERNATIONAL LAW COMMISSION, Fragmentation of International Law, (UN Doc. A/CN.4/L.682) at §45; PAUWELYN, Conflict of Norms in Public International Law, at 443 et seq.

Within the WTO dispute settlement system there are three types of complaints possible: (1) a violation cause of action; (2) a non-violation cause of action; and (3) a situation cause of action. See section 2.2 of chapter 4 .

Marceau ask the question whether the violation of a human rights provision, although not a breach of WTO law, could nullify and impair the benefits resulting from the covered agreement, and thus form the basis of a WTO non-violation claim? She finds that most doubtful. See MARCEAU, 'WTO Dispute Settlement and Human Rights', at 768.

1243 Ibid. at 755.

1244 INTERNATIONAL LAW COMMISSION, Fragmentation of International Law, (UN Doc. A/ CN.4/L.682) at §45; PAUWELYN, Conflict of Norms in Public International Law, at 460. 
Moreover, as opposed to, for example, article 38 of the Statute of the ICJ, there is no explicit provision within the WTO DSU identifying the scope of applicable law. ${ }^{1245}$

There are two positions with regard to the applicable law within the WTO. ${ }^{1246}$ Some authors argue that within the WTO dispute settlement mechanism only WTO law may be considered applicable law. ${ }^{1247}$ The WTO adjudicative bodies can clarify and apply WTO law but are not competent to interpret and decide upon the violation of other (for example human rights) treaties or customary law and therefore cannot award direct effect to human rights provisions except for jus cogens. According to Marceau, the competence (or jurisdiction) of the WTO adjudicative bodies and the applicable law concept are defined by reference to the covered agreements. As a sub-system of international law - a lex specialis system - it contains a specific applicable law. Therefore, WTO law cannot be overruled by situations and considerations belonging to another sub-system, such as international human rights law. ${ }^{1248}$ The WTO judicial bodies "do not have the competence to interpret and assess formally whether a WTO measure is compatible with human rights law."1249 Giving direct effect to human rights in any manner that would set aside or amend WTO norms would in essence entail that the panel is effectively adding to, diminishing or amending the WTO covered agreements, which is prohibited according to article 3.2 DSU. Marceau does state that the judicial bodies must be aware of the fact that all states are required to respect their human rights obligations and interpret and apply WTO law accordingly. ${ }^{1250}$ Consequently, in the unlikely situation of a genuine conflict between WTO norms and for example international human rights law, the WTO judicial bodies should conclude that human rights law cannot have direct effect in the WTO system, nor do they have the competence to formally interpret and enforce such human rights treaties. In such a situation, it is then for the states to address the conflict between the international human rights system and the system of the WTO. ${ }^{1251}$

Pauwelyn disagrees and finds that the applicable law to examine a claim must be the same wherever the case is brought. ${ }^{1252}$ Thus, the WTO adjudicative bodies may

1245 INTERNATIONAL LAW COMMISSION, Fragmentation of International Law, (UN Doc. A/ CN.4/L.682) at \$45; PAUWELYN, Conflict of Norms in Public International Law, at 465.

1246 INTERNATIONAL LAW COMMISSION, Fragmentation of International Law, (UN Doc. A/ CN.4/L.682) at $\$ 169$.

1247 MARCEAU, 'WTO Dispute Settlement and Human Rights', at 766 et seq; PAPADOPOULOU, 'TRIPS and Human Rights', at 294-295; JOEL TRACHTMAN, 'The Domain of WTO Dispute Settlement Resolution', Harvard International Law Journal, 40 (1999), 333-377 at 342.

1248 MARCEAU, 'WTO Dispute Settlement and Human Rights', at 767, 774-775. Marceau states that there is a difference between the applicable law providing effective remedies to states as WTO members and states' obligations under other regimes of international law.

1249 Ibid. at 761.

1250 Ibid. at $763-764$.

1251 Ibid. at 795 .

1252 PAUWELYN, Conflict of Norms in Public International Law, at 117, 465 et seq. See also LORAND BARTELS, 'Applicable Law in WTO Dispute Settlement Proceedings', Journal of World Trade, 35:3 (2001), 499-519. 
apply non-WTO norms as law within a dispute settlement procedure. He argues that WTO law is not a self-contained regime that operates outside of the system of international law. Therefore, provisions of non-WTO treaties (here human rights) can be invoked as a defence for an alleged breach of WTO law. If the customary conflict rules find that the non-WTO norms must prevail, the WTO rule cannot be applied. According to Pauwelyn, this does not require a panel or the Appellate Body to judicially enforce the non-WTO norm or lead to a diminishing of rights because the parties have agreed to these customary rules of conflict as part of general international law. Thus, a WTO adjudicative body does not create law (adding to, amending or diminishing the WTO covered agreements) but merely gives effect to law created elsewhere. ${ }^{1253}$ The wording of articles 3.2 and 19.2 DSU that panels cannot "add to or diminish the rights and obligations provided in the covered agreements" relates to the panel's interpretative function, not the law that it can apply. ${ }^{1254}$ Consequently, he finds that "nothing in the DSU or any other WTO rule precludes panels from addressing and, as the case may be, applying other rules of international law in order to decide the WTO claims before them." 1255 He argues that otherwise this would result in "small isolated pockets of international law, delinked from other branches of the wider corpus of international law." 1256 Such an isolationist approach would go against the unity of international law and result in conflicting judicial decisions. ${ }^{1257}$ Limiting the WTO applicable law to the covered agreements exacerbates the lack of coordination between the WTO regime and other regimes of international law such as human rights. ${ }^{1258}$

If the applicable law is the same irrespective of where the case is brought, conflicts might arise, however, if judicial bodies interpret the same applicable law in different ways. Pauwelyn argues that to streamline opinions and avoid such conflicts, judicial bodies should refer to, and take account of, each other's judgments and opinions. One could also consider consulting other judicial bodies and/or international organisations as experts within in a specific field. For example, under

1253 PAUWELYN, Conflict of Norms in Public International Law, at 473-474.

1254 He finds that more directed at applicable law are articles 7.1 and 7.2 of the DSU setting out the terms of references for panels. Article 7 DSU:

1. Panels shall have the following terms of reference unless the parties to the dispute agree otherwise within 20 days from the establishment of the panel:

"To examine, in the light of the relevant provisions in (name of the covered agreement(s) cited by the parties to the dispute), the matter referred to the DSB by (name of party) in document... and to make such findings as will assist the DSB in making the recommendations or in giving the rulings provided for in that/those agreement(s)."

2. Panels shall address the relevant provisions in any covered agreement or agreements cited by the parties to the dispute

3. $[\ldots]$

Ibid. at $465-466$.

1255 Ibid. at 466.

1256 Ibid. at 117.

1257 Ibid. at $117-118,461$.

1258 MARCEAU, 'WTO Dispute Settlement and Human Rights', at 773. 
article 13.1 DSU a panel may seek information and technical advice from any person or body deemed appropriate. Thus, in relation to human rights, a panel could also consult experts within the UN human rights system. A panel would not be bound by the information it was given, but it would have to give deference to it. Enhanced coordination between different areas of international law would limit the risk of diverging case law by different judicial bodies. It would be an important means of creating more unity in international law despite its fragmented nature of enforcement. ${ }^{1259}$

Pauwelyn's argumentation to include non-WTO law as applicable law in the WTO adjudicative process seems to make sense in an increasingly expanding and fragmented system of international law. Yet, although there is some support for a broader concept of applicable law, it is rather controversial. It seems that the prevailing view is that the DSU is clear in defining and limiting the judicial bodies' mandate to clarify WTO law and assess whether a WTO provision has been breached and therefore cannot enforce or give direct effect to human rights provisions. ${ }^{1260}$ More importantly, the AB has stated that:

We see no basis in the DSU for panels and the Appellate Body to adjudicate nonWTO disputes. Article 3.2 of the DSU states that the WTO dispute settlement system "serves to preserve the rights and obligations of Members under the covered agreements, and to clarify the existing provisions of those agreements." Accepting Mexico's interpretation would imply that the WTO dispute settlement system could be used to determine rights and obligations outside the covered agreements. ${ }^{1261}$

Consequently, it finds that adjudication of disputes under non-WTO agreements "is not the function of panels and the Appellate Body as intended by the DSU". 1262 However, this does not mean that human rights are irrelevant or meaningless in the WTO law context.

The question posed here is whether within the WTO dispute settlement mechanism "other interests", here referring to the right to health and access to medicines, might or even must be taken into account when interpreting Members' obligations under the WTO covered agreements.

In its very first report, US - Gasoline, the Appellate Body confirmed that the WTO covered agreements cannot be read in clinical isolation from public international law and that article 3.2 DSU directs the WTO adjudicative bodies to interpret the WTO covered agreements according to general international law's

1259 PAUWELYN, Conflict of Norms in Public International Law, at 118-121.

1260 MARCEAU, 'WTO Dispute Settlement and Human Rights', at 763; MAVROIDIS, 'No Outsourcing of Law?', at 450; VAN DEN BOSSCHE and ZDOUC, The Law and Policy of the World Trade Organisation, at 58, 63.

1261 WTO Appellate Body Report, Mexico - Tax Measures on Soft Drinks and Other Beverages, adopted 24 March 2006, WT/DS308/AB/R at $\$ 56$.

1262 Ibid. at $\$ 78$. 
customary rules of treaty interpretation; this has been interpreted to require reference to articles 31 and 32 VCLT. ${ }^{1263}$ Treaty interpretation is the process of giving treaty terms their appropriate meaning. According to article 31 VCLT this means examining the text of the treaty, its context and its object and purpose. A treaty must be interpreted so as to determine the common intentions of the parties to the treaty and in a way as to enable the treaty to have its appropriate effects. ${ }^{1264}$

1263 US - Gasoline, at 17. Here the Appellate Body stated that the general rule of treaty interpretation as incorporated in article 31 VCLT has attained the status of a rule of customary or general international law. "As such, it forms part of the "customary rules of interpretation of public international law' which the Appellate Body has been directed, by Article 3.2 of the DSU, to apply in seeking to clarify the provisions of the General Agreement and the other 'covered agreements' of the Marrakesh Agreement Establishing the World Trade Organization (the 'WTO Agreement'). That direction reflects a measure of recognition that the General Agreement is not to be read in clinical isolation from public international law."

See also Japan - Taxes on Alcoholic Beverages, at 10. See further AUST, Modern Treaty Law and Practice, at 232; RICHARD K. GARDINER, Treaty Interpretation (New York: Oxford University Press, 2008) at 141 et seq; INTERNATIONAL LAW COMMISSION, Fragmentation of International Law, (UN Doc. A/CN.4/L.682) at §168; MARCEAU, 'WTO Dispute Settlement and Human Rights', at 779; MAVROIDIS, 'No Outsourcing of Law?', at 443 et seq; PAUWELYN, Conflict of Norms in Public International Law, at 29.

Article 31 VCLT reads as follows:

1. A treaty shall be interpreted in good faith in accordance with the ordinary meaning to be given to the terms of the treaty in their context and in the light of its object and purpose.

2. The context for the purpose of the interpretation of a treaty shall comprise, in addition to the text, including its preamble and annexes:

(a) any agreement relating to the treaty which was made between all the parties in connection with the conclusion of the treaty;

(b) any instrument which was made by one or more parties in connection with the conclusion of the treaty and accepted by the other parties as an instrument related to the treaty.

3. There shall be taken into account, together with the context:

(a) any subsequent agreement between the parties regarding the interpretation of the treaty or the application of its provisions;

(b) any subsequent practice in the application of the treaty which establishes the agreement of the parties regarding its interpretation;

(c) any relevant rules of international law applicable in the relations between the parties.

4. A special meaning shall be given to a term if it is established that the parties so intended.

Article 32 VCLT reads as follows:

Recourse may be had to supplementary means of interpretation, including the preparatory work of the treaty and the circumstances of its conclusion, in order to confirm the meaning resulting from the application of article 31 , or to determine the meaning when the interpretation according to article 31 :

(a) leaves the meaning ambiguous or obscure; or

(b) leads to a result which is manifestly absurd or unreasonable.

Japan - Taxes on Alcoholic Beverages, at 11-12. A WTO panel has stated that "the elements referred to in Article 31 - text, context and object-and-purpose as well as good faith - are to be viewed as one holistic rule of interpretation rather than a sequence of separate tests to be applied in a hierarchical order." See WTO Panel Report, United States - Sections 301-310 of the Trade Act of 1974, adopted 27 January 2000, WT/DS152/R at $\$ 7.22$. 
Hence treaty terms cannot be interpreted in a manner which would render treaty provisions (or parts thereof) redundant, nor can it condone or incorporate concepts into a treaty which were never intended by that treaty. ${ }^{1265}$

Thus, the provisions of the TRIPS Agreement relating to patent protection should not be interpreted in isolation but in good faith giving them their appropriate meaning in light of TRIPS' preamble and other provisions such as articles 1, 7 and 8. Furthermore, the TRIPS Agreement, being an annex to the Marrakesh Agreement, must be interpreted within the wider context of the object and purpose of the WTO. In addition, TRIPS provisions must be interpreted in light of norms outside of the TRIPS Agreement. ${ }^{1266}$ Of particular relevance here, as stated above, is the Doha Declaration on TRIPS and Public Health. Taking account of "outside rules" is not a discretionary power exercised by an adjudicative body at will. ${ }^{1267}$ Any subsequent agreement, subsequent practice or relevant rule of international law in the sense of article 31.3 VCLT must be taken into account. Thus, must interpretation of TRIPS norms also occur in light of human rights norms?

Key here is article 31.3(c) VCLT which states that "any relevant rules of international law applicable in the relations between the parties" shall be taken into account when interpreting a treaty. As such, article 31.3(c) VCLT reflects a "principle of integration" promoting the unity and coherence of international law where rules should not be considered in isolation of general international law. ${ }^{1268}$ Therefore, it is argued that article 31.3(c) VCLT is likely to enable the recognition of the right to health within TRIPS, as by establishing the principle of systemic integration treaties are contextually interpreted taking into account a broader normative environment within international law. ${ }^{1269}$ The question here is whether human rights are "relevant rules of international law" to be taken into account when interpreting TRIPS provisions on patent protection for pharmaceuticals.

The reference to "rules of international law" indicates that there is no limitation to the sources of international law that may be taken into account. ${ }^{1270}$ Treaty

1265 PAUWELYN, Conflict of Norms in Public International Law, at 249; VAN DEN BOSSCHE and ZDOUC, The Law and Policy of the World Trade Organisation, at 188.

1266 See article 31.3(a) (any subsequent agreement); article 31.3(b) (any subsequent practice); article 31.3(c) (any relevant rules of international law); and article 32 (supplementary means of interpretation) of the VCLT.

1267 MARCEAU, 'WTO Dispute Settlement and Human Rights', at 779; PAUWELYN, Conflict of Norms in Public International Law, at 269; VAN DEN BOSSCHE and ZDOUC, The Law and Policy of the World Trade Organisation, at 189.

1268 MARCEAU, 'WTO Dispute Settlement and Human Rights', at 785-786; PAUWELYN, Conflict of Norms in Public International Law, at 253.

1269 FORMAN, 'An Elementary Consideration of Humanity?', at 163.

1270 In that regard a WTO Panel stated that "[i]n considering the provisions of Article 31(3)(c), we note, initially, that it refers to "rules of international law". Textually, this reference seems sufficiently broad to encompass all generally accepted sources of public international law, that is to say, (i) international conventions (treaties), (ii) international custom (customary international law), and (iii) the recognized general principles of law. In our view, there can be no doubt that treaties and customary rules of international law are "rules of international law" within the 
provisions, customary law and general principles of law may be considered in giving meaning to a treaty's terms, as long as these are "applicable" in the relations between the parties' and "relevant". ${ }^{271}$ In that regard, article 31.3(c) VCLT set limits to the extent it mandates taking into account "other rules" when interpreting TRIPS provisions. The assessment of what is relevant must be done on a case-bycase basis and seems to be most logically decided by the subject matter of the treaty term to be interpreted (here the TRIPS provisions regarding patent protection) and that of the other rule to be taken into account (i.e. possible human rights norms). ${ }^{1272}$ The mention that rules taken into account must be applicable in the relations between the parties implies that the rule(s) must be binding on the parties. ${ }^{1273}$ It has caused disagreement as to whether this refers to all the parties to a treaty (here all WTO members meaning that only treaties with identical membership to the WTO may be taken into account) or just the parties to the dispute in question. ${ }^{1274}$ The former, narrow interpretation might prove problematic and has thus also been criticised in that it significantly limits the rules that could be taken into account when interpreting WTO law possibly leading to incoherence in international law. ${ }^{1275}$ In EC - Approval and Marketing of Biotech Products the panel stated the following:

In considering this issue, we note that Article 31(3)(c) does not refer to "one or more parties". Nor does it refer to "the parties to a dispute". We further note that Article 2.1(g) of the Vienna Convention defines the meaning of the term "party" for the purposes of the Vienna Convention. Thus, "party" means "a State which has consented to be bound by the treaty and for which the treaty is in force". It may be inferred from these elements that the rules of international law applicable in the relations between "the parties" are the rules of international law applicable in the relations between the States which have consented to be bound by the treaty which is being interpreted, and for which that treaty is in force. This understanding of the term "the parties" leads logically to the view that the rules of international law to

meaning of Article 31(3)(c)." WTO Panel Report, European Communities - Measures Affecting the Approval and Marketing of Biotech Products, adopted 21 November 2006, WT/DS291/R; WT/DS292/R; WT/DS293/R at \$7.67. See further INTERNATIONAL LAW COMMISSION, Fragmentation of International Law, (UN Doc. A/CN.4/L.682) at \$426; MARCEAU, 'WTO Dispute Settlement and Human Rights', at 780; PAUWELYN, Conflict of Norms in Public International Law, at 254.

1271 See for example the reference by the Appellate Body to a number of non-WTO treaties (such as the UN Convention on the Law of the Sea and the Convention on Biological Diversity) in interpreting "exhaustible natural resources" in article XX(g) 1994 GATT. WTO Appellate Body Report, United States - Import Prohibition of Certain Shrimp and Shrimp Products, adopted 6 November 1998, WT/DS58/AB/R at $\$ 127$ et seq.

1272 MARCEAU, 'WTO Dispute Settlement and Human Rights', at 784; PAUWELYN, Conflict of Norms in Public International Law, at 263.

1273 MARCEAU, 'WTO Dispute Settlement and Human Rights', at 780.

1274 Ibid. at 781; PAUWELYN, Conflict of Norms in Public International Law, at 257 et seq.

1275 INTERNATIONAL LAW COMMISSION, Fragmentation of International Law, (UN Doc. A/ CN.4/L.682) at §471; MARCEAU, 'WTO Dispute Settlement and Human Rights', at 781. 
The Interface between Patents and Human Rights in the Context of Access to Medicines

be taken into account in interpreting the WTO agreements at issue in this dispute are those which are applicable in the relations between the WTO Members. ${ }^{1276}$

On the other hand, the Panel did not state that one cannot take account of treaties to which not all WTO members are parties, only that a panel or the AB would not be required to do so under article 31.3(c) VCLT; but it may use such treaties as informative tools when ascertaining the ordinary meaning of treaty terms. ${ }^{1277}$

The Panel's findings have been criticised and it is argued that article 31.3(c) VCLT also refers to treaties that are only binding on the parties to the dispute. ${ }^{1278}$ As was stated, article 31.3(c) indeed does not refer to all the parties, but states "any relevant rules of international law applicable in the relations between the parties." Therefore it is argued that treaties signed by a number of WTO members, not necessarily all of the members but more than one of the parties, can be taken into account, as long as the rule used to interpret the covered agreements is of "relevant international communality"1279 or reflects the "common intentions of all parties." 1280 In that line of argument, article 31.3(c) does not require all WTO members to have formally and explicitly agreed to the other non-WTO rules, nor that the rule must be legally binding on all WTO members, but that it is at least implicitly accepted or tolerated by all members and as such can reasonably be expected to express the common intentions or understanding of all members regarding the meaning of a particular WTO term. ${ }^{1281}$

1276 European Communities - Measures Affecting the Approval and Marketing of Biotech Products, at $\$ 7.68$.

1277 See ibid. at \$7.92-93. "The Panel recalls that pursuant to Article 31.1 of the Vienna Convention, the terms of a treaty must be interpreted in accordance with the "ordinary meaning" to be given to these terms in their context and in the light of its object and purpose. The ordinary meaning of treaty terms is often determined on the basis of dictionaries. We think that, in addition to dictionaries, other relevant rules of international law may in some cases aid a treaty interpreter in establishing, or confirming, the ordinary meaning of treaty terms in the specific context in which they are used. Such rules would not be considered because they are legal rules, but rather because they may provide evidence of the ordinary meaning of terms in the same way that dictionaries do. They would be considered for their informative character. It follows that when a treaty interpreter does not consider another rule of international law to be informative, he or she need not rely on it.

7.93 In the light of the foregoing, we consider that a panel may consider other relevant rules of international law when interpreting the terms of WTO agreements if it deems such rules to be informative. But a panel need not necessarily rely on other rules of international law, particularly if it considers that the ordinary meaning of the terms of WTO agreements may be ascertained by reference to other elements." PAUWELYN, Conflict of Norms in Public International Law, at 259.

WTO Appellate Body Report, European Communities - Customs Classification of Certain Computer Equipment, adopted 22 June 1998, WT/DS62/AB/R; WT/DS67/AB/R; WT/DS68/ $\mathrm{AB} / \mathrm{R}$ at $\S 84$. Here the $\mathrm{AB}$ stated that "[ $\mathrm{t}]$ he purpose of treaty interpretation under Article 31 of the Vienna Convention is to ascertain the common intentions of the parties."

1281 INTERNATIONAL LAW COMMISSION, Fragmentation of International Law, (UN Doc. A/ CN.4/L.682) at \$472; DAVID PALMETER and PETROS C. MAVROIDIS, 'The WTO Legal 
In EC - Large Civil Aircraft the Appellate Body notes that this issue has been subject to much academic debate. ${ }^{1282}$ It found that:

An interpretation of "the parties" in Article 31(3)(c) should be guided by the Appellate Body's statement that "the purpose of treaty interpretation is to establish the common intention of the parties to the treaty." This suggests that one must exercise caution in drawing from an international agreement to which not all WTO Members are party. At the same time, we recognize that a proper interpretation of the term "the parties" must also take account of the fact that Article 31(3)(c) of the Vienna Convention is considered an expression of the "principle of systemic integration" which, in the words of the ILC, seeks to ensure that "international obligations are interpreted by reference to their normative environment" in a manner that gives "coherence and meaningfulness" to the process of legal interpretation. In a multilateral context such as the WTO, when recourse is had to a non-WTO rule for the purposes of interpreting provisions of the WTO agreements, a delicate balance must be struck between, on the one hand, taking due account of an individual WTO Member's international obligations and, on the other hand, ensuring a consistent and harmonious approach to the interpretation of WTO law among all WTO Members. ${ }^{1283}$

Consequently, in light of the principle of systemic integration both the TRIPS Agreement and the ICESCR should be contextually interpreted taking into account a broader normative environment within international law so as to come to an harmonious interpretation in which a balance is struck between patents and access.

That a WTO panel or the AB may take account of international human rights law as informative tools when interpreting TRIPS is clear, although caution is required when not all WTO members have consented to the international human rights treaty. Yet, whether the WTO adjudicative bodies must take account of international human rights law, particularly the ICESCR, under article 31.3(c) VCLT is not apparent. Namely, the ICESCR is not binding on all WTO members, most notably not the US. Moreover, it is slightly problematic that especially socioeconomic rights are often drafted in broad terms and there is no international consensus on their interpretation. ${ }^{1284}$ On the other hand, it would be hard to argue that public health in general and access to medicines in particular is not part of the common intentions of WTO members considering also that the vast majority of

System: Sources of Law', American Journal of International Law, 92:3 (1998), 398-413 at 411; PAUWELYN, Conflict of Norms in Public International Law, at 261.

As a result, bilateral agreements between the parties to the dispute cannot be taken into account when interpreting WTO law pursuant to article 31.3(c) VCLT. However, those rules that may not reflect the common intentions of all the WTO members can still be taken into account to a certain extent as a subsidiary means of treaty interpretation under article 32 VCLT. Ibid. at 260.

1282 Appellate Body Report, European Communities and Certain Member States - Measures Affecting Trade in Large Civil Aircraft, adopted 1 June 2011, WT/DS316/AB/R at $\$ 844$.

1283 Ibid. at $\$ 845$

1284 MARCEAU, 'WTO Dispute Settlement and Human Rights', at 786. 
WTO members are states parties to the ICESCR. See in that regard also the WTO preamble, TRIPS' object and purpose and most obviously the Doha Declaration, all of which aim at striking a balance between promoting trade and protecting IPRs and societal values, including public health.

Yet, the main limitation concerning article 31.3(c) VCLT is that this refers to the process of interpreting treaty norms, i.e. giving meaning to explicit WTO norms in this case the TRIPS provisions regarding patent protection for pharmaceuticals. ${ }^{1285}$ Taking into account relevant rules of international law is not equal to applying them however. ${ }^{1286}$ Thus, any (human rights) norms taken into account when interpreting the provisions of TRIPS regarding patent protection can only play a role in giving meaning to TRIPS' provisions, for example when terms or provisions are ambiguous, but they cannot in anyway overrule or change TRIPS' provisions. ${ }^{1287}$ In that regard, Pauwelyn warns that the limitations of treaty interpretation (especially that the non-WTO rule must reflect the common intentions of WTO members) entail a rather limited role for non-WTO rules in the interpretation of the covered agreements and, therefore, cannot be seen as the answer for possible conflicts between WTO law and other norms of international law. ${ }^{1288}$ However, a good faith interpretation of the TRIPS Agreements should lead to striking a fair balance between promoting and ensuring access to medicines and providing for patent protection for such medicines.

\section{TRIPS-PLUS DEVELOPMENTS}

A development of importance in the discussion on the interface between patents and access to medicines and which cannot be left out is the increase in the negotiation and conclusion of free trade and bilateral investment treaties (so-called FTAs or BITs) initiated by developed countries with the object of intensifying and deepening the WTO covered agreements. In relation to IP, where such agreements aim at strengthening IPRs, they have been termed "TRIPS-plus" arrangements. As stated by the Special Rapporteur on the right to health "[s]uch agreements have extensive implications for pharmaceutical patent protection, which can directly impact access to medicines." 1289

The TRIPS Agreement does not set a ceiling for the level of IP protection that WTO members are allowed to implement. The situation is actually quite the reverse: TRIPS sets out minimum standards of IP protection which all WTO

\footnotetext{
1285 PAUWELYN, Conflict of Norms in Public International Law, at 262.

1286 HAUGEN, 'Human Rights and TRIPS Exclusion and Exception Provision', at 362.

1287 PAUWELYN, Conflict of Norms in Public International Law, at 254; SEUBA, 'Mainstreaming the TRIPS and Human Rights Interactions', at 207.

1288 PAUWELYN, Conflict of Norms in Public International Law, at 272-273.

1289 UN HUMAN RIGHTS COUNCIL, Report of the Special Rapporteur on the Right to Health, (UN Doc. A/HRC/11/12) at $\S 68$.
} 
members are obliged to implement in their national systems, however, it leaves it up to the individual members to decide whether to implement higher standards of IP protection. $^{1290}$ Thus, TRIPS-plus provisions in bilateral or regional free-trade agreements are generally consistent with members' WTO obligations.

Such trade deals mainly aim at increased market access and regulate traderelated issues concerning investment, services and government procurement among others. Often these trade deals apply a "single package approach", as in the case of the Marrakesh Final Act. Many developing countries aim at concluding FTAs with developed countries in order to gain better access to their markets, yet it is the developed countries that push for the inclusion of IP within such deals. Developed countries, with a view to protecting the interests of their national industries and respond to developing countries' more effective cooperation and increased negotiation power within the WTO, have shifted their efforts to enhance protection of IP from the multilateral to the bilateral forum. This leads to concern in that the conclusion of TRIPS-plus FTAs/BITs adds to the existing difficulties for developing and particularly least-developed members to balance their TRIPS obligations with social and developmental goals. These TRIPS-plus arrangements may therefore have a very real impact on the use of TRIPS flexibilities for developing members, upsetting the carefully negotiated balance within the TRIPS Agreement. Additionally, the bilateral approach by developed countries negates any favourable position pursued by developing members within multilateral negotiation fora. ${ }^{1291}$

Why developing countries agree to TRIPS-plus agreements will not be discussed here. There is no simple answer to this question and it will depend on political interactions happening on a range of scales, global, regional, and national. ${ }^{1292}$

In the case of the patenting of pharmaceutical products TRIPS-plus agreements may go beyond TRIPS minimum standards in a number of ways. ${ }^{1293}$ For example:

1290 See chapter 4 for a discussion on the minimum obligations set out by the TRIPS Agreement.

1291 HESTERMEYER, Human Rights and the WTO, at 289; OVETT, 'Making Trade Policies More Accountable and Human Rights Consistent', at 179; PEDRO ROFFE, CHRISTOPH SPENNEMANN, and JOHANNA VON BRAUN, 'Intellectual Property Rights in Free Trade Agreements: Moving Beyond TRIPS Minimum Standards', in Carlos M. Correa (ed.), Research Handbook on the Protection of Intellectual Property under WTO Rules. Intellectual Property in the WTO Volume 1 (Research Handbooks on the WTO; Cheltenham/Northampton: Edward Elgar, 2010) at 277-278; SUSAN K. SELL, 'TRIPS-Plus Trade Agreements and Access to Medicines', Liverpool Law Review, 28 (2007), 41-75 at 57 et seq.

1292 See further ANTONI VERGER and BARBARA VAN PAASSEN, 'Human Development VisÀ-Vis Free Trade: Understanding Developing Countries' Positions in Trade Negotiations on Education and Intellectual Property Rights', Review of International Political Economy, (2012), $1-28$.

1293 RUTH LOPERT and DEBORAH GLEESON, 'The High Price of "Free" Trade: U.S. Trade Agreements and Access to Medicines', Journal of Law, Medicine and Ethics, 41:1 (2013), 199223 at 201-202; OVETT, 'Making Trade Policies More Accountable and Human Rights Consistent', at 179-180; PEDRO ROFFE and CHRISTOPH SPENNEMANN, 'The Impact of FTAs on Public Health Policies and TRIPS Flexibilities', International Journal of Intellectual 
The Interface between Patents and Human Rights in the Context of Access to Medicines

- Patent extensions: article 33 TRIPS provides a minimum patent term of 20 years, although the real period during which the patent holder can enjoy his exclusive rights is often limited by administrative delays when granting the patent and/or the process of regulatory approval which is necessary in order to be allowed to market the product. This limitation of the effective term of protection has served as a reason to include patent term extensions in TRIPSplus agreements, although not without criticism.

- Patentability criteria: the TRIPS Agreement leaves members freedom to decide to what extent they wish to allow for the patenting of new uses or methods of using known products. ${ }^{1294}$ Certain TRIPS-plus agreements, though, provide for an obligation to make patents available for any new uses or methods of using a known product. ${ }^{1295}$ Members' freedom to assess the patentability of a pharmaceutical product is herewith limited, while already patent protected subject matter is granted additional protection resulting in delaying generic competition.

- Compulsory licensing: the TRIPS Agreement does not limit compulsory licensing to a certain set of grounds. TRIPS-plus agreements on the other hand restrict compulsory licensing to a limited number of grounds, such as anticompetitive practices, public non-commercial use and national emergencies among others. ${ }^{1296}$

- Parallel importing: the TRIPS Agreement, confirmed by the Doha Declaration, does not regulate the issue of exhaustion of IPRs and leaves members free to decide on a national, regional or international exhaustion regime. Some TRIPSplus agreements concluded by the US (with Australia, Morocco and Singapore)

Property Management, 1:1/2 (2006), 75-93 at 80 et seq; ROFFE, SPENNEMANN, and BRAUN, 'Intellectual Property Rights in Free Trade Agreements', at 280 et seq; UN HUMAN RIGHTS COUNCIL, Report of the Special Rapporteur on the Right to Health, (UN Doc. A/ $\mathrm{HRC} / 11 / 12)$ at $\$ 75$ et seq.

1294 See also section 3.4.1. of chapter 4.

1295 See for example article 15.9(2). of the USA - Morrocca FTA ("the Parties confirm that patents shall be available for any new uses or methods of using a known product") to be found at www. ustr.gov/sites/default/files/uploads/agreements/fta/morocco/asset_upload_file797_3849.pdf last accessed 10 April 2013; article 17.9(1) of the USA - Australia FTA to be found at www.ustr.gov/ sites/default/files/uploads/agreements/fta/australia/asset_upload_file469_5141.pdf last accessed 10 April 2013; and article 14.8(2) of the USA - Bahrain FTA to be found at www.ustr.gov/sites/ default/files/uploads/agreements/fta/bahrain/asset_upload_file211_6293.pdf last accessed 10 April 2013.

1296 See for example article 17.9(7) of the USA - Australia FTA ("A Party shall not permit the use of the subject matter of a patent without the authorisation of the right holder except in the following circumstances: (a) to remedy a practice determined after judicial or administrative process to be anti-competitive" ... or (b) in cases of public non-commercial use, or of national emergency, or other circumstances of extreme urgency") to be found at www.ustr.gov/sites/default/files/ uploads/agreements/fta/australia/asset_upload_file469_5141.pdf last accessed 10 April 2013; and article 16.7(6) of the USA - Singapore FTA to be found at www.ustr.gov/sites/default/files/ uploads/agreements/fta/singapore/asset_upload_file708_4036.pdf last accessed 10 April 2013. 
expressly recognise the right holder's right to prevent parallel importation via the use of contract or other means. ${ }^{1297}$

- Data exclusivity: the TRIPS Agreement requires members to protect undisclosed information against unfair competition yet leaves them the freedom to determine as to whether such data should be protected through exclusive rights or a system of unfair competition rules. Protecting clinical test data prevents regulatory authorities for a certain period from relying on the test data submitted by originator pharmaceutical manufacturers in order to grant regulatory approval to generic versions of the already approved originator (patented) pharmaceutical. Data exclusivity therefore adds an additional term of protection which, from the viewpoint of public health, might be problematic for developing countries aiming at ensuring the rapid entry of generic competition once the patent term has expired. Data exclusivity was proposed by the US during the Uruguay Round negotiations of the TRIPS Agreement, but eventually it was not accepted. Consequently the US introduced it in agreements it concluded with a number of developing members, in essence creating a new form of monopoly not required by TRIPS. ${ }^{1298}$ Here we see that the FTAs fulfil an important complementary function in US IP policy. ${ }^{1299}$

1297 See article 17.9(4) of the USA - Australia FTA ("Each Party shall provide that the exclusive right of the patent owner to prevent importation of a patented product, or a product that results from a patented process, without the consent of the patent owner shall not be limited by the sale or distribution of that product outside its territory, at least where the patentee has placed restrictions on importation by contract or other means") to be found at www.ustr.gov/sites/default/files/ uploads/agreements/fta/australia/asset_upload_file469_5141.pdf last accessed 10 April 2103; and article 15.9.4 of the USA - Morocco FTA to be found at www.ustr.gov/sites/default/files/ uploads/agreements/fta/morocco/asset upload_file797 3849.pdf last accessed 10 April 2013.

See for example 15.10.1(a) Dominican Republic-Central America FTA ("If a Party requires, as a condition of approving the marketing of a new pharmaceutical or agricultural chemical product, the submission of undisclosed data concerning safety or efficacy, the Party shall not permit third persons, without the consent of the person who provided the information, to market a product on the basis of (1) the information, or (2) the approval granted to the person who submitted the information for at least five years for pharmaceutical products and ten years for agricultural chemical products from the date of approval in the Party") to be found at www.ustr.gov/tradeagreements/free-trade-agreements/cafta-dr-dominican-republic-central-america-fta/final-text last accessed 10.04.2013; and article 17.10.1 of the USA - Chile FTA to be found at www.ustr. gov/trade-agreements/free-trade-agreements/chile-fta/final-text last accessed 10 April 2013. See also article 16.8.1 of the USA - Singapore FTA which just refers to "information" as opposed to "undisclosed" information or data implying that reliance on original data is precluded even where the information has become public ("If a Party requires the submission of information concerning the safety and efficacy of a pharmaceutical or agricultural chemical product prior to permitting the marketing of such product, the Party shall not permit third parties not having the consent of the party providing the information to market the same or a similar product on the basis of the approval granted to the party submitting such information for a period of at least five years from the date of approval for a pharmaceutical product and ten years from the date of approval for an agricultural chemical product.") to be found at www.ustr.gov/trade-agreements/ free-trade-agreements/singapore-fta/final-text last accessed 10 April 2013.

1299 ROFFE and SPENNEMANN, 'The Impact of FTAs on Public Health Policies and TRIPS Flexibilities', at 82. 
As a result, TRIPS-plus FTAs can have the following consequences: it can prohibit developing countries from using the TRIPS flexibilities, impose minimum patent standards which are beyond those required by the TRIPS Agreement and, due to the intricate structure of multiple treaties with slightly different provisions, developing countries are discouraged from using the TRIPS flexibilities so as to avoid challenges and pressure. ${ }^{1300}$

It is especially the US which has been promoting stronger IPRs in its FTAs with developing countries. ${ }^{1301}$ Yet there has been a remarkable change in the US domestic trade policy since the 2006 Congressional elections. Several bilateral trade agreements pending ratification were amended after a compromise was reached between Congressional leaders and the Administration relating to issues of IP among others. ${ }^{1302}$ The US FTAs concluded with a number of Latin American countries were amended allowing developing countries more flexibility with regard to patent extensions, data exclusivity, the linking of patent and regulatory approval, in addition to including an explicit reference to the Doha Declaration. ${ }^{1303}$ Although these concessions were rather substantial, the US Congress did note that the IP chapters of US trade agreements nevertheless represented an enhancement of IPR protection for pharmaceutical products in those markets. ${ }^{1304}$

The development of TRIPS-plus agreements brings up serious concerns not only because developing states that have concluded TRIPS-plus FTAs have further limited their ability to take advantage of TRIPS' flexibilities to ensure adequate access to affordable medicines but mainly because these TRIPS-plus rules do not only apply to the parties to the FTA but to all WTO members. ${ }^{1305}$ This is the result of the Most-Favoured-Nation Treatment principle, which is a cornerstone of the WTO system. See article 4 TRIPS which states that, subject to the exceptions provided:

[w]ith regard to the protection of intellectual property, any advantage, favour, privilege or immunity granted by a Member to the nationals of any other country

1300 HESTERMEYER, Human Rights and the WTO, at 289.

1301 See for example the US-Chile FTA, the US-Morocco FTA, the US-Dominican Republic-Central American FTA. These FTAs have often been used as benchmarks for negotiations with other developing countries. ibid. at 290.

1302 See for more information ROFFE, SPENNEMANN, and BRAUN, 'Intellectual Property Rights in Free Trade Agreements', at 289 et seq.

1303 See for example article 16.13 of the USA - Peru FTA ("The Parties affirm their commitment to the Declaration on the TRIPS Agreement and Public Health) to be found at www.ustr.gov/ webfm_send/1031 last accessed 10 April 2013; and the preamble of the USA - Chile FTA to be found at www.ustr.gov/sites/default/files/uploads/agreements/fta/chile/asset_upload_ file912_4011.pdf last accessed 10 April 2013.

1304 LOPERT and GLEESON, "The High Price of "Free" Trade: U.S. Trade Agreements and Access to Medicines', at 202.

1305 OVETT, 'Making Trade Policies More Accountable and Human Rights Consistent', at 181; ROFFE and SPENNEMANN, 'The Impact of FTAs on Public Health Policies and TRIPS Flexibilities', at 85. 
Chapter 5

shall be accorded immediately and unconditionally to the nationals of all other Members. ${ }^{1306}$

For example, that would mean that a developing country that has concluded an FTA with a developed country, both WTO members, committing itself to TRIPS-plus standards, must accord the same treatment, that is apply the TRIPS-plus provisions, to nationals of all WTO members. Therefore, WTO members that do not actively pursue a policy of concluding TRIPS-plus FTAs with developing countries benefit from the TRIPS-plus rules in states ensured through an FTA with, for example, the US. ${ }^{1307}$ Even if FTAs include references to the need to respect public health and the Doha Declaration on TRIPS and Public Health and the subsequent General Council Decision, these documents are not binding with respect to FTAs and such references will, thus, be rather meaningless if FTAs implement TRIPS-plus provisions curtailing the ability of developing countries to use the TRIPS flexibilities. ${ }^{1308}$ Thus, if developing countries do conclude bilateral or regional TRIPS-plus FTAs, they should be aware of the fact that this can severely curtail the regulatory flexibility to ensure access to affordable medicines and thus also fulfil their human rights obligations.

Furthermore the lack of transparency in trade negotiations is problematic, especially regarding FTAs. Transparency and the participation of citizens and especially civil society is essential to guaranteeing greater accountability in the trade decision-making process and ensuring that trade agreements are consistent with human rights. ${ }^{1309}$ In that regard, it has been argued that international human rights law obliges states to ensure access to information and participation in public affairs. ${ }^{1310}$ That would allow civil society to monitor the trade process, so that a developing country does not commit itself to TRIPS-plus rules which could undermine its access to affordable medicines and the realisation of this human right in general. ${ }^{1311}$

Along the same lines, the conclusion of bilateral investment treaties (BITs) may also prove challenging for developing countries trying to take advantage of the TRIPS flexibilities; a challenge which has not yet been sufficiently acknowledged.

1306 Article 4 TRIPS. What exactly constitutes an "advantage" regarding the protection of intellectual property is not entirely clear. See CORREA, Trade-Related Aspects of IPRs: A Commentary on the TRIPS Agreement, at 72; UNCTAD-ICTSD, Resource Book on TRIPS and Development, at 78.

1307 OVETT, 'Making Trade Policies More Accountable and Human Rights Consistent', at 181.

1308 HESTERMEYER, Human Rights and the WTO, at 290; OVETT, 'Making Trade Policies More Accountable and Human Rights Consistent', at 181-182.

1309 OVETT, 'Making Trade Policies More Accountable and Human Rights Consistent', at 189.

1310 See here article 19 ICCPR (the freedom to seek, receive and impart information; according to the CESCR article 12 ICESCR (the right to health) guarantees a right to access information and ideas concerning health, see CESCR, GC no. $14 \S 12$; and article 25 ICCPR (the right to participate in the conduct of public affairs.).

1311 OVETT, 'Making Trade Policies More Accountable and Human Rights Consistent', at 188-189. 
BITs are treaties governing the treatment of foreign investment, including protection against appropriation, generally concluded between a developed and developing country. The majority of concluded BITs include intellectual property as a form of protected investment. Thus, limiting of IPRs, by for example granting a compulsory license may be considered an appropriation by the standards set in a BIT. This would be problematic for (developing) countries with public health problems attempting to ensure adequate access to affordable medicines. The number of BITs concluded has grown significantly in the last two decades. The consequences of a BIT depend therefore on the interpretation of the term "intellectual property" employed in a BIT. If this term references intellectual property rights as defined in TRIPS, then the use of TRIPS flexibilities are inherent in the right itself and thus not an appropriation. However, since BITs also often provide for dispute settlement between the investor and host state, there is a risk that the arbitrators will not take the TRIPS Agreement into account in a dispute. ${ }^{1312}$ It must be stated here that the US takes the aforementioned approach and does not consider the limitation of IPRs, if they are in compliance with TRIPS standards, an appropriation of an investment. ${ }^{1313}$

Concluding, the conclusion of such TRIPS-plus FTAs obliging states to implement stronger protection for IPRs has led to a global development of everincreasing standards of IP protection, which has been termed the IP upward ratchet. ${ }^{1314}$ This development has had severe consequences for the ability of developing countries to use the TRIPS flexibilities to safeguard access to affordable medicines and has therefore upset the balance inherent in the TRIPS Agreement and the Doha Declaration on TRIPS and Public Health. ${ }^{1315}$ As such, any gains developing countries have achieved in multilateral negotiations in order to protect their policy options, such as the Doha Declaration, are slowly being lost at the bilateral level. ${ }^{1316}$

Particularly in countries facing HIV/AIDS epidemics, or with no or little domestic manufacturing capacity, the socio-economic benefits of concluding

1312 HESTERMEYER, Human Rights and the WTO, at 291-292.

1313 See for example article 6(5) of the Treaty between the Government of the USA and the Government of the Republic of Rwanda concerning the encouragement and reciprocal protection of investment (February 2008); and article 6(5) of the Treaty between the USA and Oriental Republic of Uruguay concerning the encouragement and reciprocal protection of investment (November 2005).

1314 See for more information SELL, The Global IP Upward Ratchet, Anti-Counterfeiting and Piracy Enforcement Efforts: The State of Play.

1315 BHATT, 'Amending TRIPS: A New Hope for Increased Access to Essential Medicines', at 617 et seq. See further MARGO A. BAGLEY, 'Legal Movements in Intellectual Property: TRIPS, Unilateral Action, Bilateral Agreements, and HIV/AIDS', Emory International Law Review, 17 (2003), 781-798; DANIEL GERVAIS, 'Intellectual Property, Trade \& Development: The State of Play', Fordham Law Review, 74 (2005), 505-535.

1316 See further GRAHAM DUTFIELD, 'Delivering Drugs to the Poor: Will the TRIPS Amendment Help?', American Journal of Law \& Medicine, 34 (2008), 107-124 at 115 et seq; MUZAKA, 'Developing Countries and the Struggle on Access to Medicines Front', at 1358. 
TRIPS-plus FTAs might not be as advantageous as hoped; this is due to the increased costs of the disease and limited options under the TRIPS-plus FTA in order to ensure access. ${ }^{1317}$ Therefore, states have been encouraged to take the right to health and access to medicines into account when entering into trade agreements and conduct impact assessments of the effects of such agreements on public health and the progressive realisation of the right to health. ${ }^{1318}$ An impact assessment of the effects of a FTA/BIT under negotiation on human rights compatibility, including the issue of access to medicines, could prove useful for developing states in mapping out their strategies in the negotiation process.

\section{Conclusion}

This chapter posed the question whether patents and the right of access to medicines are in conflict. This has been examined through a legal approach limited to norms arising from the TRIPS Agreement and the ICESCR. In the strict sense, there is no conflict between TRIPS and ICESCR norms, however, it has been shown that tension arises from the application of both treaties. In that regard, the SubCommission for the Promotion and Protection of Human Rights has contended that human rights should enjoy primacy over patents. Yet, is it possible to identify health as a prioritised norm under international law?

International human rights law considers certain elements of human rights - the core content of a particular right - to be prioritised. That access to medicines, either as an element of the right to health or life, is part of such peremptory norms, though, is unlikely. The concept of "minimum core content", although argued to be nonderogable by the CESCR, cannot lead to the conclusion that these aspects of a right are of prioritised or of jus cogens nature under international law.

Consequently, the principal way in which to avoid a genuine conflict between TRIPS and ICESCR is in interpreting the TRIPS Agreement in a manner conducive to promoting and protecting human rights, in this case public health and a right of access to medicines. Both WTO law and the ICESCR are lex specialis or subsystems of international law but they must be applied in a normative environment and considered within the wider corpus of international law, including general international law and other sub-systems. The object and purpose of both TRIPS and ICESCR are different; however they are not necessarily incompatible. Therefore, a good faith interpretation of the relevant WTO and human rights provisions should lead to a reading of TRIPS' obligations coherent with human rights law of which the Doha Declaration is a good example. Yet, in that regard mention must also be

1317 See further CHARLES T. COLLINS-CHASE, 'The Case against TRIPS-Plus Protection in Developing Countries Facing AIDS Epidemics', University of Pennsylvania Journal of International Law, 29:763-802 (2008).

1318 See for example, UN COMMISSION ON HUMAN RIGHTS, Resolution 2005/23, (UN Doc. E/ CN.4/RES/2005/23) at $\$ 13-14$. 
made of TRIPS-plus developments resulting in a global development of everincreasing standards of IP protection. This development has and will have severe consequences for the ability of developing countries to use the TRIPS flexibilities to safeguard access to affordable medicines, and it has consequently upset the balance inherent in the TRIPS Agreement and the Doha Declaration on TRIPS and Public Health.

Finally, this balancing act must take place at the domestic level. Therefore, part III of this study will set out three country studies to examine the interpretation and implementation of states' obligations under international law with a view to striking a balance between access to medicines and patent protection. 



\section{Part III}

\section{Country Studies}





\section{Chapter 6 Access to Medicines in South Africa}

\section{INTRODUCTION}

The first country study conducted in this research is on South Africa. It is classified as an upper middle income country with a GNI per capita of US\$ $6.090(2010) ; 1319$ it has a poverty headcount ratio of $23 \%$ of the population, ${ }^{1320}$ life expectancy of 52 years; ${ }^{1321}$ and an under-five mortality rate of 56.6. ${ }^{1322}$ South Africa is a WTO member since 1 January 1995. ${ }^{1323}$ Although South Africa is one of the most developed and influential countries in sub-Saharan Africa, it is a country experiencing one of the worst HIV/AIDS epidemics world-wide. It is a young democracy with a progressive constitution protecting the right to health. This is also shown within case law of the South African Constitutional Court which has deemed the right to health to be justiciable and enforceable. Moreover, it has been involved in a conflict with the pharmaceutical industry over the issue of access to medicines, which was one of the first instances this issue received public attention. It is a good example of how an active civil society can reach tangible results in favour of access.

The previous chapters focused on the international framework with respect to a right of access to medicines and the patenting of pharmaceutical products. It was shown that there are a number of sources within international human rights law that protect a right of access to medicines, although in varying degrees. Furthermore, the TRIPS Agreement setting out minimum standards for patent protection for all WTO members attempts to strike a balance between IPRs and access. The flexibility of the TRIPS Agreement lies firstly in the fact that WTO members are free to determine the appropriate manner of interpretation and implementation of TRIPS' obligations for themselves; and in that regard many of its provisions provide sufficient leeway to interpret these obligations in a flexible way, taking a right of access to medicines in account. Secondly, the TRIPS Agreement allows for concrete measures to curtail patent rights, such as compulsory licensing or parallel importation. Thus, this chapter asks whether South Africa has complied with both

\footnotetext{
1319 See http://data.worldbank.org/country/south-africa?display=graph last accessed 27 October 2011.

1320 National poverty rate is the percentage of the population living below the national poverty line. National estimates are based on population-weighted subgroup estimates from household surveys.

1321 Life expectancy at birth indicates the number of years a newborn infant would live if prevailing patterns of mortality at the time of its birth were to stay the same throughout its life.

1322 Under-five mortality rate is the probability per 1,000 that a newborn baby will die before reaching age five, if subject to current age-specific mortality rates.

1323 See www.wto.org/english/thewto_e/countries_e/south_africa_e.htm.
} 
its obligations to protect access to medicines under international human rights law and implement the standards and flexibilities as prescribed by TRIPS with a view to striking a balance between access and patents.

Therefore this chapter aims to investigate whether South Africa has been able to fulfil both its obligations under the international right health, focusing on ensuring that individuals have access to affordable medicines, and its obligations under the TRIPS Agreement regarding patent standards. Furthermore, this chapter assesses to what extent the so-called TRIPS flexibilities have been used in South Africa and whether they provide useful and workable tools to address the problem of lack of access to medicines, in order to determine whether a fair balance can be struck between its obligations under international human rights law and international intellectual property law. Firstly, the chapter will take a closer look at the problem of lack of access to medicines in South Africa particularly on the issue of HIV/ AIDS (section 2). Thereafter, the question is posed whether South Africa has complied with its obligation under international human rights law with respect to guaranteeing access to affordable medicines by examining the constitutional and legislative framework (section 3), and whether, and to what extent, it has implemented TRIPS' patent standards and flexibilities (section 4). Finally the essential question is whether South Africa has been able to strike a balance between protection of patents for pharmaceuticals and access to such pharmaceuticals (section 5).

\section{HIV/AIDS ANd ACCESS To Medicines}

The purpose of this section is to set out the contextual framework with regard to the issue of access to medicines for patients in South Africa. Setting out the different aspects that play a role in this issue will allow for an understanding of the complex nature of the issue at hand and put the research questions into broader context. In that regard it must be mentioned that the issue of access to medicines is a complex and multifaceted problem, one to which there is no magical solution. The role of patent protection and its effect on access is just one element, however a considerable one, in addressing this problem.

Firstly, a number of health- and IP-related indicators with respect to South Africa will be set out. South Africa ${ }^{1324}$ is classified as an upper middle income country with a GNI per capita of US\$ 6,090; has a poverty headcount ratio of $23 \%$ of the population, life expectancy of 52 years and an under-five mortality rate of 56.6. Furthermore of relevance:

1324 See http://data.worldbank.org/country/south-africa?display=graph last accessed 27 October 2011. 
- Health expenditure per capita: ${ }^{1325}$ US\$ 485.4 compared to a global health expenditure per capita of US\$ 863.6 (2009). ${ }^{1326}$

- Public health expenditure as a percentage of total health expenditure: ${ }^{1327} 40.1 \%$ compared to the global rate of $60.8 \%$ (2009). ${ }^{1328}$

- Total health expenditure as a percentage of the GDP: $13298.5 \%$ compared to the global rate of $10 \%$ (2009). 1330

- Maternal mortality ratio: ${ }^{1331} 410$ compared to the global ratio of 260 (2008). ${ }^{1332}$

- The infant mortality rate: ${ }^{1333} 40.7$ compared to the global ratio of 41 (2010). ${ }^{1334}$

- The out-of-pocket health expenditure as a percentage of private expenditure on health: ${ }^{1335} 29.6 \%$ compared to the global rate of $46.2 \%$ (2009). ${ }^{1336}$

1325 Total health expenditure is the sum of public and private health expenditures as a ratio of total population. It covers the provision of health services (preventive and curative), family planning activities, nutrition activities, and emergency aid designated for health but does not include provision of water and sanitation. Data are in current U.S. dollars.

1326 See http://data.worldbank.org/indicator/SH.XPD.PCAP/countries/1W-ZA?display=graph last accessed 27 October 2011.

1327 Public health expenditure consists of recurrent and capital spending from government (central and local) budgets, external borrowings and grants (including donations from international agencies and nongovernmental organizations), and social (or compulsory) health insurance funds. Total health expenditure is the sum of public and private health expenditure. It covers the provision of health services (preventive and curative), family planning activities, nutrition activities, and emergency aid designated for health but does not include provision of water and sanitation.

1328 See http://data.worldbank.org/indicator/SH.XPD.PUBL/countries/1W-ZA?display=graph last accessed 27 October 2011.

1329 Total health expenditure is the sum of public and private health expenditure. It covers the provision of health services (preventive and curative), family planning activities, nutrition activities, and emergency aid designated for health but does not include provision of water and sanitation.

1330 See http://data.worldbank.org/indicator/SH.XPD.TOTL.ZS/countries/1W-ZA?display=graph last accessed 27 October 2011.

1331 Maternal mortality ratio is the number of women who die during pregnancy and childbirth, per 100,000 live births. The data are estimated with a regression model using information on fertility, birth attendants, and HIV prevalence.

1332 See http://data.worldbank.org/indicator/SH.STA.MMRT/countries/1W-ZA?display=graph last accessed 27 October 2011.

1333 Infant mortality rate is the number of infants dying before reaching one year of age, per 1,000 live births in a given year.

1334 See http://data.worldbank.org/indicator/SP.DYN.IMRT.IN/countries/1W-ZA?display=graph last accessed 27 October 2011.

1335 Out of pocket expenditure is any direct outlay by households, including gratuities and in-kind payments, to health practitioners and suppliers of pharmaceuticals, therapeutic appliances, and other goods and services whose primary intent is to contribute to the restoration or enhancement of the health status of individuals or population groups. It is a part of private health expenditure.

1336 See http://data.worldbank.org/indicator/SH.XPD.OOPC.ZS/countries/1W-ZA?display=graph last accessed 27 October 2011. 
Chapter 6

- Prevalence of HIV as a percentage of total population: ${ }^{1337} 17.8 \%$ compared to the global rate of $0.8 \%$ (2009). ${ }^{1338}$

- Patent applications by non-residents: ${ }^{1339} 10,753$ (2006). ${ }^{1340}$

- Patent applications by residents: 5,549 (1995). ${ }^{1341}$

One important reason for South Africa's low life expectancy rates is its worsening HIV/AIDS epidemic. In South Africa AIDS and its associate diseases is one of the main reasons for its high mortality rate. The spread of HIV among pregnant women is an indicator of a growing infection rate among the entirety of its population. It is no longer a disease of a specific group (in the beginning that was white homosexual men) but now affects all population groups of all races, including women and children. Its spread increased dramatically during South Africa's transition to democracy as it went unnoticed in a time of social and political struggle. ${ }^{1342}$ Connected to the spread of HIV is the emergence of related diseases, such as tuberculosis which has been on the rise ever since. It is estimated that in the age group 15-49 one in five South Africans is HIV infected, which makes it the country with the highest infection rate world-wide. In addition women are disproportionately affected because of the higher risk of infection, high incidences of sexual abuse and weak socio-economic position of women. ${ }^{1343}$ Since the beginning of the 1990s, HIV/AIDS has been a political issue in South Africa, and often very controversial. $^{1344}$ For example in 2000 president Thabo Mbeki, addressing the International AIDS Conference in Durban, announced that AIDS was not caused by HIV but poverty, or the reliance of the government on Dr. Rath's so-called expert opinion that the HIV/AIDS epidemic can be controlled naturally by way of, amongst others, a vitamin enriched diet. ${ }^{1345}$

1337 Prevalence of HIV refers to the percentage of people ages 15-49 who are infected with HIV.

1338 See http://data.worldbank.org/indicator/SH.DYN.AIDS.ZS/countries/1W-ZA?display=graph last accessed 27 October 2011.

1339 Patent applications are worldwide patent applications filed through the Patent Cooperation Treaty procedure or with a national patent office for exclusive rights for an invention - a product or process that provides a new way of doing something or offers a new technical solution to a problem. A patent provides protection for the invention to the owner of the patent for a limited period, generally 20 years.

1340 See http://data.worldbank.org/indicator/IP.PAT.NRES/countries/1W-ZA?display=graph last accessed 27 October 2011.

1341 See http://data.worldbank.org/indicator/IP.PAT.RESD/countries/1W-ZA?display=graph last accessed 27 October 2011.

1342 BIRGIT KRAMER, Patentschutz Und Zugang Zu Medikamenten. Rechtliche Und Ökonomische Implikation (Köln/Berlin/München: Carl Heymanns Verlag, 2007) at 13.

1343 Ibid. at 15. JOHN C. MUBANGIZI and BEN KIROMBA TWINOMUGISHA, 'The Right to Health Care in the Specific Context of Access to HIV/AIDS Medicines: What Can South Africa and Uganda Learn from Each Other?', African Human Rights Law Journal, 10 (2007), 105-133 at 107.

1344 KRAMER, Patentschutz Und Zugang Zu Medikamenten, at 12.

1345 JOHN BLUM, PIETER CARSTENS, and NORCHAYA TALIB, 'Government Public Health Policy: Three Cautionary Tales from Malaysia, South Africa and the United States', Medicine and Law, 26 (2007), 615-642 at 629 et seq. 
This stance was maintained by the South African government until a change of leadership took place in 2009. As a result, only South Africans able to pay for private health insurance would receive ARV treatment if needed. A change was made in 2004 when the government, although reluctantly, started providing ARVs but only due to legal challenges and a nationwide public outcry. ${ }^{1346}$ By 2007 , about $27 \%$ of the people requiring ARV treatment were receiving it. ${ }^{1347}$ A number of factors have been blamed for the severity and devastation of the HIV/AIDS epidemic in South Africa, however the government's failure to act promptly and decisively was largely responsible. ${ }^{1348}$

Moreover, a number of issues are relevant to why patients are not able to adequately access the medicines they require. The public health problems experienced in South Africa, whether it is the HIV/AIDS epidemic or in relation to other (non-communicable) diseases such as cancer or diabetes, are complicated by the inheritance of a racially dividing health care system from South Africa's past apartheid system. Under the apartheid regime, resources were allocated according to race and the health care system was targeted specifically at the white minority. ${ }^{1349}$ Programmes to prevent and control diseases, such as HIV/AIDS, were weak and ineffective, especially if the disease affected the poorer black section of South Africans. The worsening HIV/AIDS epidemic has furthermore severely strained the already weak public health system. ${ }^{1350}$

The South African health system is divided into a public and private sector. Less than $20 \%$ of South Africans have private health insurance, forcing them to rely on the public health system. As such, strengthening the public health system to ensure that all South Africans, especially the poor, have adequate access to medical products, services and facilities is essential. The government has invested a lot of money in the public health sector to ensure adequate access to health care to all South Africans including the poor. These investments have increased the range and quality of care provided in state institutions, however, problems regarding infrastructure still exist. ${ }^{1351}$

High medicine prices are often considered one of the main issues within the access issue, although it was seen that medicine prices in themselves are not the only issue within South Africa's health care system. However, in the context of South Africa with its public health system troubled by a no longer functioning, historically racial system and a worsening of the public health burden partly due to the spread of HIV/AIDS, excessive medicine prices are an important aspect of the

1346 MUBANGIZI and TWINOMUGISHA, 'The Right to Health Care in the Specific Context of Access to HIV/AIDS Medicines', at 108.

1347 Ibid.

1348 CHIGWEDERE et al., 'Estimating the Lost Benefits of Antiretrovial Drug Use in South Africa', at 410 .

1349 BERGER, 'Tripping over Patents: AIDS, Access to Treatment and the Manufacturing of Scarcity', at 158.

1350 KRAMER, Patentschutz Und Zugang Zu Medikamenten, at 17.

1351 Ibid. at 18. 
access issue. Firstly, many patients are still dependant on the private sector and have to pay out of pocket for their medicines, in which case high medicine prices will mean they are unaffordable for many and thus access is lacking. Secondly, a considerable amount of the public health expenditure is directed towards procuring medicines. Although the state has a human rights obligation to ensure adequate access to essential medicines, in a developing country like South Africa resources are limited. Thus, it is a logical and rational choice for a state to attempt to regulate medicine prices. Moreover, compared to other developing countries, South Africa seems to have higher medicine prices. As was seen in chapter 3, patent protection plays a role in determining medicine prices. Although it cannot be concluded that patent protection for medicines is the main reason for high prices, it is undoubtedly true that originator patent protected medicines cost more than generics. Therefore, addressing patent protection for pharmaceuticals is one of South Africa's options to ensure the systematic and regular supply of medicines to its public health system. Another factor for South Africa's comparatively high price for medicines is the differences in wealth among its population. ${ }^{1352}$ Pharmaceutical companies find it more profitable to target that part of the population that can afford higher priced medicines, rather than produce larger quantities of cheaper medicines, however, for a group that do not have the market power to afford them.

South Africa is the only country in the SADC ${ }^{1353}$ region that has a local pharmaceutical industry with the manufacturing capacity and expertise to establish a multi-company generic pharmaceutical industry. ${ }^{1354}$ Multinational pharmaceutical companies, such as GlaxoSmithKline (GSK), Boehringer Ingelheim, Abbott, Bristol Meyers Squibb and Merck, Scharp and Dohme are also well established in South Africa.

In recent years an increase of voluntary licenses is visible allowing for the production of ARVs for sub-Saharan Africa. Aspen Pharmacare is one of the companies that has benefitted from this development by negotiating a number of voluntary licenses, most of which allow it to produce and distribute ARVs not only in South Africa but throughout sub-Saharan Africa. ${ }^{1355}$ This increase in voluntary licensing, which is also partly due to South Africa's competition legislation, as will be discussed below, has made it possible for more competitors to enter the pharmaceutical market, creating competition and, thus, bringing down drug prices. It must be noted though, that medicines prices generally only drop where several generic manufactures have entered the market. Therefore, it is desirable that patent

1352 Ibid. at 19.

1353 The Southern African Development Community.

1354 TENU AVAFIA, JONATHAN BERGER, and TRUDI HARTZENBERG, The Ability of Select Sub-Saharan African Countries to Utilise TRIPS Flexibilities and Competition Law to Ensure a Sustainable Supply of Essential Medicines: A Study of Producing and Importing Countries, Trade Law Centre for Southern Africa, (2006) at 11. A number of generic pharmaceutical manufacturers have organised themselves and established the National Association of Pharmaceutical Manufacturers (NAPM). 
holders grant non-exclusive licenses to several generic producers and not just to one single company. ${ }^{1356}$

South Africa's capacity to manufacture generic pharmaceuticals is especially relevant in the light of the 2003 WTO Ministerial Decision on compulsory licensing under TRIPS which explicitly allows for developing countries with no or inadequate production capacity to import generics from other countries. The recent developments in the South African domestic pharmaceutical industry has resulted in an increase in South Africa's (generic) manufacturing capacity, which means that it now has the potential to provide not only the sub-Sahara but also other developing countries with the generic pharmaceuticals they so desperately need to combat public health epidemics such as HIV/AIDS, TB and Malaria. The 2003 WTO Ministerial Decision refers to the use of compulsory licenses, as opposed to voluntary licenses, to make it possible to export generic pharmaceuticals to developing countries. However, at the time of writing ${ }^{1357}$ the South African government has not yet issued a compulsory license. The potential offered by the 2003 WTO Ministerial Decision seems thus not to have been fully utilised.

\section{A Human Right of Access to Medicines?}

The aim of this section is to determine whether South Africa has been able to comply with its obligation under international human rights law with respect to guaranteeing access to affordable medicines. Furthermore, it must be mentioned that South Africa, although it has signed the ICESCR, has not ratified it as of yet. This, however, does not imply that South Africa is in no way bound to the obligations set out by the Covenant. Namely, by signing the ICESCR, South Africa has expressed its consent to be bound and should refrain from any acts which would defeat the object and purpose of the Covenant. ${ }^{1358}$ Moreover, South Africa is bound by customary international law which arguably contains a right of access to lifesaving medicines in the context of pandemics and is party to the Convention on the Rights of the Child and the Convention on the Elimination of All Forms of Discrimination against Women, which both provide for the right to health which is interpreted to include access to essential medicines. Consequently, the question addressed here is whether South Africa has complied with its obligations under international human rights law by recognising the right of access to medicines within their constitutional and legislative framework.

1356 Ibid. at 16.

1357 January 2012.

1358 See article 18 of the Vienna Convention on the Law of Treaties. 


\subsection{The South African Constitution of 1996}

The South African Constitution is a relatively young constitution and it must be viewed in the context of the fundamental changes of the last two decades in South Africa with the shift from a parliamentary sovereignty under the apartheid regime to a system of constitutional democracy. The constitution created the legal foundation for establishing democracy in South Africa and building a new postapartheid society. The constitution-making process took place in two phases and the first democratic elections were held in April 1994 under the 1993 interim Constitution, after which the final constitution was negotiated and adopted by the members of the Constitutional Assembly. The Constitution of South Africa was promulgated by President Nelson Mandela on 10 December 1996 and came into effect on 4 February 1997, replacing the interim constitution. Since then it has been amended several times. The Constitution is the supreme law of the land and provides the legal foundation for the existence of the Republic, sets out the rights and duties of its citizen and defines the structure of the government. With respect to the role of international law in the South African context the Constitution contains both monist and dualist methods of governance. ${ }^{1359}$

The inclusion of social and economic rights into the Constitution proved to be a key issue of debate among the political parties, civil society and academics during the drafting process. ${ }^{1360}$ Moreover, international law and particularly the ICESCR strongly influenced the formulation of the socio-economic provisions in the

1359 See section 232 of the Constitution, which states the following:

(1) The negotiating and signing of all international agreements is the responsibility of the national executive.

(2) An international agreement binds the Republic only after it has been approved by resolution in both the National Assembly and the National Council of Provinces, unless it is an agreement referred to in subsection (3).

(3) An international agreement of a technical, administrative or executive nature, or an agreement which does not require either ratification or accession, entered into by the national executive, binds the Republic without approval by the National Assembly and the National Council of Provinces, but must be tabled in the Assembly and the Council within a reasonable time.

(4) Any international agreement becomes law in the Republic when it is enacted into law by national legislation; but a self-executing provision of an agreement that has been approved by Parliament is law in the Republic unless it is inconsistent with the Constitution or an Act of Parliament.

(5) The Republic is bound by international agreements which were binding on the Republic when this Constitution took effect.

See also section 232 of the Constituion:

Customary international law is law in the Republic unless it is inconsistent with the Constitution or an Act of Parliament.

1360 See further SANDRA LIEBENBERG, Socio-Economic Rights. Adjudication under a Transformative Constitution (Claremont: Juta \& Co, 2010) at 7 et seq. 
Constitution. ${ }^{1361}$ Objections against the inclusion of socio-economic rights were raised during the certification process. These objections correspond to those asserted against the justifiability of ESC rights, i.e. that socio-economic rights are not universally accepted fundamental rights, that positive duties under socioeconomic rights require resource expenditure and their inclusion in the Constitution would therefore be inconsistent with the doctrine of separation of powers. The Constitutional Court rejected these objections stating that "these rights are, at least to some extent, justiciable" and socio-economic rights were included in the final version of the South African Constitution. ${ }^{1362}$

Consequently, the South African Constitution includes a Bill of Rights in chapter two which guarantees civil and political rights and social and economic rights on an equal footing. Section 11 ensures that "everyone has the right to life". Furthermore, it also specifically includes a provision on the right to health in section 27 of the South African Constitution which reads as follows: ${ }^{1363}$

1. Everyone has the right to have access to [...] (a) health care services, including reproductive health care;

2. The state must take reasonable legislative and other measures, within its available resources, to achieve the progressive realisation of each of these rights.

In addition, the Constitution also contains other provisions concerning health such as section 24 protecting everyone's right to an environment that is not harmful to their health or well-being and section 28(1)a guaranteeing every child the right to basic health care services. ${ }^{1364}$ Other provisions of the Constitution, although not dealing specifically with health, are intrinsically linked to the right to health such as

1361 Many of the provisions regarding socio-economic rights in the South African Constitution are inspired by the text of the ICESCR. The Constitutional Court has also referred to the General Comments issued by the CESCR. See also, ibid. at 19; JOHN C. MUBANGIZI and BEN KIROMBA TWINOMUGISHA, 'The Right to Health Care in the Specific Context of Access to HIV/AIDS Medicines: What Can South Africa and Uganda Learn from Each Other?', African Human Rights Law Journal, 10 (2006) at 110; MARGIT TVEITEN, 'The Right to Health Secured HIV/AIDS Medicine - Socio-Economic Rights in South Africa', Nordic Journal of International Law, 72 (2003), 41-71.

1362 See South African Constitutional Court, Ex Parte Chairperson of the Constitutional Assembly: In Re Certification of the Constitution of the Republic of South Africa, 1996f, 4 SA 744 (CC).

1363 Section 27 of the Constitution further reads:

1. Everyone has the right to have access to -

$[\ldots]$

(b) sufficient food and water; and

(c) social security, including, if they are unable to support themselves and their dependents, appropriate social assistance.

$[\ldots]$

3. No one may be refused emergency medical treatment.

1364 See also section 12 (the right to bodily and psychological integrity) and section 35 (rights of arrested and detained persons). 
the rights to equality (section 9), human dignity (section 10), life (section 11), housing (section 26) and food, water and social security (section 27). Therefore, even though section 27 refers to a right of access to health care services, which seems to suggest that it is narrower in scope than the international right to health, the South African Constitution also covers the underlying preconditions of health. ${ }^{1365}$

The right to health care under section 27 includes both freedoms and entitlements; the freedom of everyone to access health care services free of discrimination and any other undue interference, and the entitlement to receive health care services according to need rather than the ability to pay. ${ }^{1366}$ Yet this does not entail that the right to health care is absolute; it is subject to the limitations clause contained in section 36 of the Constitution. ${ }^{1367}$

Section 27(2) in addition to section 7(2) sets out South Africa's constitutional obligations under the right to health care and mirrors the language of the ICESCR. ${ }^{1368}$ Section 7 firstly states that the Bill of Rights is a cornerstone of democracy in South Africa and continues that "[t]he state must respect, protect, promote and fulfil the rights in the Bill of Rights." Paragraph 2 of section 27 requires the state to take all reasonable legislative and other measures, within its available resources, to progressively achieve the realisation of the right enshrined in the Constitution. Thus, the South African Constitution introduces a similar typology of human rights obligations and the concept of progressive realisation as

1365 See also South African Constitutional Court, Lindiwe Mazibuko and Ors. v. City of Johannesburg and Ors, 2009, CCT 39/09. In this case the applicants claimed that the City's Free Basic Water policy, conflicted with the right to water under section 27(1)b of the SA Constitution and section 11 of the Water Services Act. They also challenged the legality of the installation of pre-paid water meters by the respondents. The City's Free Basic Water policy falls within the bounds of reasonableness and therefore is not in conflict with either section 27 of the Constitution or with the national legislation regulating water services. The installation of prepaid meters in Phiri is found to be lawful. Accordingly, the orders made by the Supreme Court of Appeal and the High Court are set aside.

1366 CHARLES NGWENA and REBECCA COOK, 'Four / Rights Concerning Health', in Danie Brand and Christof Heyns (eds.), Socio-Economic Rights in South Africa (Pretoria: Pretoria University Law Press, 2005) at 131-132.

1367 Article 36 of the Constitution reads as follows:

(1) The rights in the Bill of Rights may be limited only in terms of law of general application to the extent that the limitation is reasonable and justifiable in an open and democratic society based on human dignity, equality and freedom, taking into account all relevant factors, including-

(a) the nature of the right;

(b) the importance of the purpose of the limitation;

(c) the nature and extent of the limitation;

(d) the relation between the limitation and its purpose; and

(e) less restrictive means to achieve the purpose.

(2) Except as provided in subsection (1) or in any other provision of the Constitution, no law may limit any right entrenched in the Bill of Rights.

1368 See also section 8(1) of the Constitution which states that "[t]he Bill of Rights applies to all law, and binds the legislature, the executive, the judiciary and all organs of state." 
developed by the CESCR. Consequently, the South African Constitution obliges the state to act as a facilitator creating an enabling framework to allow individuals to fulfil their rights without interference (either by the state or a third party). Secondly, the state's obligations may be extended in that it has to act as a provider supplying basic resources and services in situations where the failure to do so would result in a denial of the realisation of the rights protected by the Constitution. ${ }^{1369}$

The question posed here is whether the right to health care contained in section 27 includes a right of access to essential medicines. A literal interpretation of section 27 would strongly suggest that "access to health care services" includes access to essential medicines, since it would be hard to conceive of an interpretation of "health care services" which would not include medical treatment through the use of medicines. Such a conclusion would also be in line with the interpretation of the right to health by the Committee on Economic, Social and Cultural Rights in its General Comment No. 14. ${ }^{1370}$ Moreover, as will be shown below, the Constitutional Court has confirmed that the right to health care entails access to essential medicines.

South Africa has a constitutional obligation to take all reasonable legislative and other measures, within its available resources, to progressively achieve the realisation of the right to health. This would include adopting and making use of a legislative and policy framework to facilitate access to medicines. ${ }^{1371}$ After the fall of the Apartheid regime, the first democratically elected government was faced with the enormous challenge to reform the racially divided health care system and fulfil the promises made under the newly created Constitution. One of the problems it faced, in light of an expanding HIV/AIDS epidemic, was the provision of medicines. At that time, the medicines market in South Africa was highly unregulated. ${ }^{1372}$ Problems were found in the public and private sector. Many turned to the private sector for health care, because of difficulties with the public sector's infrastructure. Public hospitals and clinics were often located too far away, were overburdened and therefore had long waiting lists or simply did not have the necessary medicines in storage to treat people adequately. ${ }^{1373}$ These infrastructural deficits continue to exist to this day, and they have forced users of the public sector to seek treatment in the private sector. However, high medicine prices in the private sector make treatment unaffordable for many South Africans, furthermore contributing to the already high pressure on the South African health care system. ${ }^{1374}$ Faced with these issues, the government issued a policy review, which

1369 BERGER, 'Tripping over Patents: AIDS, Access to Treatment and the Manufacturing of Scarcity', at 161 .

1370 CESCR, General Comment No. 14, (UN Doc. E/C.12/2000/4) at $\$ 12$.

1371 ADILA HASSIM, MARK HEYWOOD, and JONATHAN BERGER, Health \& Democracy (Westlake: Siber Ink, 2007) at 445.

1372 Ibid. at 444

1373 KRAMER, Patentschutz Und Zugang Zu Medikamenten, at 18.

1374 HASSIM, HEYWOOD, and BERGER, Health \& Democracy, at 444. 
resulted in the adoption of the National Drug Policy (NDP) in 1996. The goal of the NDP is to ensure an adequate and reliable supply of safe, cost-effective drugs of acceptable quality to all citizens of South Africa and the rational use of drugs by prescribers, dispensers and consumers. ${ }^{1375}$ It aims to promote the availability of medicines at the lowest available cost by monitoring and negotiating drug prices, rationalising the drug pricing system and promoting the use of generic medicines. ${ }^{1376}$ The NDP is an important aspect of South Africa's policy framework on medicines. However, as it was adopted in the mid-90s, it must be noted that the developments and struggles, internationally and nationally, enhancing access to medicines had not taken place yet, and therefore beliefs on available policy options was not as progressive as today. ${ }^{1377}$

The South African government has further articulated its strategies for reforming the health care system in its 1997 White Paper for the Transformation of the Health System in South Africa in which two main strategies stand out: the introduction of the District Health System and a shift to Primary Health Care. The concept of PHC has its origins in the WHO's Alma-Ata Declaration specifying a number of rights-based state obligations, including the provision of essential drugs. ${ }^{1378}$ Moreover, to provide a framework for a structured uniform health system, taking into account its constitutional obligation with regard to health services, the government adopted the National Health Act in 2004. ${ }^{1379}$ The National Health Act obliges the Minister of Health, within the limits of available of resources, to ensure the provision of essential health services, which must at

1375 See section 2 the National Drug Policy for South Africa, 1996.

1376 See section 4 (Drug Pricing) of the NDP.

1377 HASSIM, HEYWOOD, and BERGER, Health \& Democracy, at 444.

1378 WHO, Declaration of Alma-Ata, at §VII(3).

1379 Act No. 61 of 2003 adopted on 23 July 2004.

See also section 2 of the National Health Act stating the following:

The objects of this Act are to regulate national health and to provide uniformity in respect of health services across the nation by-

(a) establishing a national health system which-

(i) encompasses public and private providers of health services; and

(ii) provides in an equitable manner the population of the Republic with the best possible health services that available resources can afford;

(b) setting out the rights and duties of health care providers, health workers, health establishments and users; and

(c) protecting. respecting, promoting and fulfilling the rights of-

(i) the people of South Africa to the progressive realisation of the constitutional right of access to health care services, including reproductive health care;

(ii) the people of South Africa to an environment that is not harmful to their health or wellbeing;

(iii) children to basic nutrition and basic health care services contemplated in section 28( 1) (c) of the Constitution; and

(iv) vulnerable groups such as women, children, older persons and persons with disabilities. 
least include primary health care services. ${ }^{1380}$ In line with the NDP and the National Health Act, the Minister of Health developed a second edition of the Standard Treatment Guidelines and Essential Drugs List in 2006. All medicines on this Essential Drug List are available within the public health sector at no cost, depending on the appropriate level of care to be provided by the particular health facility. ${ }^{1381}$

In addition to the legal obligations under the South African Constitution, there is perhaps an even more important reason to ensure that patients have adequate access to treatment if necessary. That is the foundation on which the South African democracy has been built: human dignity, the importance of which has been emphasised by the Constitutional Court. ${ }^{1382}$ This is unsurprising in light of its history where for decades black South Africans were routinely and brutally discriminated against.

As was seen in Chapter 3, accountability of the state is an essential component of monitoring state compliance with its international human rights obligations. Here the focus will be mainly on judicial accountability mechanisms, as they provide individuals with concrete options to hold a state accountable for human rights violations. The South African Constitution allows for the judicial review of legislation and executive policies. Section 38 of the Constitution, under the heading of "Enforcement of rights", states the following:

Anyone listed in this section has the right to approach a competent court, alleging that a right in the Bill of Rights has been infringed or threatened, and the court may grant appropriate relief, including a declaration of rights. ${ }^{1383}$

1380 See section 3 of the National Health Act:

(1) The Minister must, within the limits of available resources-

(a) endeavour to protect, promote, improve and maintain the health of the population;

(b) promote the inclusion of health services in the socio-economic development plan of the Republic;

(c) determine the policies and measures necessary to protect, promote, improve and maintain the health and well-being of the population;

(d) ensure the provision of such essential health services, which must at least include primary health care services, to the population of the Republic as may be prescribed after consultation with the National Health Council; and

(e) equitably prioritise the health services that the State can provide.

(2) The national department, every provincial department and every municipality must establish such health services as are required in terms of this Act, and all health establishments and health care providers in the public sector must equitably provide health services within the limits of available resources.

HASSIM, HEYWOOD, and BERGER, Health \& Democracy, at 458.

BERGER, 'Tripping over Patents: AIDS, Access to Treatment and the Manufacturing of Scarcity', at 160. See also sections 1, 7, 10 and 39 of the South African Constitution, and South African Constitutional Court, Government of the Republic of South Africa v. Grootboom, 2000, Case CCT 11/00, 1 SA 46 (CC) at $\S 83$.

Section 38 of the Constitution further reads:

The persons who may approach a court are: 
Consequently, the South African Constitution renders the rights protected in the Bill of Rights justiciable;, ${ }^{1384}$ as such the courts in South Africa are required to interpret explicit provisions protecting socio-economic rights. The South African Constitution provides guidance when interpreting these rights and states that a court must take account of international law. ${ }^{1385}$ The following section will therefore examine case law by the South African Constitutional Court with regard to socio-economic rights and particularly the right to health and access to medicines and the Constitutional Court's approach to the justiciability of such rights.

\subsection{Cases before the Constitutional Court}

There are relatively few cases on the right to health care. One of the earliest cases concerns the refusal of the Department of Correctional Services to provide antiretroviral therapy for four HIV-infected prisoners who argued that this was a breach of section 35(2)e of the South African Constitution. ${ }^{1386}$ The High Court ruled that the medical treatment claimed by the applicants was in line with the "adequate medical treatment" to which they were entitled under section 35(2)e and that the state's failure to provide such treatment was an infringement of the applicant's constitutional rights. The Court's ruling has been criticised for not invoking any jurisprudence on socio-economic rights, not referring to international law and

(a) anyone acting in their own interest;

(b) anyone acting on behalf of another person who cannot act in their own name;

(c) anyone acting as a member of, or in the interest of, a group or class of persons;

(d) anyone acting in the public interest; and

(e) an association acting in the interest of its members.

1384 See Ex Parte Chairperson of the Constitutional Assembly: In Re Certification of the Constitution of the Republic of South Africa, at $\$ 78$.

1385 See section 39, which reads:

(1) When interpreting the Bill of Rights, a court, tribunal or forum -

(a) must promote the values that underlie an open and democratic society based on human dignity, equality and freedom;

(b) must consider international law; and

(c) may consider foreign law.

(2) When interpreting any legislation, and when developing the common law or customary law, every court, tribunal or forum must promote the spirit, purport and objects of the Bill of Rights.

(3) The Bill of Rights does not deny the existence of any other rights or freedoms that are recognised or conferred by common law, customary law or legislation, to the extent that they are consistent with the Bill.

See also section 233:

When interpreting any legislation, every court must prefer any reasonable interpretation of the legislation that is consistent with international law over any alternative interpretation that is inconsistent with international law.

1386 South African High Court, Cape of Good Hope Provincial Division, B. And Others v. Minister of Correctional Services and Others, 1997, 6 BCLR 789 (C). 
ordering the provision of ARVs only in respect of two of the applicants for whom such therapy had been prescribed by doctors. ${ }^{1387}$

A second case regarding the right to health was the Soobramoney v. Minister of Health (Kwazulu-Natal) case. ${ }^{1388}$ The appellant, Mr. Soobramoney approached the Constitutional Court after being refused kidney dialysis treatment by a state hospital. The hospital justified its decision on the basis of the limited number of machines available which were also very expensive to operate. Therefore, the hospital employed strict criteria for selecting those patients who would benefit most of the treatment. Mr. Soobramoney, unfortunately, also suffered from ischemic heart disease and diabetes. As a result, the hospital was unable to provide him with the dialysis treatment he requested. Mr. Soobramoney argued that, on the basis of his constitutional right to life under section 11 and right to emergency medical treatment under section 27(3), he had a right to receive dialysis treatment. ${ }^{1389}$

The Constitutional Court found that the right to life argument was inappropriate since the Constitution included an explicit provision on access to health care services. In addition, it found that section 27(3) had a narrower meaning. ${ }^{1390}$ Thus, even though the applicant had not raised the issue, the Court seized the opportunity to consider whether the individual's right to health under section 27(1) and (2) had been breached by the state by refusing Mr. Soobramoney access to medical treatment. ${ }^{1391}$ The Constitutional Court held that in these circumstances the hospital had applied criteria compatible with the Constitutional provisions and used rational grounds for their decision. ${ }^{1392}$ The selection process was not considered discriminatory because only health grounds were used to determine who would receive treatment. It stated that the right to health care services must be interpreted in the context of the availability of health care services in general. If $\mathrm{Mr}$. Soobramoney would be entitled to renal dialysis, such treatment could not be refused to other patients in similar positions, which would lead to a considerable expansion of the dialysis programme with severe financial cost to the prejudice of other people with greater health claims. ${ }^{1393}$ In this case, the Constitutional Court acknowledged the doctrine of separation of powers and stated that a court would be

1387 NGWENA and COOK, 'Four / Rights Concerning Health', at 133-134.

1388 South African Constitutional Court, Soobramoney v. Minister of Health (Kwazulu-Natal), 1997, Case CCT 32/97, 1 SA 765 (CC).

1389 Ibid. at §1-7; ALBIE SACHS, 'Enforcement of Social and Economic Rights', American University of International Law Review, 22 (2006-2007), 673-708 at 681-682. In his argument Soobramoney also referred to the practice of the Indian Supreme Court in interpreting the right to life, specifically the Paschim Banga Khet Samity v. State of West Bengal (1996) 4 SCC 37 case, which will be discussed later. The Constitutional Court noted here, that the facts of that particular case where materially different to that of Soobramoney and that there was no need to infer a right to medical treatment from the right to life since it was directly protected by section 27 of the Constitution. See Soobramoney v. Minister of Health, at $\S 18$.

1390 Soobramoney v. Minister of Health, at \$19-22.

1391 BRAND, 'Socio-Economic Rights and Courts in South Africa', at 215.

1392 Soobramoney $v$. Minister of Health, at \$24-25.

1393 Ibid. at \$28. 
slow to interfere with government decisions if these were rational and taken in good faith. ${ }^{1394}$ Thus, it held that the denial of treatment did not breach the state's constitutional obligation to provide access to health care services. ${ }^{1395}$ In doing so, the Court showed considerable deference to the government's assertion that resources were insufficient to expand the dialysis programme. ${ }^{1396}$ Consequently, the South African Constitutional Court clearly considered the right to health to be justiciable. This did not, however, entail that it would take no account of the principle of separation of powers and the financial effects a decision in favour of Soobramoney's arguments would have.

The Soobramoney case received quite some criticism, especially from the South African human rights community. ${ }^{1397}$ However, in the next case the Constitutional Court was more willing to interfere with government decisions. The Government of the Republic of South Africa v. Grootboom case, ${ }^{1398}$ although not concerned with the right to health but the right to adequate housing guaranteed in section 26(1) of the South African Constitution, is of importance here because it established the so-called reasonableness approach. Mrs. Grootboom and her children, who lived in self-made shacks, were rendered homeless when they were evicted from a piece of land earmarked for low-cost housing. Mrs. Grootboom approached the courts and claimed that the state was obliged to provide the homeless with shelter. ${ }^{1399}$

The Constitutional Court was faced with a case in which it had to decide whether or not the state had fulfilled its obligation under the Constitution to progressively realise the right to adequate housing within its available resources. The Constitutional Court focused on the text of section 26 of the Constitution and found the answer to be that the state must adopt reasonable legislative and other measures. ${ }^{1400}$ As such, it developed the reasonableness test as the standard for evaluating state compliance with its constitutional obligations. The Court stated that, irrespective of how extensive and admirable the government's housing programme was, some people were still left in situations of extreme deprivation. ${ }^{1401}$ More importantly, the fact that it did not have any special emergency provisions for people living in such dire situations, as in the case of Mrs. Grootboom, was unreasonable..$^{1402}$ Therefore, the Constitutional Court found the government's housing policy falling short of the requirements of section 26(2) of the Constitution. ${ }^{1403}$ It also referred to the indivisibility of all human rights stating that

\footnotetext{
1394 Ibid. at §29; SACHS, 'Enforcement of Social and Economic Rights', at 682-683.

1395 Soobramoney v. Minister of Health, at $\$ 36$.

1396 FORMAN, 'Justice and Justiciability: Advancing Solidarity and Justice through South Africans' Right to Health in Jurisprudence', at 669.

1397 NGWENA and COOK, 'Four / Rights Concerning Health', at 135-137.

1398 Government of the Republic of South Africa v. Grootboom.

1399 Ibid. at $\$ 4$ et seq.

1400 Ibid. at \$34-46.

1401 Ibid. at \$52-53.

1402 Ibid. at $\$ 43 \& 66$.

1403 Ibid. at $\$ 69$ \& 99(c).
} 
when evaluating the reasonableness of state action, account must also be taken of the inherent dignity of human beings. ${ }^{1404}$ Consequently, the Court found that section 26 of the Constitution had been breached and ordered the government to develop a comprehensive housing programme to remedy the situation.

The difficulty with regard to reviewing broad policy and legislative decisions to assess whether the state has complied with its socio-economic constitutional obligations does not pertain to whether or not the state has taken any measures, as required by the second paragraph of sections 26 and 27 respectively, but whether these measures are adequate. ${ }^{1405}$ Therefore, to assess state compliance with its constitutional socio-economic obligations, the Constitutional Court has established the standard of reasonableness, taking into account the state's available resources and the fact that socio-economic rights cannot always be realised immediately, but they have to be realised progressively. ${ }^{1406}$ A number of conditions for state measures to be reasonable can be inferred from the Constitutional Court's judgments. ${ }^{1407}$ Firstly, to be reasonable, a state programme must clearly allocate responsibilities and tasks and ensure sufficient financial and human resources. ${ }^{1408}$ Secondly, the programme must be comprehensive, coherent and directed towards the progressive realisation of the respective right within the state's available means. ${ }^{1409}$ Thirdly, mere legislation is not enough. Legislation must be complemented by policies and programmes which are reasonable both in their conception and implementation. ${ }^{1410}$ Fourthly, reasonable measures must be balanced and flexible and provide for possible crises situations. A programme which excludes a significant segment of society cannot be reasonable. ${ }^{1411}$ Finally, the state's measure(s) must be transparent, which means that to be properly implemented a programme must be made known appropriately to all concerned. ${ }^{1412}$

Concerning the contested justiciability of socio-economic rights, the Grootboom case is an important milestone. The Constitutional Court reaffirmed the justiciable nature of socio-economic rights and, more importantly, set out criteria to evaluate state compliance with its constitutional obligations. The obligation to progressively realise the right to health as required by section $27(2)$ employs the same wording as

\footnotetext{
1404 Ibid. at $\$ 83$.

1405 BRAND, 'Socio-Economic Rights and Courts in South Africa', at 220; FONS COOMANS, 'Reviewing Implementation of Social and Economic Rights: An Assessment of the "Reasonableness" Test as Developed by the South African Constitutional Court', Heidelberg Journal of International Law, 65 (2005), 167-196 at 175-176.

1406 BRAND, 'Socio-Economic Rights and Courts in South Africa', at 220-221.

1407 Ibid. at 221-222; FORMAN, 'Justice and Justiciability: Advancing Solidarity and Justice through South Africans' Right to Health in Jurisprudence', at 670-671.

1410 Ibid. at $\$ 42$.

1411 Ibid. at $\$ 43$.

1412 South African Constitutional Court, Minister of Health v. Treatment Action Campaign, 2002, Case CCT 8/02, 5 SA 721 (CC) at $\$ 123$.
} 
section 26(2) with regard to the right to housing. Therefore, the reasonableness test equally applies to the right to health, as is confirmed in the following case. ${ }^{1413}$

A further important case with regard to the right to health and specifically addressing access to medicines is the Minister of Health v. Treatment Action Campaign case. In this case the government's policy concerning the provision of the medicine Nevirapine, a medicine which is able to reduce the likelihood of transmission of the HIV/AIDS virus between mother and unborn child by $50 \%$, was under review. The pharmaceutical manufacturers producing Nevirapine had offered the South African government to supply the drug free of charge for five years. However, Nevirapine was made available only in a small number of test sites throughout the country. ${ }^{1414}$ The government justified this restricted provision of the medicine on the basis of the necessity to study the effectiveness of a possible future nationwide programme. ${ }^{1415}$ The NGO Treatment Action Campaign (hereinafter TAC) together with a number of doctors claimed, on behalf of a group of pregnant HIV infected women, that the state's refusal to make Nevirapine available within the public sector was a violation of section 27 of the South African Constitution.

The Constitutional Court was unanimous when it stated that the principle question here was not whether social and economic rights are justiciable, "clearly they are", ${ }^{1416}$ but whether the governmental measures adopted to provide access to health care services for HIV infected mothers and their new-born babies fulfilled the obligations under the Constitution. ${ }^{1417}$ In this case the very act of judicial review, in light of the doctrine of separation of powers, was at the heart of the state's defence. ${ }^{1418}$ The government acknowledged that the Health Ministry might be wrong in its decision; however if so, it would be accountable to the public. ${ }^{1419}$ The courts should not get involved in policy issues. On the other side, TAC and the doctors, referred to the Grootboom case and argued that not providing a medicine which is safe and has no cost implications was unreasonable. ${ }^{1420}$ Referring back to its approach in the Grootboom case, the Court contended that the state's policy to restrict the use of the drug Nevirapine to a limited number of test sites did not meet the reasonableness test. ${ }^{1421}$ The government itself had stated that the cost of the medicine was not a factor in the decision to restrict the provision of Nevirapine. ${ }^{1422}$

1413 FORMAN, 'Justice and Justiciability: Advancing Solidarity and Justice through South Africans' Right to Health in Jurisprudence', at 670.

1414 Before being made available in these few research sites the medicine Nevirapine had only been available in the private sector.

1415 Minister of Health v. Treatment Action Campaign, at \$51-55.

1416 Ibid. at $\$ 25$.

1417 Ibid.

1418 Ibid. at §22; FORMAN, 'Justice and Justiciability: Advancing Solidarity and Justice through South Africans' Right to Health in Jurisprudence', at 674.

1419 SACHS, 'Enforcement of Social and Economic Rights', at 686.

1420 Ibid.

1421 Minister of Health v. Treatment Action Campaign, at \$80-81.

1422 Ibid. at $\$ 48$. 
Therefore, any arguments centred on the lack of resources did not carry any weight. Furthermore, Nevirapine was safe and effective. ${ }^{1423}$

The Constitutional Court did not employ supervisory jurisdiction to assess the rollout of the programme, but it decided that it would be sufficient to declare the state's obligations. ${ }^{1424}$ In that respect, the Constitutional Court was reserved in its judgment and respected the separation of powers between the government and the judiciary. The Constitutional Court, however, also made clear that respecting the principle of separation of powers did not mean "that courts cannot or should not make orders that have an impact on policy." 1425 It therefore rejected the government's argument that the Constitutional Court only had the power to issue a declaratory order. ${ }^{1426}$ The Court's refusal to employ supervisory jurisdiction led to some difficulties with regard to the implementation of the judgment. It took several months of lobbying by TAC before the authorities started supplying Nevirapine. A positive judgment in itself, therefore, does not always bring about change and ensuring effective implementation can sometimes be an even greater challenge. ${ }^{1427}$

The state is obliged to realise socio-economic rights within its available resources. ${ }^{1428}$ In that respect the South African Constitutional Court has been hesitant to address the possible budgetary implications of enforcing the state's constitutional obligations. In Soobramoney the Constitutional Court accepted the state's argument that resources were limited and access to treatment had to been rationed. ${ }^{1429}$ This seems to point to an initial unwillingness to enforce positive duties under the right to health. ${ }^{1430}$ In the TAC case the issue regarding resources was less relevant since the pharmaceutical manufacturer was willing to provide the medicine Nevirapine free of charge for a period of five years. ${ }^{1431}$ As such, it was a relatively easy case to decide. The real question is what will the Constitutional Court decide if the government has legitimate arguments that it is not in a position to (immediately) provide certain health care services due to a lack of resources? ${ }^{1432}$

1423 Ibid. at $\$ 57-60$.

1424 FORMAN, 'Justice and Justiciability: Advancing Solidarity and Justice through South Africans' Right to Health in Jurisprudence', at 677; SACHS, 'Enforcement of Social and Economic Rights', at 692. Minister of Health v. Treatment Action Campaign, at $\$ 98$.

1427 IAIN BYRNE, 'Making the Right to Health a Reality: Legal Strategies for Effective Implementation', Commonwealth Law Conference, (2005) at 10.

1428 See the second paragraph of sections 26 and 27 respectively.

1429 Soobramoney v. Minister of Health, at \$24-28; BRAND, 'Socio-Economic Rights and Courts in South Africa', at 223.

1430 FORMAN, 'Justice and Justiciability: Advancing Solidarity and Justice through South Africans' Right to Health in Jurisprudence', at 668.

1431 Minister of Health v. Treatment Action Campaign, at $\S 48$; BRAND, 'Socio-Economic Rights and Courts in South Africa', at 223.

1432 MURIU, 'The Imperial - Emancipatory Paradox of International Human Rights: How Useful Is the Right to Health in Sub-Saharan Africa?', at 398-399. In a later case the Constitutional Court stated the following: "In Treatment Action Campaign No 2, the Court did order the government 
In Grootboom the Constitutional Court affirmed that the reasonableness standard is governed by the level of available resources, and that the state is not required to do more than its available resources allow. ${ }^{1433}$ The Constitutional Court stated that the reasonableness test may have budgetary implications, but that it is not directed at rearranging budgets. ${ }^{1434}$ Thus, the Constitutional Court has been willing to prioritise the needs of the vulnerable and poor over the government's competing arguments of incapacity and resource constraints. ${ }^{1435}$

Notably, in both the Grootboom ${ }^{1436}$ and $T A C^{1437}$ cases the Constitutional Court rejected the arguments by the amici to recognise a minimum core obligation, as developed by the CESCR ${ }^{1438}$ within the right to housing and the right to health respectively. ${ }^{1439}$ The Court stated that identifying the core content of a right was a complex matter and that courts are ill-equipped to make wide ranging factual and political enquiries to determine such a minimum core content. ${ }^{1440}$ In Lindiwe Mazibuko and Others $v$ City of Johannesburg and Others, a case dealing with the right of access to water enshrined in section 27 of the Constitution, the Constitutional Court first noted that it is implicit in the concept of progressive realisation that it will take time before everyone has access to sufficient water. It continued stating that "it is institutionally inappropriate for a court to determine precisely what the achievement of any particular social and economic right entails and what steps government should take to ensure the progressive realisation of the right. This is a matter, in the first place, for the legislature and executive, the

to make Nevirapine available at clinics subject to certain conditions. But it did so because government itself had decided to make Nevirapine available, though on a restricted basis, and the Court found that there was no reasonable ground for that restricted basis. Moreover Nevirapine was, at least for a period, being made freely available to government by its manufacturer. In a sense, then, all the Court did was to render the existing government policy available to all. However, the Court made it expressly clear that government might revise and amend its policies if it needed to do so. Thus, the Court expressly provided that its order did not 'preclude government from adapting its policy in a manner consistent with the Constitution if equally appropriate or better methods become available to it for the prevention of mother-tochild transmission of HIV'." As such the Constitutional Court reiterated its institutional respect for the policy-making function of the two other arms of government. See South African Constitutional Court, Lindiwe Mazibuko and Others v. City of Johannesburg and Others, 8 October 2009, at $\S 64$.

1433 Government of the Republic of South Africa v. Grootboom, at $\$ 46$.

1434 Minister of Health v. Treatment Action Campaign, at $\S 38$.

1435 FORMAN, 'Justice and Justiciability: Advancing Solidarity and Justice through South Africans' Right to Health in Jurisprudence', at 677.

Minister of Health v. Treatment Action Campaign, at \$26-39.

1438 See above and also General Comment No. 3 and specifically for the right to health General Comment No. 14.

1439 FORMAN, 'Justice and Justiciability: Advancing Solidarity and Justice through South Africans' Right to Health in Jurisprudence', at 671.

1440 Government of the Republic of South Africa v. Grootboom, at \$33; Minister of Health v. Treatment Action Campaign, at \$37-38. 
institutions of government best placed to investigate social conditions in the light of available budgets and to determine what targets are achievable in relation to social and economic rights." 1441

The rejection of the Constitutional Court to recognise the minimum core content of the right to health and housing can be criticised in as much that an inquiry into the reasonableness of the measures adopted must be assessed in relation to whether or not they are targeted at progressively realising the rights contained in section 27(1). Consequently an assessment of the reasonableness of state measures should not only focus on the procedural defects but must additionally entail an inquiry into the content of the rights. ${ }^{1442}$ The Court did state that "there may be cases where it may be possible and appropriate to have regard to the content of a minimum core obligation to determine whether the measures taken by the state are reasonable."1443

Finally, with respect to the content of the right to health, the $2005 \mathrm{New}$ Clicks case $^{1444}$ is of interest. Here pharmacies challenged government regulations which intended to reduce medicine prices, partly through a fixed dispensing fee for pharmacists. ${ }^{1445}$ The Constitutional Court considered the constitutional importance of the governmental regulations in making medicines more affordable and accessible, ${ }^{1446}$ and it upheld the constitutionality of the regulations that provided for price controls. ${ }^{1447}$ It confirmed several times that the purpose of enhancing accessibility and affordability of medicines falls within the state's constitutional obligations under section $27 .^{1448}$

\subsection{Conclusion}

The research question addressed in this section was whether South Africa complied with its obligations under international human rights law by recognising a right of access to medicines within their constitutional and legislative framework. The South African Constitution has legally recognised and implemented the right of access to medicines by incorporating a right to health which as interpreted by the Constitutional Court includes access to medicines - into its Constitution and health legislation and policy.

In line with its international human rights obligations, the Constitution obliges the government to take all reasonable steps to adopt and make use of a legal

1441 Lindiwe Mazibuko and Others v. City of Johannesburg and Others, at $\$ 61$.

1442 See also DAVID BILCHITZ, 'South Africa: Right to Health and Access to HIV/AIDS Drug Treatment', International Journal of Constiutional Law, 1:3 (2003), 524-534.

1443 Government of the Republic of South Africa v. Grootboom, at $\$ 33$.

1444 Constitutional Court, Minister of Health \& Professor D. Mcintyre No v. New Clicks South Africa (Pty) Ltd \& Others, 2005, Case CCT 59/04.

1445 The pharmacies argued that the fixed dispensing fee would cause them to operate at a loss, destroying the pharmaceutical industry and hindering access to medicines. ibid. at $\$ 30$.

1446 Ibid. at $\$ 16$.

1447 Ibid. at $\$ 13$.

1448 Ibid. at $§ 84,314,514,519 \& 704$. 
framework to facilitate access to medicines. In addition to providing services and goods if necessary, this also entails putting into place a framework which allows individuals to realise these rights through their own action. Therefore, it is also obliged to take steps to decrease medicines prices and ensure the sustainable supply of essential medicines in the private sector. ${ }^{1449}$

Although the South African Constitutional Court has decided against establishing a minimum core content of the right to health, it has demonstrated that it is possible to determine the content of the right to health and evaluate state compliance with its constitutional obligations in a specific case. As such it is clear that the right to health under section 27 of the Constitution includes a right of access to medicines. Moreover, South African case law reaffirms that the traditional distinction between civil and political rights as imposing negative duties, and socioeconomic rights as imposing positive duties no longer holds true. ${ }^{1450}$ Justiciability of economic and social rights should be considered on a sliding scale; an approach adopted by the South African Constitutional Court. ${ }^{1451}$ In Grootboom the Constitutional Court stated that the question is not "whether socio-economic rights are justiciable under the Constitution, but how to enforce them in a given case. This is a very difficult issue which must be carefully explored on a case-by-case basis." 1452 Consequently it developed the reasonableness test to assess state compliance with its socio-economic constitutional obligations. This is an innovative and flexible approach which balances the institutional and democratic implications of enforcing socio-economic rights with protecting society's most vulnerable. ${ }^{1453}$ In that regard, the Constitutional Court has overcome many of the arguments posed against the justiciability of socio-economic rights. Even so, the Court has not ignored the principle of separation of powers or arguments centred on the lack of resources. Thus, according to the Court, the positive obligations imposed upon the government by the social and economic rights enshrined in the Constitution will be enforced by the court system in at least the following ways: if the government takes no steps to realise the rights, the courts will require it to take steps; if the government's measures are unreasonable, the courts will require that they be reviewed so as to meet the standard of reasonableness; and the obligation of progressive realisation imposes a duty upon the government to review its policies continually to ensure that achievement of the rights is progressively realised. ${ }^{1454}$

\footnotetext{
1449 HASSIM, HEYWOOD, and BERGER, Health \& Democracy, at 445.

1450 FORMAN, 'Justice and Justiciability: Advancing Solidarity and Justice through South Africans' Right to Health in Jurisprudence', at 666.

1451 BRAND, 'Socio-Economic Rights and Courts in South Africa', at 226.

1452 Government of the Republic of South Africa v. Grootboom, at $\$ 20$.

1453 FORMAN, 'Justice and Justiciability: Advancing Solidarity and Justice through South Africans' Right to Health in Jurisprudence', at 672.

1454 Lindiwe Mazibuko and Others v. City of Johannesburg and Others, at $\$ 67$.
} 


\section{Patent Protection for Pharmaceuticals: Standards \& FleXibilities}

The second research question addressed in this chapter is whether South Africa has complied with its obligations under WTO law and implemented TRIPS standards' and flexibilities with a view to achieving a balance between access and protecting patents.

South Africa, qualified as a developing member, may no longer make use of the transitional periods and is therefore now under an obligation to implement TRIPS fully within their national legislative framework. The following sections will answer the research question by examining the existing legislative framework with regard to patent standards and flexibilities which include: most notably the Patents Act No. 57 of 1978 (section 4.1.) and the Medicines and Related Substances Control Act No. 101 of 1965 (section 4.2). Moreover, there have been some interesting developments using competition law to promote access to medicines which will be discussed under the Competition Act of No. 89 of 1998 (section 4.3).

\subsection{The Patents Act No. 57 of 1978}

The South African patent legislation is established by the Patents Act No. 57 of 1978 which has been amended a number of times, lastly by Act No. 20 of 2005. It sets out the law with regard to the administration, registration, application for, grant, duration and effect of, licensing of, revocation of, and infringement of patent rights within the Republic of South Africa. It sets out that the Act will apply to all patents, whether granted before or after the date of commencement of the Act, except in a number of specified cases. ${ }^{1455}$ Further, a patent will have the same effect towards the state has it has towards a person, except in the case of public noncommercial use. ${ }^{1456}$

The aim of this section is to determine whether South Africa's patent legislation has implemented TRIPS' standards and flexibilities with regard to the patenting of pharmaceuticals. First examined will be whether South Africa has implemented TRIPS' patent standards: particularly whether it allows for the patenting of pharmaceuticals under the criteria prescribed by article 27.1 TRIPS and, in case such an application is successful, whether it grants the patent holder exclusive rights for a minimum period of 20 years as stipulated by articles 28 and 33 TRIPS. Secondly examined are what exceptions the South African Patents Act allows for and whether these are compatible with articles 30 and 31 TRIPS.

1455 Section 3 of the South African Patents Act.

1456 Section 4 of the Patents Act. 


\subsubsection{Patent standards}

As was seen in chapter 4, the TRIPS Agreement sets out a number of minimum standards with regard to intellectual property rights, including patents, which must be implemented by all WTO members. Firstly, article 27.1 TRIPS states that all WTO members must allow for the patenting of inventions, whether products or processes, in all fields of technology as long as they are novel, involve an inventive step and are capable of industrial application. As was seen there is no internationally accepted approach to these concepts and TRIPS allows members to determine for themselves what would be the appropriate method of implementing the TRIPS standards within their own legal system and practice. ${ }^{1457}$ Furthermore, article 27 TRIPS requires members to respect the principle of non-discrimination. It would, therefore, not be possible to exclude pharmaceuticals from being patented within South Africa.

Section 25 of the South African Patents Act ${ }^{1458}$ states what are considered patentable inventions under South African law, and it reads as follows:

1457 Article 1.1 TRIPS.

1458 Section 25 of the Patents Act reads as follows:

(1) A patent may, subject to the provisions of this section, be granted for any new invention which involves an inventive step and which is capable of being used or applied in trade or industry or agriculture.

(2) Anything which consists of -

(a) a discovery;

(b) a scientific theory;

(c) a mathematical method;

(d) a literary, dramatic, musical or artistic work or any other aesthetic creation;

(e) a scheme, rule or method for performing a mental act, playing a game or doing business;

(f) a program for a computer; or

(g) the presentation of information,

shall not be an invention for the purposes of this Act.

(3) The provisions of subsection (2) shall prevent, only to the extent to which a patent or an application for a patent relates to that thing as such, anything from being treated as an invention for the purposes of this Act.

(4) A patent shall not be granted -

(a) for an invention the publication or exploitation of which would be generally expected to encourage offensive or immoral behaviour; or

(b) for any variety of animal or plant or any essentially biological process for the production of animals or plants, not being a microbiological process or the product of such a process.

(5) An invention shall be deemed to be new if it does not form part of the state of the art immediately before the priority date of that invention.

(6) The state of the art shall comprise all matter (whether a product, a process, information about either, or anything else) which has been made available to the public (whether in the Republic or elsewhere) by written or oral description, by use or in any other way.

(7) The state of the art shall also comprise matter contained in an application, open to public inspection, for a patent, notwithstanding that that application was lodged at the patent 
(1) A patent may, subject to the provisions of this section, be granted for any new invention which involves an inventive step and which is capable of being used and applied in trade or industry or agriculture.

Subsection 2 excludes a number of categories from being an "invention" for the purpose of this Act. Furthermore, subsection 4 states that a patent shall not be granted for inventions, the publication or exploitation of which would generally be excepted to encourage offensive or immoral behaviour, or for any variety of animal or plant, or essentially biological process for the production of animals or plants, not being a micro-biological process or the product of such a process. Section 25 continues defining when an invention is considered to be "new", that is when it does not form part of the state of the art; ${ }^{1459}$ and when an invention shall be deemed to "involve an inventive step", i.e. if it is not obvious to a person skilled in the art. ${ }^{1460}$

Of relevance for the patenting of pharmaceuticals is section 25(9), which appears to allow explicitly for the patenting of new uses of known substances or compositions. The provision refers to inventions related to substances or compositions used in methods of treatment and states that "the fact that the substance or composition forms part of the state of the art immediately before the priority date of the invention shall not prevent a patent being granted for the invention if the use of the substance or composition in any such method does not form part of the state of the art at that date". This is a TRIPS-plus provision in that

office and became open to public inspection on or after the priority date of the relevant invention, if -

(a) that matter was contained in that application both as lodged and as open to public inspection; and

(b) the priority date of that matter is earlier than that of the invention.

(8) An invention used secretly and on a commercial scale within the Republic shall also be deemed to form part of the state of the art for the purposes of subsection (5).

(9) In the case of an invention consisting of a substance or composition for use in a method of treatment of the human or animal body by surgery or therapy or of diagnosis practised on the human or animal body, the fact that the substance or composition forms part of the state of the art immediately before the priority date of the invention shall not prevent a patent being granted for the invention if the use of the substance or composition in any such method does not form part of the state of the art at that date.

(10) Subject to the provisions of section 39(6), an invention shall be deemed to involve an inventive step if it is not obvious to a person skilled in the art, having regard to any matter which forms, immediately before the priority date of the invention, part of the state of the art by virtue only of subsection (6) (and disregarding subsections (7) and (8)).

(11) An invention of a method of treatment of the human or animal body by surgery or therapy or of diagnosis practised on the human or animal body shall be deemed not to be capable of being used or applied in trade or industry or agriculture.

(12) Subsection (11) shall not prevent a product consisting of a substance or composition being deemed to be capable of being used or applied in trade or industry or agriculture merely because it is invented for use in any such method.

1459 Section 25(5) of the Patents Act. Subsections (6)-(9) of section 25 of the Patents Act further define the concept "the state of the art".

1460 Section 25(10) of the Patents Act. 
the TRIPS Agreement does not have an explicit requirement for the patenting of new uses of a known substance.

Furthermore, section 27 of the Patents Act defines who may apply for a patent (i.e. the inventor) and sections 30 further set out the conditions for the form of a patent application which requires that the application is accompanied by a provisional or complete specification ${ }^{1461}$ disclosing the subject matter of the application, i.e. the invention concerned. ${ }^{1462}$

Secondly, article 28 of the TRIPS Agreement sets out the rights conferred on patent owners granting them an exclusive right to exclude competitors from the market. Moreover, one of the major achievements of the TRIPS Agreement is that it sets out a minimum standard with regard to the patent term, namely a minimum of 20 years. ${ }^{1463}$

Section 45 of the South African Patents Act states that:

(1) The effect of a patent shall be to grant to the patentee in the Republic, subject to the provisions of this Act, for the duration of the patent, the right to exclude other persons from making, using, exercising, disposing or offering to dispose of, or importing the invention, so that he or she shall have and enjoy the whole profit and advantage accruing by reason of the invention.

Furthermore, subsection (2) of section 45 states that "the sale of a patented article by or on behalf of a patentee or his licensee shall, subject to other patent rights, give the purchaser the right to use and dispose of that article." This section does not make a preference for either the national or international principle of exhaustion of rights. The TRIPS Agreement explicitly states that for the purpose of dispute settlement, nothing in the TRIPS will be used to address the issue of the exhaustion of intellectual property rights. ${ }^{1464}$ Moreover, with regard to the patent term section 46(1) of the Patents Act lays down that the duration of a patent will be 20 years. ${ }^{1465}$

Consequently, the South African Patents Act in line with TRIPS' requirements provides for the possibility to patent pharmaceuticals for a period of 20 years as long as it is an invention which is new, involves and inventive step and is capable of

1461 See section 30(1) of the Patents Act.

1462 See section 32 of the Patents Act. See further regulations 2-67 of the 1978 Patent Regulations (last amended by Government Notice R1181 in Government Gazette 29413 of 1 December 2006).

1463 Article 33 TRIPS.

1464 Article 6 TRIPS. KRAMER, Patentschutz Und Zugang Zu Medikamenten, at 151.

1465 See Section 46 of the Patents Act:

(1) The duration of a patent shall, unless otherwise provided in this Act, be 20 years from the date of application therefor, subject to payment of the prescribed renewal fees by the patentee concerned or an agent.

(2) A patent shall lapse at the end of the period prescribed for the payment of any prescribed renewal fee, if it is not paid within that period: Provided that the registrar may upon application and subject to the payment of such additional fee as may be prescribed, extend the period for payment of any such fee for a period not exceeding six months. 
being used or applied in trade, industry or agriculture. Once an innovative pharmaceutical is patented, the patent holder has - for the duration of the patent exclusive rights with regard to the pharmaceutical.

\subsubsection{Exceptions}

The TRIPS Agreement also provides a number of exceptions to the exclusive rights of patent holders. Firstly, article 30 TRIPS, a more general provision, which establishes three conditions for possible exceptions; secondly, article 31 TRIPS is more specific and establishes a considerable number of conditions under which a Member may allow for compulsory licensing. The South African Patents Act also sets out a number of exceptions to the rights conferred under a patents, which will be examined in the next section to determine, whether South African patent law is, TRIPS compatible and has taken full advantage of articles 30 and 31 TRIPS to introduce exceptions to patent rights with a view to ensuring access to affordable medicines.

\subsubsection{BOLAR EXCEPTION}

First, the Bolar exception, which allows using a patented pharmaceutical product for the specific purpose of obtaining regulatory approval for an equivalent generic version, is an accepted exception to the exclusive rights of patent holders under article 30 of the TRIPS Agreement. South Africa amended its patent law to include the possibility for a Bolar exception in January 2003. ${ }^{1466}$ Section 69A of the Patents Act - under the heading "Acts of non-infringement" states that:

(1) It shall not be an act of infringement of a patent to make, use, exercise, offer to dispose of, dispose of or import the patented invention on a non-commercial scale and solely for the purposes reasonably related to the obtaining, development and submission of information required under any law that regulates the manufacture, production, distribution, use or sale of any product.

Possession of a patented pharmaceutical under the Bolar exception is only permitted with regard to the purpose of obtaining regulatory medicine approval. ${ }^{1467}$

The Bolar exception, as implemented by section 69A of the Patents Act, is in principle TRIPS compatible as long as it adheres to the requirements set out in TRIPS, particularly that the measure is "limited" but also does not "unreasonably conflict with a normal exploitation of the patent" or "unreasonably prejudice the legitimate interests of the patent owner, taking account of the legitimate interests of

1466 HASSIM, HEYWOOD, and BERGER, Health \& Democracy, at 461.

1467 Article 69A(2) of the Patents Act: It shall not be permitted to possess the patented invention made, used, imported or acquired in terms of subsection (1) for any purpose other than for the obtaining, development or submission of information as contemplated in that subsection. 
third parties". As we have seen, a similarly worded exception was ruled by a Panel to be in conformity with article 30 TRIPS in the Canada-Patent Protection for Pharmaceutical Products. ${ }^{1468}$

The importance of the Bolar exception with regard to access to medicines is that it makes it possible for generic producers to take all steps to acquire drug regulatory approval for a generic that is an equivalent version of a patented pharmaceutical product during the patent term of that innovative pharmaceutical, so that once the patent has expired, local production and sale of the generic can start immediately. As such the Bolar exception prevents additional delays in bringing a generic pharmaceutical onto the market. ${ }^{1469}$

\subsubsection{COMPULSORY LICENSING}

Second, as has been stated before, compulsory licensing is one of the explicit flexibilities provided for in TRIPS which can be very useful in bringing down medicine prices by introducing more actors into the market and thus creating (more) competition. It is therefore recommended that developing, and developed countries for that matter, include a compulsory licensing system within their national framework to ensure that in certain situations under certain conditions it is possible to issue a compulsory license for the production and distribution (also to other developing countries) of essential pharmaceuticals. However, it is important that for such a compulsory licensing system to be effective in bringing down medicine prices it needs to be transparent, relatively easy to apply and time-bound. The South African Patents Act explicitly allows for compulsory licensing in two instances.

Firstly, section 55 of the Patents Act allows for compulsory licensing in the case of a dependent patent, which is a patent which cannot be worked without infringing a prior patent. In such a case, the holder of the dependent patent will need a licence under the prior patent to work his own (dependent) patent. However, if no agreement can be reached, the holder of the dependent patent may apply to the Commissioner of Patents ${ }^{1470}$ for a compulsory license, but only for the purpose of working his (dependent) patent.

1468 See Canada - Patent Protection for Pharmaceutical Products, at \$7.45. In the Panel's view, however, Canada's regulatory review exception is a "limited exception" within the meaning of TRIPS Article 30. It is "limited" because of the narrow scope of its curtailment of Article 28.1 rights. As long as the exception is confined to conduct needed to comply with the requirements of the regulatory approval process, the extent of the acts unauthorized by the right holder that are permitted by it will be small and narrowly bounded.

1469 HASSIM, HEYWOOD, and BERGER, Health \& Democracy, at 461.

1470 Section 8 of the Patents Act. 


\section{Secondly, section 56 of the Patents Act allows for compulsory licensing when patent rights are abused. ${ }^{1471}$ Section 56(1) states that any interested person may}

1471 Section 56 of the Patents Act reads as follows:

(1) Any interested person who can show that the rights in a patent are being abused may apply to the commissioner in the prescribed manner for a compulsory licence under the patent.

(2) The rights in a patent shall be deemed to be abused if -

(a) the patented invention is not being worked in the Republic on a commercial scale or to an adequate extent, after the expiry of a period of four years subsequent to the date of the application for the patent or three years subsequent to the date on which that patent was sealed, whichever period last expires, and there is in the opinion of the commissioner no satisfactory reason for such non-working;

(b) [Para. (b) deleted by s. 45(b) of Act 38/1997.]

(c) the demand for the patented article in the Republic is not being met to an adequate extent and on reasonable terms;

(d) by reason of the refusal of the patentee to grant a licence or licences upon reasonable terms, the trade or industry or agriculture of the Republic or the trade of any person or class of persons trading in the Republic, or the establishment of any new trade or industry in the Republic, is being prejudiced, and it is in the public interest that a licence or licences should be granted; or

(e) the demand in the Republic for the patented article is being met by importation and the price charged by the patentee, his licensee or agent for the patented article is excessive in relation to the price charged therefor in countries where the patented article is manufactured by or under licence from the patentee or his predecessor or successor in title.

(3) The patentee or any other person appearing from the register to be interested in the patent may in the prescribed manner oppose the application.

(4) (a) The commissioner shall consider the application on its merits and may order the grant to the applicant of a licence on such conditions as he or she may deem fit, including a condition precluding the licensee from importing into the Republic any patented articles.

(b) If the commissioner is of the opinion that an order directing the grant of a licence is not justified, he may refuse the application.

(c) A licence granted under this section shall include a provision that, subject to adequate protection of the legitimate interests of the licensee, the licence shall, on application by the patentee, be terminated if the circumstances which led to its grant cease to exist and, in the opinion of the commissioner, are unlikely to recur.

(5) Any licence granted under this section shall be non-exclusive and shall not be transferable except to a person to whom the business or part of the business in connection with which the rights under the licence were exercised has been transferred.

(6) [Sub-s. (6) deleted by s. 45(f) of Act 38/1997.]

(7) In determining the conditions on which any licence is granted the commissioner shall have regard to any relevant facts, including the risks to be undertaken by the licensee, the research and development undertaken by the patentee and the terms and conditions usually stipulated in licence agreements in respect of the subject-matter of the invention, between persons who voluntarily enter into such agreements.

(7A) The commissioner may order that a licence granted in terms of this section shall be deemed to have been granted on the date on which the application has been received by the registrar.

(8) Any order of the commissioner under this section shall be made with a view to avoiding the abuse found by the commissioner to have been established.

(9) The commissioner may amend or revoke any licence granted under this section. 
apply to the registrar for a compulsory license, as long as he can demonstrate that the rights in a patent are being abused. ${ }^{1472}$ Subsection (2) of section 56 Patents Acts states that the rights in a patent shall be deemed to be abused in the following cases: ${ }^{1473}$

- the patented invention is not being worked on a commercial scale or to an adequate extent four years after the application for a patent has been made or three years after the patent has been sealed, whichever period expires last, and in case the Patent Commissioner cannot find a satisfactory reason for not working the patent; 1474

- the demand for the patented product in South Africa is not being met to an adequate extent and on reasonable terms. ${ }^{1475}$ "Demand" could be interpreted here from a public purpose perspective and would then include public health demands and inadequate access to medicines. Whether such demand is not met to an "adequate extent" and on "reasonable terms" will depend on the circumstances of each case, and with regard to the latter should refer to the price charged for the patented article; ${ }^{1476}$

- By reason of the refusal of the patent holder to grant a voluntary license(s) upon reasonable terms, the trade, industry or agriculture, or the trade of any person or group of persons, or the establishment of any new trade or industry in South

(10) Subject to the conditions that may be attached to the licence, a licensee under this section shall have the same rights and obligations as any other licensee under a patent.

(11) [Sub-s. (11) deleted by s. 45(h) of Act 38/1997.]

(12) [Sub-s. (12) deleted by s. 45(h) of Act 38/1997.]

(13) (a) The commissioner may, when ordering the grant of a licence under subsection (4)(a), award costs against the applicant or patentee concerned or any person opposing the relevant application.

(b) In so awarding costs, the commissioner shall inter alia have regard to -

(i) the nature and extent of the abuse found by him to have been established; and

(ii) whether the application for a licence under this section might have been avoided by the grant, by the patentee concerned to the applicant, of a voluntary licence on reasonable terms.

(14) For the purposes of this section the expression "patented article" includes any composition of matter or any product of a patented process or method or any product produced by a patented machine.

AVAFIA, BERGER, and HARTZENBERG, The Ability of Select Sub-Saharan African Countries to Utilise TRIPS Flexibilities and Competition Law to Ensure a Sustainable Supply of Essential Medicines, at 16.

1473 Section 56(2)(a)-(e) Patents Act.

1474 In case a patented invention is not worked in South Africa and considered abusive as defined under subsection(2)(a) which results in the commissioner granting a compulsory licence such a licence shall be non-exclusive, but shall not be transferable except to a person to whom the business or the part of the business in connection with which the rights under the licences were exercised has been transferred. See section 56(5) Patents Act. In all other cases of abuse the commissioner may grant an exclusive licence if he considers it justified. See section 56(6) Patents Act.

KRAMER, Patentschutz Und Zugang Zu Medikamenten, at 155-156. 
Africa, is being prejudiced, and it is in the public interest that a license(s) should be granted. To employ this ground for compulsory licensing, a patent holder must either outright refuse to grant a license or demand unreasonable terms for a license. Determining "reasonableness" here will again depend on the circumstances of the case, taking regard of the nature of the invention covered by the patent, the terms of the licenses (if any) already granted, the expenditure and liabilities of the patent holder in respect of the patent etc. Furthermore, the refusal to license the patent must prejudice South African trade or industry and it must serve the public interest to grant a compulsory license. Again determining these conditions will depend on the circumstances of the case. The wording, particularly the reference to public interest, allows for a broad interpretation of this ground; ${ }^{1477}$ or

- The demand for the patented product is being met by importation and the price charged for the patented article by the patent holder, his licensee or agent is excessive in relation to the price charged in the country of manufacture.

There are two main issues when it comes to compulsory licensing. Firstly, the applicant must have an interest. This may be problematic with regard to using section 56 to lower medicine prices, in that the person applying for a compulsory license which has an interest, would generally be someone in the business of manufacturing or importing medicines, such as for example a generic pharmaceutical producer. A civil society organisation, such as the ALP or the TAC, would therefore not satisfy the requirements of being an "interested person". Secondly, the applicant must demonstrate abuse as defined in section 56(2) of the Patents Act. However, it remains unclear whether this list is exhaustive or mere examples. ${ }^{1478}$ Yet the grounds permitted under section 56 do provide the South African government with the possibility to issue a compulsory license for public health purposes, including with respect to a right of access to medicines.

The Commissioner of Patents decides whether a compulsory licence is granted and on what conditions. ${ }^{1479}$ In determining the conditions for such a compulsory licence he shall "have regard to any relevant facts, including the risks to be undertaken by the licensee, the research and development undertaken by the patentee and the terms and conditions usually stipulated in licence agreements in respect of the subject-matter of the invention, between persons who voluntarily enter into such agreements." 1480 The Patents Act further states that the Commissioner may only grant a compulsory licence with the view of avoiding the abuse found by the commissioner to have been established. ${ }^{1481}$ Finally, the Patent Commissioner may, when it orders the grant of a compulsory licence, award costs

\footnotetext{
1477 Ibid. at $156-159$.

1478 HASSIM, HEYWOOD, and BERGER, Health \& Democracy, at 460.

1479 Section 56(4) Patents Act.

1480 Section 56(7) Patents Act.

1481 Section 56(8) Patents Act.
} 
against the applicant, patent holder or any other person opposing the relevant application. ${ }^{1482}$

Section 56(2) of the Patents Act, which sets out a list of grounds required for the grant of a compulsory licence, is a TRIPS-plus provision in that it goes farther than TRIPS requires. Namely, article 31 TRIPS does not entail a list of grounds permissible or necessary for the issuance of a compulsory license. Article 5.A(2) of the Paris Convention allows members to grant compulsory licenses to prevent patent abuses. ${ }^{1483}$ In that regard, the South African Patents Act is in line with the requirements set out by the TRIPS Agreement. Section 56(2)(a) of the Patents Act could be problematic as it considers a patent to be abused in case it is not worked in the Republic of South Africa. The question here is whether this requires the patent holder to manufacture the patented subject-matter in the Republic or whether "working" the patent also could entail importing the patented product, since it is argued and it seems from the, Canada Patent Protection for Pharmaceutical Products case that local working requirements are not permitted under the nondiscrimination principle of the TRIPS Agreement. ${ }^{1484}$

Article 31 TRIPS also sets out a number of requirements regarding the procedure for granting a compulsory license: authorisation on individual merits; prior negotiations; adequate remuneration; and review. ${ }^{1485}$ First, from the procedure detailed under section 56 of the Patents Act it seems acceptable to assume that the patent commissioner takes the decision to grant a compulsory license on the basis of the individual merits of each case. ${ }^{1486}$ In any case, there does not exist a system for automatic compulsory licensing for pharmaceuticals.

Second, regarding the requirement that, before granting a compulsory license an effort has been made to obtain authorisation from the right holder on reasonable commercial terms and conditions, which was not successful within a reasonable period of time, this is not explicitly mentioned in section 56 of the Patents Act, as opposed to sections 55 of the Patents Act. With respect to granting a compulsory license for medicines which are intended to treat HIV/AIDS related diseases, this

1482 Section 56(13)(a) Patents Act. In such case the patent commissioner will take into account the nature and extent of abuse found by him to have been established, and whether the application for a compulsory licence might have been avoided by the grant of a voluntary licence on reasonable terms. Section 56(13)(b) Patents Act.

1483 It also states that "a compulsory license may not be applied for on the ground of failure to work or insufficient working before the expiration of a period of four years from the date of filing of the patent application or three years from the date of the grant of the patent, whichever period expires last" and in case the patent has legitimate reasons for not working the patent. See Article 5.A(4) of the Paris Convention.

1484 See article 27.1 TRIPS: patents shall be available and patents rights enjoyable without discrimination as to the place of invention, the field of technology and where the products are imported or locally produced.

See further section 3.4.4 of chapter 4. KRAMER, Patentschutz Und Zugang Zu Medikamenten, at $153-154$.

1485 See further section 3.4.4 of chapter 4.

1486 See particularly section 56(4) \& (7) of the South African Patents Act. 
condition may be waived as South Africa, with respect to the HIV/AIDS epidemic, could argue it finds itself in a "national emergency" or "situation of extreme urgency". ${ }^{1487}$ This is arguably also true for other diseases such as tuberculosis or malaria. The condition to enter into prior negotiations is also waived in case the patented product is for public, non-commercial use. As the TRIPS Agreement does not give a definition of "public, non-commercial use" and allows members to determine for themselves the appropriate method of interpreting the TRIPS standards, a broad interpretation of the term, allowing for the exploitation of a patented product by a private entity for the benefit of the public, for example purchasing or producing anti-retroviral medicines and distributing them to public hospitals without profit, would be an acceptable and useful tool. ${ }^{1488}$

Third, and more problematic, however, is that section 56 of the Patents Act does not refer to the patent holder's right to receive adequate remuneration in case a compulsory license is granted with respect to his patent. This would be clearly contrary to the TRIPS Agreement. However, subsection 10 states that "subject to the conditions that may be attached to the license, a licensee under this section shall have the same rights and obligations as any other licensee under a patent." Therefore, the "obligations as any other licensee" must include an obligation to pay a royalty fee. ${ }^{1489}$ Moreover, when determining the conditions for a compulsory license the Commissioner shall take into account all relevant facts, including the research and development undertaken by the patent holder and the terms and conditions usually stipulated in licence agreements. ${ }^{1490}$

Finally, section 76 of the Patents Act allows for any party to the proceedings before the commissioner to appeal against any order or decision of the commissioner, which also includes an order to grant a compulsory license which satisfies the condition under TRIPS to allow for the possibility of review. ${ }^{1491}$

1487 BERGER, 'Tripping over Patents: AIDS, Access to Treatment and the Manufacturing of Scarcity', at 205.

1488 Ibid. at 206. Finally, in case a compulsory license is granted to remedy an anti-competitive practice the member state is also waived from the obligation to engage in prior negotiations.

1489 KRAMER, Patentschutz Und Zugang Zu Medikamenten, at 161.

1490 Section 56(7) Patents Act.

1491 See Section 76 of the Patents Act:

(1) Save as is otherwise provided in this Act, any party to proceedings before the commissioner may appeal against any order or decision of the commissioner pursuant to such proceedings.

(2) (a) Every appeal shall be noted and prosecuted in the manner prescribed by law for appeals against a civil order or decision of a single judge, and sections 20 and 21 of the High Court Act, 1959 (Act 59/1959), shall apply mutatis mutandis.

(b) The court may in relation to any such appeal -

(i) confirm, vary or set aside the order or decision appealed against, as justice may require;

(ii) if the record does not furnish sufficient evidence or information for the determination of the appeal, remit the matter to the commissioner with instructions in regard to the taking of further evidence or the setting out of further information; 
Article 31 TRIPS also sets a number of conditions regarding the scope of rights granted under a compulsory license: limited by purpose, non-exclusivity and nonassignable, and territoriality. First, the requirement that the compulsory license shall be limited to the purpose for which it was authorised is clearly fulfilled as it is stated in section 56(8) Patents Act that the commissioner may only order the grant of a compulsory license to avoid patent abuse. Furthermore, on application by the patent holder, a compulsory license shall be terminated if the circumstances which led to its grant cease to exist or are unlikely to recur, subject to the adequate protection of the legitimate interests of the licensee. ${ }^{1492}$ Second, a compulsory license shall be non-exclusive and non-assignable. ${ }^{1493}$ Finally, the principle of territoriality which entails that the use of the patented product under a compulsory is effective only within the territory of South Africa and that its use is predominately for the supply of the domestic market. Until now, South Africa has not made use of the possibility under the 2003 WTO Ministerial Decision to export generic medicines.

In conclusion, the importance of section 56 of the Patents Act lies in the fact that it provides a concrete mechanism - i.e. compulsory licensing - for the South African state to curtail patent rights for public health purposes. Even if a compulsory license is eventually not granted, the threat of compulsory licenses has been very useful in lowering medicine prices. For example, in 2003, the TAC and the Generic Anti-retroviral Procurement Project threatened to use section 56 of the Patents Act to sue Boehringer Ingelheim to obtain a compulsory license allowing them to import generic Nevirapine products. ${ }^{1494}$ To avoid litigation, and maybe also the first ever court-issued compulsory license, Boehringer Ingelheim agreed to issue a voluntary license to the two projects, royalty free. This case did not go to court therefore, it is still not clear how the requirements of section 56 will be interpreted. Moreover, the Aids Law Project (ALP) and the TAC have requested several times that the government make use of the possibility of issuing a compulsory license. However, the South African government has not made use of this option. ${ }^{1495}$

\subsubsection{GOVERnMENT USE}

Thirdly, it has also been argued that section 4 of the Patents Act may also be construed as allowing for the granting of compulsory licences. Section 4 of the

(iii) take any other course which may lead to the just, speedy and as far as may be possible inexpensive settlement of the case; and

(iv) make such order as to costs as justice may require.

(3)-(5) [Sub-ss. (3)-(5) inclusive deleted by s. 4(c) of Act 76/1988.].

1492 See section 56(4)c of the Patents Act.

1493 See section 56(5) of the Patents Act.

1494 HASSIM, HEYWOOD, and BERGER, Health \& Democracy, at 460.

1495 Ibid. at 459. AVAFIA, BERGER, and HARTZENBERG, The Ability of Select Sub-Saharan African Countries to Utilise TRIPS Flexibilities and Competition Law to Ensure a Sustainable Supply of Essential Medicines, at 18. 
Patents Act states that a Minister, of for example Trade and Industry or Health, "may use an invention for public purpose on such conditions as may be agreed upon with the patentee, or in default of agreement on such conditions as are determined by the Patent Commissioner on application by or on behalf of such minister and after hearing the patentee". Thus, it has been argued that ministers have the power to issue compulsory licenses either to state entities or private entities. ${ }^{1496}$ The term "public purpose" should be interpreted broadly, including the possibility to issue a compulsory license to protect public health and lower medicine prices not only in the public sector, but also in the private sector. The government is under a duty to negotiate with the patent holder. ${ }^{1497}$ In the case that agreement cannot be reached on the terms and conditions of the compulsory license, for example with regard to the royalty rate to be paid, the matter is referred to the Commissioner to be resolved. There must be a hearing, in which the patent holder can make his case, before the commissioner can take a decision. ${ }^{1498}$ Until now, this section has not (yet) been used for the importation or manufacture of generic pharmaceuticals, but its broad nature being subject to interpretation, makes it a tool of potential importance. ${ }^{1499}$ However, although the broad wording makes is a potential tool for public health purposes, the TRIPS requirements must still be met.

\subsubsection{Conclusion}

The aim of this section was to determine whether South Africa's patent legislation has implemented TRIPS' standards and flexibilities with regard to the patenting of pharmaceuticals which will be briefly recapped here. First examined are the Patent Act's provisions which implement TRIPS' patent standards:

- Section 25 of the Patents Act provides that patent protection is granted for a new invention which involves an inventive step and which is capable of being used and applied in trade, industry or agriculture;

- Section 45 of the South African Patents Act provides that a patent grants holders the right to exclude other persons from making, using, exercising, disposing or offering to dispose of, or importing the invention, so that he or she shall have and enjoy the whole profit and advantage accruing by reason of the invention; and finally

- Section 46(1) of the Patents Act provides that the duration of a patent will be 20 years.

1496 HASSIM, HEYWOOD, and BERGER, Health \& Democracy, at 459.

1497 AVAFIA, BERGER, and HARTZENBERG, The Ability of Select Sub-Saharan African Countries to Utilise TRIPS Flexibilities and Competition Law to Ensure a Sustainable Supply of Essential Medicines, at 18.

1498 HASSIM, HEYWOOD, and BERGER, Health \& Democracy, at 459.

1499 AVAFIA, BERGER, and HARTZENBERG, The Ability of Select Sub-Saharan African Countries to Utilise TRIPS Flexibilities and Competition Law to Ensure a Sustainable Supply of Essential Medicines, at 18. 
Secondly the exceptions the South African Patents Act allows for are examined:

- Section 69A of the Patents Act provides for a Bolar exception;

- Section 56 of the Patents Act provides for compulsory licensing in situations where patent rights are abused, which is a TRIPS-plus provision as it limits the ground for compulsory licensing to avoiding patent abuse;

- Section 4 of the Patents Act provides for government use of a patented invention for public purposes; and finally

- Section 61 of the Patents Act sets out a number of grounds on which a patent may be revoked, ${ }^{1500}$ which is also in line with the requirements of the TRIPS Agreement. ${ }^{1501}$

Consequently South Africa has implemented the TRIPS flexibilities according to the Doha Declaration within their legislative framework. Therefore, despite some

1500 Section 61 of the Patents Act:

(1) Any person may at any time apply in the prescribed manner for the revocation of a patent on any of the following grounds only, namely -

(a) that the patentee is not a person entitled under section 27 to apply for the patent;

(b) that the grant of the patent is in fraud of the rights of the applicant or of any person under or through whom he claims;

(c) that the invention concerned is not patentable under section 25;

(d) that the invention as illustrated or exemplified in the complete specification concerned cannot be performed or does not lead to results and advantages set out in the complete specification;

(e) that the complete specification concerned does not sufficiently describe, ascertain and, where necessary, illustrate or exemplify the invention and the manner in which it is to be performed in order to enable the invention to be carried out by a person skilled in the art of such invention;

(f) that the claims of the complete specification concerned are not-

(i) clear; or

(ii) fairly based on the matter disclosed in the specification;

(g) that the prescribed declaration lodged in respect of the application for the patent contains a false statement or representation which is material and which the patentee knew to be false at the time when the declaration was made;

(h) that the application for the patent should have been refused in terms of section 36;

(i) that the complete specification claims as an invention a microbiological process or a product thereof and that the provisions of section 32(6) have not been complied with.

(2) An application for revocation shall be served on the patentee and lodged with the registrar in the prescribed manner and shall thereafter be dealt with in the manner prescribed.

(3) The commissioner shall decide whether the patent shall be revoked or whether and, if so, subject to what amendments, if any, of the specification or claims thereof, the patent shall be upheld: Provided that the commissioner shall not allow any amendment which is in conflict with the provisions of section 51(6) or (7): Provided further that the commissioner may in the exercise of his discretion as to costs take into consideration the conduct of the patentee in framing his specification and claims and permitting them to remain as so framed.

See further regulations 89-94 of the 2006 Patent Regulations. 
shortcomings, the existing legal framework provides many opportunities for ensuring access to a sustainable supply of affordable medicines. ${ }^{1502}$

The South African Patents Act implements a framework with regard to compulsory licensing taking advantage of the flexibility TRIPS provides in that regard. However, the system contains limitations which detract from the usefulness of compulsory licensing with respect to adequate access to affordable medicines. Most notably, compulsory licensing is limited to avoiding abuse of patent rights. Although it provides for the possibility of compulsory licensing for public health purposes, particularly if the demand for a patented pharmaceutical such as ARVs is not met to an adequate extent and on reasonable terms or when the demand is met through importation but an excessive price is charged, the TRIPS Agreement does not require member states to limit compulsory licenses on any particular ground. Moreover, the system contains gaps questioning its TRIPS' compatibility, such as the fact that there is no explicit mention of the requirement to first enter into negotiations with the patent holder to achieve a voluntary license or the requirement to pay adequate remuneration to the right holder. Consequently there is room to enhance the usefulness of the compulsory license system under the Patents Act for the purpose of ensuring access to affordable medicines. This could be done, for example through not limiting the grounds for compulsory licensing, setting out reasonable concrete time frames for the obligation to first negotiate a voluntary license and the grant of a compulsory license, establishing guidelines as to what is considered "reasonable" commercial terms and conditions when negotiating a voluntary license, providing for the determination of public health crises as "national emergencies" or "situations of extreme urgency" waiving the obligation to enter into negotiations before granting a compulsory license, setting out guidelines on the factors to be taken into account when determining the adequate remuneration to be paid to the patent holder, including public health interests and the need to ensure access to affordable medicines, and finally notifying its intention to use the 2003 Waiver Decision to export generic medicines to countries without manufacturing capacity.

\subsection{The Medicines and Related Substances Act No. 101 of 1965}

After the first democratic elections in the mid-90s, the South African government, while in the process of reforming its health care system, incorporated a number measures specifically intended to enhance the availability and (economic) accessibility of medicines within their legislative framework through a number of amendments to the Medicines and Related Substances Act 101 (hereinafter the Medicines Act), which was enacted in 1965 and most recently amended in 2008 by the Medicine and Related Substances Amendment Act No. 72 of 2008. Together with the 2003 General Regulations No. 510 Made in Terms of the Medicines and Related Substances Act (hereinafter the General Regulations), the Medicines Act

1502 HASSIM, HEYWOOD, and BERGER, Health \& Democracy, at 451. 
allows for a number of measures of relevance for South Africa's ability to balance patent protection for pharmaceuticals with ensuring access to medicines. Most notably it introduced a rather controversial provision providing the Minister of Health with broad powers to ensure the supply of affordable medicines (section 4.2.1) in addition to a range of other measures intended to also enhance the availability and accessibility of medicines (section 4.2.2).

One of the most important amendments to the Medicines Act is the Medicines and Related Substances Control Amendment Act No. 90 of 1997 (hereinafter the Amendment Act No. 90). It took a number of years, however, before the Amendment Act No. 90 came into force due to the fact that the pharmaceutical industry perceived the amendments to the Medicines Act to be an unjustifiable state interference with their intellectual property rights. Therefore, in February 1998, the Pharmaceutical Manufacturer's Association (PMA) applied to Pretoria High Court to prevent President Mandela from promulgating the Amendment Act No. 90 of 1997. However, with support from civil society, notably the Treatment Action Campaign, the government defended the Act and the PMA withdrew its legal challenge in 2001. ${ }^{1503}$

\subsubsection{Section 15C: Measures to Ensure the Supply of Affordable Medicines}

Section $15 \mathrm{C}$ of the Medicines Act is one of the most controversial measures introduced by the 1997 Amendment Act No. 90 as it provides the Minister of Health with broad powers to ensure the supply of affordable medicines. ${ }^{1504}$ The Patents Act does not make an explicit preference for a national or international exhaustion regime. By introducing section $15 \mathrm{C}$, South Africa adopts an international exhaustion regime affording the Health Minister the power to prescribe conditions under which a patented medicine (once it has been put on the market) can be parallel imported into South Africa. Section 15C(a) provides that, irrespective of the provisions of the Patents Act, the Minister of Health has the power to determine that the rights with regard to any medicine under patent in South Africa shall not

1503 Ibid. at 452.

1504 Section $15 \mathrm{C}$ of the Medicines Act reads as follows:

The Minister may prescribe conditions for the supply of more affordable medicines in certain circumstances so as to protect the health of the public, and in particular may-

(a) notwithstanding anything to the contrary contained in the Patents Act, 1978 (Act 57 of 1978), determine that the rights with regard to any medicine under a patent granted in the Republic shall not extend to acts in respect of such medicine which has been put onto the market by the owner of the medicine, or with his or her consent;

(b) prescribe the conditions on which any medicine which is identical in composition, meets the same quality standard and is intended to have the same proprietary name as that of another medicine already registered in the Republic, but which is imported by a person other than the person who is the holder of the registration certificate of the medicine already registered and which originates from any site of manufacture of the original manufacturer as approved by the Authority in the prescribed manner, may be imported;

(c) prescribe the registration procedure for, as well as the use of, the medicine referred to in paragraph (b). 
extend to acts in respect of such a medicine which has been legally marketed by the owner of the medicine or with his consent. Section $15 \mathrm{C}(\mathrm{b})$ refers particularly to importation and states that the Minister may prescribe the conditions for importation of "any medicine which is identical in composition, meets the same quality standard and is intended to have the same proprietary name as that of another medicine already registered in the Republic, but which is imported by a person other than the person who is the holder of the registration certificate of the medicine already registered and which originates from any site of manufacture of the original manufacturer as approved by the [South African Health Products Regulatory] Authority in the prescribed manner". Section $15 \mathrm{C}(\mathrm{b})$ has been implemented by Regulation 7 of the 2003 General Regulations. ${ }^{1505}$ Regulation 7

1505 Regulation 7 of the 2003 General Regulations reads as follows:

7.1 A medicine referred to section in $15 \mathrm{C}(\mathrm{b})$ of the Act may be sold if:

(a) the medicine is being sold outside the Republic with the consent of the holder of the patent of such medicine;

(b) the medicine is imported from a person licenced by a regulatory authority recognised by the council;

(c) the person desiring to import such medicine is in possession of a permit issued by the Minister; and

(d) the medicine is registered in terms of the Act.

7.2 A person desiring to import a medicine referred to in sub-regulation (1) must submit to the Minister:

(a) a duly completed application on a form approved and provided by the Minister;

(b) a certified copy of his or her identity document or in the case of a juristic person, a certificate of registration as such in the Republic;

(c) a certified copy of his, her or its registration in terms of the Pharmacy Act, 1974, where applicable;

(d) a certified copy of a licence in respect of premises in terms of -

(i) section 19 of Customs and Excise Act, 1964 (Act No. 91 of 1964); and

(ii) section 22 of the Pharmacy Act, 1974;

(e) documentary proof -

(i) that the medicine is under patent in the Republic;

(ii) that the medicine is registered in its country of export by a regulatory authority recognised by the council;

(iii) regarding the lowest price at which the medicine is sold in the Republic;

(iv) regarding the price at which the medicine will be sold in the Republic;

(v) that he, she or it is able to comply with good manufacturing and distribution practices as determined by the council; and

(f) an undertaking that he, she or it will ensure the continued safety, efficacy and quality of the medicine.

7.3 The Minister -

(a) may approve the application referred to in sub-regulation (2) with or without conditions;

(b) must if he or she approves the application, issue the applicant with a permit, which is valid for a period of two years;

(c) may cancel the permit if the holder thereof fails to comply with the conditions of the permit or on any other good cause shown.

7.4 The permit issued in terms of sub-regulation (3) may only be transferred with the approval of the Minister. 
allows for parallel importation and specifies a number of conditions, such as which medicines can be imported under section $15 \mathrm{C}(\mathrm{b})$, namely only patented medicines; what must be included in an application for a license to parallel import; and the Minister's power to approve licenses. ${ }^{1506}$

Unsurprisingly, section 15C was the main focus of the PMA's challenge. They argued that the vague wording of this section and the extensive powers assigned to the Minister of Health was incompatible with the South African Constitution and the TRIPS Agreement. The US supported the PMA's claim and put South Africa on its "watch list", a list drawn up by the US Trade Representative to signal countries, and permitting the US President to demand action against such countries, which portray unjustifiable or unreasonable trade practices, specifically including IP issues. The case was taken up by South Africa's civil society and received widespread international attention and as a result was withdrawn in April 2001. ${ }^{1507}$

Since the PMA withdrew its legal challenge, the High Court never interpreted section $15 \mathrm{C}$ and it is still unclear what exact powers the Minister of Health has under the provision. ${ }^{1508}$ It has been argued that section $15 \mathrm{C}$ (a) would allow for compulsory licensing and may even be used to override patents with a view to protecting public health. ${ }^{1509}$ However, with regard to section $15 \mathrm{C}(\mathrm{a})$ the General

7.5 A person issued with a permit in terms of sub-regulation (3) must apply to the council for the registration of the medicine specified in the permit by submitting to the Registrar-

(a) a certified copy of that permit;

(b) a duly completed application form approved and provided by the council; and

(c) an application fee as determined by the council.

7.6 The council-

(a) must, if satisfied that the application referred to in sub-regulation (5) complies with the requirements of the Act and these regulations and those of the council regarding the safety, efficacy and quality of the medicine, and that its registration is in the public interest, approve the application with or without conditions; and

(b) may issue the person referred to in sub-regulation (5) with a certificate of registration in respect of such medicine under the name approved by the council.

7.7 The certificate of registration referred to in sub-regulation (6) may only be transferred with the approval of the council.

7.8 A person importing a medicine in terms if this regulation shall in writing inform-

(a) the Minister of any change of facts in relation to the application for a permit issued in terms of sub-regulation (5)or conditions under which such permit was issued;

(b) the council of any amendments to the application for the registration of medicines or the conditions for the registration of such medicine;

(c) the holder of a certificate of registration in the Republic of the registration of the medicine in terms of this regulation.

7.9 A medicine registered in terms of this regulation may only be sold to the State or a person authorised to sell medicines in terms of the Act or any other legislation.

HASSIM, HEYWOOD, and BERGER, Health \& Democracy, at 453.

KRAMER, Patentschutz Und Zugang Zu Medikamenten, at 167-168. See further SUSAN K. SELL, 'TRIPS and the Access to Medicines Campaign', Wisconsin International Law Journal, 20:3 (2001-2002), 481-522 at 501-502.

HASSIM, HEYWOOD, and BERGER, Health \& Democracy, at 453.

KRAMER, Patentschutz Und Zugang Zu Medikamenten, at 167. 
Regulations are silent. Such a broad interpretation would most probably not be TRIPS compatible, particularly with regard to the requirements for compulsory licensing under article 31 TRIPS. ${ }^{1510}$ With respect to the adoption of an international principle of exhaustion of rights and thus allowing for parallel importation we have seen that TRIPS specifically states that, for the purposes of dispute settlement the issue of exhaustion of IPRs is excluded. ${ }^{1511}$

\subsubsection{Further Measures under the Medicines Act}

The Medicines Act has introduced a number of further measures with a view to enhancing the availability and accessibility of medicines, which will only be touched upon briefly in this section. First, the Medicines Act aims to achieve transparency with regard to the pricing of pharmaceuticals. It prohibits the use of financial and other incentives, which have been used in the past by the pharmaceutical industry to ensure that their pharmaceutical products were prescribed and dispensed. ${ }^{1512}$ Moreover, the Medicines Act introduced a Pricing Committee whose primary task is to advise the Minister of Health on a transparent pricing system and the setting of a single exit price. ${ }^{1513}$ The Minister of Health, on the recommendation of the Pricing Committee, issued the Regulations No. 533

1510 KRAMER, Patentschutz Und Zugang Zu Medikamenten, at 169 et seq.

1511 Article 6 TRIPS.

1512 See section 18A of the Medicines Act:

1. No person shall supply any product, medical device or IVD according to a bonus system, rebate system or any other incentive scheme.

2. Notwithstanding subsection (1), the Minister may prescribe acceptable and prohibited acts in relation to subsection (1).

See also section $18 \mathrm{~B}$ of the Medicines Act:

1. No person shall sample any product, medical devices or IVD.

2. Use of products, medical devices or IVDs for exhibition or appraisal purposes shall be as prescribed.

3. For the purposes of this section 'sample' means the free supply of products, medical devices or IVDs by a device or IVD establishment, manufacturer or wholesaler or its agent to a pharmacist, medical practitioner, dentist, veterinarian, practitioner, nurse or other person registered under the Health Professions Act, 1974, or any professional or person authorised to use the device.

1513 See section $22 \mathrm{G}$ of the Medicines Act:

1. The Minister shall appoint, for a period not exceding five years, such persons as he or she may deem fit to be members of a committee to be known as the pricing committee.

2. The Minister may, on the recommendation of the pricing committee, make regulations-

(a) on the introduction of a transparent pricing system for all medicines and Scheduled substances sold in the Republic;

(b) on an appropriate dispensing fee to be charged by a pharmacist or by a person licensed in terms of section $22 \mathrm{C}$ (1) (a).

(c) on an appropriate fee to be charged by wholesalers or distributors or any other person selling Schedule O medicines.

3. (a) The transparent pricing system contemplated in subsection (2) (a) shall include a single exit price which shall be published as prescribed, and such price shall be the only price 
Relating to a Transparent Pricing System for Medicines and Scheduled Substances. The Pricing Regulations were promulgated on 30 April 2004, and intended to come into effect on 2 May 2004. ${ }^{1514}$ However, because of a dispute challenging the constitutionality of these Pricing Regulations, their full implementation was delayed. ${ }^{1515}$

Secondly the Medicines Act, as recommended by the 1996 National Drug Policy, promotes the generic substitution of medicines as an effective way to reduce medicine expenditure. Section $22 \mathrm{~F}$ of the Medicines Act promotes the use of generic medicines, especially when medicines are no longer protected by patents, but also for generics produced under a voluntary license or a compulsory license. ${ }^{1516}$ With respect to generics, section $22 \mathrm{~F}$ refers to "interchangeable multi-source medicines" which are defined as: "medicines that contain the same active substances which are identical in strength or concentration, dosage form and route of administration and meet the same or comparable standards, which comply with

at which manufacturers shall sell medicines and Scheduled substances to any person other than the State.

(b) No pharmacist or person licensed in terms of section $22 \mathrm{C}$ (1) (a) or wholesaler or distributor shall sell a medicine at a price higher than the price contemplated in paragraph (a).

(c) Paragraph (b) shall not be construed as preventing a pharmacist or person licensed in terms of this Act to charge a dispensing fee as contemplated in subsection (2) (b).

4. To the members of the pricing committee who are not in the full-time employment of the State may be paid such remuneration and allowances as the Minister, with the concurrence of the Minister of Finance, may determine.

1514 HASSIM, HEYWOOD, and BERGER, Health \& Democracy, at 454.

1515 See Minister of Health v. New Clicks South Africa.

1516 See section 22F of the Medicines Act:

1. Subject to subsections (2), (3) and (4), a pharmacist or a person licensed in terms of section $22 \mathrm{C}(1)$ (a) shall-

(a) inform all members of the public who visit the pharmacy or any other place where dispensing takes place, as the case may be, with a prescription for dispensing, of the benefits of the substitution for a branded medicine by an interchangeable multi-source medicine, and shall, in the case of a substitution, take reasonable steps to inform the person who prescribed the medicine of such substitution; and

(b) dispense an interchangeable multi-source medicine instead of the medicine prescribed by a medical practitioner, dentist, practitioner, nurse or other person registered under the Health Professions Act, 1974, unless expressly forbidden by the patient to do so.

2. If a pharmacist is forbidden as contemplated in subsection (1) (b), that fact shall be noted by the pharmacist on the prescription.

3. When an interchangeable multi-source medicine is dispensed by a pharmacist he or she shall note the brand name or where no such brand name exists, the name of the manufacturer of that interchangeable multi-source medicine in the prescription book.

4. A pharmacist shall not sell an interchangeable multi-source medicine-

(a) if the person prescribing the medicine has written in his or her own hand on the prescription the words 'no substitution' next to the item prescribed;

(b) if the retail price of the interchangeable multi-source medicine is higher than that of the prescribed medicine; or

(c) where the product has been declared not substitutable by the Authority. 
the requirements for therapeutic equivalence as prescribed". The principle rule is that branded and patented pharmaceuticals must be substituted by a generic medicine when the branded product cost the same or more than the generic version. However, generic substitution may not take place in cases where the prescribing health care provider, or the Medicines Control Council, has indicated that the branded medicine is non-substitutable; or where the patient has expressly rejected substitution. The person dispensing the medicine must also take reasonable steps to inform the health care provider that generic substitution has taken place. ${ }^{1517}$

Thirdly, there is no reference of test data protection within the Patents Act. The Medicines Act, overseeing the regulation of medicines in South Africa, does contain general confidentiality provisions related to medicines. Sections 22B and 34, read together, would suggest that there is general protection of information submitted in respect of the regulation of medicines against unfair commercial use; namely, "for self-gain or for the benefit of his employer". ${ }^{1518}$ Section 22B, however, permits the Director General of Health to disclose information relating to medicines where it is deemed "expedient and in the public interest".

Finally, the Medicines Act initially provided for a fast-track procedure of registration for those medicines included in South Africa's Essential Drug List, however, this provision was repealed by the Medicines and Related Substances Amendment Act No. 72 of 2008.

\subsubsection{Conclusion}

Section 15C of the Medicines Act gives the Minister of Health broad powers to ensure medicines are accessible and affordable. It has been argued that section $15 \mathrm{C}$ (a) would allow for the possibility of compulsory licensing, although it is doubtful whether this would be TRIPS compatible. More importantly, though, the government has not made use of section $15 \mathrm{C}$ (a) for the purpose of compulsory licensing. ${ }^{1519}$ In addition section $15 \mathrm{C}(\mathrm{b})$ applies an international principle of exhaustion of rights and thus allows for parallel importation, which is permissible

1517 HASSIM, HEYWOOD, and BERGER, Health \& Democracy, at 457.

1518 See section 22B of the Medicines Act:

1. Notwithstanding the provisions of section 34 the council may, if it deems it expedient and in the public interest, disclose information in respect of the prescribing, dispensing, administration and use of a medicine, Scheduled substance or medical device.

2. The Director-General may publish the information referred to in subsection (1) or release it to the public in a manner which he thinks fit.

See section 34 of the Medicines Act:

No person shall, except for the purpose of the exercise of his powers or the performance of his functions under this Act, or for the purpose of legal proceedings under this Act, or when required to do so by any competent court or under any law, or with the written authority of the Director-General, disclose to any other person any information acquired by him in the exercise of his powers or the performance of his functions under this Act and relating to the business or affairs of any person, or use such information for self-gain or for the benefit of his employer. 
under TRIPS. Yet the process to parallel import under Regulation 7 is complex and its usefulness therefore most probably limited.

Although the withdrawal of the PMA's challenge to section $15 \mathrm{C}$ entails that there is no clarification on the powers this section confers on the Minister of Health and its compatibility with TRIPS, it highlighted the importance of civil society as regards the impact of patent protection on public health. The success of the international campaign illustrates that it is no longer possible for developed countries to exert pressure in order to safeguard the interests of the pharmaceutical industry without repercussions. ${ }^{1520}$

Finally, the Medicines Act introduced a number of other measures to ensure medicines are available and affordable, for example by means of a transparent pricing system, and as recommended by the 1996 National Drug Policy, promoting the generic substitution of medicines. Moreover, it confirmed that the government has a constitutional duty to take measures to ensure the provision of affordable medicines, and stressed that, when the state regulates, it must do so in a reasonable fashion, ensuring that measures intended to make medicines affordable do not by design or accident make them unavailable.

\subsection{The Competition Act No. 89 of 1998}

Finally, this section will address an innovative manner of addressing the lack of access to affordable medicines, namely by using competition law. Developing countries should make use of all regulatory tools available to ensure adequate access to affordable essential medicines, which includes using competition law and policy where it can be useful to achieve this goal. ${ }^{1521}$ The use of competition rules to ensure that anti-competitive practices do not excessively restrict access to patent protected pharmaceuticals is in line with the TRIPS Agreement. ${ }^{1522}$ For example, article 31 TRIPS, which allows for the granting of compulsory licenses, waives the obligations for WTO members to engage in prior negotiations and that use of a compulsory license should predominantly be for the domestic market in case a

1520 VERMA, 'The Doha Declaration and Access to Medicines by Countries without Manufacturing Capacity', at 630.

1521 AVAFIA, BERGER, and HARTZENBERG, The Ability of Select Sub-Saharan African Countries to Utilise TRIPS Flexibilities and Competition Law to Ensure a Sustainable Supply of Essential Medicines, at 29. See also FREDERICK M. ABBOTT, 'The "Rule of Reason" and the Right to Health: Integrating Human Rights and Competition Principles in the Context of TRIPS', in Thomas Cottier, Joost Pauwelyn, and Elisabeth Bürgi (eds.), Human Rights and International Trade (New York: Oxford University Press, 2005).

1522 AVAFIA, BERGER, and HARTZENBERG, The Ability of Select Sub-Saharan African Countries to Utilise TRIPS Flexibilities and Competition Law to Ensure a Sustainable Supply of Essential Medicines, at 29. See further, BEATRIZ CONDE CALLEGO, 'Intellectual Property Rights and Competition Policy', in Carlos M. Correa (ed.), Research Handbook on the Protection of Intellectual Property under WTO Rules. Intellectual Property in the WTO Volume 1 (Research Handbooks on the WTO; Cheltenham/Northampton: Edward Elgar, 2010). 
compulsory license is granted to remedy an anti-competitive practice. ${ }^{1523}$ Moreover, the TRIPS Agreement does not define the term "anti-competitive practice" which gives WTO members the freedom to define the term themselves. ${ }^{1524}$

Competition law and policy is a field of law which allows for implementation by a strong and independent competition authority. This has the advantage that, unlike patent law, using competition law effectively is not dependent on the actions of certain, sometimes reluctant parties. ${ }^{1525} \mathrm{~A}$ range of interested actors, other than the state and the generic pharmaceutical industry, may take up an issue without the risk of years of expensive litigation. ${ }^{1526}$ As will be seen below,in South Africa the Aids Law Project and the Treatment Action Campaign have taken up this role with considerable success. In that regard, South Africa's experience with using competition legislation and policy to ensure a sustainable supply of affordable essential medicines is an interesting case study which could provide useful insights and lessons for other developing countries dealing with similar public health problems. It must be mentioned that the sole use of competition law and policy to ensure adequate access to medicines of patients in developing countries is not sufficient. Developing countries should also take full advantage of the flexibilities as set out in the Doha Declaration on the TRIPS Agreement and Public Health. Regulatory tools within competition law and policy should, therefore, be considered complementary to the so-called TRIPS flexibilities. ${ }^{1527}$

South Africa's Competition Act No. 89 of 1998 has been in force since September $1^{\text {st }}, 1999^{1528}$ and intends to promote and protect competition between companies, so as to safeguard the interests of consumers and promote economic growth. The Preamble of the Competition Act states that "an efficient, competitive economic environment, balancing the interests of workers, owners and consumers and focussed on development, will benefit all South Africans." Thus, the Competition Act must be interpreted in "a manner that is consistent with the Constitution and gives effect to the purposes set out in section 2" and "in compliance with the international law obligations of the Republic." The purposes of the Competition Act

1523 Article 31(k) TRIPS.

1524 BERGER, 'Tripping over Patents: AIDS, Access to Treatment and the Manufacturing of Scarcity', at 202.

1525 AVAFIA, BERGER, and HARTZENBERG, The Ability of Select Sub-Saharan African Countries to Utilise TRIPS Flexibilities and Competition Law to Ensure a Sustainable Supply of Essential Medicines, at 30; BERGER, 'Tripping over Patents: AIDS, Access to Treatment and the Manufacturing of Scarcity', at 202.

1526 AVAFIA, BERGER, and HARTZENBERG, The Ability of Select Sub-Saharan African Countries to Utilise TRIPS Flexibilities and Competition Law to Ensure a Sustainable Supply of Essential Medicines, at 30.

1527 Ibid. at 31 .

1528 Except for a number of provisions which came into force on 30 November 1998 the Competition Act as whole came into force on 1 September 1999. 
include providing consumers with competitive prices and product choices and also advancing the social and economic welfare of South Africans. ${ }^{1529}$

The Competition Act has a specific system of dealing with complaints. A complaint must be first filed with the Competition Commission, which is an independent investigative body. The Commission looks into the complaint, within the timeframe of a year, and if it finds that competition law has been infringed, it will send the complaint on to the Competition Tribunal. If the Competition Commission does not refer the complaint to the Tribunal, the complainant may refer the case independently. The Competition Tribunal will assess the case on its merits and make an order. The decisions of the Tribunal may be appealed at the Competition Appeal Court; and decision of the Appeal Court may be taken on appeal to the Supreme Court of Appeal or to the Constitutional Court, if they raise constitutional issues. Additionally, decisions of the Competition Commission, Tribunal and Appeal Court may be brought before the High Court on review, which will assess the fairness of the procedures adopted, as opposed to the correctness of a decision. ${ }^{1530}$

The Competition Act provides a number of provisions which could be of use in challenging anti-competitive practices in the health and pharmaceutical sector, which are set out in chapter two of the Act, which is divided into Part A ("Restrictive Practice") and Part B ("Abuse of a Dominant Position"). The focus here will on the abuse by a pharmaceutical corporation of its dominant position.

\subsubsection{Abuse of Dominance}

A patent grants the right holder a monopoly position to exercise a number of exclusive rights, such as manufacturing, using, offering for sale, selling etc. the patented product for a period of time, which is 20 years as required by TRIPS. In connection with the pharmaceutical industry, dominance of the pharmaceutical market is often related to patent protection. However, the existence of patent protection does not automatically lead to a dominant position on the market. Moreover, having a dominant position on a particular market is not problematic in

1529 Section 2 of the Competition Act reads as follows:

The purpose of this Act is to promote and maintain competition in the Republic in order -

(a) to promote the efficiency, adaptability and development of the economy;

(b) to provide consumers with competitive prices and product choices;

(c) to promote employment and advance the social and economic welfare of South Africans;

(d) to expand opportunities for South African participation in world markets and recognise the role of foreign competition in the Republic;

(e) to ensure that small and medium-sized enterprises have an equitable opportunity to participate in the economy; and

(f) to promote a greater spread of ownership, in particular to increase the ownership stakes of historically disadvantaged persons.

HASSIM, HEYWOOD, and BERGER, Health \& Democracy, at 463. 
itself. Competition law comes into play when a company abuses its dominant position.

Section 8 of the Competition Act is the central provision dealing with abuse of dominance and reads as follows:

It is prohibited for a dominant firm to -

(a) charge an excessive price to the detriment of consumers;

(b) refuse to give a competitor access to an essential facility when it is economically feasible to do so;

(c) engage in an exclusionary act, other than an act listed in paragraph (d), if the anti-competitive effect of that act outweighs its technological, efficiency or other pro-competitive gain; or

(d) engage in any of the following exclusionary acts, unless the firm concerned can show technological, efficiency or other pro-competitive gains which outweigh the anti-competitive effect of its act-

(e) requiring or inducing a supplier or customer to not deal with a competitor;

(f) refusing to supply scarce goods to a competitor when supplying those goods is economically feasible;

(g) selling goods or services on condition that the buyer purchases separate goods or services unrelated to the object of a contract, or forcing a buyer to accept a condition unrelated to the object of a contract;

(h) selling goods or services below their marginal or average variable cost; or

(i) buying-up a scarce supply of intermediate goods or resources required by a competitor.

Moreover, section 1 of the Competition Act gives the definition of a number of terms used in the Act. Thus, the following actions could be recognised as abuse and are relevant for the issue of access to medicines: ${ }^{1531}$

\subsubsection{EXCESSIVE PRICING}

Section 8(a) of the Competition Act prohibits (pharmaceutical) corporations from charging excessive prices. The Competition Act defines an "excessive price" as a price for a good or service which bears no reasonable relation to the economic value of that good or service and is higher than the economic value of that good or service. ${ }^{1532}$

\subsubsection{REFUSING TO LICENCE GENERIC MANUFACTURERS}

Section $8($ b) of the Competition Act, states as an example of abuse of dominance, "refusing access to an essential facility when it is economically feasible to do so." The Competition Act defines an "essential facility" as an infrastructure or resource

1531 Ibid. at 464.

1532 Section 1(ix) Competition Act. 
that cannot reasonably be duplicated and without access to which competitors cannot reasonably provide goods or services to their customers. ${ }^{1533}$ Section 8(c) of the Competition Act prohibits engaging in an exclusionary act. An "exclusionary act" is defined as an action by for example a pharmaceutical corporation which impedes or prevents the entering into the market of a (generic) pharmaceutical manufacturer, or impedes or prevents a (generic) manufacture expanding within an existing market. ${ }^{1534}$

It has been argued that the refusal to grant a voluntary license to use, manufacture, import, sell etc. a patented pharmaceutical may in certain situations constitute an abuse of a dominant position. ${ }^{1535}$ For example it is suggested that an "essential facility" could include a voluntary license, because a generic pharmaceutical producer, which in all other respects could produce generic pharmaceuticals, could not do so without a license. ${ }^{1536}$ Furthermore, as the Patents Act allows the granting of compulsory licences under certain conditions, actions to obstruct the ordinary working of a compulsory license could be considered as "exclusionary acts". 1537

However, in general this is not the case: the right to refuse a license is seen as part of the right of exclusion inherent in IPRs. ${ }^{1538}$ Preventing the entry of competitors into a market is exactly what a patent aims to do. Such acts are acceptable if it can be shown that they are technological, efficiency or other procompetitive gains to be reached by acting in such a manner that, outweigh the anticompetitive effect. ${ }^{1539}$ In that sense, patents are by their very nature exclusionary, but they serve the purpose to induce innovation.

1533 Section 1(viii) Competition Act.

1534 Section 1(x) Competition Act.

1535 See further BROOK K. BAKER, 'Arthritic Flexibilities for Accessing Medicines: Analysis of WTO Action Regarding Paragraph 6 of the Doha Declaration on the TRIPS Agreement and Public Health', Indiana International \& Comparative Law Review, 14 (2003-2004), 613-715 at 683 et seq.

1536 HASSIM, HEYWOOD, and BERGER, Health \& Democracy, at 465. See also below the findings of the Competition Commission in the complaint by Hazel Tau v. GlaxoSmithKline and Boehringer Ingelheim.

1537 BERGER, 'Tripping over Patents: AIDS, Access to Treatment and the Manufacturing of Scarcity', at 203.

1538 GALLEGO, 'Intellectual Property Rights and Competition Policy', at 258.

The European Court of Justice has recognised that this right might be limited in exceptional circumstances in which access to the IPR is indispensable to compete in a secondary market, and where the refusal to license results in precluding the appearance of a new product for which there is potential consumer demand and which is not objectively justified. The idea behind this jurisprudence is that competition law based limitations to IPRs should be restricted to those cases in which the right holder's conduct runs contrary to the objective of promoting innovation. See for example European Court of Justice, Rte and Itp v Commission ("Magill"), 6 April 1995, C-241/91 \& C-242/91; European Court of Justice, Ims Health, 29 April 2004, C-418/01; European Court of Justice, Microsoft v Commission, 17 September 2007, T-201/04. 


\subsubsection{Competition Cases}

Section 8 of the Competition Act provides a range of regulatory tools to challenge various anticompetitive practices within the health and pharmaceutical sector. Especially when taking into account the constitutional recognition of the right to health and a right of access to medicines and the (positive) duties imposed on the South African government in that regard, these regulatory tools available under the Competition Act could, and to a certain extent have been employed to, ensure a sustainable supply of affordable medicines. This section will therefore address one case in which excessive pricing by a pharmaceutical company was challenged under the Competition Act. Unsurprisingly, the case did not make it to court, but was settled.

\subsubsection{Complaint to the Competition Commission by Hazel Tau v. GlaxoSmithKline and Boehringer Ingelheim}

In September 2002, as part of a national campaign to increase access to treatment for HIV/AIDS patients, a number of individuals and organisations lodged a complaint against two pharmaceutical companies, Boehringer Ingelheim (BI) and GlaxoSmithKline, arguing that they were abusing their dominant market position by charging excessive prices for their patented anti-retroviral medicines which could not be objectively justified even if taking into account the cost of research and development, production and an acceptable margin of profit. They stated that the respondents' actions were directly responsible for the "premature, predictable and avoidable loss of life." 1540 The Competition Commission examined the complaint, found evidence in support of it and, therefore, decided to refer the case to the Competition Tribunal. However, before the Tribunal could review the case it was resolved in an out-of-court settlement. The companies agreed to grant a voluntary license to competitors to produce and/or import generic anti-retroviral medicines and agreed that those generics that were produced locally could be sold throughout Africa. Thus, this created competition which in the end resulted in lower prices for anti-retroviral medicines. ${ }^{1541}$

The complainants acted under section 49B (2)(b) of the Competition Act which allows any person to "submit a complaint against an alleged prohibited practice to the Competition Commission in the prescribed form." 1542 Moreover, although the complaint was lodged under the Competition Act, the complainants referred to the broader context in the sense of the public health issues faced by South Africa, more specifically the HIV/AIDS epidemic, and the government's constitutional obligations regarding health and access to medicines. It must be mentioned that at

\footnotetext{
1540 See the Statement of Complaint in terms of Section 49B(2)b of the Competition Act No. 89 of 1998 to the South African Competition Commission by Hazel Tau and others v. GlaxoSmithKline and Boehringer Ingelheim of September 2002 at $\$ 107$.

1541 HASSIM, HEYWOOD, and BERGER, Health \& Democracy, at 464.

1542 Section 49B(2)(b) of the Competition Act.
} 
the time the complaint was brought, it was not possible to receive antiretroviral treatment within the public health sector in South Africa. ${ }^{1543}$ In that regard the complaint was directed at ensuring that people living with HIV/AIDS were able to receive the life-saving treatment they so desperately needed which was otherwise not available to them. ${ }^{1544}$ The complainants were cautious in making their complaint and focused solely on the issue of excessive pricing as prohibited under section 8(a) of the Competition Act. ${ }^{1545}$ The excessive pricing angle was complex and required a number of difficult issues to be addressed, such as defining the relevant market and the impact of patents on market definition and determining dominance within that relevant market. ${ }^{1546}$ In essence, the complainants believed that this tactic would be most successful in getting the pharmaceutical companies to take their complaint serious. The reason for this being that an excessive pricing claim could potentially lead to a forced public disclosure of costing models, having to demonstrate why and how the price for pharmaceutical products set by the respondents was justifiable and not an abuse of a dominant position. The complainants believed this would be something that the two pharmaceutical companies would try to avoid at all costs. Moreover a public disclosure of their costing models would most probably draw much public attention. As such, the complaint was also the basis for a larger nation-wide campaign on the issue. This tactic seems to have worked because the case was eventually settled. ${ }^{1547}$

Settlement negotiations with GSK started almost a year after the complaint was lodged, in September 2003. While BI was initially not interested, this changed in time due to a couple of events. Two non-profit organisations formally requested a compulsory license from BI under section 56 of the Patents Act to import into South Africa, and to use, offer to dispose of and dispose of in South Africa, and to export from South Africa, a by BI patented anti-retroviral medicine. ${ }^{1548}$ Moreover, the

1543 AVAFIA, BERGER, and HARTZENBERG, The Ability of Select Sub-Saharan African Countries to Utilise TRIPS Flexibilities and Competition Law to Ensure a Sustainable Supply of Essential Medicines, at 36. In general at that time there were three options for patients in South Africa to receive antiretroviral treatment:

- by privately purchasing the required medicines form pharmacies;

- via a medical scheme ("health insurance"); or

- via an employer funded workplace treatment programme for uninsured workers.

1544 Here it must be briefly mentioned that the term "availability" here is meant including "affordability" of (essential) medicines. See also chapter 3.

1545 See Statement of Complaint by Hazel Tau and others v. GlaxoSmithKline and Boehringer Ingelheim at $\S 17$.

1546 See Statement of Complaint by Hazel Tau and others v. GlaxoSmithKline and Boehringer Ingelheim at $\$ 53$ et seq.

1547 AVAFIA, BERGER, and HARTZENBERG, The Ability of Select Sub-Saharan African Countries to Utilise TRIPS Flexibilities and Competition Law to Ensure a Sustainable Supply of Essential Medicines, at 37-38.

1548 Ibid. at 38. Section 56(1) of the Patents Act reads as follows:

Any interested person who can show that the rights in a patent are being abused may apply to the registrar in the prescribed manner for a compulsory licence under the patent. 
Competition Commission, after conducting its investigation had found enough evidence to refer Hazel Tau's complaint to the Competition Tribunal. It concluded that GSK and BI had both abused their dominant position by: selling their patented products in South Africa at prices (between 5-15 times higher than that of generic equivalents) unaffordable to almost all South Africans living with HIV; refusing competitors access to their patents that were non-duplicable resources, which were necessary to enable the competitors to provide the medicines; and by impeding generic suppliers from entering the South African market for anti-retroviral medicines by refusing to grant licenses to generic manufacturers at reasonable royalty rates when there were no legitimate business reasons for such refusals and where the anti-competitive effects of the refusals significantly outweighed any technological, efficiency or other pro-competitive gains from the refusals. Consequently, they had engaged in practices restricted under the Competition Act, i.e. excessive pricing, denying a competitor access to an essential facility, and engaging in an exclusionary act. ${ }^{1549}$ The risk of this case possibly resulting in the grant of the first compulsory was a strong enough incentive for BI to join the settlement negotiations.

Thus, in December 2003, both companies entered into separate settlement agreements, opening up the market for these medicines to generic manufacturers. ${ }^{1550}$ The result was that for the first time generic versions of these patented antiretroviral pharmaceuticals were commercially available in South Africa. Considering the urgency of the matter, the fact that the public ARV treatment programme at that time was being finalised and it was essential to ensure a sustainable supply of affordable medicines, the decision to settle the case seems justified. ${ }^{1551}$

\subsubsection{Conclusion}

The interface between patent law and competition law is complex and competitive. Namely, patents are by definition anti-competitive. They grant the patent holder a monopoly position for a specific period. However, it is generally agreed that exercising patent rights does not lead to, within the scope of competition law, "anticompetitive" behaviour; and a patent holder would have to abuse its patent rights for competition law to come into play. ${ }^{1552}$ The nature and extent of the reach of

1549 See THE SOUTH AFRICAN COMPETITION COMMISSION, 'Commission Questions Conduct of Anti-Retroviral Companies', Competition News. The Official Newsletter of the Competition Commission, Edition 14 (2003).

1550 See THE SOUTH AFRICAN COMPETITION COMMISSION, 'GSK and BI Issue AntiRetroviral Licenses', Competition News. The Official Newsletter of the Competition Commission, Edition 15 (2004).

1551 AVAFIA, BERGER, and HARTZENBERG, The Ability of Select Sub-Saharan African Countries to Utilise TRIPS Flexibilities and Competition Law to Ensure a Sustainable Supply of Essential Medicines, at 40.

1552 BERGER, 'Tripping over Patents: AIDS, Access to Treatment and the Manufacturing of Scarcity', at 202; HASSIM, HEYWOOD, and BERGER, Health \& Democracy, at 462. 
competition law within the field of patent law is however still uncertain. ${ }^{1553}$ Yet, it is clear that in the field of patents for pharmaceuticals both the Patents Act as well as the Competition Act play a role and should therefore be read as complementary to each other. ${ }^{1554}$

For example, in the context of ensuring access to essential medicines developing members could introduce a competition law based compulsory licensing scheme. The advantage of this would be that under the TRIPS requirements it is not necessary to enter into prior negotiations, nor does the license need to be granted predominantly for the supply of the domestic market. In addition, the nature of the anti-competitive behaviour may be reflected in the decision on the amount of remuneration considered adequate. The South African Competition Act does not explicitly allow for the granting of a compulsory licence as a remedy to an anticompetitive practice. Yet, the broad authority to make "appropriate" orders under Section 58 of the Competition Act may, arguably, allow the Tribunal to recommend the granting of a compulsory licence. The final authority here lies with the Patents Commissioner under the Patents Act. The grant of a compulsory licensing as a remedy would be possible in a situation of abusive pricing, yet it would be questionable in situations in which an originator pharmaceutical corporation refuses to license a patented pharmaceutical since such a right to refuse a license is inherent in the protection patents grant. ${ }^{1555}$

What we have seen in South Africa is that the value of using competition law to enhance access to medicines lies in the incentive it provides for pharmaceutical corporations to negotiate voluntary licensing agreements, particularly once the Competition Commission's has found evidence of anti-competitive practices. See for example the Hazel Tau case. ${ }^{1556}$ Particularly, possibly being forced to publicly disclose their costing models in order to defend high medicine prices but also unfavourable findings of an independent adjudicator provides a strong incentive to settle out of court. Furthermore, the Competition Act allows a complaint to be submitted by any person, thus including civil society and health organisations. This was also the case in the Hazel Tau complaint which was submitted by a number of individual complainants including the Treatment Action Campaign. Consequently it is a particularly useful tool in situations in which the more traditional actors such as the government or the generic industry are unable or unwilling to act. ${ }^{1557}$

1553 AVAFIA, BERGER, and HARTZENBERG, The Ability of Select Sub-Saharan African Countries to Utilise TRIPS Flexibilities and Competition Law to Ensure a Sustainable Supply of Essential Medicines, at 32.

1554 BERGER, 'Tripping over Patents: AIDS, Access to Treatment and the Manufacturing of Scarcity', at 202.

1555 GALLEGO, 'Intellectual Property Rights and Competition Policy', at 258-259.

1556 Ibid. at 257.

1557 AVAFIA, BERGER, and HARTZENBERG, The Ability of Select Sub-Saharan African Countries to Utilise TRIPS Flexibilities and Competition Law to Ensure a Sustainable Supply of Essential Medicines, at 38-40. 
However, using competition law in such a manner is still novel and undeveloped. ${ }^{1558}$ Moreover, especially in countries where legal change is slow, legislation often only exists on paper and court processes are unduly timeconsuming and not very user-friendly, the successful implementation of competition legislation and policy will require the necessary political will and technical support. ${ }^{1559}$

\section{Conclusion: Striking a Balance?}

The research question addressed in this chapter is twofold. Firstly, has South Africa complied with its obligations under international human rights law by recognising a human right of access to medicines? South Africa indeed recognises a right of access to medicines through the incorporation of the right to health within its constitution, setting out clear obligations for the state in that regard. It has further implemented the right of access to medicines through the National Drug Policy and Essential Medicines List and the Medicines Act, granting broad powers to the Minister of Health to ensure medicines are accessible and affordable. In addition to legally recognising and implementing the right to health, the Constitutional Court has recognised the enforceable and justiciable nature of the right to health allowing individuals to approach the court system directly to hold the state responsible and seek redress in case their right to health or access to medicines is violated.

Secondly it was addressed in this chapter whether South Africa has complied with its obligations under the TRIPS Agreement to implement TRIPS' minimum standards and flexibilities with a view to balancing access and protecting patents. The South African Patents Act has implemented TRIPS standards with regard to patent protection and allows for the protection of patents granting the right holder a set of exclusive rights for a period of 20 years for inventions, including pharmaceuticals, if they are novel, involve an inventive step and capable of being used and applied in trade, industry or agriculture. The Patents Act, in combination with the Medicines Act, attempts to strike a balance by providing concrete measures for the state to adopt with a view to enhancing access to medicines, most notably the Bolar exception; ccompulsory licensing in situations where patent rights are abused; government use; and parallel importation. Thus it is clear that South Africa has implemented the TRIPS flexibilities according to the Doha Declaration within their legislative framework. Therefore, despite some shortcomings, the existing legal framework provides many opportunities for ensuring access to a sustainable supply of affordable medicines.

1558 HASSIM, HEYWOOD, and BERGER, Health \& Democracy, at 462.

1559 AVAFIA, BERGER, and HARTZENBERG, The Ability of Select Sub-Saharan African Countries to Utilise TRIPS Flexibilities and Competition Law to Ensure a Sustainable Supply of Essential Medicines, at 28. 
A clear lesson from the South African case study is the importance of civil society and health-advocacy groups in ensuring state compliance with their constitutional obligations and employing, sometimes innovative, regulatory tools to enhance adequate access to affordable medicines. ${ }^{1560}$ Particularly, the use of judicial mechanisms by civil society has led to tangible results. See for example the TAC and Hazel Tau cases; both cases were initiated by South African based health NGOs. By employing human rights language to the issue of access to medicines and patent protection, the TAC succeeded in making real changes in South Africa and changing the discourse with respect to the interface between patents and human rights not only in South Africa but worldwide. ${ }^{1561}$ Furthermore, the Hazel Tau case demonstrates the usefulness of competition law in enhancing access to medicines. In the context of South Africa, it might even be the most valuable tool for civil society to ensure the affordability of medicines.

1560 See also UN HUMAN RIGHTS COUNCIL, Implementation of General Assembly Resolution 60/251 of 15 March 2006 Entitled "Human Rights Council". Report of the Special Rapporteur on the Right of Everyone to the Enjoyment of the Highest Attainable Standard of Physical and Mental Health, Paul Hunt (UN Doc. A/HRC/4/28; 2007).

1561 DUNCAN MATTHEWS, The Right to Health and Patents, Queen Mary University of London, School of Law, Legal Studies Research Paper No. 156/2013, (2013) at 13. 


\section{Chapter 7 \\ Access to Medicines in India}

\section{INTRODUCTION}

The second country study conducted in this research is on India. India is classified as a lower middle income country with a GNI per capita of US\$ 1,330 (2010); 1562 it has a poverty headcount ratio of $37.2 \%$ of the population, life expectancy of 65 years, and a under-five mortality rate of 63. India is a WTO member since 1 January 1995. ${ }^{1563}$ Although still a developing country, India is an up-and-coming economic power house. For years it has made use of the lack of (product) patent protection for pharmaceuticals to copy and produce pharmaceuticals, resulting in it now being one of the largest producers and exporters of generic medicines. However, the end of the transitional periods of the TRIPS Agreement for India in 2005 has lead to significant changes in its patent law. In implementing its TRIPS obligations in several instances it has tried to make use of the flexibilities available, such as for example section $3 \mathrm{~d}$ of its Patents Act, which attempts to prevent ever-greening. ${ }^{1564}$ Moreover, although the Indian Constitution protects health as a non-justiciable directive principle of state policy, its extremely progressive judiciary has interpreted the right to life to include health rights, indirectly making it a justiciable right.

The aim of this country study is to examine whether India has complied both with its obligations under international human rights law and the TRIPS Agreement with a view to achieving a balance between access to medicines and patent protection. Firstly, this chapter will take a closer look at the problem of lack of access to medicines in India (section 2). Thereafter, the question is posed whether India has complied with its obligation under international human rights law with respect to guaranteeing access to affordable medicines by examining the constitutional and legislative framework (section 3); and whether, and to what extent, it has implemented TRIPS' patent standards and flexibilities (section 4). In addition, TRIPS-plus developments are also briefly touched upon (section 5) before, finally, posing the essential question, namely whether India has been able to strike a balance between protection of patents for pharmaceuticals and access to such pharmaceuticals (section 6).

\footnotetext{
1562 See http://data.worldbank.org/country/india?display=graph last accessed 27 October 2011.

1563 See www.wto.org/english/thewto_e/whatis_e/tif_e/org6_e.htm.

1564 With "ever-greening" is referred to the practice of the pharmaceutical industry to effectively extend the term of protection for patented pharmaceuticals by obtaining related patents for minor modifications made to the original product, new delivery systems for the pharmaceuticals, or new uses of the pharmaceutical etc.
} 


\section{The Generic Pharmaceutical Industry and Access to Medicines}

This section aims to provide the contextual framework within which to place the analysis of the research questions. India is an interesting country study in that it capitalised on not having a patent system for pharmaceutical products. As a result, it has a strong generic pharmaceutical industry which manufactures generic versions of a wide range of pharmaceutical products both for domestic use and exportation. As such, is it also termed the "pharmacy of the poor". On the other hand one should not lose sight of the fact that India is still developing as a country and many of its citizens live in extreme poverty. It is estimated that 800 million Indians live on less than two US dollars a day. Unfortunately, most of these people do not have a safety net to catch them if hit by hard times. Moreover, India's health care system has proved to be ineffective and been described as "operating in a state of perpetual crisis." 1565 The Committee on Economic, Social and Cultural Rights has expressed its concern that India's universal health-care scheme falls short of providing for universal coverage, excluding a significant proportion of the Indian population. ${ }^{1566}$ According to the Federation of Indian Chambers of Commerce and Industry, less than $15 \%$ of India's population has any kind of health-care cover. ${ }^{1567}$ In addition, it is estimated that in India between $50-65 \%$ of the people do not have regular access to essential medicines. ${ }^{1568}$

According to data of the World Bank, India is classified as a lower middle income country with a GNI per capita of US\$1,330 (2010): ${ }^{1569}$ it has a poverty headcount ratio of $37.2 \%$ of the population, life expectancy of 65 years, and an under-five mortality rate of 63 . Furthermore:

- Health expenditure per capita:1570 US\$44.8 compared to a global health expenditure per capita of US\$863.6 (2009). ${ }^{1571}$

1565 JANICE M. MUELLER, 'The Tiger Awakens: The Tumultuous Transformation of India's Patent System and the Rise of the Indian Pharmaceutical Innovation', University of Pittsburgh Law Review, 68 (2007), 491-641 at 543.

1566 CESCR, Consideration of Reports Submitted by States Parties under Articles 16 and 17 of the ICESCR. Concluding Observations: India (UN Doc. E/C.12/IND/CO/5; 2008) at 338 .

1567 'India Tries to Break Cycle of Health-Care Debt', Bulletin of the World Health Organisation, 88:7 (2010), 486-487.

1568 CHAUDHURI, The WTO and India's Pharmaceuticals Industry, at 222, 257 et seq. See for more information ORGANISATION OF PHARMACEUTICAL PRODUCERS OF INDIA, Commemorative Publication. Improving Access, Innovation \& Reach of Healthcare in India, OPPI, (2012).

1569 See http://data.worldbank.org/country/india?display=graph last accessed 27 October 2011.

1570 Total health expenditure is the sum of public and private health expenditures as a ratio of total population. It covers the provision of health services (preventive and curative), family planning activities, nutrition activities, and emergency aid designated for health but does not include provision of water and sanitation. Data are in current U.S. dollars.

1571 See http://data.worldbank.org/indicator/SH.XPD.PCAP/countries/1W-IN?display=graph last accessed 27 October 2011. 
- Public health expenditure as percentage of total health expenditure: $157232.8 \%$ compared to the global rate of $60.8 \%$ (2009). ${ }^{1573}$

- Total health expenditure as a percentage of the GDP: $15744.2 \%$ compared to the global rate of $10 \%$ (2009). ${ }^{1575}$

- Maternal mortality ratio::1576 230 compared to the global ratio of 260 (2008). ${ }_{1577}$

- The infant mortality rate: ${ }^{1578} 48.2$ compared to the global ratio of 41 (2010). ${ }^{1579}$

- The out-of-pocket health expenditure as a percentage of private expenditure on health: ${ }^{1580} 74.4 \%$ compared to the global rate of $46.2 \%$ (2009). ${ }^{1581}$

- Prevalence of HIV as a percentage of total population: ${ }^{1582} 0.3 \%$ compared to the global rate of $0.8 \%$ (2009). ${ }^{1583}$

1572 Public health expenditure consists of recurrent and capital spending from government (central and local) budgets, external borrowings and grants (including donations from international agencies and nongovernmental organizations), and social (or compulsory) health insurance funds. Total health expenditure is the sum of public and private health expenditure. It covers the provision of health services (preventive and curative), family planning activities, nutrition activities, and emergency aid designated for health but does not include provision of water and sanitation.

1573 See http://data.worldbank.org/indicator/SH.XPD.PUBL/countries/1W-IN?display=graph last accessed 27 October 2011.

1574 Total health expenditure is the sum of public and private health expenditure. It covers the provision of health services (preventive and curative), family planning activities, nutrition activities, and emergency aid designated for health but does not include provision of water and sanitation.

1575 See http://data.worldbank.org/indicator/SH.XPD.TOTL.ZS/countries/1W-IN?display=graph last accessed 27 October 2011.

1576 Maternal mortality ratio is the number of women who die during pregnancy and childbirth, per 100,000 live births. The data are estimated with a regression model using information on fertility, birth attendants, and HIV prevalence.

1577 See http://data.worldbank.org/indicator/SH.STA.MMRT/countries/1W-IN?display=graph last accessed 27 October 2011.

1578 Infant mortality rate is the number of infants dying before reaching one year of age, per 1,000 live births in a given year.

1579 See http://data.worldbank.org/indicator/SP.DYN.IMRT.IN/countries/1W-IN?display=graph last accessed 27 October 2011.

1580 Out of pocket expenditure is any direct outlay by households, including gratuities and in-kind payments, to health practitioners and suppliers of pharmaceuticals, therapeutic appliances, and other goods and services whose primary intent is to contribute to the restoration or enhancement of the health status of individuals or population groups. It is a part of private health expenditure.

1581 See http://data.worldbank.org/indicator/SH.XPD.OOPC.ZS/countries/1W-IN?display=graph last accessed 27 October 2011.

1582 Prevalence of HIV refers to the percentage of people ages 15-49 who are infected with HIV.

1583 See http://data.worldbank.org/indicator/SH.DYN.AIDS.ZS/countries/1W-IN?display=graph last accessed 27 October 2011. 
- Patent applications by non-residents: ${ }^{1584} 23,626$ (2006). ${ }^{1585}$

- Patent applications by residents: 5,314 (2006). ${ }^{1586}$

The situation in India regarding the patenting of pharmaceutical products is of international importance, because India has emerged as a global source of low cost medicines. ${ }^{1587}$ This is due to the fact that the 1970 Patents Act did not allow for the patenting of pharmaceuticals in India, enabling pharmaceutical companies to copy and produce many of the pharmaceuticals patented in developed countries. With the ending of the TRIPS' transitional periods in 2005, India has had to make some radical changes to its patent system, in particular introducing product patents for pharmaceutical products. The effect of the introduction of a product patent system on medicine prices is still inconclusive. It is argued that the introduction of product patents for pharmaceuticals will likely increase average medicine prices, although the extent to which product patents increase prices can vary significantly. Chaudhuri concludes that the consumer welfare loss of introducing product patent protection will be substantial. ${ }^{1588}$

Additionally, there are different views on whether India's introduction of a stronger patent regime will benefit or hurt India's pharmaceutical industry. ${ }^{1589}$ This is partly due to the fact that the structure of India's pharmaceutical industry is extremely fragmented. In its simplest form the Indian pharmaceutical industry can be divided into two major groups: foreign multinational corporations (MNCs), and the domestic (Indian-owned) corporations. India is one of the few countries where

1584 Patent applications are worldwide patent applications filed through the Patent Cooperation Treaty procedure or with a national patent office for exclusive rights for an invention - a product or process that provides a new way of doing something or offers a new technical solution to a problem. A patent provides protection for the invention to the owner of the patent for a limited period, generally 20 years.

1585 See http://data.worldbank.org/indicator/IP.PAT.NRES/countries/1W-IN?display=graph last accessed 27 October 2011.

1586 See http://data.worldbank.org/indicator/IP.PAT.RESD/countries/1W-IN?display=graph last accessed 27 October 2011.

1587 RADHIKA BHATTACHARYA, 'Are Developing Countries Going Too Far on TRIPS? A Closer Look at the New Laws in India', American Journal of Law \& Medicine, 34 (2008), 395421 at 396; CHAUDHURI, The WTO and India's Pharmaceuticals Industry, at 223.

1588 CHAUDHURI, The WTO and India's Pharmaceuticals Industry, at 226-227.

1589 MUELLER, 'The Tiger Awakens', at 532. See for example PRESS INFORMATION BUREAU OF THE GOVERNMENT OF INDIA, 'Minister of Commerce and Industry Kamal Nath's Statement on the Ordinance Relating to Patents (Third) Amendment', $<$ http://pib.nic.in/newsite/ erelease.aspx?relid=6074>, accessed 30 April 2012. Here he stated that the amendment of the Patents Act would provide for an "enabling environment" for the pharmaceutical industry. In addition, he asserted that the fear that medicine prices would rise was unfounded. For more information see SAJEEV CHANDRAN, ARCHNA ROY, and LOKESH JAIN, 'Implications of New Patent Regime on Indian Pharmaceutical Industry: Challenges and Opportunities', Journal of Intellectual Property Rights, 10 (2005), 269-280. 
domestic corporations dominate the pharmaceutical market as opposed to the foreign-owned multinationals. ${ }^{1590}$

Historically, MNCs did not have a strong position in the Indian market, due to the weak patent protection system, government price controls and other restrictions regarding their activities in India. The change in its patent system (due to the TRIPS Agreement) has therefore made India a far more investment worthy market. Now there are a multitude of MNCs with subsidiaries in India. Also as a result of a highly skilled workforce and relatively low cost labour, these corporations have been able to successfully conduct a wide variety of drug manufacturing activities. The MNCs, which are organised in two trade groups, the Indian Pharmaceutical Association (IPA) and the Organisation of Pharmaceutical Producers of India (OPPI), were also at the forefront in demanding stronger patent protection while India was implementing the TRIPS Agreement. ${ }^{1591}$

In addition to these MNCs, a wide range of domestic firms are also active within India's pharmaceutical market and it is this domestic sector which is highly fragmented. ${ }^{1592}$ A number of larger Indian corporations conduct innovative research and development into new pharmaceutical products, in addition to manufacturing generic medicines. A multitude of smaller Indian firms concentrate on generic manufacturing of pharmaceuticals through reverse-engineering pharmaceuticals off-patent in India (many of which are patented in other countries), or they primarily produce bulk pharmaceuticals (that is the active ingredients needed for the manufacturing of a medicine). ${ }^{1593}$ The main major Indian corporations are: Ranbaxy Laboratories Ltd., Cipla Ltd., and Dr. Reddy's Laboratories Ltd., which are developing significant independent research and development capacity. Moreover, since the end of the 1980s, both the larger as well as the smaller domestic pharmaceutical corporations have been exporting pharmaceuticals to a wide range of markets. As opposed to the stance of the MNCs, many Indian-owned pharmaceutical corporations, organised through the Indian Drug Manufacturers' Association, opposed the patent reforms. However, those Indian firms with growing R\&D capacity took a less opposing stance towards the strengthening of the patent regime. ${ }^{1594}$ This reflects the fragmented character of the Indian pharmaceutical sector. It is, therefore, also too simplistic to regard the debate on strengthening of the Indian patent system as merely two-sided: the MNCs opposing the domestic corporations.

Although it is true that the changes to the patent system will have, and has already had, an effect on the Indian generic pharmaceutical sector, it seems unrealistic and overdramatic to assume that it will wipe-out generic manufacturing

\footnotetext{
1590 MUELLER, 'The Tiger Awakens', at 533.

1591 Ibid. at 534-535.

1592 Ibid. at 536.

1593 Ibid. at 537, 539.

1594 Ibid. at 539-540.
} 
in India. ${ }^{1595}$ It has been argued that the new patent regime will lead to increasing levels of FDI and force Indian pharmaceutical corporations to invest in growing their innovative R\&D capacity. ${ }^{1596}$ In the long term this could prove to be the best strategy as long as the patent system finds a balance between promoting innovation through IPRs while ensuring that social and public health needs are taken into account. ${ }^{1597}$ On the other hand, it has been argued that the anticipated benefit of the introduction TRIPS' standards in India has not provided an incentive to local companies to invest resources $\mathrm{R} \& \mathrm{D}$ for medicines more suited to the needs of developing countries. ${ }^{1598}$

\section{A Human Right of Access to Medicines?}

This chapter first intends to identify whether India has complied with its obligations, under international human rights law with respect to ensuring that individuals have access to affordable medicines. It is bound by international human rights law, particularly the ICESCR, ${ }^{1599}$ the Convention on the Rights of the Child, the Convention on the Elimination of All Forms of Discrimination against Women, and customary law. Consequently, the question addressed here is whether India has complied with its obligations under international human rights law with respect to the right of access to medicines within their constitutional and legislative framework.

\subsection{The Indian Constitution of 1949}

The Constitution of India was enacted by the Constituent Assembly on 26 November 1949 and came into force on 26 January 1950, proclaiming India to be a sovereign, democratic Republic. It contained the founding principles of the law of the land which would govern India after its independence from British rule. The Indian Constitution lays down the framework defining fundamental political principles, establishes the structure, procedures, powers, and duties of government

1595 See further CARSTEN FINK, 'Patent Protection, Transnational Corporations and Market Structure: A Simulation Study of the Indian Pharmaceutical Industry', in Carsten Fink and Keith E. Maskus (eds.), Intellectual Property and Development. Lessons from Recent Economic Research (New York: The World Bank - Oxford University Press, 2005).

1596 RAJNISH KUMAR RAI, 'Effect of the TRIPS-Mandated Intellectual Property Rights on Foreign Direct Investment in Developing Countries: A Case Study of the Indian Pharmaceutical Industry', The Journal of World Intellectual Property, 11:5/6 (2009), 404-431 at 423.

1597 AMY KAPCZYNSKI, 'Harmonisation and Its Discontents: A Case Study of TRIPS Implementation in India's Pharmaceutical Sector', California Law Review, 97 (2009), 1571-1650 at 1583-1584; MUELLER, 'The Tiger Awakens', at 541.

1598 See further CHAUDHURI, Is Product Patent Protection Necessary in Developing Countries for Innovation?, at 6 et seq.

1599 India acceded to the ICESCR on 10 April 1979. 
institutions, and sets out fundamental rights, directive principles, and the duties of citizens. It was amended several times. The Indian Constitution is the supreme law of the land and, as stated in its preamble, resolves to ensure the welfare of the Indian people and bring about social justice. ${ }^{1600}$ As such, the Constitution contains a range of rights, both civil and political rights, and economic and social rights. All laws must be in accordance with the Constitution and any law which is inconsistent with, or derogates from the fundamental rights protected by the Constitution is void. 1601

As a dualist country, treaties and international agreements are not enforceable in India until they have been transformed into domestic law. ${ }^{1602}$ The Supreme Court, however, has invoked international human rights instruments in its jurisprudence and as such, has stated that these international human rights instruments can be read to expand the fundamental rights protected by the Indian Constitution. ${ }^{1603}$ Moreover, the 1993 Protection of Human Rights Act (amended last by the Protection of Human Rights (Amendment) Act No. 43 of 2006) establishes a National and State Human Rights Commission(s) with a view to better protect human rights, meaning here the rights relating to life, liberty, equality and dignity of the individual guaranteed by the Constitution or embodied in international conventions and enforceable by the courts. ${ }^{1604}$

The Indian Constitution does make a distinction between civil and political rights on the one hand and socio-economic rights on the other. Part III is titled Fundamental Rights, including the traditional civil and political rights such as the right to life ${ }^{1605}$ and the right to equality. ${ }^{1606}$ These fundamental rights are directly enforceable and justiciable before a court of law. ${ }^{1607}$ Economic and social rights, on the other hand, are incorporated in Part IV as Directive Principles of State Policy (hereinafter DPSP). Article 37 states that these DPSP "shall not be enforceable by any court" but are, nevertheless, fundamental in the governance of the country.

\footnotetext{
1600 JULIE GEORGE, India Position Paper, Lawyers Collective HIV/AIDS Unit, (2010) at 1.

1601 Article 13 of the Constitution.

1602 Article 253 of the Constitution:

Notwithstanding anything in the foregoing provisions of this Chapter, Parliament has power to make any law for the whole or any part of the territory of India for implementing any treaty, agreement or convention with any other country or countries or any decision made at any international conference, association or other body.

GEORGE, India Position Paper, at 2. See for example Indian Supreme Court, Vishaka and Ors. v. State of Rajasthan, 13 August 1997, 6 SCC 241.

1604 See section 2(d) of the Protection of Human Rights Act.

1605 See article 21 of the Constitution, which reads: No person shall be deprived of his life or personal liberty except according to procedure established by law.

1606 Article 14 of the Constitution.

1607 See article 32 of the Constitution.
} 
Article 38 reaffirms it is the state's duty to strive to promote the welfare of the Indian people by securing and protecting a social order of justice. ${ }^{1608}$

The Indian Constitution expressly protects public health in article 47 of the DPSP, ${ }^{1609}$ which reads:

The State shall regard the raising of the level of nutrition and the standard of living of its people and the improvement of public health as among its primary duties. ${ }^{1610}$

As stated above, article 37 of the Constitution precludes the justiciability of these DPSP. The Supreme Court has, however, found a way around that by interpreting the right to health as forming part of the right to life protected under article 21, making it directly enforceable and justiciable. ${ }^{1611}$ Therefore, the following section will address a number of health-related cases to examine whether such an implied right to health would guarantee access to affordable medicines in line with ICESCR's obligations.

The court-system in India deals with an extremely high case load; for example since the 1950s the Supreme Court has dealt with more than a million cases, only a fraction of which concern the right to health and even fewer access to medical treatment. ${ }^{1612}$ One reason for such a low caseload could be that up until now generic medicines in India are relatively inexpensive. However, with the end of TRIPS' transitional periods, increased patenting of medicines and possible higher prices, litigation on access to medicines might increase in the next decade. ${ }^{1613}$

1608 Artice 38 of the Constitution:

(1) The State shall strive to promote the welfare of the people by securing and protecting as effectively as it may a social order in which justice, social, economic and political, shall inform all the institutions of the national life.

(2) The State shall, in particular, strive to minimise the inequalities in income, and endeavour to eliminate inequalities in status, facilities and opportunities, not only amongst individuals but also amongst groups of people residing in different areas or engaged in different vocations.

1609 See also article 39e \& f and 42 of the DPSP in Part IV of the Constitution.

1610 Article 47 of the Constitution continues stating that the state shall particularly endeavour to bring about prohibition of the consumption except for medicinal purposes of intoxicating drinks and of drugs which are injurious to health.

1611 MANOJ KUMAR SINHA, Enforcement of Economic, Social and Cultural Rights. International and National Perspectives (New Delhi: Manak Publications, 2006) at 166-167.

1612 SHYLASHRI SHANKAR and PRATAP BHANU MEHTA, 'Courts and Socioeconomic Rights in India', in Varun Gauri and Daniel M. Brinks (eds.), Courting Social Justice. Judicial Enforcement of Social and Economic Rights in the Developing World (New York: Cambridge University Press, 2008) at 152-153.

1613 Ibid. at 158. 


\subsection{Cases before the Supreme Court}

An important element in the enhancement of protecting socio-economic rights in India was the Public Interest Litigation Movement. ${ }^{1614}$ India's internal problems in the mid 1970s, which led to widespread human rights violations, resulted in a change of perception by the judiciary in the working of the Constitution. The judiciary acknowledged that the individualistic and adversarial nature of the existing system of litigation was ill-suited to the demands of the most vulnerable. ${ }^{1615}$ Consequently, at the end of the 1970s the Supreme Court used its constitutional powers $^{1616}$ to initiate a movement towards PIL; a movement which was completely judge-led and judge-dominated. ${ }^{1617}$ Furthermore, courts started incorporating socio-economic elements, such as health, food, education, and shelter, into the fundamental rights of equality (article 14) and life and liberty (article 21), thus in effect recognising the justiciability of socio-economic rights incorporated in the DPSP. 1618

The judiciary considered PIL to provide the solution for many problems within the working of the Indian legal system. ${ }^{1619}$ It, firstly, expanded the definition of standing to allow any individual to bring forth a case before the High Courts or Supreme Court, even if that individual was not seeking any relief but acting on behalf or for the benefit of an indeterminate group of people. Secondly, it was no longer required to bring a formal petition, written in legal language, before the court; now any letter addressed to the Court would suffice. Thirdly, irrespective of how brief the facts of the case, the Court will proceed with the case as long as it is one of genuine public interest. Additionally, the Court may appoint socio-legal commissions to gather and verify information. ${ }^{1620}$ Furthermore, the Supreme Court has been able to frame uniquely suited judicial remedies, often containing detailed enforcement mechanisms. ${ }^{1621}$

1614 S. MURALIDHAR, 'Judicial Enforcement of Economic and Social Rights: The Indian Scenario', in Fons Coomans (ed.), Justiciability of Economic and Social Rights. Experiences from Domestic Systems. (Antwerpen/Oxford: Intersentia, 2006) at 240.

1615 SHEETAL B. SHAH, 'Illuminating the Possible in the Developing World: Guaranteeing the Human Right to Health in India', Vanderbilt Journal of Transnational Law, 32 (1999), 436-485 at 467.

1616 See article 32 of the Constitution.

1617 MURALIDHAR, 'Judicial Enforcement of Economic and Social Rights: The Indian Scenario', at 240; SHAH, 'Illuminating the Possible in the Developing World: Guaranteeing the Human Right to Health in India', at 467-469.

1618 SHANKAR and MEHTA, 'Courts and Socioeconomic Rights in India', at 149.

1619 MURALIDHAR, 'Judicial Enforcement of Economic and Social Rights: The Indian Scenario', at 241.

1620 Ibid; SHAH, 'Illuminating the Possible in the Developing World: Guaranteeing the Human Right to Health in India', at 469-471.

1621 SHAH, 'Illuminating the Possible in the Developing World: Guaranteeing the Human Right to Health in India', at 471. 
The Supreme Court's most innovative step in protecting socio-economic rights is its recognition of the justiciability of socio-economic rights. ${ }^{1622}$ The Supreme Court was initially conservative in its interpretation of the DPSP. ${ }^{1623}$ This changed in the 1970s when it decided that the fundamental rights under the Constitution and the DPSP were complementary. ${ }^{1624}$ Furthermore, the Supreme Court, through creative interpretation, expanded the fundamental right to life, which traditionally entails an obligation for the state to abstain from interfering with an individual's right to life and liberty, to include positive obligations for the state. ${ }^{1625}$ It has, thus, overcome the objections raised against the justiciability of socio-economic rights. ${ }^{1626}$ The Supreme Court continued on this path and creatively interpreted the right to life to include "the right to live with human dignity and all that goes with it, namely, the bare necessities of life such as adequate nutrition, clothing and shelter and facilities for reading, writing and expressing oneself in diverse forms, freely moving about and mixing and commingling with fellow human beings". ${ }^{627}$

One of the first cases in which the Supreme Court explicitly recognised the right to health (in this case of a worker) to be an integral part of a meaningful right to life is the Consumer Education and Research Centre v. Union of India ${ }^{1628}$ case. In subsequent cases the Supreme Court has expanded the fundamental right to life obliging the state to create the conditions necessary to ensure good health. In that regard an important judgment relating to the right to health is the PIL case of Paschim Banga Khet Samity v. State of West Bengal. ${ }^{1629}$ In that case an agricultural labourer fell of a train and seriously injured his head. In seeking treatment he was refused at seven state-run hospitals due to a lack of the necessary facilities for treating this type of injury, or because of a lack of vacant beds. The Supreme Court had to address the question whether this non-availability of facilities for emergency medical treatment resulted in a breach of his fundamental right to life guaranteed under Article 21 of the Constitution. ${ }^{1630}$ The Supreme Court first stated that the Constitution envisaged the establishment of a welfare state both on a federal and state level, where the state has the primary duty to secure the welfare of the people, including the provision of adequate medical facilities. It further stated that the

1622 Ibid. at 474.

1623 MURALIDHAR, 'Judicial Enforcement of Economic and Social Rights: The Indian Scenario', at 239; SINHA, Enforcement of ESC Rights, at 167.

1624 Indian Supreme Court, Kesavananda Bharati v. State of Kerala, 1973, 4 SCC 225.

1625 SHAH, 'Illuminating the Possible in the Developing World: Guaranteeing the Human Right to Health in India', at 475.

1626 MURALIDHAR, 'Judicial Enforcement of Economic and Social Rights: The Indian Scenario', at 240 .

1627 Indian Supreme Court, Francis Coralie Mullin v. The Administrator, Union Territory of Delhi, 1981, 2 SCR 516 at $\$ 6$.

1628 Indian Supreme Court, Consumer Education and Research Centre v. Union of India, 1995, 3 SCC 42 at $\$ 26$.

1629 Indian Supreme Court, Paschim Banga Khet Samity v. State of West Bengal, 1996, 4 SCC 37.

1630 Ibid. at $\$ 4$. 
preservation of human life is of paramount importance and that under article 21 the state had an obligation to safeguard the right to life of every person. ${ }^{1631}$ Thus, it re-conceptualised the right to life to impose a positive duty on the state. ${ }^{1632}$ In the present case the labourer's right to life under article 21 of the Constitution had been violated and he was awarded compensation by way of redress. ${ }^{1633}$ In addition, the Supreme Court ordered a number of remedial measures to prevent the recurrence of such incidents in the future. ${ }^{1634}$ In Paschim Banga Khet Samity v. State of West Bengal the Supreme Court seems, although implicitly, to recognise that emergency medical treatment is part of the minimum core content of the right to health. ${ }^{1635}$ It acknowledged that financial resources were required to provide adequate facilities, but at the same it could not be ignored that the state had a constitutional obligation to provide adequate medical services to the Indian people. It reaffirmed that the state could not avoid its constitutional obligations due to resource constraints. ${ }^{1636}$

Concerning the issue of resource constraints, in State of Punjab v. Ram Lubhaya Bagga, ${ }^{1637}$ the Supreme Court had to address the question whether the state's new policy, which reduced government employees' entitlement to reimbursement of medical expenses incurred in a non-governmental hospital, violated article 21 of the Indian Constitution. The State of Punjab argued that the reduction in entitlements to medical care was justified by financial constraints. It argued that no right under the Constitution is absolute and that the right to life has to be balanced with the need and resources available. The Supreme Court firstly acknowledged the principle of separation of powers stating that in questioning the validity of government policy it is not within the domain of any court to weigh the pros and cons of such policy, except where it is arbitrary or in violation of any constitutional, statutory or other provision of law. It further stated that article 21 and 47 of the Constitution involve a primary duty for the state to secure the health of its citizens and that fulfilling this duty will require financial resources. However, it went on to state that:

1631 Ibid. at $\$ 9$.

1632 BYRNE, 'Making the Right to Health a Reality: Legal Strategies for Effective Implementation', at 16.

1633 Paschim Banga Khet Samity v. State of West Bengal, at $\$ 9$.

1634 Ibid. at \$15; BYRNE, 'Making the Right to Health a Reality: Legal Strategies for Effective Implementation', at 17.

1635 MURALIDHAR, 'Judicial Enforcement of Economic and Social Rights: The Indian Scenario', at 245 .

1636 The Indian Supreme Court, by referring to another case, further stated that: "Whatever is necessary for this purpose has to be done. In the context of the constitutional obligation to provide free legal aid to a poor accused this Court has held that the State cannot avoid its constitutional obligation in that regard on account of financial constraints. (See Khatri (II) $v$. State of Bihar (1981) 1 SCC 627, at 631). The said observations would apply with equal, if not greater, force in the matter of discharge of constitutional obligation of the State to provide medical aid to preserve human life." Paschim Banga Khet Samity v. State of West Bengal, at $\$ 16$.

1637 Indian Supreme Court, State of Punjab v. Ram Lubhaya Bagga, 1998, 4 SCC 117, 130. 
No State of any country can have unlimited resources to spend on any of its projects. That is why it only approves its projects to the extent it is feasible. The same holds good for providing medical facilities to its citizen including its employees. Provision of facilities cannot be unlimited. It has to be to the extent finance permits.

Thus, the Supreme Court accepted the state's justification of resource constraints and held that the new policy did not breach article 21 . The right to health could not be absolute in a welfare state. It, herewith, extended the state's margin of appreciation. ${ }^{1638}$ Although the Supreme Court in previous cases has stated that "whatever is necessary [...] has to be done"1639, it is does not consider the right to health to be absolute. It is probably better to state that arguing resource constraints is not a legitimate excuse for the government to discharge its constitutional obligations. However, just as in the South African legal system, the Indian Supreme Court will take account of the available resources for realising socio-economic rights and grant the state a margin of appreciation in achieving these rights.

Finally, with respect to the question whether an implied right to health would guarantee access to affordable medicines in line with ICESCR's obligations, it must be first noted that the Supreme Court's broad interpretation of the fundamental right to life and its emphasis on health as the foundation for a meaningful life with dignity would seem to include access to medicines. This would be especially true for access to essential, life-saving medicines, which are a prerequisite for a healthy life with dignity. Furthermore in a PIL case, Vincent Panikurlangara v. Union of India,${ }^{1640}$ in which the Supreme Court was asked to ban a number of hazardous drugs, it held that maintenance and improvement of public health is an important obligation for the state as this is indispensable to the very physical existence of the community. It stated that the state has an obligation to ensure that medicines are available at reasonable prices, so as to be within the common man's reach. Moreover, the Allahabad High Court has also recognised the importance of protecting patients' access to reasonably priced medicines. ${ }^{1641}$

\subsection{Conclusion}

The research question addressed in this section is whether India has complied with its obligations under international human rights law by recognising a right of access

1638 MURALIDHAR, 'Judicial Enforcement of Economic and Social Rights: The Indian Scenario', at 245 .

1639 Paschim Banga Khet Samity v. State of West Bengal, at $\$ 16$.

1640 Indian Supreme Court, Vincent Panikurlangara v. Union of India, 1987, 2 SCC 165.

1641 Allahabad High Court, Prayag Vyapar Mandal and Others v. State of Uttar Pradesh and Others, 12 April 1996. This case concerned a petition to prohibit the establishment of a pharmacy within the hospital to provide patients with medicines at all hours. It was found that the nearest pharmacy was not open 24 hours and charged excessively high prices. The Court dismissed the petition, because it considered the petition to be brought with malafide intentions, for the petitioners personal rather than for the public interest. 
to medicines within their constitutional and legislative framework. The Indian Constitution states that the improvement of public health is among the state's primary duties, however, it considers this duty to be a Directive Principle of State Policy. This would lead to the conclusion that the Indian state does not recognise the right to health and access to medicines as a justiciable and enforceable human right. However, the Supreme Court expanded the fundamental right to life, which traditionally entails an obligation for the state to abstain from interfering with an individual's right to life and liberty, to include positive obligations for the state also with respect to access to medicines. It has, furthermore, issued instructions to the government to fulfil its obligations under the Indian Constitution. ${ }^{1642}$ Although the Supreme Court has been progressive when interpreting the right to life to include socio-economic rights, in State of Punjab v. Ram Lubhaya Bagga, it did acknowledge the principle of separation of powers and accepted that resources are not unlimited and that, therefore, the right to health could not be considered absolute. ${ }^{1643}$ Consequently, the Supreme Court has played a crucial role in acknowledging the justiciability and enforceability of the right to health; even though the right to health, which is protected as a DPSP in the Indian Constitution, is formally considered non-justiciable. ${ }^{1644}$ Consequently, it is argued that the right to health - and as such also a right of access to essential medicines - is now considered a fundamental right under the Indian Constitution allowing individuals to turn to the Indian courts in order to challenge state actions that violate their rights. ${ }^{1645}$ On the other hand, the CESCR has expressed its concern that despite the progressive approach of the Supreme Court "the [ICESCR] is not given its full effect in the legal system of the State party due to the absence of relevant domestic legislation." It is further concerned by the non-implementation of court decisions by state authorities. ${ }^{1646}$

The possibility of PIL, enabling a wide group of persons to bring a claim regarding alleged human rights violations before the Supreme Court and its progressive attitude towards enforcing socio-economic rights, has substantially strengthened the standing of socio-economic rights within the Indian legal system. This active stance of the Supreme Court and the judge-led movement to a system of PIL has also led to a heated debate on the limits of such overt judicial activism. ${ }^{1647}$ The Supreme Court, however, justifies its active stance as being necessary to make up for the lack of a strong executive and legislature. ${ }^{1648}$

1642 SINHA, Enforcement of ESC Rights, at 271.

1643 MURALIDHAR, 'Judicial Enforcement of Economic and Social Rights: The Indian Scenario', at 240 .

1644 Article 37 of the Indian Constitution.

1645 GEORGE, India Position Paper, at 2.

1646 CESCR, Concluding Observations: India, (UN Doc. E/C.12/IND/CO/5) at $\$ 9$.

1647 See MURALIDHAR, 'Judicial Enforcement of Economic and Social Rights: The Indian Scenario', at 264-265; SHANKAR and MEHTA, 'Courts and Socioeconomic Rights in India'.

1648 COURTIS, Courts and the Legal Enforcement of ESC Rights, at 85, 87-88; SHAH, 'Illuminating the Possible in the Developing World: Guaranteeing the Human Right to Health in India', at 472. 


\section{Patent Protection for Pharmaceuticals: Standards \& FleXibilities}

The second research question addressed in this chapter is whether India has complied with its obligations under WTO law and implemented TRIPS standards' and flexibilities with a view to achieving a balance between access and protecting patents. India did not grant product patent protection for pharmaceuticals until it was required to do so under the TRIPS Agreement in 2005. This section will therefore discuss India's patent legislation and evaluate to what extent India has been able to implement TRIPS' minimum obligations regarding patents for pharmaceuticals and the extent to which it has made use of the flexibilities within TRIPS to balance the interests of patent holders with that of the consumer of products protected by a patent, here the patients. In that regard, India provides a critical test case for the TRIPS flexibilities and will allow us to determine whether and how national patent systems are able to accommodate domestic economic conditions and cultural norms while still having to fulfil international minimum standards. ${ }^{1649}$

\subsection{The Patents Act of $\mathbf{1 9 7 0}$}

The development of India's patent regime over time mirrors the country's development from colonisation to independence to an emerging global power. The first patent acts were introduced by the British in the late $19^{\text {th }}$ century. ${ }^{1650}$ India gained independence in 1947. At that time, multinational pharmaceutical corporations, mostly foreign-owned, controlled India's pharmaceutical industry. In order to push for the domestic production of affordable pharmaceuticals, there was a demand for changes within India's patent regime. However, due to political division within India on the role patent protection should play, it took until 1970 before it enacted its first patent act: the 1970 Patents Act. ${ }^{1651}$ The 1970 Patents Act intended to limit the influence of foreign companies and foreign owned patents. It prohibited product patent protection for products such as pharmaceuticals and food, shortened the patent term for chemical processes and expanded the availability of compulsory licensing. As such the changes made to the Patents Act were influenced by social and poverty related issues for fear that high food and medicine prices could deny Indian citizens access to resources and therewith violate the right to life enshrined

\footnotetext{
1649 MUELLER, 'The Tiger Awakens', at 504.

1650 KAPCZYNSKI, 'Harmonisation and Its Discontents: A Case Study of TRIPS Implementation in India's Pharmaceutical Sector', at 1576; FEROZ ALI KHADER, The Law of Patents. With a Special Focus on Pharmaceuticals in India (Guragon: LexisNexis Butterworths Wadhwa Nagpur, 2009) at 12; MUELLER, 'The Tiger Awakens', at 504-505.

1651 MUELLER, 'The Tiger Awakens', at 505, 510 et seq.
} 
in the Indian Constitution. ${ }^{1652}$ In that line, India also did not sign any of the existing IP conventions, hoping to develop independently without "arm-twisting" from developed nations. ${ }^{1653}$ The introduction of the 1970 Patents Act caused a significant increase in the domestic production of generic medicines, resulting in an impressive development of the Indian generic pharmaceutical industry and a reduction of medicine prices. ${ }^{1654}$ Consequently, this development led India to get a reputation as a "pirate nation" copying medicines invented and patented in other countries. This stigmatisation is not entirely correct though, as it did not violate any foreign patent laws and it would contradict the basic principle of territoriality in patent law. As said above, the decision for this kind of patent system was a deliberate choice and as such, India is the clearest example in modern history of a country "restructuring its patent laws as a tool to achieve its national priorities." 1655

From the mid-1980s on, India played an important role in the discussions regarding the inclusion of intellectual property protection within the GATT framework, which would later become the World Trade Organisation. Together with a number of other advanced developing countries, such as Brazil, Argentina and Mexico, it led the opposition against the inclusion of intellectual property rights in a GATT framework. ${ }^{1656}$ This effort however was unsuccessful and eventually intellectual property rights were included in the TRIPS Agreement as an annex to the Agreement establishing the WTO. These developments have led to a significant strengthening of India's patent regime.

India's latest changes to its patent system were fundamental: going from a patent system which did not allow for patenting of pharmaceutical products to a fullyfledged patent regime in line with the requirements of the TRIPS Agreements. In addition to complying with TRIPS, India's transformation of its patent system was also driven by a deliberate choice to stimulate domestic innovation in new medicines. ${ }^{1657}$ The absence of product patents for pharmaceuticals may have led to a booming generic pharmaceutical industry, however it did not stimulate research

1652 SRIVIDHYA RAGAVAN, 'Of the Inequals of the Uruguay Round', Marquette Intellectual Property Law Review, 10 (2006), 273-304 at 285.

1653 MUELLER, 'The Tiger Awakens', at 512.

1654 GEORGE, India Position Paper, at 4-5; BRENDA PAMELA MEY, 'Unfettered Consumer Access to Affordable Therapies in the Post-TRIPS Era: A Dead-End Journey for Patients? Kenya and India Case Studies', The Journal of World Intellectual Property, 13:3 (2010), 403473 at 411.

1655 MUELLER, 'The Tiger Awakens', at 514. See further DUNCAN MATTHEWS, When Framing Meets Law: Using Human Rights as a Practical Instrument to Facilitate Access to Medicines in Developing Countries, Queen Mary University of London, School of Law, Legal Studies Research Paper, No. 92/2011, (2011) at 27 et seq.

1656 KAPCZYNSKI, 'Harmonisation and Its Discontents: A Case Study of TRIPS Implementation in India's Pharmaceutical Sector', at 1581; MUELLER, 'The Tiger Awakens', at 517.

1657 See for example PRESS INFORMATION BUREAU OF THE GOVERNMENT OF INDIA, 'Minister of Commerce and Industry Kamal Nath's Statement on the Ordinance Relating to Patents (Third) Amendment', <http://pib.nic.in/newsite/erelease.aspx?relid=6074>, accessed 30 April 2012. 
and development into new chemical entities. It is stated that there are early signals indicating that the shift to a product patent system is having a positive effect on the Indian economy. It is too early, though, for empirical evidence to establish whether there is a visible shift from producing generic medicines to domestic pharmaceutical innovation. 1658

\subsubsection{Transitional Periods TRIPS}

For developing WTO members, like India, that did not initially provide patent protection for pharmaceutical products, the TRIPS Agreement sets out a framework for implementation in three stages:

- From 1 January 1995 TRIPS required the introduction of the so-called "mailbox" system, a facility to allow for receiving and holding patent applications for pharmaceuticals (and agricultural chemicals) and in certain situations the granting of exclusive marketing rights (EMRs). ${ }^{1659}$

- Developing countries were granted until 1 January 2005 to implement the obligations under the TRIPS Agreement, except for articles 3, 4 and 5 TRIPS. 1660

- Finally, full implementation of TRIPS' obligations for developing countries was required from 1 January $2005 .{ }^{1661}$ From that moment on India is also under the obligation to examine the patent applications held in the mailbox.

Partly as a result of the opposition against the TRIPS Agreement within India, it took quite some time before India implemented these obligations. A first attempt to implement these provisions was made at the end of 1994 by introducing an Ordinance, which however lapsed due to the fact that it was not followed up by the required legislation within the six week time limit. ${ }^{1662}$ After that, the government introduced a Bill, which was passed in the Lower House of the Parliament (the Lok Sabha) but met with considerable opposition in the Upper House (the Rajya Sabha). The Bill was referred to a Select Committee whose report could not be submitted before Parliament dissolved in May 1996. ${ }^{1663}$

The TRIPS Agreement requires members to set up a mailbox or mechanism to "allow the filing of applications for patents for pharmaceutical and agricultural chemical products from 1 January 1995 and preserve the dates of filing and

\footnotetext{
1658 MUELLER, 'The Tiger Awakens', at 495-498.

1659 Article 70.8-9 TRIPS.

1660 Article 65.2 TRIPS.

1661 Article 65.4 TRIPS.

1662 CHAUDHURI, The WTO and India's Pharmaceuticals Industry, at 65-66; MUELLER, 'The Tiger Awakens', at 520.

1663 CHAUDHURI, The WTO and India's Pharmaceuticals Industry, at 66; MUELLER, 'The Tiger Awakens', at 520.
} 
priority of those applications, so that the criteria for patentability may be applied as of those dates, and so that the patent protection eventually granted is dated back to the filing date". ${ }^{1664}$ Furthermore, under certain conditions article 70.9 TRIPS requires the granting of exclusive marketing rights for patent applications to the mail-box system. India contended that it had established, through "administrative instructions", a means consistent with Article 70.8(a) of the TRIPS Agreement. Furthermore it maintained that there is nothing in the text of Article 70.9 that creates an obligation to make a system for the granting of an exclusive marketing rights system generally available in the domestic law before the events listed in Article 70.9 have occurred. The US and the EC disagreed and filed a complaint at the WTO Dispute Settlement Body. Two Panels were set up under the DSU, which agreed with the US and EC and ruled that India was not fulfilling its obligations under the TRIPS Agreement. 1665 India appealed the Panel's decision. However, the Appellate Body rejected India's appeal agreeing with the Panel that India's manner of implementing the mail-box system was inconsistent with article 70.8 TRIPS. ${ }^{1666}$ Furthermore, it stated that India has an obligation to implement the provisions of Article 70.9, effective as from the date of entry into force of the WTO Agreement, that is, 1 January 1995. Since India conceded that legislation was necessary to implement this obligation and it had not enacted any legislation, the Appellate Body found that India was in violation of article 70.9 TRIPS. ${ }^{667}$ Consequently the DSB requested India to comply with its obligations under the TRIPS Agreement.

An Ordinance was introduced and followed up by an Act passed in March 1999: the Patents (Amendment) Act, 1999, which amended the 1970 Patents Act and introduced the mail-box system as required by TRIPS retrospectively from 1 January 1995. ${ }^{1668}$ Mailbox applications went into a symbolic "black box" and were not to be taken out nor published until 1 January 2005, the date when the transition period for India to fully implement TRIPS ended. Over 4,790 mailbox applications for pharmaceuticals had been filed in July 2004. ${ }^{1669}$ And by 1 January 2005, after a 10 year transitional period, just short of 9,000 mailbox applications

1664 WTO Appellate Body Report, India - Patent Protection for Pharmaceutical and Agricultural Chemical Products, 19 December 1997, WT/DS50/AB/R at $\$ 56$.

1665 WTO Panel Report, India - Patent Protection for Pharmaceutical and Agricultural and Chemical Products, Complaint by the United States, adopted 16 January 1998 (as modified by AB report WT/DS50/AB/R), WT/DS50/R; WTO Panel Report, India - Patent Protection for Pharmaceutical and Agricultural and Chemical Products, Complaint by the European Communities, adopted 22 September 1998, WT/DS79/R.

1666 India-Patent Protection for Pharmaceutical and Agricultural and Chemical Products, at \$70-71. 1667 Ibid. at $\$ 83-84$.

1668 See Chapter IVA (section 24A-F) of the Patents Act, which was omitted by the 2005 Patents (Amendment) Act. See further CHAUDHURI, The WTO and India's Pharmaceuticals Industry, at 66; KHADER, The Law of Patents. With a Special Focus on Pharmaceuticals in India, at 232 et seq; MUELLER, 'The Tiger Awakens', at 521.

1669 As a result of a parliamentary question, the Ministry of Commerce and Industry revealed that on 23 July 2004, 5637 mail box applications were filed, 4792 of which related to pharmaceutical 
had been filed in the Indian Patent Office, the vast majority of which were owned by non-Indian entities. ${ }^{1670}$

There was widespread apprehension in India that the mailbox system required by TRIPS would lead to a large number of applications for exclusive marketing rights, however, this fear turned out be unjustified as there were only a few applications for EMRs. ${ }^{1671}$ The grant of an EMR would have entailed an exclusive right to sell or distribute the invention in India for a period of five years, until a patent was granted from the mailbox application or the mailbox application was rejected, whichever was earlier. ${ }^{1672}$ It is argued that the complicated list of conditions required for the grant of an EMR could be one reason why less than 20 mailbox applications applied for EMRs, and even fewer were successfully enforced. ${ }^{1673}$

However, one case where EMRs were granted did turn out to be controversial: namely, the case where EMRs were granted to Novartis for an anti-cancer drug (imatinib mesylate) with the brandname Gleevec or Glivec. ${ }^{1674}$ The reason for this is that the TRIPS Agreement does not require a member to grant protection, whether in the form of a patent or an EMR, to any subject matter which had already entered the 'public domain' before the WTO was set up, that is January $1^{\text {st }}, 1995.1675$ In this case, a patent was granted to Novartis for its new chemical entity, imatinib mesylate, in the US before 1995. As India did not grant full patent protection for pharmaceutical products before 2005, Novartis could not apply for a patent in India; however, it did file a mailbox application and an application for an EMR, which was granted in November 2003. However, a number of Indian generic manufacturers were already producing and marketing a generic version of Gleevec at a price between Rs 8,000-12,000 per month, which is a marked difference if compared to the cost of Novartis' product which was at Rs 120,000 per month. Consequently, Novartis filed a series of infringement suits against the generic companies who were manufacturing and marketing imatinib mesylate. While the Madras High

products and 4398 by foreign corporations. See CHAUDHURI, The WTO and India's Pharmaceuticals Industry, at 69.

1670 MUELLER, 'The Tiger Awakens', at 521-522, 524; KARIN TIMMERMANS, 'Ensuring Access to Medicines in 2005 and Beyond', in Pedro Roffe, Geoff Tansey, and David VivasEugui (eds.), Negotiating Health. Intellectual Property and Access to Medicines (London: Earthscan, 2006) at 43.

1671 According to Sudip Chaudhuri only 13 EMR applications were filed by August 2004. This information was obtained from the Office of the Controller of Patents and Designs in Calcutta. See CHAUDHURI, The WTO and India's Pharmaceuticals Industry, at 68.

1672 See section 24B of the 1970 Patents Act as amended by the 1999 Patents (Amendment) Act. MUELLER, 'The Tiger Awakens', at 525.

1673 See section 24A of the 1970 Patents Act as amended by the 1999 Patents (Amendment) Act. MUELLER, 'The Tiger Awakens', at 526.

1674 CHAUDHURI, The WTO and India's Pharmaceuticals Industry, at 68.

1675 See article 70.3 TRIPS which reads as follows: There shall be no obligation to restore protection to subject matter which on the date of application of this Agreement for the Member in question has fallen into the public domain. 
Court granted an interim injunction in favour of Novartis, interestingly the Bombay High Court refused to grant an injunction allowing Indian companies to continue the production of the generic version of imatinib mesylate. ${ }^{1676}$ Eventually, the patent application for imatinib mesylate was rejected by the Controller; a decision challenged by Novartis. ${ }^{1677}$

In December 1999 a second Bill was introduced to implement the other changes in the patent system as required by TRIPS, which also met with opposition and was referred to a joint parliamentary committee. ${ }^{1678}$ The Committee submitted a revised Bill in December 2001 which, with a few changes, was passed by the Parliament in May 2002: the Patents (Amendment) Act, 2002, which took effect 25 June 2002, made 64 amendments to the 1970 Patents Act with respect to patent terms, exceptions to the exclusive rights of patent holders, compulsory licensing among others. ${ }^{1679}$ Furthermore, it formally recognised India's accession to two leading intellectual property treaties, as required by the TRIPS Agreement: the Paris Convention for the Protection of Industrial Property and the Patent Cooperation Treaty (both of which had entered into force for India on 7 December 1998).

To replace the mailbox and exclusive marketing rights system and bring India into full compliance with TRIPS at the end of the transitional period a third Bill was introduced in December 2003. However, Parliament dissolved before the Bill could be passed. After the elections in May 2004, the new government referred the issue to a Group of Ministers. The discussions and recommendations of the Group of Ministers were never made public, even though there was much public interest in the matter and demands by public interest groups to make the recommendations public and hold a debate before finalising the amendments. In the end, a fullyfledged product patent system was introduced from 1 January 2005 through a Presidential Decree without having been discussed in Parliament: the Patents (Amendment) Ordinance, 2004. The Ordinance was widely opposed by civil society and public interest groups in India and from abroad arguing that it failed to strike a fair balance between guaranteeing access to medicines and protection of patent rights. As required by law the Ordinance had to be followed up by legislation passed by parliament, and in the three months following the promulgation of the Ordinance intense public debate led to a significantly revised law passed by parliament in March 2005: the Patents (Amendment) Act, 2005. 1680 The amendments made to the

1676 CHAUDHURI, The WTO and India's Pharmaceuticals Industry, at 68-69; GEORGE, India Position Paper, at 15; KHADER, The Law of Patents. With a Special Focus on Pharmaceuticals in India, at 235.

1677 The Indian Cancer Patients Aid Association challenged the grant of the EMR, but before the case was decided the Patents Act was amended deleting the provisions with respect to EMRs. Consequently, Novartis applied for a patent which was rejected. Novartis challenged the rejection of the patent which is discussed further below in $\S 4.1 .2 .1$.

1678 CHAUDHURI, The WTO and India's Pharmaceuticals Industry, at 66.

1679 Ibid. at 66-67; MUELLER, 'The Tiger Awakens', at 526.

1680 BHATTACHARYA, 'Are Developing Countries Going Too Far on TRIPS?', at 400-401; CHAUDHURI, The WTO and India's Pharmaceuticals Industry, at 67-68; KAPCZYNSKI, 
2004 Ordinance included changes to the provisions on compulsory licensing, such as defining the "reasonable period" that an applicant must undertake efforts to obtain a voluntary license to less than six months and that a compulsory license predominantly for the supply of the Indian market or to remedy anti-competitive practices does not preclude the possibility of exporting the patent product; changes to the pre- and post-grant opposition including specifically defined time frames; and changes limiting the scope of patentable subject matter in response to the fear of 'evergreening'.

So from 1 January 2005 India now grants patent protection to pharmaceutical products. Logically, the immediate consequence has been an enormous flood of product patent applications awaiting examination. ${ }^{1681}$ Additionally, the mailbox applications also had to be considered for the granting of patents. The first product patent for a pharmaceutical was granted to Hoffman-La Roche in March 2006 for its Hepatitis C therapy (brand name Pegasys). ${ }^{1682}$

There has been some apprehension about what will happen to the generic pharmaceutical producers that were manufacturing and marketing products that will most probably be granted patent protection in the near future. ${ }^{1683}$ However, section 11A(7) of the 1970 Patents Act as amended by the Patents (Amendment) Act, 2005 stated that for mailbox applications, patent rights would only take effect from the moment of the grant of the patent and infringement cases cannot be filed before the grant of the patent. ${ }^{1684}$ Thus generic manufacturers do not have to

'Harmonisation and Its Discontents: A Case Study of TRIPS Implementation in India's Pharmaceutical Sector', at 1587-1588; MUELLER, 'The Tiger Awakens', at 529-530.

In 2009-10 India granted 6,168 patents; 37,334 patents were in force, of which 6,781 were granted to Indians and 30,554 to foreigners resident abroad. Patent applications increased from 4,824 in 1999-2000 to 36,877 in 2008-09; the number of applications examined rose from 2,824 to 10,296 and the number granted increased from 1,591 to 16,061.355. See WTO TRADE POLICY REVIEW BODY, Trade Policy Review. Report by the Secretariat on India (Revision) (WT/TPR/S/249/Rev.1; 2011) at §258.

1682 MUELLER, 'The Tiger Awakens', at 548.

1683 CHAUDHURI, The WTO and India's Pharmaceuticals Industry, at 69.

1684 See section $11 \mathrm{~A}(7)$ of the Indian Patents Acts: On and from the date of publication of the application for patent and until the date of grant of a patent in respect of such application, the applicant shall have the like privileges an rights as if a patent for the invention had been granted on the date of publication of the application:

Provided that the applicant shall not be entitled to institute any proceedings for infringement until the patent has been granted:

Provided further that the rights of a patentee in respect of applications made under sub-section (2) of section 5 before the 1st day of January, 2005 shall accrue from the date of grant of the patent:

Provided also that after a patent is granted in respect of applications made under sub-section (2) of section 5, the patent-holder shall only be entitled to receive reasonable royalty from such enterprises which have made significant investment and were producing and marketing the concerned product prior to the 1st day of January, 2005 and which continue to manufacture the product covered by the patent on the date of grant of the patent and no infringement proceedings shall be instituted against such enterprises. 
suspend production and marketing of such pharmaceuticals until a patent in a mailbox application has actually been granted. The fact that Indian patent law provides different treatment to owners of patents on mailbox inventions compared to regular patent holders raises serious issues under TRIPS; whether this provisions is TRIPS compatible is an open question, which will not be discussed here. ${ }^{1685}$

Finally, a number of the provisions introduced through the amendments are controversial and have been criticised. ${ }^{1686}$ Many of these have also not yet been interpreted by the Indian courts. The aim of the next section is to determine whether India's Patents Act as amended by the 1999, 2002 and 2005 Patents (Amendment) Acts, has implemented TRIPS' standards and flexibilities with regard to the patenting of pharmaceuticals. In that regard use will also be made of the latest version of the Manual of Patent Office Practice and Procedure. It must be mentioned, however that the Manual may be considered to be a practical guide yet it does not constitute rule making and thus also does not have the force and effect of law. ${ }^{1687}$ First whether India has implemented TRIPS patent standards will be examined: particularly whether it allows for the patenting of pharmaceuticals under the criteria prescribed by article 27.1 TRIPS and in case such an application is successful, whether it grants the patent holder exclusive rights for a minimum period of 20 years as stipulated by articles 28 and 33 TRIPS. Secondly what exceptions the Indian Patents Act allows for and whether these are compatible with articles 30 and 31 TRIPS are examined.

\subsubsection{Patent Standards}

Article 27.1 TRIPS requires WTO members to provide patents for any invention without discrimination as to the place of the invention, the field of technology, and whether products are imported or produced locally as long as the invention is novel, involves an inventive step and is capable of industrial application.

The major amendment made to bring the Indian Patents Act into compliance with the TRIPS Agreement is the elimination of the prohibition of product patents for inventions claiming substances intended for use, or capable of being used, as food, medicine or drugs, or relating to substances prepared or produced by chemical processes, which previously only enjoyed protection through process patents. ${ }^{1688}$ Section 4 of the 2005 Patents (Amendment) Act repealed that provision. As a result,

1685 See further CHAUDHURI, The WTO and India's Pharmaceuticals Industry, at 70; CYNTHIA $\mathrm{HO}$, Access to Medicine in the Global Economy. International Agreements on Patents and Related Rights (New York: Oxford University Press, 2011) at 112 et seq; MUELLER, 'The Tiger Awakens', at 575 et seq.

1686 MUELLER, 'The Tiger Awakens', at 546-547.

1687 THE PATENT OFFICE INDIA, Manual of Patent Office Practice and Procedure (The Office of Controller General of Patents, Designs \& Trademarks; 2011) at Preface.

1688 Section 5 of the original 1970 Patents Act, reads as follows:

(1) In the case of inventions- 
it is now possible to be granted a product patent for a wide range of inventions, including pharmaceuticals.

Section 7(1) of the Indian Patents Act states that: "[e] very application for a patent shall be for one invention only and shall be made in the prescribed form and filed in the patent office." Section 2(1)j of the Patents Act defines "invention" as "a new product or process involving an inventive step and capable of industrial application". ${ }^{1689}$ Any person, whether Indian or of foreign nationality, whether an individual or a legal person, may apply for a patent as long as he is the true and first inventor of the invention. ${ }^{1690}$ An application for a patent shall be accompanied by a specification setting out the scope of the invention and disclosing the best method of performing it. 1691

The Patents Act further defines a "new invention" as "any invention or technology which has not been anticipated by publication in any document or used in the country or elsewhere in the world before the date of filing of patent application with complete specification, i.e. the subject matter has not fallen in public domain or that it does not form part of the state of the art"; 1692 "inventive step" as "a feature of an invention that involves technical advance as compared to the existing knowledge or having economic significance or both and that makes the invention not obvious to a person skilled in the art"; 1693 and "capability of industrial application" as meaning "that the invention is capable of being made or used in an industry."1694 India's definition of "inventive step" is unique in that it is stricter than in most other countries as it requires an invention to involve a "technical advance," "economic significance," or both, in addition to the fact that the invention is not obvious to a person skilled in the art. ${ }^{1695}$ With regard to the last criteria, the 2002 Patents (Amendment) Act introduced the concept of industrial

a. claiming substances intended for use, or capable of being used, as food or as medicine or drug, or

b. relating to substances prepared or produced by chemical processes (including alloys, optical glass, semi-conductors and inter-metallic compounds),

no patent shall be granted in respect of claims for the substances them selves, but claims for the methods or processes of manufacture shall be patentable.

Section 2(1)j was introduced by s. 3(f) of the 2002 Patents (Amendment) Act.

Section 6 of the Indian Patents Act. See also KHADER, The Law of Patents. With a Special Focus on Pharmaceuticals in India, at 183 et seq.

Section 7(4) of the Indian Patents Act. Sections 9 to 11 of the Patents Act deal with specification, its content and its priority dates. Chapter II and III of the Patent Rules deal with (international) applications for patents. See also ibid. at 109 et seq; THE PATENT OFFICE INDIA, The 2011 Manual of Patent Office Practice and Procedure, (The Office of Controller General of Patents, Designs \& Trademarks) at chapter 3.

See section 2(1)1 of the Patents Act.

See section 2(1)ja of the Patents Act.

Section 2(1)ac of the Patents Act introduced by section 3 of the 2002 Patents (Amendment) Act. GEORGE, India Position Paper, at 8; HO, Access to Medicine in the Global Economy, at 97; KAPCZYNSKI, 'Harmonisation and Its Discontents: A Case Study of TRIPS Implementation in India's Pharmaceutical Sector', at 1593; THE PATENT OFFICE INDIA, The 2011 Manual of 
application, in line with the requirements of the TRIPS Agreement, which before that did not figure in the Patents Act. ${ }^{169}$ In the previous Patents Act for an invention to be patentable, it had to relate to a new and useful manner of manufacture. ${ }^{1697}$

Consequently, this definition includes the elements as required by article 27.1 TRIPS with respect to patentable subject matter. ${ }^{1698}$ TRIPS does not define the concepts of novelty, inventiveness and capability of industrial application, however and as such leaves considerable flexibility for WTO members to decide the manner in which to implement and interpret this obligation. ${ }^{1699}$ As opposed to developed countries that often have very broad patent standards, like for example the US, some commentators have argued that developing countries should interpret these concepts restrictively and adopt an higher bar for patentability. ${ }^{1700}$ India has made use of this flexibility by introducing a unique, but also ambiguous, section regarding patentable subject matter, which will be discussed in the next section.

\subsubsection{Section 3D: Inventions not Patentable}

The three requirements novelty, inventiveness, industrial application need to be fulfilled before patent protection may be granted. However, not all inventions are patentable, and before applying the conditions for patentability, the invention should be examined against the statutory exceptions of sections $3 \& 4$ of the Patents Act. ${ }^{1701}$ In its Chapter II (Inventions Not Patentable), the Patents Act sets out what subject matter is not considered patentable under the Patents Act. Section 3 comprises of an extensive list of exclusions to patentable subject matter, some of which are ambiguous and will require further interpretation, and others which have

Patent Office Practice and Procedure, (The Office of Controller General of Patents, Designs \& Trademarks) at $§ 08.03 .03$.

KHADER, The Law of Patents. With a Special Focus on Pharmaceuticals in India, at 36.

1697 Even though the present definition of "invention" has replaced the requirement of "any manner of new manufacture", the way this concept has been interpreted by the courts would still be relevant for understanding the development of law with respect to the rapid technological and scientific changes. To examine whether an invention comprises a manner of new manufacture the Commonwealth courts have created the "vendibility test". For more information on the manner of interpretation of the phrase "manner of manufacture" and the "vendibility test", see KHADER, The Law of Patents. With a Special Focus on Pharmaceuticals in India, at 36 \& 39 et seq.

MUELLER, 'The Tiger Awakens', at 563.

1699 See also article 1 TRIPS. CHAUDHURI, The WTO and India's Pharmaceuticals Industry, at 71; MUELLER, 'The Tiger Awakens', at 563.

1700 CHAUDHURI, The WTO and India's Pharmaceuticals Industry, at 71; MUELLER, 'The Tiger Awakens', at 563.

1701 KHADER, The Law of Patents. With a Special Focus on Pharmaceuticals in India, at 34-35, 42 et seq. 
proven to be quite controversial and arguably not in compliance with the TRIPS Agreement. ${ }^{1702}$ From the wording of the two sections, it can be derived that the given list of non-patentable inventions is exhaustive. In general, the list of exceptions can be divided into two categories: absolute exceptions, which are unqualified and cannot be derogated from (for example section 4), and limited or conditional exceptions, which are limited to a specific circumstance or are

1702 Section 3 of the Indian Patents Act reads as follows:

The following are not inventions within the meaning of this Act, -

a) an invention which is frivolous or which claims anything obvious contrary to well established natural laws;

b) an invention the primary or intended use or commercial exploitation of which would be contrary to public order or morality or which causes serious prejudice to human, animal or plant life or health or to the environment;

c) the mere discovery of a scientific principle or the formulation of an abstract theory or discovery of any living thing or non-living substance occurring in nature;

d) the mere discovery of a new form of a known substance which does not result in the enhancement of the known efficacy of that substance or the mere discovery of any new property or new use for a known substance or of the mere use of a known process, machine or apparatus unless such known process results in a new product or employs at least one new reactant;

Explanation. - For the purposes of this clause, salts, esters, ethers, polymorphs, metabolites, pure form, particle size, isomers, mixtures of isomers, complexes, combinations and other derivatives of known substance shall be considered to be the same substance, unless they differ significantly in properties with regard to efficacy;

e) a substance obtained by a mere admixture resulting only in the aggregation of the properties of the components thereof or a process for producing such substance;

f) the mere arrangement or re-arrangement or duplication of known devices each functioning independently of one another in a known way;

g) -

h) a method of agriculture or horticulture;

i) any process for the medicinal, surgical, curative, prophylactic, diagnostic, therapeutic or other treatment of human beings or any process for a similar treatment of animals to render them free of disease or to increase their economic value or that of their products;

j) plants and animals in whole or any part thereof other than micro-organisms but including seeds, variety and species and essentially biological processes for production or propagation of plants and animals;

k) a mathematical or business method or a computer programme per se or algorithms;

1) a literary, dramatic, musical or artistic work or any other aesthetic creation whatsoever including cinematographic works and televisions productions;

m) a mere scheme or rule or method of performing mental act or method of playing game;

n) a presentation of information;

o) topography of integrated circuits;

p) an invention which, in effect, is traditional knowledge or which is an aggregation or duplication of known properties of traditionally known component or components.

See also Section 4 of the Indian Patents Act:

No patent shall be granted in respect of an invention relating to atomic energy falling within sub-section (1) of section 20 of the Atomic Energy Act, 1962 (33 of 1962). 
patentable if certain conditions apply (for example section 3(e) \& (d) respectively). ${ }^{1703}$

One of the most controversial and discussed provisions, is section 3(d) of the Patents Act, which introduces the notion of "efficacy" for secondary patents. ${ }^{1704}$ Section 3(d) of the Patents Act was introduced by section 3 of the 2005 Patents (Amendment) Act, and restricts patenting of the mere discovery of a new form of a known substance which does not result in the enhancement of the known efficacy of that substance; or the mere discovery of new properties or new uses of a known substance, ${ }^{1705}$ or the mere use of a known process unless such known process results in a new product or employs at least one new reactant; or the mere use of a known machine or apparatus. ${ }^{1706}$ As such, this provision introduces a test to differentiate discovery from invention. The introduction of this section demonstrates the awareness and acknowledgement in India of the interface between patents and access to medicines in that it signifies India's concerns with respect to frivolous patents and "evergreening" and that (un)affordability is an important obstacle to patients' access to medicines. ${ }^{1707}$

Firstly, section 3(d) prohibits patents for derivatives - i.e. new forms of known substances - except if it can be shown that they provide a significantly enhanced efficacy. As such, this is a conditional exception to patentability. This provision is unique; and is not found in any other patent regime. ${ }^{1708}$ Moreover, in the context of medicines, it makes "evergreening" of pharmaceutical patents almost impossible, which is exactly the purpose for which it was introduced. ${ }^{1709}$ Indian patent law does not completely bar variations of old compounds from patentability, as they may still be patented if they show significantly improved "efficacy." The patenting of derivatives is further tightened by section 3(d)'s Explanation which requires not only that there is an enhanced efficacy, but that the derivative and the known substance "differ significantly in properties with regard to efficacy". Section 3(d),

1703 KHADER, The Law of Patents. With a Special Focus on Pharmaceuticals in India, at 42.

1704 MUELLER, 'The Tiger Awakens', at 550.

1705 New properties or new uses of a known substance can also be referred to as 'new, second or subsequent (medical) use', an innovative 'method of use' of a known product or within the European context as "Swiss type" claims.

1706 THE PATENT OFFICE INDIA, The 2011 Manual of Patent Office Practice and Procedure, (The Office of Controller General of Patents, Designs \& Trademarks) at §08.03.05.04.

1707 GEORGE, India Position Paper, at 7; KAPCZYNSKI, 'Harmonisation and Its Discontents: A Case Study of TRIPS Implementation in India's Pharmaceutical Sector', at 1590-1591; R.A. MASHELKAR et al., Report of the Technical Expert Group on Patent Law Issues (Government of India, Ministry of Commerce \& Industry, Department of Industrial Policy \& Promotion; December 2006) at §5.16; MATTHEWS, The Right to Health and Patents, at 7; MEY, 'Unfettered Consumer Access to Affordable Therapies in the Post-TRIPS Era', at 440.

1708 MUELLER, 'The Tiger Awakens', at 550.

1709 Ibid. at 551. With "ever-greening" is referred to the practice of the pharmaceutical industry to effectively extend the term of protection for patented pharmaceuticals by obtaining related patents for minor modifications made to the original product, new delivery systems for the pharmaceuticals, or new uses of the pharmaceutical etc. 
therefore, raises a number of issues: what kind of data is required to prove "efficacy, ${ }^{1710}$ and when is an improvement in the efficacy of the known substance sufficiently "significant". ${ }^{1711}$ These are issues that the Indian Patent Office will assess on a case-to-case basis before granting a patent for a derivative of a known substance. ${ }^{1712}$

Additionally, section 3(d) contains an absolute exception to patentability by stating that the mere discovery of any new property of or new use for a known substance is not considered patentable. ${ }^{1713}$ India's restrictive position on this matter contrasts with the lenient approach in the US' and Europe's in patenting second or subsequent medical uses of known pharmaceuticals. ${ }^{1714}$ That begs the question whether India's restrictive approach is in line with the standards of the TRIPS Agreement, specifically article 27.1 TRIPS. Even though article 27 provides that WTO members must provide patents for process in all fields of technology, it does not define "processes". Actually, it allows members to exclude diagnostic, therapeutic and surgical methods for the treatment of humans or animals from patentability. ${ }^{1715}$ However, these methods of treatment are already specifically excluded from patentability in section 3(i) of the Patents Act. This would lead to the conclusion that section 3(d) must cover a broader ground, namely methods of use beyond those mentioned in section 3(i). As a result, methods of use eligible for patent protection are narrowed down considerably to only new uses of new substances for purposes other than treatment of humans or animals. ${ }^{1716}$

There is disagreement on the TRIPS compliant nature of these provisions. ${ }^{1717}$ According to a technical expert group on patent law issues it would be inconsistent with TRIPS to limit the granting of patents for pharmaceutical substances to NCEs (i.e. New Chemical or Medical Entities) only. This is an approach which would also not be justified by reference to article 7 and 8 TRIPS and the Doha Declaration on TRIPS and Public Health. ${ }^{1718}$ Yet, the report does not address whether, to this extent, the Patents Act is consistent with TRIPS, but it states that there is a "perception" that current provisions in the Patents Act could be held to be TRIPS inconsistent and that restricting patentability to NCEs could therefore have legal

1710 According to Khader, the term "efficacy" is well-understood in the pharmaceutical field: a degree of potency as a pharmaceutical. See KHADER, The Law of Patents. With a Special Focus on Pharmaceuticals in India, at 66.

1711 MUELLER, 'The Tiger Awakens', at 553.

1712 THE PATENT OFFICE INDIA, The 2011 Manual of Patent Office Practice and Procedure, (The Office of Controller General of Patents, Designs \& Trademarks) at §08.03.05.04.

1713 KHADER, The Law of Patents. With a Special Focus on Pharmaceuticals in India, at 69 et seq; MUELLER, 'The Tiger Awakens', at 557.

1714 MUELLER, 'The Tiger Awakens', at 557.

1715 Article 27.3 TRIPS.

1716 MUELLER, 'The Tiger Awakens', at 557-558.

1717 HO, Access to Medicine in the Global Economy, at 95; MUELLER, 'The Tiger Awakens', at 558.

1718 MASHELKAR et al., Mashelkar Committee Report, (Government of India, Ministry of Commerce \& Industry, Department of Industrial Policy \& Promotion) at §5.6-5.7. 
and scientific ramifications. ${ }^{1719}$ Consequently it seems safe to assume that section $3 \mathrm{~d}$ does not limit patent protection to NCEs only. ${ }^{1720}$

The TRIPS Agreement does not define the concept of "inventions" or "inventive step", and it is silent about the novelty of purpose or use. TRIPS leaves WTO members considerable freedom to decide the manner in which to implement and interpret their obligations under the Agreement. The question will be problematic, however, whether section 3(d) discriminates against a field of technology, i.e. pharmaceuticals. A WTO panel did state that not all differential treatment could be considered discrimination. ${ }^{1721}$ Section $3(\mathrm{~d})$ was introduced with a view to medicines and fears surrounding the public health implications of "evergreening"; this was a concern also recognised by the Mashelkar Report which states that "every effort must be made to provide drugs at affordable prices to the people of India."1722 India's best option to justify differential treatment for pharmaceuticals would be to interpret the non-discrimination principle in line with article 8 TRIPS and the Doha Declaration on TRIPS and Public Health; particularly the latter also seems to focus on pharmaceutical products for special treatment. ${ }^{1723}$ Though, until now, no WTO member has formally challenged this provisions within the WTO dispute settlement mechanisms since it came into effect in $2005 .{ }^{1724}$

\section{"Efficacy" under section 3(d) of the Patents Act: The Novartis Case}

The fundamental question to be answered under the newly introduced section 3(d) is the extent of the claimed derivative's "efficacy". ${ }^{1725}$ The term "efficacy" is not defined in the Indian Patents Act. The ambiguity of the language of section 3(d) does not provide much guidance to the Patent Office in deciding on this matter, except that the "enhanced efficacy" must be determined in reference to the "known efficacy". ${ }^{1726}$ Considering the underlying objective it is likely that the threshold for determining "efficacy" is high. The 2011 Manual of Patent Office Practice and Procedure does not define the term "efficacy" either but refers to a case relating to pharmaceutical substance - Novartis AG v. Union of India - decided by the High Court of Madras, in which it observed that: ${ }^{1727}$

\footnotetext{
1719 Ibid. at $\$ 5.11$.

1720 KHADER, The Law of Patents. With a Special Focus on Pharmaceuticals in India, at 86.

1721 Canada-Patent Protection for Pharmaceutical Products, at $\$ 7.94$ and 7.101.

1722 MASHELKAR et al., Mashelkar Committee Report, (Government of India, Ministry of Commerce \& Industry, Department of Industrial Policy \& Promotion) at $\$ 5.16$.

$1723 \mathrm{HO}$, Access to Medicine in the Global Economy, at 96.

1724 See also KAPCZYNSKI, 'Harmonisation and Its Discontents: A Case Study of TRIPS Implementation in India's Pharmaceutical Sector', at 1595 et seq.

1725 MUELLER, 'The Tiger Awakens', at 553.

1726 KHADER, The Law of Patents. With a Special Focus on Pharmaceuticals in India, at 68; MUELLER, 'The Tiger Awakens', at 553-554.

1727 THE PATENT OFFICE INDIA, The 2011 Manual of Patent Office Practice and Procedure, (The Office of Controller General of Patents, Designs \& Trademarks) at §08.03.05.04.
} 
going by the meaning for the word "efficacy" and "therapeutic" [...], what the patent applicant is expected to show is, how effective the new discovery made would be in healing a disease/having a good effect on the body? In other words, the patent applicant is definitely aware as to what is the "therapeutic effect" of the drug for which he had already got a patent and what is the difference between the therapeutic effect of the patented drug and the drug in respect of which patent is asked for.

Due to the advanced technology in all fields of science, it is possible to show by giving necessary comparative details based on such science that the discovery of a new form of a known substance had resulted in the enhancement of the known efficacy of the original substance and the derivatives so derived will not be the same substance, since the properties of the derivatives differ significantly with regard to efficacy.

In this high-profile case, the High Court of Madras dismissed a challenge to the Indian Patent Office's decision that Novartis' new variation of an anti-cancer drug was inadequately efficacious, while also declining to consider Novartis's challenge of the law as either inconsistent with the Indian Constitution or TRIPS.

After the TRIPS transitional period passed and India introduced product patents for pharmaceuticals, the Controller ordered the opening and examining of the patent applications contained in the mailbox. Among these was an application by Novartis for the beta-crystalline of imatinib mesylate brand name Gleevec or Glivec - which is used to treat a form of cancer. The Indian Cancer Patients Aid Association, with help from the Lawyers Collective HIV/AIDS Unit, filed a pregrant opposition to oppose the grant of a patent. The Patent Office upheld the challenge denying the grant of a patent on the grounds that the application did not satisfy patentability criteria under the Patents Act, including section 3(d). It was considered a minor modification to an already existing off-patent pharmaceutical. ${ }^{1728}$ Consequently, in May 2006, Novartis filed two petitions for the Madras High Court challenging the Patent Office's decision ${ }^{1729}$ and section 3(d) of the Patents Act arguing that section 3(d) was unconstitutional, arbitrary and failed to meet standards set out in the TRIPS Agreement (article 27). The Madras High Court rejected Novartis' challenge upholding the constitutional validity of section 3(d) while refraining from examining the TRIPS compatibility of the section as this fell under the exclusive jurisdiction of the WTO Dispute Settlement Mechanism. ${ }^{1730}$

1728 GEORGE, India Position Paper, at 15.

1729 At that time the appellate authority under the Patents Act had not yet become functional which is the reason for Novartis turning to the Madras High Court. After the formation of the Intellectual Property Appellate Board (IPAB) the petitions challenging the orders of the Controller were referred from the High Court to IPAB in April 2007. On June 262009 the IPAB dismissed the appeals against the Controller's orders holding that the patentability of the subject product failed to meet the test of section 3(d) of India's Patents Act.

1730 TAHIR AMIN, The Patent Challenge: Protecting the Public Domain and Access to Affordable Medicines, Initiative for Medicines, Access \& Knowledge (2007); KHADER, The Law of Patents. With a Special Focus on Pharmaceuticals in India, at 86 et seq. 
In August 2009, Novartis then approached the Supreme Court of India challenging the interpretation and application of section 3(d) by the Indian court system and Patent Offices. The Supreme Court delivered its final verdict in April 2013 rejecting all of Novartis' claims. ${ }^{1731}$ It affirmed that Gleevec failed the test of section 3(d) and clarified that "efficacy" must be read to mean "therapeutic efficacy".

The Supreme Court was very much aware of the broader debate and controversy surrounding the case, acknowledging arguments made that India is under an obligation to faithfully comply with its treaty commitments countered by arguments to protect India's status as "the pharmacy of the world" and that an error of judgement will put life-saving medicines beyond the reach of a great number of patients not only in India but in many developing and least-developed countries. It found here it was its task to strike a balance between the need to promote scientific and technological research and development while also keeping private monopoly to a minimum. ${ }^{1732}$

The Court started by stating that in order to understand what the law really is, it is essential to know the "why" and "how" of the law. Consequently it examined the legislative history of the law of patents in India, India's membership to the WTO citing the relevant provisions of the TRIPS Agreement it is bound to comply with, and referred to the adoption of the Doha Declaration on TRIPS and Public health. ${ }^{1733}$ The government of India stated that the TRIPS Agreement is sufficiently flexible to enable members to control patent rights in a manner supportive of public health. Consequently it maintained that the patent law of India, as it stands today, is fully TRIPS compliant, but it insisted "that the Indian law must be judged and interpreted on its own terms, and not on the basis of standards of patentability prescribed in some countries of the Western world."1734

The Court recognised the concern, both domestic and internationally, caused by the re-introduction of patent protection for pharmaceutical products taking note of statements made by the WHO and UNAIDS ${ }^{1735}$ and the parliamentary debate on the amendments necessary to bring India's patent law in line with TRIPS standards. ${ }^{1736}$ In that regard, the Court notes that interestingly the appellant in this case, Novartis, repeatedly featured in the debate particularly with respect to the excessively high prices fixed for its product Gleevec after the grant of EMRs and concerns that increasing prices would likely be the result of introducing product patents for pharmaceuticals. ${ }^{1737}$ Moreover, the Court noted that the parliamentary

\footnotetext{
1731 Indian Supreme Court, Novartis AG v. Union of India \& Others, 1 April 2013, Civil Appeal Nos. 2706-2716.

1732 Ibid. at $\$ 4$.

1733 Ibid. at $\$ 4$ et seq.

1734 Ibid. at $\$ 65$.

1735 Ibid. at \$76-77.

1736 Ibid. at $\$ 79$.

1737 Ibid. at $\$ 82$.
} 
debate on the introduction of section 3(d) reveals that the debate centred on medicines and the fears regarding the abuses to which product patents for medicines may be vulnerable. Consequently, the Court is of the opinion that section 3(d) "sets up a second tier of qualifying standards for chemical substances/pharmaceutical products in order to leave the door open for true and genuine inventions but, at the same time, to check any attempt at repetitive patenting or extension of the patent term on spurious grounds." 1738

The first issue for the Supreme Court to decide was whether the mesylate salt form of imatinib had been disclosed and is thus a known substance. The Court found that it was. ${ }^{1739}$ As such, it turned to the beta crystal form of imatinib mesylate examining whether it met the test of section 3(d) of the Patents Act, i.e. does the subject product have any "enhanced efficacy" over the known substance of which it is a new form? ${ }^{1740}$ In that regard, it found a major weakness in Novartis' case, in that it was not clear at all as to what is the substance immediately preceding the subject product. ${ }^{1741}$ Moreover, the efficacy studies reported by Novartis were rather odd as no materials were produced making a comparison of efficacy between the beta crystalline form and the non-crystalline form of imatinib mesylate. ${ }^{1742}$ Rather Novartis demonstrated an enhanced efficacy in comparison to the "free base" form of imatinib, a pharmaceutical not marketed because it is not soluble.

In order to determine enhanced efficacy it had to interpret "efficacy" in the context of section 3(d). It found that the test of efficacy can only be "therapeutic efficacy". Referring to the genesis of section 3(d) and the circumstances in which it was amended, the Court had no doubt that the therapeutic efficacy of a medicine must be judged strictly and narrowly. As such, it is evident to the Court that "not all advantageous or beneficial properties are relevant, but only such properties that directly relate to efficacy, which in case of medicine [...] is its therapeutic efficacy." 1743

The Court found that the physico-chemical properties of the beta crystalline form of imatinib mesylate, properties relating to production and storage (e.g., heat stability) may be otherwise beneficial but cannot be taken into account for the purpose of the section 3(d) test as they have nothing to do with therapeutic efficacy. ${ }^{1744}$ Additionally, as regards the $30 \%$ increased bioavailability, as compared to the imatinib in free base form, it could not be determined as no evidence of superior (therapeutic) efficacy was offered in that regard. ${ }^{1745}$ Consequently, on the basis of the materials brought before this Court, the subject product, that is, the beta

$\begin{array}{ll}1738 & \text { Ibid. at } \$ 103 . \\ 1739 & \text { Ibid. at } \$ 157 . \\ 1740 & \text { Ibid. at } \$ 162 . \\ 1741 & \text { Ibid. at } \$ 165 . \\ 1742 & \text { Ibid. at } \$ 171 . \\ 1743 & \text { Ibid. at } \$ 180 . \\ 1744 & \text { Ibid. at } \S 187 . \\ 1745 & \text { Ibid. at } \$ 189 .\end{array}$ 
crystalline form of imatinib mesylate, failed the test of section 3(d). ${ }^{1746}$ As remarked by Frederick M. Abbot, "[i]t is important to note what the Supreme Court did not say. It did not say that a new form of a known compound may never be patented. It did not say that improving the bioavailability characteristics of the drug may never result in enhanced efficacy." 1747 In that regard the Court stated that it would be "a grave mistake to read this judgment to mean that section 3(d) was amended with the intent to undo the fundamental change brought in the patent regime by deletion of section 5 from the Patent Act" i.e. the reintroduction of patent protection for pharmaceutical products. ${ }^{1748}$

Finally, at the very end of the judgment, the Court remarked that it appeared that what was marketed as Gleevec was actually the older form, imatinib mesylate, and not the subject product, the beta crystalline form of imatinib mesylate. If so, the claim for patent protection for the beta crystalline form would appear as an attempt to obtain a patent for imatinib mesylate, which would not be permissible under the Indian Patents Act, and thus showed Novartis "in rather poor light". 1749

The Supreme Court's verdict was hailed as a victory for patients' right of access to medicines by civil society. ${ }^{1750}$ While the case was under review, domestic and international civil society and health groups organised a mass mobilisation engaging in media and legislative advocacy to raise awareness about the case and Novartis' actions. ${ }^{1751}$ Novartis on the other hand, pointed to the possible detrimental effects the decision would have on its investments, and those of other companies, in research development. Civil society reacted here to by referring to the importance of the US National Institutes of Health and health charities in developing Gleevec. It argued that Novartis did not need a patent in India in order to recoup its research and development costs or protect its profits. ${ }^{1752}$

\subsubsection{PATENT Rights}

Article 28 of the TRIPS Agreement sets out the rights conferred on patent owners granting them an exclusive right to exclude competitors from the market. Moreover, one of the major achievements of the TRIPS Agreement is that it sets out a

\footnotetext{
1746 Ibid. at $\$ 190$.

1747 FREDERICK M. ABOTT, 'Inside Views: The Judgment in Novartis v India: What the Supreme Court of India Said', <www.ip-watch.org/2013/04/04/the-judgment-in-novartis-v-india-whatthe-supreme-court-of-india-said/>, accessed 15 April 2013.

1748 Novartis $A G$ v. Union of India, at $\$ 191$.

1749 Ibid. at $\$ 193$.

1750 See MÉDECINS SANS FRONTIÈRES, 'Indian Supreme Court Delivers Verdict in Novartis Case', <www.msfaccess.org/about-us/media-room/press-releases/indian-supreme-courtdelivers-verdict-novartis-case>, accessed 15 April 2013.

1751 GEORGE, India Position Paper, at 15-16.

1752 See further ELLEN 'T HOEN, 'Commentary. A Victory for Global Public Health in the Indian Supreme Court', Journal of Public Health Policy, (2013).
} 
minimum standard with regard to the patent term, namely a minimum of 20 years. ${ }^{1753}$

Section 48 of the Indian Patents Act states the following:

Subject to the other provisions contained in this Act and the conditions specified in section 47, a patent granted under this Act shall confer upon the patentee -

(a) where the subject matter of the patent is a product, the exclusive right to prevent third parties, who do not have his consent, from the act of making, using, offering for sale, selling or importing for those purposes that product in India;

(b) where the subject matter of the patent is a process, the exclusive right to prevent third parties, who do not have his consent, from the act of using that process, and from the act of using, offering for sale, selling or importing for those purposes the product obtained directly by that process in India.

Furthermore, section 53 provides that the patent term shall be 20 years from the date of filing of the application for the patent. ${ }^{1754}$

\subsubsection{Procedural Mechanisms: Opposition Proceedings \& Revocation}

The Indian Patents Act provides third parties with the opportunity to oppose the grant of a patent under its Chapter V: the pre- and post-grant opposition proceeding.

Section 25(1) of the Indian Patents Act states that "[w]here an application for a patent has been published but a patent has not been granted, any person may, in writing, represent by way of opposition to the Controller against the grant of patent" on the grounds mentioned in sub-sections (a) through (k); for example that the invention is not an invention within the meaning of this Act, is not patentable under this Act, or is obvious and clearly does not involve any inventive step.

Pre-grant opposition is not novel to India's patent system; the 1970 Patents Act first introduced pre-grant opposition procedures, most probably modelled on the

1753 Article 33 TRIPS.

1754 Section 53 of the Patents Act reads as follows:

(1) Subject to the provisions of this Act, the term of every patent granted, after the commencement of the Patents (Amendment) Act, 2002, and the term of every patent which has not expired and has not ceased to have effect, on the date of such commencement, under this Act, shall be twenty years from the date of filing of the application for the patent.

Explanation. - For the purposes of this sub-section, the term of patent in case of International applications filed under the Patent Cooperation Treaty designating India, shall be twenty years from the international filing date accorded under the Patent Cooperation Treaty.

(2) A patent shall cease to have effect notwithstanding anything therein or in this Act on the expiration of the period prescribed for the payment of any renewal fee, if that fee is not paid within the prescribed period or within such extended period as may be prescribed.

(3) [omitted.]

(4) Notwithstanding anything contained in any other law for the time being in force, on cessation of the patent right due to non-payment of renewal fee or on the expiry of the term of patent, the subject matter covered by the said patent shall not be entitled to any protection. 
English patent law of that time. Yet, currently there are only few countries whose patent law includes such a feature. ${ }^{1755}$ India's pre-grant opposition procedure is remarkable in that it has an expansive standing provision. It refers to "any person", which includes generic manufacturers but also civil society. Not surprisingly, the Indian generic pharmaceutical industry favours the possibility of pre-grant opposition, and it is probable that such firms will make frequent use of this option. NGOs and healthcare advocacy groups are also able to take advantage of pre-grant opposition proceedings in challenging the granting of patents on essential medicines. ${ }^{1756}$ Civil society groups have already been very active in opposing patent applications for pharmaceuticals. ${ }^{1757}$ For example, the first patent opposition filed by civil society in India concerned Norvatis' anti-cancer medicine, Gleevec and in 2006 a patent opposition was filed against GlaxoSmithKline's patent application of an ARV, Combivir. As seen above, the Gleevec case ended up at the Supreme Court. Moreover the grounds for pre-grant opposition are broad, including virtually all patentability criteria that also includes lack of an inventive step, noninvention under section 3 or an insufficient or unclear description of the invention in the specification.

Pre-grant opposition works to the benefit of opponents as the grant of a patent may be avoided entirely or delayed for a period during which competitors can continue to manufacture and market the invention without fear of an infringement proceeding. Proponents of strong(er) patents systems, on the other hand, do not favour the preservation of pre-grant opposition in the amended Patents Act as it would unduly lengthen the procedure resulting in the granting of a patent.

Section 25(2) of the Indian Patents Act states "[a]t any time after the grant of patent but before the expiry of a period of one year from the date of publication of grant of a patent, any person interested may give notice of opposition to the Controller in the prescribed manner on any of the following grounds" mentioned in subsection (a) through (k).

Unlike pre-grant opposition, post-grant opposition proceedings are new to India's patent law and were introduced by section 23 of the 2005 Patents (Amendment) Act. Furthermore, post-grant opposition differs from pre-grant opposition in that the standing is limited to "any interest person", explained by section 2(1)t of the Indian Patents Act as including "a person engaged in, or in promoting, research in the same field as that to which the invention relates". The grounds for post-grant opposition are identical to those under pre-grant opposition.

The combination of pre- and post grant opposition within the Indian Patents Act is an important tool in ensuring access to medicines is not diminished in that it effectively filters fortuitous patent claims. ${ }^{1758}$ It allows third parties to assist patent

1755 MUELLER, 'The Tiger Awakens', at 568.

1756 Ibid. at $569-571$.

1757 See further GEORGE, India Position Paper, at 14 et seq.

1758 MEY, 'Unfettered Consumer Access to Affordable Therapies in the Post-TRIPS Era', at 443. 
offices and thus decrease costs of identifying an examining suspect claims by giving examiners information relevant in determining the patentability of an invention. ${ }^{1759}$

There is no specific TRIPS provision regarding opposition and as such the TRIPS compliant nature of the Indian provisions regarding opposition proceedings must be evaluated against the general requirement regarding procedures for the granting of patents. As such TRIPS compatibility will depend on whether it is a "reasonable" procedure as regards article 62 of the TRIPS Agreement. ${ }^{1760}$ Yet "reasonable" is not defined by TRIPS. Thus it has been argued that the provisions regarding opposition in the Indian Patents Act provisions have a clear and legitimate purpose, namely that of improving patent quality and providing relevant information to the patent office. The flexibility of the term "reasonable" and the fact that the TRIPS takes account of the special position of developing countries and the

1759 KAPCZYNSKI, 'Harmonisation and Its Discontents: A Case Study of TRIPS Implementation in India's Pharmaceutical Sector', at 1602.

1760 Article 62 of the TRIPS Agreement reads as follows:

1. Members may require, as a condition of the acquisition or maintenance of the intellectual property rights provided for under Sections 2 through 6 of Part II, compliance with reasonable procedures and formalities. Such procedures and formalities shall be consistent with the provisions of this Agreement.

2. Where the acquisition of an intellectual property right is subject to the right being granted or registered, Members shall ensure that the procedures for grant or registration, subject to compliance with the substantive conditions for acquisition of the right, permit the granting or registration of the right within a reasonable period of time so as to avoid unwarranted curtailment of the period of protection.

3. [...]

4. Procedures concerning the acquisition or maintenance of intellectual property rights and, where a Member's law provides for such procedures, administrative revocation and inter partes procedures such as opposition, revocation and cancellation, shall be governed by the general principles set out in paragraphs 2 and 3 of Article 41.

5. Final administrative decisions in any of the procedures referred to under paragraph 4 shall be subject to review by a judicial or quasi-judicial authority. However, there shall be no obligation to provide an opportunity for such review of decisions in cases of unsuccessful opposition or administrative revocation, provided that the grounds for such procedures can be the subject of invalidation procedures.

Article 41 of the TRIPS Agreement reads as follows:

1. $[\ldots]$

2. Procedures concerning the enforcement of intellectual property rights shall be fair and equitable. They shall not be unnecessarily complicated or costly, or entail unreasonable time-limits or unwarranted delays.

3. Decisions on the merits of a case shall preferably be in writing and reasoned. They shall be made available at least to the parties to the proceeding without undue delay. Decisions on the merits of a case shall be based only on evidence in respect of which parties were offered the opportunity to be heard.

4. $[\ldots]$

5. $[\ldots]$. 
resource constraints developing countries face, is argued to entail that the Indian provisions should meet the requirements set out by TRIPS. ${ }^{1761}$

Finally, the Indian Patents Act also sets out a number of grounds on which a patent may be revoked, ${ }^{1762}$ which is also in line with the requirements of the TRIPS Agreement. ${ }^{1763}$

\subsubsection{Exceptions}

The TRIPS Agreement also provides a number of exceptions to the exclusive rights of patent holders. Firstly, article 30 TRIPS, a more general provision, which establishes three conditions for possible exceptions; secondly, article 31 TRIPS which is more specific and establishes a considerable number of conditions under which a Member may allow for compulsory licensing. The Indian Patents Act also sets out a number of exceptions to the rights conferred under a patent, which will be examined in the next section to determine whether Indian patent law is TRIPS compatible and has taken full advantage of articles 30 and 31 TRIPS to introduce exceptions to patent rights with a view of ensuring access to affordable medicines.

\subsubsection{BOLAR EXCEPTION}

The Indian Patents Act introduces a Bolar exception - that is an exception which allows using a patented pharmaceutical product for the specific purpose of obtaining regulatory approval for an equivalent generic version - in its section 107A(a) which reads as follows:

For the purposes of this Act, -

(a) any act of making, constructing, using, selling or importing a patented invention solely for uses reasonably relating to the development and submission of information required under any law for the time being in force, in India, or in a country other than India, that regulates the manufacture, construction, use, sale or import of any product;

A similarly worded exception was ruled by a Panel to be in conformity with article 30 TRIPS in the Canada Patent Protection for Pharmaceutical Products. ${ }^{1764}$

1761 HO, Access to Medicine in the Global Economy, at 102; KAPCZYNSKI, 'Harmonisation and Its Discontents: A Case Study of TRIPS Implementation in India's Pharmaceutical Sector', at 1604-1605.

1762 See section 64 of the Patents Act. See also THE PATENT OFFICE INDIA, The 2011 Manual of Patent Office Practice and Procedure, (The Office of Controller General of Patents, Designs \& Trademarks) at chapter 12 .

1763 Article 32 TRIPS.

1764 See Canada - Patent Protection for Pharmaceutical Products, at §7.45. "In the Panel's view, however, Canada's regulatory review exception is a 'limited exception' within the meaning of TRIPS Article 30. It is 'limited' because of the narrow scope of its curtailment of Article 28.1 rights. As long as the exception is confined to conduct needed to comply with the requirements 
Thus, the Bolar exception as implemented by section 107A (a) of the Patents Act, is TRIPS compatible. ${ }^{1765}$

\subsubsection{PARAllel Importation}

Since medicines are offered at different prices in different countries, parallel importation allows states to shop around for the medicines offered at the lowest price. This is possible because the TRIPS Agreement leaves every member free to decide what sort of exhaustion regime it wants to implement. ${ }^{1766}$ The TRIPS Agreement gives members the freedom to choose between adopting a national exhaustion regime, where once a product has been put on the market the IP rights of that product are only exhausted in that specific market and not across the border, thus prohibiting parallel importation; or an international exhaustion regime in which the IP rights of a product are exhausted once the product has been legally put on a market anywhere in the world, allowing parallel importation. The freedom to choose between either exhaustion regime, has also been confirmed by the Doha Declaration on TRIPS and Public Health.

Under India's 1970 Patent Act importation was not listed as an exclusive right of the patent holder. ${ }^{1767}$ This changed with the 2005 Patents (Amendment) Act to ensure conformity with the TRIPS Agreement. ${ }^{1768}$ Regarding parallel importation section 107A (b) of the amended Patents Act reads as follows:

importation of patented products by any person from a person who is duly authorised under the law to produce and sell or distribute the product shall not be considered an infringement of patent rights.

Consequently, India adopted an international exhaustion regime allowing for parallel importation. ${ }^{1769}$ Yet the provision is rather ambiguous in that a literal reading would suggest that the first sale need not be authorised by the patent holder. This is a novel interpretation of international exhaustion in that it would allow for cases of parallel importation, for example under a compulsory license, where the

of the regulatory approval process, the extent of the acts unauthorized by the right holder that are permitted by it will be small and narrowly bounded." HO, Access to Medicine in the Global Economy, at 106.

Article 6 TRIPS.

CHAUDHURI, The WTO and India's Pharmaceuticals Industry, at 79.

See article 28 TRIPS and section 48 of the 2005 Patent (Amendment) Act. CHAUDHURI, The WTO and India's Pharmaceuticals Industry, at 79. HO, Access to Medicine in the Global Economy, at 107-108; MEY, 'Unfettered Consumer Access to Affordable Therapies in the Post-TRIPS Era', at 428; MUELLER, 'The Tiger Awakens', at 609. 
Access to Medicines in India

patent holder did not profit from an initial global sale. Consequently this provision is controversial and arguably incompatible with TRIPS. ${ }^{1770}$

\title{
4.1.4.3. Research ANd ExPERIMENTAL Use ExCEPtion
}

Furthermore, section 47(3) of the 1970 Patents Act, which has subsequently not been amended, introduces the so-called research and experimental use exception and reads as follows:

\begin{abstract}
The grant of a patent under this Act shall be subject to the condition that-
3. any machine, apparatus or other article in respect of which the patent is granted or any article made by the use of the process in respect of which the patent is granted, may be made or used, and any process in respect of which the patent is granted may be used, by any person, for the purpose merely of experiment or research including the imparting of instructions to pupils;
\end{abstract}

It has been argued that this exception can also be used for scientific research with commercial purposes. ${ }^{1771}$ However, to avoid any uncertainties it must be clear that third parties may only make or use the patented product with the objective to conduct experiments or research. This exception, as implemented by section 47(3) of the Indian Patents Act, is in principle TRIPS compatible as long as it adheres to the requirements set out in article 30 TRIPS; particularly, that the measure is "limited" but also does not "unreasonably conflict with a normal exploitation of the patent" or "unreasonably prejudice the legitimate interests of the patent owner, taking account of the legitimate interests of third parties". Although this will depend on the circumstances of each case, the wording of the provisions seems to suggest that these requirements are met. Moreover, it is argued that allowing for such experimentation will further the promotion of technological innovation and the transfer and dissemination of technology, which are objectives of the TRIPS Agreement as stated in article 7 TRIPS. Therefore, permitting the experimental use of patented products for R\&D purposes allows domestic companies to develop efficient processes and be ready to use them whenever they are authorised to do so. ${ }^{1772}$

\footnotetext{
1770 HO, Access to Medicine in the Global Economy, at 108. See further SHAMNAD BASHEER and MRINALINI KOCHUPILLAI, "'Exhausting" Paten Rights in India: Parallel Imports and TRIPS Compliance', Journal of Intellectual Property Rights, 13 (2008), 486-497 at 490 et seq.

1771 CHAUDHURI, The WTO and India's Pharmaceuticals Industry, at 80; UNCTAD-ICTSD, Resource Book on TRIPS and Development, at 101.

1772 CHAUDHURI, The WTO and India's Pharmaceuticals Industry, at 80.
} 


\subsubsection{COMPUlsory LicENSING}

A well-functioning compulsory licensing system is one of the main tools advocated to balance protecting IP so as to promote R\&D and ensuring access to the products protected by IP such as medicines. ${ }^{1773}$ Although using compulsory licensing to introduce generic competition will only be effective as long as the required royalty payments are reasonable and the procedure to receive a compulsory licence is simple and easy so as to ensure generic production is still economically viable. ${ }^{1774}$ The question here is whether India has taken advantage of this TRIPS flexibility and introduced a simple and effective compulsory licence system.

Regarding patenting of pharmaceuticals the 1970 Patents Act had a clear objective: to eliminate the monopoly of foreign multinational pharmaceutical corporations and enable domestic firms to manufacture innovative pharmaceuticals it abolished product patents for pharmaceuticals. ${ }^{1775}$ In such a regime, a compulsory licensing system was unnecessary. ${ }^{1776}$ However, now that India has introduced a fully-fledged patent regime, a simple and effective compulsory licensing system will be essential to its ability to ensure adequate access to essential medicines.

For the topic under review, there are three possibilities to grant a compulsory license under the Indian Patents Act: section 84 (three years after the sealing of the patent), section 92 (anytime after the sealing of the patent regarding a patent categorised by the government as eligible for a compulsory licensing) and section 92A (for export of patented pharmaceutical products in certain exceptional circumstances). But before going into detail into these two provision, the general provisions regarding compulsory licensing in the Patents Act will first be addressed.

Chapter XVI on Working of Patents, Compulsory Licenses and Revocation of the Patents Act deals with compulsory licensing. The 2002 Patents (Amendment) Act replaced the entire Chapter XVI of the principal Act, and the 2005 Patents (Amendment) Act makes a number of further changes. Section $83^{1777}$ gives an impressive list of General Principles which must be taken into account when exercising the powers conferred by a patent under the Act, namely:

\footnotetext{
1773 Ibid. at $83-84$.

1774 Ibid. at 86.

1775 Ibid. at 89.

1776 The 1970 Patents Act did provide provisions for compulsory licensing of pharmaceutical processes in sections $87 \& 88$. Every process patent related to a pharmaceutical was to be endorsed with the words "licenses of right" within three years of sealing the patent, allowing anyone to ask for a license to use the patented process on mutually agreed terms. CHAUDHURI, The WTO and India's Pharmaceuticals Industry, at 89.

1777 Section 83 was amended by the 2002 Patents (Amendment) Act. The 1970 Patents Act included only subsection a) and b).
} 
a) that patents are granted to encourage inventions and to secure that the inventions are worked in India on a commercial scale and to the fullest extent that is reasonably practicable without undue delay;

b) that they are not granted merely to enable patentees to enjoy a monopoly for the importation of the patented article;

c) that the protection and enforcement of patent rights contribute to the promotion of technological innovation and to the transfer and dissemination of technology, to the mutual advantage of producers and users of technological knowledge and in a manner conducive to social and economic welfare, and to a balance of rights and obligations;

d) that patents granted do not impede protection of public health and nutrition and should act as instrument to promote public interest specially in sectors of vital importance for socio-economic and technological development of India;

e) that patents granted do not in any way prohibit Central Government in taking measures to protect public health;

f) that the patent right is not abused by the patentee or person deriving title or interest on patent from the patentee, and the patentee or a person deriving title or interest on patent from the patentee does not resort to practices which unreasonably restrain trade or adversely affect the international transfer of technology; and

g) that patents are granted to make the benefit of the patented invention available at reasonably affordable prices to the public.

From a right of access to medicines perspective, the principle listed last is essential as it explicitly states that patents are granted to ensure that the benefits of the patented invention, for example a pharmaceutical product, are available to the Indian public at affordable prices. Moreover, the list contains several references to public health and the right of the government to take measure, to protect the public. It is obvious from this section that the Indian government was very much aware of the problem of accessibility and affordability of patented products including pharmaceuticals when it amended the original 1970 Act. It is also remarkable that sub-section c) and d) are almost identical in wording to article 7 and 8 of the TRIPS Agreement. Similarly, sub-section e) mirrors paragraph 4 of the Doha Declaration on TRIPS and Public Health.

Section 89 states that the powers regarding compulsory licenses (granted under section 84) shall be exercised with a view to secure the following general purposes: that the patented inventions are worked on a commercial scale within India without undue delay and to the fullest extent reasonably possible; and that the interests of any person working or developing an invention protected under patent in India are not unfairly prejudiced. 
A compulsory license may firstly be granted under section 84 of the Patents Act, which states that "at any time after the expiration of three years from the date of the grant of a patent, any person interested may make an application to the Controller for grant of compulsory licence". ${ }^{1778}$ Section $84(1)$ lists three grounds on which a compulsory licence may be granted:

1778 Section 84 of the Patents Act reads as follows:

(1) At any time after the expiration of three years from the date of the grant of a patent, any person interested may make an application to the Controller for grant of compulsory licence on patent on any of the following grounds, namely:

(a) that the reasonable requirements of the public with respect to the patented invention have not been satisfied, or

(b) that the patented invention is not available to the public at a reasonably affordable price, or

(c) that the patented invention is not worked in the territory of India.

(2) An application under this section may be made by any person notwithstanding that he is already the holder of a licence under the patent and no person shall be estopped from alleging that the reasonable requirements of the public with respect to the patented invention are not satisfied or that the patented invention is not worked in the territory of India or that the patented invention is not available to the public at a reasonably affordable price by reason of any admission made by him, whether in such a liccnce or otherwise or by reason of his having accepted such a licence.

(3) Every application under sub-section (1) shall contain a statement setting out the nature of the applicant's interest together with such particulars as may be prescribed and the facts upon which the application is based.

(4) The Controller, if satisfied that the reasonable requirements of the public with respect to the patented invention have not been satisfied or that the patented invention is not worked in the territory of India or that the patented invention is not available to the public at a reasonably affordable price, may grant a licence upon such terms as he may deem fit.

(5) Where the Controller directs the patentee to grant a licence he may, as incidental thereto, exercise the powers set out in section 88 .

(6) In considering the application filed under this section, the Controller shall take into account, -

(i) the nature of the invention, the time which has elapsed since the sealing of the patent and the measures already taken by the patentee or any licensee to make full use of the invention;

(ii) the ability of the applicant to work the invention to the public advantage;

(iii) the capacity of the applicant to undertake the risk in providing capital and working the invention, if the application were granted;

(iv) as to whether the applicant has made efforts to obtain a licence from the patentee on reasonable terms and conditions and such efforts have not been successful within a reasonable period as the Controller may deem fit:

Provided that this clause shall not be applicable in case of national emergency or other circumstances of extreme urgency or in case of public noncommercial use or on establishment of a ground of anti-competitive practices adopted by the patentee, but shall not be required to take into account matters subsequent to the making of the application. 
a) that the reasonable requirements of the public with respect to the patented invention have not been satisfied; 1779

b) that the patented invention is not available to the public at a reasonably affordable price; or

c) that the patented invention is not worked in the territory of India.

Section 84(1) of the Patents Act, which sets out a list of grounds required for the granting of a compulsory licence, is a TRIPS-plus provision in that it goes farther than TRIPS requires. Namely, article 31 TRIPS does not entail a list of grounds permissible or necessary for the issuance of a compulsory license. However, with regard to the issue at stake here - ensuring that patent protection is balanced with adequate access to affordable medicines - the Indian Patents Act provides suitable grounds for compulsory licensing in order to achieve such a balance, particularly the reference to availability of patented invention "at a reasonably affordable price". As such, the issue of reasonable and affordable pricing for patented pharmaceuticals was taken into account when the Patents Act was amended to bring into line with

Explanation.- For the purposes of clause (iv), "reasonable period" shall be construed as a period not ordinarily exceeding a period of six months.

(7) For the purposes of this Chapter, the reasonable requirements of the public shall be deemed not to have been satisfied -

(a) if, by reason of the refusal of the patentee to grant a licence or licences on reasonable terms, -

(i) an existing trade or industry or the development thereof or the establishment of any new trade or industry in India or the trade or industry of any person or class of persons trading or manufacturing in India is prejudiced; or

(ii) the demand for the patented article has not been met to an adequate extent or on reasonable terms; or

(iii) a market for export of the patented article manufactured in India is not being supplied or developed; or

(iv) the establishment or development of commercial activities in India is prejudiced; or

(b) if, by reason of conditions imposed by the patentee upon the grant of licences under the patent or upon the purchase, hire or use of the patented article or process, the manufacture, use or sale of materials not protected by the patent, or the establishment or development of any trade or industry in India, is prejudiced; or

(c) if the patentee imposes a condition upon the grant of licences under the patent to provide exclusive grant back, prevention to challenges to the validity of patent or coercive package licensing, or

(d) if the patented invention is not being worked in the territory of India on a commercial scale to an adequate extent or is not being so worked to the fullest extent that is reasonably practicable, or

(e) if the working of the patented invention in the territory of India on a commercial scale is being prevented or hindered by the importation from abroad of the patented article by -

(i) the patentee or persons claiming under him; or

(ii) persons directly or indirectly purchasing from him; or

(iii) other persons against whom the patentee is not taking or has not taken proceedings for infringement.

1779 Section 84(7) gives a list of situations when the reasonable requirements of the public shall be deemed to have not been satisfied. 
the TRIPS Agreement. However, the Patents Act does not provide any guidance though as to what should be considered "reasonable and affordable", this must be assessed on a case-by-case approach. One could question the consistency of this ground with the non-discrimination principle enshrined in TRIPS. ${ }^{170}$ Yet this ground applies to all inventions, not just pharmaceuticals; and there is therefore no explicit discrimination. If this provision were only used to issue compulsory licences for patented pharmaceuticals there might be an issue of discrimination, although one could try to argue that it would be justified due to public health reasons. ${ }^{1781}$ Furthermore, the ground that a patented invention must be "worked in the territory of India" could also prove problematic. Similar to South African patent law, the question here is whether this provision requires the patent holder to manufacture the patented subject-matter in India or whether "working" the patent also could entail importing the patented product. Namely, from the Canada - Patent Protection for Pharmaceutical Products case it seems that local working requirements are not permitted under the non-discrimination principle of the TRIPS Agreement. On the other hand, there is no definitive WTO ruling on this issue. In 2000 the US requested consultations with Brazil concerning a local working requirement in Brazilian legislation, yet the dispute was resolved without the involvement of a panel. ${ }^{1782}$

Article 31 TRIPS also sets out a number of requirements regarding the procedure for granting a compulsory license and the scope of rights granted under a compulsory license: authorisation on individual merits; prior negotiations; adequate remuneration; review; limited by purpose, non-exclusivity and non-assignable and territoriality.

Any interested person is permitted to make an application for a compulsory license under section 84(1). An application under this section must contain a "statement setting out the nature of the applicant's interest together with such particulars as may be prescribed and the facts upon which the application is based." 1783 The Controller holds a sizeable degree of discretion when it comes to the granting of a compulsory licence, ${ }^{1784}$ since he decides whether one of the three above-mentioned grounds apply and if so he "may grant a licence upon such terms as he may deem fit." 1785 In considering the application, the Patents Act does specifies a number of factors the Controller must take into account, such as the nature of the invention, the time elapsed since the granting of the patent and the

1780 See article 27.1 TRIPS: patents shall be available and patents rights enjoyable without discrimination as to the place of invention, the field of technology and where the products are imported or locally produced. See further chapter 4, section 3.4.4. 
measures taken by the patent holder to work the patent, the ability of the patent holder to work the invention for the public good, the capacity of the applicant to be able to work the invention if the application were granted, and also "whether the applicant has made efforts to obtain a licence from the patentee on reasonable terms and conditions and such efforts have not been successful within a reasonable period" as determined by the Controller. ${ }^{1786}$ Thus, one could reasonably assume that the Controller takes the decision to grant a compulsory license on the basis of the individual merits of each case.

The requirement that the applicant must try to negotiate a voluntary licence before applying for a compulsory licence must not be met in cases of national emergency, other circumstances of extreme urgency, in cases of public noncommercial use, or on the establishment of a ground of anti-competitive practices adopted by the patentee. ${ }^{1787}$ The 2002 Patents (Amendment) Act did not give a time limit for the "reasonable period" an applicant has to try to negotiate a voluntary license with the patent holder. The 2005 Patents (Amendment) Act rectifies this by adding an "explanation" stating that for the purposes of this provision "reasonable period" is considered to mean a period not ordinarily exceeding six months. This is a welcome amendment to the Patents Act, especially since many of the so-called "Big Pharma" corporations are reluctant to issue commercial voluntary licenses. ${ }^{1788}$

Once the Controller has considered the application and is satisfied that a prima facie case has been made for the granting of a compulsory licence, the application must be published, which then entails that the application is open for opposition. ${ }^{1789}$ Any notice of opposition shall set out the grounds on which the application is opposed. ${ }^{1790}$ The Controller shall then notify the patent holder and give both the applicant and the patent holder the opportunity to be heard before deciding the case. ${ }^{1791}$

The Controller decides whether to make an order for the granting of a compulsory license or not, and if he decides to do so, sets out the terms and conditions of that licence. ${ }^{1792}$ In such a case the licensee is granted a broad set of rights: it may not only compete with the patent holder in the manufacturing and marketing of the patented pharmaceutical, but it may also enforce the patent against infringers if the patent holder fails to do so. ${ }^{1793}$ In return the licensee is obliged to pay royalty to the patent holder. For a compulsory licensing scheme to be effective in introducing competition and reducing prices, the required royalty payments may not constitute a barrier to (generic) manufacturers applying for a compulsory license. The Patents Act does not set out the terms and conditions for determining

1786 Section 84(6)i-iv Patents Act.

1787 Section 84(6) Patents Act.

1788 MEY, 'Unfettered Consumer Access to Affordable Therapies in the Post-TRIPS Era', at 431.

1789 Section 87(2) Patents Act.

1790 Section 87(3) Patents Act.

1791 Section 87(4) Patents Act.

1792 Section 90 Patents Act.

1793 Section 110 of the Patents Act. 
such a royalty but does state it must be "reasonable" having regard to "the nature of the invention, the expenditure incurred by the patent holder in making the invention or developing it and obtaining a patent and keeping it in force, and other relevant factors" while also ensuring that "the patented articles are made available to the public at a reasonably affordable price". ${ }^{1794}$ The Controller shall furthermore endeavour to secure: ${ }^{1795}$ that the patented invention is worked to the fullest extent by the licensee and with reasonable profit to him; that the licence granted is nonexclusive and non-assignable; that the licence is for the balance term of the patent unless a shorter term is consistent with public interest; that the licence is granted with the predominant purpose of supplying the Indian market and that the licensee may also export the patented product; ${ }^{1796}$ that in case the licence is granted to remedy a practice determined after a judicial or administrative process to be anticompetitive, the licensee shall be permitted to export the patented product, if need be. ${ }^{1797}$

If a compulsory licence is granted by the Controller there is also the possibility of appealing that decision, which will be considered by an Appellate Board. ${ }^{1798}$ This is in line with the TRIPS Agreements which requires the legal validity of any decision relating to the authorisation of such use shall be subject to judicial review or another independent review by a distinct higher authority. That process is considered to be excessively legalistic allowing patent holders to hold off granting a compulsory licence through litigation. Thus, it could take years before a compulsory licence is actually granted. Moreover, many generic producers may not even apply for a compulsory licence because having to fight the multinational pharmaceutical industry in court will involve substantial legal costs. ${ }^{1799}$

Finally, the patent holder (or any other person deriving title or interest in the patent) may apply to the Controller for the termination of a compulsory licence granted under section 84, if and when the circumstances that gave rise to the granting of a licence have seized to exist and are unlikely to recur. ${ }^{1800}$ The holder of the compulsory license will have a right to object to such a termination. ${ }^{1801}$

Consequently, the framework with regard to compulsory licensing implemented by the Indian Patents Act seems consistent with TRIPS' provisions in that regard. ${ }^{1802}$

\footnotetext{
1794 Section 90(1)i \& iii Patents Act.

1795 Section 90(1) Patents Act.

1796 This clause was inserted by the 2005 Patents (Amendment) Act, section 54.

1797 This clause was inserted by the 2005 Patents (Amendment) Act, section 54.

1798 Section 117A(2) Patents Act.

1799 CHAUDHURI, The WTO and India's Pharmaceuticals Industry, at 92.

1800 Section 94(1) Patents Act.

1801 Section 94(1) Patents Act.

1802 See also HO, Access to Medicine in the Global Economy, at 144 et seq.
} 


\section{S. 92 Patents Act: National Emergency, Circumstance of Extreme Urgency or Public Non-commercial Use}

In addition to section 84 , there is another section which may provide the basis for compulsory licensing, namely section 92 of the Indian Patents Act. Section 92(1) reads as follows:

If the Central Government is satisfied, in respect of any patent in force in circumstances of national emergency or in circumstances of extreme urgency or in case of public non-commercial use, that it is necessary that compulsory licences should be granted at any time after the sealing thereof to work the invention, it may make a declaration to that effect, by notification in the Official Gazette, and thereupon the following provisions shall have effect, that is to say-

(i) the Controller shall, on application made at any time after the notification by any person interested, grant to the applicant a licence under the patent on such terms and conditions as he thinks fit;

(ii) in settling the terms and conditions of a licence granted under this section, the Controller shall endeavour to secure that the articles manufactured under the patent shall be available to the public at the lowest price consistent with the patentees deriving a reasonable advantage from their patent rights.

The same procedure applies as for compulsory licenses under section 84 of the Patents Act. ${ }^{1803}$ The main difference is that in a situation of emergency the applicant is not required to first try to negotiate a voluntary licence with the patent holder. ${ }^{1804}$

Furthermore, if the Controller believes that, after considering the application, it is necessary in a circumstance of national emergency, or extreme urgency or in case of public non-commercial use (including public health crises relating to HIV/AIDS, tuberculosis, malaria or other epidemics) which may arise or is required, he shall not apply the procedure set out under section 87 (i.e. opposition against the grant of a compulsory license). ${ }^{1805} \mathrm{But}$, as soon as it is practicable, he shall inform the patent holder concerned. ${ }^{1806}$ This is a positive amendment to the 1970 Patents Act which, if there would be a simple and easy to administer procedure, could prove very useful in granting compulsory licenses to bring medicine prices down. ${ }^{1807}$ Unfortunately, the Patent Rules have not done so. Moreover, it must be noted that even though the normal procedure does not apply, any decision by the Controller under section 92 can be challenged and referred to the Appellate Board. ${ }^{1808}$

\footnotetext{
1803 Moreover, sections 83, 87, 88, 89 and 90 shall apply in the same way to the grant of licences under section 92 as they do to licenses granted under section 84. See section 92(2) Patents Act.

1804 CHAUDHURI, The WTO and India's Pharmaceuticals Industry, at 97.

1805 Section 92(3) Patents Act.

1806 Section 92(3) Patents Act.

1807 CHAUDHURI, The WTO and India's Pharmaceuticals Industry, at 97.

1808 Section 117A(2) Patents Act.
} 


\section{S. 92 A Patents Act: Export of Patented Pharmaceutical Products}

Concern was raised with respect to the article 31(f) TRIPS requirement that use under a compulsory license must be "predominately for the supply of the domestic market" and the usefulness of compulsory licensing for developing members, which lack adequate manufacturing capacity. ${ }^{1809}$ Moreover, India's generic pharmaceutical industry is largely targeted at foreign markets. Consequently, the 2005 Patents (Amendment) Act has implemented the WTO General Council Decision of 2003 providing a temporary waiver to the limitation of article 31(f) TRIPS. ${ }^{1810}$ Section 92A of the Patents Act allows for compulsory licensing for the export of patented pharmaceutical products in certain exceptional circumstances. ${ }^{1811}$ It prescribes that compulsory licenses shall be available for the manufacture and export of patented pharmaceutical products to countries with insufficient manufacturing capacity to enable them to address public health problems, on the condition that such a country issues a compulsory license or grants a notification allowing the importation of patented products from India. The latter a mere notification by the importing country does not seem entirely in line with the General Council Decision, which specifically requires a compulsory license from the exporting and importing member assuming that the pharmaceutical product intended for export is also patented in the importing member. Moreover, section 92A nowhere refers to the obligation of the Indian government to specify the amount of the pharmaceuticals that will be exported, to specially label or mark those products, or to make public the information concerning the export.

\footnotetext{
1809 See section 5.1 of chapter 5.

1810 WTO GENERAL COUNCIL, 2003 Decision on the Implementation of Paragraph 6 of the Doha Declaration, (WT/L/540). HESTERMEYER, Human Rights and the WTO, at 261 et seq.
}

1811 Section $92 \mathrm{~A}$ of the Patents Act reads as follows:

(1) Compulsory licence shall be available for manufacture and export of patented pharmaceutical products to any country having insufficient or no manufacturing capacity in the pharmaceutical sector for the concerned product to address public health problems, provided compulsory licence has been granted by such country or such country has, by notification or otherwise, allowed importation of the patented pharmaceutical products from India.

(2) The Controller shall, on receipt of an application in the prescribed manner, grant a compulsory licence solely for manufacture and export of the concerned pharmaceutical product to such country under such terms and conditions as may be specified and published by him.

(3) The provisions of sub-sections (1) and (2) shall be without prejudice to the extent to which pharmaceutical products produced under a compulsory licence can be exported under any other provision of this Act.

Explanation. - For the purposes of this section, "pharmaceutical products" means any patented product, or product manufactured through a patented process, of the pharmaceutical sector needed to address public health problems and shall be inclusive of ingredients necessary for their manufacture and diagnostic kits required for their use. 


\subsubsection{GOVERNMENT USE}

Public use or government use is a standard feature in most patent laws around the world. In the Indian Patents Act this is in Chapter XVII, Use of Inventions for Purposes of Government and Acquisition of Inventions by Central Government (sections 99-103). Since India did not previously have a product patent regime for pharmaceuticals, it did not use these special provisions to make medicines more affordable and accessible. ${ }^{1812}$ There is, therefore, no history of such use. It is argued that, as a result of the previous lack of use of these provisions regarding governments use, the effectiveness there of in enhancing medicines' affordability will depend on the existence of efficient administrative and judicial systems. Another factor will be the manner in which India will be able to deal with the pressure by other governments, especially from developed countries, trying to dissuade effective use of these provisions by the Indian government. ${ }^{1813}$

Section 99 of the Patents Act states that "for the purposes of this Chapter, an invention is said to be used for the purposes of Government if it is made, used, exercised or vended for the purposes of the Central Government, a State Government or a Government undertaking." Section 100 of the Patents Act, sets out the powers of the central government regarding the use of invention for public use. It provides that notwithstanding anything contained in the Patents Act, the Central Government (or any person authorised) may, at any time after an application for a patent has been made or a patent has been granted, use the invention for government purposes in accordance with the provision of this chapter. ${ }^{1814}$ Section 100(2) reads as follows:

Where an invention has, before the priority date of the relevant claim of the complete specification, been duly recorded in a document, or tested or tried, by or on behalf of the Government or a Government undertaking [...] any use of the invention by the Central Government or any person authorised in writing by it for the purposes of Government may be made free of any royalty or other remuneration to the patentee.

Moreover, section 100(3) reads as follows:

If and so far as the invention has not been so recorded or tried or tested as aforesaid, any use of the invention made by the Central Government or any person authorised by it under sub-section (1), at any time after the grant of the patent or in consequence of any such communication as aforesaid, shall be made upon terms as may be agreed upon either before or after the use, between the Central Government or any person authorised under sub-section (1) and the patentee, or, as may in default of agreement be determined by the High Court on a reference under section 103:

1812 CHAUDHURI, The WTO and India's Pharmaceuticals Industry, at 95.

1813 Ibid. at 96.

1814 Section 100(1) Patents Act. 
Provided that in case of any such use of any patent, the patentee shall be paid not more than adequate remuneration in the circumstances of each case, taking into account the economic value of the use of the patent.

The authorisation to use inventions for government purposes may be given at any time, either before or after the grant of a patent and either before or after the acts in respect of which such authorisation is given or done, and to any person. ${ }^{1815}$ Furthermore, in case of government use, under this section the Government must notify the patent holder of such use as soon as practicable, except in cases of national emergency or other circumstances of extreme urgency or for non-commercial use. ${ }^{1816}$ The right to make, use, exercise and vend an invention for Government purposes under this section shall include the right to sell, on a non-commercial basis, the goods which have been made in exercise of that right; and a purchaser of goods so sold, and a person claiming through him, shall have the power to deal with the goods as if the Central Government or the person authorised under section 100(1) were the patent holder of the invention. ${ }^{1817}$ The 2002 Patents (Amendment) Act restricted the government's power to sell the goods, under this section of the Patents Act, only on a non-commercial basis. Although this a significant change compared to the original 1970s Patent Act, the government still has wide ranging powers under this section, powers which can be utilised to make medicines more affordable. ${ }^{1818}$ As long as the government does not intend to make a profit there from, these provisions of the Indian Patents Act should be TRIPS compliant. ${ }^{1819}$ Finally, section 103 of the Patents Act includes the possibility to refer a dispute regarding government use by the government of an invention to the High Court.

\subsection{Conclusion}

The aim of this section was to determine whether India's patent legislation has implemented TRIPS' standards and flexibilities with regard to the patenting of pharmaceuticals which will be briefly recapped here. The Patent Act's provisions which implement TRIPS' patent standards which were examined are:

- Section 4 of the 2005 Patents (Amendment) Act repealed the prohibition of product patents for pharmaceuticals;

- Section 2(1)j of the Patents Act defines "invention" as a "new product or process involving an inventive step and capable of industrial application";

\footnotetext{
1815 Section 100(4) Patents Act.

1816 Section 100(5) Patents Act.

1817 Section 100(6) Patents Act.

1818 CHAUDHURI, The WTO and India's Pharmaceuticals Industry, at 96.

1819 Ibid; KAPCZYNSKI, 'Harmonisation and Its Discontents: A Case Study of TRIPS Implementation in India’s Pharmaceutical Sector', at 1612.
} 
- Section 3(d) of the Patents Act: defines inventions considered not patentable with a view to prevent ever-greening. The TRIPS compatibility of this provision is contested, however, TRIPS leaves members the freedom to decide on the appropriate implementation of TRIPS requirements. As such this provides a useful tool to ensure that patent protection is not granted for minor inventions in the field of pharmaceuticals;

- Section 48 of the Patents Act set outs the exclusive rights for patent holders; and

- Section 53 of the Patents Act grants patent holders a 20 year patent term.

Secondly the exceptions, the Indian Patents Act allows for and whether these are compatible with articles 30 and 31 TRIPS are examined:

- Section 107A(a) of the Patents Act provides for a Bolar exception;

- Section 107A(b) of the Patents Act provides for the possibility of parallel importation;

- Section 47(3) of the Patents Act provides for a research and experimental use exception;

- Section 84 of the Patents Act provides for compulsory licensing with respect to public requirements, including availability at an affordable price and the nonworking of a patent;

- Section 92 Patents Act provides for compulsory licensing in case of national emergency, circumstance of extreme urgency or public non-commercial use;

- Section 92A Patents Act provides for compulsory licensing for the export of patented pharmaceutical products. Herewith the Indian Patents Act implements the WTO General Council Decision of 2003 providing a temporary waiver to the limitation of article 31(f) TRIPS; and

- Section 99 of the Patents Act provides for government use of a patented pharmaceutical.

Consequently the Indian Patents Act incorporates a wide range of measures for the government to take in order to ensure that medicines are available, accessible and affordable. ${ }^{1820}$

The changes made to the original 2004 Ordinance through the 2005 Patents (Amendment) Act are indicative of the flexibility incorporated into the Indian patent system, allowing a balance between stimulating innovation and economic growth and preserving the right to health. ${ }^{1821}$ This means that the government's application

1820 MEY, 'Unfettered Consumer Access to Affordable Therapies in the Post-TRIPS Era', at 455.

1821 See also PRABHU RAM, 'India's New “TRIPS-Compliant” Patent Regime. Between Drug Patents and the Right to Health', Chicago-Kent Journal of Intellectual Property, 5 (2006), 195-206 at 205.

Contrary: MEY, 'Unfettered Consumer Access to Affordable Therapies in the Post-TRIPS Era', at 456. Mey advises India to consider revising certain provisions of its Patents Act that, according to her, are directly or indirectly in conflict with TRIPS or that may, in the long run, prevent foreign and domestic innovators from investing in health-related research. Examples 
of the Patents Act is absolutely critical to the effectiveness of the flexibility in the Patents Act. India's interpretation through statutes, case law and regulations will determine the degree to which the Act will preserve or diminish access to medicines. ${ }^{1822}$ Moreover, it has been questioned whether India has the institutional capacity to implement its strengthened patent system. ${ }^{1823}$

A number of issues with respect to the TRIPS compatibility of some provisions remain open, for example section 11a (7) and the local working requirement under section No. 84. In the end TRIPS compliance will depend mainly on the manner in which India implements and effectuates those provisions. Furthermore any ambiguous terms in the Patent Act need to be defined in order to prevent misunderstandings and disagreements in law, which might lead to drawn out court cases as was the situation regarding section 3(d) of the Patents Act in the Novartis case. ${ }^{1824}$

Concluding, the Indian Patents Act is in many ways an example of how developing members can take full advantage of the TRIPS flexibilities in order to strike a balance between access to medicines and patent protection.

\section{TRIPS-PLUS DEVELOPMENTS}

The TRIPS flexibilities are only useful to the extent that they allow members the regulatory freedom to adapt their national IP systems with a view to promoting access to medicines. However, the manner in which TRIPS' flexibilities are often interpreted does not give members that freedom, or in the very least it does not give them enough freedom to utilise the manoeuvring room within the TRIPS Agreement fully. This becomes apparent for example in the negotiation of so-called TRIPS-plus free trade agreements establishing IP standards going above and beyond the minimum standards required by TRIPS.

The EU and India initiated negotiations on a bilateral free trade and investment agreement in June 2007, with the initial intent to conclude negotiations by the end of 2009; yet at the time of writing - April 2013 - such an agreement has not yet been concluded. The negotiations have witnessed many hurdles with both sides having major differences on crucial issues. Moreover, much of the negotiations are being conducted out of the view of the public and thus also without public accountability. Consequently NGOs have voiced their concern about several provisions within drafts of the agreement that would have serious negative implications for access to medicines and public health. With the progression of the

mentioned include: compulsory licensing, parallel importation, giving immunity to generic manufacturers to continue producing generic alternative of new medicines, which are in the mailbox, restricting what may be patented among others.

BHATTACHARYA, 'Are Developing Countries Going Too Far on TRIPS?', at 404.

1823 MUELLER, 'The Tiger Awakens', at 613 et seq.

1824 MEY, 'Unfettered Consumer Access to Affordable Therapies in the Post-TRIPS Era', at 423. 
negotiation, some of these provisions have been removed, for example those in relation to patent term extensions. The agreement will also not introduce data exclusivity provisions. In that regard the EU has publicly acknowledged India's right and capacity to manufacture and export life-saving medicines to other developing countries facing public health problems. Consequently it proposed to include in the FTA a clause to ensure that nothing in it would limit India's freedom to do so in accordance with the TRIPS Agreement and the Doha Declaration on the TRIPS Agreement and Public Health. ${ }^{1825}$ However, concern among civil society and health advocacy groups on the possible impact of the Agreement remains particularly with respect to the enforcement and investment provisions of the draft agreement which are argued to go beyond the requirements of TRIPS. ${ }^{1826}$ This concern has been shared by the CESCR. 1827

In addition to the conclusion of TRIPS-plus agreements by developed countries demanding for higher standards of IP protection, multinational pharmaceutical corporations have also advocated that TRIPS-plus requirements be included in Indian patent law. Moreover, companies have approached the court system in order to bring about a policy change in favour of stronger IP protection. ${ }^{1828}$ See for example the Novartis case discussed above, but also, for example, the case of Bayer which has filed a case before the Delhi High Court in 2008 against the Government of India and an Indian pharmaceutical company seeking the Court to restrain the drug regulatory authority from granting marketing approval to Cipla's generic version of its anti-cancer medicine as this would, allegedly, violate Bayer's patent. Herewith Bayer intends to introduce patent linkages.

\section{Conclusion}

The research questions addressed in this chapter is twofold. Firstly, has India complied with its obligations under international human rights law by recognising a human right access to medicines? As was shown, the Indian Constitution incorporates a duty to protect public health, however, as a non-justiciable DPSP. Yet the Supreme Court, through its progressive stance has interpreted the fundamental and justiciable right to life to include a number of socio-economic rights, including a right to health. In view of the Supreme Court's case law, the right to life would therefore also entail a right of access to medicines. The Supreme Court did acknowledge the principle of separation of powers and accepted that resources are not unlimited and that, therefore, the right to health could not be considered

\footnotetext{
1825 See EU, 'Factsheet - Access to Medicines and the Eu-India Trade Negotiations', <http://trade. ec.europa.eu/doclib/html/150989.htm>, accessed 24 May 2013.

1826 See for example MÉDECINS SANS FRONTIÈRES, Briefing Document. The Enforcement Provisions of the Eu - India FTA. Implications for Access to Medicines, Médecins Sans Frontières Access Campaign, (January 2013).

1827 CESCR, Concluding Observations: India, (UN Doc. E/C.12/IND/CO/5) at $\$ 46$.

1828 GEORGE, India Position Paper, at 13.
} 
absolute, but it must be realised progressively. By interpreting the right to life to include health-related rights, the Supreme Court allows individuals the opportunity to approach the court system directly to seek redress in case their right to health and/or access to medicine has been violated. Thus, Public Interest Litigation and judicial activism has proven to be essential in strengthening the standing of socioeconomic rights within the Indian legal system

Secondly it is addressed here whether India has complied with its obligations under the TRIPS Agreement to implement TRIPS' minimum standards and flexibilities with a view to balancing access and protecting patents. As was shown, the Indian Patents Act no longer denies product patents for pharmaceutical products, and now in line with its obligations under TRIPS it allows for the granting of patent protection for an invention, which is a new product or process involving an inventive step and capable of industrial application, granting the patent holder exclusive rights for the 20 year patent term. The amendment of the Patents Act sparked much public debate on the effect of patent protection on access to medicines, also by civil society. It shows that India was well aware of the possible implications of TRIPS compliance with regard to access to affordable medicines.

The Patents Act furthermore implements a wide range of measures to ensure that a balance can be struck between granting patent protection on the one hand and ensuring such protection does not hinder access on the other. One of the most innovative ways in which it does so is by employing a wide definition of not patentable inventions in its section $3 \mathrm{~d}$ and therewith effectively preventing "evergreening". Furthermore, it introduces a number of concrete options, such as a Bolar exception, a research and experimental use exceptions, parallel importation, government use and a compulsory licensing system. Thus we see that India has implemented the TRIPS flexibilities according to the Doha Declaration within their legislative framework; particularly its section 3(d) of the Patents Act is a creative and useful tool to ensure patents are only granted if these indeed are truly novel and inventive inventions. Moreover, it has incorporated an extensive compulsory licensing framework. Therefore the existing legal framework provides the tools in order to balance protection for patent in line with TRIPS' requirements while also ensuring access to a sustainable supply of affordable medicines. ${ }^{1829}$ Moreover, India is best suited to take full advantage of the TRIPS flexibilities because it has the capacity and infrastructure to produce generic medicines on a large scale. However, some problems remain with regard to the effective exploitation of TRIPS' flexibilities, such as TRIPS-plus developments and especially the hard-line stance of the multinational pharmaceutical industry with respect to safeguarding IPRs. 


\section{Chapter 8 Access to Medicines in Uganda}

\section{INTRODUCTION}

The final and third country study conducted in this research is on Uganda. Uganda is classified as a low income country with a GNI per capita of US\$500 (2010): ${ }^{1831}$ it has a poverty headcount ratio of $24.5 \%$ of the population; a life expectancy of 53 years; and an under-five mortality rate of 98.9. Being a leastdeveloped country it has high poverty and morbidity and mortality levels. Even so, it is one of the few African countries that has had declining HIV rates and performs above expected in its response to HIV/AIDS. ${ }^{1832}$ The costs of antiretroviral medicines to manage HIV have decreased in the last two decades, although they are still unaffordable for many Ugandans. Most medicines are imported from countries such as China and India, and with the TRIPS transition period ending for India prices for second generation pharmaceuticals will most probably rise in the future. This is a serious problem as Uganda has limited drug manufacturing capacity.

Uganda is a member of the World Trade Organisation since January $1^{\text {st }}, 1995$, and therefore it is bound by the TRIPS Agreement. ${ }^{1833}$ However, as a leastdeveloped country, it benefits from the extension of the TRIPS transitional periods which allows it to implement TRIPS (except for articles 3, 4 and 5 TRIPS) until 1 July $2021 .{ }^{1834}$ Uganda has already started the process of reforming its intellectual property system in order to bring it in line with the TRIPS' requirements. In that regard, this chapter first examines whether and to what extent Uganda already provides patents for pharmaceuticals. Moreover, the question will posed whether the draft Industrial Property Bill fully implements TRIPS standards and flexibilities with a view to achieving a balance between access and protecting patents within their legal framework.

This chapter aims to examine the issue of lack of access to medicines from a least-developed country perspective. First, though, a closer look will be had at the problem of lack of access to medicines in Uganda from a least-developed country perspective (section 2). Thereafter, the question is posed whether Uganda has

1831 See http://data.worldbank.org/country/uganda?display=graph last accessed at 27 October 2011.

1832 See for example DESMOND et al., 'Relative Response: Raking Country Responses to HIV/ AIDS'.

1833 See www.wto.org/english/thewto_e/countries_e/uganda_e.htm.

1834 See article 66.1 TRIPS. WTO COUNCIL FOR ${ }^{-}$TRADE-RELATED ASPECTS OF INTELLECTUAL PROPERTY RIGHTS, Extension of the Transition Period under Article 66.1 for Least Developed Members, (IP/C/64). Additionally, article 65.5 TRIPS does not apply to article 66 , and, thus also not to least-developed countries, which left them free to roll back their level of IP protection and make full use of the transition periods. 
complied with its obligation under international human rights law with respect to guaranteeing access to affordable medicines by examining the constitutional and legislative framework (section 3); and whether, and to what extent, it has implemented TRIPS' patent standards and flexibilities (section 4). Finally the essential question is posed namely whether Uganda has been able to strike a balance between protection of patents for pharmaceuticals and access to such pharmaceuticals (section 5).

\section{Least-Developed Countries and Access to Medicines}

The purpose of this section is to set out the contextual framework with regard to the issue of access to medicines for patients in Uganda. Setting out the different aspects that play a role in this issue will enable an understanding of the complex nature of the issue at hand and put the research questions into broader context. In that regard it must mentioned that the issue of access to medicines is a complex and multifaceted problem, particularly in the context of least-developed countries. The role of patent protection and its effect on access is just one element, however a considerable one, in addressing this problem.

Firstly, a number of health- and IP-related indicators with respect to Uganda will be set out. Uganda is classified as a low income country with a GNI per capita of US\$500 (2010); ${ }^{1835}$ it has a poverty headcount ratio of $24.5 \%$ of the population; a life expectancy of 53 years; and an under-five mortality rate of 98.9. Furthermore:

- Health expenditure per capita:1836 US\$42.5 compared to a global health expenditure per capita of US\$863.6 (2009). ${ }^{1837}$

- Public health expenditure as percentage of total health expenditure: ${ }^{1838}$ 19\% compared to the global rate of $60.8 \%$ (2009). ${ }^{1839}$

1835 See http://data.worldbank.org/country/uganda?display=graph last accessed at 27 October 2011.

1836 Total health expenditure is the sum of public and private health expenditures as a ratio of total population. It covers the provision of health services (preventive and curative), family planning activities, nutrition activities, and emergency aid designated for health but does not include provision of water and sanitation. Data are in current U.S. dollars.

1837 See http://data.worldbank.org/indicator/SH.XPD.PCAP/countries/1W-UG?display=graph last accessed at 27 October 2011.

1838 Public health expenditure consists of recurrent and capital spending from government (central and local) budgets, external borrowings and grants (including donations from international agencies and nongovernmental organizations), and social (or compulsory) health insurance funds. Total health expenditure is the sum of public and private health expenditure. It covers the provision of health services (preventive and curative), family planning activities, nutrition activities, and emergency aid designated for health but does not include provision of water and sanitation.

1839 See http://data.worldbank.org/indicator/SH.XPD.PUBL/countries/1W-UG?display=graph last accessed 27 October 2011. 
- Total health expenditure as percentage of the GDP:1840 $8.2 \%$ compared to the global rate of $10 \%$ (2009). ${ }^{1841}$

- Maternal mortality ratio: ${ }^{1842} 430$ compared to the global ratio of 260 (2008). ${ }^{1843}$

- The infant mortality rate: ${ }^{1844} 63$ compared to the global ratio of 41 (2010). ${ }^{1845}$

- The out-of-pocket health expenditure as a percentage of private expenditure on health: ${ }^{1846} 65.4 \%$ compared to the global rate of $46.2 \%$ (2009). ${ }^{1847}$

- Prevalence of HIV as a percentage of total population: ${ }^{1848} 6.5 \%$ compared to the global rate of $0.8 \%$ (2009). ${ }^{1849}$

- Patent applications by non-residents: ${ }^{1850} 1$ (2007). ${ }^{1851}$

- Patent applications by residents: 6 (2007). ${ }^{1852}$

Uganda is a country coping with severe public health problems. In Uganda, between 70,000 and 110,000 people die from malaria every year; over a million of people

1840 Total health expenditure is the sum of public and private health expenditure. It covers the provision of health services (preventive and curative), family planning activities, nutrition activities, and emergency aid designated for health but does not include provision of water and sanitation.

1841 See http://data.worldbank.org/indicator/SH.XPD.TOTL.ZS/countries/1W-UG?display=graph last accessed 27 October 2011.

1842 Maternal mortality ratio is the number of women who die during pregnancy and childbirth, per 100,000 live births. The data are estimated with a regression model using information on fertility, birth attendants, and HIV prevalence.

1843 See http://data.worldbank.org/indicator/SH.STA.MMRT/countries/1W-UG?display=graph last accessed 27 October 2011.

1844 Infant mortality rate is the number of infants dying before reaching one year of age, per 1,000 live births in a given year.

1845 See http://data.worldbank.org/indicator/SP.DYN.IMRT.IN/countries/1W-UG?display=graph last accessed 27 October 2011.

1846 Out of pocket expenditure is any direct outlay by households, including gratuities and in-kind payments, to health practitioners and suppliers of pharmaceuticals, therapeutic appliances, and other goods and services whose primary intent is to contribute to the restoration or enhancement of the health status of individuals or population groups. It is a part of private health expenditure.

1847 See http://data.worldbank.org/indicator/SH.XPD.OOPC.ZS/countries/1W-UG?display=graph last accessed 27 October 2011.

1848 Prevalence of HIV refers to the percentage of people ages 15-49 who are infected with HIV.

1849 See http://data.worldbank.org/indicator/SH.DYN.AIDS.ZS/countries/1W-UG?display=graph last accessed 27 October 2011.

1850 Patent applications are worldwide patent applications filed through the Patent Cooperation Treaty procedure or with a national patent office for exclusive rights for an invention - a product or process that provides a new way of doing something or offers a new technical solution to a problem. A patent provides protection for the invention to the owner of the patent for a limited period, generally 20 years.

1851 See http://data.worldbank.org/indicator/IP.PAT.RESD/countries/1W-UG?display=graph last accessed 27 October 2011.

1852 See http://data.worldbank.org/indicator/IP.PAT.RESD/countries/1W-UG?display=graph last accessed 27 October 2011. 
have died as a result of contracting HIV/AIDS. ${ }^{1853}$ The appalling public health situation is perpetuated by Uganda's high poverty levels. ${ }^{1854}$ Uganda's poor and vulnerable have severely limited access to life-saving medicines, even though medicine prices have decreased in the last decade, they are still unaffordable for the majority of Ugandans. In 2005, just over 50\% of those in need of antiretroviral treatment received such treatment. It is estimated that over 100,000 people in Uganda require antiretroviral treatment. ${ }^{1855}$ Prices for ARVs have decreased in Uganda in recent years, yet considering the poverty levels in Uganda, the medicines are still too costly for many Ugandans. Consequently, indicators of affordability of medicines suggest that the price households pay for medicines is an obstacle to households accessing medicines. ${ }^{1856}$ The harsh reality of Ugandan life is that in many cases poverty forces people to make a choice between health expenditure and crucial expenditures such as food, shelter and education.

The first case of HIV/AIDS detected in Uganda was in 1982. ${ }^{1857}$ The early spread of the epidemic was severe and by 1987 Uganda was the epicentre of the disease. ${ }^{1858}$ Not long after, that the National Resistance Movement came to power and adopted a policy of openness, frankness and truth which made the HIV/AIDS epidemic one of the most publicised campaigns in the country. ${ }^{1859}$ The government sought expert advice and assistance internationally, including from the WHO. An open and multidimensional approach has set an unprecedented record in that it not just halted but reversed the spread of the HIV virus in Uganda. It is the only country where infection rates steadily decreased over time from a staggering $37 \%$ in the 1990 s to about $6.5 \%$ at this point in time, representing less than one million Ugandans. ${ }^{1860}$ Yet, this does not in any way mean that Uganda now is no longer suffering under the HIV/AIDS pandemic. The political will and commitment to fight the epidemic, strong government leadership as well as broad-based partnership

1853 BEN KIROMBA TWINOMUGISHA, 'Implications of the TRIPS Agreement for the Protection of the Right of Access to Medicines in Uganda', Malawi Law Journal, 2:2 (2008), 253-278 at 253-254.

1854 Depending on the area poverty levels (that is the percentage of the population living under the poverty line) range between $31 \%$ and $60 \%$.

1855 TWINOMUGISHA, 'Implications of the TRIPS Agreement for the Protection of the Right of Access to Medicines in Uganda', at 254.

1856 See UGANDAN MINISTRY OF HEALTH, Access to and Use of Medicines by Households in Uganda. Report of a Survey Conducted 2008 (December 2008).

1857 GEORGE W. KANYEIHAMBA, Kanyeihamba's Commentaries on Law, Politics and Governance (Kampala: Renaissance Media, 2006) at 116.

1858 MUBANGIZI and TWINOMUGISHA, 'The Right to Health Care in the Specific Context of Access to HIV/AIDS Medicines', at 106.

1859 See for more information JOSEPH TUMUSHABE, The Politics of HIVIAIDS in Uganda, United Nations Research Institute for Social Development, Social Policy and Development Programme Paper No. 28, (August 2008).

1860 KANYEIHAMBA, Kanyeihamba's Commentaries on Law, Politics and Governance, at 116117. 
and a widespread public education campaign are reasons Uganda has been successful in reversing the HIV/AIDS epidemic. ${ }^{1861}$

The socio-economic burden of diseases such as TB, malaria and HIV is enormous, especially for young adults, in that it impacts their ability to work and leads to a loss in earnings. Many patients have to spend their limited resources on treatment. As such, the disease does not just affect the patient alone but also their families who have to pitch in or are dependent on the patient.

Uganda's health care system is liberalised; government facilities operate alongside the private health sector. In 1993 Uganda decentralised its health care system and incorporated the Primary Health Care Strategy (PHC) as the key component of its decentralisation policy. The PHC concept is derived from the 1978 Alma-Ata International Conference on Primary Health Care and entails that essential health care is based on practical, scientifically sound and socially acceptable methods and technology made universally accessible to individuals and families in the community through their full participation and at a cost that the community can afford to maintain at every stage of their development in the spirit of self-determination. ${ }^{1862}$

Uganda's health system has had some problems in guaranteeing the availability and accessibility of health care services and goods. ${ }^{1863}$ Firstly, the Ugandan health sector is generally underfunded. According to a report on the right to health care in Uganda by the Foundation for Human Rights Initiative, the lack of available medicines is a major shortfall in the quality of health care in Uganda. ${ }^{1864}$ The National Drug Authority has been criticised as being ineffective in controlling the sale of medicines throughout the countries with devastating consequences. ${ }^{1865}$ Patients are able to purchase medicines without consultation by a professional which can result in an overdose or under dose, or they have received expired or counterfeit medicines which in the worst case scenario can lead to death.

There have also been problems with the government's procurement of medicines policy, resulting in perpetual drug stock-outs. It has been documented that many health facilities regularly run out of even the most basic medicines. ${ }^{1866}$ The National Medical Stores (NMS) are responsible for procuring and distributing essential

1861 MUBANGIZI and TWINOMUGISHA, 'The Right to Health Care in the Specific Context of Access to HIV/AIDS Medicines', at 106-107.

1862 WHO, Declaration of Alma-Ata.

1863 See for the full report on the right to healthcare in Uganda FHRI, The Right to Healthcare in Uganda. Report for the Period January - June 2010, Foundation for Human Rights Initiative, (2010). See also HEPS-UGANDA, Right to Essential Medicines. Tracking Uganda's Health Sector in Budgeting, Financing and Delivery of Essential Medicines, Coalition for Health Promotion and Social Development, (August 2010).

1864 FHRI, The Right to Healthcare in Uganda. Report for the Period January - June 2010, at 30.

1865 TENYWA ALOYSIUS MALAGALA, 'Human Rights-Based Accountability for Healthcare in Uganda', East African Journal of Peace \& Human Rights, 17:1 (2011), 89-124 at 95.

1866 FHRI, The Right to Healthcare in Uganda. Report for the Period January - June 2010, at 8. 
medicines to health facilities throughout Uganda. Yet many cases have been reported of the NMS delivering (almost) expired medicines, or medicines expiring in stores while hospital pharmacies all over the countries are experiencing drug stock-outs. ${ }^{1867}$ The Ministry of Health introduced a new policy in 2009 to improve the supply system. ${ }^{1868}$ It seems, though, that the new policy is even more ineffective than previous one. The services of the NMS have been severely criticised. The problem is stated to be two-fold: a limited budget allocation for the procurement of medicines and an extremely inefficient medicine store and supply system. ${ }^{1869}$ Even if the Ministry of Health could rectify the problems with the NMS and the drug supply system, the lack of funding to procure drugs would still lead to drug shortages in the public health sector. ${ }^{1870}$

Uganda has in recent years made considerable efforts to eradicate poverty, and in its Poverty Eradication Action Plan it states that industrialisation is one of its main strategies to develop further. Uganda's limited manufacturing capacity is problematic however, which is also an issue within the pharmaceutical sector. It is a small economy with low levels of research and development and poor infrastructure, factors which do not make it interesting for potential investors. There are only six pharmaceutical companies active in Uganda. Due to concerns about the possibility that access to generics from India will not be sustainable in the long-term, Uganda decided to start manufacturing ARVs through a joint venture between the Indian company Cipla and a Ugandan privately owned pharmaceutical corporation, Quality Chemicals Ltd. ${ }^{1871}$ However, these companies are dependent on the import of active chemical ingredients. Moreover, locally produced generic medicines are still only a very small part of the overall number of medicines used in Uganda. Over $90 \%$ of the medicines consumed in Uganda are imported, and the majority of these medicines (about 80\%) are generics. ${ }^{1872}$ Uganda imports most of it medicines from Asian countries such as India, China since these are often cheaper. ${ }^{1873}$

1867 Ibid. at 30; BEN KIROMBA TWINOMUGISHA, Beyond Social Programmes: Protection of the Right of Access to Malaria Treatment in Uganda, Human Rights \& Peace Centre, Working Paper No. 22, (November 2008) at 10.

1868 The National Medical Stores now delivers medicines to public health facilities throughout the country without prior orders from the respective districts, as used to be the case. The NMS is directly funded by the Ministry of Finance.

1869 FHRI, The Right to Healthcare in Uganda. Report for the Period January - June 2010, at 30.

1870 Ibid. at 33.

1871 STINE JESSEN HAAKONSSON and LISA ANN RICHEY, 'TRIPS and Public Health: The Doha Declaration and Africa', Development Policy Review, 25:1 (2007), 71-90 at 85.

1872 TWINOMUGISHA, 'Implications of the TRIPS Agreement for the Protection of the Right of Access to Medicines in Uganda', at 274-275.

1873 WTO TRADE POLICY REVIEW BODY, Trade Policy Review. Report by the Secretariat on the East African Community (Revision). Annex 5 -Uganda (WT/TPR/S/271/Rev.1 2013) at \$22. 


\section{A Human Right of Access to Medicines?}

The aim of this section is to examine whether Uganda has complied with its obligations under international human rights law with respect to a right of access to medicines. In that regard, Uganda is bound by the ICESCR since 1987, in addition to the Convention on the Rights of the Child, the Convention on the Elimination of All Forms of Discrimination against Women, and customary law. Consequently, the question addressed here is whether Uganda has complied with its obligations under international human rights law with respect to the right of access to medicines within their constitutional and legislative framework.

\subsection{The Ugandan Constitution of $\mathbf{1 9 9 5}$}

Uganda's constitutional history has been haphazard and difficult. ${ }^{1874}$ Since its independence from the British in October 1962 Uganda has had a number of different constitutions, the first one being the independence constitution of 1962. ${ }^{1875}$ Unfortunately this did not lead to peace, security and stability in Uganda. When Idi Amin and the army seized power in 1971 Uganda suffered an eight year long reign of tyranny, oppression and exploitation. During that time the Constitution was totally disregarded. ${ }^{1876}$ Uganda continued to experience serious internal conflicts until the National Resistance Army (now the National Resistance Movement/NRM) took power in January 1986. In his first speech Yoweri Museveni said that the Movement's mission was to bring about fundamental change in all aspects of life and restore democracy. 1877 The process to make a new Constitution started at the end of 1988. It took until 1993 before a bill was presented to establish a constituent assembly to debate and enact a new constitution. ${ }^{1878}$ The Constituent Assembly started its work in May 1994 and Uganda's new Constitution was eventually enacted in September 1995 and promulgated on 8 October 1995.

The making of the Ugandan Constitution was a truly participatory process and it is therefore correctly stated that it is a constitution whose nature and content has been determined through the consensus of the Ugandan people. ${ }^{1879}$ The Constituent Assembly which debated and promulgated the Constitution was as widely representative as possible. It included directly elected delegates and representatives from special interest groups, such as women, the National Resistance Army, the

1874 See for an elaborate account of Uganda's constitutional history DAVID MUKHOLI, A Complete Guide to Uganda's Fourth Constitution. History, Politics and the Law (Kampala: Fountain Publishers, 1995) at chapter 2.

1875 Ibid. at 11.

1876 Ibid. at 19-20.

1877 Ibid. at 26-27.

1878 Ibid. at 35.

1879 KANYEIHAMBA, Kanyeihamba's Commentaries on Law, Politics and Governance, at 19. 
National Organisation of Trade Unions, political parties, the National Youth Council, the National Union of Disabled Persons and a number of presidential nominees. ${ }^{1880}$ It has been stated that the protection of human rights in the Constitution is one of the finest and best structured bill of rights adopted by a state. ${ }^{1881}$ Yet, reality is that since 1996 the Ugandan Government under leadership of the National Resistance Movement has systematically and effectively dismantled most of the legislative's powers and to great a extent imposed the manner in which those powers will be exercised. ${ }^{1882}$ Under severe pressure of the government the Constitution was amended in 2005 when, among other issues, the presidential term limit was removed. ${ }^{1883}$

The Constitution is the supreme law of Uganda and starts with the preamble and a set of National Objectives and Directive Principles of State Policy (NODPSP). It is a flexible living instrument committed to building a better future by establishing a socio-economic and political order through a popular and durable national constitution based on the principles of unity, peace, equality, democracy, freedom, social justice, and progress. ${ }^{1884}$ Chapter 4 of the Constitution recognises, promotes and protects fundamental and other human rights and freedoms. It also protects a number of socio-economic rights, such as a right to education in its article 30 , a right to culture in article 37, a right to a clean and healthy environment, and a number of work-related rights under the heading economic rights in article 40 . Although Uganda has ratified a number of international and regional treaties protecting health rights, the Ugandan Constitution does not explicitly recognise the human right to health, nor does it make any reference to guaranteeing accessibility of (essential) medicines.

The fact that the right to health is not codified in the Constitution does bring up some, maybe not insurmountable but definitely considerable, barriers in adjudicating and enforcing the right to health and a right of access to medicines. ${ }^{1885}$ However, it has also been stated that non-codification of the right to health in national law does not automatically lead to the conclusion that it cannot be adjudicated or enforced. ${ }^{1886}$ It is argued that the Ugandan Constitution does contain a number of other provisions which could effectively protect the right of access to

\footnotetext{
1880 MUKHOLI, A Complete Guide to Uganda's Fourth Constitution, at 36-37.

1881 KANYEIHAMBA, Kanyeihamba's Commentaries on Law, Politics and Governance, at 28, 33.

1882 Ibid. at 21.

1883 Ibid. at $36-38$.

1884 See the preamble of the Ugandan Constitution.

1885 TWINOMUGISHA, 'Implications of the TRIPS Agreement for the Protection of the Right of Access to Medicines in Uganda', at 259; MUBANGIZI and TWINOMUGISHA, 'The Right to Health Care in the Specific Context of Access to HIV/AIDS Medicines', at 120; BEN KIROMBA TWINOMUGISHA, Protection of the Right to Health Care of Women Living with HIV/AIDS in Uganda. The Case of Mbarara Hospital, Human Rights \& Peace Centre, Working Paper No. 5, (April 2007) at 19.

1886 TWINOMUGISHA, Protection of the Right to Health Care of Women Living with HIV/AIDS in Uganda, at 19 .
} 
medicines. ${ }^{1887}$ In that regard reference is made to the preambular part of the Constitution called the National Objective and Directive Principles of State Policy (NODPSP). ${ }^{1888}$

Section XIV of the NODPSP, referring to the general social and economic objectives, states that "the state shall endeavour to fulfil the fundamental rights of all Ugandans to social justice and economic development". In particular, to ensure that:

all Ugandans enjoy rights and opportunities and access to education, health services, clean and safe water, work, decent shelter, adequate clothing, food security and pension and retirement benefits.

Moreover, section XX of the NODPSP regarding Medical Services states that:

The State shall take all measures to ensure the provision of basic medical services to the population.

The NODPSP, being objectives and principles located outside of the substantive sections of the Constitution, reflect a commitment but are not considered legally binding rights conferring duties onto the state. ${ }^{1889}$ As was discussed earlier there are differing views on the justiciable nature of socio-economic rights. However, as was demonstrated in the South African case study, all rights whether civil, political, social, economic or cultural rights are interrelated, interdependent and indivisible. As such all rights consist of negative and positive components and may be justiciable on a sliding scale. In the Ugandan context, the views on this matter differ too. It has been argued that in a country like Uganda, which is facing severe resource constraints, the right to health and access to treatment should not be considered a justiciable and enforceable right. ${ }^{1890}$ Moreover, the fact that health and access is not included in the substantive section but as a NODPSP does complicate the manner in which such a right can be enforced. Yet that does not mean it is impossible. Uganda is obliged under international human rights law to take steps to their maximum available resources to progressively realise the right to health. This takes account of the resource constrained setting Uganda operates in, but it does not

1887 TWINOMUGISHA, 'Implications of the TRIPS Agreement for the Protection of the Right of Access to Medicines in Uganda', at 259.

1888 Ibid. at 260.

1889 TWINOMUGISHA, Protection of the Right to Health Care of Women Living with HIV/AIDS in Uganda, at 19; MALAGALA, 'Human Rights-Based Accountability for Healthcare in Uganda', at 94.

1890 TWINOMUGISHA, Protection of the Right to Health Care of Women Living with HIVIAIDS in Uganda, at 8, who refers to works by N. Byamukama, 'What Is the Right to Health?', Your Rights. The Uganda Human Rights Commission Magazine, 3/8 (2000); A. Wandira, The Legal Aspects and Practice Relating to the Access to and Use of Antiretroviral Drugs in Uganda, LL.M. Dissertation, Makerere University, Uganda, 2005. 
free Uganda from its obligation to take steps towards full realisation and ensuring at least the minimum essential levels of the right to health, including the provision of essential medicines. ${ }^{1891}$

The Constitution is clear in that the NODPSP are intended to "guide all organs and agencies of the state, all citizens, organisations and other bodies and persons in applying or interpreting the Constitution or any other law and in taking and implementing any policy decisions for the establishment and promotion of a just, free and democratic society." 1892 This would include courts when applying and interpreting the Constitution. ${ }^{1893}$ Moreover, section 4 of the 2005 Constitution (Amendment) Act introduced article 8A into the Ugandan Constitution, which reads as follows:

1) Uganda shall be governed based on principles of national interest and common good enshrined in the national objectives and directive principles of state policy.

2) Parliament shall make relevant laws for purposes of giving full effect to clause (1) of this article.

Twinomugisha argues that as this section is included in the substantive part of the Constitution, it renders the NODPSP justiciable. ${ }^{1894}$ Although this amendment reaffirms the importance of the NODPSP for interpreting and implementing the Constitution and legislation, it cannot be interpreted as granting the NODPSP justiciable stature.

A different strategy to enforce the right to health is through the creative interpretation of other constitutionally protected rights such as the right to life. ${ }^{1895}$ The protection of health rights in the form of national objectives and state principles is similar to the Indian context, where public health is protected in the Directive Principles of State Policy (DPSP) of the Indian Constitution. ${ }^{1896}$ However, the Indian Supreme Court has found a way around the non-justiciable nature of the Indian DPSP ${ }^{1897}$ by interpreting the justiciable right to life ${ }^{1898}$ to include a right to

1891 CESCR, General Comment No. 3, (UN Doc. E/1991/23) at $\$ 10$.

1892 Section I of the NODPSP reads as follows:

(i) The following objectives and principles shall guide all organs and agencies of the State, all citizens, organisations and other bodies and persons in applying or interpreting the Constitution or any other law and in taking and implementing any policy decisions for the establishment and promotion of a just, free and democratic society.

(ii) The President shall report to Parliament and the nation at least once a year, all steps taken to ensure the realisation of these policy objectives and principles.

1893 TWINOMUGISHA, Protection of the Right to Health Care of Women Living with HIV/AIDS in Uganda, at 20 .

1894 Ibid.

1895 CHRISTOPHER MBAZIRA, 'Enforcement of Economic, Social and Cultural Rights in Uganda. A Brief Overview', ESR Review, 10:1 (2009), 14-17.

1896 See article 47 of the Indian DPSP.

1897 Article 37 of the Indian Constitution precludes the justiciability of the DPSP.

1898 Article 21 of the Indian Constitution. 
health. ${ }^{1899}$ As such, the Indian Supreme Court expanded the fundamental right to life to include positive obligations for the state. ${ }^{1900}$ The proactive and bold stance of the Indian judiciary has thus installed the Indian DPSP with great legal significance. That there are grounds to argue that the right to life includes positive measures to protect human life, and thus maybe also a right of access to life-saving medicines, is also supported by the Human Rights Committee's interpretation of the right to life enshrined in the International Covenant on Civil and Political Rights. ${ }^{1901}$ Furthermore, other countries have taken a similar approach in this matter. ${ }^{1902}$

Arguably such an approach could also be possible within the Ugandan context, as the Ugandan Constitution does protect the right to life in article 22 of the Constitution. ${ }^{1903}$ Furthermore, article 20 of the Constitution confirms that individuals' fundamental rights and freedoms are inherent and not granted by the state. The rights and freedoms enshrined in the Constitution shall be respected, upheld and promoted by all organs and agencies of government and by all persons. ${ }^{1904}$ Additionally, it has been argued that since the enactment of the new Constitution the Ugandan judiciary "have breathed life into the constitutional provision on the right to life."1905 Therefore, following the Indian approach a bold and creative judiciary could grant the NODPSP a stronger legal status by interpreting the right to life to include socio-economic rights such as health and

1899 For further information on this issue see section 3 of chapter 7.

1900 SHAH, 'Illuminating the Possible in the Developing World: Guaranteeing the Human Right to Health in India', at 475; MUBANGIZI and TWINOMUGISHA, 'The Right to Health Care in the Specific Context of Access to HIV/AIDS Medicines', at 121.

1901 See HRCEE, General Comment 6, (UN Doc. HRC/GC/6).

1902 See section 3.4.3. of chapter 3.

1903 Section 22 of the Constitution reads as follows:

(1) No person shall be deprived of life intentionally except in execution of a sentence passed in a fair trial by a court of competent jurisdiction in respect of a criminal offence under the laws of Uganda and the conviction and sentence have been confirmed by the highest appellate court.

(2) No person has the right to terminate the life of an unborn child except as may be authorised by law.

1904 Section 20 of the Constitution:

(1) Fundamental rights and freedoms of the individual are inherent and not granted by the State.

(2) The rights and freedoms of the individual and groups enshrined in this Chapter shall be respected, upheld and promoted by all organs and agencies of Government and by all persons.

1905 Here the author refers to the Salvatori Abuki and Another v Attorney General case, where an exclusion order made under section 7 of the Witchcraft Act was challenged as being inconsistent with the Constitution, because it deprived the petitioner of his property and the right to reside and settle in any part of Uganda. The Constitutional Court held that the exclusion order was inconsistent with the Constitution as it threatened the right to life through deprivation of shelter, food and essential sustenance. TWINOMUGISHA, 'Implications of the TRIPS Agreement for the Protection of the Right of Access to Medicines in Uganda', at 261; MUBANGIZI and TWINOMUGISHA, 'The Right to Health Care in the Specific Context of Access to HIV/AIDS Medicines', at 121; TWINOMUGISHA, Beyond Social Programmes, at 6-7. 
access to medicines. ${ }^{1906}$ Such an approach is supported by article 45 of the Ugandan Constitution stating that the rights, duties, declarations and guarantees relating to the fundamental and other human rights and freedoms specifically mentioned in the Constitution shall not be regarded as excluding others not specifically mentioned. ${ }^{1907}$ Consequently, one could - arguably - conclude that as Uganda has ratified a number of international conventions protecting the right to health, and even though it is not explicitly included in the Constitution, the right to life provides the possibility for a court to legally recognise and enforce the right to health. ${ }^{1908}$

The Constitutional Court had the opportunity to do just that with the filing of a constitutional petition under articles $137(3)$ and (4) $)^{1909}$ and 45 of the Constitution by a Ugandan health organisation claiming that the state failed to provide basic indispensible health commodities in government health facilities for expectant mothers resulting in a violation of the state's constitutional duties. ${ }^{1910}$ The state

1906 TWINOMUGISHA, Beyond Social Programmes, at 6.

1907 See article 45 of the Constitution:

The rights, duties, declarations and guarantees relating to the fundamental and other human rights and freedoms specifically mentioned in this Chapter shall not be regarded as excluding others not specifically mentioned.

1908 MUBANGIZI and TWINOMUGISHA, 'The Right to Health Care in the Specific Context of Access to HIV/AIDS Medicines', at 120; TWINOMUGISHA, Beyond Social Programmes, at 7.

1909 Article 137 of the Constitution:

(1) Any question as to the interpretation of this Constitution shall be determined by the Court of Appeal sitting as the constitutional court.

(2) When sitting as a constitutional court, the Court of Appeal shall consist of a bench of five members of that court.

(3) A person who alleges that -

(a) an Act of Parliament or any other law or anything in or done under the authority of any law; or

(b) any act or omission by any person or authority, is inconsistent with or in contravention of a provision of this Constitution, may petition the constitutional court for a declaration to that effect, and for redress where appropriate.

1910 See Ugandan Constitutional Court, Centre for Health, Human Rights and Development (CEHURD) vs. Attorney General, 5 June 2012, Constitutional Petition No. 16 of 2011. The petitioners framed the following issues for the Court to determine:

- whether the right to the highest attainable standard of health is a constitutional right by virtue of Article 45 of the Constitution;

- whether the inadequate human resource for maternal health specifically midwives and doctors, frequent stock-outs of essential medicines for maternal health and lack of Emergency Obstetric Care (EmOC) services at Health Centres III, IV and hospitals is an infringement of the right of health;

- whether non provision of basic maternal health care services in health facilities contravenes Article 8A, objective XIV and XX of the constitution;

- whether the Governments' non provision of basic maternal health care package in government hospitals resulting into the death of expectant mothers and their children is a violation of the right to life as guaranteed under Article 22 of the Constitution;

- whether the health workers and government failure to attend to expectant mothers subjects them to degrading and inhuman treatment and there by contravening Article 24 and 44(a) of the Constitution; 
responded by stating that the way in which the petition was framed would require the Court to make a judicial decision involving and affecting political questions and thus interfering with political discretion which by law is reserved for the executive and legislature. The Court agreed with the government stating that:

\begin{abstract}
[m] uch as it may be true that government has not allocated enough resources to the health sector and in particular the maternal health care services, this court is [...] reluctant to determine the questions raised in this petition. The executive has the political and legal responsibility to determine, formulate and implement polices of Government, for inter-alia, the good governance of Uganda. This duty is a preserve of the executive and no person or body has the power to determine, formulate and implement these polices except in the executive. ${ }^{1911}$
\end{abstract}

It continued by stating that although it appreciated the concerns of the petitioners the solution to this problem is not through a Constitutional Petition of a nature requiring the Court to resolve a political question. The Constitution provides other legal alternatives here for. ${ }^{1912}$

With respect to enforcement of human rights, the constitution provides for the concept of public interest litigation under article 50 which states that any person who claims that a fundamental or other right or freedom has been infringed or threatened, is entitled to apply to a competent court for a declaration to that effect and for redress which may include compensation. ${ }^{1913}$ Moreover, any person or organisation may bring an action against the violation of another person's or group's

- whether the high rates of maternal mortality in Uganda contravene Article 33(1), (2) and (3) of the Constitution; and

- whether the families of Sylvia Nalubowa and Jennifer Anguko who died in Mityana District hospital and Arua Regional referral Hospital due to non availability of basic maternal commodities respectively are entitled to compensation.

Ibid. at 16.

1912 Ibid. at 16-17.

1913 Article 50 of the Constitution reads as follows:

(1) Any person who claims that a fundamental or other right or freedom guaranteed under this Constitution has been infringed or threatened, is entitled to apply to a competent court for redress which may include compensation.

(2) Any person or organisation may bring an action against the violation of another person's or group's human rights.

(3) Any person aggrieved by any decision of the court may appeal to the appropriate court.

(4) Parliament shall make laws for the enforcement of the rights and freedoms under this Chapter.

See also article 137(3) of the Ugandan Constitution which states that: "A person who alleges that -
(a) an Act of Parliament or any other law or anything in or done under the authority of any law; or
(b) any act or omission by any person or authority, is inconsistent with or in contravention of a provision of this Constitution, may petition the constitutional court for a declaration to that effect, and for redress where appropriate. 
human right. ${ }^{1914}$ Although there are reports of widespread human rights abuses also with respect to the right to health, there has not been any judicial review regarding the right to health. ${ }^{1915}$

If the Constitutional Court is willing, judicial activism could lead to an advancement of the promotion and protection of human rights similar to the development in India. ${ }^{1916}$ Article 126(1) of the Ugandan Constitution provides that the judicial power is derived from the people, and paragraph 2 of the same article states that "substantive justice shall be administered without undue regard to technicalities." 1917 According to Kanyeihamba "[a]n analysis of Uganda laws and rules of courts as well as examination of the recent court decisions illustrate, quite clearly, that Ugandan Courts, have not only the jurisdiction, the power and courage to intervene in cases where the rights and freedoms of citizens are allegedly violated or the exercises of government powers challenged but have also been prepared to grant appropriate remedies."1918 Twinomugisha goes a step further and states "[c]ourts therefore have the legitimacy and competence to adjudicate socioeconomic rights including the right of access to medicines."1919 A progressive judiciary, within boundaries however, and an increase in case law with respect to socio-economic rights would be of importance because it would clarify the content, nature and scope of socio-economic rights and the state's obligations in that regard. An active and progressive judiciary might provide a counterbalance and address inappropriate action or inaction by the government. ${ }^{1920}$

\footnotetext{
1914 See article 50(2) of the Constitution.

1915 MALAGALA, 'Human Rights-Based Accountability for Healthcare in Uganda', at 94.

1916 KANYEIHAMBA, Kanyeihamba's Commentaries on Law, Politics and Governance, at 51.

1917 Article 126 of the Constitution:
}

(1) Judicial power is derived from the people and shall be exercised by the courts established under this Constitution in the name of the people and in conformity with law and with the values, norms and aspirations of the people.

(2) In adjudicating cases of both a civil and criminal nature, the courts shall, subject to the law, apply the following principles -

(a) justice shall be done to all irrespective of their social or economic status;

(b) justice shall not be delayed;

(c) adequate compensation shall be awarded to victims of wrongs;

(d) reconciliation between parties shall be promoted; and

(e) substantive justice shall be administered without undue regard to technicalities.

KANYEIHAMBA, Kanyeihamba's Commentaries on Law, Politics and Governance, at 55. Yet it must be noted that he does not give any reference to such an analysis and examination of case law.

1919 TWINOMUGISHA, 'Implications of the TRIPS Agreement for the Protection of the Right of Access to Medicines in Uganda', at 274.

1920 TWINOMUGISHA, Beyond Social Programmes, at 26; TWINOMUGISHA, 'Implications of the TRIPS Agreement for the Protection of the Right of Access to Medicines in Uganda', at 272. 


\subsection{Health Legislation and Policy}

Although the Ugandan Constitution does not explicitly recognise the right to health, it has committed itself to the progressive realisation of this right through its accession to the ICESCR. ${ }^{1921}$ Moreover, it was demonstrated that a right of access to medicines is an integral part of the right to health. The right to health requires states parties to take a range of different measures, legislative, administrative and judicial measures, to ensure the realisation of this right. The CESCR has recognised that states parties have a certain degree of freedom in implementing an appropriate set of measures. Therefore this section will examine to what extent Uganda has implemented the right of access to medicines within its legislative and policy framework.

Uganda does not have any legislation that specifically deals with the right to health in the domestic setting. ${ }^{1922}$ As such none of the international and regional treaties which protect the right to health and access to medicines have been directly incorporated into national law. ${ }^{1923}$ There is legislation with respect to health rights yet it is considered to be outdated and inadequate in protecting the right to health. ${ }^{1924}$ The Public Health Act provides for measures such as quarantine, compulsory notification and treatment. This has been argued to be adversative to a human rights approach to health. ${ }^{1925}$ Furthermore, the Act has not been updated to keep track of the rapid and extensive developments within science and technology regarding prevention, treatment and care and has thus lost much of its relevance. ${ }^{1926}$

The National Drug Policy and Authority Act establishes the National Drug Authority (NDA), whose mandate requires it to regulate pharmacies and medicines, including quality control and promoting rational use of medicines. The Act requires a continuous review of the needs, knowledge and resources of essential medicines. The NDA is mandated with ensuring that essential, efficacious and cost-effective medicines are available to the Ugandan people at all times, so as to ensure the provision of satisfactory health care and safeguard the appropriate use of pharmaceuticals. As such, it is charged with implementing the National Drug Policy, particularly: 1) to estimate medicine needs to ensure that the needs are met as economically as possible; 2) to control the importation, exportation and sale of

\footnotetext{
1921 UN COMMISSION ON HUMAN RIGHTS, Report of the Special Rapporteur on the Right to Health. Addendum. Mission to Uganda, (UN Doc. E/CN.4/2006/48/Add.2) at §15.

1922 MUBANGIZI and TWINOMUGISHA, 'The Right to Health Care in the Specific Context of Access to HIV/AIDS Medicines', at 121.

1923 Ibid. at 122

1924 TWINOMUGISHA, Protection of the Right to Health Care of Women Living with HIV/AIDS in Uganda, at 22. TWINOMUGISHA, Beyond Social Programmes, at 9.

1925 TWINOMUGISHA, Protection of the Right to Health Care of Women Living with HIV/AIDS in Uganda, at 22.

1926 TWINOMUGISHA, Beyond Social Programmes, at 9-10.
} 
medicines; 3) to promote and control local production of essential medicines; 4) to control the quality of medicines; and 5) to promote the rational use of medicines through appropriate professional training. The NDA Essential Drugs List defines those essential medicines which satisfy the needs of the majority of the population and should therefore always be available in adequate amounts and appropriate dose forms. The National Medical Stores Act establishes the National Medical Stores, whose mandate is to efficiently and economically procure, store, administer, distribute and supply pharmaceuticals. It is also charged with advising the NDA on the estimation of drug needs and the distribution and use of medicines in the public service.

The Uganda AIDS Commission Act established the Uganda AIDS Commission, which is charged with formulating the policy and setting up of programme priorities to control the AIDS epidemic and manage its nationwide consequences. In managing the epidemic it also supervises the activities with regard to health care and counselling of AIDS patients and handling the socio-economic, cultural and legal issues related to HIV/AIDS.

With respect to the HIV/AIDS epidemic, there exists a relative elaborate policy framework. ${ }^{1927}$ The Poverty Eradication Action Plan is the overarching framework on the government's effort to eradicate poverty. Here it is stated that people that do not have the resources to access private health care should have access to the public health care system. However, it does not consider health as a fundamental human right. ${ }^{1928}$ The Ministry of Health has developed policies, including a second National Health Policy (2010), and a Health Sector Strategic Plan, setting a number of targets to improve public health. The Ministry has also set up a National Strategic Plan on HIV/AIDS and an Antiretroviral Treatment Policy which aims at universal access for all HIV infected persons who are clinically eligible to receive treatment. There is no control or regulation of prices for ARVs in the private sector.

The second Health Sector Strategic Plan (HSSP II) for the period 2005/06 2009/10 provided for a Minimum Health Care Package (MHCP) which entailed the government's commitment to ensure the most basic services to its citizens. Although the Ministry of Health stated that the MHCP was not a commitment by the government, but "... an aspiration because the costing was done with components that were aspirations since there was no money to match the plan."1929 The health budget, as a percentage of the national budget, has been estimated for the year $2009 / 2010$ to be at $10.3 \%$ which falls short of the $15 \%$ commitment made by the government through the Abuja Declaration. ${ }^{1930}$

\footnotetext{
1927 MUBANGIZI and TWINOMUGISHA, 'The Right to Health Care in the Specific Context of Access to HIV/AIDS Medicines', at 122.

1928 MALAGALA, 'Human Rights-Based Accountability for Healthcare in Uganda', at 110.

1929 FHRI, The Right to Healthcare in Uganda. Report for the Period January - June 2010, at 3.

1930 ORGANISATION OF AFRICAN UNITY, Abuja Declaration on HIVIAIDS, Tuberculosis and Other Related Infectious Diseases, (OAU/SPS/ABUJA/3).
} 


\subsection{Conclusion}

The question addressed here is whether Uganda has complied with its obligations under international human rights law by recognising a right of access to medicines within their constitutional and legislative framework. Uganda does not explicitly recognise the right to health in its Constitution. The NODPSP however recognises the state's obligation to endeavour to ensure that all Ugandans enjoy access to health and medical services. Yet it is questionable though whether the NODPSP represent legally enforceable rights; it is more likely that they reflect a commitment by the state to take all possible measures to achieve realisation of these rights. In that regard, it has been argued that the Ugandan Constitutional Court should adopt an approach similar to that of the Indian Supreme Court, progressively interpreting the right to life to include socio-economic elements. Particularly article 45 of the Constitution is argued to give the court system the mandate to adjudicate rights not explicitly codified in the Constitution. This would enable individuals to hold the state accountable for right to health violations. However, until now the Constitutional Court seems hesitant to do so. Another option would be to make use of quasi-judicial or political means such as the Uganda Human Rights Commission, human rights organisations or members of parliament. There is limited evidence, though, that these mechanisms are actually employed by individuals (or groups) who feel that their right to health has been violated. ${ }^{1931}$

Uganda has set up a relatively successful policy framework for providing medicines for HIV-infected patients. This does demonstrate that the constitutional recognition of the right to health is not necessarily determinative in ensuring adequate access to affordable medicines. However, policies are not legally binding; they contain political obligations. ${ }^{1932}$ The policy framework does not recognise the right to health, or access to medicines, as an enforceable and justiciable human right and as such Uganda has not met its obligations under international human rights law. ${ }^{1933}$

\section{Patent Protection for Pharmaceuticals: Standards \& Flexibilities}

As opposed to the case studies on South Africa and India, this chapter will not address the question whether Uganda has complied with its obligations under WTO law and implemented TRIPS standards' and flexibilities due to the fact that Uganda, qualified as a least-developed member, is not yet under a legal obligation to fully

1931 MALAGALA, 'Human Rights-Based Accountability for Healthcare in Uganda', at 116.

1932 MUBANGIZI and TWINOMUGISHA, 'The Right to Health Care in the Specific Context of Access to HIV/AIDS Medicines', at 129.

1933 BEN KIROMBA TWINOMUGISHA, 'Protecting the Right of Access to Malaria Treatment in Uganda', ESR Review, 10:1 (2009), 17-22. 
implement the TRIPS Agreement. Therefore, the second research question addressed in this chapter is whether Uganda provides for patents for pharmaceuticals, and if so, to what extent (section 4.1)

Uganda is a member of the World Trade Organisation since January $1^{\text {st }}, 1995$, and therefore is bound to the TRIPS Agreement. From the perspective of leastdeveloped, and also developing countries, the level of IP protection prescribed by the TRIPS Agreement has been criticised as being overly burdensome, particularly considering the relatively weak negotiation position of developing countries during the TRIPS negotiation process. However, as a least-developed country, the TRIPS' transitional arrangement allows it an additional 10 years to implement TRIPS (except for articles 3 and 4 TRIPS which must be implemented immediately), until 1 January $2016^{1934}$ which was extended only recently (June 2013) to 1 July 2021. ${ }^{1935}$ Consequently, it is now essential that Uganda takes full advantage of the flexibilities within TRIPS in order to ensure access to medicines. ${ }^{1936}$ Uganda has already started the process of reforming its intellectual property in order to bring it in line with the TRIPS' requirements. Therefore, the question will be posed whether the draft Industrial Property Bill fully implements TRIPS standards and flexibilities with a view to achieving a balance between access and protecting patents (section 4.2).

\subsection{The Patents Act of 1993}

Uganda's legal system traces its origins to colonial times under British rule. Prior to Uganda's independence in 1962, the IP laws of Britain were already being applied to Uganda, although the bulk of its current IP laws were enacted postindependence. ${ }^{1937}$ The Patents Act was enacted in 1993 mainly with a view to implementing Uganda's obligations under international IP law, particularly the 1883 Paris Convention for the protection of Industrial Property. The Patents Act

1934 See article 66.1 TRIPS. WTO COUNCIL FOR TRADE-RELATED ASPECTS OF INTELLECTUAL PROPERTY RIGHTS, Extension of the Transition Period under Article 66.1 of the TRIPS Agreement for Least-Developed Country Members for Certain Obligations with Respect to Pharmaceutical Products, (IP/C/25). Additionally, article 65.5 TRIPS does not apply to article 66, and, thus also not to least-developed countries, which left them free to roll back their level of IP protection and make full use of the transition periods.

1935 Or until such a date on which they cease to be a least-developed country member, whichever date is earlier. See WTO COUNCIL FOR TRADE-RELATED ASPECTS OF INTELLECTUAL PROPERTY RIGHTS, Extension of the Transition Period under Article 66.1 for Least Developed Members, (IP/C/64).

1936 See also NICHODEMUS RUDAHERANWA and VERNETTA BARUNGI ATINGI-EGO, 'Uganda's Participation in WTO Negotiations: Institutional Challenges', in Peter Gallagher, Patrick Low, and Andrew L. Stoler (eds.), Managing the Challenges of WTO Participation. 45 Case Studies (New York: Cambridge University Press, 2005.

1937 EDGAR TABARO, 'Patent Law Reform in Uganda: Addressing Priorities and Strategies', The Journal of World Intellectual Property, 12:6 (2009), 571-599 at 575. 
was amended in 2000 to make provisions for the implementation of the Patent Cooperation Treaty. ${ }^{1938}$ The Ugandan Patents Act sets out the law with regard to the administration, registration, application for, grant, duration and effect of, licensing of, revocation of, and infringement of patent rights within the territory of Uganda.

Firstly - with respect to the patent standards as set out by this Act - section 8 of the Patents Act states that:

An invention is patentable if it is new, involves an inventive step and is industrially applicable.

Section 7(1) of the Ugandan Patents Act defines an invention as "a solution to a specific technological problem and may be or may relate to a product or process."1939 It also sets out a number of activities which do not fall within the scope of an invention, such as methods for treatment of the human body by surgery or therapy as well as diagnostic methods. Furthermore, section 9 states that "an invention is new if it is not anticipated by prior art"; section 10 states that an inventive step is involved if the invention "would not have been obvious to a person skilled in the art"; and section 11 states that an invention is "industrially applicable if, according to its nature, it can technologically be made or used in any kind of industry." Moreover, the Minister responsible for the supervision of the patents registry may, in the public interest, exclude certain products or process from patentability for a maximum of two years. ${ }^{1940}$

Furthermore, section 13 set out the conditions for the form of a patent application which requires that it is accompanied by a sufficiently clear and complete

1938 Ibid. at 582.

1939 Section 7 of the Patents Act reads as follows:

(1) For the purposes of this Act, "invention" means a solution to a specific technological problem and may be or may relate to a product or process.

(2) The following shall not be regarded as inventions within the meaning of subsection (1) -

(a) discoveries and scientific and mathematical theories;

(b) plant or animal varieties or essentially biological processes for the production of plants or animals, other than biological processes and the products of those processes;

(c) schemes, rules or methods for doing business, performing purely mental acts or playing games;

(d) methods for treatment of the human or animal body by surgery or therapy as well as diagnostic methods, but the restriction under this paragraph shall not apply to products for use in any of these methods; and

(e) mere presentation of information.

1940 Section 12 of the Patents Act:

The Minister may, in the public interest, by statutory instrument, exclude from patentability, inventions concerning certain kinds of products or processes for the manufacture of those products, for a period not exceeding two years. 
description of the subject matter of the application. ${ }^{1941}$ Thus, we see that the provisions of the current Patents Act are in line with the criteria for patentability under article 27.1 TRIPS, although the possibility to exclude certain products or processes from patentability might result in incompatibility with the nondiscrimination principle.

The grant of a patent confers onto the patent holder a number of rights and obligations. Section 25(1) of the Patents Act grants the patent owner an "exclusive right to make, use, exercise and vend the invention" and to "preclude any person from exploiting the patented invention without his or her authorisation."1942 In return the patent holder is obliged to disclose the invention and work the patented

1941 Section 13 of the Patents Act:

(1) An application for the grant of a patent shall be made to the registrar, but where the applicant ordinarily resides or has his or her place of business outside Uganda, he or she shall be represented by an agent admitted to practise before the patents registry.

(2) The application shall be accompanied by the following -

(a) a description disclosing the invention in a manner sufficiently clear and complete for the invention to be evaluated and to be carried out by a person skilled in the art and shall, in particular, indicate the best mode known to the applicant for carrying out the invention;

(b) a clear and concise claim or claims defining the matter for which protection is sought and fully supported by the description;

(c) any drawing which may be essential for understanding the invention;

(d) an abstract serving the purpose of technical information but which shall not be taken into account for the purpose of interpreting the scope of the protection sought; and

(e) the prescribed fee.

(3) The application shall state the name of any other prescribed data concerning the applicant, the inventor and the agent, if any, and the title of the invention.

(4) Where the applicant is not the inventor, the application shall be accompanied by a statement justifying the applicant's right to the patent.

(5) The appointment of an agent under subsection (1) shall be indicated by designation of the agent in the application or by furnishing of a power of attorney signed by the applicant.

1942 Section 25 of the Patents Act:

(1) The owner of a patent has an exclusive right to make, use, exercise and vend the invention, and may preclude any person from exploiting the patented invention without his or her authorisation, by any of the following acts -

(a) when the patent has been granted in respect of a product -

(i) making, importing, offering for sale, selling and using the product;

(ii) stocking the product for the purposes of offering for sale, selling or using the product;

(b) when the patent has been granted in respect of a process -

(i) using the process;

(ii) doing any of the acts referred to in paragraph (a) of this subsection in respect of a product obtained directly by means of the process.

(2) After the grant of the patent, and within the limits defined in section 27, the owner of the patent has a right to preclude any person from exploiting the patented invention in the manner referred to in subsection (1).

(3) The owner of a patent may assign or transfer by succession the application for a patent or the patent.

See also section 26 of the Patents Act: 
invention in Uganda. ${ }^{1943}$ Again, the language employed in these provisions is in line with the obligations under articles 28 and 29 TRIPS.

The Patents Act main departure from TRIPS standards is with respect to the patent term, which will expire after 15 years, as opposed to the 20 years mandate by TRIPS, although the patent holder may apply for an additional five year extension of the patent term. ${ }^{1944}$ Finally, the Patents Act also sets out a number of grounds on which a patent may be revoked. ${ }^{1945}$

(1) Subject to sections 27, 28 and 37, where a person other than the owner of a patent or a licensee does any of the acts specified in section 25(1) in respect of the patented invention, that act shall constitute infringement of the patent.

(2) If the owner of a patent or the licensee is of the opinion that his or her patent has been or is about to be infringed, he or she may institute infringement proceedings in the High Court for the following relief -

(a) damages;

(b) an injunction to prevent infringement or continuing infringement of the patent; and

(c) any other civil remedy.

(3) Where a defendant to infringement proceedings can prove that the acts done by him or her do not constitute an infringement, he or she may pray the court for a declaration that the patent in question has not been infringed.

(4) If a patent relates to a process for the manufacture of a product showing novel features, the product shall, in the absence of proof to the contrary, be presumed to have been manufactured by that process.

1943 Section 24 of the Patents Act:

The owner of a patent shall have the following obligations -

(a) to disclose the invention in a clear and complete manner and, in particular, to indicate the best mode for carrying out the invention in accordance with the requirements and subject to the sanctions applicable under this Act;

(b) to work the patented invention in the country within the time limit prescribed; and

(c) to pay the prescribed fees to the registry.

1944 See section 31 of the Patents Act:

(1) Subject to subsection (2), a patent shall expire at the end of the fifteenth year after the date of the grant of the application.

(2) Where the owner of a patent makes a request to the registrar for extension of a patent and -

(a) accompanies the request with the prescribed fee; and

(b) satisfies the registrar that -

(i) the invention which is the subject of the patent is being worked in Uganda at the date of the request; or

(ii) there is a legitimate reason for failing to so work the invention, the registrar may grant the extension for a further period of five years; but the request under this subsection shall be made not less than one month before the expiration of the patent.

(3) For the purposes of this section, a patented invention is worked if the patented product is effectively used in Uganda on a scale which is reasonable in the circumstances, but importation does not constitute working.

1945 Section 36 of the Patents Act:

(1) The court may, at the request of a party to proceedings under this Act, invalidate and revoke a patent on any of the following grounds -

(a) that the invention claimed is not patentable within the meaning of sections 7 to 11 ;

(b) that the invention claimed is excluded from patentability under section 12 ; 
Secondly - with respect to possible exceptions to patent rights - the Ugandan Patents Act provides a number of possibilities. Section 28 states that acts done in pursuance of scientific research or in respect of articles which have been put on the market in Uganda by the owner of the patent or with his or her express consent, do not infringe the patent holder's exclusive rights. ${ }^{1946}$ Furthermore, section 29 of the Patents Act allows for the exploitation of a patented invention by the government and states the following:

Where the Minister is of the opinion that it is in the vital public interest to do so, he or she, in consultation with the registrar, and without the authority of the owner of a patent, may direct that a patented invention be exploited by a Government agent or other person designated by the Minister. ${ }^{1947}$

(c) that the description and claims accompanying the application for grant of a patent did not comply with the requirements of section 13(2); or

(d) that the person to whom the patent was granted had no right to it and the patent has since the grant not been assigned to the person who has the right to it.

(2) An invalidated patent, or claim or part of a claim, shall be regarded as null and void from the date of the grant of the patent.

1946 Section 28 of the Patents Act:

The rights of an owner of a patent shall extend only to the use of the patented invention for industrial or commercial purposes, but those rights shall not be deemed to be infringed by the following -

(a) acts done in pursuance of scientific research;

(b) acts in respect of articles which have been put on the market in Uganda by the owner of the patent or with his or her express consent;

(c) the use of the patented article on foreign aircrafts, land vehicles or vessels of other countries which temporarily or accidentally enter the airspace, territory or waters of Uganda;

(d) acts performed by any person who in good faith, before the filing or, where priority is claimed, before the priority date of the application on which the patent is granted and in Uganda, was using the invention or was making effective and serious preparations for such use, to the extent that those acts do not differ in nature or purpose from the actual or envisaged prior use and provided that the right of the prior user referred to in this section may be transferred or devolve only together with the enterprise or business, or with that part of the enterprise or business, in which the use or preparations for use have been made.

1947 Section 29 of the Patents Act reads as follows:

(1) Where the Minister is of the opinion that it is in the vital public interest to do so, he or she, in consultation with the registrar, and without the authority of the owner of a patent, may direct that a patented invention be exploited by a Government agent or other person designated by the Minister, on the following conditions -

(a) that the owner of the patent and any licensee has been given an opportunity to be heard before the direction is made; and

(b) that the Government provides for the payment of adequate remuneration, as fixed by the registrar, to the owner of the patent for the use of his or her invention.

(2) The owner of any patent affected by any direction of the Minister under this section may appeal to the High Court -

(a) against the direction of the Minister;

(b) against a decision of the registrar fixing the amount of remuneration under subsection (1), but an appeal shall not suspend the effect of the direction of the Minister under subsection (1). 
The consent of the patent holder is not required, however he must be heard and paid adequate remuneration; 1948 furthermore, the patent holder has the opportunity to appeal the decision. ${ }^{1949}$ Moreover, vital public interest is defined as "matters of paramount importance pertaining to national security, public health, public order and morality and the national economy". 1950

In addition to government use, the Ugandan Patents Act also provide for compulsory licensing under a limited number of grounds. In that regard section 30 of the Patents Act states the following: ${ }^{1951}$

[...] any person may, in proceedings instituted by him or her against the owner of the patent or in proceedings instituted against him or her by the owner request the court for the grant of a compulsory license on any of the following grounds-

(a) that the patented invention, being capable of being worked in Uganda, has not been so worked;

(b) that the existing degree of working of the patented invention in Uganda does not meet on reasonable terms the demand for the patented product on the domestic market or for the purposes of exploitation;

(3) For the purposes of this section, "vital public interest" includes matters of paramount importance pertaining to national security, public health, public order and morality and the national economy.

(4) For the purposes of forming an opinion under subsection (1), the Minister may consult with such technical experts in the particular field of the patented invention as may be necessary.

Section 29(1) of the Patents Act.

1949 Section 29(2) of the Patents Act.

1950 Section 29(3) of the Patents Act.

1951 Section 30 of the Patents Act:

(1) At any time after four years from the filing date of an application or three years from the grant of a patent, whichever period last expires, any person may, in proceedings instituted by him or her against the owner of the patent or in proceedings instituted against him or her by the owner request the court for the grant of a compulsory licence on any of the following grounds -

(a) that the patented invention, being capable of being worked in Uganda, has not been so worked;

(b) that the existing degree of working of the patented invention in Uganda does not meet on reasonable terms the demand for the patented product on the domestic market or for the purposes of exploitation;

(c) that the working of the patented invention in Uganda is being hindered or prevented by the importation of the patented product; and

(d) that, by reason of the refusal of the owner of the patent to grant licences on reasonable terms, the establishment or development of industrial or commercial activities in Uganda, or the possibilities of exportation from Uganda, are unfairly and substantially prejudiced.

(2) A compulsory licence under this section shall be on such terms as to payment of remuneration by the licensee to the owner of the patent and otherwise as the court may consider just.

(3) Where the patented invention is a process, "patented product" in subsection (1) means a product obtained directly by means of the process. 
(c) that the working of the patented invention in Uganda is being hindered or prevented by the importation of the patented product; and

(d) that, by reason of the refusal of the owner of the patent to grant licences on reasonable terms, the establishment or development of industrial or commercial activities in Uganda, or the possibilities of exportation from Uganda, are unfairly and substantially prejudiced.

Thus, section 30 restricts the ground on which a compulsory license may be issued. As was shown, TRIPS' conditions do not entail a list of grounds permissible or necessary for the issuance of a compulsory license. Furthermore, any person may apply to the court for the grant of a compulsory license, although it is not specified whether this person must have "an interest" such as for example a generic pharmaceutical producer or whether a civil society organisation may also apply for the grant of a patent. Finally, the patent holder must be paid remuneration. Here it can be seen that, unlike many other provisions of the Ugandan Patents Act, this section does not follow TRIPS' requirements with regard to the procedure and scope of a compulsory license; for example there is no mention made of an obligation to undertake prior negotiations with the patent holder before a compulsory license may be granted, the limitation of the compulsory license to the purpose for which it was granted, or the principle of territoriality. Yet this is not problematic, since Uganda is not under a legal obligation to implement TRIPS conditions.

The essential question here is whether the Patents' Act provisions - especially those relating to the patentability of pharmaceuticals, limitation of patent rights, government use and compulsory licensing - can be effectively used to enhance access to affordable medicines in Uganda. The main problem in Uganda is that it has a very limited pharmaceutical manufacturing capacity, which in reality entails that even if an order for government use or compulsory license on public health grounds would be issued, it would not have the capacity to produce generic medicines to the extent that this would make a significant difference in Uganda. As such Uganda is dependent on the importation of generic medicines. In that regard it is unfortunate that the Patents Act does not make an explicit preference for an international exhaustion of rights regime permitting parallel importation. Consequently, even if the Patents Act was far more access oriented, for example by explicitly excluding patent protection for pharmaceuticals - which it surprisingly does not do - it would not provide the Ugandan state with the framework necessary to significantly enhance access to medicines. However, a weaker patent system than the current one may, as was the case in India, encourage local manufacturing capacity; yet whether such a result will be achieved will depend on more factors than merely the level of IP protection. 


\subsection{Uganda's Law Reform: The Draft Industrial Property Bill of 2009}

As addressed earlier, Uganda is categorised as a least-developed WTO member and, therefore, has until 2021 to implement the patent standards as required by TRIPS. Since 2000 the Uganda Law Reform Commission (ULRC) has been the main actor in Uganda's commercial law reform process. The ULRC has conducted a study report on the legal implementation of the WTO agreements seeking views from different stakeholders on issues pertaining to the implementation of the WTO Agreements, such as TRIPS. In the study the ULRC noted that it may be "expedient to implement the entire Agreement on TRIPS for political considerations and in order to complete the framework for promoting investment." 1952 On the other hand, it recognises that there are serious doubts as to whether protection of intellectual property actually attracts technology. This consideration, and the fact that there are legal implications of copying existing patented products, has led it to state that "there is need for more debate to ascertain the balance between the interests of right-holders and the development needs of Uganda." 1953 It is argued that this debate should move beyond focusing on trade as the main development need of Uganda and include considerations of social welfare. ${ }^{1954}$

The ULRC has also conducted a study report on industrial property, justified by the need to repeal and replace the existing Patents Act as it did not stimulate technological growth and, partly, because Uganda is required to bring its intellectual property legislation in line with the TRIPS Agreement. ${ }^{1955}$ It found that reform of its IP legislation should strike a balance between protecting and respecting the rights of right holders, especially patent holders, and public interest concerns, especially with respect to access to essential medicines as Uganda suffers greatly from nationwide pandemics such HIV/AIDS and malaria. The study made a number of recommendations. It recommended that pharmaceuticals should be exempted from patent protection until 2016. ${ }^{1956}$ Furthermore it recommended that non-patentable inventions as allowed for in articles 27.2 and 27.3 TRIPS should be provided for in the law; that the patent term is extended to 20 years as required by article 33 TRIPS; that the provisions for the exploitation of patent inventions by the government or a third party authorised by the government are revised to conform with the TRIPS Agreement; and that parallel importation is allowed for in law. Regarding this last

\footnotetext{
1952 UGANDA LAW REFORM COMMISSION, A Report on the Background Study on the Legal Implementation of the World Trade Organisation Agreements (Law Com Pub. No. 32; 2004) at 50 .

1953 Ibid.

1954 SEATINI, TRIPS Compliance and Social Welfare. The Implications of Intellectual Property Law Reform for Uganda Social-Economic Development, Southern and Eastern African Trade Information and Negotiations Institute, (April 2010) at 8.

1955 Ibid. at 12.

1956 UGANDA LAW REFORM COMMISSION, A Study Report on Industrial Property Law (Patents, Industrial Designs Technovations and Utility Models) (Law Com Pub. No. 12; 2004a) at $\mathrm{xx}$.
} 
recommendation, it states that parallel importation might well be the best way to improve access to essential medicines because of limited local capacity to produce and undertake drug manufacturing. ${ }^{1957}$ As a result the ULRC, in consultation with various stakeholders, had an Industrial Property Bill drafted aiming to domesticate its obligations under TRIPS. It received criticism and has undergone a number of changes before reflecting the TRIPS flexibilities. ${ }^{1958}$ The final version is the 2009 Industrial Property Bill No. 5, which will be discussed below.

The Bill makes use of the transition period for least-developed countries which was originally set at 2016. However, it does not provide for any further extension as granted by the TRIPS Council, which would entail that in such a case parliament would have to amend the law. ${ }^{1959}$ Section 1 of the memorandum to the Bill states: "the object of this Bill is to provide for the promotion of inventive and innovative activities, to facilitate the acquisition of technology through the grant and regulation of patents utility models, technovations and industrial designs."

\subsubsection{Patent standards}

For Uganda to bring its Patents Act into conformity with the TRIPS Agreement, it must incorporate TRIPS' minimum standards. Firstly, article 27.1 TRIPS states that all WTO members must allow for the patenting of inventions, whether products or processes, in all fields of technology as long as they are novel, involve an inventive step and are capable of industrial application. There is no internationally accepted approach to these concepts and TRIPS allows members to determine for themselves what would be the appropriate method of implementing the TRIPS standards within their own legal system and practice. ${ }^{1960}$ Furthermore, article 27 TRIPS requires members to respect the principle of non-discrimination.

Section 9 of the Ugandan Industrial Property Bill states that:

An invention is patentable if it is new, involves an inventive step, and is industrially applicable. ${ }^{1961}$

Section 2 of the Bill defines an invention as "a new and useful art (whether producing a physical effect or not), process, machine, manufacture or composition of matter which is not obvious, or any new and useful improvement thereof which is not obvious, capable of being used or applied in trade or industry and includes an alleged

1957 Ibid. at xxi.

1958 SEATINI, TRIPS Compliance and Social Welfare, at 13.

1959 Ibid.

1960 Article 1.1 TRIPS.

1961 In addition, section 13 of the Industrial property Bill excludes a number of inventions from patentability:

The following are not patentable-

(a) plant varieties as provided for in the law providing for the protection of Plant varieties;

(b) inventions contary to public order, morality, public health and safety, principles of humanity and environmental conservation. 
invention"; section 8 of the Bill states that "invention" means a solution to a specific technological problem which may relate to a product or process. ${ }^{1962}$ Importantly, section 8(3) specifies what is not considered an invention under this Bill, including "pharmaceutical products until $1^{\text {st }}$ January 2016." Furthermore, the Industrial Property Bill defines "novelty" as an invention which is "not anticipated by prior art"; 1963 "inventive step" as an invention which "would not have been obvious to a person skilled in the art to which the invention relates"; 1964 and "industrial capability" as an invention which "can be made or used in any kind of industry". ${ }^{965}$

1962 Section 8 of the Industrial Property Bill reads as follows:

(1) For the purposes of this Part' "invention" means a solution to a specific problem in the field of technology

(2) Subject to subsection (3), an invention may be, or may relate to, a product of a process.

(3) The following shall not be regarded as inventions and shall be excluded from patent protection -

(a) discoveries, scientific theories and mathematical methods;

(b) schemes, rules or methods for doing business, performing purely mental acts or playing games;

(c) diagnostic, therapeutic and surgical methods for the treatment of humans or animals;

(d) mere presentation of information;

(e) plants and animals other than micro-organisms, and essentially biological processes for the production of plants or animals other than non-biological and micro-biological processes and

(d) pharmaceutical products until 1st January 2016.

1963 Section 10 of the Industrial Property Bill:

(1) An invention is new if it is not anticipated by prior art.

(2) For the purposes of this Act, everything made available to the public anywhere in the world by means of written disclosure including drawings and other illustrations or by oral disclosure, use, exhibition or other non-written means shall be considered prior art where the disclosure occurred before the date of filing of the application or, if priority is claimed, before the priority date validly claimed in respect of the application

(3) For the purpose of the evaluation of novelty, an application for the grant of a patent or a utility model certificate in Uganda shall be considered to have been comprised in the prior art as from the filing date of the application, or if priority is claimed, as from the date of its validly claimed priority, to the extent to which its content is available, or is later made available, to the public in accordance with this Act or in accordance with the Patent Cooperation Treaty'

(4) For the purposes of subsection (2), a disclosure of the invention shall not be taken into consideration if it occurred within twelve months before the filing date or, where applicable, the priority date of the application and if it was by reason or in consequence of -

(a) acts committed by the applicant or his or her predecessor in title; or

(b) an evident abuse committed by a third party in relation to the applicant or his or her predecessor in title.

1964 Section 11 of the Industrial Property Bill:

An invention shall be considered as involving an inventive step if, having regard to the prior art relevant to the application claiming the inventions, it would not have been obvious to a person skilled in the art to which the invention relates on the date of the filing of the application or, if priority is claimed on the date validly claimed in respect of the invention.

1965 Section 12 of the Industrial Property Bill:

An invention shall be considered industrially applicable if, according to its nature, it can be made or used in any kind of industry including agriculture, medicine, fishery and other services. 
The inventor may apply for the grant of a patent, ${ }^{1966}$ and to do so he must provide a sufficiently clear and complete description of the subject matter of the application. ${ }^{1967}$

1966 Section 17 of the Industrial Property Bill:

Subject to this section, the right to a Patent belongs to the inventor.

(2) Where two or more persons have jointly made an invention the right to the patent belongs to them jointly.

(3) Where two or more persons have made the same invention independently of each other, the person whose application has the earliest filing date, or if priority is claimed, the earliest validly claimed priority date that leads to the grant of a patent, has the right to the patent.

(4) The right to a patent may be assigned or may be transferred by succession.

(5) Sections 51 to 65 apply, with the necessary modifications, to contracts assigning the right to a patent.

1967 Section 21 of the Industrial Property Bill:

(1) An application for a patent shall be filed with the registrar and shall contain -

(a) a request;

(b) a description of the invention;

(c) one or more claims;

(d) one or more drawings, where necessary;

(e) an abstract; and

(f) such other details as shall be prescribed by the regulations made under this Act of Uganda

(2) Where the applicant's ordinary residence or principal place of business is outside Uganda, the applicant shall be represented by an advocate of the High Court of Uganda.

(3) The request shall state the name and prescribed data concerning, the applicant, the inventor and the agent, if any, and the title of the invention and where the applicant is not the inventor the request shall be accompanied by a statement justifying the applicant's right to the patent.

(4) The appointment of an agent shall be indicated by the designation of the agent in the request or by furnishing a power of attorney signed by the applicant and, where subsection (2) applies, the agent shall be designated in the request.

(5) The description shall -

(a) disclose the invention and at least one mode of carrying out the invention, in full, clear, concise and exact terms as to enable a person who has ordinary skills in the art to make use of and to evaluate the invention; and

(b) include any drawings and relevant deposits as in the case of micro-organisms and selfreplicable material which are essential for the understanding of the invention'

(6) Disclosure of the claimed invention shall be considered sufficiently clear and complete if it provides information which is sufficient to allow that invention to be made and used by a person skilled in the art on the filing date, without undue experimentation

(7) For the purposes of assessing sufficiency of disclosure, the disclosure contained in the description, claims and drawings, as established on the date in which the sufficiency of disclosure was examined, shall be taken into account.

(8) The description shall contain a clear identification of the origin of genetic or biological resources collected in the territory of Uganda and that were directly or indirectly used in the making of the claimed invention as well as of any element of traditional knowledge associated or not with those resources and that was directly or indirectly used in the making of the claimed invention without the prior informed consent of its individual or collective creators.

(9) For the purposes of this section, a person shall be taken as having ordinary skill in the art if that person is a citizen of Uganda who has studied and carries out his or her profession in Uganda, and has acquired an average expertise and experience in the technical field of the claimed invention. 
Secondly, article 28 of the TRIPS Agreement sets out the rights conferred on patent owners granting them an exclusive right to exclude competitors from the market. Moreover, Uganda would have to extend its patent term to a minimum of 20 years. ${ }^{1968}$

The Ugandan Industrial Property Bill states that once a patent has been granted, the patent holder has a number of rights ${ }^{1969}$ and obligations; ${ }^{1970}$ section 39 confers onto the patent holder the following exclusive rights:

(10) The registrar may, before granting the patent, require the description in a foreign patent application to be adapted to the ordinary skill in the art of the citizens of Uganda so as to ensure technology dissemination.

(11) The abstract, which must be concise and precise, shall only serve the purpose of technical information; and shall not be taken into account when interpreting the scope of the protection.

(12) The abstract shall only serve the purpose of providing technical information; and it shall not be taken into account when interpreting the scope of the protection sought.

(13) The applicant may, at any time before the grant of the patent, withdraw the application.

(14) Where the application has been withdrawn without having being opened to public inspection, and-

(a) no priority rights have been claimed by virtue of that application; and

(b) no rights are outstanding in Uganda in connection with the application, a subsequent application may be filed in Uganda in respect of the same invention.

(15) The subsequent application shall be regarded as the first application in Uganda in respect of that invention.

(16) Priority rights shall not be claimed on the withdrawn application after the lodging of the subsequent application.

(17) The details of the requirements with which the application must comply shall be prescribed by regulations made under this Act.

Article 33 TRIPS.

1969 Section 39 of the Industrial Property Bill:

(1) The applicant or the owner of an invention has the right -

(a) on fulfilling the relevant requirements under this Act, to be granted the Patent;

(b) to make, use, exercise and sell the invention exclusively, and may preclude any person from exploiting the patented invention without his or her authorization by any of the following acts-

(i) where the patent has been granted in respect of a product, making, importing, offering for sale, selling and using the product or stocking the product for the purposes of offering for sale, selling or using the product;

(ii) where the patent has been granted in respect of a process or doing any of the acts referred to in paragraph (a) in respect of a product obtained by means of that process;

(c) where the patent has been granted in respect of a new use, of putting the patented product or process into a new use without the prior authorisation of the owner of the patent.

(2) After the grant of the patent, and within the terms of this section, the owner of the patent has the right to preclude any person from exploiting the patented invention in the manner referred to in subsection(1).

(3) The owner of a patent may assign or transfer by succession the application for patent or the patent.

(4) The applicant or the owner of a patent may conclude license contracts as provided for in Part $\mathrm{X}$ of this Act and be subject to the obligations referred to in section 39.

1970 Section 39 of the Industrial Property Bill:

The applicant or the owner of an invention shall have the following obligations: 
[.] (b) to make, use, exercise and sell the invention exclusively, and may preclude any person from exploiting the patented invention without his or her authorization by any of the following acts -

(i) where the patent has been granted in respect of a product, making, importing, offering for sale, selling and using the product or stocking the product for the purposes of offering for sale, selling or using the product;

(ii) where the patent has been granted in respect of a process or doing any of the acts referred to in paragraph (a) in respect of a product obtained by means of that process; ...

Finally section 46 of the Bill increases the patent term from 15 to 20 years, ${ }^{1971}$ bringing Ugandan patent law in line with TRIPS standards.

\subsubsection{Exceptions}

In addition to setting out minimum standards with regard to patents, the TRIPS Agreement also provides a number of exceptions to the exclusive rights of patent holders.

Section 43 of the Ugandan Industrial Property Bill provides for the limitation of patent rights in a number of situations. ${ }^{1972}$ Subsection (2) of section 43 of the Industrial Property Bill makes an important amendment to Uganda's existing patent law and states that the rights under a patent do not extend to acts in respect of

(a) to disclose the invention in a clear and complete manner and in particular to indicate at least one mode for carrying out the invention, in accordance with the requirements, and subject to the sanctions, applicable under this Act;

(b) to give information concerning corresponding foreign applications and grants;

(c) to pay fees to the registrar as prescribed in this Act and the regulations, subject to the sanctions provided for under this Act;

(d) to work the patented invention in the country within the time limit prescribed;

(e) in connection with licence contracts and contracts assigning patents or patent applications, to refrain from making undesirable provisions referred to in section 55 .

1971 Section 46 of the Industrial Property Bill:

A patent shall expire at the end of twenty years from the filing date of the application.

1972 Section 43 of the Industrial Property Bill:

(1) The rights under the patent extend only to acts which are done for industrial or commercial purposes but do not extend to acts which are done for scientific research.

(2) The rights under the patent do not extend to acts in respect of articles which have been put on the market in Uganda or in any other country or imported into Uganda by the owner of the patent or with his or her consent.

(3) The rights under the patent do not extend to the use of articles on aircraft, land vehicles or vessels of other countries, which temporarily or accidentally enter the airspace, territory or waters of Uganda.

(4) The rights under the patent shall not affect the acts performed by a person who in good faith, before the filing or, where priority is claimed, before the priority date of the application on which the patent is granted and in Uganda, is using the invention or is making effective and serious preparations for use, to the extent that those acts do not differ in nature or purpose from the actual or envisaged prior use. 
articles which have been put on the market in Uganda or in any other country or imported into Uganda by the owner of the patent or with his or her consent. Consequently, it has an explicit preference for an international exhaustion of rights regime, thus providing for the possibility of parallel importation.

Section 44 of the Industrial Property Bill further provides for a number of exceptions to patent holders' exclusive rights. ${ }^{1973}$ Importantly it states that "acts, including testing, using, making or selling a patented invention solely for the purposes reasonably related to the development and submission of information required under any law of Uganda or of another country which regulates the manufacture, construction, use or sale of any product" is not an infringement of a patent. ${ }^{1974}$ As such, it will introduce a Bolar exception within Ugandan patent legislation.

The Industrial Property Bill also provides a framework for compulsory licensing which seems to follow the provisions of the TRIPS Agreement. Section 58 of the Bill states the following: ${ }^{1975}$

(5) The right of prior user referred to in this section may be transferred or devolve only together with the enterprise of business, or with that part of the enterprise or business, in which the use or preparations for use have been made.

(6) The rights under the patent shall be limited by the terms of the patent.

(7) The rights under the patent shall be limited by the provisions on compulsory licenses for reasons of public interest, the interdependence of patents, or the exploitation of patented inventions by the state.

(8) The rights of the patent do not extend to variants or mutants of living forms or replicable living matter that is distinctively different from the original for which patents were obtained where those mutants or variants are deserving of separate patents.

1973 Section 44 of the Industrial Property Bill:

It is not an infringement of a patent to use the patented invention without the authorization of the patent holder in any of the following circumstances -

(a) to carry out any acts related to experimental use on the patented invention, whether for scientific or commercial purposes;

(b) to make use of a patented invention for teaching purposes;

(c) to carry out acts, including testing, using, making or selling a patented invention solely for the purposes reasonably related to the development and submission of information required under any law of Uganda or of another country which regulates the manufacture, construction, use or sale of any product

(d) to make use of the patented invention in relation to the preparation for individual cases, in a pharmacy or by a medical doctor, of a medicine in accordance with a medical prescription; and

(e) to manufacture and export to another country a patented healthcare invention where the export of the invention addresses a health need identified by the other country, where -

(i) the product is either not patented in the third country; or

(ii) the government of another country has authorised use of the patent without the consent of the patent owner and the production for export of the invention is intended only for the market of the third country.

1974 Section 44(c) of the Industrial Property Bill.

1975 Section 58 of the Industrial Property Bill:

(1) After the expiration of four years from the filing date of an application or three years from the grant of a patent, whichever last expires, a person my apply to the court for a licence to 
Chapter 8

[...] a person may apply to the court for a licence to exploit the patented invention on the grounds that the market for the patented invention is not being supplied on reasonable terms, in Uganda.

The precondition for a grant of compulsory licenses are set out in section 60 of the Bill; ${ }^{1976}$ it provides that an applicant requesting a compulsory license must enter into negotiations with the patent holder to obtain a voluntary license on reasonable commercial terms and within a reasonable timeframe. This requirement is waived in cases of a national emergency or other circumstances of extreme urgency. In addition, section 61 - with respect to the grant and term of a compulsory license provides that the patent holder must be paid remuneration which is equitable having regard to all the circumstances of the case, including the economic and social value of the licence. ${ }^{1977}$

exploit the patented invention on the grounds that the market for the patented invention is not is not being supplied on reasonable terms, in Uganda.

(2) Notwithstanding subsection (1), a non-voluntary licence shall not be granted if the owner of the patent satisfies the court that circumstances exist which justify the fact that the market for the patented invention is not being supplied, or is not being supplied on reasonable terms, in Uganda.

1976 Section 60 of the Industrial Property Bill:

(1) A compulsory licence shall not be granted unless the person requesting the licence -

(a) satisfies the court that he or she has requested the owner of the patent for a contract licence but has been unable to obtain the licence contract on reasonable commercial terms and within a reasonable time; and

(b) offers a guarantee satisfactory to the court to work the relevant invention sufficiently to remedy the deficiencies or to satisfy the requirements which gave rise to his or her request.

(2) The requirement under subsection (1)a shall be waived in the case of a national emergency or other circumstances of extreme urgency or where the application is based on anticompetitive practices; except that the registrar shall notify the owner of the patent as soon as reasonably possible of the waiver.

1977 Section 61 of the Indistrual Property Bill:

(1) When considering a request for a compulsory licence, the court shall decide whether a compulsory licence may be granted and shall, if it decides in favour of the grant and after taking into account any terms agreed by the parties, proceed to fix the terms which shall be taken to constitute a valid contract between the parties and shall be governed by provisions on constractual licenses.

(2) When fixing the terms under subsection (1), the court shall ensure that the compulsory licence -

(a) is limited, in scope and duration, to the purpose for which it was authorized, and in the case of semi-conductor technology, shall only be for public non-commercial use or to remedy a practice determined after a judicial or administrative process to be anticompetitive;

(b) is limited predominantly for the supply of the regional market;

(c) does not entitle the licensee to grant further licences without the consent of the owner of the patent;

(d) is non-exclusive; and 
Section 60(1)a of the Bill does not, however, specify the period to be respected when seeking a voluntary license from the patent holder. TRIPS leaves members free in this regard and it might be useful for Uganda to set an appropriate timeframe with regard to seeking a voluntary license. ${ }^{1978}$ Furthermore, to apply for a compulsory license the court must be approached. This has been argued to possibly create delay in granting the compulsory license as the procedure may prove to be laborious and technical. ${ }^{1979}$ Moreover, a judicial procedure can be expensive and open up the door to endless litigation by pharmaceutical corporations. A simple and fast administrative procedure, with time limits fixed, may therefore prove to be a more appropriate alternative. It is further argued that guidelines should be set out to simplify the process to determine the amount of remuneration awarded to the patent holder. ${ }^{1980}$

Furthermore, the applicant must guarantee the court that he will work the relevant invention sufficiently to remedy the deficiencies or to satisfy the requirements which gave rise to his request. ${ }^{1981}$ This presupposes that there is just one applicant and a need to guarantee sufficient supply. Yet in case there are several applications for a compulsory license but none of these can fulfil this requirement individually, the question arises whether this entails that none will be granted the compulsory license. ${ }^{1982}$

Finally, the Industrial Property Bill also provides for the exploitation of a patented invention by the government where the public interest, including public health, requires it to do so. ${ }^{1983}$

(e) provides for the payment to the owner of the patent of remuneration which is equitable having regard to all the circumstances of the case, including the economic and social value of the licence.

(3) A representative of the registrar and the patent owner shall have the right to appear and be heard at the hearing before the court of an application for a compulsory licence.

1978 SEATINI, TRIPS Compliance and Social Welfare, at 15.

1979 TWINOMUGISHA, 'Implications of the TRIPS Agreement for the Protection of the Right of Access to Medicines in Uganda', at 270; SEATINI, TRIPS Compliance and Social Welfare, at 14.

1980 TWINOMUGISHA, 'Implications of the TRIPS Agreement for the Protection of the Right of Access to Medicines in Uganda', at 270.

1981 Section section 60(1)b of the Industrial Property Bill.

1982 SEATINI, TRIPS Compliance and Social Welfare, at 14.

1983 Section 66 of the Industrial Property Bill:

(1) Subject to this section, where-

(a) the public interest, in particular, national security nutrition, health, environmental conservation, national emergency or the development of other vital sectors of the national economy requires; or

(b) the registrar determines that the manner of exploitation of an invention by the owner of the patent or his or her licensee is not competitive, the Minister may, upon application to him or her in the prescribed form and after consultation with the registrar and the owner of the patent order that the protected invention shall be exploited by a Government ministry, a department an agency or other person as the Minister may 


\subsection{Conclusion}

The research question addressed in this section, firstly, examined whether Uganda's existing legal system protects patents for pharmaceuticals. Under the current Patents Act, Uganda provides for patent protection for pharmaceuticals in line with TRIPS conditions even though it is not under a legal obligation to fully implement the TRIPS Agreement. In that regard, it grants the patent owner an "exclusive right

designate in the order subject to the payment of adequate compensation to the owner of the patent in accordance with this section.

(2) An order under subsection (2) shall remain in force until it is revoked by the Minister in writing, after giving six months prior notice of his or her intention to revocate to the party named or described in the order.

(3) An order made under subsection (2) shall not require the payment of compensation to the owner of the patent or licence holder or any other party interested.

(4) The Minister may, notwithstanding any of the measures set out in this section, by written order authorise the utilisation of any process for the manufacture, sale or supply of any molecule or substance, by any individual, corporation, society or other enterprise named or described in the order without notice to the patent holder or any other noticeable party.

(5) An order under subsection (4) and that order shall remain in force until revoked by the Minister in writing, after giving six months prior notice of intention to revocate to the party named or described in the order.

(6) An application shall not be made under subsection (1) unless the applicant has unsuccessfully sought a licence contract from the owner of the patent.

(7) Subsection (1) shall not apply in a case of national emergency or other extreme urgency and in that case the Minister shall cause the contents of the order to be communicated to the owner of the patent as soon as practicable.

(8) An order under this section shall be subject to conditions that the Minister considers necessary.

(9) Where an order under this section is made, the Minister shall determine the amount of compensation to be paid to the owner of the patent, and the compensation shall be equitable having regard to all the circumstances of the case and in particular, the economic and social value of the patent.

(10) An order under this section shall not preclude the owner of the patent from concluding a licence contract or from exercising the powers conferred by section 38 .

(11) The Minister may, upon the request of the owner of the patent or the Government ministry, a department, an agency or other person designated by the Minister for the purpose of any order under this section and after hearing all interested parties, vary the terms of the order to the extent that changed circumstances justify the variation.

(12) The Minister may, upon the request of the owner of a patent and after hearing all interested parties, revoke an order under this section -

(a) if satisfied that the circumstances necessitating the order have ceased and are unlikely to recur; or

(b) where the Government Ministry, department, agency or other entity or person designated for the purposes of the order is in breach of any condition imposed under subsection (7).

(13) The authorisation of a person in an order under this section shall not be transferable except to a business or enterprise owned or operated by that person.

(14) The exploitation of the invention under an order made under this section shall be primarily for the regional market. 
to make, use, exercise and vend the invention" and to "preclude any person from exploiting the patented invention without his or her authorisation." 1984 The Patents Act's main departure from TRIPS standards is with respect to the patent term, which expires after 15 years, as opposed to the 20 years mandate by TRIPS, although the patent holder may apply for an additional five-year extension of the patent term. ${ }^{1985}$

The Ugandan Patents Act also provides for a number of exceptions to patent rights:

- Section 28 of the Ugandan Patents Act provides for limitations of patent holders' rights with respect to acts done in pursuance of scientific research, or in respect of articles which have been put on the market in Uganda by the owner of the patent or with his or her express consent. The latter adopting a national exhaustion of rights regime and thus prohibiting the possibility of parallel importation.

- Section 29 of the Ugandan Patents Act provides for the exploitation of a patented invention for a vital public interest, including public health; and

- Section 30 provides for compulsory licensing under a limited number of grounds.

As a least-developed member, Uganda has until 2021 to fully implement TRIPS. However, it has already started the process of reforming its intellectual property in order to bring it in line with the TRIPS' requirements. In a study conducted by the ULRC on the drafting of an Industrial Property Bill, the Commission noted that it may be expedient to implement the entire Agreement on TRIPS for political considerations and in order to complete the framework for promoting investment. On the other hand it has also stated that reform of its IP legislation should strike a balance between protecting and respecting the rights of right holders, especially patent holders, and public interest concerns, especially with respect to access to essential medicines as Uganda suffers greatly from nationwide pandemics such as HIV/AIDS and malaria. Therefore, the following question was posed: does the draft Industrial Property Bill fully implement TRIPS standards and flexibilities with a view to achieving a balance between access and protecting patents within their legal framework?

The Bill makes use of the transition period for least-developed countries and states that applications for patent protection of pharmaceuticals may only be granted from 2016 onwards. However, it does not provide for any further extension as granted by the TRIPS Council, which would entail that in such a case parliament would have to amend the law. First the Patent Act's provisions are examined which implement TRIPS' patent standards:

1984 Section 25 of the Patents Act.

1985 See section 31 of the Patents Act. 
- section 9 of the Ugandan Industrial Property Bill states that an invention is patentable if it is new, involves an inventive step, and is industrially applicable;

- section 39 of the Ugandan Industrial Property Bill confers onto the patent holder a set of exclusive rights; and

- section 46 of the Ugandan Industrial Property Bill increases the patent term from 15 to 20 years, bringing Ugandan patent law in line with TRIPS standards.

Secondly the exceptions the Ugandan Patents Act allows for are examined and it is explored whether these are compatible with articles 30 and 31 TRIPS:

- Section 43(2) of the Ugandan Industrial Property Bill makes an important amendment to Uganda's existing patent law, in that it applies an international exhaustion of rights regime and thus allows for parallel importation, which is not possible under the current Patents Act

- Section 44 of the Ugandan Industrial Property Bill provides for a number of exceptions to patent holders' exclusive rights and as such will introduce a Bolar exception within Ugandan patent legislation; and

- Section 58 of the Ugandan Industrial Property Bill provides a framework for compulsory licensing.

Interestingly, the existing level of patent protection in Uganda is remarkably close to that of the TRIPS Agreement which is surprising considering the status of Uganda as a LDC. As such, it is not taking full advantage of the fact that it is not yet obliged to fully comply with TRIPS. Furthermore Uganda's law reform demonstrates the difficulties developing members face when implementing TRIPS with the hope of attracting foreign investment but at the same time incorporating flexibilities targeted at their specific needs. ${ }^{1986}$

\section{Conclusion}

The research questions addressed in this chapter are threefold. Firstly, has Uganda complied with its obligations under international human rights law by recognising a right access to medicines? Uganda does not recognise the right to health or access to medicines as an enforceable and justiciable human right and in that regard falls short of the obligations imposed on it by the ICESCR. It does not explicitly recognise the right to health in its Constitution. Any reference to the right to health within the Constitution is incorporated as NODPSP, which although reflects a commitment by the Constitution, do not contain justiciable and enforceable rights. And even though Uganda has set up a relatively successful framework for providing

1986 See further IKECHI MGBEOJI, 'TRIPS and TRIPS-Plus Impacts in Africa', in Daniel Gervais (ed.), Intellectual Property, Trade and Development. Strategies to Optimise Economic Development in a TRIPS-Plus Era (New York: Oxford University Press, 2007). 
medicines for HIV-infected patients these policies are not legally binding but only contain political obligations and guidelines. ${ }^{1987}$

Secondly, does Uganda protect patents for pharmaceuticals, and if so to what extent? Under the current legal system Uganda does provide for patent protection for pharmaceutical products, however, only for a patent term of 15 years. As a leastdeveloped country it is not yet under the obligation to fully implement TRIPS. However, to ensure that it complies with its TRIPS obligations once the transitional period ends, Uganda has started the process of reforming its intellectual property legislation in order to bring it in line with the TRIPS' requirements. Consequently, the third question is whether the draft Industrial Property Bill fully implements TRIPS standards and flexibilities with a view to achieving a balance between access and protecting patents within their legal framework? Firstly, the Bill makes full use of the transition period for least-developed countries. In addition to incorporating TRIPS standards and thus extending the patent term to 20 years, the Ugandan Industrial Property Bill also implements the TRIPS flexibilities in line with the Doha Declaration into its legislative framework, such as a Bolar exception, parallel importation, compulsory licensing, and government use. However, it is questionable here whether the Bill's provisions - particularly those relating to compulsory licensing - will provide effective tools for Uganda to enhance access to affordable medicines. Namely, the main problem in Uganda is that it has a very limited pharmaceutical manufacturing capacity, which in reality entails that even if an order for government use or compulsory license on public health grounds would be issued, it would not have the capacity to produce generic medicines to the extent that this would make a significant difference in Uganda. As such, Uganda is dependent on the importation of generic medicines. Therefore the explicit preference for an international exhaustion of rights regime permitting parallel importation will potentially be the most important flexibility to strike a balance between access and patent protection.

1987 MUBANGIZI and TWINOMUGISHA, 'The Right to Health Care in the Specific Context of Access to HIV/AIDS Medicines', at 129. 



\section{Chapter 9 \\ Findings, Conclusions And Recommendations}

\section{Patents - Access: Interference}

Poor patients worldwide continue to face difficulties in obtaining or purchasing essential medicines because of scarce availability and high prices. ${ }^{1988}$ The focus of this research is the interface between patent and human rights law with regard to access to essential medicines in the context of developing countries. The argument often made in that regard is that patents negatively impact patients' access to medicines as patent protection for medicines results in higher prices. Therefore, before turning to the examination of the relationship of patent protection for medicines and access to such medicines, a preliminary question had to be asked:

Does patent protection for medicines interfere with patients' access to essential medicines?

Access in the context of this research entails that medicines are available, physically accessible and affordable on a non-discriminatory basis (in addition to being culturally acceptable and of good quality). The focus here is on the element of "affordability" of essential medicines within a developing country context. Namely, for (developing) countries operating in a resource constrained setting it is a continuous struggle to find and allocate the resources necessary to maintain and improve the public health care system and, as a result of inadequate public health systems, many patients in developing countries are forced to privately finance medicine use. Moreover, it is especially developing countries with poor public health systems which suffer disproportionately from widespread public health problems such as HIV/AIDS, tuberculosis and malaria and a systematic lack of access to affordable medicines. It is therefore crucial that developing countries ensure that medicine prices are as low as is realistically possible.

Both economic theory (the fact that patent protection in the majority of situations leads to a monopoly position) and a number of empirical studies find that in general patent protection for medicines go hand-in-hand with higher medicine prices. Consequently, patent protection for medicines may interfere with access to such medicines. These higher prices are then argued, particularly by the pharmaceutical industry, to be justified due to the fact that patents are essential in order to enable pharmaceutical corporations to recoup their substantial research and development costs; without patent protection companies would have no incentive to invest in innovation. Although the incentive to innovate function of patent protection is not

1988 See also MDG GAP TASK FORCE, Millennium Development Goal 8. The Global Partnership for Development: Making Rhetoric a Reality, United Nations, (2012) at 61 et seq. 
contested here, an important observation must be made. Patent protection only provides an incentive to innovate in situations in which the innovator has a real possibility to recoup his investment, i.e. a profitable market. Unfortunately, however, the majority of patients in developing countries, lacking resources, do not provide such a profitable market. As a result, the largest part of health-related research and development is invested in diseases that either affect patients worldwide (such as cancer or diabetes) or affect mainly patients in the developed world. Lacking, though, is research and development targeted at diseases mainly prevalent in developing countries, also referred to as neglected and poverty-related diseases. As such, there is concern that even though funding for health-related R\&D has been steadily growing, this does not necessarily lead to an increase in the number of new medicines developed, particularly for neglected and poverty-related diseases. Moreover, it is unclear whether introducing strong(er) patent systems in developing countries would encourage more (local) R\&D targeted at such neglected and poverty related diseases or more broadly facilitate technology transfer and achieve economic and social development. For example, after a 10-year transitional period to implement TRIPS just short of 9,000 mailbox applications had been filed in the Indian Patent Office, the majority pertaining to pharmaceuticals and owned by non-Indian entities. ${ }^{1989}$ Considering that between 2000 and 2004163 NCEs were marketed worldwide, this begs the question how many of these applications are trivial or "me-too" patents. Yet, it is almost impossible to make broad generalisations in that regard since developing countries are not a homogenous group and the effect of a patent system will depend on a variety of factors including scientific, technological and manufacturing capacity. Consequently, it is essential that developing countries implement a patent system suited to their domestic needs enabling them to strike a balance between, on the one hand, ensuring access to medicines while also providing for a patent system that fosters (local) R\&D and technology transfer.

\section{A Human Right of Access to (Essential) Medicines}

After having identified that patent protection for medicines may interfere with access to such medicines the focus turned to the following question:

\section{Is access to medicines protected under international human rights law? If yes, how?}

The starting point is that the primary objective of human rights is to safeguard the dignity of human beings. The creation and development of international human rights norms and standards has mainly taken place within the UN human rights framework, which has been very successful in that regard with the adoption of many treaties, declarations and instruments on human rights since the 1948

MUELLER, 'The Tiger Awakens', at 521-522, 524. 
Universal Declaration of Human Rights. Chapter 3 addressed the research question whether and how international human rights law protects a right of access to (essential) medicines. This question was answered in the affirmative. There are a number of sources which protect access to essential medicines in varying degrees. The most obvious and logical starting point is article 12 ICESCR which includes a right of access to essential medicines as part of the minimum core content of the right to health. The Committee on Economic, Social and Cultural Rights has interpreted the scope of the right to health to entail the availability, accessibility and affordability of essential medicines on a non-discriminatory basis. In addition to the ICESCR, other international human rights treaties containing health rights have also been interpreted to include access to medicines.

The conclusion that access to medicines is a right under international human rights law is supported by the analysis of other sources, particularly the right to life, the right to benefit from science and customary international law. However, the exact scope of a right of access to medicines differs depending on the source. For example under the right to health states parties to the ICESCR are obliged to ensure access to essential medicines, while under the right to life the scope is narrowed down to access to life-saving medicines. Under a possibly emerging customary right state practice is mainly concerned with access to medicines in the context of pandemics such as HIV/AIDS, tuberculosis and malaria.

Within the country studies varying degrees of protection of the right of access to medicines was seen. South Africa constitutionally recognises the right to health while India and Uganda do not do so. A literal interpretation of the right to health incorporated in the South African Constitution must lead to the conclusion that it includes access to (essential) medicines. This is also supported by jurisprudence of the Constitutional Court, most notably in the Minister of Health v. Treatment Action Campaign case. Moreover, the constitutional provisions on socio-economic rights mirror the language employed in the ICESCR referring to the state's duties to progressively realise and respect, protect, promote and fulfil the right to health. However, the South African Constitutional Court has not followed the approach of the CESCR by establishing a minimum core content for the right to health.

India's and Uganda's Constitutions do not recognise health as a justiciable and enforceable right, although both include public health as a directive principle of state policy. The Indian Constitution states that improving public health is the primary duty of the state but it also explicitly states that this duty is not enforceable through the Indian court system. Remarkably, however, this has not barred the Indian Supreme Court from finding a way to adjudicate state compliance with a number of socio-economic rights through creatively interpreting the right to life to include positive obligations, also with regard to health. As such, and in line with the Supreme Court's existing jurisprudence, it seems justified to conclude that the right to life protected under the Indian Constitution includes a right of access to medicines. It is unclear though whether such a creative interpretation would be limited to only life-saving medicines or whether it would also include other (essential) medicines. The Indian Supreme Court justifies its expansive 
interpretation of the right to life on the basis of human dignity which would suggest the latter. Within the Ugandan context, a similar approach to socio-economic rights may be possible. The NODPSP, part of the preamble to the Ugandan Constitution, include a right of access to health services. However since these NODPSP fall outside of the Constitution's substantive section on human rights they are not considered justiciable and enforceable rights. Rather they reflect the commitment of the state to ensure access to and provide where necessary basic health services. The Ugandan Constitution does not bar a progressive approach to socio-economic rights incorporated in the NODPSP by creatively interpreting the right to life protected as a fundamental human right. Yet, in order to do so, the Ugandan Constitutional Court must be willing to take a more bold stance and until now it seems to be hesitant to do so. Only recently the Ugandan Constitutional Court struck out a petition concerning maternal health care due to it being a political question which should be left to the discretion of the executive and legislative branches of the government. The Indian experience illustrates that constitutional recognition of the right to health (and implicitly access to medicines) is not necessarily a prerequisite for adequately protecting access to medicines by allowing for an enforceable and justiciable right. On the other hand, it can be questioned whether such an overtly progressive approach by the judiciary does not overstep the boundaries of democracy and separation of powers.

Although the Ugandan Constitution does not formally recognise the right to health, the government has implemented an elaborate policy framework, particularly with respect to managing the country's HIV/AIDS epidemic, recognising the importance of ensuring that ARVs are adequately available, accessible and affordable. This policy framework though does not recognise the right to health, or access to medicines, as an enforceable and justiciable human right. As such, Uganda would benefit from formally recognising the right to health, including access to medicines, within their constitutional and legislative framework. By incorporating the Bill of Rights into the substantive part of the Constitution it would explicitly affirm their enforceable and justiciable nature. ${ }^{1990}$ Yet constitutionalising the right to health alone is not sufficient. An appropriate legislative and policy framework must be in place to give effect to the right. ${ }^{1991}$ To properly give effect to the right to health, the state's obligation to respect, promote, protect and fulfil the right must be reiterated in legally binding legislation and not just in a non-binding policy framework. ${ }^{1992}$ Such a framework should domesticate the international and regional human rights instruments recognising the right to health, as ratified by Uganda.

1990 BEN KIROMBA TWINOMUGISHA, Beyond Social Programmes: Protection of the Right of Access to Malaria Treatment in Uganda, Human Rights \& Peace Centre, WP No. 22, (November 2008) at 25.

1991 MUBANGIZI and TWINOMUGISHA, 'The Right to Health Care in the Specific Context of Access to HIV/AIDS Medicines', at 130.

1992 TWINOMUGISHA, Beyond Social Programmes, at 25. 
States parties to the ICESCR have the obligation to progressively realise the right to health and a core obligation to provide essential medicines. The concept of progressive realisation brings with it a margin of discretion when complying with the Covenant's obligations. As such, states parties are free to determine the exact manner in which to implement the right to health, as long as they take all appropriate measures to the maximum of their available resources in order to ensure that the right to health and access to medicines is respected, protected and fulfilled. Both India and Uganda are parties to the ICESCR, however, South Africa is not (yet) formally a party, although it has signed the Covenant and should therefore refrain from any acts which would defeat the object and purpose of it. Moreover, it is party to a number of other human rights treaties which include health-related rights. Interestingly, of the three country studies, it is the only one formally recognising the right to health within its Constitution mirroring much of the language of the ICESCR determining the state's constitutional duties in that regard.

The CESCR interprets the right to health to include a number of core obligations, including the provision of essential medicines; these are considered to be of a nonderogable nature entailing that non-compliance can never be justified, also not with reference to lacking resources. The non-derogable nature of such core obligations is questionable considering that fulfilment of the minimum core content and more generally the progressive realisation of the right to health is intimately linked to a state party's availability of resources. Providing essential medicines is therefore particularly problematic for least-developed and developing countries battling widespread public health epidemics while facing sometimes severe resource constraints. This is so for all three country studies and particularly Uganda which is classified as a low-income country. In that regard, is it really realistic to expect a least-developed country like Uganda to provide essential medicines free of charge to its population? Moreover, what is then the value of applying a human rights approach to access to medicines within the context of developing countries? Even well-meaning governments can only provide essential medicines to the extent that resources are available. Moreover, the provision of essential medicines must be balanced with other resource intensive rights, such as housing, education etc. Yet a human rights approach to access to medicines and the formal recognition of the right to health brings with it an important advantage, namely the possibility of assessing state compliance with its constitutional duties while also holding duty bearers accountable for possible violations.

The CESCR noted, in its General Comment No. 14 on the right to health, that when determining whether a state has violated the right to health, one must distinguish between a state party's inability from its unwillingness to comply with its obligations under the ICESCR. For example South Africa's initial position denying HIV-infected patients access to ARVs would constitute an example of unwillingness, as opposed to Uganda's relatively successful HIV/AIDS policy framework. 
South Africa's example demonstrates the importance of applying a human rights approach to access to medicines allowing for the state to be held accountable for human rights violations. In that regard, the involvement of civil society and health advocacy groups has also proven to be of essential importance. In South Africa, but also in Uganda, civil society have been at the forefront of the struggle in holding the state accountable for violating human rights obligations. This is particularly important since there is no effective enforcement mechanism within the international human rights framework to ensure that states comply with their obligations under international human rights treaties. Monitoring and accountability mechanisms should be established at the national level. There are different ways to ensure accountability of the state, the focus here however is on judicial mechanisms. Namely, to be truly effective human rights must be justiciable and enforceable. In that regard the jurisprudence of the South African Constitutional Court reaffirms the importance of allowing individuals to approach the courts and demand that their rights are respected, protected and fulfilled. In Grootboom the Constitutional Court stated that the question is not "whether socio-economic rights are justiciable under the Constitution, but how to enforce them in a given case. This is a difficult issue which must be carefully explored on a case-by-case basis."1993 Consequently it developed the reasonableness test to assess state compliance with its socioeconomic constitutional obligations. This is an innovative and flexible approach which balances the institutional and democratic implications of enforcing socioeconomic rights with protecting society's most vulnerable. ${ }^{1994}$ As such, the Constitutional Court has overcome many of the arguments posed against the justiciability of socio-economic rights. Even so, the Court has not ignored the principle of separation of powers or arguments centred on the lack of resources.

Essentially the realisation of economic, social and cultural rights within a state party's territory is primarily the duty of that particular state party. As such, the ICESCR's scope is principally territorial in nature. However, due to the process of globalisation and the growing international interaction between an increasing number of actors, the need for international cooperation has come to the forefront. As such, the realisation of economic, social and cultural rights has increasingly international dimensions. Article 2 ICESCR states that all state parties must take steps, individually and through international and assistance and cooperation to progressively realise the Covenant's rights. Consequently, least-developed and developing states parties struggling to comply with their obligation to progressively realise the right to health due to a lack of resources must seek assistance from the international community.

One of the major problems for Uganda in ensuring adequate access to medicines is a lack of funding. As such, even the use of generic medicines still means that these are out of reach for the majority of Ugandans. The government has turned to

1993 Government of the Republic of South Africa v. Grootboom, at \$20.

1994 FORMAN, 'Justice and Justiciability: Advancing Solidarity and Justice through South Africans' Right to Health in Jurisprudence', at 672. 
donor support to fill the gaps in government funding, yet this is by no means a sustainable solution. ${ }^{1995}$ It also requested international (technical) assistance to promote the availability and accessibility of medicines. In that regard, the donor community must be credited for the assistance provided to Uganda's health sector. In the long-term, however, this is an unsatisfactory solution.

Moreover, the debate has been put forward whether developed countries have a duty under international law to provide assistance to least-developed and/or developing countries. It seems unlikely that states have more than a moral obligation to provide assistance. However, there is increasing recognition by authoritative bodies, such as the CESCR, the Special Rapporteur and also to a certain degree the international community, of the responsibility of states that are in a position to assist to do so. See for example recent developments such as the 2012 Maastricht Principles on Extraterritorial Obligations of States in the area of Economic, Social and Cultural Rights or the establishment of a Global Fund to Fight HIV/AIDS, Tuberculosis and Malaria. On the other hand, the establishment of a Global Fund dependent on voluntary contributions by governments suggests that developed countries reject the notion of a legal obligation to assist.

Sufficient resources are a major factor in the ability of states to provide essential medicines and thus comply with their human rights obligations. However, in addition, other factors are also of importance, particularly the political will within countries to take all possible and reasonable steps towards full realisation. For example, state parties to the ICESCR are under an obligation to give due account to the right to health both when concluding international agreements and when taking actions as members of international organisations. Therefore, the ICESCR obliges states parties to ensure that when negotiating and ratifying agreements in the area of IPRs these agreements do not curtail or inhibit a state's capacity to fulfil the right to health including access to medicines. The conclusion of (bilateral) trade agreements, without conducting a right to health or human rights impact assessment, and consequent interference with access to affordable medicines would be a violation of the right to health. That would certainly hold true for the (developing) state obliging itself to protect higher standards of IPRs without due regard to the possible negative impact on access to medicines. It is questionable, however, to what extent the (developed) state pushing for such stronger IPRs in its negotiations with developing states would also be considered as not taking due regard of the right to health and thus in violation of its obligations under ICESCR. ${ }^{1996}$

Finally, even though a state may be facing resource constraints, it is still under an obligation to take steps through all appropriate means to fully realise the right of access to medicines. Measures relating to IPRs for pharmaceuticals which do not necessarily imply resources may positively (or negatively) affect the availability,

1995 TWINOMUGISHA, Beyond Social Programmes, at 14.

1996 See further PAUL HUNT and RAJAT KHOSLA, 'The Human Right to Medicines', SUR International Journal on Human Rights, 5:8 (2008), 99-114 at 105. 
accessibility and affordability of medicines within the domestic context. Yet, with the inclusion of the TRIPS Agreement in the WTO, its members are no longer free to adopt a system of IP protection to their liking. Therefore the following question is to examine the standards and flexibilities the TRIPS Agreement provides in that regard.

\section{Trips Minimum Standards for Patent Protection}

In order to assess the interface between access to medicines and patents chapter 4 posed the following question:

What are TRIPS' minimum standards and flexibilities, with respect to the patenting of pharmaceuticals?

The focus in this dissertation is on the TRIPS Agreement as it is one of the most recent and far-reaching international agreements within the field of intellectual property protection. Furthermore, the TRIPS Agreement was concluded within the framework of the World Trade Organisation making it subject to its dispute settlement mechanism.

The inclusion of intellectual property within the framework of the WTO is one of the most significant developments in the area of IP protection. The negotiation of TRIPS started from two opposing standpoints; developed countries aimed at a more effective international regulation of IP while developing countries attempted to lower existing standards of IP protection. Moreover, the WTO is a single undertaking, entailing that the results of the negotiations formed a single package to be implemented as one treaty. Thus the WTO Agreement could only be adopted by member states in a "single package approach", meaning that potential members either had to adopt all agreements or not become a member to the WTO: "a take-itor-leave-it" approach.

A second crucial element of IPRs being included into the WTO is that the WTO set up a strong dispute settlement mechanism - a marked difference compared to the weak and ineffective monitoring system within the UN human rights framework. A key reason for the inclusion of IPRs within the WTO framework was the lack of enforcement mechanisms within existing IP conventions. Nor did these conventions require any form of domestic enforcement of IPRs. The TRIPS Agreement remedies these shortcomings rather effectively. For example, the EC and US filed a complaint before the WTO Dispute Settlement Mechanism to ensure that India complied with its obligation to establish a mailbox system for receiving and holding patent applications for pharmaceuticals and in certain situations the granting of exclusive marketing rights. Consequently India adopted an amendment to its patent legislation in order to fully comply with its TRIPS obligations. Moreover, the value for right holders of TRIPS' minimum substantive standards depends on the ability to effectively enforce such a right. Consequently the TRIPS 
Agreement sets out minimum procedural standards in relation to the acquisition, maintenance and enforcement of IPRs.

There has been some concern that the dispute settlement mechanism under the WTO has mostly negative effects for developing countries in that, as economically weaker states, they are in a disadvantaged position compared to developed states. Namely, as a result of developing members' comparative economic weakness vis-àvis developed members the DSB's authorisation to suspend concessions to a developed member will likely have a more adverse affect on the developing members' economy than on that of the developed member. Yet, the WTO dispute settlement system has been used by both developed and developing members; and developing members have proved successful even against much larger developed members. ${ }^{1997}$ Developing members could strengthen their position within the WTO by bringing allegations of TRIPS violations before the WTO dispute settlement system where they will be assessed on the basis of the law by the impartial WTO adjudicatory bodies contributing to the predictability and transparency of the dispute settlement system. ${ }^{1998}$ See, for example, the complaints brought by India and Brazil in relation to repeated seizures by EU custom officials of generic medicines in transit alleging that this constitutes a breach of the TRIPS Agreement. 1999 On the other hand, developing countries are likely more concerned with their ability to take full advantage of the TRIPS flexibilities than ensuring that developed states comply with TRIPS' minimum standards.

First addressed in chapter 4 were the substantive minimum standards with regard to patent protection for pharmaceuticals which TRIPS requires developing members to implement within their national legal system. Article 27 TRIPS has introduced one of the major changes for developing members, namely the extension of patent protection to all fields of technology. As a result, members are now obliged to incorporate patent protection for pharmaceuticals into their legislative framework. Articles 28 and 33 TRIPS oblige members to grant patent holders a set of exclusive rights for a minimum period of 20 years.

Secondly it was addressed whether the TRIPS Agreement provides the flexibility for members to balance patent protection for pharmaceuticals with public health objectives, particularly the right of access to medicines. As seen earlier, the objective and purpose of the TRIPS Agreement - as can be found in its preamble and articles 7 and 8 and confirmed by the Doha Declaration - does not limit itself to the protection of intellectual property rights, but it recognises the necessity to find a balance: a balance between free trade and IP protection, between the needs of highly developed

\footnotetext{
1997 VAN DEN BOSSCHE and ZDOUC, The Law and Policy of the World Trade Organisation, at 158.

1998 SKY, 'Developing Countries and Intellectual Property Enforcement Measures', at 425 et seq; UNCTAD-ICTSD, Resource Book on TRIPS and Development, at 686.

1999 WTO, European Union and a Member State - Seizure of Generic Drugs in Transit. Request for Consultations by Brazil (WT/DS409/1; 2010); WTO, European Union and a Member StateSeizure of Generic Drugs in Transit. Request for Consultations by India (WT/DS408/1; 2010).
} 
and developing and least-developed countries, and between the private rights of the right holders and underlying public policy objectives, including technological and developmental objectives of national systems of IP protection. Furthermore, TRIPS allows members a degree of freedom when implementing and interpreting TRIPS in line with national legal systems and policy objectives. In that regard, many of the TRIPS provisions, such as the terms "novelty" and "inventiveness" found in article 27 TRIPS, allow a degree of interpretative flexibility and can be interpreted in a manner conducive to social welfare and public health.

TRIPS also takes account of the special needs of developing and least-developed countries by providing for transitional periods. Pre-TRIPS India did not provide for product patents for pharmaceuticals. Thus it was under an obligation to do so by the end of TRIPS' transitional periods. In addition to complying with TRIPS, India's transformation of its patent system was also driven by a deliberate choice to stimulate domestic innovation in new medicines. The absence of product patents for pharmaceuticals may have led to a booming generic pharmaceutical industry, but it did not stimulate research and development into new chemical entities. It is too early, though, for empirical evidence to establish whether there is a visible shift from producing generic medicines to domestic pharmaceutical innovation. Uganda, being a least-developed WTO member has until July 2021 to fully implement the TRIPS Agreement (except for article 3 and 4). Yet, it has already started the process of reforming its patent law in order to bring it in line with the TRIPS' requirements.

In addition to the flexibility inherent in the TRIPS' objective to balance patent protection with access, it also provides a number of concrete options for developing members to balance patent protection with the right of access to medicines, particularly articles 30 and 31 TRIPS. Consequently, within the limits of TRIPS, developing members can incorporate a number of tools to ensure a balance is struck, such as a Bolar exception, compulsory licensing, government use and parallel importation. Finally, however, the value of the flexibility within TRIPS will depend much on the manner in which it is actually implemented by member states.

\section{The Interface between Patents and Access: Tension?}

With respect to the IP and human rights interface there are two distinct conceptual approaches: the conflict and coexistence approach. In the case of access to medicines, the former approach argues that patent protection for pharmaceutical products undermines the right to health and life. See for example the statement of the Sub-Commission on the Protection and Promotion of Human Rights that "there are apparent conflicts between the intellectual property rights regime embodied in the TRIPS Agreement, on the one hand, and international human rights law, on the other." 2000 Accordingly, to resolve this conflict the normative primacy of human

2000 UN SUB-COMMISSION ON HUMAN RIGHTS, Resolution 2000/7. Intellectual Property Rights and Human Rights, (UN Doc. E/CN.4/SUB.2/RES/2000/7) at \$2. 
rights law over intellectual property law must be recognised in situations where specific treaty obligations conflict. The coexistence approach considers human rights and intellectual property rights to be essentially compatible and concerned with the same fundamental question: namely determining how a fair balance between patents and access should be struck.

This research addressed the interface between international trade law and intellectual property law and international human rights law in the context of patent protection for pharmaceuticals and a right of access to medicines. The issue of access to medicines sits on the cross-point between the two systems and is one illustrative example of how these two systems interact. As such chapter 5 posed the following questions addressing the interface between patents - access:

Does the right of access to (essential) medicines within the framework of international human rights law conflict with patent standards for pharmaceuticals as required by the TRIPS Agreement? If so, may these allegedly conflicting norms be interpreted harmoniously in order to strike a fair balance between promoting and ensuring access on the one hand and protecting patents on the other?

This dissertation is limited to examining the relationship between those provisions of the TRIPS Agreement dealing with protection of patents and international human rights law, mainly the provisions of the ICESCR, encompassing the right of access to medicines. The majority of WTO members are also party to the ICESCR and therefore faced with possible conflicting norms between the TRIPS Agreement and ICESCR. Although the two treaties, at a first glance seem to address different subject matters (protection of human rights vs. protection of intellectual property rights) it has been shown that there are clear links between access to medicines, the right to health, and intellectual property rights, particularly patents for pharmaceuticals.

The question whether one can identify a conflict between patent standards for pharmaceuticals as required by TRIPS and a right of access to medicines as protected by ICESCR depends on the definition of conflict. If defined narrowly, as mutually exclusive obligations, no conflict between TRIPS and ICESCR can be identified. However, this is an unduly narrow definition of conflict. Therefore a wider notion of conflict is adopted here, referred to as possible tension between the TRIPS Agreement and the ICESCR in that both suggest different, arguably even contradictory, ways of dealing with the issue of access to medicines.

In that regard, this tension between TRIPS and the ICESCR may lead to conflicts in applicable law, where the implementation of or compliance with one norm breaches another norm. Namely, compliance with, and national implementation of TRIPS' patent standards may lead to non-compliance and thus a violation of states' obligations under the ICESCR. In order to comply with their obligations under ICESCR states parties must take steps by all appropriate measures to progressively achieve the right to health. From a developing country perspective, this would entail that states parties must take full advantage of the transitional provisions and flexibilities of the TRIPS Agreement. Yet, situations have arisen in 
which the use of TRIPS' flexibilities with a view to enhancing access to medicines has led (developed) states and pharmaceutical corporations to argue that this constitutes a failure to comply with TRIPS' obligations. See for example the country studies on India and South Africa; both countries made changes to their patent legislation in order to enhance the availability, accessibility and affordability which were challenged by pharmaceutical corporations (and in the case of South Africa backed by the US) as being incompatible with the TRIPS Agreement.

Moreover, it seems likely that (developing) members will lean more towards compliance with their obligations under TRIPS than under the ICESCR, since TRIPS may be enforced far more effectively through the WTO dispute settlement mechanism compared to the weak enforcement mechanisms in international human rights law. Consequently, even if human rights are considered morally superior, the lack of legal recognition and effective enforcement gives them a weaker position compared to international trade rules establishing a factual hierarchy, independent of any normative hierarchy. Then, the question must be whether this tension between TRIPS and ICESCR is a "real" or genuine conflict in that it cannot be resolved through conflict-avoidance techniques, for example, through interpretation.

As such, the following step is to determine how to resolve such tension between the TRIPS Agreement and the ICESCR. If one can prove that the right to health and/or access to medicines has reached a position of superiority in international law, any tension is easily resolved in favour of the superior norm. Yet this is not so, as there is insufficient evidence to conclude that access to essential or life-saving medicines is considered to be of a superior status under international law. Consequently, the way in which tension can be avoided between TRIPS and ICESCR is by interpreting the TRIPS Agreement in a manner conducive to promoting and protecting human rights, in this case public health and a right of access to medicines. If this proves to be impossible, the tension between ICESCR and TRIPS would be considered a genuine conflict.

In international law there is a strong presumption against conflict. It is assumed that when states create new obligations under international law, they do not derogate from their already existing obligations. Consequently, where possible, WTO norms should be interpreted in a manner so as to avoid any conflict or tension with other rules of international law. The assumption therefore is that the tension between TRIPS and ICESCR is an apparent tension and not a genuine conflict.

Every sub-system of international law must be considered in the light of the wider corpus of general international law, including general international law and other sub-systems. Such a "fall-back" on other norms of international law can take the form of interpretation (giving meaning to the terms of a particular norm) and the application of TRIPS and ICESCR in the context and together with other norms of international law. The rules of treaty interpretation and especially article 31.3(c) of the Vienna Convention on the Law of Treaties facilitate this process. This is referred to as the principle of systemic integration. In that regard, article 31.3(c) 
VCLT is seen as a linking device between disparate bodies international law, and it is argued that it will enable the recognition of the right to health within TRIPS.

As such the question posed was whether within the WTO dispute settlement mechanism "other interests", here referring to the right to health and access to medicines, might or even must be taken into account when interpreting Members' obligations under the WTO covered agreements. In that regard, it must firstly be noted that international human rights law is not directly applicable law in the WTO framework. Therefore, human rights law cannot be enforced or given primacy by the WTO adjudicative bodies if this would lead to the setting aside, diminishing or amending of the covered agreements. Thus, WTO members violating the right of access to medicines in favour of patent protection could not be held responsible within the WTO system. They could on the other hand be held responsible for any human rights violations within the system of international human rights law. Yet, as was seen, this is problematic in that the lack of any sort of effective enforcement system within international human rights law creates a factual hierarchy favouring the WTO.

The WTO Appellate Body has confirmed that the WTO covered agreements, and thus also the TRIPS Agreement, cannot be read in clinical isolation from public international law. A WTO panel or the AB may take account of international human rights law as interpretative tools when interpreting TRIPS is clear, although caution is required when not all WTO members have consented to the international human rights treaty in question. Yet, whether the WTO adjudicative bodies must take account of international human rights law, particularly the ICESCR, under article 31.3(c) VCLT is not apparent. However, in light of the principle of systemic integration, both the TRIPS Agreement and the ICESCR should be interpreted contextually taking into account a broader normative environment within international law so as to come to a harmonious interpretation in which a balance is struck between patents and access.

\section{Striking a Balance}

Within the UN framework, several human rights monitoring and export bodies, such as the CESCR, but also the High Commissioner for Human Rights and the Special Rapporteur on the Right to Health, have addressed the interface between IPRs and human rights finding that essentially they are not incompatible. Balancing incentives with access is not something unknown within international human rights law; similarly balancing public and private interests is not unfamiliar to intellectual property laws. Yet the essential question is where to strike the appropriate balance.

A good faith interpretation of the relevant WTO and human rights provisions should lead to a reading of TRIPS' obligations in a way that is coherent with human rights law of which the Doha Declaration is a good example. The Doha Declaration is the first public acknowledgment by the WTO of the interface between the TRIPS 
Agreement with public health. It is explicit in the manner in which members should reconcile the tension between the interests of IP right holders and users of IP protected subject matter; namely that the TRIPS Agreement can and should be interpreted and implemented in a manner supportive of WTO members' right to protect public health and, in particular, to promote access to medicines for all. This reference suggests that the Doha Declaration refers, although implicitly, to the promotion and protection of human rights. However, this balancing act must take place at the domestic level. Therefore, the country studies addressed the interpretation and implementation of states' obligations under international law and asked:

Have the developing countries selected been able to strike a balance between access to medicines and patent protection?

As such, it is argued here that with respect to intellectual property rights a "onesize-fits-all" approach is undesirable. States have different levels of development and different needs. Striking a fair balance between incentives for inventiveness and creativity and the dissemination of creative and innovative productions is at the heart of intellectual property policy. For a developing country to be able to maximise domestic welfare it must make a trade-off between innovating and imitating; the difficulty is to get the balance right. For example, for a country like Uganda with almost no pharmaceutical manufacturing capacity it is unrealistic to aim at innovative pharmaceutical research and development; it is more realistic to begin with the small-scale production of generic medicines, which it has done. Thus, a (developing) state may want to set different levels of intellectual property protection for different industries, depending on where its comparative advantage lies and the specific domestic issues it is facing, such as for example an HIV/AIDS epidemic. $^{2001}$

The conclusion of the TRIPS Agreement, however, led to much concern on how the establishment of global minimum levels of intellectual property protection would affect developing countries' ability to improve public health, and more generally economic and technological development, particularly if introducing (product) patents for pharmaceuticals would increase medicine prices and limit the available sources of pharmaceuticals. The most pragmatic solution to address these concerns is to make use of the flexibilities and transitional periods incorporated in the TRIPS Agreement to offset the adverse price effects the introduction of higher levels of patent protection would result in for consumers in developing countries.

India has very clearly made full use of the transition period by providing product patent protection only in 2005 on the expiry of their TRIPS deadline, while Uganda

2001 BERGER, 'Tripping over Patents: AIDS, Access to Treatment and the Manufacturing of Scarcity', at 200; DUNCAN MATTHEWS, Patents in the Global Economy. A Report to the Strategic Advisory Board for Intellectual Property Policy (SABIP), Queen Mary University of London, School of Law, Legal Studies Research Paper, No. 73/2010, (2010) at 26. 
has already started the process of reforming its patent legislation in order to bring it in line with TRIPS' requirements, although with respect to patent protection for pharmaceuticals it has until July 2021. Uganda has the opportunity to shape their patent law within the limits of the TRIPS boundaries to their specific domestic needs, taking full account of recent developments such as the Doha Declaration on TRIPS Public Health. The success of this reform with a view to enhancing access to medicines will depend on the recognition of the impact of full TRIPS compliance on access to affordable medicines and the political willingness to take full advantage of TRIPS flexibilities. As was seen with India's reform of its patent legislation, the possible impact of TRIPS compliance on access to affordable medicines was recognised very clearly. See for example the debate on section 3(d) of the Patents Act which was introduced with the intent to restrict "ever-greening" and recognised the concerns of TRIPS compliance on the affordability of medicines. Civil society raising awareness on socio-economic issues connected to full compliance to the TRIPS Agreement has been essential here.

The Uganda Law Reform Commission has indicated that it might be politically advantageous, in order to promote (foreign) investment, to implement TRIPS before the expiry of the deadline. Although this position is understandable from a political perspective, it must be warned against relinquishing regulatory freedom easily without a thorough inquiry into its effects, both short- and long-term, on their ability to address socio-economic problems such as public health. In that regard, it must be stated that the ULRC does recognise the need to strike a balance.

The TRIPS Agreement obliges members to give effect to its provisions, yet it also states that "[m]embers shall be free to determine the appropriate method of implementing the provisions of this Agreement within their own legal system and practice." 2002 Thus, developing states have a certain amount of freedom when implementing the TRIPS provisions, as long as they stay in line with their TRIPS obligations.

Article 27.1 TRIPS lays down the provisions with respect to patentable subject matter and conditions for patentability. The fact that (pharmaceutical) product patents may not be excluded from protection was one of the major achievements of TRIPS. This entails a significant restriction of developing countries' freedom to regulate patent protection for pharmaceuticals. A country like India, which initially did not allow pharmaceuticals to be granted product patent protection (patents for pharmaceutical processes were allowed), was therefore able to develop a strong generic pharmaceutical industry. Even though it is no longer possible to exclude medicines from patent protection, article 27.1 gives a certain amount of freedom in interpreting the patentable subject matter and conditions for patentability. It states that a patent must be available if an invention is novel, involves an inventive step and is capable of industrial application, yet it does not define these terms. This is

2002 Article 1.1 TRIPS. 
left to the member who can thus interpret and implement these conditions in a manner best suited for its specific domestic needs.

Here India provides the clearest example of how developing members may comply with their TRIPS obligations while balancing their need to ensure access to affordable medicines by introducing an efficacy requirement for patent protection through the adoption of section 3(d) of the Patents Act. The aim underlying section $3(\mathrm{~d})$ is the intent to prevent "ever-greening" of patents by pharmaceutical corporations and ensure that patent protection is granted to only truly novel inventions. The introduction of an efficacy requirement has stirred up quite some controversy about the TRIPS compatibility of this provision. Novartis challenged the constitutionality and TRIPS compatibility of section 3(d) when the Indian Patent Office refused to grant it a patent for its cancer medicine, Gleevec. The case was litigated up to the Indian Supreme Court which upheld the constitutionality of the provision and found that it was not competent to decide on its TRIPS compatibility. The Supreme Court was very much aware of the broader debate on patent protection and access to medicines and the need to find a balance between the two. This was probably also due to the focus of civil society and health advocacy groups on the importance of this case for patients' access to medicines, not only in India but worldwide. Consequently it received much media attention.

There are also a number of exception provisions within TRIPS that could provide useful tools for developing countries in balancing access and patent protection, among them most notably articles 30 and 31 TRIPS. As was stated by the WTO Panel in the Canada - Patent Protection for Pharmaceutical Products case, the very existence of article 30 amounts to recognition that the patent holders' rights as contained in article 28 would need certain adjustments. ${ }^{2003}$ It is argued that under certain circumstances these exceptions can be used to limit patent rights justified by being based on strong reasons of public interests, such as access essential medicines.

Article 30 TRIPS provides a more general exception to the rights conferred to patent holders. It refers to a limited exception, which does not conflict with a normal exploitation of the patent and does not unreasonably prejudice the legitimate interest of the patent owner while taking account of the legitimate interests of third parties. This last element - the legitimate interests of third parties - in addition to the objectives and principles of TRIPS, could be used to balance the rights of patent holders with public interests, such as health. The Panel stated that "legitimate interests" are not purely legal interests but referred to "a normative claim calling for protection of interests that are 'justifiable' in the sense that they are supported by relevant public policies or other social norms." 2004 On the other hand, the panel's interpretation of the term "limited" (that an exception in itself is a limited derogation which is narrowed even further by expressing that it must be limited $)^{2005}$

2003 Canada-Patent Protection for Pharmaceutical Products, at §7.26.

2004 Ibid. at $\$ 7.69$.

2005 Ibid. at \$7.30; GERVAIS, The TRIPS Agreement: Drafting History and Analysis, at 243. 
has been criticised as being "unduly narrow". It is argued that the Panel should have more clearly taken into account TRIPS' objectives and principles, especially when assessing exceptions that pursue the purposes laid down in articles 7 and $8 .^{2006}$ Here the panel acknowledged that article 8.1 TRIPS had some interpretative force, but the existence of article 30 and the narrow way in which it was worded, was an indicator that article 8.1 should not be read to alter the "negotiated" balance exhibited by the TRIPS Agreement. It seems that the panel finds that the balancing act as found in article 8.1 is already exemplified by the negotiated TRIPS provisions.

As was confirmed by Canada-Patent Protection for Pharmaceutical Products, article 30 TRIPS allows for a so-called Bolar exception. Such an exception permits a competing (generic) pharmaceutical manufacturer to use the patented invention before the expiry of the patent term to obtain the obligatory drug approval for their generic version. That would enable the generic manufacturer to market the (competing) generic pharmaceutical immediately once the patent term has expired. Otherwise competing pharmaceutical manufacturers would be prevented from using the patented invention to receive market approval until the patent terms expire, which would result in an extended term of monopoly for the patent holder. ${ }^{2007}$ Both South Africa's and India's patent legislation contain Bolar exceptions while Uganda's existing patent law does not; however, Uganda's draft IP Bill intends to introduce a Bolar exception.

The second exception under TRIPS is article 31, which refers to compulsory licensing. The use of compulsory licensing could be a valuable tool for developed and developing countries in ensuring that access to patented (pharmaceutical) products can be guaranteed. Of course a patent holder, like for example a pharmaceutical corporation, can always grant a third party a voluntary license to produce or use its patented product or process. However, especially in cases in which such a pharmaceutical corporation is unwilling to grant a compulsory license, or merely the threat thereof, can be a useful tool to increase generic production, importation and/or domestic competition and reduce medicine prices. TRIPS leaves members free in to determine the legitimate grounds upon which a compulsory license might be granted. In the light of the Doha Declaration, concerns regarding public health and access to medicines are without a doubt a legitimate ground for compulsory licensing.

All three case study countries provide for compulsory licensing within their respective patent laws. Interestingly, all three also limit the grounds for compulsory licensing, although this is not required by the TRIPS Agreement. South Africa for example limits compulsory licensing to avoiding abuse of patent rights and India specifies three grounds, namely to satisfy the reasonable requirements of the public, ensuring the availability of patented products at reasonable prices and that a patent is worked. Although technically this goes beyond the minimum standards of TRIPS, both patent laws provide suitable grounds for compulsory licensing for

2006 HESTERMEYER, Human Rights and the WTO, at 235-236.

2007 Canada-Patent Protection for Pharmaceutical Products, at $\$ 7.3$. 
public health purposes. Uganda's draft IP Bill limits compulsory licensing to cases where patented inventions are not being supplied on reasonable terms. This is more limited in comparison to the other two countries and its effectiveness will depend largely on the interpretation of "reasonable terms".

Compulsory licensing is possible provided a series of conditions have been met. However, using compulsory licensing to introduce generic competition will only be effective as long as the procedure to receive a compulsory licence is simple and easy and the required royalty payments are reasonable so as to ensure generic production is still economically viable. In that regard India's compulsory licensing system provides a good example in that it defines the "reasonable period" in which an applicant must negotiate a voluntary license with the patent holder. Consequently, a pharmaceutical corporation unwilling to grant a voluntary license cannot unduly delay the grant of a compulsory license. Furthermore it makes an exception to the duty of the applicant to first negotiate a voluntary license in cases of national emergency, other circumstances of extreme urgency, public non-commercial use, or establishment of anti-competitive behaviour by the patent holder.

A compulsory license must be granted predominantly for the supply of the domestic market. This condition has proven to be a hurdle to granting compulsory licenses for pharmaceuticals in developing countries, particularly least-developed countries such as Uganda, as they seldom have the pharmaceutical manufacturing capacity to effectively make use of the possibility of compulsory licensing. As such, it is argued that article 31 TRIPS failed its purpose, because the countries which most need it are not able to take advantage of it. ${ }^{2008}$ Moreover, those countries that do have sufficient domestic manufacturing capacity, like for example India and Brazil, are not able to authorise the production of cheaper generic medicines under a compulsory license for export to least-developed or developing countries without sufficient domestic manufacturing capacity. This issue was recognised by the Doha Declaration, and an attempt was made to rectify it in the August 2003 WTO General Council Decision leading to a proposed amendment of the TRIPS Agreement. Yet, this mechanism has been criticised that it is too burdensome for especially least-developed but also developing countries to be a truly effective tool in removing barriers to access to affordable medicines. The many administrative conditions required to make use of the system will obstruct the very purpose underlying it. In that regard, it must be mentioned that the system has only been used once by Rwanda to import generic HIV/AIDS medicines from Canada and the process took around 3 years. ${ }^{2009}$ Therefore, whether the TRIPS Amendment will truly provide a tool for countries like Uganda seems unlikely.

2008 MERCURIO, 'Resolving the Public Health Crisis in the Developing World: Problems and Barriers of Access to Essential Medicines', at 7.

2009 WTO, 'TRIPS: TRIPS and Public Health "Paragraph 6" System. Notifications by Importing WTO Members', <www.wto.org/english/tratop_e/trips_e/public_health_notif_import_e.htm>, accessed 18 May 2013. 
Consequently, in theory, compulsory licensing provides a useful tool to ensure access to medicines, yet the many conditions TRIPS requires, also with respect to the proposed article 31bis, the complexity, length and cumbersomeness of such a procedure, lacking administrative and legal infrastructure and the fear of possible (trade) sanctions are all reasons that so few developing countries have made use of this tool in order to boost generic production, importation and/or domestic competition and reduce medicine prices. ${ }^{2010}$ On the other hand, the main value of compulsory licensing lies mainly with the threat of use more so than the actual use.

Although not technically an exception, parallel importation can also provide a useful tool for developing countries with regard to ensuring adequate access to medicines. ${ }^{2011}$ Article 6 of the TRIPS Agreement gives members the freedom to decide freely how to address the issue of exhaustion of intellectual property rights. Within a developing country context, applying an international principle of exhaustion of rights would make parallel importation of patented pharmaceutical products possible. This then could be a useful tool for meeting public health needs, since it would permit a developing member to purchase the cheapest drugs offered anywhere in the world. ${ }^{2012}$ Both South Africa and India have adopted an international exhaustion regime while Uganda currently does not, although it intends to do so in its draft IP Bill. In that regard Uganda, as a country with limited manufacturing capacity, has recognised the importance of parallel importation as the most valuable TRIPS flexibility in order to acquire cheaper generic medicines.

In addition to substantive standards for patent protection, the TRIPS Agreement sets out minimum procedural standards. It leaves members considerable freedom to establish mechanisms for the acquisition, maintenance and granting of patents. In that regard it allows members to provide for mechanisms of opposition to patent applications before (pre-grant) and after (post-grant opposition and revocation proceedings) the grant of a patent. Such proceedings provide a useful tool for enhancing access to medicines, particularly where they expand standing to include interested stakeholders, including civil society and health advocacy groups, as opposed to being limited to government and competitors. Moreover, such proceedings assist already understaffed and overburdened patent offices in examining patent applications. ${ }^{2013}$ India includes both pre-grant and post-grant opposition proceedings in its patent law and civil society groups have already been very active in opposing patent applications for the granting of patents for pharmaceuticals.

2010 VERMA, 'The Doha Declaration and Access to Medicines by Countries without Manufacturing Capacity', at 640.

2011 CIPR, Integrating Intellectual Property Rights and Development Policy, at 42; UN SUBCOMMISSION ON HUMAN RIGHTS, Report of the High Commissioner on the Impact of the TRIPS Agreement on Human Rights (UN Doc. E/CN.4/Sub.2/2001/13) at $\$ 48$.

2012 CORREA, Trade-Related Aspects of IPRs: A Commentary on the TRIPS Agreement, at 80; HESTERMEYER, Human Rights and the WTO, at 231.

2013 UN HUMAN RIGHTS COUNCIL, Report of the Special Rapporteur on the Right to Health, (UN Doc. A/HRC/11/12) at $§ 50-51$. 
Finally, the South African case study has demonstrated that the use of competition law to enhance access to medicines may provide a particularly valuable tool. See for example the Hazel Tau case. ${ }^{2014}$ Particularly the possibility of being forced to publicly disclose costing models in order to defend high medicine prices, but also unfavourable findings of an independent adjudicator, provides a strong incentive for pharmaceutical companies to settle out of court. As such, the value of using competition law to enhance access to medicines lies mainly in the incentive it provides for pharmaceutical corporations to negotiate voluntary licensing agreements. Furthermore, the South African Competition Act allows a complaint to be submitted by any person, thus including civil society and health organisations. This was also the case in the Hazel Tau complaint which was submitted by a number of individual complainants including the Treatment Action Campaign. Consequently, it is particularly useful tool in situations where the more traditional actors such as the government or the generic industry are unable or unwilling to act. $^{2015}$

In conclusion, have the developing countries selected been able to strike a balance between access to medicines and patent protection? Unfortunately, there is no simple answer to this question. As shown, all three countries have attempted to do so, particularly through use of the TRIPS flexibilities, although with varying degrees of success. As such, the TRIPS Agreement does not implement a "one-sizefits-all" approach to the protection of IPRs and allows for taking into account the special needs of developing and least-developed countries; on the other hand issues, such as the potential of the proposed amendment to the TRIPS Agreement, remain unresolved. Moreover, the manner in which the TRIPS Agreement is sometimes interpreted does not give members the freedom to fully utilise the manoeuvring room within the TRIPS Agreement. Namely, the conclusion of TRIPS-plus FTAs obliging states to implement stronger protection for IPRs has led to a global development of ever-increasing standards of IP protection. This development has had, and will have, severe consequences for the ability of developing countries to use the TRIPS flexibilities to safeguard access to affordable medicines and has therefore upset the balance inherent in the TRIPS Agreement and the Doha Declaration on TRIPS and Public Health. As such, any gains developing countries have achieved in multilateral negotiations in order to protect their policy options, such as the Doha Declaration, are slowly being lost at the bilateral level. In addition, developing countries are continuously pressured by (some) developed states and pharmaceutical corporations to not take full advantage of TRIPS' flexibilities and even accept TRIPS-plus arrangements. See for example the pro-IP strategy of the US, which it aggressively pursues in its conclusion of free trade agreements with developing countries. It does so by placing countries on a (priority) watch list and

2014 GALLEGO, 'Intellectual Property Rights and Competition Policy', at 257.

2015 AVAFIA, BERGER, and HARTZENBERG, The Ability of Select Sub-Saharan African Countries to Utilise TRIPS Flexibilities and Competition Law to Ensure a Sustainable Supply of Essential Medicines, at 38-40. 
demanding action against unjustifiable or unreasonable trade practices, specifically including IP issues. This was (and still is) a very effective strategy employed by the US. ${ }^{2016}$ In 1996, when South Africa amended its Medicines Act to promote access to medicines the US placed it on its Special 301 Watch List. With the support of the US, 39 pharmaceutical companies filed a suit challenging the amendments arguing that they would destroy patent protection. Similarly India faced pressure for its introduction of section 3(d) to address "ever-greening" in 2005 when Novartis filed suit challenging this provision. In both these cases, but also many other situations worldwide, public pressure by civil society and health advocacy groups have opposed TRIPS-plus developments and the unilateral actions of major pharmaceutical companies to strengthen IPRs with considerable success. ${ }^{2017}$

\section{Conclusion \& Recommendations}

There is no inherent or genuine conflict between the ICESCR and the TRIPS Agreement. A pro-development interpretation and implementation of the TRIPS Agreement should allow developing members to strike a balance between complying with their obligations under TRIPS and international human rights law. In that regard, the country studies illustrated that an essential element for successfully balancing access with patent protection is the awareness and acknowledgement of the interface between the two concepts. The recognition that patent protection for pharmaceuticals may interfere with patients' access to medicines and the political will to achieve a balance between access, as required under international human rights law, and minimum standards of patent protection, as required by the TRIPS Agreement, are therefore crucial factors in successfully achieving such a balance. The role of civil society and health advocacy groups must be emphasised in that regard. There are ample examples in the country studies of civil society raising awareness of the possible implications of overly favouring the position of right holders of IPRs over public interest concerns. By framing the interface between access to medicines and patents in human rights language civil society has fundamentally changed the discourse in that regard. On the other side, some developed countries and pharmaceutical corporations have warned against weakening patent laws, having possible negative effects on foreign investment,

2016 ILARDI and BLAKENEY, International Encyclopaedia of Intellectual Property Treaties, at 40; WATAL, Intellectual Property Rights in the WTO and Developing Countries, at 18, 24-26.

2017 3D, Switzerland. Missing Policy Coherence: Trade Interests Overriding Right to Health? Report Submitted to the CESCR Pre-Sessional Working Group; BUKO PHARMA-KAMPAGNE and INSTITUTE OF PUBLIC HEALTH BENGALURU, At Any Price? Examination of the Business Behaviour of Boehringer Ingelheim, Bayer and Baxter in India, BUKO Pharma-Kampagne and Institute of Public Health, Bengaluru, Pharma-Brief Special, Vol. 1, (March 2011). See also VERGER and PAASSEN, 'Human Development Vis-à-Vis Free Trade: Understanding Developing Countries' Positions in Trade Negotiations on Education and Intellectual Property Rights', at 16. 
technology transfer and economic development. These concerns are not unfounded but the continuing pressure exerted by a number of developed countries and pharmaceutical corporations on developing countries has tipped the balance in favour of stronger IPRs. Consequently it is essential for developing countries to restore the balance inherent in the TRIPS Agreement to ensure that patients worldwide have access to the medicines they so desperately need.

Consequently, framing patents within a human rights framework in combination with social movement can provide a powerful tool for raising the priority of health needs of the global poor. As such, human rights, and here particularly the right to health, can have both legal and normative force to mitigate any restrictive impact of the TRIPS Agreement on access to medicines. The following recommendations may assist in doing so:

- Constitutional recognition of the right to health;

- Establishment of accountability mechanisms to provide for the possibility to hold the state responsible for human rights violations;

- Particularly for least-developed countries facing severe resource constraints, seeking international (technical) assistance in order to comply with their obligations under international human rights law and strengthen their technical and infrastructural capacity to fully implement the TRIPS flexibilities;

- Being aware of the implications of TRIPS-plus agreements for the availability, accessibility and affordability of medicines and conducting a human rights impact assessment prior to conclusion of such agreements;

- Taking full advantage of the TRIPS flexibilities by interpreting these in line with the right of access to medicines and fully implementing these within their national legal frameworks.

With regard to the latter, the country studies have provided some valuable insights. Some concrete options to take full advantage of the TRIPS flexibilities include:

- restricting patent protection to truly novel inventions;

There is an underlying presumption that once a patent has been granted it is valid. Yet, reality is that many patent offices, especially in developing countries where they operate under sometimes severe resource constraints, not all patent applications are (thoroughly) examined as to whether they really meet the patentability criteria of novelty, inventive step and industrial application. Therefore, states should not only focus on exceptions to patent rights but also on whether a patent should be granted or not. Namely, the rationale for a patent system lies with its ability to provide an incentive to innovate and disclose knowledge which would otherwise not be publicly available. 
- providing for pre- and post-grant opposition proceedings;

States could allow for both pre- and post-grant opposition, enabling local and generic companies, as well as other interested parties, such as civil society organisations, to challenge and prevent the grant of trivial patents without litigation, which is time-consuming and costly.

- adopting a simple and effective compulsory licensing system;

For example another option is by not limiting the grounds for compulsory licensing, setting out reasonable and concrete time frames for the obligation to first negotiate a voluntary license and the grant of a compulsory license, establishing guidelines as to what is considered "reasonable" commercial terms and conditions when negotiating a voluntary license, providing for the determination of public health crises as "national emergencies" or "situations of extreme urgency" waiving the obligation to enter into negotiations before granting a compulsory license, setting out guidelines on the factors to be taken into account when determining the adequate remuneration to be paid to the patent holder, including public health interests and the need to ensure access to affordable medicines, and finally where applicable notifying its intention to use the 2003 Waiver Decision to either import or export generic medicines.

- and, finally, adopting an international regime of exhaustion to allow for parallel importation.

There is a focus on the exceptions to patent rights, particularly compulsory licensing as being the solution to the access issue. Yet, although compulsory licensing provides a useful tool, there are other, maybe better, ways to ensure access to medicines particularly for developing countries with limited manufacturing capacity. Consequently the use of parallel importation provides a more valuable tool to promote access to medicines.

Ultimately, intellectual property is a social product and has a social function. Therefore the implementation of a patent system should be done keeping in mind its underlying rationale, namely to ensure both access and availability in the short and long term of the fruits of scientific and technological progress. 



\section{BIBLIOGRAPHY}

-, 'India Tries to Break Cycle of Health-Care Debt', Bulletin of the World Health Organisation, 88:7 (2010), 486-487.

3D, Switzerland. Missing Policy Coherence: Trade Interests Overriding Right to Health? Report Submitted to the CESCR Pre-Sessional Working Group, 3D $\rightarrow$ Trade - Human Rights - Equitable Economy, (23-26 November 2009).

Abbott, Frederick M. and Graham Dukes, Global Pharmaceutical Policy. Ensuring Medicines for Tomorrow's World (Cheltenham: Edward Elgar, 2009).

Abbott, Frederick M., 'Dispute Settlement', in UN Conference on Trade and Development (ed.), World Trade Organisation. 3.14 TRIPS (New York/Geneva: United Nations, 2003).

Abbott, Frederick M., 'The "Rule of Reason" and the Right to Health: Integrating Human Rights and Competition Principles in the Context of TRIPS', in Thomas Cottier, Joost Pauwelyn, and Elisabeth Bürgi (eds.), Human Rights and International Trade (New York: Oxford University Press, 2005).

Abbott, Frederick M., 'TRIPS and Human Rights: Preliminary Reflections', in Frederick M. Abbott, Christine Breining-Kaufmann, and Thomas Cottier (eds.), International Trade and Human Rights. Foundations and Conceptual Issues (Studies in International Economics. The World Trade Forum, Volume 5: The University of Michigan Press, 2006).

Abott, Frederick M., 'Inside Views: The Judgment in Novartis v. India: What the Supreme Court of India Said', <www.ip-watch.org/2013/04/04/the-judgment-in-novartis-vindia-what-the-supreme-court-of-india-said/>, accessed 15 April 2013.

Abramovich, Victor and Laura Pautassi, 'Judicial Activism in the Argentine Health System: Recent Trends', Health and Human Rights, 10:2 (2008), 53-65.

Adede, Adronico O., 'Origins and History of the TRIPS Negotiations', in Christophe Bellmann, Graham Dutfied, and Ricardo Meléndez-Ortiz (eds.), Trading in Knowledge. Development Perspective on TRIPS, Trade and Sustainability (London: Earthscan Publications, 2003).

Alston, Philip and Gerard Quinn, 'The Nature and Scope of States Parties' Obligations under the International Covenant on Economic, Social and Cultural Rights', Human Rights Quarterly, 9 (1987), 156-229.

Alston, Philip, 'Ships Passing in the Night: The Current State of the Human Rights and Development Debate Seen through the Lens of the Millennium Development Goals', Human Rights Quarterly, 27 (2005), 755-829.

Amin, Tahir, The Patent Challenge: Protecting the Public Domain and Access to Affordable Medicines, Initiative for Medicines, Access \& Knowledge (2007).

Anderson, Robert D. and Hannu Wager, 'Human Rights, Development, and the WTO: The Cases of Intellectual Property and Competition Policy', Journal of International Economic Law, 9:3 (2006), 707-747. 
Bibliography

Attaran, Amir, 'How Do Patents and Economic Policies Affect Access to Essential Medicines in Developing Countries?', Health Affairs, 23:3 (2004), 155-166.

Aust, Anthony, Modern Treaty Law and Practice (2 ${ }^{\text {nd }}$ edn.; New York: Cambridge University Press, 2007).

Avafia, Tenu, Jonathan Berger, and Trudi Hartzenberg, The Ability of Select Sub-Saharan African Countries to Utilise TRIPS Flexibilities and Competition Law to Ensure a Sustainable Supply of Essential Medicines: A Study of Producing and Importing Countries, Trade Law Centre for Southern Africa, (2006).

Backman, Gunilla, et al., 'Health Systems and the Right to Health: An Assessment of 194 Countries', The Lancet, 372 (2008).

Baer, A. Bryan, 'Price Controls through the Back Door: The Parallel Importation of Pharmaceuticals', Journal of Intellectual Property Law, 9 (2001-2002), 109-136.

Bagley, Margo A., 'Legal Movements in Intellectual Property: TRIPS, Unilateral Action, Bilateral Agreements, and HIV/AIDS', Emory International Law Review, 17 (2003), 781-798.

Baker, Brook K., 'Arthritic Flexibilities for Accessing Medicines: Analysis of WTO Action Regarding Paragraph 6 of the Doha Declaration on the TRIPS Agreement and Public Health', Indiana International \& Comparative Law Review, 14 (2003-2004), 613-715.

Baker, Brook K., 'Ending Drug Registration Apartheid: Taming Data Exclusivity and Patent/Registration Linkage', American Journal of Law \& Medicine, 34 (2008), 303344.

Bakhoum, Mor, TRIPS, Patent Rights and Right to Health: "Price" or "Prize" for Better Access to Medicine?, Max Planck Institute for Intellectual Property, Competition and Tax Law, 10-07, (2007).

Bartels, Lorand, 'Applicable Law in WTO Dispute Settlement Proceedings', Journal of World Trade, 35:3 (2001), 499-519.

Basheer, Shamnad and Mrinalini Kochupillai, "'Exhausting” Paten Rights in India: Parallel Imports and TRIPS Compliance', Journal of Intellectual Property Rights, 13 (2008), 486-497.

Bates, Ed, 'Avoiding Legal Obligations Created by Human Rights Treaties', International and Comparative Law Quarterly, 57 (2008), 751-788.

BBC News, 'HIV', <http://news.bbc.co.uk/2/hi/health/medical_notes/4756660.stm>, accessed 12 March 2008.

Benedek, Wolfgang, 'The World Trade Organisation and Human Rights', in Wolfgang Benedek, Koen de Feyter, and Fabrizio Marrella (eds.), Economic Globalisation and Human Rights (New York: Cambridge University Press, 2007).

Berger, Jonathan Michael, 'Tripping over Patents: AIDS, Access to Treatment and the Manufacturing of Scarcity', Connecticut Journal of International Law, 17 (20012002), 157-248.

Bhatt, Tina S., 'Amending TRIPS: A New Hope for Increased Access to Essential Medicines', Brooklyn Journal of International Law, 33 (2007-2008), 597-628. 
Bhattacharya, Radhika, 'Are Developing Countries Going Too Far on TRIPS? A Closer Look at the New Laws in India', American Journal of Law \& Medicine, 34 (2008), 395-421.

Bilchitz, David, 'South Africa: Right to Health and Access to HIV/AIDS Drug Treatment', International Journal of Constiutional Law, 1:3 (2003), 524-534.

Blakeney, Michael and Getachew Mengistie, 'Intellectual Property and Economic Development in Sub-Saharan Africa', The Journal of World Intellectual Property, 14:3 (2011), 1-27.

Blum, John, Pieter Carstens, and Norchaya Talib, 'Government Public Health Policy: Three Cautionary Tales from Malaysia, South Africa and the United States', Medicine and Law, 26 (2007), 615-642.

Bohanes, Jan and Fernanda Garza, 'Going Beyond Stereotypes: Participation of Developing Countries in WTO Dispute Settlement', Trade, Law and Development, 4:1 (2012), $45-124$.

Borrell, Joan-Ramon, 'Pricing and Patent of HIV/AIDS Drugs in Developing Countries', Applied Economics, 39:4 (2007), 505-518.

Boudreault, François, 'Idenitfying Conflicts of Norms: The ICJ Approach in the Case of the Jurisdictional Immunities of the State Germany (Germany v. Italy: Greece Intervening)', Leiden Journal of International Law, 25 (2012), 1003-1012.

Brand, Danie, 'Socio-Economic Rights and Courts in South Africa: Justiciability on a Sliding Scale', in Fons Coomans (ed.), Justiciability of Economic and Social Rights. Experiences from Domestic Systems. (Antwerpen/Oxford: Intersentia, 2006).

Braun, Johanna Von and Meir P. Pugatch, 'The Changing Face of the Pharmaceutical Industry and Intellectual Property Rights', The Journal of World Intellectual Property, 8:5 (2005), 599-623.

Brems, Eva, 'Human Rights: Minimum and Maximum Perspectives', Human Rights Law Review, 9:3 (2009), 349-372.

Bright, Keren and Lois Muraguri, 'Access to Medicines: Intellectual Property Rights, Human Rights and Justice', in Aurora Voiculescu and Helen Yanacopulos (eds.), The Business of Human Rights (London: Zed Books, 2011).

Buko Pharma-Kampagne and Institute of Public Health Bengaluru, At Any Price? Examination of the Business Behaviour of Boehringer Ingelheim, Bayer and Baxter in India, BUKO Pharma-Kampagne and Institute of Public Health, Bengaluru, PharmaBrief Special, Vol. 1, (March 2011).

Buko Pharma-Kampagne, Indien: Behandlung Von AIDS-Patientinnen Gefährdet, BUKO Pharma-Kampagne, Pharma-Brief Nr.3/2005, (April/May 2005).

Byrne, Iain, 'Making the Right to Health a Reality: Legal Strategies for Effective Implementation', Commonwealth Law Conference, (2005).

Callego, Beatriz Conde, 'Intellectual Property Rights and Competition Policy', in Carlos M. Correa (ed.), Research Handbook on the Protection of Intellectual Property under WTO Rules. Intellectual Property in the WTO Volume 1 (Research Handbooks on the WTO; Cheltenham/Northampton: Edward Elgar, 2010). 
Chandran, Sajeev, Archna Roy, and Lokesh Jain, 'Implications of New Patent Regime on Indian Pharmaceutical Industry: Challenges and Opportunities', Journal of Intellectual Property Rights, 10 (2005), 269-280.

Chapman, Audrey R. and Sage Russell (eds.) Core Obligations: Building a Framework for Economic, Social and Cultural Rights (Antwerp/Oxford/New York: Intersentia, 2002).

Chapman, Audrey R., 'A "Violations Approach” for Monitoring the International Covenant on Economic, Social and Cultural Rights', Human Rights Quarterly, 18 (1996), 23-66.

Chapman, Audrey R., 'A Human Rights Perspective on Intellectual Property, Scientific Progress, and Access to the Benefits of Science', Intellectual Property and Human Rights. A Panel Discussion to Commemorate the 50 th Anniversary of the Universal Declaration of Human Rights (Geneva: World Intellectual Property Organisation Office of the United Nations High Commissioner for Human Rights, 1999).

Chapman, Audrey R., 'Conceptualising the Right to Health: A Violations Approach', Tennessee Law Review, 65 (1997-1998), 389-418.

Chapman, Audrey R., 'The Human Rights Implication of Intellectual Property Protection', Journal of International Economic Law, 5:4 (2002), 861-882.

Chaudhuri, Sudip, Is Product Patent Protection Necessary in Developing Countries for Innovation? R\&D by Indian Pharmaceutical Companies after TRIPS, Indian Institute of Management Calcutta, Working Paper Series, WPS No. 614, (2007).

Chaudhuri, Sudip, P.K. Goldberg, and P. Jia, 'Estimating the Effects of Global Patent Protection in Pharmaceuticals: A Case Study of Quinolones in India', American Economic Review, 96:5 (2006), 1477-1514.

Chaudhuri, Sudip, The WTO and India's Pharmaceuticals Industry. Patent Protection, TRIPS and Developing Countries (New Delhi: Oxford University Press, 2005).

Chigwedere, Pride, et al., 'Estimating the Lost Benefits of Antiretrovial Drug Use in South Africa', Journal of Acquired Immune Deficiency Syndroms, 49:4 (2008), 410-415.

Chirac, Pierre and Els Torreele, 'Global Framework on Essential Health R\&D', The Lancet, 367 (2006), 1560-1561.

Chirwa, Danwood Mzikenge, 'The Right to Health in International Law: Its Implications for the Obligations of State and Non-State Actors in Ensuring Access to Essential Medicines', South African Journal of Human Rights., 19 (2003), 541-566.

CIPR, Integrating Intellectual Property Rights and Development Policy. Report of the Commission on Intellectual Property Rights, UK Commission on Intellectual Property Rights, (2002).

Claude, Richard Pierre, 'Scientists' Rights and the Human Right to the Benefits of Science', in Audrey Chapman and Sage Russel (eds.), Core Obligations: Building a Framework for Economic, Social and Cultural Rights (Antwerp/Oxford/New York: Intersentia, 2002).

Collins-Chase, Charles T., 'The Case against TRIPS-Plus Protection in Developing Countries Facing AIDS Epidemics', University of Pennsylvania Journal of International Law, 29:763-802 (2008). 
Conforti, Benedetto, 'Consistency among Treaty Obligations', in Enzo Cannizzaro (ed.), The Law of Treaties Beyond the Vienna Convention (New York: Oxford University Press, 2011).

Coomans, Fons (ed.), Justiciability of Economic and Social Rights. Experiences from Domestic Systems (Antwerpen/Oxford: Intersentia, 2006).

Coomans, Fons, 'Application of the International Covenant On Economic, Social and Cultural Rights in the Framework of International Organisations', Max Planck Yearbook of United Nations Law, 11 (2007), 359-390.

Coomans, Fons, Fred Grünfeld, and Menno Kamminga, 'A Primer', in Fons Coomans, Fred Grünfeld, and Menno Kamminga (eds.), Methods of Human Rights Research (Antwerp/Oxford/Portland: Intersentia, 2009).

Coomans, Fons, 'Reviewing Implementation of Social and Economic Rights: An Assessment of the "Reasonableness" Test as Developed by the South African Constitutional Court', Heidelberg Journal of International Law, 65 (2005), 167-196.

Coomans, Fons, 'Sovereignty Fading Away? Prioritising Domestic Health Needs Versus Promoting Free Trade', in Ineke Boerefijn and Jenny Goldschmidt (eds.), Changing Perceptions of Sovereignty and Human Rights: Liber Amicorum Cees Flinterman (Antwerp: Intersentia, 2008).

Coomans, Fons, 'The Extraterritorial Scope of the International Covenant on Economic, Social and Cultural Rights in the Work of the United Nations Committee on Economic, Social and Cultural Rights', Human Rights Law Review, 11:1 (2011), 1-35.

Coriat, Benjamin, 'Introduction: A New Stage in the Fight against the HIV/AIDS Pandemic. An Economic Perspective', in Benjamin Coriat (ed.), The Political Economy of HIV/ AIDS in Developing Countries. TRIPS, Public Health Systems and Free Access (Cheltenham: Edward Elgar, 2008).

Cornides, Jakob, 'European Union Adopts Regulation on Compulsory Licensing of Pharmaceutical Products for Export', The Journal of World Intellectual Property, 10:1 (2007), 70-77.

Correa, Carlos M., A Guide to Pharmaceutical Patents. Vol. I, South Centre, (July 2008).

Correa, Carlos M., 'Data Exclusivity for Pharmaceuticals: TRIPS Standards and Industry's Demand in Free Trade Agreements', in Carlos M. Correa (ed.), Research Handbook on the Protection of Intellectual Property under WTO Rules. Intellectual Property in the WTO Volume 1 (Cheltenham/Northampton: Edward Elgar, 2010).

Correa, Carlos M., Implementation of the WTO General Council Decision on Paragraph 6 of the Doha Declaration on the TRIPS Agreement and Public Health, World Health Organisation, (April 2004).

Correa, Carlos M., Trade-Related Aspects of Intellectual Property Rights: A Commentary on the TRIPS Agreement, eds Prof. Philip Alston, Prof. Vaughan Lowe, and Prof. Robert House (Oxford Commentaries on International Law. GATT/WTO Agreements; New York: Oxford University Press, 2007).

Cottier, Thomas, Joost Pauwelyn, and Elisabeth Bürgi (eds.) Human Rights and International Trade, ed. John H. Jackson (International Economic Law Series, New York: Oxford University Press, 2005). 
Courtis, Christian, Courts and the Legal Enforcement of Economic, Social and Cultural Rights. Comparative Experiences of Justiciability (Geneva: International Commission of Jurists, 2008).

Courtis, Christian, 'Socio-Economic Rights before the Courts of Argentina', in Fons Coomans (ed.), Justiciability of Economic and Social Rights (Antwerpen/Oxford: Intersentia, 2006).

Craven, Matthew C. R., The International Covenant on Economic, Social and Cultural Rights: A Perspective on Its Development (New York: Oxford University Press, 1995).

Cullet, Phillippe, 'Patents and Medicines: The Relationship between TRIPS and the Human Right to Health', International Affairs, 79:1 (2003), 139-160.

D’Almeida, Cristina, et al., 'New Antiretroviral Treatments and Post-2005 TRIPS Constraints: First Moves Towards IP Flexibilisation in Developing Countries', in Benjamin Coriat (ed.), The Political Economy of HIVIAIDS in Developing Countries. TRIPS, Public Health Systems and Free Access (Cheltenham: Edward Elgar, 2008).

Damme, Isabelle Van, 'Treaty Interpretation by the WTO Appellate Body', European Journal of International Law, 21:3 (2010), 605-648.

Dankwa, Victor, Cees Flinterman, and Scott Leckie, 'Commentary to the Maastricht Guidelines on Violations of Economic, Social and Cultural Rights', Human Rights Quarterly, 20 (1998), 705-730.

Deere-Birkbeck, Carolyn, 'Developing Countries in the Global IP System before TRIPS: The Political Context for the Negotiations', in Carlos M. Correa (ed.), Research Handbooks on the Protection of Intellectual Property under WTO Rules. Intellectual Property in the WTO Volume 1 (Series Research Handbooks on the WTO; Cheltenham/Northampton: Edward Elgar, 2010).

Desmond, Chris, et al., 'Relative Response: Raking Country Responses to HIV/AIDS', Health and Human Rights, 10:2 (2008), 105-119.

Dimasi, Joseph A., et al., 'Cost of Innovation in the Pharmaceutical Industry', Journal of Health Economics, 10 (1991), 107-142.

Dimasi, Joseph A., Ronald W. Hansen, and Henry G. Gabrowski, 'The Price of Innovation: New Estimates of Drug Development Costs', Journal of Health Economics, 22 (2003), 151-185.

Dinstein, Yoram, 'The Erga Omnes Applicability of Human Rights', Archiv des Völkerrechts, 30:1 (1992), 16-21.

Dommen, Caroline, 'Raising Human Rights Concerns in the World Trade Organisation: Actors, Processes and Possible Strategies', Human Rights Quarterly, 24 (2002), 1-50.

Durojaye, Ebenezer, 'Compulsory Licensing and Access to Medicines in Post Doha Era: What Hope for Africa?', Netherlands International Law Review, 55:1 (2008), 33-71.

Dutfield, Graham, 'Delivering Drugs to the Poor: Will the TRIPS Amendment Help?', American Journal of Law \& Medicine, 34 (2008), 107-124.

Dutfield, Graham, Intellectual Property Rights and the Life Science Industries. A Twentieth Century History. (Aldershot/Burlington: Ashgate, 2003).

Dutfield, Graham, Lois Muraguri, and Florian Leverve, 'Exploring the Flexibilities of TRIPS to Promote Biotechnology in Developing Countries', in Carlos M. Correa (ed.), 
Research Handbook on the Protection of Intellectual Property under WTO Rules. Intellectual Property in the WTO Volume 1 (Research Handbooks on the WTO; Cheltenham/Northanmpton: Edward Elgar, 2010).

Epstein, Richard A. and A. Scott Kieff, Questioning the Frequency and Wisdom of Compulsory Licensing for Pharmaceutical Patents, The University of Chicago Law School John M. Olin Law \& Economic Working Papers, WP No. 527, (2010).

EU, 'Factsheet - Access to Medicines and the Eu-India Trade Negotiations', <http://trade. ec.europa.eu/doclib/html/150989.htm>, accessed 24 May 2013.

European Commission, Pharmaceutical Sector Inquiry, (8 July 2009).

Falvey, Rod, Neil Foster, and David Greenaway, 'Intellectual Property Rights and Economic Growth', Review of Development Economics, 10:4 (2006), 700-719.

Feyter, Koen De, 'Treaty Interpretation and the Social Sciences', in Fons Coomans, Fred Grünfeld, and Menno Kamminga (eds.), Methods of Human Rights Research (Antwerp/Oxford/Portland: Intersentia, 2009).

FHRI, The Right to Healthcare in Uganda. Report for the Period January - June 2010, Foundation for Human Rights Initiative, (2010).

Fink, Carsten, 'Patent Protection, Transnational Corporations and Market Structure: A Simulation Study of the Indian Pharmaceutical Industry', in Carsten Fink and Keith E. Maskus (eds.), Intellectual Property and Development. Lessons from Recent Economic Research (New York: The World Bank - Oxford University Press, 2005).

Fink, Carsten, 'Patent Protection, Transnational Corporations, and Market Structure: A Simulation Study of the Indian Pharmaceutical Industry', Journal of Industry, Competition and Trade, 1:1 (2001), 101-121.

Follesdal, Andreas, 'Methods of Philosophical Research on Human Rights', in Fons Coomans, Fred Grünfeld, and Menno Kamminga (eds.), Methods of Human Rights Research (Antwerp/Oxford/Portland: Intersentia, 2009).

Forman, Lisa, 'An Elementary Consideration of Humanity? Linking Trade-Related Intellectual Property Rights to the Human Right to Health in International Law', The Journal of World Intellectual Property, 14:2 (2011), 155-175.

Forman, Lisa, 'Justice and Justiciability: Advancing Solidarity and Justice through South Africans' Right to Health in Jurisprudence', Medicine and Law, 27 (2008), 661-683.

Foster, Sharon E., 'Prelude to Compatibility between Human Rights and Intellectual Property', Chicago Journal of International Law, 9 (2008), 171-211.

Frank, R.B and D.S. Salkever, 'Generic Entry and the Pricing of Pharmaceuticals', Journal of Economics and Management Strategy, 6:1 (1997), 75-90.

Freeman, Michael, Human Rights. An Interdisciplinary Approach (Cambridge: Polity Press, 2002).

Fukuda-Parr, Sakiko, 'What Does Feminization of Poverty Mean? It Isn't Just Lack of Income', Feminist Economics, 5:2 (1999), 99-103.

Gad, Mohamed Omar, 'TRIPS Dispute Settlement and Developinc Country Interests', in Carlos M. Correa and Abdulqawi A. Yusuf (eds.), Intellectual Property and International Trade: The TRIPS Agreement (Aphen aan den Rijn: Kluwer Law International, 2008). 
Gallego, Beatriz Conde, 'Intellectual Property Rights and Competition Policy', in Carlos M. Correa (ed.), Research Handbook on the Protection of Intellectual Property under WTO Rules. Intellectual Property in the WTO Volume 1 (Research Handbooks on the WTO; Cheltenham/Northampton: Edward Elgar, 2010).

Gamharter, Katharina, Access to Affordable Medicines: Developing Responses under the TRIPS Agreement and EC Law (Europainstitut Wirtschaftsuniversität Wien Publication Series, Vol. 25; Vienna: SpringerWienNewYork, 2004).

Gardiner, Richard K., Treaty Interpretation (New York: Oxford University Press, 2008).

Gelders, Susanne, et al., Price, Availability and Affordability. An International Comparison of Chronic Disease Medicines. Background Report Prepared for the WHO Planning Meeting on the Global Initiative for Treatment of Chronic Diseases Held in Cairo in December 2005, WHO/ Health Action International (2006).

Genovesi, Luis Mariano, 'The TRIPS Agreement and Intellectual Property Rights Exhaustion', in Carlos M. Correa (ed.), Research Handbook on the Protection of Intellectual Property under WTO Rules. Intellectual Property in the WTO Volume 1 (Research Handbooks on the WTO; Cheltenham/Northampton: Edward Elgar, 2010).

George, Julie, India Position Paper, Lawyers Collective HIV/AIDS Unit, (2010).

Gervais, Daniel, 'Intellectual Property, Trade \& Development: The State of Play', Fordham Law Review, 74 (2005), 505-535.

Gervais, Daniel, 'The Relationship between Intellectual Property and Human Rights', in Paul L.C. Torremans (ed.), Intellectual Property and Human Rights. Enhanced Edition of Copyright and Human Rights (Alphen aan den Rijn: Kluwer Law International, 2008).

Gervais, Daniel, The TRIPS Agreement: Drafting History and Analysis (second edn.; London: Sweet \& Maxwell Ltd., 2003).

Gervais, Daniel, The TRIPS Agreement: Drafting History and Analysis (Third edn.; London: Thomson Reuters - Sweet \& Maxwell, 2008).

Golay, Christophe, The Optional Protocol to the International Convention on Economic, Social and Cultural Rights, Europe - Third World Centre, Critical Report No. 2, (November 2008).

Grabowski, H.G. and J.M. Vernon, 'Brand Loyalty, Entry and Price Competition in Pharmaceuticals after the 1984 Drug Act', Journal of Law and Economics, 35:2 (1992), 331-350.

Griffey, Brian, 'The "Reasonableness" Test: Assessing Violations of State Obligations under the Optional Protocol to the International Covenant on Economic, Social and Cultural Rights', Human Rights Law Review, 11:2 (2011), 275-327.

Grosse Ruse-Kahn, Henning, Policy Space for Domestic Public Interest Measures under TRIPS, South Centre, Research Papers 22, (2009).

Haakonsson, Stine Jessen and Lisa Ann Richey, 'TRIPS and Public Health: The Doha Declaration and Africa', Development Policy Review, 25:1 (2007), 71-90.

Harrison, James, The Human Rights Impact of the World Trade Organisation (Oxford/ Portland: Hart Publishing, 2007). 
Hassim, Adila, Mark Heywood, and Jonathan Berger, Health \& Democracy (Westlake: Siber Ink, 2007).

Haugen, Hans Morten, 'Patent Rights and Human Rights: Exploring Their Relationships', The Journal of World Intellectual Property, 10:2 (2007), 97-124.

Helfer, Laurence R. and Graeme W. Austin (eds.) Human Rights and Intellectual Property: Mapping the Global Interface (New York: Cambridge University Press, 2011).

Helfer, Laurence R., 'Human Rights and Intellectual Property: Conflict or Coexistence? ', Minnesota Journal of Law, Science \& Technology, 5 (2003), 47-61.

Helfer, Laurence R., 'The New Innovation Frontier? Intellectual Property and the European Court of Human Rights', Harvard International Law Journal, 49:1 (2008), 1-52.

Helfer, Laurence R., 'Toward a Human Rights Framework for Intellectual Property', University of California, Davis Law Review 40:3 (2007), 971-1020.

HEPS-Uganda, Right to Essential Medicines. Tracking Uganda's Health Sector in Budgeting, Financing and Delivery of Essential Medicines, Coalition for Health Promotion and Social Development, (August 2010).

Hestermeyer, Holger, Human Rights and the WTO: The Case of Patents and Access to Medicines (Oxford: Oxford University Press, 2007).

Ho, Cynthia, Access to Medicine in the Global Economy. International Agreements on Patents and Related Rights (New York: Oxford University Press, 2011).

Hogerzeil, Hans V., et al., 'Is Access to Essential Medicines as Part of the Fulfilment of the Right to Health Enforceable through the Courts?', The Lancet, 368 (2006), 305-311.

Hogerzeil, Hans V., Melanie Samson, and Jaume Vidal Casanova, Ruling for Access. Leading Court Cases in Developing Countries on Access to Essential Medicines as Part of the Fulfilment of the Right to Health, World Health Organisation - Dept. of Essential Drugs and Medicines Policy, (November 2004).

Hunt, Paul and Rajat Khosla, 'The Human Right to Medicines', SUR - International Journal on Human Rights, 5:8 (2008), 99-114.

Hunt, Paul and Sheldon Leader, 'Developing and Applying the Right to the Highest Attainable Standard of Health. The Role of the UN Special Rapporteur (2002-2008)', in John Harrington and Maria Stuttaford (eds.), Global Health and Human Rights. Legal and Philosophical Perspectives (Abingdon: Routledge, 2010).

IFPMA, Principle Focus and Actions of the Research-Based Pharmaceutical Industry in Contributing to Global Health, International Federation of Pharmaceutical Manufacturers \& Associations, (27 February 2008).

IFPMA, 'Research \& Development. Position 2005-2008', <www.ifpma.org/Issues/index. php?id=421>, accessed 10 April 2008.

Ilardi, Alfredo and Michael Blakeney, International Encyclopaedia of Intellectual Property Treaties (Oxford: Oxford University Press, 2004).

International Law Commission, Draft Articles of the Law of Treaties with Commentaries (Yearbook of the International Law Commission. Vol. II; 1966).

International Law Commission, Fragmentation of International Law: Difficulties Arising from the Diversification and Expansion of International Law. Report of the Study 
Group of the International Law Commission. Finalised by Martti Koskenniemi (UN Doc. A/CN.4/L.682; 2006).

Ishay, Micheline R., The History of Human Rights. From Ancient Times to the Globalisation Era (second edn.; Berkeley/Los Angeles/London: University of Califorina Press, 2008).

Joseph, Sarah and Joanna Kyriakakis, 'The United Nations and Human Rights', in Sarah Joseph and Adam McBeth (eds.), Research Handbook on International Human Rights Law (Cheltenham: Edward Elgar, 2010).

Kanyeihamba, George W., Kanyeihamba's Commentaries on Law, Politics and Governance (Kampala: Renaissance Media, 2006).

Kapczynski, Amy, 'Harmonisation and Its Discontents: A Case Study of TRIPS Implementation in India's Pharmaceutical Sector', California Law Review, 97 (2009), $1571-1650$

Khader, Feroz Ali, The Law of Patents. With a Special Focus on Pharmaceuticals in India (Guragon: LexisNexis Butterworths Wadhwa Nagpur, 2009).

Kramer, Birgit, Patentschutz Und Zugang Zu Medikamenten. Rechtliche Und Ökonomische Implikation (Köln/Berlin/München: Carl Heymanns Verlag, 2007).

Kumar, Nagesh, 'Intellectual Property Rights, Technology and Economic Development: Experiences of Asian Countries', Economic and Political Weekly, 38:3 (2003), 209226.

Landman, Todd, 'Social Science Methods and Human Rights', in Fons Coomans, Fred Grünfeld, and Menno Kamminga (eds.), Methods of Human Rights Research (Antwerp/Oxford/Portland: Intersentia, 2009).

Landman, Todd, Studying Human Rights (London/New York: Routledge, 2006).

Lanjouw, Jean O. and Margaret Macleod, Statistical Trends in Pharmaceutical Research for Poor Countries, Commission on Intellectual Property Rights, Innovation and Public Health, WHO, (2005).

Li, Xuan, 'The Impact of Higher Standards in Patent Protection for Pharmaceutical Industries under the TRIPS Agreement: A Comparative Study of China and India', The World Economy, (2008), 1367-1382.

Liebenberg, Sandra, Socio-Economic Rights. Adjudication under a Transformative Constitution (Claremont: Juta \& Co, 2010).

Lim, Hoe, 'Trade and Human Rights. What's at Issue?', Journal of World Trade, 35:2 (2001), $275-300$.

Lippert, Owen, 'A Market Perspective on Recent Developments in the TRIPS and Essential Medicines Debate', in Brigitte Granville (ed.), The Economics of Essential Medicines (London: Royal Institute of International Affairs, 2002).

Lopert, Ruth and Deborah Gleeson, "The High Price of "Free" Trade: U.S. Trade Agreements and Access to Medicines', Journal of Law, Medicine and Ethics, 41:1 (2013), 199-223.

Macqueen, Hector, Charlotte Waelde, and Graeme Laurie, Contemporary Intellectual Property. Law and Policy (Oxford: Oxford University Press, 2008). 
Mahon, Claire, 'Progress at the Front: The Draft Optional Protocol to the International Covenant on Economic, Social and Cultural Rights', Human Rights Law Review, 8:4 (2008), 617-646.

Malagala, Tenywa Aloysius, 'Human Rights-Based Accountability for Healthcare in Uganda', East African Journal of Peace \& Human Rights, 17:1 (2011), 89-124.

Mapulanga-Hulston, J.K., 'Examining the Justiciability of Economic, Social and Cultural Rights', The International Journal of Human Rights, 6:4 (2002), 29-48.

Marceau, Gabrielle, 'WTO Dispute Settlement and Human Rights', European Journal of International Law, 13:4 (2002), 753-814.

Mashelkar, R.A., et al., Report of the Technical Expert Group on Patent Law Issues (Government of India, Ministry of Commerce \& Industry, Department of Industrial Policy \& Promotion; December 2006).

Maskus, Keith E., 'A Review of the Economic Literature', in Ricardo Meléndez-Ortiz and Pedro Roffe (eds.), Intellectual Property and Sustainable Development. Development Agendas in a Changing World (Cheltenham: Edward Elgar Publishing, 2009).

Matthews, Duncan, 'Intellectual Property Rights, Human Rights and the Right to Health', in Willem Grosheide (ed.), Intellectual Property Rights and Human Rights: A Paradox (Cheltenham: Edward Elgar, 2010).

Matthews, Duncan, Patents in the Global Economy. A Report to the Strategic Advisory Board for Intellectual Property Policy (SABIP), Queen Mary University of London, School of Law, Legal Studies Research Paper, No. 73/2010, (2010).

Matthews, Duncan, The Right to Health and Patents, Queen Mary University of London, School of Law, Legal Studies Research Paper No. 156/2013, (2013).

Matthews, Duncan, When Framing Meets Law: Using Human Rights as a Practical Instrument to Facilitate Access to Medicines in Developing Countries, Queen Mary University of London, School of Law, Legal Studies Research Paper, No. 92/2011, (2011).

Matthews, Duncan, 'WTO Decision on Implementation of Paragraph 6 of the Doha Declaration on the TRIPS Agreement and Public Health: A Solution to the Access to Essential Medicines Problem?', Journal of International Economic Law, 7:1 (2004), 73-107.

Mavroidis, Petros C., 'No Outsourcing of Law? WTO Law as Practiced by WTO Courts', American Journal of International Law, 102 (2008), 421-474.

Mbazira, Christopher, 'Enforcement of Economic, Social and Cultural Rights in Uganda. A Brief Overview', ESR Review, 10:1 (2009), 14-17.

MDG Gap Task Force, Millennium Development Goal 8. The Global Partnership for Development: Making Rhetoric a Reality, United Nations, (2012).

Médecins Sans Frontières, Briefing Document. The Enforcement Provisions of the EuIndia FTA. Implications for Access to Medicines, Médecins Sans Frontières Access Campaign, (January 2013).

Médecins Sans Frontières, 'Indian Supreme Court Delivers Verdict in Novartis Case', $<$ www.msfaccess.org/about-us/media-room/press-releases/indian-supreme-courtdelivers-verdict-novartis-case>, accessed 15 April 2013. 
Meier, Benjamin Mason, 'Employing Health Rights for Global Justice: The Public Health Response to the Insalubrious Ramifications of Globalisation', Cornell International Law Journal, 39 (2006), 711-777.

Mercurio, Bryan, 'Resolving the Public Health Crisis in the Developing World: Problems and Barriers of Access to Essential Medicines', Northwestern Journal of International Human Rights, 5:1 (2006).

Mey, Brenda Pamela, 'Unfettered Consumer Access to Affordable Therapies in the PostTRIPS Era: A Dead-End Journey for Patients? Kenya and India Case Studies', The Journal of World Intellectual Property, 13:3 (2010), 403-473.

Mgbeoji, Ikechi, 'TRIPS and TRIPS-Plus Impacts in Africa', in Daniel Gervais (ed.), Intellectual Property, Trade and Development. Strategies to Optimise Economic Development in a TRIPS-Plus Era (New York: Oxford University Press, 2007).

Mitchell, Andrew D. and TANIA VOON, 'Patents and Public Health in the WTO, FTAs and Beyond: Tension and Conflict in International Law', Journal of World Trade, 43:3 (2009), 571-601.

Moghadam, Valentine M., The 'Feminization of Poverty' and Women's Human Rights, UNESCO, SHS Papers in Women Studies/Gender Research, (2005).

Mok, Emily A., 'International Assistance and Cooperation for Access to Essential Medicines', Health and Human Rights, 12:1 (2010), 73-81.

MSF, HIV/AIDS Treatment in Developing Countries: The Battle for Long-Term Survival Has Just Begun, Médecins Sans Frontière Campaign for Access to Essential Medicines, (2009).

Mubangizi, John C. and Twinomugisha, Ben Kiromba, 'The Right to Health Care in the Specific Context of Access to HIV/AIDS Medicines: What Can South Africa and Uganda Learn from Each Other?', African Human Rights Law Journal, 10 (2007), $105-133$.

Mueller, Janice M., 'The Tiger Awakens: The Tumultuous Transformation of India's Patent System and the Rise of the Indian Pharmaceutical Innovation', University of Pittsburgh Law Review, 68 (2007), 491-641.

Mukholi, David, A Complete Guide to Uganda's Fourth Constitution. History, Politics and the Law (Kampala: Fountain Publishers, 1995).

Müller, Amrei, 'Limitations to and Derogation from Economic, Social and Cultural Rights', Human Rights Law Review, 9:4 (2009), 557-601.

Muralidhar, S., 'Judicial Enforcement of Economic and Social Rights: The Indian Scenario', in Fons Coomans (ed.), Justiciability of Economic and Social Rights. Experiences from Domestic Systems. (Antwerpen/Oxford: Intersentia, 2006).

Muriu, Daniel Wanjau, 'The Imperial - Emancipatory Paradox of International Human Rights: How Useful Is the Right to Health in Sub-Saharan Africa?', International Community Law Review, 9:4 (2007), 387-403.

Musungu, Sisule F. and Cecilia Oh, The Use of Flexibilities in TRIPS by Developing Countries: Can They Promote Access to Medicines?, Commission on Intellectual Property Rights, Innovation and Public Health, Study 4C, (August 2005). 
Muzaka, Valbona, 'Developing Countries and the Struggle on Access to Medicines Front: Victories Won and Lost', Third World Quarterly, 30:7 (2009), 1343-1361.

Nandkumar, Anand, 'Was the TRIPS Worthwhile?', Forbes India, (2012).

Ngwena, Charles and Rebecca Cook, 'Four / Rights Concerning Health', in Danie Brand and Christof Heyns (eds.), Socio-Economic Rights in South Africa (Pretoria: Pretoria University Law Press, 2005).

Niëns, Laurens M., et al., 'Quantifying the Impoverishing Effects of Purchasing Medicines: A Cross-Country Comparison of the Affordability of Medicines in the Developing World', PLoS Medicine, 7:8 (2010), 1-8.

Nolan, Aoife, 'The Child's Right to Health and the Courts', in John Harrington and Maria Stuttaford (eds.), Global Health and Human Rights. Legal and Philosophical Perspectives (Abingdon: Routledge, 2010).

Organisation of Pharmaceutical Producers of India, Commemorative Publication. Improving Access, Innovation \& Reach of Healthcare in India, OPPI, (2012).

Ovett, Davinia, 'Making Trade Policies More Accountable and Human Rights Consistent: A NGO Perspective of Using Human Rights Instruments in the Case of Access to Medicines', in Wolfgang Benedek, Koen de Feyter, and Fabrizio Marrella (eds.), Economic Globalisation and Human Rights (New York: Cambridge University Press, 2007).

Oxfam, Investing for Life. Meeting Poor People's Needs for Access to Medicines through Responsible Business Practices, Oxfam International Oxfam Briefing Paper 109, (November 2007).

Palmeter, David and Petros C. Mavroidis, 'The WTO Legal System: Sources of Law', American Journal of International Law, 92:3 (1998), 398-413.

Papadopoulou, Frantzeska, 'TRIPS and Human Rights ', in Annette Kur and Marianne Levin (eds.), Intellectual Property Rights in a Fair World Trade System. Proposals for Reform of TRIPS (Cheltenham: Edward Elgar, 2011).

Pauwelyn, Joost, Conflict of Norms in Public International Law. How WTO Law Relates to Other Rules of International Law (Cambridge Studies in International and Comparative Law; New York: Cambridge University Press, 2003).

Perehudoff, S.K., R.O. Laing, and H.V. Hogerzeil, 'Access to Essential Medicines in National Constitutions', Bulletin World Health Organisation, 88:11 (2010).

Press Information Bureau of The Government of India, 'Minister of Commerce and Industry Kamal Nath's Statement on the Ordinance Relating to Patents (Third) Amendment', <http://pib.nic.in/newsite/erelease.aspx?relid=6074>, accessed 30 April 2012.

Prévost, Denise, Balancing Trade and Health in the SPS-Agreement: The Development Dimension (Nijmegen: Wolf Legal Publishers, 2009).

Pugatch, Meir P., 'Intellectual Property, Data Exclusivity, Innovation and Market Access', in Pedro Roffe, Geoff Tansey, and David Vivas-Eugui (eds.), Negotiating Health. Intellectual Property and Access to Medicines (London: Earthscan, 2006).

Pugatch, Meir P., Rachel Diamant, and Helen Davison, Promoting Technology Transfer in Developing Countries: Lessons from Public-Private Partnerships in the Field of 
Bibliography

Pharmaceuticals, The Stockholm Network, Expert Series on Pharmaceutical IPRs, (2007).

Ragavan, Srividhya, 'Of the Inequals of the Uruguay Round', Marquette Intellectual Property Law Review, 10 (2006), 273-304.

Raghavan, Chakravarthi, 'WTO Concerned over Human Rights Appraisal Report', <www. twnside.org.sg/title/appraisal.htm>, accessed 1 March 2014.

Rai, Rajnish Kumar, 'Effect of the TRIPS-Mandated Intellectual Property Rights on Foreign Direct Investment in Developing Countries: A Case Study of the Indian Pharmaceutical Industry', The Journal of World Intellectual Property, 11:5/6 (2009), 404-431.

Ram, Prabhu, 'India's New “TRIPS-Compliant” Patent Regime. Between Drug Patents and the Right to Health', Chicago-Kent Journal of Intellectual Property, 5 (2006), 195206.

Ranjan, Prabhash, 'International Trade and Human Rights: Conflicting Obligations', in Thomas Cottier, Joost Pauwelyn, and Elisabeth Bürgi (eds.), Human Rights and International Trade (New York: Oxford University Press, 2005).

Rehman, Javaid, International Human Rights Law (Second edn.; Essex: Pearson Education Ltd, 2010).

Reichman, Jerome H., 'Compulsory Licensing of Patented Pharmaceutical Inventions: Evaluating the Options', in Carlos M. Correa (ed.), Research Handbook on the Protection of Intellectual Property under WTO Rules. Intellectual Property in the WTO Volume 1 (Research Handbooks on the WTO; Cheltenham/Northampton: Edward Elgar, 2010).

Reichman, Jerome H., 'The International Legal Status of Undisclosed Clinical Trial Data: From Private to Public Goods?', in Pedro Roffe, Geoff Tansey, and David VivasEugui (eds.), Negotiating Health. Intellectual Property and Access to Medicines (London: Earthscan, 2006).

Reiffen, D. and M.R. WARD, 'Generic Drug Industry Dynamics', The Review of Economics and Statistics, 87:1 (2005), 37-49.

Robertson, Robert E., 'Measuring State Compliance with the Obligation to Devote the "Maximum Available Resources" to Realising Economic, Social and Cultural Rights', Human Rights Quarterly, 16 (1994), 693-714.

Roffe, Pedro and Christoph Spennemann, 'The Impact of FTAs on Public Health Policies and TRIPS Flexibilities', International Journal of Intellectual Property Management, 1:1/2 (2006), 75-93.

Roffe, Pedro, Christoph Spennemann, and Johanna Von Braun, 'Intellectual Property Rights in Free Trade Agreements: Moving Beyond TRIPS Minimum Standards', in Carlos M. Correa (ed.), Research Handbook on the Protection of Intellectual Property under WTO Rules. Intellectual Property in the WTO Volume 1 (Research Handbooks on the WTO; Cheltenham/Northampton: Edward Elgar, 2010).

Rozanski, Felix, Developing Countries and Pharmaceutical Intellectual Property Rights: Myths and Reality, The Stockholm Network Experts' Series on Pharmaceutical Intellectual Property Rights, (2007). 
Rudaheranwa, Nichodemus and Vernetta Barungi Atingi-Ego, 'Uganda's Participation in WTO Negotiations: Institutional Challenges', in Peter Gallagher, Patrick Low, and Andrew L. Stoler (eds.), Managing the Challenges of WTO Participation. 45 Case Studies (New York: Cambridge University Press, 2005).

Sachs, Albie, 'Enforcement of Social and Economic Rights', American University of International Law Review, 22 (2006-2007), 673-708.

Schaaber, Jörg, Keine Medikamente Für Die Armen? Hindernisse Auf Dem Weg Zu Einer Gerechten Arzneimittelversorgung Am Beispiel AIDS (Frankfurt am Main: MabuseVerlag, 2005).

Scherer, F.M. and Jayashree Watal, Post-TRIPS Options for Access to Patented Medicines in Developing Countries, Commission on Macroeconomics and Health, Working Paper Series, Paper No. WG4:1, (2001).

Schoukens, Paul, 'The Right to Access Health Care: Health Care According to European Social Security Law Instruments', Medicine and Law, 27 (2008), 501-533.

Seatini, TRIPS Compliance and Social Welfare. The Implications of Intellectual Property Law Reform for Uganda Social-Economic Development, Southern and Eastern African Trade Information and Negotiations Institute, (April 2010).

Sell, Susan K., The Global IP Upward Ratchet, Anti-Counterfeiting and Piracy Enforcement Efforts: The State of Play (2008).

Sell, Susan K., 'TRIPS and the Access to Medicines Campaign', Wisconsin International Law Journal, 20:3 (2001-2002), 481-522.

Sell, Susan K., 'TRIPS-Plus Trade Agreements and Access to Medicines', Liverpool Law Review, 28 (2007), 41-75.

Sembrano, Gilbert, 'Mechanisms and Avenues for Judicial and Quasi-Judicial Implementation of ESC Rights: The Philippine Experience', in Fons Coomans (ed.), Justiciability of Economic and Social Rights (Antwerpen/Oxford: Intersentia, 2006).

Sepúlveda Carmona, Magdalena, 'The Obligations of 'International Assistance and Cooperation' under the International Covenant on Economic, Social and Cultural Rights. A Possible Entry Point to a Human Rights-Based Approach to Millennium Development Goal 8', The International Journal of Human Rights, 13:1 (2009), 86-109.

Sepúlveda, M. Magdalena, The Nature of the Obligations under the International Covenant on Econonomic, Social and Cultural Rights (School of Human Rights Research, Vol. 18; Antwerpen/Oxford/New York: Intersentia, 2003).

Seuba, Xavier, 'Mainstreaming the TRIPS and Human Rights Interactions', in Carlos M. Correa (ed.), Research Handbook on the Protectioin of Intellectual Property under WTO Rules. Intellectual Property in the WTO Volume 1 (Research Handbooks on the WTO; Cheltenham/Northampton: Edward Elgar, 2010).

Shah, Sheetal B., 'Illuminating the Possible in the Developing World: Guaranteeing the Human Right to Health in India', Vanderbilt Journal of Transnational Law, 32 (1999), 436-485.

Shankar, Shylashri and Pratap Bhanu Mehta, 'Courts and Socioeconomic Rights in India', in Varun Gauri and Daniel M. Brinks (eds.), Courting Social Justice. Judicial 
Bibliography

Enforcement of Social and Economic Rights in the Developing World (New York: Cambridge University Press, 2008).

Shany, Yuval, 'Stuck in a Moment in Time: The International Justiciability of Economic, Social and Cultural Rights', in Daphne Barak-Erez and Aeyal M. Gross (eds.), Exploring Social Rights: Between Theory and Practice (Oxford: Hart Publishing, 2007).

Shaw, Malcolm N., International Law (Fifth edn.; Cambridge: Cambridge University Press, 2003).

Singh, Someshwar, 'UN Human Rights Commissioner', <www.globalpolicy.org/component/ content/article/209/43850.html>, accessed 1 March 20142014.

Sinha, Manoj Kumar, Enforcement of Economic, Social and Cultural Rights. International and National Perspectives (New Delhi: Manak Publications, 2006).

Skogly, Sigrun I., 'Extraterritoriality: Universal Human Rights without Universal Obligations?', in Sarah Joseph and Adam McBeth (eds.), Research Handbook on International Human Rights Law (Cheltenham: Edward Elgar, 2010).

Sky, Melissa Blue, 'Developing Countries and Intellectual Property Enforcement Measures: Improving Access to Medicines through WTO Dispute Settlement', Trade, Law and Development, 3:2 (2011), 407-440.

Slade, Alison, 'Article 7 and 8 of the TRIPS Agreement: A Force for Convergence within the International IP System', The Journal of World Intellectual Property, 14:6 (2011), 413-440.

Smits, Jan, 'Redefining Normative Legal Science: Towards and Argumentative Discipline', in Fons Coomans, Fred Grünfeld, and Menno Kamminga (eds.), Methods of Human Rights Research (Antwerp/Oxford/Portland: Intersentia, 2009).

Ssenyonjo, Manisuli, 'Economic, Social and Cultural Rights: An Examination of State Obligations', in Sarah Joseph and Adam McBeth (eds.), Research Handbook on International Human Rights Law (Cheltenham: Edward Elgar, 2010).

Sutherland, Peter, et al., The Future of the WTO. Addressing Institutional Challenges in the New Millennium. Report by the Consultative Board to the Director-General Supachai Panitchpakdi, World Trade Organisation, (2004).

'T Hoen, Ellen F.M., The Global Politics of Pharmaceutical Monopoly Power. Drug Patents, Access, Innovation and the Application of the WTO Doha Declaration on TRIPS and Public Health (Diemen: AMB, 2009).

'T Hoen, Ellen, 'Commentary. A Victory for Global Public Health in the Indian Supreme Court', Journal of Public Health Policy, (2013).

Tabaro, Edgar, 'Patent Law Reform in Uganda: Addressing Priorities and Strategies', The Journal of World Intellectual Property, 12:6 (2009), 571-599.

The Global Fund, 'Government Doners', <www.theglobalfund.org/en/donors/public/>, accessed 18 January 2013.

The Global Fund, The Framework Document. Global Fund Governance and Core Documents, The Global Fund to Fight AIDS, Tuberculosis and Malaria, (2001).

The Global Fund, The Global Fund Strategy 2012-2016: Investing for Impact, The Global Fund to Fight AIDS, Tuberculosis and Malaria, (2011). 
The Patent Office India, Manual of Patent Office Practice and Procedure (The Office of Controller General of Patents, Designs \& Trademarks; 2011).

The South African Competition Commission, 'Commission Questions Conduct of AntiRetroviral Companies', Competition News. The Official Newsletter of the Competition Commission, Edition 14 (2003).

The South African Competition Commission, 'GSK and BI Issue Anti-Retroviral Licenses', Competition News. The Official Newsletter of the Competition Commission, Edition 15 (2004).

Timmermans, Karin, 'Ensuring Access to Medicines in 2005 and Beyond', in Pedro Roffe, Geoff Tansey, and David Vivas-Eugui (eds.), Negotiating Health. Intellectual Property and Access to Medicines (London: Earthscan, 2006).

Toebes, Birgit C.A., The Right to Health as a Human Right in International Law (School of Human Rights Research Series, Vol. 1; Antwerpen/Groningen/Oxford: Intersentia, 1999).

Tomuschat, Christian, Human Rights. Between Idealism and Realism, eds Philip Alston, Gráinne de Búrca, and Bruno de Witte (The Collected Courses of the Academy of European Law; New York: Oxford University Press, 2003).

Tomuschat, Christian, Human Rights: Between Idealism and Realism, eds Marise Cremona, et al. (second edn., The Collected Courses of the Academy of European Law; New York: Oxford University Press, 2008).

Trachtman, Joel, 'The Domain of WTO Dispute Settlement Resolution', Harvard International Law Journal, 40 (1999), 333-377.

Trouiller, Patrice, et al., 'Drug Development for the Neglected Diseases: A Deficient Market and a Public-Health Policy Failure', The Lancet, 359 (2002), 2188-94.

Tumushabe, Joseph, The Politics of HIVIAIDS in Uganda, United Nations Research Institute for Social Development, Social Policy and Development Programme Paper No. 28, (August 2008).

Tveiten, Margit, 'The Right to Health Secured HIV/AIDS Medicine - Socio-Economic Rights in South Africa', Nordic Journal of International Law, 72 (2003), 41-71.

Twinomugisha, Ben Kiromba, Beyond Social Programmes: Protection of the Right of Access to Malaria Treatment in Uganda, Human Rights \& Peace Centre, Working Paper No. 22, (November 2008).

Twinomugisha, Ben Kiromba, 'Implications of the TRIPS Agreement for the Protection of the Right of Access to Medicines in Uganda', Malawi Law Journal, 2:2 (2008), 253 278.

Twinomugisha, Ben Kiromba, 'Protecting the Right of Access to Malaria Treatment in Uganda', ESR Review, 10:1 (2009), 17-22.

Twinomugisha, Ben Kiromba, Protection of the Right to Health Care of Women Living with HIVIAIDS in Uganda. The Case of Mbarara Hospital, Human Rights \& Peace Centre, Working Paper No. 5, (April 2007).

Uganda Law Reform Commission, A Report on the Background Study on the Legal Implementation of the World Trade Organisation Agreements (Law Com Pub. No. 32; 2004). 
Bibliography

Uganda Law Reform Commission, A Study Report on Industrial Property Law (Patents, Industrial Designs Technovations and Utility Models) (Law Com Pub. No. 12; 2004).

Ugandan Ministry Of Health, Access to and Use of Medicines by Households in Uganda. Report of a Survey Conducted 2008 (December 2008).

UNCTAD-ICTSD, Resource Book on TRIPS and Development (New York: Cambridge University Press, 2005).

Vadi, Valentina, 'Balancing the Human Right to Health and Intellectual Property Rights after Doha', Italian Yearbook of International Law, XIV (2004), 195-223.

Van Den Bossche, Peter and Werner Zdouc, The Law and Policy of the World Trade Organisation (Third edn.; New York: Cambridge University Press, 2013).

Verger, Antoni and Barbara Van Paassen, 'Human Development Vis-À-Vis Free Trade: Understanding Developing Countries' Positions in Trade Negotiations on Education and Intellectual Property Rights', Review of International Political Economy, (2012), $1-28$.

Verma, S.K., 'The Doha Declaration and Access to Medicines by Countries without Manufacturing Capacity', in Carlos M. Correa (ed.), Research Handbook on the Protection of Intellectual Property under WTO Rules. Intellectual Property in the WTO Volume 1 (Research Handbooks on the WTO; Cheltenham/Northampton: Edward Elgar, 2010).

Verma, Shivani, Justiciability of Economic, Social and Cultural Rights. Relevant Case Law, The International Council on Human Rights Policy. Review Meeting, (2005).

Viljoen, Frans, International Human Rights Law in Africa (New York: Oxford University Press, 2007).

Watal, Jayashree, Intellectual Property Rights in the WTO and Developing Countries (The Hague/London/Boston: Kluwer Law International, 2001).

Weissbrodt, David and Connie De La Vega, International Human Rights Law. An Introduction, ed. Jr. Bert. B Lockwood (Pennsylvania Studies in Human Rights; Philadelphia: University of Pennsylvania Press, 2007).

Weissbrodt, David and Kell Schoff, 'Human Rights Approach to Intellectual Property Protection: The Genesis and Application of Sub-Commission Resolution 2000/7', Minnesota Intellectual Property Review, 5:1 (2003), 1-46.

Weissbrodt, David and Kell Schoff, 'The Sub-Commission's Initiative on Human Rights and Intellectual Property', Netherlands Quarterly of Human Rights, 22:2 (2004), 181215.

WHO and Health Action International, Medicine Prices. A New Approach to Measurement, WHO/HAI (2003).

WHO, 'Access to Medicines', WHO Drug Information, 19:3 (2005), 236-241.

WHO, 'Equitable Access to Essential Medicines: A Framework for Collective Action', Policy Perspectives on Medicines, 8 (2004b).

WHO, 'Essential Medicines', <www.who.int/medicines/services/essmedicines_def/en/print. html $>$, accessed 28 January 2008.

WHO, 'Globalisation, TRIPS and Access to Pharmaceuticals', Policy Perspectives on Medicines, 3 (2001). 
WHO, 'The Selection of Essential Medicines', Policy Perspectives on Medicines, 4 (2002).

Wiles, Ellen, 'Aspirational Principles or Enforceable Rights? The Future for SocioEconomic Rights in National Law', American University of International Law Review, 22 (2006-2007), 35-64.

Wojahn, Patrick L., 'A Conflict of Rights: Intellectual Property under TRIPS, the Right to Health, and AIDS Drugs', UCLA Journal of International Law \& Foreign Affairs, 6 (2001-2002), 463-497.

World Intellectual Property Organisation, Introduction to Intellectual Property. Theory and Practice (London: Kluwer Law International, 1997).

Wouters, Jan and Cedric Ryngaert, The Impact of Human Rights and International Humanitarian Law on the Process of the Formation of Customary International Law, Katholieke Universiteit Leuven, Faculty of Law. Institute for International Law, Working Paper No. 121, (February 2008).

WTO, 'Intellectual Property: TRIPS and Public Health. Members' Laws Implementing the 'Paragraph 6' System', <www.wto.org/english/tratop_e/trips_e/par6laws_e.htm>, accessed 18 May 2013.

WTO, "TRIPS: TRIPS and Public Health "Paragraph 6" System. Notifications by Importing WTO Members', <www.wto.org/english/tratop_e/trips_e/public_health_notif_ import_e.htm>, accessed 18 May 2013.

Yamin, Alicia Ely, 'Not Just a Tragedy: Access to Medications as Right under International Law', Boston University International Law Journal, 21 (2003), 325-371.

Young, Bob and Michael Surrusco, Rx R\&D Myths: The Case against the Drug Industry's $R \& D$ “Scare Card”, Public Citizen's Congress Watch, (2001).

Young, Katherine G., 'The Minimum Core of Economic and Social Rights: A Concept in Search of Content', Yale Journal of International Law, 33 (2008), 113-175.

$\mathrm{Yu}$, Peter K., 'Reconceptualising Intellectual Property Interests in a Human Rights Framework', University of California, Davis, Law Review, 40 (2006-2007), 10391150.

Yu, Peter K., 'Ten Common Questions About Intellectual Property and Human Rights', Georgia State University Law Review, 23 (2007), 709-753.

Yu, Peter K., 'The Objectives and Principles of the TRIPS Agreement', in Carlos M. Correa (ed.), Research Handbook on the Protection of Intellectual Property under WTO Rules. Intellectual Property in the WTO Volume 1 (Research Handbooks on the WTO; Cheltenham/Northampton: Edward Elgar, 2010).

\section{Documents}

\section{United Nations}

UN Commission on Human Rights, Resolution 2001/33. Access to Medication in the Context of Pandemics Such as HIV/AIDS (UN Doc. E/CN.4/RES/2001/33; 2001).

-, Resolution 2002/32. Access to Medication in the Context of Pandemics Such as HIVIAIDS (UN Doc. E/CN.4/RES/2002/32; 2002). 
Bibliography

-, Resolution 2002/31. The Right of Everyone to the Enjoyment of the Highest Attainable Standard of Physical and Mental Health (UN Doc. E/CN.4/2002/31; 2002).

-, Resolution 2003/29. Access to Medication in the Context of Pandemics Such as HIV/ AIDS, Tuberculosis and Malaria (UN Doc. E/CN.4/RES/2003/29; 2003).

-, Report of the Secretary-General on Access to Medication in the Context of Pandemics Such as HIV/AIDS (UN Doc. E/CN.4/2003/48; 2003).

-, Report of the Special Rapporteur on the Right of Everyone to the Enjoyment of the Highest Attainable Standard of Physical and Mental Health, Paul Hunt, Submitted in Accordance with Commission Resolution 2002/31 (UN Doc. E/CN.4/2003/58; 2003).

-, Report of the Secretary General on Access to Medication in the Context of Pandemics Such as HIVIAIDS, Tuberculosis and Malaria (UN Doc. E/CN.4/2004/39; 2003).

-, Resolution 2004/27. The Right of Everyone to the Enjoyment of the Highest Attainable Standard of Physical and Mental Health (UN Doc. E/CN.4/RES/2004/27; 2004).

-, Resolution 2004/26. Access to Medication in the Context of Pandemics Such as HIV/ AIDS, Tuberculosis and Malaria (UN Doc. E/CN.4/RES/2004/26; 2004).

-, Report of the Special Rapporteur on the Right of Everyone to the Enjoyment of the Highest Attainable Standard of Physical and Mental Health, Paul Hunt. Addendum. Mission to the WTO (UN Doc. E/CN.4/2004/49/add.1; 2004).

-, Report of the Special Rapporteur on the Right of Everyone to the Enjoyment of the Highest Attainable Standard of Physical and Mental Health, Paul Hunt (Un Doc. E/ CN.4/2004/49; 2004).

-, Sixtieth Session. Summary Record of the 51 ${ }^{\text {st }}$ Meeting (UN Doc. E/CN.4/2004/SR.51; 2004).

-, Resolution 2005/23. Access to Medication in the Context of Pandemics Such as HIV/ AIDS, Tuberculosis and Malaria (UN Doc. E/CN.4/RES/2005/23; 2005).

-, Report of the Secretary General on Access to Medication in the Context of Pandemics Such as HIV/AIDS, Tuberculosis and Malaria (UN Doc. E/CN.4/2005/38; 2005).

-, Report of the Special Rapporteur on the Right of Everyone to the Enjoyment of the Highest Attainable Standard of Physical and Mental Health, Paul Hunt. Addendum. Mission to Uganda (UN Doc. E/CN.4/2006/48/Add.2; 2006).

-, Report of the Secretary General on Access to Medication in the Context of Pandemics Such as HIV/AIDS, Tuberculosis and Malaria (UN Doc. E/CN.4/2006/39; 2006).

UN Sub-Commission on the Promotion and Protection of Human Rights, Resolution 2000/7. Intellectual Property Rights and Human Rights (UN Doc. E/CN.4/SUB.2/ RES/2000/7; 2000).

-, Prelimiary Report Submitted by J. Oloka-Onyango and Deepika Udagama, in Accordance with Sub-Commission Resolution 1999/8 on Globalisation and Its Impact on the Full Enjoyment of Human Rights (UN Doc. E/CN.4/Sub.2/2000/13; 2000).

-, Progress Report Submitted by J. Oloka-Onyango and Deepika Udagama, in Accordance with Sub-Commission Resolution 1999/8 and Commission on Human Rights Decision 2000/102 on Globalisation and Its Impact on the Full Enjoyment of Human Rights (UN Doc. E/CN.4/Sub.2/2001/10; 2001). 
-, Report of the Secretary General on Intellectual Property Rights and Human Rights. Addendum (UN Doc. E/CN.4/Sub.2/2001/12/Add.1; 2001).

-, Report of the Secretary General on Intellectual Property Rights and Human Rights (UN Doc. E/CN.4/Sub.2/2001/12; 2001).

-, Report of the High Commissioner on the Impact of the Agreement on Trade-Related Aspects of Intellectual Property Rights on Human Rights (UN Doc. E/CN.4/ Sub.2/2001/13; 2001).

UN Economic and Social Council, Resolution 1985/17. Review of the Composition, Organisation and Administrative Arrangements of the Sessional Working Group of Governmental Experts on the Implementation of the International Covenant on Economic, Social and Cultural Rights (1985).

UN General Assembly, Resolution 30/3384. Declaration on the Use of Scientific and Technological Progress in the Interests of Peace and for the Benefit of Mankind (UN Doc. A/RES/30/3384; 1975).

-, Resolution S-26/2. Declaration of Commitment on HIV/AIDS (UN Doc. A/RES/S-26/2; 2001).

-, Interim Report of the Special Rapporteur of the Commission on Human Rights on the Right of Everyone to the Highest Attainable Standard of Physical and Mental Health, Mr. Paul Hunt (UN Doc. A/58/427; 2003).

-, Report of the Special Rapporteur on the Right of Everyone to the Enjoyment of the Highest Attainable Standard of Physical and Mental Health (UN Doc. A/59/422; 2004).

-, Resolution 58/179. Access to Medication in the Context of Pandemics Such as HIV/AIDS, Tuberculosis and Malaria (UN Doc. A/RES/58/179; 2004).

-, Resolution 60/251. Human Rights Council (UN Doc. A/RES/60/251; 2006).

-, Report of the Special Rapporteur on the Right of Everyone to the Enjoyment of the Highest Attainable Standard of Physical and Mental Health (UN Doc. A/61/338; 2006).

-, Resolution 60/262. Political Declaration on HIV/AIDS (UN Doc. A/RES/60/262; 2006).

-, Optional Protocol to the International Covenant on Economic, Social and Cultural Rights (UN Doc. A/RES/63/117; 2008).

-, Resolution 65/1. Keeping the Promise: United to Achieve the Millennium Development Goals (UN Doc. A/RES/65/1; 2010).

-, Resolution 65/277. Political Declaration on on HIV/AIDS: Intensifying Our Efforts to Eliminate HIV/AIDS (UN Doc. A/RES/65/277; 2011).

UN Human Rights Council, Implementation of the General Assembly Resolution 60/251 of 15 March Entitled "Human Rights Council". Report of the Secretary-General on the Protection of Human Rights in the Context of Human Immunodeficiency Virus (HIV) and Acquired Immunodefiency Syndrome (AIDS) (UN Doc. A/HRC/4/110; 2007).

-, Implementation of General Assembly Resolution 60/251 of 15 March 2006 Entitled "Human Rights Council". Report of the Special Rapporteur on the Right of Everyone to the Enjoyment of the Highest Attainable Standard of Physical and Mental Health, Paul Hunt (UN Doc. A/HRC/4/28; 2007). 
Bibliography

-, Resolution 5/1. Institution-Building of the United Nations Human Rights Council (UN Doc. A/HRC/RES/5/1; 2007).

-, Report of the Special Rapporteur on the Right of Everyone to the Enjoyment of the Highest Attainable Standard of Physical and Mental Health. Addendum: Missions to the WB and the IMF in Washington, D.C. And Uganda (UN Doc. A/HRC/7/11/Add.2; 2008).

-, Annual Report of the UN High Commissioner for Human Rights and Reports of the Office of the High Commissioner and the Secretary-General on Access to Medication in the Context of Pandemics Such as HIVIAIDS, Tuberculosis and Malaria (UN Doc. A/ $\mathrm{HRC} / 7 / 30 ; 2008)$.

-, Resolution 6/29. The Right of Everyone to the Enjoyment of the Highest Attainable Standard of Physical and Mental Health (UN Doc. A/HRC/RES/6/29; 2009).

-, Resolution 11/8. Preventable Maternal Mortality and Morbidity and Human Rights (UN Doc. A/HRC/RES/11/8; 2009).

-, Resolution 12/24. Access to Medicines of the Right of Everyone to the Enjoyment of the Highest Attainable Standard of Physical and Mental Health (UN Doc. A/HRC/ $\mathrm{RES} / 12 / 24 ; 2009)$.

-, Report of the Special Rapporteur on the Right of Everyone to the Enjoyment of the Highest Attainable Standard of Physical and Mental Health, Anand Grover (UN Doc. A/HRC/11/12; 2009).

-, Report of the Secretary-General on the Protection of Human Rights in the Context of Human Immunodeficiency Virus (HIV) and Acquired Immunodefiency Syndrome (AIDS) (UN Doc. A/HRC/16/69; 2010).

-, Report of the Special Rapporteur on the Right of Everyone to the Enjoyment of the Highest Attainable Standard of Physical and Mental Health. Expert Consultation on Access to Medicines as a Fundamental Component of the Right to Health (UN Doc. $\mathrm{A} / \mathrm{HRC} / 17 / 43 ; 2011)$.

-, Resolution 16/28. The Protection of Human Rights in the Context of Human Immunodeficiency Virus (HIV) and Acquired Immunodeficiency Sydrome (AIDS) (UN Doc. A/HRC/RES/16/28; 2011).

-, Resolution 17/14. The Right of Everyone to the Enjoyment of the Highest Attainable Standard of Physical and Mental Health in the Context of Development and Access to Medicines (UN Doc. A/HRC/RES/17/14; 2011).

-, Report of the Special Rapporteur on the Right of Everyone to the Highest Attainable Standard of Physical and Mental Health, Anand Grover, on Access to Medicines (UN Doc. A/HRC/23/42; 2013).

UN World Conference on Human Rights, Vienna Declaration and Programme of Action (UN Doc. A/CONF.157/23; 1993).

\section{UN Treaty Monitoring Bodies}

CEDAW, General Recommendation No. 24. Article 12 of the Convention on the Elimination of All Forms of Discrimination against Women: Women and Health (UN Doc. CEDAW/GR 24; 1999). 
CESCR, General Comment No. 3. The Nature of States Parties Obligations (UN Doc. E/1991/23; 1990).

-, General Comment No. 9. The Domestic Application of the Covenant (UN Doc. E/C.12/1998/24; 1998).

-, Protection of Intellectual Property under the TRIPS Agreement. Background Paper Submitted by the Secretariat of the WTO (UN Doc. E/C.12/2000/18; 2000).

-, General Comment No. 14. The Right to the Highest Attainable Standard of Health (UN Doc. E/C.12/2000/4; 2000).

-, Statement Adopted by the Committee on Economic, Social and Cultural Rights on 4 May 2001. Substantive Issues Arising in the Implementation of the ICESCR: Poverty and the ICESCR (UN Doc. E/C.12/2001/10; 2001).

-, General Comment No. 17. The Right of Everyone to Benefit from the Protection of the Moral and Material Interests Resulting from Any Scientific, Literary or Artistic Production of Which He or She Is the Author (Article 15, Paragrapg 1(c), of the Covenant) (UN Doc. E/C.12/GC/17; 2005).

-, Consideration of Reports Submitted by States Parties under Articles 16 and 17 of the ICESCR. Concluding Observations: India (UN Doc. E/C.12/IND/CO/5; 2008).

CRC, General Comment No. 3. HIV/AIDS and the Rights of the Child (UN Doc. CRC/ $\mathrm{GC} / 2003 / 3 ; 2003)$.

-, General Comment No. 4. Adolescent Health and Development in the Context of the Convention on the Rights of the Child (UN Doc. CRC/GC/2003/4; 2003).

-, General Comment No. 7. Implementing Child Rights in Early Childhood (UN Doc. CRC/C/GC/7/Rev.1; 2005).

-, General Comment No. 9. The Rights of Children with Disabilities (UN Doc. CRC/C/ $\mathrm{GC} / 9 ; 2006)$.

HRCee, General Comment No. 6. The Right to Life (Article 6 of the International Covenant on Civil and Political Rights) (UN Doc. HRC/GC/6; 1982).

\section{World Health Organization}

WHA, Prevention and Control of Noncommunicable Diseases (Fifty-third World Health Assembly. WHA53.17; 2000).

-, Scaling up the Response to HIVIAIDS (Fifty-Fourth World Health Assembly. WHA54.10; 2001).

-, WHO Medicines Strategy (Fifty-Fourth World Health Assembly. WHA54.11; 2001).

-, Ensuring Accessibility of Essential Medicines (Fifty-Fifth World Health Assembly. WHA55.14; 2002).

-, Global Health-Sector Strategy for HIV/AIDS (Fifty-Sixth World Health Assembly. WHA56.30; 2003).

-, Scaling up Treatment and Care within a Coordinated and Comprehensive Response to HIV/AIDS (Fifty-Seventh World Health Assembly. WHA57.14; 2004).

-, WHO HIVIAIDS Strategy for 2011-2015 (Sixty-Third World Health Assembly. WHA63.19; 2010). 
Bibliography

-, Global Health Sector Strategy on HIV/AIDS, 2011-2015 (Sixty-Fourth World Health Assembly. WHA64.14; 2011).

WHO, Declaration of Alma-Ata. International Conference on Primary Health Care (1978).

-, The World Medicines Situation 2004 (2004).

-, The World Medicines Situation 2011. Selection of Essential Medicines (2011).

-, The World Medicines Situation 2011. Rational Use of Medicines (2011).

-, The World Medicines Situation 2011. Medicines Prices, Availability and Affordability (2011).

-, The World Medicines Situation 2011. Medicine Expenditures (2011).

\section{World Trade Organisation}

GATT, Punta Del Este Ministerial Declaration (20 September 1986).

GATT Trade Negotiations Committee, Multilateral Trade Negotiations. The Uruguay Round. Meeting at Level of High Officials, (Geneva, 5-8 April 1989).

WTO, Brazil - Measures Affecting Patent Protection. Request for Consultations by the United States (WT/DS199/1; 2000).

-, Brazil - Measures Affecting Patent Protection. Notification of Mutually Agreed Solution (WT/DS199/4; 2001).

-, Implementation-Related Issues and Concerns Adopted at the Doha Ministerial Conference, Fourth Session (WT/MIN(01)/17; 2001).

-, Doha Declaration on the TRIPS Agreement and Public Health Adopted at the Doha Ministerial Conference, Fourth Session (WT/MIN(01)/DEC/2; 2001).

-, European Union and a Member State - Seizure of Generic Drugs in Transit. Request for Consultations by India (WT/DS408/1; 2010).

-, European Union and a Member State - Seizure of Generic Drugs in Transit. Request for Consultations by Brazil (WT/DS409/1; 2010).

WTO Committee on Technical Barriers to Trade, Decision of the Committee on Principles for the Development of International Standards, Guides and Recommendations with Relation to Articles 2, 5 and Annex 3 of the Agreement, in Decisions and Recommendations Adopted by the TBT Committee since 1 January 1995 (G/TBT/1/ Rev.10; 2011).

WTO Council for Trade-Related Aspects of Intellectual Property Rights, Submission by the African Group, Barbados, Bolivia, Brazil, Cuba, Dominican Republic, Ecuador, Honduras, India, Indonesia, Jamaica, Pakistan, Paraguay, Philippines, Peru, Sri Lanka, Thailand and Venezuela (IP/C/W/296; 2001).

-, Special Discussion on Intellectual Property and Access to Medicines. Held in the Centre William Rappard During the Meeting of the Council from 18 to 22 June 2001 (IP/C/M/31; 2001).

-, Extension of the Transition Period under Article 66.1 of the TRIPS Agreement for LeastDeveloped Country Members for Certain Obligations with Respect to Pharmaceutical Products (IP/C/25; 2002).

-, Extension of the Transition Period under Article 66.1 for Least-Developed Country Members (IP/C/40; 2005). 
-, Minutes of Meeting. Held in the Centre William Rappard on 27-28 October and 6 November 2009 (IP/C/M/61; 2010).

-, Minutes of Meeting. Held in the Centre William Rappard on 26-27 October 2010 (IP/C/M/64; 2011).

-, Annual Review of the Decision on the Implementation of Paragraph 6 of the Doha Declaration on TRIPS and Public Health (IP/C/63; 2012).

-, Minutes of Meeting. Held in the Centre William Rappard on 24-25 October and 17 November 2011 (IP/C/M/67; 2012).

-, Extension of the Transition Period under Article 66.1 for Least Developed Members (IP/C/64; 2013).

WTO General Council, Least-Developed Country Members. Obligations under Article 70.9 of the TRIPS Agreement with Respect to Pharmaceutical Products (WT/L/478; 2002).

-, General Council Chairperson's Statement. Excerpt of the Minutes of the General Council Meeting 30 August 2003 (Paragraph No. 29) (WT/GC/M/82; 2003).

-, Decision of 30 August 2003 on the Implementation of Paragraph 6 of the Doha Declaration on the TRIPS Agreement and Public Health (WT/L/540; 2003).

-, Amendment of the TRIPS Agreement (WT/L/641; 2005).

WTO Trade Policy Review Body, Trade Policy Review. Report by the Secretariat on India (Revision) (WT/TPR/S/249/Rev.1; 2011).

-, Trade Policy Review. Report by the Secretariat on the East African Community (Revision). Annex 5 -Uganda (WT/TPR/S/271/Rev.1 2013).

\section{Other}

Organisation of African Unity, Abuja Declaration on HIVIAIDS, Tuberculosis and Other Related Infectious Diseases. African Summit on HIV/AIDS, Tuberculosis and Other Related Infectious Diseases in Abuja, Nigeria from 24-27 April 2001 (OAU/SPS/ ABUJA/3; 2001).

The Limburg Principles on the Implementation of the International Covenant on Economic, Social and Cultural Rights, (2-6 June 1986).

The Maastricht Guidelines on Violations of Economic, Social and Cultural Rights, (2226 January 1997).

The Maastricht Principles on Extraterritorial Obligations of States in the Area of Economic, Social and Cultural Rights, (29 February 2012).

\section{JURISPRUDENCE}

\section{International Court of Justice}

International Court of Justice, Corfu Channel Case (United Kingdom of Great Britain and Northern Ireland v. Albania), 9 April 1949.

International Court of Justice, Asylum Case (Colombia v. Peru), 20 November 1950. 
Bibliography

International Court of Justice, Fischeries Case (United Kingdom v. Norway), 18 December 1951.

International Court of Justice, Right of Passage over Indian Territory - Preliminary Objections (Portugal v. India), 26 November 1957.

International Court of Justice, North Sea Continental Shelf Cases (Federal Republic of Germany v. Denmark; Federal Republic of Germany v. Netherlands), 20 February 1969.

International Court of Justice, Barcelona Traction, Light and Power Company, Limited Case (Belgium v. Spain), 5 February 1970.

International Court of Justice, Questions of Interpretation and Application of the 1971 Montreal Convention Arising from the Aerial Incident at Lockerbie (Libyan Arab Jamahiriya v. United States of America). Order for Provisional Measures, 14 April 1992.

International Court of Justice, Separate Opinion of Judge Ad Hoc Lauterpach in the Case Concerning the Application of the Convention on the Prevention and Punishment of the Crime of Genocide (Bosnia and Herzegovina v. Serbia and Montenegro). Further Requests for the Indication of Provisional Measures., Order of 13 September 1993.

International Court of Justice, Advisory Opinion on the Legality of the Threat or Use of Nuclear Weapons, 8 July 1996.

International Court of Justice, Jurisdictional Immunities of the State (Germany v. Italy: Greece Intervening), 2012.

\section{World Trade Organization}

WTO Appellate Body Report, Japan - Taxes on Alcoholic Beverages, adopted 1 November 1996, WT/DS8/AB/R; WT/DS10/AB/R; WT/DS11/AB/R.

WTO Appellate Body Report, United States - Standards for Reformulated and Conventional Gasoline, adopted 20 May 1996, WT/DS2/AB/R.

WTO Appellate Body Report, India - Patent Protection for Pharmaceutical and Agricultural Chemical Products, adopted 16 January 1998, WT/DS50/AB/R.

WTO Panel Report, India - Patent Protection for Pharmaceutical and Agricultural and Chemical Products, Complaint by the United States, adopted 16 January 1998 (as modified by AB report WT/DS50/AB/R), WT/DS50/R.

WTO Panel Report, India - Patent Protection for Pharmaceutical and Agricultural and Chemical Products, Complaint by the European Communities, adopted 22 September 1998, WT/DS79/R.

WTO Appellate Body Report, United States - Import Prohibition of Certain Shrimp and Shrimp Products, adopted 6 November 1998, WT/DS58/AB/R.

WTO Appellate Body Report, European Communities - Customs Classification of Certain Computer Equipment, adopted 22 June 1998, WT/DS62/AB/R; WT/DS67/AB/R; WT/ DS68/AB/R.

WTO Panel Report, Korea - Measures Affecting Government Procurement, adopted 19 June 2000, WT/DS163/R. 
WTO Panel Report, United States - Sections 301-310 of the Trade Act of 1974, adopted 27 January 2000, WT/DS152/R.

WTO Appellate Body Report, Canada - Term of Patent Protection, adopted 18 September 2000, WT/DS170/AB/R.

WTO Panel Report, Canada - Patent Protection for Pharmaceutical Products, adopted 7 April 2000, WT/DS114/R.

WTO Panel Report, United States - Import Prohibition of Certain Shrimp and Shrimp Products (Recourse to Article 21.5 DSU by Malaysia), adopted 21 November 2001 (upheld by AB report WT/DS58/AB/RW) 2001, WT/DS58/RW.

WTO Appellate Body Report, United States - Section 211 Omnibus Appropriations Act of 1998, adopted 1 February 2002, WT/DS176/AB/R.

WTO Panel Report, European Communities - Measures Affecting the Approval and Marketing of Biotech Products, adopted 21 November 2006, WT/DS291/R; WT/ DS292/R; WT/DS293/R.

WTO Appellate Body Report, Mexico - Tax Measures on Soft Drinks and Other Beverages, adopted 24 March 2006, WT/DS308/AB/R.

WTO Appellate Body Report, European Communities and Certain Member States Measures Affecting Trade in Large Civil Aircraft, adopted 1 June 2011, WT/DS316/ $\mathrm{AB} / \mathrm{R}$.

WTO Appellate Body Report, United States - Measures Affecting the Production and Sale of Clove Cigarettes, adopted 24 April 2012, WT/DS406/AB/R.

WTO Appellate Body Report, United States - Measures Concerning the Importation, Marketing and Sale of Tuna and Tuna Products, adopted 13 June 2012, WT/DS381/ $\mathrm{AB} / \mathrm{R}$.

\section{South Africa}

South African Constitutional Court, Ex Parte Chairperson of the Constitutional Assembly: In Re Certification of the Constitution of the Republic of South Africa, 1996, 4 SA 744 (CC).

South African High Court, Cape of Good Hope Provincial Division, B. And Others v. Minister of Correctional Services and Others, 1997, 6 BCLR 789 (C).

South African Constitutional Court, Soobramoney v. Minister of Health (Kwazulu-Natal), 1997, Case CCT 32/97, 1 SA 765 (CC).

South African Constitutional Court, Government of the Republic of South Africa v. Grootboom, 2000, Case CCT 11/00, 1 SA 46 (CC).

South African Constitutional Court, Minister of Health v. Treatment Action Campaign, 2002, Case CCT 8/02, 5 SA 721 (CC).

South African Constitutional Court, Minister of Health \& Professor D. Mcintyre No v. New Clicks South Africa (Pty) Ltd \& Others, 2005, Case CCT 59/04.

South African Constitutional Court, Laugh It Off Promotions v. South African Breweries, 27 May 2005, Case CCT 42/04.

South African Constitutional Court, Lindiwe Mazibuko and Ors. v. City of Johannesburg and Ors, 8 October 2009, CCT 39/09. 
Bibliography

\section{India}

Indian Supreme Court, Kesavananda Bharati v. State of Kerala, 1973, 4 SCC 225.

Indian Supreme Court, Francis Coralie Mullin v. The Administrator, Union Territory of Delhi, 1981, 2 SCR 516.

Indian Supreme Court, Vincent Panikurlangara v. Union of India, 1987, 2 SCC 165.

Indian Supreme Court, Consumer Education and Research Centre v. Union of India, 1995, 3 SCC 42.

Allahabad High Court, Prayag Vyapar Mandal and Others v. State of Uttar Pradesh and Others, 12 April 1996.

Indian Supreme Court, Paschim Banga Khet Samity v. State of West Bengal, 1996, 4 SCC 37. Indian Supreme Court, Vishaka and Ors. v. State of Rajasthan, 13 August 1997, 6 SCC 241. Indian Supreme Court, State of Punjab v. Ram Lubhaya Bagga, 1998, 4 SCC 117, 130.

Indian Supreme Court, Novartis AG v. Union of India \& Others, 1 April 2013, Civil Appeal Nos. 2706-2716.

\section{Uganda}

Ugandan Constitutional Court, Centre for Health, Human Rights and Development (CEHURD) v. Attorney General, 5 June 2012, Constitutional Petition No. 16 of 2011.

\section{Other}

Argentinian Supreme Court, Asociación Benghalensis y Otros c. Ministerio de Salud y Acción Social, File no. A.186.XXXIV, June 1, 2000.

Argentinian Supreme Court, Ana Carina v. Ministerio de Salud y Acción Social, File no. C.823.XXXV, October 24, 2000.

Colombian Constitutional Court, Alonso Muñoz Ceballos vs Instituto de Seguros Sociales (ISS), Judgment no. T-484, 11 August 1992.

Colombian Constitutional Court, Diego Serna Gómez vs Hospital Universitario del Valle, Judgment no. T-505, 28 August 1992.

Colombian Constitutional Court, $X$ vs Instituto de Seguros Sociales (ISS), Judgement no. T-271 of 23 June 1995.

Colombian Constitutional Court, $X$ vs Secretaríia de Salud Pública Municipal de Cali, Judgement no. T-177, 18 March 1999.

Colombian Constitutional Court, Diana María Pinilla Sandoval vs Salud Colpatria EPS, Judgement no. 170, 8 March 2002.

Costa Rican Constitutional Court, Sidonia Vargas vs Hospital San Juan de Dios, File no. 2390-C-94, 7 September 1994.

Costa Rican Constitutional Court, William García Álvarez vs Caja Costarricense de Seguro Social, File no. 5778-V-97, 23 September 1997. 
Costa Rican Constitutional Court, Ombudsman for Mrs Ledi Orellana Martínez vs Caja Costarricense de Seguro Social (CCSS), File no. 02-007871, 24 September 2002.

El Salvador Constitutional Court, Jorge Odir Miranda Cortez vs la Directora del Instituto Salvadoreño del Seguro Social, File no. 348-99, 4 April 2001.

European Court of Human Rights, D. v. the United Kingdom, Application no. 30240/96, 2 May 1997.

European Court of Human Rights, N. v. the United Kingdom, Application no. 26565/05, 27 May 2008.

European Court of Justice, Rte and Itp v Commission ("Magill”), 6 April 1995, C-241/91P \& C-242/91P.

European Court of Justice, Ims Health, 29 April 2004, C-418/01.

European Court of Justice, Microsoft v Commission, 17 September 2007, T-201/04.

Nairobi High Court, Patricia Asero Ochieng and Others v. the Attorney General \& Another, 20 April 2012, Petition No. 409 of 2009.

Philippine Supreme Court, Del Rosario v. Bengzon, Judgment 180 SCRA 521, 21 December 1989.

US Supreme Court, Sosa v. Alvarez-Manchain Et Al, (2004) 542 US 692.

Venezuelan Supreme Court, N.A., Y.F. et al. vs Ministerio de Sanidad y Asistencia Social, expediente no.14625, 14 August 1998.

Venezuelan Supreme Court, Cruz del Valle Bermúdez et al. vs Ministerio de Salud y Acción Social, expediente no.15789, 15 July 1999.

Venezuelan Supreme Court, Glenda López et al. vs Instituto Venezolano de Seguros Sociales, expediente no.00-1343, 6 April 2001.

\section{LIST OF RESEARCH VISITS AND INTERVIEWS}

July 2009 research visit to South Africa. Meetings with:

- Byron Towell (Management MoP, previously worked on HIV/AIDS in SA);

- Frans Viljoen, Centre for Human Rights, University of Pretoria;

- Enga Kameni, Centre for Human Rights, University of Pretoria;

- Muriel Mushariwa, University of Witwatersrand, Johannesburg;

- Kristy McLean, Centre for Applied Legal Studies, University of Witwatersrand, Johannesburg;

- David Bilchitz, South African Institute for Advanced Constitutional, Public, Human Rights and International Law, Johannesburg;

- Adilla Hassim, Aids Law Project, Johannesburg;

- Leslie London, School of Public Health and Family Medicines, University of Cape Town, Cape Town;

- Nathan Ford, School of Public Health and Family Medicines, University of Cape Town, Cape Town;

- William Kerfoot, Legal Resources Centre, Cape Town;

- Johanna von Braun, Faculty of Law, University of Cape Town, Cape Town;

- Amanda Barrat, Faculty of Law, University of Cape Town, Cape Town. 
Bibliography

January 2010 research visit to the Queen Mary Intellectual Propety Archive, \& Institute of Advanced Legal Studies Library, University of London, London.

August - September 2010 research visit to the World Trade Organisation, Geneva. Meetings with:

- Ai Hoe Lim, WTO;

- Hannu Wager, WTO;

- Jayashree Watal, WTO.

November 2010 research visit to Uganda. Meetings with:

- Moses Mulumba, Centre for Health, Human Rights and Development, Kampala;

- Paul Asiimwe, practising lawyer, Kampala;

- Anthony Kakooza, Uganda Law Reform Commission, Kampala;

- Kabumba Busingye, Human Rights and Peace Centre, Makerere University, Kampala;

- Jane Nalunga, SEATINI, Kampala;

- Paul Okirig, Ministry of Justice and Constitutional Affairs, Kampala;

- Denis Kibira, HEPS-Uganda, Kampala;

- Kyomuhendo Bisereko, Registration Services Bureau, Kampala;

- Elisabeth Tamale, Ministry of Trade, Kampala;

- Dr. Twinomugisha, Faculty of Law, Makerere University, Kampala;

- Edgar Tabaro, practising lawyer; Kampala;

- George W. Baguma, Quality Chemicals, Kampala;

- Freda Nalumansi, Uganda Human Rights Commission; Kampala

January 2011 research visit to New Delhi, India. Meetings with:

- Maheshwar Singh, National Law University Delhi, New Delhi;

- Babu Mathew, National Law University Delhi, New Delhi;

- Prathiba Siva, Lawyers Collective, New Delhi;

- Amit Sengupta, People's Health Movement, New Delhi;

- K.M. Gopakumar, Third World Network, New Delhi;

- Leena Menghaney, Médecins sans Frontières, New Delhi;

- Dr. Santhosh, CENTAD, New Delhi;

- Tahir Amin, I-mak (via Skype). 


\section{Curriculum Vitae}

Jennifer Anna Sellin (Aachen, 1984) studied law at Maastricht University. In 2005 she obtained her bachelor in law and, in 2007, she obtained a master European Law School (cum laude) specialising in international and European law. During her studies she worked as a student-assistant for the Maastricht Centre for Human Rights (Maastricht University) and did an internship at FIAN International, a human rights NGO located in Heidelberg, Germany.

In September 2007 Jennifer started working at the Faculty of Law of Maastricht University as a Ph.D. researcher with the Maastricht Centre for Human Rights. During her appointment she taught various courses at the Faculty of Law mainly in the field of international and European law. In addition to her research and teaching, she was active as the vice-chairperson of the PhD Committee of the Law Faculty and ProVUM, the Maastricht University Ph.D. Association.

Since September 2012 she works full-time as a lecturer with the department of international and European law of the Faculty of Law, Maastricht University. She teaches various courses in the field of international law and European at the Faculty of Law and Arts and Social Sciences (European Studies Programme) of Maastricht University and the Faculty of Law of the University of Hasselt. She has also taught the summer course "Law and Politics, Current Topics in the EU" at the Centre for European Studies, Maastricht. 



\section{School of Human Rights Research Series}

The School of Human Rights Research is a joint effort by human rights researchers in the Netherlands. Its central research theme is the nature and meaning of international standards in the field of human rights, their application and promotion in the national legal order, their interplay with national standards, and the international supervision of such application. The School of Human Rights Research Series only includes English titles that contribute to a better understanding of the different aspects of human rights.

Editorial Board of the Series:

Prof. dr. J.E. Goldschmidt (Utrecht University), Prof. dr. D.A. Hellema (Utrecht University), Prof. dr. W.J.M. van Genugten (Tilburg University), Prof. dr. M.T. Kamminga (Maastricht University), Prof. dr. P.A.M. Mevis (Erasmus University Rotterdam), Dr. J.-P. Loof (Leiden University) and Dr. O.M. Ribbelink (Asser Institute).

For previous volumes in the series, please visit http://shr.intersentia.com.

Published titles within the Series:

56. Martine Boersma, Corruption: A Violation of Human Rights and a Crime Under International Law? ISBN 978-1-78068-105-4

57. Hendrik J. Lubbe, Successive and Additional Measures to the TRC Amnesty Scheme in South Africa ISBN 978-1-78068-116-0

58. Hana van Ooijen, Religious Symbols in Public Functions: Unveiling State Neutrality. A Comparative Analysis of Dutch, English and French Justifications for Limiting the Freedom of Public Officials to Display Religious Symbols ISBN 978-1-78068-119-1

59. Sarah Haverkort-Speekenbrink, European Non-Discrimination Law. A Comparison of EU Law and the ECHR in the Field of Non-Discrimination and Freedom of Religion in Public Employment with an Emphasis on the Islamic Headscarf Issue ISBN 978-1-78068-126-9

60. Johannes Keiler, Actus Reus and Participation in European Criminal Law ISBN 978-1-78068-135-1

61. Simone F. van den Driest, Remedial Secession. A Right to External Self-Determination as a Remedy to Serious Injustices? ISBN 978-1-78068-153-5

62. Ramona Biholar, Transforming Discriminatory Sex Roles and Gender Stereotyping: The implementation of Article 5(a) CEDAW for the realisation of women's right to be free from gender-based violence in Jamaica ISBN 978-1-78068-167-2

63. Jasper Krommendijk,The Domestic Impact and Effectiveness of the Process of State Reporting under UN Human Rights Treaties in the Netherlands, New Zealand and Finland. Paper-pushing or policy prompting?

ISBN 978-1-78068-244-0 
